\begin{tabular}{l} 
MERENTUTKIMUSLAITOKSEN JULKAISU \\
HAVSFORSKNINGSINSTITUTETS SKRIFT No 114 \\
\hline
\end{tabular}

ÜBER DIE EISVERHÄLTNISSE.

DES

BALTISCHEN MEERES AN DEN KÜSTEN FINNLANDS

NEBST EINEM ATLAS

VON
RISTO JURVA

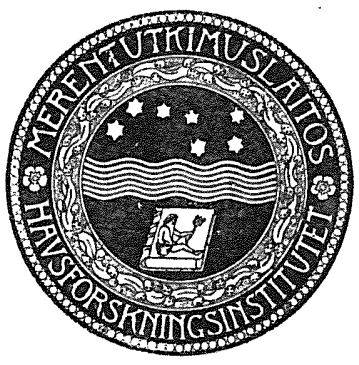

HELSINKI 1937 HELSINGFORS 

MERENTUTKIMUSLAITOKSEN JULKAISU $1 / 4$ HAVSFORSKNINGSINSTITUTETS SKRIFT N:o H+

\title{
ÜBER DIE EISVERHÄLTNISSE DES
}

\section{BALTISCHEN MEERES AN DEN KÜSTEN FINNLANDS}

NEBST EINEM ATLAS

\author{
VON \\ RISTO JURVA
}

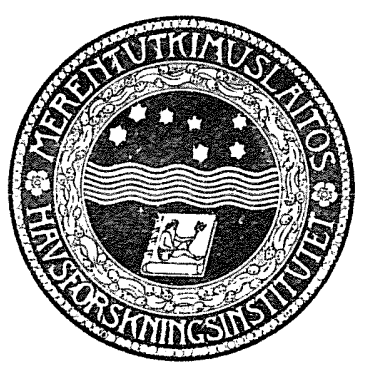

HELSINKI 1937 HELSINGFORS 
Helsinki 1937. Valtioneuvoston kirjapaino. 


\section{VORWORT.}

Dieser Band, der hiermit nebst dem »Atlas der Eisverhältnisse des Baltischen Meeres an den Küsten Finnlands» vorgelegt wird, umfasst die beiden ersten Teile einer umfangreicheren Untersuchung. Im ersten Teil wird das Material besprochen, im zweiten Teil eine methodische Auseinandersetzung gegeben. Diese beiden Teile mit dem Atlas und dem dritten, aus technischen Gründen später erscheinenden Teil »Die Eisarten, der Aufbau des Meereseises und der Bräme des festen Küsteneises» bilden jedoch nur die Einleitung der eigentlichen Untersuchung. Diese beginnt mit dem im finnischen Manuskript fertigen vierten Teil »Die Eisstadien der Meeresteile Finnlands oder die S-Stadien». Im Manuskript liegen auch der fünfte Teil »Die Eisstadien der Meere Finnlands oder die Generalstadien G» und der sechste Teil »Die Dicke des Eises» vor. In Bearbeitung sind der siebente und achte Teil, welche "Die Eiswochenzahlen» und "Die Bewegung des Eises» behandeln. Für den neunten und letzten Teil »Die Zeitanalysen des Eiswinterverlaufes» sind die Analysen vom Jahre 1850 an mittels der d- oder G-Stadien, seit 1915 mittels aller Normalstadien, d. h. der a-, b-, c-, d- und e-sowie G-Stadien durchgeführt und zum grössten Teil auf Arbeitsdiagrammen gezeichnet worden. Für die Zeit vor 1850 sind G-Analysen nur in den Fällen, wo vorläufig hinreichendes Material zur Verfügung stand, vorgenommen worden.

Nachdem die Bearbeitung des umfangreichen Materials, die ich infolge der Beschaffenheit desselben und verschiedener im Zusammenhang damit stehender Probleme in allen Einzelheiten selbst auszuführen gezwungen war, sowie die methodische Behandlung durchgeführt und der Atlas erschienen ist, dürften der Herausgabe der ïbrigen Teile keine weiteren Schwierigkeiten im Wege stehen. Ich hoffe, dass die fehlenden Teile später erscheinen werden und die ganze Untersuchung damit ihren Abschluss finden wird.

Die Anfertigung und Drucklegung des Atlas und des vorliegenden Bandes waren selbstverständlich mit grossen Kosten verknüpft. Die Ausführung der Untersuchung wurde ermöglicht durch geldliche 
Beihilfe seitens der Sohlbergschen Delegation der Finnischen Wissenschaftsgesellschaft und der Kordelinschen Stiftung. Ich benutze die Gelegenheit den erwähnten Institutionen meinen Dank auszusprechen. In diesem Zusammenhang möchte ich auch dem früheren Direktor des Instituts für Meeresforschung, Herrn Prof. Dr. Rolf Witting, der mich zu der vorliegenden Untersuchung angeregt und mir wertvolle Ratschläge erteilt hat, bestens danken. Dem Zeichner des Hydrographischen Bureaus, Herrn RaOul SృöBlom, der mit grosser Sorgfalt die Karten des Atlas reingezeichnet hat, bin ich zu Dank verpflichtet. - Das finnische Manuskript der vorliegenden Untersuchung ist von Fräulein Kand. d. Rechte Elisapeth Lisitzin ins Deutsche übersetzt und von Herrn Universitätslektor Dr. HEINRICH SCHLÜCKING sprachlich überprüft worden.

Helsinki, im Mai 1937.

Der Verfasser. 


\section{Inhalt.}

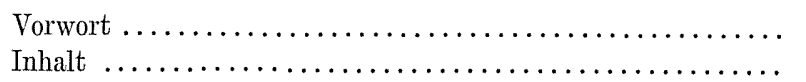

Seite.

III

$\mathrm{V}$

ERSTER TEIL.

Das Material.

Erster Abschnitt: Allgemeine Bemerkungen. Historische Übersicht $\ldots \ldots \ldots \ldots$

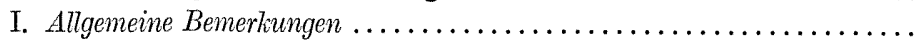

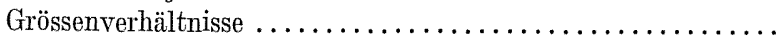

Die unterschiedenen Gebiete $\ldots \ldots \ldots \ldots \ldots \ldots \ldots \ldots$

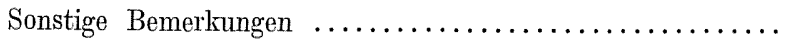

II. Das Eisbeobachtungsmaterial bis zum Winter 1890. Der Beginn des Winterseeverkehrs und der Programmentwurf von $188^{\prime 7}$.............

A. Die ältesten Aufzeichnungen. Das Material vor $1850 \ldots \ldots \ldots \ldots$.

B. Das Material aus den Wintern $1850-1889$.................

C. Der Beginn des Winterverkehrs und der Programmentwurf von 1887

$1-42$

$1-42$

$1-4$

1

2

$4-13$

4

III. Das Eisbeobachtungsmaterial aus den Jahren 1890-1914 und die Beobachtungsarbeit der Hydrographisch-biologischen Kommission ........

A. Das Material aus den Jahren $1890-1897 \ldots \ldots \ldots \ldots \ldots \ldots \ldots \ldots$. . . . .

B. Das Material aus den Jahren $1898-1910 \ldots \ldots \ldots \ldots \ldots \ldots \ldots \ldots$

$13-25$

C. Die Beobachtungsarbeit der Hydrographisch-biologischen Kommission. Das Material aus den Jahren $1911-1914 \ldots \ldots \ldots \ldots \ldots \ldots$

IV. Die definitive Umgestaltung der Eisbeobachtungsarbeit im Anfang des Jahres 1915, die weitere Entwicklung der Eisarbeit und das Eisbeobachtungsmaterial seit dem Winter 1915

A. Die definitive Umgestaltung der Eisbeobachtungsarbeit im Anfang des Jahres 1915. Die erste Übersichtskarte der Eisverhältnisse an

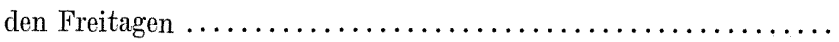

B. Das Material seit dem Winter 1915 und die weitere gleichzeitige Entwicklung der Eisbeobachtungsarbeit ................

Zweiter Abschnitt: Das Spezialmaterial. Einleitende Bemerkungen über die

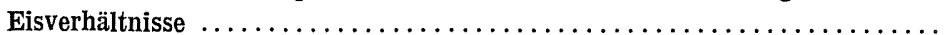

I. Die Übersichtskarten der Eisverhältnisse oder die Eislagen ...........

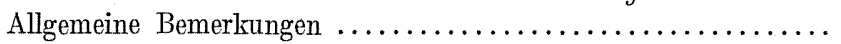

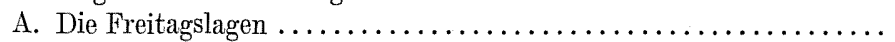

B. Die Eisverhältnisse am Freitag den 21. März 1924 ............

C. Die Freitagslagen der Winter $1915-1925 \ldots \ldots \ldots \ldots \ldots \ldots \ldots$

D. Die Eislagen anderer Wochentage als der Freitage ...........

II. Die Beobachtungen über die Dicke des Eises .................

III. Die Beobachtungen und Karten über die Bewegung des Eises 


\section{Die Methode und einige ihrer Endergebnisse.}

Erster Abschnitt: Die ersten S- und G-Stadien

I. Der erste Versuch den allgemeinen Verlauf des Eiswinters kartographisch darzustellen

Einleitende Bemerkungen ..........................

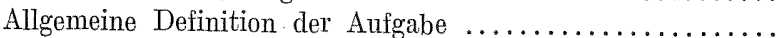

A. Elemente der Darstellung des allgemeinen Verlaufs des Eiswinters:

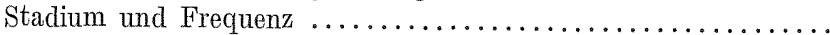

a. Normale Eislage oder Normalstadium ..................

b. Relatives Auftreten oder Frequenz des Meereseises ........

B. Allgemeiner oder normaler Verlauf des Eiswinters im Schärenmeergebiet

II. Der zweite Versuch den allgemeinen Verlauf des Eiswinters kartographisch darzustellen

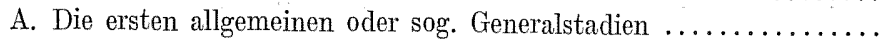

a. Die Bräme des festen Küsteneises der Generalstadien .......

b. Bestimmung der Frequenzzahlen der Generalstadien. Frequenzzahlen des losen und des zusammengefrorenen Meeres-

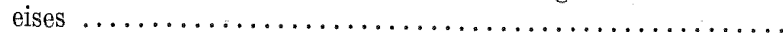

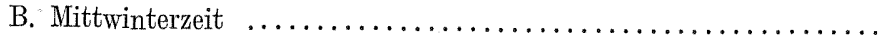

C. Eintrittszeiten der Generalstadien .......................

III. Ergänzung und Vervollständigung der Normalstadien. Der Aufbau der

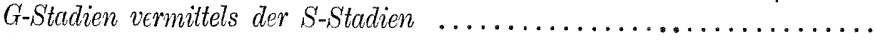

A. Ergänzung und Vervollständigung in bezug auf die Bräme des festen Küsteneises und die Frequenzzahlen ..............

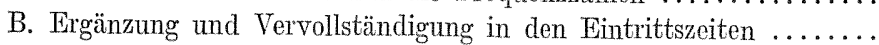

C. Der Aufbau der G-Stadien vermittels der S-Stadien ............

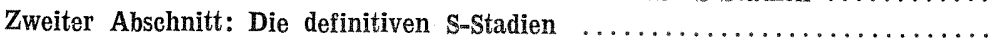

I. Definitive Bestimmung der Nomalstadien und des allgemeinen Verlaufs des Eiswinters der Meeresteile ..............................

A. Gruppierung der Freitagskarten der Winter 1915-1925 für die verschiedenen Meeresteile

a. Die erste Gruppierung der Freitagskarten in drei Hauptgruppen, die dem Vor- oder Herbstwinter, Mittwinter und Spätoder Frühlingswinter entsprechen ....................

b. Verteilung der Hauptgruppen auf Untergruppen, von denen jede die Eislagen umfasst, die einem Normalstadium ent-

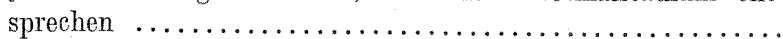

B. Die Sammelkarten Sn und Fn, von denen das n. Normalstadium

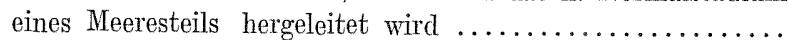

a. Die Sammelkarten a Sn, b Sn, c Sn, d Sn und e Sn ..........

b. Die Sammelkarten a Fn, b Fn, c Fn, d Fn und e Fn ........

C. Ergänzung der Frequenzzahlen durch Kennzeichen des neugebildeten, dünnen Blaueises, des treibenden und des zusammengefrorenen Meereseises

D. Ausgleichung des Verlanfes der Schar der Ränder des festen Küsteneises bzw. der Frequenzkurven zwischen den Untergruppen eines und desselben Meeresteils 
E. Definitives Stadium des Eiswinters eines Meeresteils ohne die Eintrittszeiten und die Dicke des Eises ......................

F. Allgemeiner Verlauf des Eiswinters eines Meeresteils, durch die Normalstadien ohne Berücksichtigung ihrer Zeitepochen dargestellt

II. Anknüpfung der Zeit an die Normalstadien der Meeresteile ...........

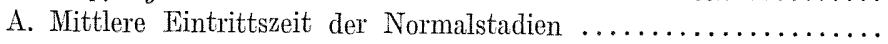

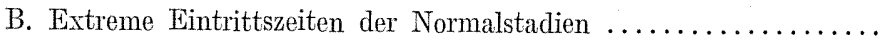

C. Normalstadien der Meeresteile mit ihren Zeitepochen ............

IV. Wahrscheinlichkeit des jährlichen Eintretens der Normalstadien der Meeresteile ........................................ 100-107

V. Kurzer (k-), mittellanger (m-) und langer (l-) Winter der Meeresteile 107-110

VI. Diẹ Eisverhältnisse ausserhalb des Gesichtskreises der festen Beobachtungs-

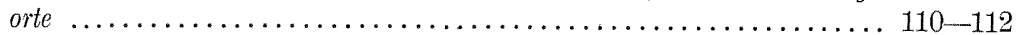

Dritter Abschnitt: Die definitiven G-Stadien $\ldots \ldots \ldots \ldots \ldots \ldots \ldots \ldots \ldots \ldots \ldots \ldots \ldots$ 113-132

I. Aufbau des allgemeinen Normalstadiums oder G-Stadiums aus den Normalstadien der Meeresteile oder S-Stadien .................... 113

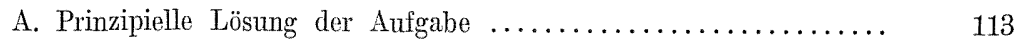

B. Ausführung der Aufgabe $\ldots \ldots \ldots \ldots \ldots \ldots \ldots \ldots \ldots \ldots . .6 \ldots$

a. Erster Fall: sämtliche zum Aufbau eines G-Stadiums benutzten S-Stadien haben dieselbe Wahrscheinlichkeit des jährlichen

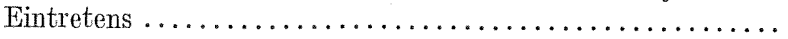

b. Zweiter Fall: die zum Aufbau eines G-Stadiums benutzten S-Stadien weisen verschiedene Wahrscheinlichleit des jähr-

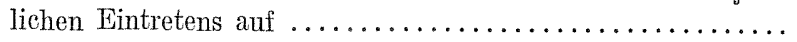

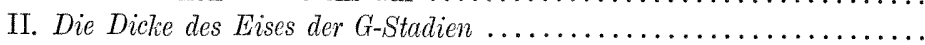

III. Extreme Eintrittszeiten der G-Stadien $\ldots \ldots \ldots \ldots \ldots \ldots \ldots \ldots \ldots$

IV. Der Aufbau der mittwinterlichen G-Stadien ...................

Vierter Abschnitt: Die Zeitdiagramme der S- und G-Stadien. Die Länge des Winters bzw. Winterteils, berechnet nach der Ausbreitung und dem Rückgang der Bräme des festen Küsteneises ......................... 133-192

I. Die Zeitdiagramme ............................... 133-171

A. Die Zeitdiagramme im allgemeinen $\ldots \ldots \ldots \ldots \ldots \ldots \ldots \ldots . . \ldots \ldots$

B. Die Spiegelbilder des frühjahrlichen Teiles der Zeitdiagramme.

Die im Vergleich mit dem ml-Winter symmetrischen, asymmetrischen

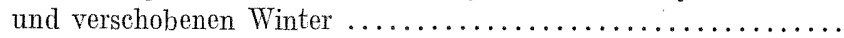

Einige Beispiele von Zeitanalysen ..................

C. Die Länge der einfachsten, auf Grund der Kurven BB, CC und DD der Zeitdiagramme bestimmten Winter zwischen bestimmten Nor-

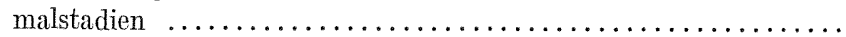

II. Die Länge des ganzen bzw. ganz bestimmter Teile des sk-, bzw. ml-und sl-Winters, berechnet nach der Ausbreitung und dem Rückgang der Bräme des festen Küsteneises in den verschiedenen Meeresteilen ........... 171-187

III. Tabelle betr. die Anzahl der Tage zwischen den G-Stadien in dem sk-, bzw. ml-und sl-Winter ............................. 187-192

Fünfter Abschnitt: Die Einordnung der Eislagen in die von den Zeitpunkten

der S-und G-Stadien bestimmten Zeitintervalle . . . . . . . . . . . . 193-208

I. Einordnung der Eislagen in Zeitintervalle ............... 193-207 
Seite.

II. Wahrscheinlichkeit des Eintretens der Eislagen in den verschiedenen Zeitintervallen

Sechster Abschnitt: Die Eiswochenzahlen ...................... 209-243

I. Die Eiswochenzahlen der Küste und des Meeres .................. 209-220

A. Begriff und Herleitung der Eiswochenzahlen ............... 209

B. Die Schwankungen oder die Variation der Eiswochenzahlen .... 219

II. Die aus den G-Stadien unter Berücksichtigung der Wahrscheinlichkeit des jührlichen Eintretens derselben berechneten Eiswochenzahlen des "normalens sk-, ml- und sl-Winters ..................... 220-243

Literaturverzeichnis 
ERSTER TEIL.

\section{Das Material.}

\section{Erster Abschnitt: Allgemeine Bemerkungen. Historische Übersicht.}

\section{Allgemeine Bemerkungen.}

1. Grössenverhältnisse. Die an Finnland grenzenden Teile des Baltischen Meeres sind im Westen der Bottnische Meerbusen, das Alandsmeer und das Schärenmeer, im Süden die Ostsee und der Finnische Meerbusen. Der seichte Kvark teilt den Bottnischen Meerbusen in zwei Teile: nördlich vom Kvark liegt die Bottenwiek und südlich die Bottensee. Das stellenweise sehr schmale und tiefe, die Ålandsinseln westlich und südwestlich umspülende Alandsmeer und das zwischen Aland und Finnland gelegene, recht breite und seichte, inselreiche Schärenmeer verbinden die Bottensee mit der Ostsee. Zwischen der Ostsee und dem Finnischen Meerbusen gibt es weder ein Übergangsgebiet noch eine natürliche Grenze, z. B. eine Meerenge oder Schwelle. Der Finnische Meerbusen erstreckt sich als länglicher Meerbusen unmittelbar aus dem nördlichen Teil der Ostsee nach Osten.

Folgende Linien können wir nach Witring (75) als Grenzen zwischen den Meeresgebieten annehmen:

zwischen der Bottenwiek und der Bottensee die Linie: Iskmo-Replot-Björkö-Lappören-Valsörarna-die Landspitze Haddingen;

zwischen der Bottensee und dem $\mathrm{Sch}$ ärenmeer die Linie: Lokalahti-Kaurissalo-Landtö_-die nördliche Landspitze bei Saltvik auf Aland;

zwischen der Bottensee und dem $\AA$ landsmeer die Linie: Eckerö-Långö-Märket-Märkeskallan-Norrskär-Ormödie Nordostspitze von Söderö; 
zwischen dem S c hären $\mathrm{m}$ e e r und der Osts e e die Linie Hangö-Vänö-Kalkskär-Utö-Föglöudd und gerade nordwärts gegen die Ostspitze von Degerö;

zwischen dem $\AA$ la $\mathrm{ndsm}$ e e r und der $\mathrm{O}$ st s e e die Linie: Föglöudd-die Bank auf $59^{\circ} 39^{\prime} \mathrm{N}$ Lat. und $20^{\circ} 37^{\prime} \mathrm{E}$ Long.-die Bank auf $59^{\circ} 42^{\prime} \mathrm{N}$ Lat. und $20^{\circ} 19^{\prime} \mathrm{E}$ Long.-Röderskären-Rådmansö; und zwischen dem $\mathrm{F}$ in $\mathrm{n}$ is $\mathrm{ch}$ e $\mathrm{n}$ M e e $\mathrm{r}$ buse $\mathrm{n}$ und der $\mathrm{O}$ sts e e die Linie: Spithamn-Odensholm-Hangöudd.

Innerhalb dieser Grenzen ist nach WITTING (75) die Länge der B ot te nw i e k ca. $270 \mathrm{~km}$, ihre Breite zwischen Raahe und Piteå ca. $145 \mathrm{~km}$, zwischen Lohtaja und Bjuröklubb ca. $95 \mathrm{~km}$. Die Länge der B ot t e n s e e von Märket im Süden bis Skagsudde im Norden beträgt ca. $350 \mathrm{~km}$, ihre Breite zwischen Rauma und Söderhamn ca. $230 \mathrm{~km}$, zwischen Kaskö und Hernösand dagegen nur ca. $160 \mathrm{~km}$. Die Breite des $\mathrm{Sch}$ ärenmeeres von Norden nach Süden ist von Utö bis Kustavi ca. $80 \mathrm{~km}$, von Hangö bis Åland dagegen über $150 \mathrm{~km}$. Die Länge des $\AA$ l a $\mathrm{n} \mathrm{d} \mathrm{s} \mathrm{m} \mathrm{e} \mathrm{e} \mathrm{res} \mathrm{von} \mathrm{der} \mathrm{Bank} \mathrm{nörd-}$ lich von Bogskär bis Märket beläuft sich auf $90 \mathrm{~km}$, der kürzeste Abstand zwischen Åland und Schweden ist etwas über $35 \mathrm{~km}$. Die Länge des Finnischen Meerbusens von Leningrad bis Hangöudd beträgt ca. $420 \mathrm{~km}$, seine Breite ist auf der Linie NarvaJoesuu-Virolahti ca. $120 \mathrm{~km}$ und auf der Linie Wulfö-Porkkala ca. $45 \mathrm{~km}$.

Näheres über Areal und Volumen sowie maximale und mittlere Tiefe der einzelnen Meeresgebiete ist in der folgenden, nach WiтTIN aufgestellten Tabelle angegeben.

Tabelle 1.

\begin{tabular}{|l|c|c|c|c|}
\hline \multicolumn{1}{|c|}{ Meeresgebiet } & $\begin{array}{c}\text { Areal } \\
\text { in } 1000 \mathrm{~km}^{2}\end{array}$ & $\begin{array}{c}\text { Mittlere Tiefe } \\
\mathrm{m}\end{array}$ & $\begin{array}{c}\text { Volumen } \\
\mathrm{km}^{3}\end{array}$ & $\begin{array}{c}\text { Grösste Tiefe } \\
\mathrm{m}\end{array}$ \\
\hline Die Bottenwiek & 37.0 & 42 & 1540 & 146 \\
Die Bottensee & 66.6 & 69 & 4595 & 294 \\
Das Schärenmeer & 8.3 & 23 & 195 & 146 \\
Das Aland meer & 5.2 & 77 & 405 & 301 \\
Der Finnische Meerbusen & 29.5 & 38 & 1125 & 121 \\
\hline
\end{tabular}

2. Die unterschiedenen Gebiete. Da es sich erwiesen hatte, dass die Feststellung des a $1 \mathrm{lg}$ e meinen Verlaufes des Eiswinters in den an Finnland grenzenden Teilen des Baltischen Meeres nur durch Herleitung des Winters jedes Meeresteiles geschehen konnte, war es eine der ersten Aufgaben der vorliegenden Arbeit Finnlands Meeresgebiet in zweckentsprechende Meeresteile zu gliedern. Diese mussten so bestimmt werden, dass sie einander zum Teil deckten. Denn nur unter dieser Voraussetzung konnten die einander 
in bezug auf die Zeit entsprechenden Eisstadien oder Phasen des Eiswinters der Meeresteile konnektiert werden. Ausserdem erschien es angebracht zwischen der Bottenwiek und der Bottensee, die in manchen Hin-

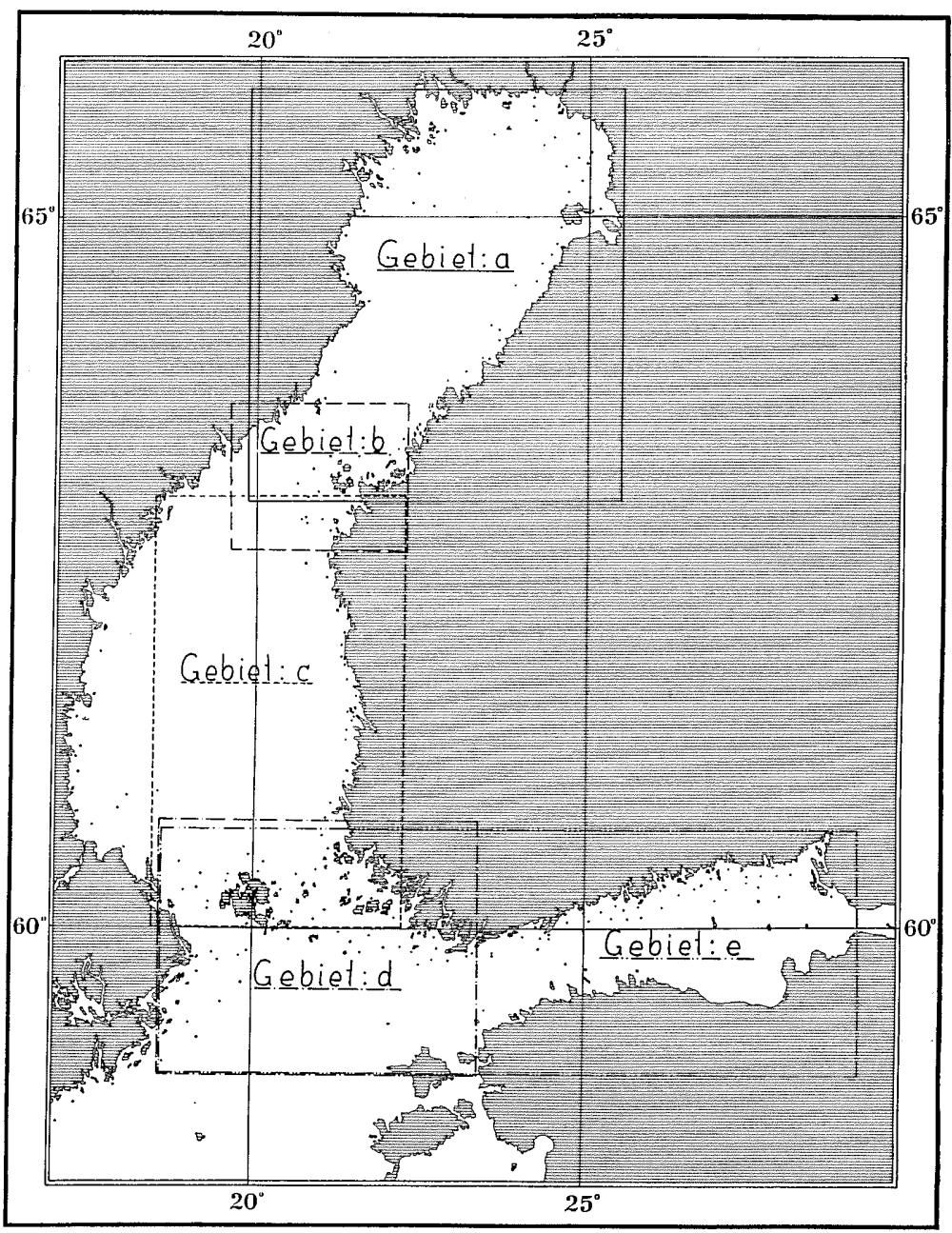

Fig. 1. Die Meeresteile oder Gebiete a, b, c, d und e.

sichten grundverschieden sind, ein besonderes Übergangsgebiet einzuschieben, das zugleich den Kvark vertritt. Es erwies sich ferner zweckmässig die für die Schiffahrt sowohl des Bottnischen wie des Finnischen Meerbusens so wichtigen Teile: die nördliche Ostsee, das Alandsmeer und die Mündung des Finnischen Meerbusens zusammen 
mit dem Schärenmeer in bezug auf die Eisverhältnisse als einheitliches Gebiet zu betrachten. So ergaben sich die Meeresteile oder Gebiete a, b, e, $\mathbf{d}$ und $\mathbf{e}$ (Fig. 1), deren Eisstadien herzuleiten die erste Aufgabe der vorliegenden Arbeit war, damit der Ausgangspunkt für eine definitive Beschreibung der Eisverhältnisse in den Finnland umgebenden Meeren erhalten wurde.

Die Meeresteile $\mathbf{a}, \mathbf{b}, \mathbf{c}, \mathbf{d}$ und e entsprechen, die anliegenden Grenzgebiete einbegriffen, der Reihe nach: a der Bottenwiek, $\mathbf{b}$ dem Kvark, e der Bottensee, d dem Ålandsmeer, dem Schärenmeer und der nördlichen Ostsee sowie e dem Finnischen Meerbusen. Die Grenzen der einzelnen Meeresteile sowie ihre Einteilung in Unterteile werden im später erscheinenden vierten Teil näher dargelegt.

3. Sonstige Bemerkungen. Die vorliegende Untersuchung basiert auf Beobachtungen der Eisverhältnisse an den Küsten Finnlands und in den Finnland umgebenden Meeren. Wenn wir aus irgendwelchem Grunde Angaben über die Eislegung oder den Eisgang der Flüsse und bisweilen auch der Seen verwerten, so wird das jedesmal ausdrücklich erwähnt.

Als Jahreszahl eines Winters gilt im allgemeinen der zweite Teil seiner doppelten Jahreszahl. So versteht man z. B. unter dem Winter 1867 den Winter 1866/67.

\section{Das Eisbeobachtungsmaterial bis zum Winter 1890 . Der Beginn des Winterseeverkehrs und der Programmentwurf von $188 \overline{\text {. }}$}

\section{A. Die ältesten Aufzeichnungen. Das Material vor $\mathbf{1 8 5 0 .}$}

4. Die ältesten vor dem Beginn des 19. Jahrhunderts gemachten Aufzeichnungen über die Eisverhältnisse an den Küsten Finnlands und in den Finnland umgebenden Meeren haben wir in finnischen und ausländischen geschichtlichen Arbeiten sowie in den ältesten Zeitungen Schwedens und Finnlands angetroffen. Von den benutzten ausländischen Arbeiten muss SPEerschneIders (54) verdienstvolle und mit wertvollen kritischen Anmerkungen versehene Arbeit über die Eisverhältnisse in Dänemarks Gewässern vor allem erwähnt werden. Zwar bietet diese Arbeit ebensowenig wie die Eastons (3) oder Hennings (30) ganz neues Material für die Meere Finnlands. Aber indirekt ist es uns möglich auf Grund der Angaben der er- 
wähnten Arbeit von SpeerschneIder einige Berechnungen über frihere strenge Winter in der nördlichen Ostsee, d. h. im d-Gebiet zu machen. Auf diese Weise können wir, obwohl nur indirekt, mit ziemlich grosser Wahrscheinlichkeit das Verzeichnis der strengen Winter auf Zeiten ausdehnen, von denen wir, was das Gebiet Finnlands anbetrifft, heute sehr wenig oder gar nichts wissen. Wir werden später bei den Analysen des Verlaufs der Eiswinter und bei den Untersuchungen über die eventuelle Periodizität oder andere langjährige Schwankungen im Grossverlauf der Eiswinter zeigen, auf welche Weise und innerhalb welcher Grenzen die strengen Winter in der nördlichen Ostsee mit Hilfe der Arbeit von SpeErschneIder festgestellt werden können.

5. Was die finnischen Quellen anbetrifft, so sind unsere zeitraubenden, auf Erforschung der ältesten eventuell vorhandenen Eisaufzeichnungen gerichteten Archivstudien noch nicht abgeschlossen. Trotzdem ist es uns gelungen manche sehr wertvolle Aufzeichnungen $\mathrm{zu}$ finden, die sich im allgemeinen auf die Eisverhältnisse in den Finnland umgebenden Meeren beziehen oder Aufklärung über frühere Eiswinter geben. Wenn sich noch eine Zeitangabe an die Eisaufzeichnung anschliesst, so können wir unter Verwertung unserer Durchschnittszahlen für die Charakterisierung des betreffenden Eiswinters anwendbare Daten erhalten. Auf solche Weise können wir nach und nach die überdies schon recht lange Reihe der bekannten Eiswinter erweitern.

Noch in einer anderen Hinsicht bieten die ältesten in finnischen Quellen von uns angetroffenen Aufzeichnungen eine interessante Ergänzung für eine Untersuchung der Eisverhältnisse in den an Finnland grenzenden Teilen des Baltischen Meeres, und zwar in der Hinsicht, dass sie, indem sie zuverlässige Beschreibungen über ehemalige Eiswinter enthalten, einen Vergleich zwischen den jetzigen und den früheren Eisverhältnissen möglich machen. So z. B. ermöglicht die älteste von uns gefundene Aufzeichnung (76), die aus dem Jahre 1561 stammt und darüber berichtet, wann die Eislegung des Meeres vor Helsinki zu erwarten war, einen solchen Vergleich, und der Bericht (56) über den Angriff der Tataren im Jahre 1577 von Estland aus über den eisbedeckten Finnischen Meerbusen auf Helsinki und die Landschaft Uusimaa enthält eine ganz richtige Beschreibung über die Lage und den Umfang, den die Packeiswälle bei südlichem Wind ausserhalb des äusseren Schärenhofes vor Helsinki annehmen können und wie rasch, wenn der Wind sich wendet, wieder offenes Wasser auftritt, d. h. wie leicht offene Seerinnen daselbst entstehen können. 
6. Die älteste das Meeresgebiet Finnlands unmittelbar betreffende Eisaufzeichnung stammt aus dem Winter 1269 (31), wo man mit Schlitten über das Eis von Schweden nach Gotland und von Estland nach Schweden gefahren sein soll. Das letztere besagt wohl eine Fahrt quer über den Finnischen Meerbusen die Küste Finnlands entlang und weiter quer über das Ålandsmeer nach Schweden. Von dem Winter 1306 berichten die Chroniken $(53,54)$, dass die Ostsee zwischen Öland, Gotland und Estland mit Eis bedeckt war. Aus dem 14. Jahrhundert besitzen wir Eisaufzeichnungen für 19 Winter. Sie betreffen entweder unmittelbar Finnlands Meeresgebiet oder sie erlauben uns auf die Strenge jener Winter zu schliessen. Aus dem 15. Jahrhundert besitzen wir ähnliche Eisaufzeichnungen für 16 Winter. Aus dem 16. Jahrhundert liegen Eisaufzeichnungen für 33 Winter vor. Davon sind mehrere recht umfangreich, wie aus den oben angeführten Beispielen hervorgeht. Aus dem 17. Jahrhundert können wir schon 55 Winter einigermassen charakterisieren und aus dem 18. Jahrhundert fehlen Eisaufzeichnungen nur aus 6 Wintern.

\%. Das finnische Eisbeobachtungsmaterial, auf das wir uns im folgenden beschränken, ist teils für die erste Hälfte des 19. Jahrhunderts von uns für diese Untersuchung aus der Literatur und den finnischen Zeitungen gesammelt, teils im Archiv des Institutes für Meeresforschung vorhanden.

Aus dem ersten Jahrzehnt des 19. Jahrhunderts besitzen wir-von den Aufzeichnungen über die Vereisung oder den Eisgang der Flüsse abgesehen-fast ausschliesslich das d-Gebiet betreffendes Material, wobei nur für Eckerö auf Åland mehrere Aufzeichnungen aus demselben Winter vorliegen. Aus dem folgenden Jahrzehnt, d.h. aus den Wintern 1810-1819, stehen uns vorläufig nur unvollständige Eisaufzeichnungen zur Verfügung. Das gilt besonders von den Wintern 1810 - 13. Dagegen besitzen wir aus den letzten Jahren dieses Jahrzehntes mehrere Aufzeichnungen aus demselben Winter und zwar wieder von Eckerö und Finström Godby auf Åland.

Die Eismeldungen aus den zwanziger Jahren des 19. Jahrhunderts sind immer noch recht unvollständig. Aus dem d-Gebiet besitzen wir Aufzeichnungen von 2-5 Orten, darunter nur von Finström Godby mehrere aus demselben Winter. Über die Eisverhältnisse an den übrigen Küsten Finnlands haben wir nur vereinzelte Aufzeichnungen. Aus den drei letzten Jahren dieses Jahrzehntes sind auch von Hailuoto aus der Bottenwiek oder vom a-Gebiet mehrere Aufzeichnungen aus demselben Winter vorhanden. Ausserdem besitzen wir Meldungen über das Auslöschen und Anzünden der Leuchttürme auf 
Utö und Porkkala. Aber die Verwertung dieser Meldungen zwecks Charakterisierung der Eisverhältnisse eines Winters bereitet so grosse Schwierigkeiten, dass ihre Bedeutung für dieses Jahrzehnt wie auch späterhin sehr gering ist.

Aus den dreissiger Jahren des 19. Jahrhunderts besitzen wir schon etwas mehr Eisaufzeichnungen aus jedem Winter, hauptsächlich edoch aus dem d-Gebiet und auch hier nur von Godby und Eckerö. Für das a-Gebiet haben wir mehrere Eisaufzeichnungen aus demselben Winter von Hailuoto und Oulu? Für das e-Gebiet liegen nur spärliche Aufzeichnungen vor.

Die Eisaufzeichnungen aus den vierziger Jahren des 19. Jahrhunderts sind im allgemeinen, mit Ausnahme der zwei letzten Jahre, gleich denjenigen des vorhergehenden Jahrzehntes. Die meisten Eisaufzeichnungen aus demselben Winter stammen vom Schärenmeergebiet. Für das Gebiet des Bottnischen Meerbusens gibt es aus einigen Jahren Aufzeichnungen über Eisverhältnisse bei Vaasa, Oravainen, Raahe und Oulu. Was die Küsten des Finnischen Meerbusens anbetrifft, gibt es nur von Helsinki Aufzeichnungen über die Eislegung und den Eisgang. Dagegen besitzen wir vom Ende des Jahrzehntes recht viele Meldungen über das Auslöschen und Anzünden der Leuchttürme.

Auf Grund dieses ältesten Eisbeobachtungsmaterials, dessen Quellen später eingehend verzeichnet und welches Material selbst grösstenteils referiert werden soll, haben wir versucht - soweit es in Anbetracht der Beschaffenheit der vorliegenden Eisaufzeichnungen möglich war — zu bestimmen, welcherlei Winter im allgemeinen oder welcher Phase des Winters eine jede Eisaufzeichnung entspricht.

\section{B. Das Material aus den Wintern 1850-1889.}

8. Im Jahre 1846 begann man auf J. J. Nervanders Anregung seitens der Wissenschaftsgesellschaft in Finnland klimatologisch "fôrderliche» Beobachtungen zu machen (77). Das Programm umfasste auch Eisaufzeichnungen. Obwohl diese hauptsächlich die Eislegung und den Eisgang der Flüsse und Seen betrafen, so häufte sich doch aus den letzten Wintern der vierziger Jahre sowie aus nahezu allen Wintern der fünfziger Jahre Beobachtungsmaterial über Eisverhältnisse an den Küsten. So besitzen wir, die Meldungen über Auslöschen und Anzünden der Leuchtfeuer - trotz ihrer recht zweifelhaften Bedeutung für die Eisforschung - mitgerechnet, Aufzeich- 
nungen von durchschnittlich 14 Beobachtungsorten. Tabelle 2, Gruppe 1850 + zeigt, wie die Anzahl der Beobachtungsorte in den verschiedenen Gebieten während dieses Jahrzehntes schwankte. Das Gebiet $\mathbf{a}+\mathbf{b}+\mathbf{c}$ entspricht dem Bottnischen Meerbusen bis zum

Tabelle 2.

Anzahl der Beobachtungsorte, die entweder den Beginn der Eislegung oder die Enteisung oder auch beides in den Wintern 1850-1889 meldeten (Kolumne $N$ ), und ihre Gruppierung in den verschiedenen Gebieten. An einigen Beobachtungsorten (Kolumne $\mathbf{n}$ ) wurden jedoch auch andere Eisaufzeichungen im Laufe desselben Winters gemacht.

\begin{tabular}{|r|r|r|r|r|r|}
\hline $\begin{array}{c}\text { Jahr } \\
+\end{array}$ & $\mathrm{N}$ & $\begin{array}{r}\mathrm{a} \\
+\mathrm{b} \\
+\mathrm{c}\end{array}$ & $\mathrm{d}$ & $\mathrm{e}$ & $\mathbf{n}$ \\
\hline 0 & 25 & 7 & 13 & 5 & $\mathbf{2}$ \\
1 & 15 & 3 & 8 & 4 & $\mathbf{1}$ \\
2 & 16 & 6 & 6 & 4 & $\mathbf{1}$ \\
3 & 18 & 4 & 9 & 5 & $\mathbf{2}$ \\
4 & 13 & 5 & 5 & 3 & $\mathbf{0}$ \\
5 & 13 & 3 & 6 & 4 & $\mathbf{1}$ \\
6 & 14 & 4 & 7 & 3 & $\mathbf{1}$ \\
7 & 8 & 2 & 1 & 5 & $\mathbf{1}$ \\
8 & 11 & 1 & 6 & 4 & $\mathbf{1}$ \\
9 & 5 & 1 & 1 & 3 & $\mathbf{1}$ \\
\hline Mittel & 14 & 4 & 6 & 4 & $\mathbf{1}$ \\
\hline
\end{tabular}

\begin{tabular}{|c|r|r|r|r|r|}
\hline \multicolumn{7}{|c|}{$1860+$} \\
\hline $\begin{array}{c}\text { Jahr } \\
+\end{array}$ & $\mathrm{N}$ & $\begin{array}{r}\mathrm{a} \\
+\mathrm{b} \\
+\mathrm{c}\end{array}$ & $\mathrm{d}$ & $\mathrm{e}$ & $\mathrm{n}$ \\
\hline 0 & 11 & 6 & 2 & 3 & $\mathbf{5}$ \\
1 & 19 & 14 & 3 & 2 & $\mathbf{7}$ \\
2 & 23 & 15 & 3 & 5 & $\mathbf{4}$ \\
3 & 23 & 13 & 6 & 4 & $\mathbf{2}$ \\
4 & 11 & 8 & 1 & 2 & $\mathbf{4}$ \\
5 & 15 & 8 & 2 & 5 & $\mathbf{5}$ \\
6 & 12 & 7 & 2 & 3 & $\mathbf{7}$ \\
7 & 21 & 11 & 7 & 3 & $\mathbf{1 0}$ \\
8 & 19 & 11 & 4 & 4 & $\mathbf{7}$ \\
9 & 46 & 20 & 14 & 12 & $\mathbf{5}$ \\
\hline Mittel & 20 & 11 & 4 & 4 & $\mathbf{6}$ \\
\hline
\end{tabular}

$1870+$

\begin{tabular}{|c|r|r|r|r|r|}
\hline $\begin{array}{c}\text { Jahr } \\
+\end{array}$ & $\mathrm{N}$ & $\begin{array}{r}\mathrm{a} \\
+\mathrm{b} \\
+\mathrm{c}\end{array}$ & $\mathrm{d}$ & $\mathrm{e}$ & $\mathbf{n}$ \\
\hline 0 & 36 & 16 & 11 & 9 & $\mathbf{5}$ \\
1 & 37 & 13 & 14 & 10 & $\mathbf{9}$ \\
2 & 38 & 16 & 13 & 9 & $\mathbf{4}$ \\
3 & 33 & 14 & 9 & 10 & $\mathbf{5}$ \\
4 & 35 & 13 & 11 & 11 & $\mathbf{4}$ \\
5 & 34 & 12 & 13 & 9 & $\mathbf{7}$ \\
6 & 45 & 17 & 17 & 11 & $\mathbf{1 0}$ \\
7 & 37 & 15 & 10 & 12 & $\mathbf{1 1}$ \\
8 & 27 & 12 & 9 & 6 & $\mathbf{9}$ \\
9 & 19 & 8 & 4 & 7 & $\mathbf{7}$ \\
\hline Mittel & 34 & 14 & 11 & 9 & 7 \\
\hline
\end{tabular}

\begin{tabular}{|c|r|r|r|r|r|}
\hline \multicolumn{1}{|c|}{$1880+$} \\
$\begin{array}{c}\text { Jahr } \\
+\end{array}$ & $\mathbb{N}$ & $\begin{array}{r}a \\
+b \\
+\mathbf{c}\end{array}$ & $\mathrm{d}$ & $\mathrm{e}$ & $\mathbf{n}$ \\
\hline 0 & 19 & 5 & 7 & 7 & $\mathbf{9}$ \\
1 & 27 & 10 & 7 & 10 & $\mathbf{1 2}$ \\
2 & 24 & 6 & 7 & 11 & $\mathbf{1 1}$ \\
3 & 26 & 9 & 7 & 10 & $\mathbf{1 2}$ \\
4 & 28 & 7 & 9 & 12 & $\mathbf{1 3}$ \\
5 & 29 & 10 & 9 & 10 & $\mathbf{1 3}$ \\
6 & 27 & 10 & 7 & 10 & $\mathbf{1 4}$ \\
7 & 24 & 7 & 8 & 9 & $\mathbf{1 7}$ \\
8 & 28 & 9 & 9 & 10 & $\mathbf{1 6}$ \\
9 & 25 & 6 & 10 & 9 & $\mathbf{1 6}$ \\
\hline Mittel & 26 & 8 & 8 & 10 & $\mathbf{1 3}$ \\
\hline
\end{tabular}

Leuchtturm von Isokari-Enskär, das d-Gebiet dem Schärenmeer, dem Ålandsmeer und der nördlichen Ostsee, das e-Gebiet dem Finnischen Meerbusen von Hangö an. Mehrere Eisaufzeichnungen im Laufe desselben Winters besitzen wir, wie die Ziffer in der Kolumne $\mathbf{n}$ zeigt, von einem oder höchstens zwei Beobachtungsorten. 
Im Laufe der sechziger Jahre des 19. Jahrhunderts beginnen die Aufzeichnungen der Leuchtturmstationen über die Eisverhältnisse in den Finnland umgebenden Meeren schon mehr zu enthalten als blosse Angaben, wann das Leuchtfeuer ausgelöscht und wann es wieder angezündet wurde. Als ganz neue Beobachtungsorte erscheinen einige Lotsenstationen, die entweder den Beginn der Eisbildung oder die definitive Enteisung oder auch beides melden. Die Anzahl der letztgenannten Stationen schwankt jedoch bedeutend in den verschiedenen Jahren. Aus Tabelle 2, Gruppe 1860+ ersieht man die Anzahl der Beobachtungsorte. Die Leuchttürme, die nur das Einstellen und Wiederaufnehmen ihrer Wirksamkeit meldeten, sind jedoch nicht mehr mitgerechnet.

Obwohl die Eisaufzeichnungen aus den sechziger Jahren des 19. Jahrhunderts hauptsächlich nur über Eislegung und Eisgang berichten, so besitzen wir doch, wie aus Tabelle 2, Gruppe $1860+$ hervorgeht, von durchschnittlich 6 Beobachtungsorten mehrere Aufzeichnungen aus demselben Winter.

Die Anzahl der Beobachtungsorte in den siebziger Jahren des 19. Jahrhunderts (Tabelle 2, Gruppe 1870+) ist verhältnismässig gross, durchschnittlich 34 pro Winter. Aus diesem Jahrzehnt können wir die Meldungen beinahe aller Lotsenstationen, die überhaupt Aufzeichnungen gemacht haben, verwerten. Kolumne n zeigt jedoch, dass solche Stationen, die mehrere Aufzeichnungen im Laufe desselben Winters gemacht haben, noch immer sehr gering an Zahl - durchschnittlich nur 7 - waren. So erhalten wir noch kein klares Bild von dem Verlauf der verschiedenen Eiswinter dieses Jahrzehntes. Dagegen besitzen wir hinreichendes Material über Anfang und Ende des Eiswinters und somit auch über die Länge des Winters an der Küste in den verschiedenen Teilen Finnlands. In den achtziger Jahren des 19. Jahrhunderts ist die gesamte Anzahl der benutzten Beobachtungsorte - durchschnittlich 26 pro Winter - kleiner als in dem vorhergehenden Jahrzehnt. Dagegen enthalten die Eisaufzeichnungen von durchschnittlich 13 Beobachtungsorten ausführlichere Angaben über Eisverhältnisse. Solche Beobachtungsorte sind vor allem die meisten Leuchttürme, deren Aufzeichnungen schon jetzt, was ihre Anzahl und Beschaffenheit betrifft, recht grossen Anforderungen genügen. Die Verminderung der gesamten Anzahl der Beobachtungsorte, die Eisaufzeichnungen gemacht haben, beruht einzig darauf, dass wir jetzt, da wir ziemlich viel eingehendes Material besitzen, nicht mehr blosse Meldungen der Lotsenstationen über Anfang und Ende des Eiswinters zu verwenden brauchen. Näheres über die Anzahl und Gruppierung der Beobach- 
tungsorte ersehen wir aus Tabelle 2, Gruppe 1880+. Auf Grund dieses Materials können wir den allgemeinen Verlauf der Winter in den achtziger Jahren des 19. Jahrhunderts, zum mindesten was das d-Giebet betrifft, recht eingehend verfolgen.

9. Das Eisbeobachtungsmaterial aus den Wintern 1850-1889 war grösstenteils schon früher im Archiv des Instituts für Meeresforschung gesammelt. Die Eisaufzeichnungen sind teils den Publikationen der Wissenschaftsgesellschaft, teils den verschiedenen Tagebüchern der Leuchttürme und Lotsenstationen sowie anderen Originalquellen entnommen. Über lange und schwere Winter haben wir in der Literatur und in den Zeitungen noch eine grosse Anzahl wertvoller Mitteilungen gefunden.

10. Auf Grund des Eisbeobachtungsmaterials aus den Wintern 1850 - 89 haben wir die Dauer dieser Eiswinter bestimmt. Als Vergleichungswinter haben wir die Karten "Zeit mit Eis" unseres Atlas (S. 46-51) benutzt. Ausserdem haben wir, in den Fällen, wo das Beobachtungsmaterial hinreichend war, die grossen Schwankungen in dem allgemeinen Verlauf der Eiswinter festzustellen versucht. Diese Eiswinteranalysen haben wir bis auf den Winter 1879 vermittels der von uns hergeleiteten G-Stadien (S. 30-44 des Atlas) durchgeführt, vom Winter 1880 an haben wir haupt. sächlich die d-Stadien (S. 16-18 des Atlas) verwendet. Später werden wir bei der Analyse des Verlaufes der Eiswinter das ganze Eisbeobachtungsmaterial eingehend beschreiben.

11. Das aus den Jahren 1850-89 vorliegende, aber noch sehr unvollständige Eisbeobachtungsmaterial zeigt ganz deutlich, warum die Auffassung, die man zu jener Zeit über Eisverhältnisse besass, sehr mangelhaft, teils sogar fehlerhaft war. In dem Masse, wie sich der finnische Seehandel entwickelte und seine Unterbrechung im Winter besonders der Butterausfuhr (52) Schwierigkeiten bereitete, erwies es sich jedoch als unerlässlich über die wirklichen Eisverhältnisse unterrichtet zu sein.

\section{c. Der Beginn des Winterverkehrs und der Programmentwurf von $188 \%$.}

12. Obschon bereits im November 1870 (4) der kleine von der schwedischen Postbehörde erbaute Dampfer $» P$ ostilj o n» gewissermassen den Winterverkehr im modernen Sinne des Wortes aufgenommen hatte, indem er Post und Passagiere über das Ålandsmeer zwischen Schweden und Åland beförderte, und obwohl der 
schwedische Dampfer S of i a (52) im Dezember desselben Jahres, allerdings ohne Erfolg, den Winterverkehr zwischen Stockholm und Baltischport einzuleiten versucht hatte, so können wir erst vom Dezember 1877 an (52) von einem wirklichen Winterseeverkehr in Finnland sprechen.

Damals begann nämlich die in der finnischen Winterseeverkehrsgeschichte so bekannte S/S »Express II», später kurz »Express» genannt, unter Kapitän A. A. Granrotr ihre Arbeit, von der im Jahre 1894 gesagt wurde, dass sie $\gg .$. im erheblichen Grad beigetragen hat, das Vorurteil gegen die Unmöglichkeit eines Winterseeverkehrs auf der Ostsee zu beseitigen.... (52) und dass sie»... bahnbrechend gewesen ist, da sie bewiesen hat, dass ein Winterseeverkehr auf $60^{\circ}$ nördlicher Breite, mit Ausnahme der ungünstigsten Fälle, möglich war, etwas was wohl damals, als dieser Verkehr begann, allgemein bezweifelt wurde.».

Wir wollen hier nicht näher darauf eingehen, wie durch die Pionierarbeit der »Express» der Winterseeverkehr sich allmählich zu entwickeln begann, wie um diesen Verkehr sicherzustellen die Beschaffung eines Eisbrechers sich bald als durchaus notwendig erwies und wie der Erstling der finnischen Eisbrecherflotte $S / S$ »M u r t a j a» schliesslich im Jahre 1890 fertig wurde und am 1. April desselben Jahres seine Arbeit in Finnland begann - was diese Fragen anbelangt, weisen wir auf die Arbeit (52) von Palmén hin. Dagegen wollen wir untersuchen, in welcher Weise der begonnene Winterverkehr auf die Eisbeobachtungsarbeit einwirkte und wie diese allmählich die Formen erhielt, die sie im grossen ganzen - abgesehen von der ausserordentlichen Entwicklung der Nachrichtenübermittelung - beibehalten hat.

13. Der Winterseeverkehr warf die Frage auf, ob es nicht möglich wäre, vermittels einer Untersuchung der Eisverhältnisse geeignetere Verkehrsstrassen zu finden und dadurch die schwersten Eisbildungen, die u. a. bisweilen vor Hangö entstehen, zu vermeiden, was wiederum die Regelmässigkeit des Verkehrs sicherstellen und die Eisgefahren verringern würde (40). Der erste Entwurf zu einer solchen Untersuchung der Eisverhältnisse in den Finnland umgebenden Meeren wurde im Jahre 1887 (17) ausgearbeitet. Sein Verfasser war der Schiffskapitän D. J. SJöstrand.

Da man diesen Entwurf des Kapitäns SJöstrand als Ausgangspunkt der später eingeleiteten gründlichen Organisierung der Eisbeobachtungsarbeit betrachten kann, dürfte es angebracht sein ihn hier etwas näher zu prüfen. 
Kapitän SJöstrand erbot sich in einem der vorgesetzten Behörde, dem Kaiserlichen Senat, eingereichten Schreiben, unter der Bedingung, dass ihm eine angemessene finanzielle Unterstützung bewilligt werde, im Winter 1888, nachdem das Eis an den Küsten "... fest geworden ist und das Treibeis sich gebildet hatte, präliminäre Untersuchungen den äusseren Schärenhof entlang vom Leuchtturm Söderskär an rings um den äusseren Schärenhof Ålands nordwärts bis nach Reposaari vorzunehmen, um $u$.a. die Grenzen und die Dicke des festen Eises, die Menge des Treibeises und seine Bewegung bei verschiedenen Winden usw. zu erforschen.» (5).

14. In diesem Entwurf, dessen Aufgabe war eine orientierende Zusammenfassung zu geben und die ersten zuverlässigen Grundlagen für die Kenntnis der Eisverhältnisse zu schaffen, sind zum ersten Mal. die kennzeichnenden Eigenschaften der Eis lagen kurz und klar angegeben. Es sind die "Ecksteine» der vorliegenden Arbeit: das an der Küste beginnende feste, un bewegliche Eis, die $\mathrm{E}$ is b r ä $\mathrm{m}$ e in ihrer weitesten Bedeutung, das ausserhalb der Bräme liegende lose, bewegliche Eis und die Dicke des Eis es.

15. Der Entwurf des Kapitäns SJöstrand zielte jedoch weiter. Er brachte nämlich in Vorschlag, dass auf Grund der durch die Untersuchungen erworbenen Kenntnisse "... ein Abkommen ... unter den Ostseestaaten über künftige Untersuchungen an verschiedenen Orten zum angedeuteten Zweck ... zustandegebracht werden sollte und dass tägliche Meldungen der Resultate an eine Zentralstation oder an die Winterverkehrshäfen gemacht werden sollten» (5).

Ohne weiter auf den Entwurf einzugehen, erwähnen wir nur, dass es über 30 Jahre gedauert hat, bis der tägliche Meldedienst in diesem Umfang — dank der grossartigen Entwicklung der Nachrichtenmittel, welche ihren Höhepunkt im Radio erhalten haben schliesslich verwirklicht werden konnte.

16. Vom Senat wurde der Entwurf der Wissenschaftsgesellschaft und dem Lotsenamt zur Begutachtung übersandt. Die meteorologische Kommission der Wissenschaftsgesellschaft, die aus den Herren Moberg, Lemström and Sundexl bestand, plante zusammen mit dem Chef des Lotsenamtes und dem Direktor der Meteorologischen Zentralanstalt anlässlich des Entwurfes von SJöstrand ein Eisbeobachtungsjournal. Später wurde auf Grund dieses Projektes und der Vorarbeiten der Lotsendirektion ein $n$ e u es Eis b e o b a c htungsprogramm sowie das Projekt eines Eisbeobachtungsjournals entworfen, das in grossen Zügen die- 
selben Elemente enthielt wie das heutige Eisbeobachtungsjournal des Institutes für Meeresforschung. Die eigentlichen Eisbeobachtungsstationen sollten u. a. Aufzeichnungen über 1) die Richtung und die Stärke des Windes, 2) den Wasserstand, 3) die Dicke des Eises, 4) die Lage der festen Eisbräme, 5) die Richtung und Breite der offenen Seerinnen, 6) die Grenze des Treibeises, seine Ausdehnung, Beschaffenheit, Bewegungsrichtung und Geschwindigkeit, 7) die Witterungsverhältnisse und den Schiffsverkehr usw. machen (40). Auf allen Lotsenstationen sollte ausserdem die Zeit der Eislegung und des Eisganges sowie auch, wenn das Eis aus dieser oder jener Ursache zerbrach oder in Bewegung geriet oder auch ganz verschwand, festgestellt werden (5). Nach Ansicht einiger Ausschussmitglieder war die Beobachtungsarbeit mit der Zeit einem speziell zu gründenden nautisch-meteorologischen Bureau zu übertragen. Diesem Bureau sollte das Sammeln und Bearbeiten des Beobachtungsmaterials obliegen. Auch sollte es »den Seefahrern und Häfen Rat und Auskunft über die Eisverhältnisse» erteilen (40).

1\%. Das neue Eisbeobachtungsprogramm sowie das Projekt eines Beobachtungsjournals waren im März 1889 fertig, aber erst im Winter 1893 wurden auf Veranlassung des Lotsenamtes in Hangö Beobachtungen über die Eisverhältnisse zum ersten Mal in speziell gedruckte Journale eingetragen. Ausserdem wurden einmal in der Woche oder öfter, wenn bedeutendere Veränderungen in den Eisverhältnissen eingetroffen waren, auf besonderen Karten die Grenzen des Eises, die Packeiswälle usw. eingezeichnet (52).

Fünf Jahre waren somit seit dem Entwurf des Kapitäns SJöSTRAND vergangen, bevor eine planmässige Eisbeobachtungsarbeit mit Eisjournalen und Eiskarten, welche das in physikalischer Hinsicht richtigste Eisbeobachtungssystem bilden, zuerst in Hangö, dann auf einigen Leuchttürmen in Gang kam.

\section{Das Eisbeobachtungsmaterial aus den Jahren 1890_191/1 und die Beobachtungsarbeit der Hydrographisch- biologischen Kommission.}

\section{A. Das Material aus den Jahren 1890-1897.}

18. Wie erwähnt fand weder die Eingabe von Sృöstrand noch diejenige der Wissenschaftsgesellschaft genügend Beachtung. Die Beobachtungen wurden - abgesehen von den in Hangö im Winter 1893 gemachten - in derselben Weise wie früher fortgesetzt, und 
eine a $11 \mathrm{~g}$ e m e i n e, die Beobachtungsarbeit bestimmende Norm scheint nicht vorhanden gewesen zu sein. Dessenungeachtet sind die Eisaufzeichnungen einiger Leuchttürme aus diesen Wintern wie auch aus einigen Wintern der vorhergchenden Jahrzehnte so ausführlich, dass man die Veränderungen im Gesichtskreis der betreffenden Leuchttürme zeitweise beinahe von Tag zu Tag verfolgen kann. Ausserdem besitzen wir recht ausführliche Eistagebücher für einige Häfen.

19. Das Eisbeobachtungsmaterial aus den Wintern 1890-1895 ist in extenso in A. HEINRICHs' Arbeit »Isförhållandena i Östersjön och dess vikar» (17) veröffentlicht. Ausserdem enthalten HeINRICHs' Finnlands Schnee- und Eisverhältnisse in denselben Jahren behandelnde Abhandlungen (18-23) noch einige Angaben. Das Beobachtungsmaterial aus den Wintern 1896 und 1897 liegt, mit Ausnahme der in den Publikationen von HeInRICHs (24) und KorHoneN (26) erschienenen Eisaufzeichnungen, unveröffentlicht im Archiv des Instituts für Meeresforschung.

Tabelle 3.

Die Anzahl (N) der Eisbeobachtungsorte in den Wintern 1890-189\%. Vollständigere Aufzeichnungen von $n$ Orten.

\begin{tabular}{|c|c|c|}
\hline Winter & $\mathrm{N}$ & $\mathrm{n}$ \\
\hline 1890 & 71 & 10 \\
$1 \& 91$ & 85 & 11 \\
1892 & 85 & 11 \\
1893 & 77 & 19 \\
1894 & 68 & 19 \\
1895 & 78 & 23 \\
1896 & 50 & 16 \\
1897 & 55 & 16 \\
Im Mittel & 73 & 16
\end{tabular}

HeINRICHs hat in seinen obenerwähnten Untersuchungen im allgemeinen seine Bearbeitung des Eisbeobachtungsmaterials darauf beschränkt, dass er nach einigen Aufzeichnungen die Zahlen der Eistage berechnet und die Kurven der Eistage und der Enteisung auf Finnlands Meeresgebiet ausgedehnt hat. Es sei noch bemerkt, dass HeINRICHs in seiner Untersuchung über die Eisverhältnisse im Jahre 1892 u.a. die Frage der Einwirkung der meteorologischen Faktoren auf die Veränderungen in den Eisverhältnissen behandelte. Später werden wir im Zusammenhang mit anderen Fragen auf HEINRICHs' Ergebnisse zurückkommen. 
20. Je nachdem auf welche Weise man einige Beobachtungsorte wie Lotsenstationen, Leuchttürme usw. gruppiert, wechselt die Anzahl der Beobachtungsorte in den Wintern 1890-1897. Nach unserer Gruppierung (Tabelle 3) gab es durchschnittlich 73 Beobachtungsorte pro Jahr. Am wenigsten (nur 50 Beobachtungsorte) finden wir im Winter 1896 und am meisten (85) in den Wintern 1891 und 1892. Vollständigere Aufzeichnungen besitzen wir durchschnittlich von 16 Beobachtungsorten, im Winter 1890 nur von 10, im Winter 1895 dagegen von 23 Beobachtungsorten. Hangö, das sich zum wichtigsten Winterhafen Finnlands entwickelt hatte, nimmt eine Sonderstellung ein, da man dort, wie schon oben erwähnt wurde, seit dem Winter 1893 ausser den regelmässigen Eisbeobachtungen noch auf besonderen zu diesem Zwecke gedruckten Karten von Zeit zu Zeit die Eisgrenzen, die offenen Seerinnen, Eiswälle usw. einträgt.

21. Wie wertvoll diese in Hangö begonnene programmässige Eisbeobachtungsarbeit, vor allem wegen der Karten, für eine richtige Auffassung der Eisverhältnisse im Meeresgebiet Finnlands war, geht deutlich aus den Sitzungsprotokollen der Gesellschaft für die Geographie Finnlands vom 20. Oktober 1894 und 19. Januar 1895 hervor. In dem ersteren wird u. a. erwähnt, dass »Ingenieur K. E. PaLméN ... über das Packeisband Bericht erstattet hat, das in den strengen Wintern der letzten Jahre die Schiffahrt ausserhalb Hangö gehindert hat. Es scheint von grossem ... Interesse zu sein zu ermitteln, wie diese Barriere ihre Lage verändert, und wie weit sie ostwärts innerhalb des Finnischen Meerbusens und nordwärts die Westküste entlang auftritt. Dasselbe gilt von den offenen Seerinnen, die sich von der offenen Ostsee ausserhalb des erwähnten Packeisbandes erstrecken»; im letzteren: "... die bis jetzt (in Hangö) gezeichneten Karten geben eine ausserordentlich gute Beleuchtung der Eisverhältnisse und lassen vermuten, dass solche Beobachtungen auch an anderen Orten sehr lehrreich sein würden ... Kritisch behandelt dürften diese Beobachtungen ein Urteil sowohl über die Ausdehnung des Eises als die allgemeine Lage und Festigkeit der Eisbräme in milden und kalten Wintern ermöglichen.» (5)

Die obenangeführte Auffassung von der Bedeutung der in Hangö ausgeführten systematischen Eisbeobachtungsarbeit - nebst ihrer Ergänzung durch die Eiskarten - war ganz richtig. Eine auf diese Weise organisierte Beobachtungsarbeit war in der Tat notwendig, bevor die Darstellung der Eisverhältnisse in unserem Meer ganz allgemein die den Erscheinungen am besten entsprechende sog. kartographische Form erhalten konnte, wie sie in dieser Untersuchung zur Anwendung kommt. 


\section{B. Das Material aus den Jahren 1898-1910.}

22. Erst im Jahre 1896 wurde der Vorschlag der Meteorologischen Kommission der Wissenschaftsgesellschaft vom März 1889 wieder aufgenommen. Das Komitee, das im Zusammenhang mit dem Bau des neuen Eisbrechers, später $S / S$ » $S$ a $m$ p o» genannt, eingesetzt war, erhielt u. a. den Auftrag vorzuschlagen, wie der Winterschiffahrt dienliche Beobachtungen über Eis-, Wind- und Stromverhältnisse am besten vorgenommen, und wie die Resultate zusammengestellt und veröffentlicht werden konnten (40). Das Komitee entwarf zusammen mit den von ihm herangezogenen Sachverständigen einen Vorschlag, der sich an den Vorschlag der meteorologischen Kommission der Wissenschaftsgesellschaft anschloss und die Gründung eines nautisch-meteorologischen Bureaus, das bis auf weiteres eine Abteilung der Meteorologischen Zentralanstalt bilden sollte, unterstützte (40). Bevor der Vorschlag des Komitees, der seinerseits von der Meteorologischen Kommission behandelt wurde, irgend ein endgültiges Stadium erreichte, wurde die Frage einer planmässigen Arbeit auf andere Weise gelöst.

Die Behörden der Stadt Helsinki, welche einsahen, was für eine Bedeutung die Kenntnis der Eisverhältnisse für die Organisierung eines regelmässigen Winterverkehrs nach Helsinki hatte, ersuchten im Jahre 1897 das Lotsenamt um das Recht (40) auf den Leuchttürmen von Söderskär, Harmaja, Porkkala und Jussarö Eisbeobachtungen vornehmen zu dürfen. Die Zustimmung wurde sogleich erteilt und schon im Herbst desselben Jahres wurde die Beobachtungsarbeit auf den erwähnten Leuchttürmen begonnen. Dabei befolgte man ein Programm, das später auf einigen Stationen der Meteorologischen Zentralanstalt zur Anwendung kam und das die Grundzüge des Vorschlags der Meteorologischen Kommission vom März 1889 verwirklichte.

23. Im Laufe des Jahres 1898 geriet die Frage der Gründung eines nautisch-meteorologischen Bureaus und damit auch die allgemeine Organisation der Beobachtungsarbeit in neue Geleise.

Auf dem Kongress der skandinavischen Naturforscher im Sommer 1898 in Stockholm wurde ein Vorschlag gemacht, der auf das Zusammenarbeiten von Finnland, Schweden, Norwegen und Dänemark auf dem Gebiet der hydrographischen Untersuchungen abzielte. Seitens der Regierung Finnlands beauftragte man die Meteorologische Kommission der Wissenschaftsgesellschaft die vorgeschlagenen Expeditionen zu organisieren. Es ergab sich sofort von selbst, dass die Anknüpfung der nautisch-meteorologischen Beobachtungen - 
die Eisbeobachtungen einbegriffen - an die hydrographischen Untersuchungen den Wert der letzteren bedeutend erhöhen würde. In ihrem Schreiben vom 20. November 1898 (40) schlug dann auch die Meteorologische Kommission vor, die Frage eines nautischmeteorologischen Bureaus vorderhand fallen zu lassen, statt dessen aber meteorologische, hydrographische und Eisbeobachtungen auf den Leuchtturmstationen von Bogskär, Utö, Hangö, Porkkala und Harmaja sowie auf dem Feuerschiff Äransgrund vorzunehmen. Die auf den Leuchtturmstationen von Porkkala und Harmaja schon eingeleitete Eisbeobachtungsarbeit sollte von der Meteorologischen Zentralanstalt finanziert werden. Ausserdem schlug die Kommission vor, dass auch die Winterliniendampfer sich an der Eisbeobachtungsarbeit beteiligten, indem sie auf besonderen Kartenvordrucken die Lage des während der Fahrt beobachteten Eises angaben (78).

24. Auf den obenerwähnten Leuchtturmstationen sollten Eisbeobachtungen über die Dicke des festen Eises, des Breieises, des Schneebreies und der Schneedecke, über die Lage des Randes des festen Eises, über das Treibeis, seine Menge und Beschaffenheit sowie Bewegungsrichtung, über Packeis und Packeisbänder, über offene Seerinnen, ihre Lage und Breite gemacht werden. Die Beobachtungen sollten in besondere Eisjournale eingetragen und auf besonderen Kartenvordrucken die Grenzen der Eisarten, der Rand des eisfreien Wassers, die offenen Seerinnen usw. angegeben werden. Die Beobachtungen sollten zweimal in der Woche gemacht werden, am Dienstag und am Freitag, wobei auch die Karten zu zeichnen waren. Falls grössere Veränderungen in der Eislage eintraten, sollten Beobachtungen auch an anderen Wochentagen gemacht werden (40). Das Programm der Eisbeobachtungsarbeit war somit ganz dasselbe wie jenes, das schon im Winter 1893 in Hangö befolgt wurde.

25. Im Herbst 1899 genehmigte die Regierung die Vorschläge der Meteorologischen Kommission und bewilligte der Meteorologischen Zentralanstalt zunächst auf fünf Jahre die nötigen Mittel. Schon im Dezember desselben Jahres konnte die Beobachtungsarbeit - die vollständigen Eisbeobachtungen mit einbegriffen - auf dem Leuchtturm von Utö beginnen. Auf den Leuchttürmen von Bogskär und Hangö wurde sie Anfang 1900 eingeleitet. Aus derselben Zeit stammen auch die ersten Eiskarten der Winterliniendampfer auf den Linien Finnland-Schweden und Finnland-Dänemark. Später wurde die Eisbeobachtungsarbeit auf den Leuchtturmstationen von Märket und Säppi (im Jahre 1906), von Ulkokalla (im Jahre 1907) sowie von Valsörarna und Norrskär (im Jahre 1908) begonnen. 
26. Das Eisbeobachtungsmaterial aus den Wintern 1898-1910 umfasst hauptsächlich auf dreierlei Weise gemachte Aufzeichnungen. Ausser dem auf den obenerwähnten Leuchttürmen, d. h. zunächst auf Söderskär, Harmaja, Porkkala und Jussarö, dann auf Utö und Bogskär, später auch auf anderen Leuchttürmen befolgten Programm machte man auf den Leuchtturmstationen fortlaufende, teilweise tägliche Aufzeichnungen über die Eisverhältnisse. Auf anderen Eisbeobachtungsstellen, wie den Lotsenstationen, enthielten die Eisaufzeichnungen nur eine Meldung darüber, wann das erste Eis sich gezeigt hatte, wann es Fussgänger trug usw.

Das Beobachtungsmaterial aus den Wintern 1898-1910 ist somit, was seine Beschaffenheit betrifft, im allgemeinen sehr verschieden. Auf Grund der teilweise sehr umständlichen und fortlaufenden Aufzeichnungen sowie des Eiskartenmaterials; das zuerst den Finnischen Meerbusen und die Nördliche Ostsee, dann auch andere Gebiete umfasste, ist es bedeutend besser als vorher. So konnte denn auch KARSTEN in seiner Untersuchung der Eisverhältnisse im Finnischen Meerbusen und in der Nördlichen Ostsee in den Wintern 1898-1902 (40) exakter, als es früher möglich gewesen war, die äussere Grenze der Bräme des festen Küsteneises und die Lage des Treibeises bestimmen (Fig. 2).

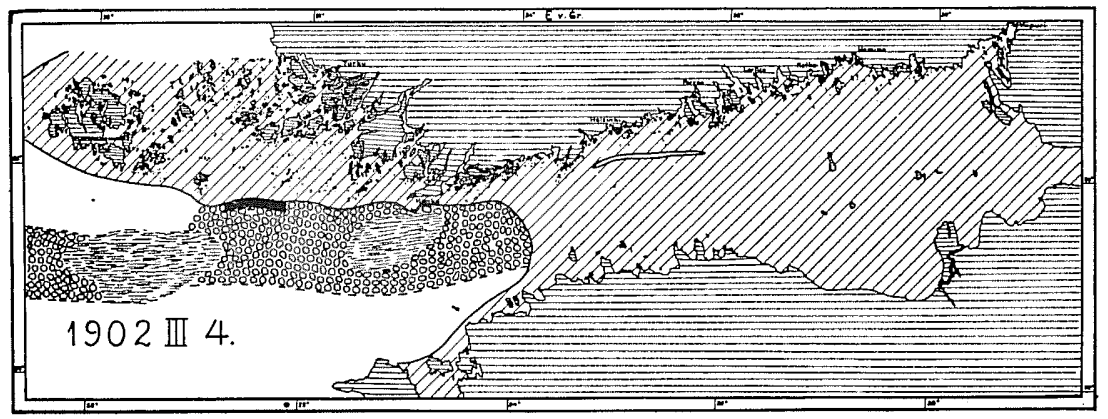

Fig. 2. Bräme des festen Küsteneises und Lage des ausserhalb der Bräme liegenden losen Meereseises im Finnischen Meerbusen 1902 III. 4. Nach Karsten (40) 1911.

2\%. Das Eisbeobachtungsmaterial aus den Wintern 1898-1910 ist schon zum Teil in verschiedenen Untersuchungen veröffentlicht worden. So umfasst Karstens oben erwähnte Untersuchung (40) das Material für den Finnischen Meerbusen und die nördliche Ostsee sowie den daran grenzenden Teil des Schärenmeeres aus den Wintern 1898-1902, und die Untersuchung von HELLsTröm über die Eisverhältnisse in der Bottensee in den Wintern 1900-1909 (27) enthält, 
ausser dem eigentlichen Bottensee-Material, auch Angaben über Eisverhältnisse im Ålandsmeer, dem Schärenmeer und der nördlichen Ostsee. Schon früher hatte WITTING in seiner grossen Arbeit über die Wasserbewegungen und die Wasserumsetzung in den Finnland umgebenden Meeren (74) das Eisbeobachtungsmaterial des Bottnischen Meerbusens aus den Wintern 1904-1905 veröffentlicht. Ausserdem hat Witring im Atlas von Finnland vom Jahre 1910 (57) und in den Hydrographisch-biologischen Untersuchungen N:o 7 (75) die Eiskarten des ganzen Meeresgebietes Finnlands aus den Jahren 1904 und 1905 herausgegeben. Ferner enthalten die Publikationen von HEINRICHS und KorHONEN über die Schnee- und Eisverhältnisse in Finnland (18-26, 41-49) auch Eisaufzeichnungen. In der vorliegenden Untersuchung haben wir uns auf die Angaben der obenerwähnten Arbeiten gestützt, ohne jedesmal die Originalquelle anzugeben.

\section{Tabelle 4.}

Kolumne $N$ gibt die totale Anzahl der Eisbeobachtungsorte, Kolumne $n$ die Anzahl der Beobachtungsorte, deren Aufzeichnungen benutzt sind, an. Von den letztgenannten haben $\mathbf{n}$ Orte den ganzen Eiswinter beobachtet oder sind die Beobachtungen in anderer Hinsichț vollständiger.

\begin{tabular}{|c|c|c|c|c|c|c|c|c|c|c|c|}
\hline Jahr & N & n & n & Jahr & N & n & n & Jahr & N & n & n \\
\hline & & & & & & & & & & & \\
1898 & 64 & 25 & 20 & 1903 & 46 & 34 & 22 & 1908 & 60 & 48 & 22 \\
1899 & 62 & 25 & 19 & 1904 & 53 & 45 & 21 & 1909 & 63 & 51 & 23 \\
1900 & 61 & 40 & 21 & 1905 & 51 & 43 & 23 & 1910 & 44 & 44 & 23 \\
1901 & 65 & 42 & 20 & 1906 & 61 & 42 & 23 & & & & \\
1902 & 64 & 39 & 21 & 1907 & 58 & 49 & 23 & Mittel & 56 & 40 & 22 \\
\hline
\end{tabular}

Das in den obenerwähnten Arbeiten veröffentlichte Beobachtungsmaterial umfasst jedoch nur einen Teil des ganzen Materials aus den Jahren 1898-1910, der übrige Teil liegt unveröffentlicht im Archiv des Instituts für Meeresforschung, u. a. das ganze Material aus dem Jahre 1910. Die Anzahl der Beobachtungsorte in diesen Wintern ergibt sich aus Tabelle 4, wo Kolumne $\mathrm{N}$ die totale Anzahl der Beobachtungsorte angibt. Davon haben wir in dieser oder jener Weise die Aufzeichnungen von in Kolumne $\mathrm{n}$ angegebenen Beobachtungsorten verwendet. Die letztgenannten Beobachtungen waren entweder ununterbrochen den ganzen Winter lang fortgeführt worden oder in anderer Hinsicht vollständiger als die Aufzeichnungen anderer Beobachtungsorte. $\mathrm{Zu}$ diesen gehörten die meisten Leuchtturmstationen, darunter auch die sog. eigentlichen Eisbeobachtungsstationen des Lotsenamtes und der Meteorologischen Zentralanstalt (2). 
Ausser dem erwähnten, an den Beobachtungsorten gesammelten Material wurden in den Wintern seit 1899 auf den Winterliniendampfern der Linien Finnland-Schweden und Finnland-Dänemark besondere Eiskarten gezeichnet, die eine wertvolle Ergänzung des Eisbeobachtungsmaterials der festen Beobachtungsorte bedeuten.

28. Karsten, Witting und Helcström haben das Eisbeobachtungsmaterial auf verschiedene Weise bearbeitet. Wir werden uns hier nur auf einige Bemerkungen beschränken.

KARSTEN war der erste, der auf Grund des Materials aus den Wintern 1898-1902 Eiskarten des Finnischen Meerbusens und der Nördlichen Ostsee gezeichnet hat, auf denen die feste Eisbräme der

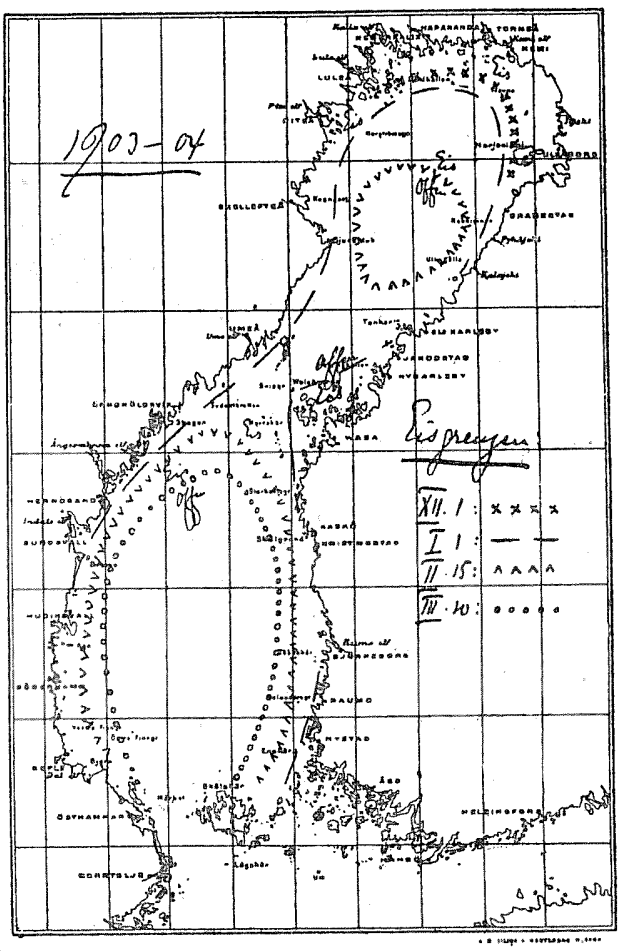

Fig. 3. Ungeführe Eisgrenze im Winter 1904 im Bottnischen Meerbusen. Nach WrTrrg (74) 1908.
Küste deutlich vom losen Eis zu unterscheiden ist (Fig. 2). Auch sind die Packeisbände auf den Karten angegeben. KaRsten hat ausserdem die Veränderungen in der Ausbreitung des festen Eises und des Treibeises im Umkreise einiger Leuchttürme graphisch dargestellt und die Dicke des Eises und seiner Bedeckung in denselben Wintern durch Kurven veranschaulicht.

WiTriag hat zuerst den Verlauf des Eiswinters im Bottnischen Meerbusen behandelt, nämlich für die Winter 1904 und 1905 (74). Was den erstgenannten Winter anbetrifft, so hat er ungefähre Eisgrenzen für 8 Zeitpunkte, im Winter 1905 für 7 Zeitpunkte angegeben.

Im Atlas von Finnland 1910 hat Wrтrrisg den Verlauf des Eiswinters 1905 im ganzen Meeresgebiet Finnlands mittels 6 Karten dargestellt. 
HeLLSTRöm hat in seiner erwähnten ersten Untersuchung über die Eisverhältnisse in der Bottensee den Verlauf der Winter 1900 bis 1909 unter Berücksichtigung der Witterungsverhältnisse bestimmt. Dabei hat er auch die Veränderungen in der Ausdehnung des Eises kartographisch dargestellt (Fig. 5).
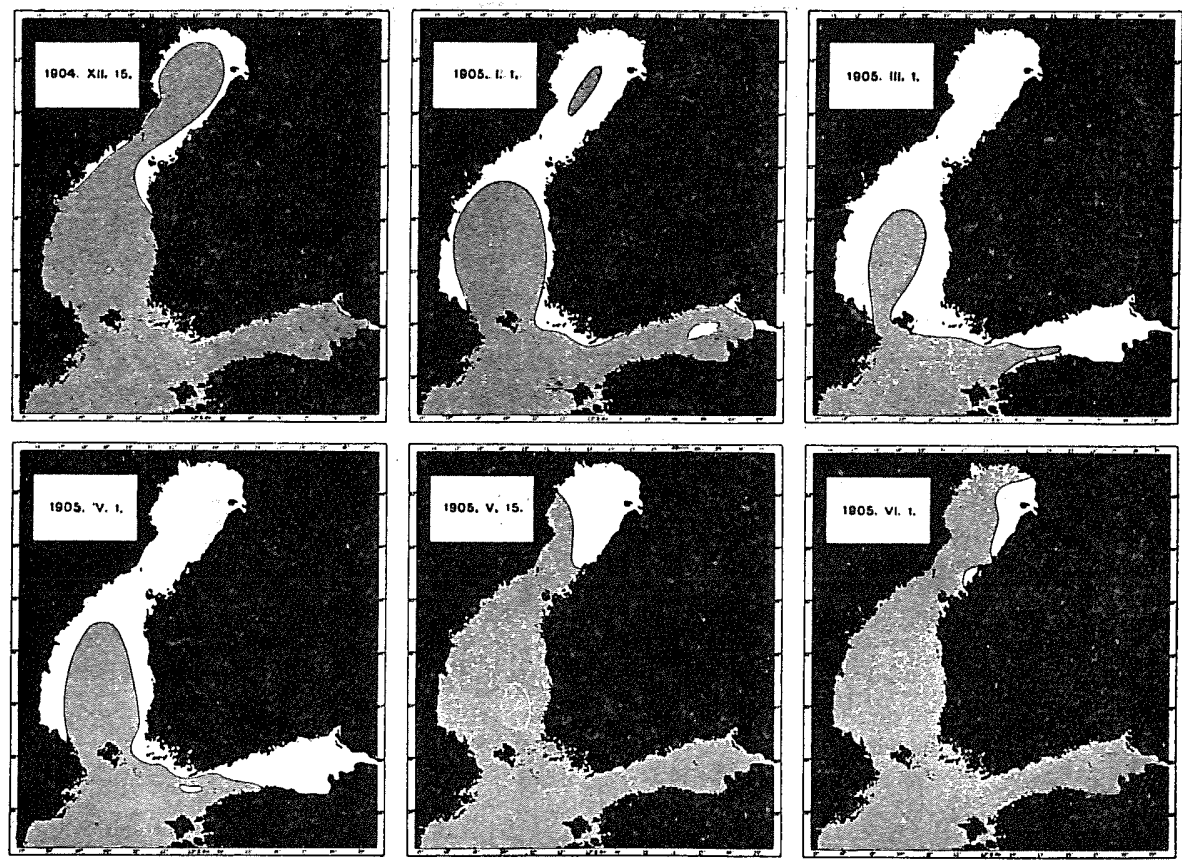

Fig. 4. Der Verlauf des Eiswinters 1905, durch 6 Eislagen veranschaulicht. Nach Witring (57) 1911.

Auf Grund seiner zehnjährigen Periode hat HELLSTRöm die durchschnittlichen Zeitpunkte der Eislegung und des Eisganges und somit die Dauer des Eiswinters in der Bottensee und den angrenzenden Meeren bestimmt. Ausserdem hat er die Einwirkung meteorologischer und hydrographischer Faktoren auf die Eisverhältnisse der Bottensee dargelegt. In seiner zweiten Untersuchung (28) über die Eisverhältnisse der Bottensee will er »eine Darstellung der Wirkung der Lufttemperatur, der Winde und der Niederschläge auf die Gestaltung der Eisverhältnisse in der Eislegungs- und Eisgangsperiode in der Bottensee geben sowie feststellen, ob diese meteorologischen Hauptfaktoren der Entwicklung der Eisverhältnisse eines ganzen Winters ihr Gepräge geben können, d.h. ob sie an der Entwicklung der verschiedenen Typen der Eiswinter mitwirken.» 
29. In der vorliegenden Untersuchung haben wir auf Grund des Beobachtungsmaterials aus den Jahren 1898-1910 u. a. den Verlauf der Eiswinter und die Dauer derselben bestimmt. Ausserdem haben wir die Angaben über Eisdicke, Treibeisbände, Packeiswälle usw. beachtet. Was den sehr kurzen Eiswinter 1910 betrifft, haben wir

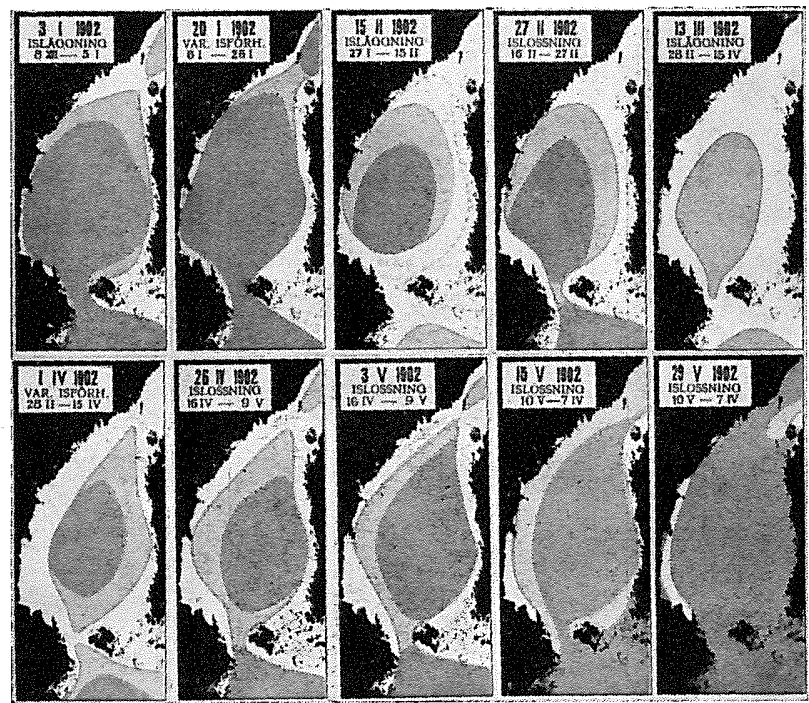

Fig. 5. Der Verlauf des Eiswinters 1902 in der Bottensee. Nach HeLLSTRöM (27) 1913.

das Beobachtungsmaterial ganz durchgearbeitet und, in dem Masse, wie es möglich war, den Freitagslagen des Winters entsprechende Eislagen gezeichnet. Von diesen sind in Fig. 37 zwei Eislagen für das d-Gebiet wiedergegeben.

\section{Die Beobachtungsarbeit der Hydrographisch-biologischen Kom- mission. Das Material aus den Jahren 1911-1914.}

30. Nachdem im Mai 1902 die Hydrographisch-biologische Kommission als eine selbständige, obwohl der Wissenschaftsgesellschaft untergeordnete Organisation gegründet war, liess sich erwarten, dass mit der Zeit die Eisbeobachtungsarbeit auf diese übergehen würde, da sie, wie der Ausschuss der Wissenschaftsgesellschaft schon früher bemerkt hatte, eine natürliche und notwendige Ergänzung der eigentlichen hydrographischen Arbeiten bildete. Im Jahre 1911 wurde auch das Eisbeobachtungsmaterial, das bis dahin von der Meteorologischen Zentralanstalt gesammelt wurde, von den Hydrographisch- 
biologíschen Meeresuntersuchungen übernommen (67) und im Jahre 1912 wurde auf Veranlassung WiтTiNGs als Leiters der Meeresuntersuchungen das früher gesammelte Material geprüft, bevor man die Eisbeobachtungsarbeit zu organisieren begann.

31. Massnahmen zur Verbesserung und Erweiterung der Eisbeobachtungsarbeit im Jahre 1913. Bis zum Jahre 1912 wurden bei den Eisbeobachtungen praktisch betrachtet drei verschiedene Verfahren angewendet: entweder wurden die Beobachtungen nach der Vorschrift der Meteorologischen Kommission an bestimmten Tagen, am Dienstag und Freitag, ausgeführt, wobei die die Eisverhältnisse angebenden Karten gezeichnet wurden, oder nach einem speziellen Frageformular betr. die erste Eislegung, definitive Eislegung usw. oder die Beobachtungen wurden dauernd von Tag zu Tag ausgeführt und auf speziellen Monatsformularen verzeichnet, in den beiden letzteren Fällen nach den Instruktionen des Lotsenamtes (68).

Anstatt dieser drei Beobachtungsverfahren wurde nun beschlossen nur eins in Anwendung zu nehmen, nämlich das dritte von den genannten, und im Jahre 1913 wurde die fortlaufende, tägliche Eisbeobachtungsarbeit mit Monatsjo urnalen begonnen. In den neuen Eisjournalen (Formular C, 1913 XII der Meeresuntersuchungen) hatte jede Eisart ihre eigene Kolumne. Ausserdem gab es auch besondere Kolumnen für die Angaben, wie viel Zehntel des ganzen Beobachtungsgebietes von einer jeden Eisart bedeckt waren. Nach Ablauf eines Monats sollten die Eisjournale an die Kommission zurückgesandt werden. Jene Beobachtungsorte, die schon früher Karten zu zeichnen beauftragt waren, sollten ihre Arbeit fortsetzen. Gleichzeitig versuchte man neue Kartenzeichnungsstationen zu gründen und Lücken in der Beobachtungsarbeit durch freiwillige Arbeit auszufüllen (68).

Diese Neuerungen bedeuteten eine wichtige Verbesserung in der Beobachtungsarbeit. Die Resultate waren jedoch nicht so befriedigend, wie man hätte erwarten können. So schreibt Wiтring im Jahre 1914 " . . . es ist jedoch meine Überzeugung, dass ein geordnetes zusammenhängendes (Eisbeobachtungs-) System kaum auf die Dauer aufrechterhalten werden kann, falls nicht die Möglichkeit vorliegt, die Beobachter zu besolden.» (69).

32. Das Beobachtungsmaterial aus den Eiswintern 1911, 1912 und 1913 ist in den von Wiтrisg herausgegebenen Finnländischen hydrographisch-biologischen Untersuchungen in extenso publiziert worden (71-73). Das Material aus dem Eiswinter 1914 ist ebenfalls in 
extenso in die von Granqvist herausgegebene Publikation N:o 3 des Instituts für Meeresforschung aufgenommen (6).

In diesen Wintern war die Anzahl der Beobachtungsorte durchschnittlich 102, wobei jedoch einige Beobachter nicht beachtet wurden. In der vorliegenden Untersuchung sind die Eisaufzeichnungen von durchschnittlich 80 Beobachtungsorten verwertet worden. Tabelle 5 zeigt die Schwankungen in der Anzahl der Beobachtungsorte.

Tabelle 5.

Zeile $N$ zeigt die totale Anzahl der Beobachtungsorte. Davon sind in dieser Untersuchung die Aufzeichnungen von $\boldsymbol{n}$ Orten verwertet.

\begin{tabular}{|c|r|r|r|c|}
\hline Beobachtungsorte & 1911 & 1912 & 1913 & 1914 \\
\hline $\mathrm{N}$ & 112 & 105 & 95 & 94 \\
$\mathbf{n}$ & 57 & 95 & 85 & 84
\end{tabular}

WIтTING hat in seinen obenerwähnten Publikationen eine Übersicht über den Verlauf der Eiswinter nebst erläuternden Eiskarten

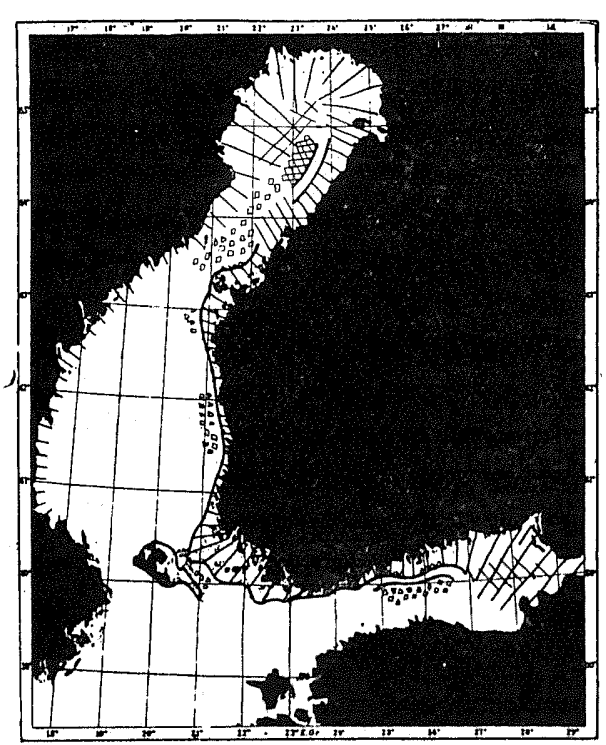

Fig. 6. Die Eislage am 4. April 1911. Nach WitTING (71) 1912. (aus den Wintern 1911 und 19138 Eiskarten, aus dem Winter $1912 \quad 10$ Eiskarten) gegeben. Auf diesen Karten (Fig. 6) hat er durch besondere Schraffierung oder Zeichen das feste Eis, das Breieis, das Treibeis, das zusammengefrorene Treibeis und die Packeisbände bezeichnet. Wenn der Rand des Eises bekannt war, wurde er durch eine ausgezogene Linie angegeben. Ausserdem sind in den Publikationen die Eiskarten einiger Leuchtturmstationen veröffentlicht worden. 
GRANQVIST hat in seiner erwähnten Untersuchuing - unter etwas ausführlicherer Berücksichtigung der meteorologischen Faktoren - die Eisverhältnisse des Winters 1914 vermittels 4 Eiskarten dargelegt. (Fig. 7). GraNQVISTs Karten wie auch diejenigen WITrings geben ein klares und anschauliches Bild von der Ausdehnung und Beschaffenheit des Eises in den verschiedenen Stadien des Eiswinters.

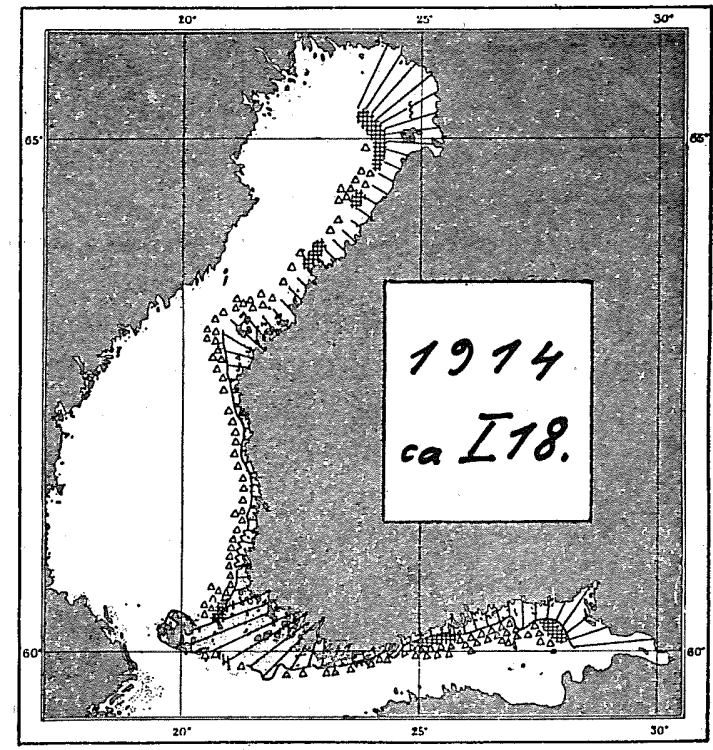

Fig. 7. Die Eislage um den 18. Januar 1914. Nach Granqvist (6) 1921.

\section{Die definitive Umgestaltung der Eisbeobachtungsarbeit im Anfang des Jahres 1915, die weitere Entwicklung der Eisarbeit und das Eisbeobachtungsmaterial seit dem Winter 1915.}

A. Die definitive Umgestaltung der Eisbeobachtungsarbeit im Anfang des Jahres 1915. Die erste Übersichtskarte der Eisverhältnisse an den Freitagen.

33. Die Umbildung der Eisbeobachtungsarbeit im Jahre 1913 entsprach also nicht, was ihre Resultate betrifft, den Erwartungen. Sie war auch insofern mangelhaft, dass man die Entwicklung der Eisverhältnisse im Laufe des Winters nicht genügend schnell verfolgen konnte, da die Beobachtungen entweder monatlich oder nach Verlauf des Eiswinters eingesandt wurden.

Um diese Mängel einigermassen zu beseitigen, wurde zusammen mit dem Lotsenamt eine Beobachtungsinstruktion ausgearbeitet (Formular 451915 XII der Meeresuntersuchungen), in der man u. a. die zu beobachtenden Eisarten bestimmte. Weiter wurden neue wöchentliche Eisjournale (Formular 431915 II der Meeresunter- 
suchungen) und Spezialkarten, welche die Küste von Seivästö im Finnischen Meerbusen bis Ii in der Bottenwiek umfassten, ausgearbeitet. Ausser diesen Spezialkarten, deren Anzahl 28 war, verwendete man auch ältere Karten. Einige Karten wurden für mehrere Beobachtungsorte benutzt.

Die Beobachtungsarbeit wurde jetzt so geordnet, dass die Wochenjournale, in die man täglich Aufzeichnungen über das feste Eis, das Treibeis, das Packeis, die Menge der verschiedenen Eisarten, in Zehnteln des Beobachtungsgebietes ausgedrückt, das offene Wasser, die offenen Seerinnen, die Bewegungsrichtung und die Dicke des Eises machte, an den Freitagen abgeschlossen und nebst einer am selben Tage gezeichneten K a r t e zur Post gebracht werden sollten. So war es möglich schon am folgenden Dienstag die Eiskarte des vorhergehenden Freitags zu zeichnen (70).

Diese Umgestaltung der Beobachtungsarbeit war jedoch nur durch die ganz ungewöhnlichen Verhältnisse, die während des Weltkrieges in Finnland herrschten, ermöglicht. Der schnelle Eismeldedienst war nämlich aus militärischen Gründen notwendig und das Personal der Leuchtturm- und Lotsenstationen konnte somit zur Beobachtungsarbeit einfach kommandiert werden (58).

34. Die erste Generalkarte der Freitagseisla ge. Die erste nach der Umgestaltung der Beobachtungsarbeit gezeichnete Generalkarte der Freitagseislage ist die vom 12. März 1915. Granquist hat sie in der Übersicht über die Eisverhältnisse des Winters 1914-15 veröffentlicht (7). Da die Generalkarten der Freitagseislagen das Material, aus dem wir den normalen Verlauf des Eiswinters herleiten, bilden, werden wir sie später im zweiten Abschnitt dieses Teils näher beschreiben.

\section{B. Das Material seit dem Winter 1915 und die weitere gleichzeitige Entwicklung der Eisbeobachtungsarbeit.}

35. In den Kriegsjahren wurde die Eisbeobachtungsarbeit nach dem neuen System fortgesetzt. Das Hauptmaterial bilden die Wochenjournale und Karten. In dem Kriegswinter 1918 lag die Beobachtungsarbeit beinahe danieder. Erst nach Beendigung des Freiheitskrieges wurde sie im Jahre 1919 wieder aufgenommen, und zwar durch die auf Grund der Verordnung vom 19. November 1918 zum Instit ut für. M e e r e sfors c h u n g umgebildete Hydrographisch-biologische Kommission (58). 
Einen Begriff von dem Umfang der Beobachtungsarbeit in den Wintern 1915-1930 gibt uns Tabelle 6, die auf Grund der Jahresberichte und -Übersichten des Instituts für Meeresforschung aufgestellt ist.

Tabelle 6.

Kolumne $N$ zeigt die Gesamtzahl der Beobachtungsorte, Kolumne J die Anzahl der Beobachtungsorte, die Wochenjournale einsandten, Kolumne $K$ die Anzahl der Beobachtungsorte, die Eiskarten zeichreten.

\begin{tabular}{|c|r|r|r|r|r|r|r|}
\hline Winter & N & J & K & Winter & N & J & K \\
\hline & & & & & & & \\
1915 & 80 & 65 & 56 & 1923 & 111 & 92 & 85 \\
1916 & 67 & 63 & 54 & 1924 & 102 & 93 & 85 \\
1917 & 68 & 62 & 49 & 1925 & 92 & 91 & 91 \\
1918 & 35 & 26 & 15 & 1926 & 105 & 93 & 85 \\
1919 & 76 & 74 & 58 & 1927 & 107 & 92 & 86 \\
1920 & 111 & 73 & 64 & 1928 & 111 & 95 & 88 \\
1921 & 108 & 87 & 73 & 1929 & 104 & 92 & 88 \\
1922 & 104 & 96 & 87 & 1930 & 98 & 88 & 67 \\
\hline
\end{tabular}

Ausser den Wochenjournalen und Eiskarten besitzen wir Eismeldungen der Hafenbehörden, der staatlichen Eisbrecher, der Winterliniendampfer usw. Die letztgenannten wurden durch die Verordnung vom 11. Februar 1927 verpflichtet ein besonderes Eistagebuch zu führen, in das sie während der Fahrt Beobachtungen über Eisverhältnisse und Verkehrsmöglichkeiten, Richtung und Geschwindigkeit des Treibeises, Richtung und Stärke des Windes sowie sichtbare Eisgrenzen eintragen sollten.

36. Nach der Wiederaufnahme der Eisbeobachtungsarbeit im Jahre 1919 schritt man zur Verwirklichung einer schnellen und direkten U̇bermittlung der Eisbeobachtungen. Alle Freitage sollten jetzt bestimmte Beobachtungsorte auf der südlichen und der westlichen Küste bis Pori die Eislage telephonisch melden. Auf Grund dieser Meldungen wurde am selben Tage eine Übersicht über die Eisverhältnisse gegeben und eine präliminäre Freitagskarte gezeichnet. Der erste »Freitagsbericht» nebst Karte ist vom 24. Januar 1919 (58).

Im Herbst 1920 unterhandelte man mit der Deutschen Seewarte über den Austausch der Radiotelegramme über Eisverhältnisse. Mit behördlicher Erlaubnis begann dieser Radiodienst am 12. Februar 1921. Die Radioberichte, die zweimal jeden Sonnabend, bei Bedarf auch am Mittwoch, gegeben wurden, bezogen sich auf die Eisverhältnisse von 9. Städten des Küstengebietes von Viipuri bis Vaasa (59). 
Am 16. Februar 1922 begann das Institut für Meeresforschung mit behördlicher Erlaubnis tägliche Eisberichte auszusenden. Sie enthielten chiffrierte Nachrichten über Eisverhältnisse und Schifffahrtsmöglichkeiten von 15 Gewässern oder Orten (60). Gleichzeitig empfing man Eismeldungen aus dem Auslande, die man nebst dem eigentlichen Eisbericht an die Behörden und Zeitungen weitergab.

Im September $1923 \mathrm{kam}$ ein neues tägliches Eisberichtsystem zur Anwendung. Die Anzahl der nunmehr genauer abgegrenzten Orte, die der Eisbericht umfasste, war 36. Die Radiostation in Hangö wiederholte auf Ersuchen die Eisnachricht (61). Im Oktober 1924 umfasste der Eisbericht 60 verschiedene Gewässer und Orte (62), im folgenden Jahr war ihre Anzahl 63. Im Herbst 1925 wurde in Finnland, Estland und Schweden dasselbe Chiffresystem für Eismeldungen eingeführt (63). Am 7. Januar 1927 begaṇ an den Wochentagen ein Radiotelephondienst, der in finnischer und schwedischer Sprache kurze Eisübersichten vermittelte. Seit dem 22 . Februar desselben Jahres wiederholte sie die Radiostation in Hangö unter Berücksichtigung der im Laufe des Tages eingetroffenen Veränderungen (64). In Übereinstimmung mit den Wünschen der Tallinner Konferenz vom August 1927 wurden seit dem Winter 1928 die Eisberichte des Instituts für Meeresforschung auf finnisch, schwedisch und deutsch gegeben; die Radiostation in Hangö vermittelte die Eisnachrichten auch in englischer Sprache (65). In den Wintern 1929 und 1930 wurde der tägliche Eismeldedienst in derselben Weise fortgesetzt.

3\%. Für die Eiswinter 1915-1921, 1923, 1925, 1927-1930 sind jährliche Übersichten nebst Tabellen und Karten über die Eislagen publiziert. Das Material aus den Wintern 1922, 1924 und 1926 ist von mir bearbeitet, jedoch noch nicht veröffentlicht worden.

Die U̇bersichten der Eiswinter 1915, 1916, 1918, 1921, 1923, 1925, 1927, 1928, 1929 und 1930 sind alle von dem Vorstand der Eisabteilung des Instituts für Meeresforschung, dem Thalassologen GRANQVIST (7-16), die Übersichten der Eiswinter 1917 und 1919 von dem Assistenten der Eisabteilung dieses Instituts Pacmén (50, 51) und die Übersicht des Eiswinters 1920 von mir ausgearbeitet worden (33). Die Übersichten der Eiswinter 1920, 1921 und 1923 enthalten das Beobachtungsmaterial in finnischer (Eiswinter 1920) oder schwedischer (Eiswinter 1921) oder auch in beiden Sprachen (Eiswinter 1923) in extenso.

Diese Übersichten geben eine Beschreibung des Eisbeobachtungsmaterials, eine Darlegung der Entwicklung des meteorologischen und thalassologischen Winters sowie eine Darstellung des Verlaufes des 
Eiswinters. Ferner enthalten die Übersichten Tabellen mit Angaben über die Eisdicke, seit dem Winter 1925 auch über die Dicke des Schnees auf dem Eise. Seit dem Winter 1920 wurden in den Übersichten auch die Schiffahrtsverhältnisse in einer Tabelle berücksichtigt.

Die Freitagskarten der Eisverhältnisse sind in den Übersichten im Verhältnis $1: 5$ und ein wenig generalisiert und bezüglich der Eisarten vereinfacht reproduziert worden. In den Übersichten der Eiswinter 1920 und 1921 sind die Karten des Meeresgebietes jedoch in zwei Teilen wiedergegeben (ungef. im Verhältnis 1:4), von denen der eine die Nördliche Ostsee mit dem Finnischen Meerbusen, der andere die Nördliche Ostsee mit dem Bottnischen Meerbusen umfasst. Die Archivkarten sind achtfarbig (vgl. S. $30 \mathrm{ff}$ ). In den Übersichten sind die Farben durch Schraffierung und Zeichen ersetzt (11). Eine Ausnahme bilden nur die zweifarbigen Karten der Übersichten von 1920 und 1921.

In der vorliegenden Untersuchung haben wir stets die originalen Archivkarten, nicht die generalisierten und verkleinerten Karten der Übersichten benutzt. 


\section{Zweiter Abschnitt: Das Spezialmaterial. Einleitende Bemerkungen über die Eisverhältnisse.}

\section{Die Ũbersiehtskarten der Eisverhältnisse oder die Eislagen.}

3\%. Allgemeine Bemerkungen. Im folgenden bezeichnen wir mit Eislagekarte eine Karte, welche die Eisverhältnisse eines bestimmten Tages darstellt.

Die verschiedenen Eisarten und Eisbildungen nennen wir, ohne sie hier näher zu beschreiben, Eishaut, Breieis, Tellereis, ebenes festes Eis, Glatteis, festes Küsteneis, Treibeis, Packeis, Packeiswälle, zusammengefrorenes Treibeis, zusammengefrorenes Packeis usw.

\section{A. Die Freitagslagen.}

38. Da die Freitageislagen des Instituts für Meeresforschung aus den Jahren 1915 bis 1925 der wesentlichste Teil des "Eismaterials» dieser Untersuchung bei der Herleitung des allgemeinen Verlaufs des Eiswinters waren, wollen wir hier etwas eingehender über sie berichten.

Diese Karten werden nach den ausführlichen Aufzeichnungen und den Kartenskizzen (im Massstab 1: 100000 oder $1: 200000$ ), die von den Beobachtern des Instituts für Meeresforschung an den Freitagen gemacht werden, gezeichnet und durch Meldungen der Eisbrecher und Winterliniendampfer, der Behörden usw. ergänzt, so dass die Karten schliesslich - durch später einlaufende Meldungen ergänzt - in ihrer endgültigen Form ein möglichst vollständiges Bild der Eislage geben.

Fig. 8 stellt eine sowohl im Original als auch für die Reproduktion im Verhältnis etwa $1: 4$ der Deutlichkeit halber mit etwas "kompakterer Farbengebung» von mir gezeichnete, originale Freitagslage dar, die jedoch hier nur als Autotypie-Reproduktion erscheint und erst später zusammen mit dem dritten Teil als kolorierte Karte veröffentlicht wird. 
Auf den achtfarbigen Originalkarten bezeichnen die verschiedenen Farben: $\mathrm{b} l$ a $\mathrm{u}$ offenes Wasser, auch offene Seerinnen, g e $1 \mathrm{~b}$ Eishaut oder dünnes Jungeis, Blaueis, v i o le t t festes Küsteneis und ebenes Eis, letzteres, falls es vorkommt, auch auf offener See, g r ü n Treibeis, bra u Packeis, d u n k lg ra u zusammengefrorenes Treibeis, dunkelbraun zusammengefrorenes Packeis, rot Packeisbände und -wälle. Die Farbenzusammensetzungen besagen, dass den verschiedenen Farben entsprechende Eisarten an den betr. Stellen anzutreffen sind.

39. Der an der Küste beginnende, in Fig. 8 Finnlands ganze Küste umgebende und auch das Schärenmeergebiet bedeckende violette Eisgürtel ist die Bräme des festen Küsteneises.

Die Bildung dieser der Küste unmittelbar anliegenden und daher recht beständigen Eisbräme wird von der Topographie der Küste bestimmt. Der Schärenhof, die Gründe und Untiefen geben nämlich der Eisdecke "Anhaltspunkte», die das Zerbrechen und Spalten des Eises erschweren. Die weiteste Ausdehnung der Bräme wird von den äussersten Inseln, den Inseln des Aussenmeeres, den Gründen und den Untiefen bestimmt. Jene Teile der Eisbräme, welche die seichten Strandgewässer und die Buchten der Küste sowie die vor dem Winde geschützte Küstenseite des Schärenhofgebiets bedecken, bestehen meist aus ebenem Eis. An solchen Stellen, die mehr dem Winde ausgesetzt sind, sowie auf den weiten Schärenfjärden, zerbricht das ursprünglich gebildete ebene Eis ziemlich leicht. Dort häuft sich bisweilen vor der endgültigen Eislegung, besonders nach reichlichem Schneefall, Breieis und Schneebrei an. Manchmal bildet sich dort unter besonderen meteorologischen und thalassologischen Umständen wirkliches Tellereis, oder es wird dahin verschiedenartiges, anderswo gebildetes Eis getrieben. Dadurch wird der Aufbau der äusseren Teile der Eisbräme ziemlich heterogen, obgleich ihre Oberfläche ganz glatt sein kann. Recht oft kommt es jedoch vor, dass auch diese Teile der Bräme von Anfang an ebenes Eis sind, welches infolge günstiger Witterungsverhältnisse im Anfang des Winters dermassen fest geworden ist, dass es ohne zu zerbrechen bis zur Enteisung fortbesteht.

40. Praktisch gesehen gibt es übrigens beinahe in allen Stadien der Bräme des festen Küsteneises, sowohl in der Zeit des Anwachsens als während des Rückganges, eine längere oder kürzere Strecke an der Bräme entlang loses Eis. Je nach dem Winde schliesst sich dieses Eis entweder unmittelbar an den äusseren Eisrand an oder ist durch eine schmalere oder breitere 
Seerinne davon getrennt. Im Anfang des Winters beginnt dieser Gürtel losen Eises weit von den innersten Teilen der Meere und verlängert sich mit der Zeit so, dass er mitten im Winter - zum mindesten auf den "Mittelbildern" - sich an der ganzen Eisbräme entlang erstreckt. In der zweiten Hälfte des Winters geschieht der Rückgang des losen Eisgürtels in entgegengesetzter Richtung, so dass dieses Eis zuletzt in den innersten Teilen der Meere verschwindet. Manchmal kann dieses lose Eis bei günstigen Winden auch zur Zeit seiner Bildung so weit ins Meer getrieben werden, dass es dort scheinbar verschwindet oder unter gewissen Umständen auch wirklich verschwindet. Bei rascher Eisbildung besteht der äusserste lose Eisgürtel aus zerbrechlichem dünnem Jungeis oder Blaueis, dessen äussere Teile an Tellereis erinnern oder vielleicht auch solches sind. Bis die Bräme des festen Küsteneises ihren letzten Anhaltspunkt an den äussersten Inseln und Gründen erlangt und somit ihre grösste Ausdehnung erreicht hat, geschieht der Zuwachs etwa in der Weise, dass loses Eis bei genügender Kälte unmittelbar an die feste Eisbräme anfriert, oder auch, dass nach Zerstreuung des losen Eisgürtels durch den Wind neues Eis sich in dem hierdurch geöffneten Wasser bildet. Dies letztere geschieht natürlich auch, wenn überhaupt kein loser Eisgürtel dagewesen ist. Dieses neue Eis verbreitet sich so weit, wie die meteorologischen Umstände es erlauben, und es umfasst öfters durch Zusammenfrieren das vielleicht vorhandene, früher gebildete zerstreute lose Eis.

41. Wie sich die Bräme des festen Eises auch jedesmal bilden mag, so wird ihr Zuwachs, nachdem die Deckschicht des Meeres ihren im Laufe des Sommerhalbjahres angesammelten Vorrat an Wärme abgegeben hat, von meteorologischen Faktoren, den Winden und der Kälte, bestimmt. Deswegen wechselt der Zuwachs des Eises von Jahr zu Jahr sehr stark. Als allgemeine Regel können wir jedoch, was die Mittelbilder anbetrifft, ansehen, dass, je bre iter die die Küste umgebende Bräme desfesten Eises im. La u e des Winters wird, destowechselnder ist der Aufbau ihrer äusseren Teile. Die in dieser Bräme in Fig. 8 sichtbaren, von dünnen Linien begrenzten, voneinander deutlich getrennten Gebiete sind gerade solche auf verschiedene Weise und aus verschiedenen Eisarten entstandene Zuwachsgebiete. So verwandelt sich das ebene Eis der Küstenbuchten und windgeschützten Küstenteile auf seiner Wanderung nach den äusseren Lagen der Bräme allmählich in ein sehr wechselndes Eiskonglomerat. Später im dritten Teil ist der Aufbau der Bräme des festen Eises im Mittwinter durch einige Beispiele eingehend 
beleuchtet worden. Es sei jedoch bemerkt, dass unter günstigen Umständen die Bräme des festen Eises an einem Teil der Küste bis zu den äussersten Inseln und Gründen, bisweilen sogar auf dem Meere, ganz aus ebenem Eis bestehen kann. Doch bilden solche Fälle eine Ausnahme.

42. In den ersten Stadien der Bräme des festen Eises, die an den verschiedenen Teilen der Küste zu verschiedenen Zeiten eintreten, ist das lose Eis anfänglich meistens Schneebrei oder Breieis, zerbrochenes Jungeis und Blaueis oder Tellereis oder auch aus diesen Eisarten in verschiedenem Verhältnis zusammengesetztes Eis. Der Schneebrei sowie das Breieis können bei gewissen Winden sich am Rande des festen Eises in grossen Mengen anhäufen und dadurch bereits im Anfang des Winters die Schiffahrt an vielen Orten erschweren. Der Schneebrei und das Breieis sind auf den Originalkarten bis zum Jahre 1927 durch abwechselnd blaue und gelbe, später gelb-grüne Farbe bezeichnet. Wenn das lose Eis allmählich ausserhalb des Schärenhofgebietes entstanden ist, d. h. M e e reseis ist, wird es mit der grünen Farbe des Treibeises oder des treibenden Eises bezeichnet. Falls das Breieis- und Treibeisgebiet gepackt oder fest an den Rand des festen Eises gedrückt ist, wird es mit brauner und je nach dem Pressungsgrad sogar teilweise mit roter Farbengebung bezeichnet. Schon in den früheren Zuwachsstadien der Bräme des festen Eises ist wenigstens ein Teil davon durch im offenen Meer entstandenes Eis, folglich M e e res e is, gebildet, und je breiter die Bräme wird, um so mehr Meereseis enthalten ihre äusseren Teile, bis diese schliesslich ganz aus Meereseis bestehen.

43. Die Farbe des 1 o s e n M e e r e s i s es ist auf den Originalkarten, wie schon erwähnt wurde, grün und braun. Mit grün ist im allgemeinen ebenes Meereseis bezeichnet, das noch nicht oder nicht nennenswert andere mechanische Prozesse als Zerbrechen und Zerspalten erlitten hat. Das mit braun bezeichnete Meereseis ist von den Winden und Meeresströmungen gegen die Bräme des festen Eises oder andere Eisanhäufungen gedrückt und gepackt worden. Solche Treibeis- und Packeisgebiete sehen wir in Fig. 8 nur noch in der Mündung des Finnischen Meerbusens, in der Nördlichen Ostsee und im Ålandsmeer. Die anderen Meeresteile bedeckt z u s a mmengefrorenes Treibeis (die grauen Gebiete) und zusammengefrorenes Packeis (die dunkelbraunen Gebiete). Wo das zusammengefrorene Meereseis sich unmittelbar an die Bräme des festen Eises anschliesst, wie in den östlichen Teilen des Finnischen Meerbusens, dem nördlichen Teil des Schärenmeeres und der Bottensee, bildet es gewissermassen eine Fortsetzung der Bräme 
des festen Eises, kann aber im allgemeinen leicht von derselben unterschieden werden. Das Meereseis, sei es nun lose oder zusammengefroren, entfernt sich nämlich ziemlich leicht von der Bräme des festen Eises; so dass zwischen ihm und dem äusseren Eis eine offene Seerinne entsteht. In Fig. 8 erstreckt sich eine stellenweise eisfreie, stellenweise mit Blaueis bedeckte Seerinne aus den östlichen Teilen des Finnischen Meerbusens bis zum Kvark und der Bottenwiek, wo bei Ulkokalla noch eine Spalte zu bemerken ist. Durch die Beweglichkeit des Meereseises entstehen an dessen innerem Rande gegen die feste Eisbräme, vor den äusseren Inseln, auf den Gründen und Untiefen, ja sogar auf den Eismassen im Aussenmeer mit roter Farbe bezeichnete hohe Eisanhäufungen, die sog. Eisbänder und Eiswälle.

Wenn die Bräme des festen Eises - an verschiedenen Stellen natürlich zu verschiedenen Zeiten - so breit geworden ist, dass sie die äusseren Inseln, die äusseren Gründe und Untiefen umschliesst und somit ihre grösste Breite erreicht hat, sind ihre äussersten Teile ausschliesslich aus Meereseis aufgebaut. Dies kann entweder aus bei windstiller Kälte entstandenem ebenem Eis oder zusammengefrorenem Treib- und Packeis oder auch aus diesen Bestandteilen in verschiedenem Verhältnis zusammengesetztes Eis sein. Jedenfalls ist dieses Eis ausschliesslich Meereseis.

44. Aber auch in dem Falle, dass das Meereseis das Meer "vollständig» bedeckt und ganz zusammengefroren ist, zeigt es eine gewisse Bewegungstendenz. So können wir z. B. aus der Mittwintereislage des 21. März 1924 ersehen, dass sowohl in den inneren Teilen des Finnischen Meerbusens wie in der Bottenwiek, welche beide mit zusammengefrorenem Meereseis bedeckt waren, infolge von wenn auch minimaler Beweglichkeit Eisspalten (ausserhalb Ulkokalla) und sehr schmale Seerinnen (östlich von Hochland) entstanden waren. Solche Eisspalten und sehr schmale Seerinnen können bei bedeutenden Schwankungen im Wasserstand entstehen. Andererseits deuten auf Beweglichkeit die im zusammengefrorenen Meereseise entstehenden »Pressungsfugen», d. h. grössere oder kleinere Eisanhäufungen oder Eiswallbildungen. Je breiter das Meeresbecken wird, wie in der Mündung des Finnischen Meerbusens, südlich und nördlich vom Allandsmeer sowie in der Bottensee, um so grösser ist im allgemeinen die Beweglichkeit des Meereseises. Sogar bei strenger Kälte, insofern nur der Wind eine passende Richtung hat und ausserdem stark und anhaltend genug oder stürmisch ist, kann das. Meereseis beinahe ganz in Bewegung kommen und hierbei entweder gegen die feste Eisbräme gedrückt werden oder sich davon entfernen, wobei gleich- 
zeitig in den in Bewegung befindlichen Eismassen sowohl Eispressung als Spaltung vorkommen kann. Den Beweglichkeitsgrad kennzeichnen einerseits die entstandenen Packeisgebiete und Eiswälle, sowie die Länge und Breite der offenen Seerinnen, andererseits der Grad der Zusammenschiebung oder der Zerstreuung des Meereseises.

45. Je weiter nach dem Meere zu, desto dünner wird das mechanisch ungestörte Eis. Am Rande des offenen Meeres kann das bei windstiller Kälte entstandene Eis ganz glatt sein, aber der Wellenschlag zerbricht dieses Eis bald zu Breieis, tellerförmigem Eis oder grossen Eisschollen. Bei Wind und Wellenschlag oder wenn das Eis aus irgend einem anderen Grunde in Bewegung kommt, wird auch dieses Eis leicht aufeinandergetrieben, zusammengeschoben und -gepresst, und im Laufe des Winters sind auch die äussersten Teile des Meereseises so kräftigen und verschiedenen mechanischen Prozessen ausgesetzt, dass das Eis auch dort allgemein zusammengeschoben und mehr oder weniger uneben ist und stellenweise auch wirkliche Packungsbildungen vorkommen.

46. Die Beweglichkeit des Meereseises nimmt mit dem Nahen des Frühlings zu. Dann beginnt in allen Finnland umgebenden Meeren ein sich immer weiter ausdehnendes Spalten des Eises. Grosse Seerinnen öffnen sich sowohl zwischen dem festen Eis und dem Meereseis als zwischen den verschiedenen Meereseisgebieten, und die Beweglichkeit des Eises wird nach und nach allgemein. Das Abnehmen des Eisvolumens beginnt zuerst in dem Eis weit draussen im Meere, wo der Rückgang des Eises manchmal - allerdings unter Mitwirkung des Windes - unerwartet schnell vor sich gehen kann. Binnen kurzer Zeit beginnen erst unbedeutende, dann immer stärkere Veränderungen auch in der festen Eisbräme, bis endlich die noch verhältnismässig dicke Bräme ziemlich rasch schmilzt und verschwindet. Noch Anfang Juni treffen wir loses, treibendes Eis in den nördlichen Teilen der Bottenwiek. Dieses letzte in der Bottenwiek umhertreibende Eis besteht aus schwer schmelzenden Packeis- und Eiswallüberresten. Im dritten Teil werden wir näher auf diese Vorgänge eingehen.

4\%. Wenn wir den ganzen Verlauf des Eiswinters verfolgen, merken wir, dass die in der ersten Hälfte des Winters eintretende Vereisung, d. h. der Zuwachs des Eises, viel langsamer erfolgt als der Rückgang und das Verschwinden des Eises in der zweiten Hälfte des Winters. Der Verlauf des Eiswinters ist somit im Verhältnis zur Zeit asymmetrisch.

Nach diesen einleitenden Bemerkungen werden wir die Eisverhältnisse am Freitag den 21. März 1924 eingehender untersuchen. 


\section{B. Die Eisverhältnisse am Freitag den 21. März 1924.}

48. Die Eislage des betreffenden Tages (1924 III. 21., Fig. 8) gehört zu den Kulminationsstadien des Mittwinters. Die Bräme des festen Küsteneises hatte damals ihre grösste Ausdehnung erreicht, die Meeresteile bis zur Nördlichen Ostsee waren mit Eis "gefüllt». In den östlichen und mittleren Teilen des Finnischen Meerbusens sowie im Alandsmeer, in der Bottensee und der Bottenwiek war das Eis zusammengefroren, obgleich es sich gleichzeitig in grossen Massen bewegte. Ganz »loses〉 Meereseis gab es nur in der Mündung des Finnischen Meerbusens und in der Nördlichen Ostsee, möglicherweise auch in der Bottensee.

In Fig. 8 ist der äussere Rand der festen Eisbräme mit einer dicken Grenzlinie angegeben. Weit im Norden kommt dieser Rand in den Sehkreis der Beobachtungsorte im mittleren Teile der Bottenwiek, nördlich von dem Leuchtturm Ulkokalla in der Nähe der Untiefe Nahkiainen. Südlich von dem Leuchtturm von Ulkokalla sowie in der Nähe des Leuchtturmes von Tankar sehen wir eine schmale Seerinne. In südlicher Richtung können wir den Rand der Bräme wegen Mangel an Beobachtungen nicht verfolgen; er geht jedoch wohl hier, wie anderswo, an den äussersten Inseln und Gründen entlang bis Valsörarna und von dort nach der Untiefe von Snipan im Kvark. Von dort wendet sich der Rand erst gegen Süden und verläuft dann wieder an den Gründen und Untiefen des Aussenmeeres entlang ungefähr in der Richtung der Küste der Bottensee bis zur Höhe von Vekara in dem äusseren Schärenhof vor Uusikaupunki. Etwas südlicher, in der Nähe des Leuchtturmes von Isokari geht der Rand erst in südwestlicher Richtung und verschwindet dann bald aus dem Sehkreis der Beobachtungsorte. Er kommt jedoch nördlich von Aland wieder zum Vorschein. Nachdem der Rand der Bräme Aland westlich und südwestlich umkreist hat, geht er südlich von dem Schärenmeer in der Nähe der Inseln Grimsörarne ausserhalb des Leuchtturmes von Utö in östlicher Richtung in den Finnischen Meerbusen, wo wir ihn wiederum an den äusseren Inseln und Gründen entlang bis Luppi nördlich von Hochland deutlich verfolgen können.

Nordwestlich und nördlich von Nahkiainen sowie in den südlichen Teilen der Bottenwiek und östlich und südöstlich von Hochland hat sich die Bräme des festen Küsteneises durch das mit demselben zusammengefrorene Treib- und Packeis zu einer Eismassenformation erweitert, die gewissermassen »umfassender» ist als die eigentliche "Bräme der festen Küsteneises». In dem südöstlichen offenen Teil der Bottensee bildet ebenfalls das zusammengefrorene Treib- 
und Packeis - soweit die Beobachtungen sich erstrecken - eine ähnliche unmittelbare Fortsetzung der eigentlichen Bräme des festen Küsteneises.

In ihren innersten Teilen-die im Herbst und Anfang des Winters im Schutze des Schärenhofes entstehen - besteht jetzt, wie beinahe immer, die Bräme des festen Küsteneises hauptsächlich aus ebenem Eis. Die äusseren Teile der Bräme dagegen bestehen aus zu verschiedenen Zeitpunkten unmittelbar daran gebildetem Eis oder auch aus daran festgefrorenem M e e r s e i s. Solche, zu verschiedenen Zeiten und auf verschiedene Weise entstandenen Zuwachsgebiete der Eisbräme sind die auf der Karte von dünnen Linien begrenzten Gebiete.

D ü nnes B la u e is sehen wir in der Nördlichen Ostsee und in der Mündung des Ålandsmeeres. Dünnes Blaueis oder neugebildetes Eis bedeckt die Seerinnen, die am Rande der Bräme des festen Küsteneises im Finnischen Meerbusen und im Ålandsmeer entstanden sind. Im östlichen Teil des Finnischen Meerbusens zwischen Luppi, Someri und Narvi bemerken wir von mechanischen Prozessen ganz unberührtes ebenes Eis, das an Stelle des vom Wind zerbrochenen und dann weggetriebenen Meereseises entstanden ist.

Frei treibendes und somit jedenfalls noch nicht vollständig zusammengefrorenes $\mathrm{Treib}$ - und $\mathrm{Packeis}$ sehen wir im Finnischen Meerbusen westlich von der Linie Nargön-Segelskär, in der Nördlichen Ostsee sowie im westlichen Teil des Ålandsmeeres, wo es jedoch grösstenteils Packeis ist. Ausserdem gibt es $\mathrm{Pa} \mathrm{ckeis}$ inmitten des Treibeises in der Nördlichen Ostsee und im Finnischen Meerbusen.

Zusammengefrorenes Treib- und Packeis füllte, wie schon erwähnt wurde, teils als Fortsetzung der Bräme des festen Küsteneises, teils durch eine offene Seerinne davon getrennt die ganze Bottenwiek, den grössten Teil der Bottensee sowie die östlichen Teile des Finnischen Meerbusens bis an die Linie NargönSegelskär im Westen.

Die höchsten Eisanhäufungen, die Eiswälle, sind auf der Karte schon grösstenteils von der Bräme des festen Küsteneises umschlossen. An einigen Stellen bezeichnen die Wälle die früheren Ränder der Bräme, gegen die das lose Meereseis sich gepresst hat. An anderen Stellen sind die Wälle im Treibeisgebiet selbst oder an den äusseren Inseln des Schärenhofes oder auch auf Untiefen und Gründen entstanden.

Schmale, offene Seerinnen sind in der Bottenwiek, wie gesagt, vor Ulkokalla und Tankar zu sehen. Vom Kvark im Nor- 
den verläuft eine anfänglich sehr breite, dann sich verengernde, grosse Seerinne der Bottensee, die ungefähr in der Nähe von Rauma endet. Von hier erstreckt sich das zusammenhängende Meereseis so weit, wie man von den Beobachtungsorten aus sehen konnte. Im östlichen Teil des Ålandsmeeres befindet sich eine offene Seerinne, die gleich der grossen Seerinne im Finnischen Meerbusen schon am 21. März mit Blaueis bedeckt war.

Offenes Wasser sehen wir in einem ausgedehnten Gebiet in der Nördlichen Ostsee südlich vom Schärenmeer. Das Meereseis ist von hier in südöstlicher Richtung abgetrieben worden. Aber das e ig e n tliche, noch ganz eisfreie Meer beginnt erst weiter in der Ostsee. Der Rand des eisfreien Meeres verläuft ausserhalb Ösel und Dagö und weiter von der Höhe von Dagerort in der Richtung gegen Grönskär ausserhalb des schwedischen Schärenhofes.

Die Pfeile auf der Karte Fig. 8 bezeichnen die Richtu n g, in der das Meereseis abgetrieben wurde. Das Eis, im Kvark wurde teils nordwärts, teils südwärts, das Eis der Bottensee im allgemeinen südwärts getrieben. In der Nördlichen Ostsee bewegte sich das Eis, wie gesagt, in südöstlicher Richtung.

Die Zahlen auf der Karte bezeichnen die $\mathrm{Dicke} d \mathrm{es}$ E ises (Zähler) sowie die Dicke seiner Schneedecke (Nenner) an der Station, die mit der entsprechenden Bruchzahl durch eine dünne Linie verbunden ist. Die Dicke des Eises war somit in der Bottenwiek von Norden nach Süden $75-45 \mathrm{~cm}$, im Kvark $50-40 \mathrm{~cm}$, in den nördlichen Teilen der Bottensee ungefähr $60 \mathrm{~cm}$, im mittleren Teil ungefähr $50 \mathrm{~cm}$ und in den südlichen Teilen ungefähr $50-45 \mathrm{~cm}$. Im Schärenmeergebiet wechselte die Dicke des Eises zwischen 50 und $20 \mathrm{~cm}$ und im Finnischen Meerbusen zwischen 30 und $60 \mathrm{~cm}$, wobei wir die höchsten Werte in dem letztgenannten Gebiet im Osten antreffen.

49. Wir wollen nach dieser etwas umständlichen Wiedergabe in der Weise, wie wir später bei der Beschreibung der sog. Normalstadien die Eisverhältnisse charakterisieren, die Eislage am Freitag den 21. März 1924 kurz rekapitulieren.

Eine ununterbrochene feste $\mathrm{E}$ is b r äm e umgab Finnlands ganze Küste, das Schärenmeergebiet mitgerechnet. Ausserhalb des Küstengebietes war das Eis grösstenteils durch und durch zusammengefroren, nur in der Mündung des Finnischen Meerbusens, der Nördlichen Ostsee, im Alandsmeer und wahrscheinlich teilweise in den mittleren Teilen der Bottensee gab es noch loses Meereseis. Das ganz eisfreie Meer begann weiter draussen in der Nördlichen Ostsee. 
Durch die Bewegung des Meereseises waren in allen Meeresteilen am Rand der festen Eisbräme entlang auf einer längeren oder kürzeren Strecke offene Seerinnen entstanden. Die schmalen offenen Seerinnen in der Bottenwiek zeigen jedoch, besonders wenn man die unmittelbar vorhergehenden und darauffolgenden Freitagskarten berücksichtigt, dass die Bottenwiek mit Eis gefüllt war. Die Entstehung der grossen offenen Seerinne der Bottensee, 'die in der südlichen Mündung des Kvark beginnend in der Richtung der Küste der Bottensee verlief, zeigte wiederum, dass dieses Meer nicht im selben Mass wie die Bottenwiek mit Eis gefüllt war. Das Meereseis konnte in der Bottensee noch bedeutend zusammengetrieben werden, obgleich das Meer zeitweise ganz mit Eis bedeckt war. Zu bemerken ist jedoch, dass die Bewegungsrichtung des Meereseises, die am 21. März 1924 südlich war, besonders günstig für das Zusammentreiben des Eises war. Die Bewegung ging nämlich in der Längsrichtung des Meeres, in der auch die Meeresströmungen am stärksten sind und ausserdem in der Richtung, in der die Eisdicke abnahm, vor sich. Eine beinahe das ganze Meeresgebiet umschliessende Seerinne kann jedoch im kältesten Teil des Winters vorkommen, so dass sie an und für sich uns nicht erlaubt einen ganz sicheren Schluss über die Ausdehnung der Vereisung der Bottensee und über die Dicke des Eises zu ziehen. Obwohl in den mittleren und westlichen Teilen des Finnischen Meerbusens eine g r o s s e offene Seerinne entstanden war, so war das Meer doch tatsächlich mit Eis »gefüllt».

\section{Die Freitagslagen der Winter 1915-1925.}

50. Aus diesen Freitagslagen, von denen wir oben als Beispiel die Freitagslage vom 21. März 1924 erwähnten, w e r d e n wir den Verlauf der Eiswinter in den Finnland umgebenden Meeren herleiten. Bei diesen Eislagen kann natürlich die "Ausdehnung» des Eises zwischen »Eis überall» und »eisfrei überall» wechseln.

Aus den Wintern 1915-1925 besitzen wir im ganzen 329 Freitagslagen. Von den Originalkarten (wie Fig. 8), die sich im Archiv des Instituts für Meeresforschung befinden, sind ein wenig generalisierte Kopien gezeichnet worden, die gewissermassen "deutlicher» und betreffs der Eisarten etwas einfacher koloriert sind als die entsprechenden Archivkarten. Es sei hier erwähnt, dass ich von den Originalkarten auf Grund der Eisbeobachtungen und Eiskarten 
sowie anderer Eisangaben 194 Karten selbst gezeichnet habe, was beinahe zwei Dritteln sämtlicher Originalkarten aus dem erwähnten Zeitraum entspricht. Somit ist also auch der Hauptteil des für diese Untersuchung benutzten Eislagematerials zum grossen Teil von mir ausgearbeitet.

Das Netz der Eisbeobachtungsorte erstreckte sich in den Wintern 1915-1918 im Norden bis nach Ii (nördlich von Oulu). Erst seit dem Eiswinter 1919 sind die Eisverhältnisse nördlich von Ii auf den Freitagskarten gezeichnet worden. Wir haben jedoch diese Lücke, wie später aus dem vierten Teil hervorgeht, einigermassen durch Beobachtungen der nahegelegenen Beobachtungsorte, vor allem von Marjaniemi, ausiüllen können.

Die Freitagskarten aus der Zeit des Weltkrieges sind ausserdem, besonders aus dem Gebiet zwischen der Mündung des Finnischen Meerbusens und dem Alandsmeer, unvollständig. Die mangelnden Angaben haben wir, was das Ålandsmeer und teilweise auch die Nördliche Ostsee anbetrifft, einigermassen durch die Eisbeobachtungen des schwedischen Lotsenamtes (80) ergänzen können, wodurch der Verlauf der Eislegung und die weiteste Ausdehnung der Eisdecke auch in der Nördlichen Ostsee wenigstens innerhalb bestimmter Grenzen auf eine befriedigende Weise festgelegt wurden. Wir werden später im vierten Teil auf diese Frage zurückkommen. Andererseits besitzen wir aus den Kriegsjahren Eisbeobachtungen aus der Bottensee, die besonders geeignet sind uns ein richtiges Bild (29) über die dortigen Eisverhältnisse im Mittwinter zu geben. Solche Eisbeobachtungen fehlen meistens gänzlich aus anderen Wintern.

51. Um den Verlauf eines $\mathrm{kurz}$ en $\mathrm{W}$ in $\mathrm{t}$ e $\mathrm{r}$ s besser kennen zu lernen habe ich auf Grund des Beobachtungsmaterials aus dem Eiswinter 1910, soweit es möglich war, die den Freitagen dieses Winters entsprechenden Eislagen in dem ganzen Gebiet dargestellt. Dieser Eiswinter war nämlich zur Zeit seiner Bearbeitung - mit Ausnahme des Winters 1925 - einer der kürzesten, aus denen wir hinreichendes Material besitzen. Unsere Absicht war neben dem Jahr 1925 ein anderes kurzes Eisjahr zu erhalten. Später, vor Beendigung der vorliegenden Untersuchung, ist jedoch der mildeste Eiswinter seit mehr als hundert Jahren im Jahre 1930 eingetroffen.

\section{Die Eislagen anderer Wochentage als der Freitage.}

52. Ausser den Freitagskarten habe ich auf Grund des vorhandenen originalen Eisbeobachtungsmaterials auch die Eislagen anderer Wochentage während einiger Winter dargestellt. Diese Eislagen 


\section{MERENTUTKIMUSLAITOS - HAVSFORSKNINGSINSTITUTET}

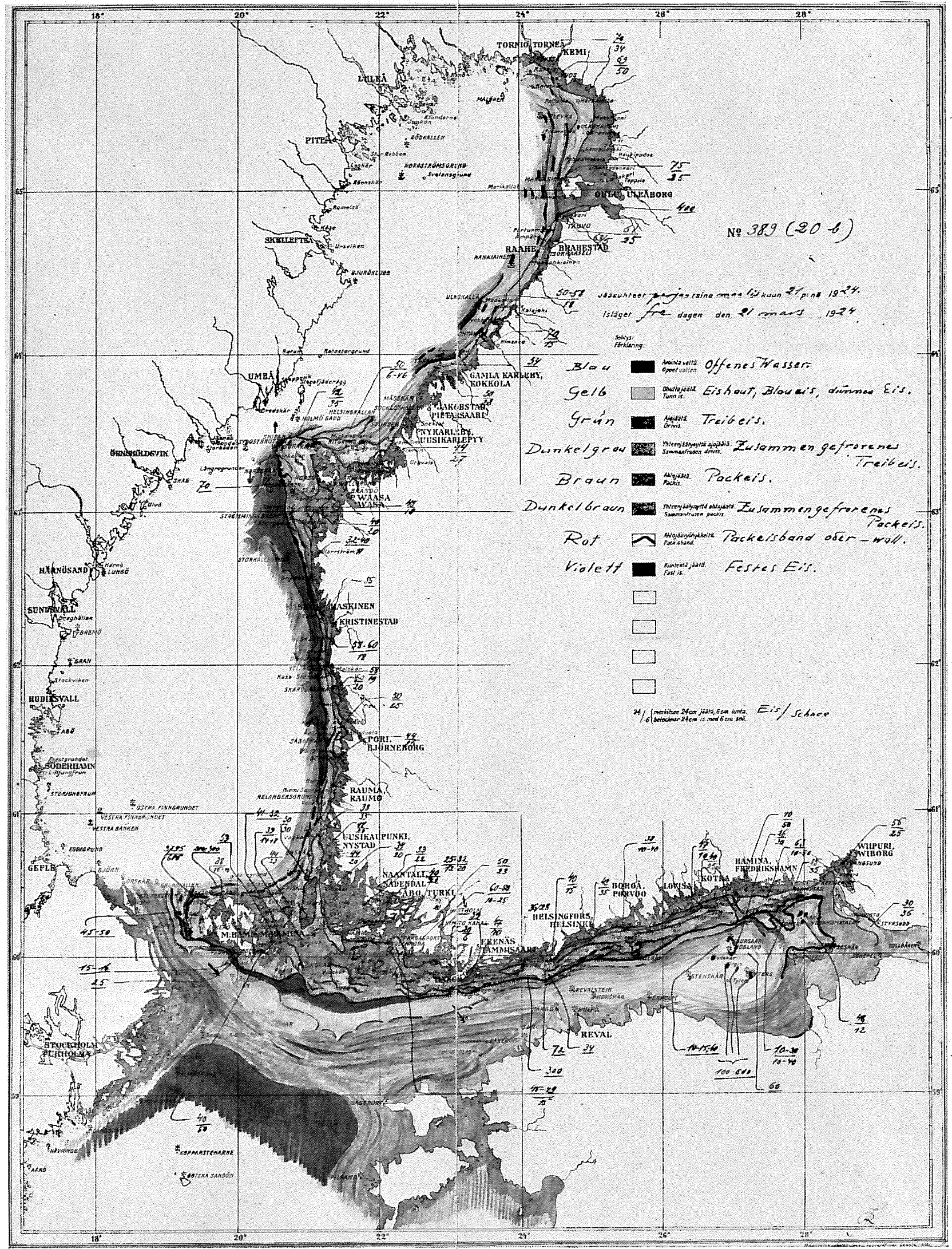



umfassen teils die ganze Küste, teils nur einen Teil derselben (siehe unten 54). Unsere Absicht war vermittels dieser Eiskarten entweder einige spezielle Fragen, wie z. B. die Bewegung des Eises im Finnischen Meerbusen, in der Nördlichen Ostsee und im Ålandsmeer im Eiswinter 1928 zu erörtern oder auch besondere Eisverhältnisse, wie z. B. die grösste Ausdehnung der Eisdecke in den Wintern 1929 und 1930 usw. klarzulegen.

\section{Die Beobachtungen über die Dicke des Eises.}

53. Später im sechsten Teil werden bei der Bestimmung der durchschnittlichen Dicke des Eises sowohl des normalen als des kurzen und langen Winters die Eisdickemessungen an den Freitagen verwendet. Wenn an irgend einem Freitage aus diesem oder jenem Grunde Messungen nicht gemacht worden sind, haben wir den fehlenden Wert durch die bekannte Dicke des Eises der nächstvorhergehenden oder darauffolgenden Tage ersetzt. Bei der graphischen Darstellung der Dicke des Eises im langen und im kurzen Winter haben wir wegen der geringen Anzahl der einerseits kurzen, andererseits langen Eiswinter in dem von uns bearbeiteten Zeitraum auch die Zahlen für den Mittwinter u.a. der Jahre 1926-1930 berücksichtigt.

Bei der Zusammenstellung der la nge $\mathrm{n}$ Eis d i ckereihen haben wir auch älteres Material als aus dem Eiswinter 1915 in dem Masse, wie es sich als notwendig erwies, verwendet. Hierbei haben wir die Angaben über die Dicke des Eises teils älteren Publikationen, teils dem Material im Archiv des Instituts für Meeresforschung entnommen. Ausserdem haben wir einige Aufzeichnungen über die Eisdicke einer im Archiv des Lotsenamts als Manuskript aufbewahrten geschichtlichen Übersicht der finnischen Leuchttürme benutzt (79).

\section{Die Beobachtungen und Karten über die Bewegung des Eises.}

54. Später im siebenten Teil, in dem neben dem eigentlichèn Treiben des Eises auch die dabei wenigstens irgendwo eintretende, aber in bezug auf die Grösse und Stärke innerhalb sehr weiter Grenzen sowohl stellenweise als zeitweise wechselnden Erscheinungen, wie das Zusammengehen der Rinnen, die Verschiebung und Zusammenpackung des Eises, das Zerbrechen und Spalten desselben und das Entstehen der Öffnungen und Seerinnen u. a. behandelt wird, ha- 
ben wir sowohl früher bearbeitetes Beobachtungsmaterial als speziell für die vorliegende Untersuchung von uns gezeichnete Eiskarten verwendet.

Um die Frage nach dem Treiben des Eises zu erörtern, haben wir sämtliche 484 Freitagskarten aus den Jahren 1915-1930 verwendet. Aber ausserdem wurden für jeden Tag des Eiswinters 1926 besondere, etwas schematisierte Eiskarten, die Finnlands ganzes Meeresgebiet umfassen, gezeichnet. Da ihre Anzahl 168 beträgt, besitzen wir im ganzen 621 solcher Finnlands ganzes Meeresgebiet umfassenden Karten. Ferner wurden für jeden Tag des Eiswinters 1928 im ganzen 147 Eislagen gezeichnet, die die Eisverhältnisse im Finnischen Meerbusen, in der Nördlichen Ostsee und im Ålandsmeer darstellen. Somit besitzen wir für die letztgenannten Gebiete bis Ende des Winters 1930 im ganzen 727 Eislagen.

Auf allen erwähnten Karten habe ich ausser der Bewegungsrichtung des Eises auch die Richtung und Stärke der von den Küstenstationen des Morgens beobachteten Winde angegeben. Auf den Karten der Eislagen des Winters 1928 habe ich ausser dem Wind die von den Küsten und Meeresstationen des Morgens beobachtete Bewölkung und Temperatur sowie die täglichen Messungen der Dicke des Eises eingezeichnet.

Das Material über Treib- und Packeis, Eiswälle, Eisspaltung sowie über offene Seerinnen und über die Bewegung des Meereises im allgemeinen stammt somit hauptsächlich aus den Eiswintern 1915 -1930. Wir haben jedoch, wie bereits erwähnt wurde, teilweise auch älteres Material benutzt. 


\section{Die Methode und einige ihrer Endergebnisse. Erster Abschnitt: Die ersten S- und G-Stadien.}

\section{Der erste Versuch den allgemeinen Verlauf des Eiswinters kartographisch darzustellen.}

55. Einleitende Bemerkungen. Die kartographis che Methode, welche ich zwecks Feststellung des allgemeinen Verlaufes des Eiswinters an den Küsten Finnlands und in den Finnland umgebenden Meeren entwickelt und schliesslich angewandt habe, gründet sich auf den tatsächlich im grossen und ganzen recht regelmässigen Gang der hier zu erklärenden Erscheinung. Diese Regelmässigkeit geht aus den beinahe jeden Winter wiederkehrenden lokalen, annähernd gleich verlaufenden und geographisch begründeten Eisgrenzen hervor, sowohl während der Zunahme des Eises als während seiner Abnahme. Obgleich die Anwendung der kartographischen Methode somit ohne weiteres begreiflich ist, soll hier doch betont werden, dass die Voraussetzung dieser Methode ein solches Eisbeobachtungsmaterial ist, welches von Anfang an, d. h. schon für die erste Bearbeitung, genügend eingehend kartographisch beschreibend ist oder jedenfalls in einer zuverlässig richtigen kartographischen Form zu erhalten ist.

Erst durch die vollständige Umorganisierung der Eisbeobachtungsarbeit am 1. März 1915 haben wir, wie schon im vorhergehenden Teil eingehender dargelegt worden ist, ein solches Eisbeobachtungsmaterial sowie auf Grund desselben gezeichnete Eislagekarten erhalten.

Der durchaus deutliche Aufbau der Eisverhältnisse an einem Eiswintertage erhellt genügend aus der als Beispiel genommenen, die Eislage in einem Mittwinter beleuchtenden Karte in Fig. 8. 
Solche Eislagekarten, welche die Eisverhältnisse an Freitagen oder an anderen Eiswintertagen zeigen, enthalten eine ausserordentlich grosse Menge Fakta. Durch Tabellen und Text kann man kaum dieselbe einheitliche Auffassung von der Erscheinung und ihrer Regelmässigkeit erhalten wie aus der entsprechenden kartographischen Darstellung. Das Herleiten der verschiedenen "Stadien» im Verlauf des Eiswinters an den Küsten und in den Meeresteilen Finnlands war aus diesem Grunde so auszuführen, dass die E is l a g e n an Fre it a g e n-- entweder als solche, d. h. als Finnlands ganzes Meeresgebiet umfassende, oder auch den verschiedenen Meeresteilen entsprechende Teilkarten - bei der Lösung der Aufgabe d a s eigentliche Arbeitselement bildeten, also nicht die Menge der Tatsachen der Eislagekarten in Ziffern oder "Worten».

56. Allgemeine Definition der Aufgabe. Im Winter 1920, als ich das Zeichnen der Freitagskarten im Institut für Meeresforschung begann, wurde meine Aufmerksamkeit beim Aufzeichnen der Eislagen des Mittwinters auf den meiner Ansicht nach unerwartet gleichartigen Verlauf gerichtet, welchen "die gros se Se erinne» des Finnischen Meerbusens durch ihr wiederholtes Aufgehen aufwies. Als dann im Herbst 1921 das Institut im Auftrag der finnisch-schwedischen Verkehrskommission die Eisverhältnisse der Fahrstrassen zwischen Finnland und Schweden zu. untersuchen hatte, wurde diese Aufgabe mir anvertraut. Ich beschloss hierbei anstatt der $\mathrm{numeris}$ chen Methode, die bei derartigen Untersuchungen gewöhnlich benutzt wird, ein Verfahren, das besser dem Aufbau der Erscheinung entspricht und sich unmittelbar auf die Eislagen stützt, zu verwenden. Bei einem solchen Verfahren würde z. B. die genannte Regelmässigkeit in den Lagen der grossen offenen Seerinne des Finnischen Meerbusens deutlich zum Ausdruck kommen. Unter Zuhilfenahme einer kartog ra ph is chen Methode versuchte ich dann auf Grund des den Freitagen der Winter 1913-1922 entsprechenden Eismaterials den allgemeinen Verlauf des Eiswinters im Schärenmeer aufzubauen.

Was die in den früher ausgeführten Untersuchungen, die den allgemeinen Verlauf des Eiswinters darstellen, benutzte numerische Methode betrifft, so war sie hinsichtlich des Eismaterials bis zum Jahre 1915 ganz natürlich. Das Beobachtungsmaterial war nämlich, wie schon in ersten Teil gezeigt ist, im grossen und ganzen allzu allgemein und mangelhaft. Ich habe dies selbst erfahren, als ich auf Grund dieses älteren Materials die Freitagskarten für das ganze Meeresgebiet des Winters 1910, für das Schärenmeergebiet der Winter 1912-1914 und die Übersichtskarten des Atlas von Finnland 1925 (1) 
zeichnete, sowie später, als ich den zeitlichen Verlauf der Eiswinter des 19. Jahrhunderts analysierte. Seit dem Anfang des Jahres 1915 ist dagegen die von mir benutzte Methode die natürlichste.

Unsere Aufgabe war somit un mittelbar a uf Grund der Freitagskarten des Instituts für Meeresforschung den allgemeinen Verlauf des Eiswinters an den Küsten Finnlands und in den Finnland umgebenden Meeren zu bestimmen. Dass die Aufgabe - zunächst für das Gebiet des Schärenmeeres - wirklich auf diese Weise zu definieren war, beruhte ausschliesslich, wie schon erwähnt wurde, darauf, dass in den nach den neuen Eisbeobachtungen gezeichneten Eislagen, in »der Bräme des festen Küsteneises» sowohl zur Zeit ihres Zuwachses als zur Zeit ihres Rückganges eine deutliche, topographisch bedingte Regelmässigkeit festzustellen war.

5\%. Eine Auffassung davon, wie gleichmässig die jährliche Entwicklung der Bräme des festen Eises beispielsweise im Schärenmeer verläuft, gibt uns Fig. 9 und 10 .

Der Rand der Bräme in fünf verschiedenen Eiswintern ist hier dargestellt. Hierbei haben wir jenes Stadium des Winters gewählt, in dem der innere, aus grossen Inseln bestehende Schärenhof des Schärenmeeres und Alland von der Bräme umschlossen sind. Die grössten Abweichungen bemerken wir ganz allgemein in jenen Teilen des Schärenhofes, wo wir grössere offene Gebiete antreffen oder wo solche angrenzen. Der Rand der Bräme kann hier was seine allgemeine Lage anbetrifft - bedingt durch

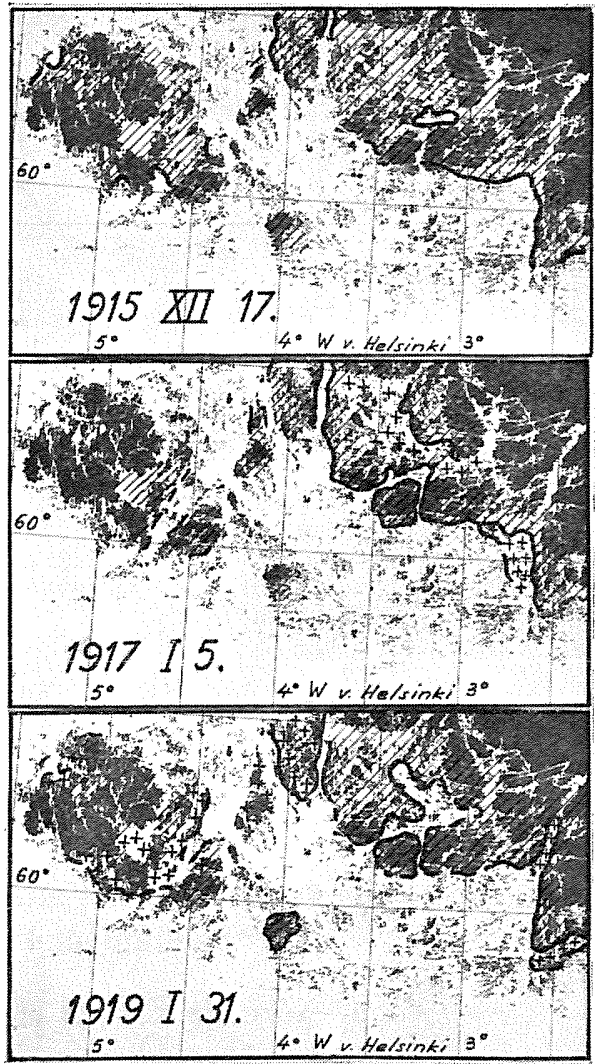

Fig. 9. Augenscheinlich demselben Stadium im allgemeinen Verlauf des Eiswinters jm Schärenmeergebiet entsprechende Ei s la gen. 


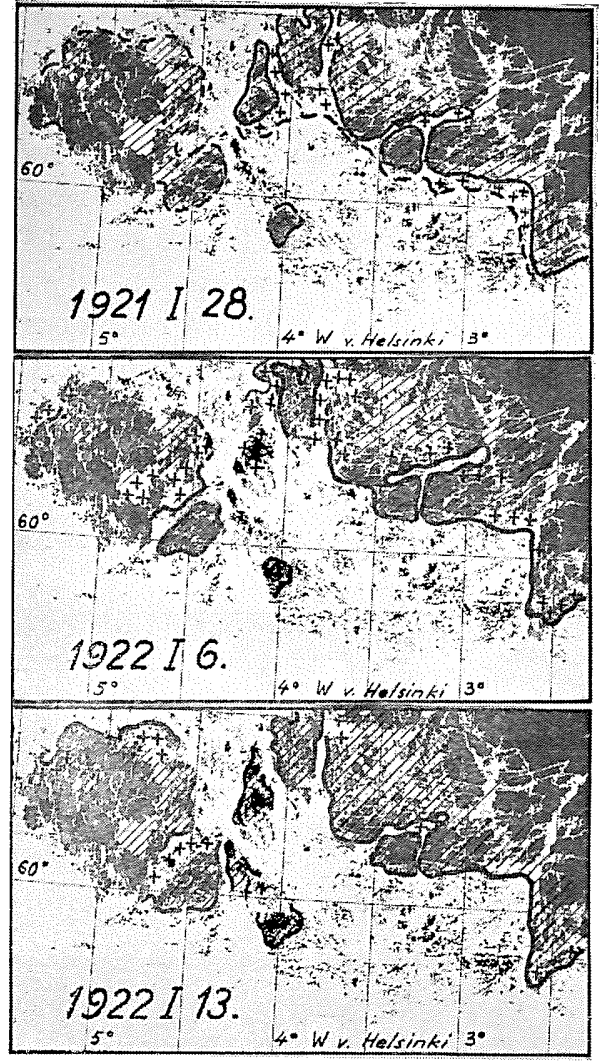

Fig. 10. Augenscheinlich demselben Stadium im allgemeinen Verlauf des Eiswinters im Schärenmeergebiet entsprechende E is I a g e n, zusammen mit Fig. 9 in fünf verschiedenen Wintern. die Umstände zur Zeit seiner Entstehung, einigermassen wechseln. So kann die Vereisung in weiten offenen Gebieten - im Verhältnis zu den geschützten inneren Teilen des Schärenhofes — sich mehr oder weniger verspäten. In erster Linie hängt dies von der Stärke und Dauer der Kälte, dem Winde, den Tiefenverhältnissen und anderen Umständen ab. Andererseits entsteht, nachdem die Kälte abgenommen und das Wetter gelinder und windiger geworden ist, beim Zerbrechen des Eises ein neuer Rand, der seinerseits von der Richtung und Stärke des Windes, von der Dicke des Eises und von anderen Umständen abhängig, in seinem allgemeinen Verlauf etwas wechseln kann. Aus den hier erwähnten wie auch aus anderen Gründen kann die einem und demselben "Moment» in dem allgemeinen Verlauf des Winters unzweifelhaft entsprechende

Eislage der Bräme des festen Küsteneises in den verschiedenen Jahren etwas in ihrer Lage variieren, die Abweichungen sind aber oft, wie z.B. Fig. 9 und 10 zeigt, doch verhältnismässig gering.

A. Elemente der Darstellung des allgemeinen Verlauis des Eiswinters: Stadium und Frequenz.

\section{a. Normale Eislage oder Normalstadium.}

58. Wie die Eislagen in Fig. 9 und 10 zeigen, folgt der Rand der Bräme des festen Küsteneises deutlich der Topographie des Schärenmeeres. Man konnte somit mit recht grosser Wahrschein- 
lichkeit daraus schliessen, dass in dem Schärenhofgebiet während des ganzen Winters eine solche Abhängigkeit zwischen dem topographischen Aufbau dieses Meeresteiles und der Lage des Eisrandes besteht.

Um diese Abhängigkeit feststellen zu können hatte ich zuerst alle Freitags lagen mit möglichst gleichem Verlauf des Randes der Bräme desfesten Küstereises auszuwählen. Eine Gruppe solcher Eislagen entsprach natürlich einem ganz bestimmten 》M oment» oder »Stadium» in dem a $11 \mathrm{gemei-}$ nen Verlauf des Eiswinters. Und nach diesen zu derselben Gruppe gehörenden und einander entsprechenden Eislagen war dann kartographisch die allgemeine, diesen Lagen entsprechende normale Eislage oder das Normalstadium des Eiswinters zu bestimmen. Da die Gruppierung der Eislagen für die Bestimmung der Normalstadien somit ausschliesslich unter Berücksichtigung der verschiedenen Phasen der zu untersuchenden physikalischen Erscheinung - in diesem Falle der Entwickelung der Eisbräme - geschieht, verlor die Z e it - in unserem Falle das Datum der Eislagen - als der den Verlauf der Erscheinung bestimmende Faktor anfänglich ihre zentrale Bedeutung. Erst später, nachdem der allgemeine Verlauf des Winters durch die Normalstadien endgültig bestimmt war, wurde die Zeit, als ein die Reihenfolge der Stadien näher bestimmender Faktor wieder in die Erscheinung eingeschaltet.

59. Als ich zum erstenmal den allgemeinen Verlauf der Eiswinter im Schärenmeer vermittels der Freitagslagen in den Wintern 1913-1922 (36) festzustellen versuchte, war mir die Ausführung der Arbeit noch nicht ganz klar. Es galt damals nachzuforschen und zu versuchen. Deshalb wurde auch diese erste Arbeit auf eine andere Weise ausgeführt als die darauf folgenden Untersuchungen, nämlich folgendermassen:

Die vier, eventuell fünf Freitagskarten eines jeden Eiswintermonats wurden alle auf eine sog. Monatssammelkarte übertragen. Dann wurden die Monatssammelkarten in drei Gruppen eingeteilt, die dem Vorwinter oder Herbst, dem Mittwinter und dem Nachwinter oder Frühling im Verlauf des Winters entsprachen. Die erste Gruppe umfasste alle Eislagen des Vorwinters oder Herbstes bis auf die, in welchen die feste Eisbräme sich über das ganze Schärenmeer erstreckt. Die zweite Gruppe enthielt die Eislagen des Mittwinters, in denen das feste Eis das Schärenmeer bedeckt und 


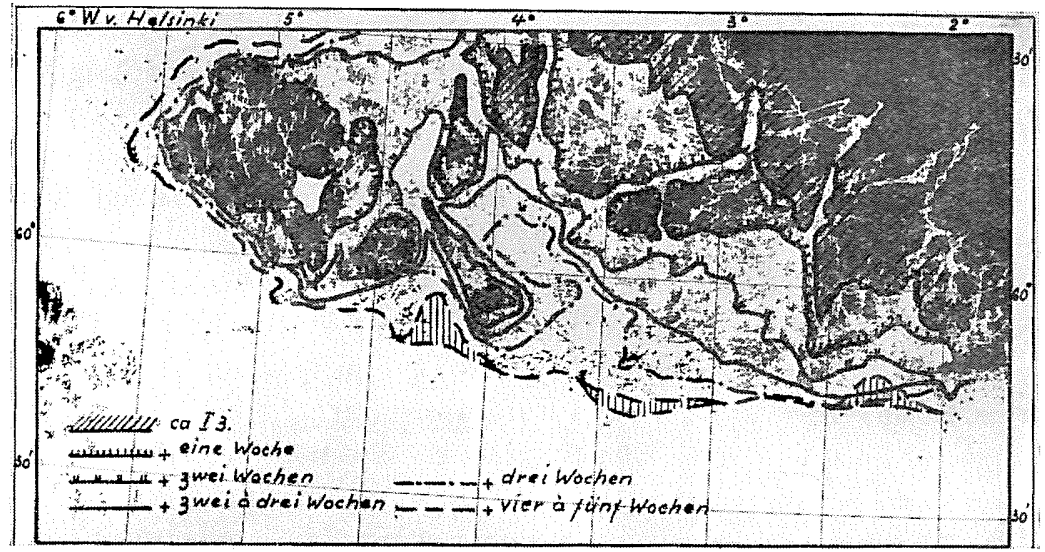

Fig. 11. Aus dem ersten Versuch den allgemeinen Verlauf des Eiswinters kartographisch vermittels der Freitagslagen darzustellen: D i e Vor w in t e r- od e r Herbststadien im Schärenmeer. Als Material die Freitagslagen der Eiswinter 1913-1922.

die fortgesetzte Ausbreitung des Eises, wie später der Rückgang des Eises, ausserhalb der Schärenhofzone im Meer stattfindet. Das mit Eis bedeckte Gebiet erreicht in den Eislagen dieser Gruppe seine weiteste Ausdehnung. Die dritte Gruppe umfasste schliesslich jene Eislagen des Frühlings, in denen, nachdem das Meereseis grösstenteils schon verschwunden ist, der Rückgang der festen Eisbräme bis zu ihrem Verschwinden vor sich geht.

In den Gruppen der Monatssammelkarten des Herbstes und des Frühlings bestimmte ich dann die Lagen des Randes des festen Eises, die im grossen und ganzen derselben Ausdehnung des festen

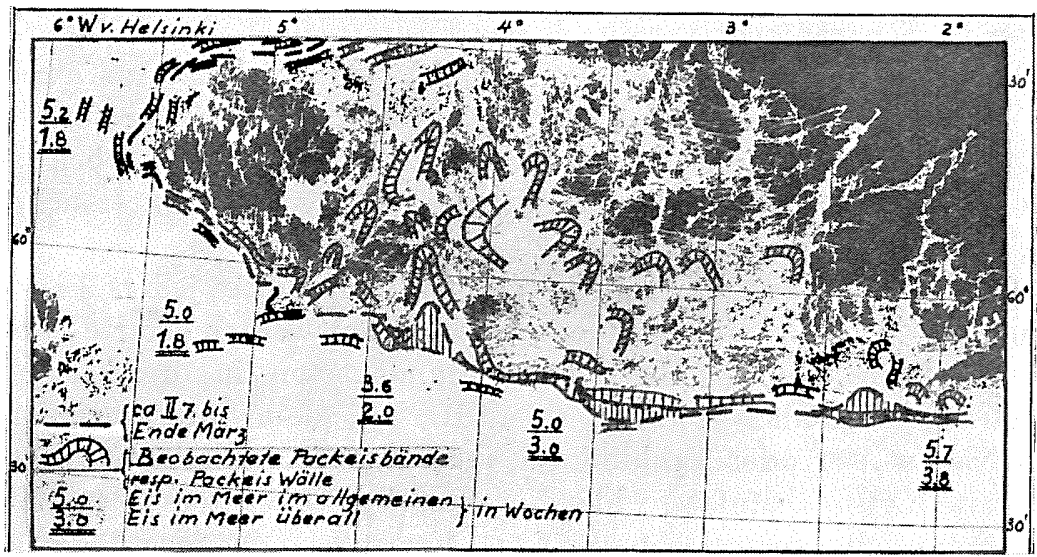

Fig. 12. Aus dem ersten Versuch den allgemeinen Verlauf des Eiswinters kartographisch vermittels der Freitagslagen darzustellen: D i e M it t w in t e r z e it i m S c h är e n m e e r. Als Material die Freitagslagen der Eiswinter 1913-1922. 
Eises oder denselben Stadien im Verlauf des Vor- und Nachwinters entsprechen wie die durchschnittlichen Zeitpunkte ihres Auftretens. Der Beginn der Herbststadien wurde von dem Zeitpunkt der ersten Eislegung, d.h. vơn der Eislegung der seichten Küstengewässer an gerechnet. Der Beginn. der Frühlingsstadien wurde von dem Endpunkt des Mittwinters an gerechnet. Als durchschnittliche Dauer des Mittwinters wurden die Mittelwerte der Differenzen zwischen dem End- und dem Anfangsdatum der Mittwintersammelkarten angesehen. Als Zeiteinheit wurde die Woche gewählt.

\section{b. Relatives Auftreten oder Frequenz des Meereseises.}

60. Die Eisverhältnisse in den an das Schärenmeer grenzenden und dieses umgebenden Meeresteilen wurden von mir in der ersten Untersuchung nur durch einige Zahlen beleuchtet. Ich bestimmte nämlich nur, wie lange - die Woche als Zeiteinheit - das Meer ausserhalb der Beobachtungsorte einerseits teilweise, andererseits so weit man sehen konnte, mit Eis bedeckt war. Diese einigermassen unbestimmten, aber miteinander doch vergleichbaren und dadurch relativen Zahlen des Auftretens des Meereseises oder die Frequenzzahlen desselben sind auf der Mittwinterkarte (Fig. 12) ausserhalb der Bräme des festen Eises in den entsprechenden Meeresteil eingezeichnet. Die Eisverhältnisse der ausserhalb des Schärenmeeres gelegenen Meeresteile wurden erst in der folgenden Untersuchung (35) in etwas anschaulicherer Weise durch Kurven von mir dargestellt (Fig. 14).

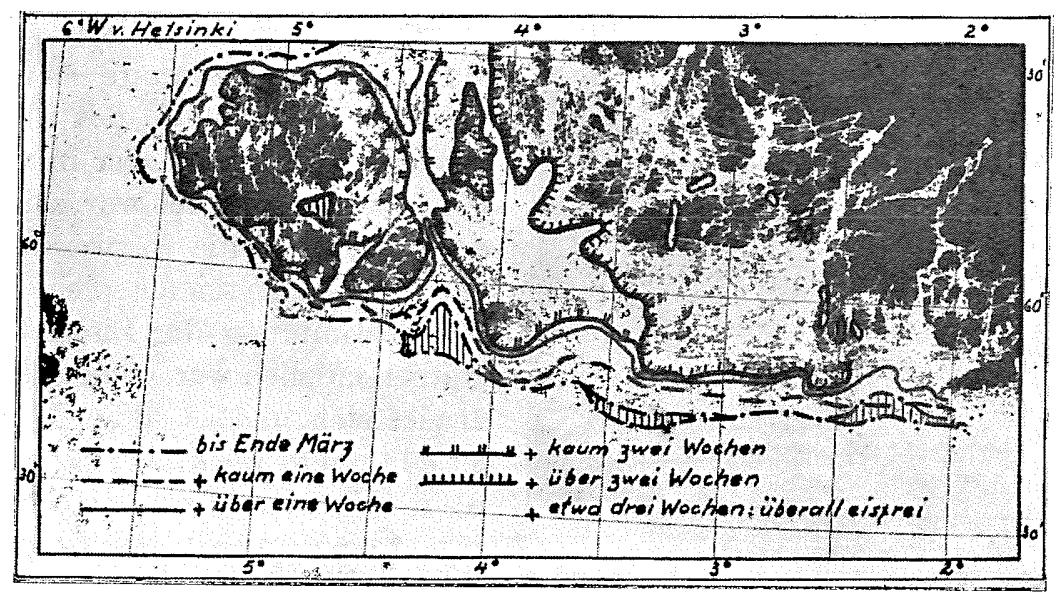

Fig. 13. Aus dem ersten Versuch den allgemeinen Verlauf des Eiswinters kartographisch vermittels der Freitagslagen darzustellen: $\mathrm{D}$ i e $\mathrm{N} \mathrm{a} \mathrm{c} \mathrm{h} \mathrm{w} \mathrm{in} \mathrm{t} \mathrm{e} \mathrm{r-} \mathrm{od} \mathrm{e} \mathrm{r}$ Frühlingsstadien im Schärenmeer. Als Material die Freitagslagen der Eiswinter 1913-1922. 


\section{B. Allgemeiner oder normaler Verlauf des Eiswinters im Schären- meergebiet.}
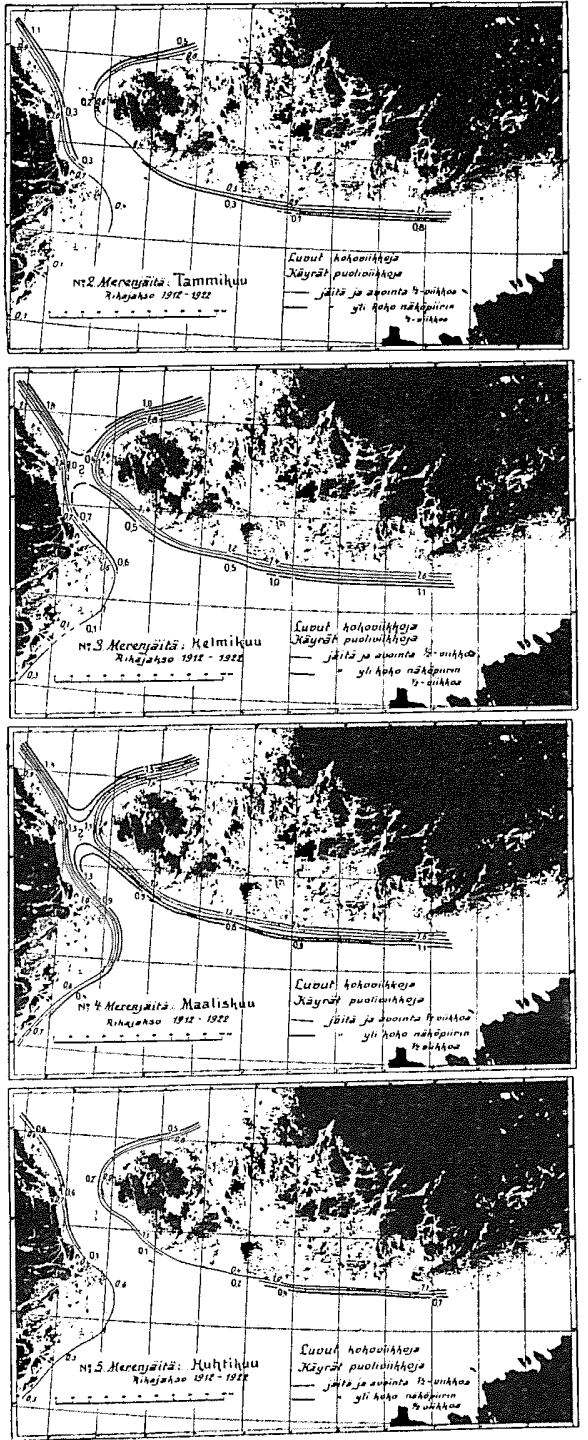

Fig. 14. Die relativen $Z$ ahlen oder die Frequenz des A uftretens des $\mathrm{E}$ is e s in den an das Schärenmeer grenzenden und es umgebenden Meeresteilen $\mathrm{d} u \mathrm{r} \mathrm{ch}$ Kurven veransehaulicht. Die Mittelwerte von Januar bis April 1913-1922.
61. In der obenerwähnten Weise erhielten wir - als Elemente die Bräme des festen Küsteneises der Freitagskarten, die Zahlen des relativen Auftretens des Meereseises und die diesen beiden entsprechenden Zeiten benutzend - einige Stadien in dem allgemeinen Verlauf des Eiswinters im Schärenmeergebiet und den angrenzenden Meeresteilen, nämlich: vom Herbst oder Anfang des Winters, von der ersten Eislegung gerechnet, 6 Stadien; vom Mittwinter 2, oder, unter Berücksichtigung der Frequenzzahlen, 4 Stadien; und vom Frühling oder Ende des Winters 5 Stadien, d. h. insgesamt 15 Eiswinterstadien (Fig. 11, 12 und 13).

62. So approximativ wie der auf die obenerwähnte Weise hergeleitete Verlauf des Eiswinters im Schärenmeer in vielen Beziehungen auch war, zeigte er doch, dass die Verwendung der Freitagskarten als solche für die Bestimmung der Eiswinterstadien möglich war. Gleichzeitig erwies sich, dass di e Darstellung des allgemeinen Verlaufs des Eiswinters sich auf die denselben Stadien des Winters entsprechenden Eislagen basieren musste, und nicht, wie 
es in derartigen Untersuchungen üblich ist, auf bestimmten Zeitpunkten entsprechende $\mathrm{E}$ is lagen. Und erst nachdem die wirklichen Stadien des allgemeinen Verlaufs des Winters bestimmt worden waren, konnten für diese die Zeitpunkte für ihr durchschnittliches Auftreten bestimmt werden.

\section{Der zweite Versuch den allgemeinen Verlauf des Eis- winters kartographisch darzustellen.}

\section{A. Die ersten allgemeinen oder sog. Generalstadien.}

\section{a. Die Bräme des festen Küsteneises der Generalstadien.}

63. Um versuchsweise die Bräme des festen Küsteneises eines Generalstadiums, d.h. eines Finnlands ganze Küste und alle Meeresteile gleichzeitig umfassenden Stadiums zu bestimmen, gruppierten wir die in den Wintern 1920-1924 einander und somit auch einem ganz bestimmten Moment des Eiswinters entsprechenden Freitageislagen zu besonderen Gruppen. Hiernach zeichneten wir auf einer gemeinsamen Karte alle zur selben Gruppe gehörenden gleichverlaufenden Teile der Bräme. Von diesen erhielten wir dann die Bräme des festen Küsteneises für diesen Moment in dem allgemeinen Verlauf des Winters oder für das normale $\mathrm{Stadium}$ des Eiswinters, welches den zu der Gruppegehörenden Freitagskarten entspricht in der Weise, dass auf einer neuen Karte eine Kurve - der äussere Rand der Bräme des Stadiums - gezogen wurde, die in der Mitte der Schar der Ränder der Bräme des festen Küsteneises zu liegen kam.

Auf die oben erwähnte Weise bekamen wir für den ganzen Winter insgesamt 17 allgemeine Normal-oder G-Stadien des Eiswinters.

In Fig. 15 und 18 sehen wir einige solche G-Stadien. In Fig. 15 sind diejenigen G-Stadien des Vorwinters - der Ordnungszahl nach das 6., 7., 8. und 9. Stadium - während denen das ganze Schärenmeergebiet mit Eis bedeckt wird, dargestellt. In Fig. 18 wiederum sind diejenigen G-Stadien des Nachwinters - der Ordnungszahl nach das 10., 11., 12. und 13. Stadium - in denen der Rückgang des Eises im Schärenmeergebiet so weit fortgeschritten ist, dass die Eisbrücke zwischen dem Festlande und Åland endgültig verschwunden ist, angegeben. 


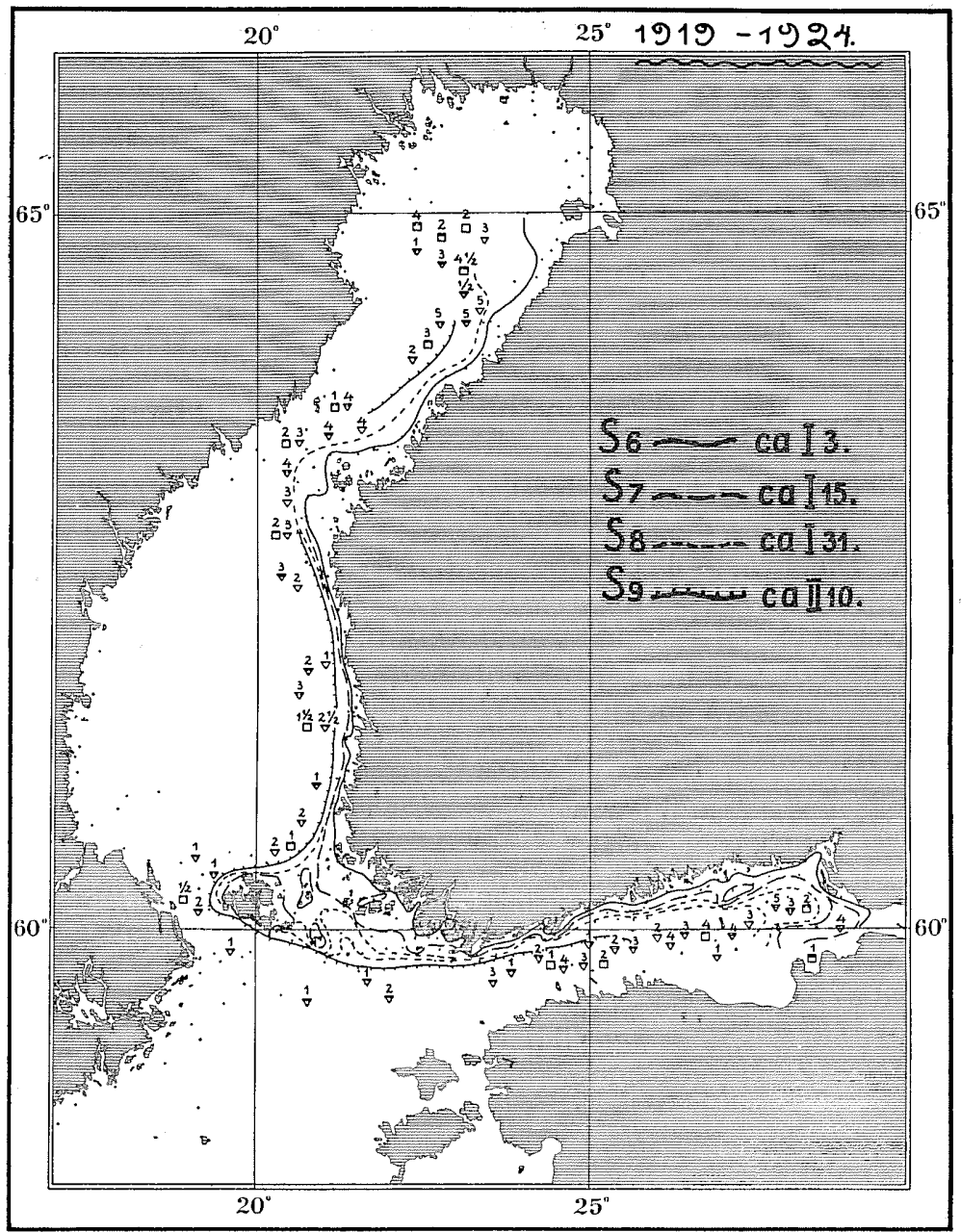

Fig. 15. Aus dem zweiten Versuch den allgemeinen Verlauf des Eiswinters vermittels der Freitagslagen der Winter 1920-1924 kartographisch darzustellen: Die Generalstadien $S_{6}, S_{7}, S_{8}$ und $S_{9}$, dieder Reihe nach ungefähr den Daten I.3., I. 15., I. 31. und II. 10. entsprechen. Die Zahl oberhalb des Dreiecks $(\nabla)$ ist die Frequenzzahl des ausserhalb der Bräme des festen Küsteneises gelegenen losen Eises, die Zahl oberhalb des Vierecks ( $\square$ ) wiederum die Frequenzzahl des zusammengefrorenen Meereseises.

\section{b. Bestimmung der Frequenzzahlen der Generalstadien. Frequenz- zahlen des losen und des zusammengefrorenen Meereseises.}

64. Wie aus der Untersuchung (35), welche die Eisverhältnisse in den das Schärenmeergebiet umgebenden Meeresteilen behandelt, hervorgeht, beleuchten die Frequenzzahlen als solche - im Vergleich 


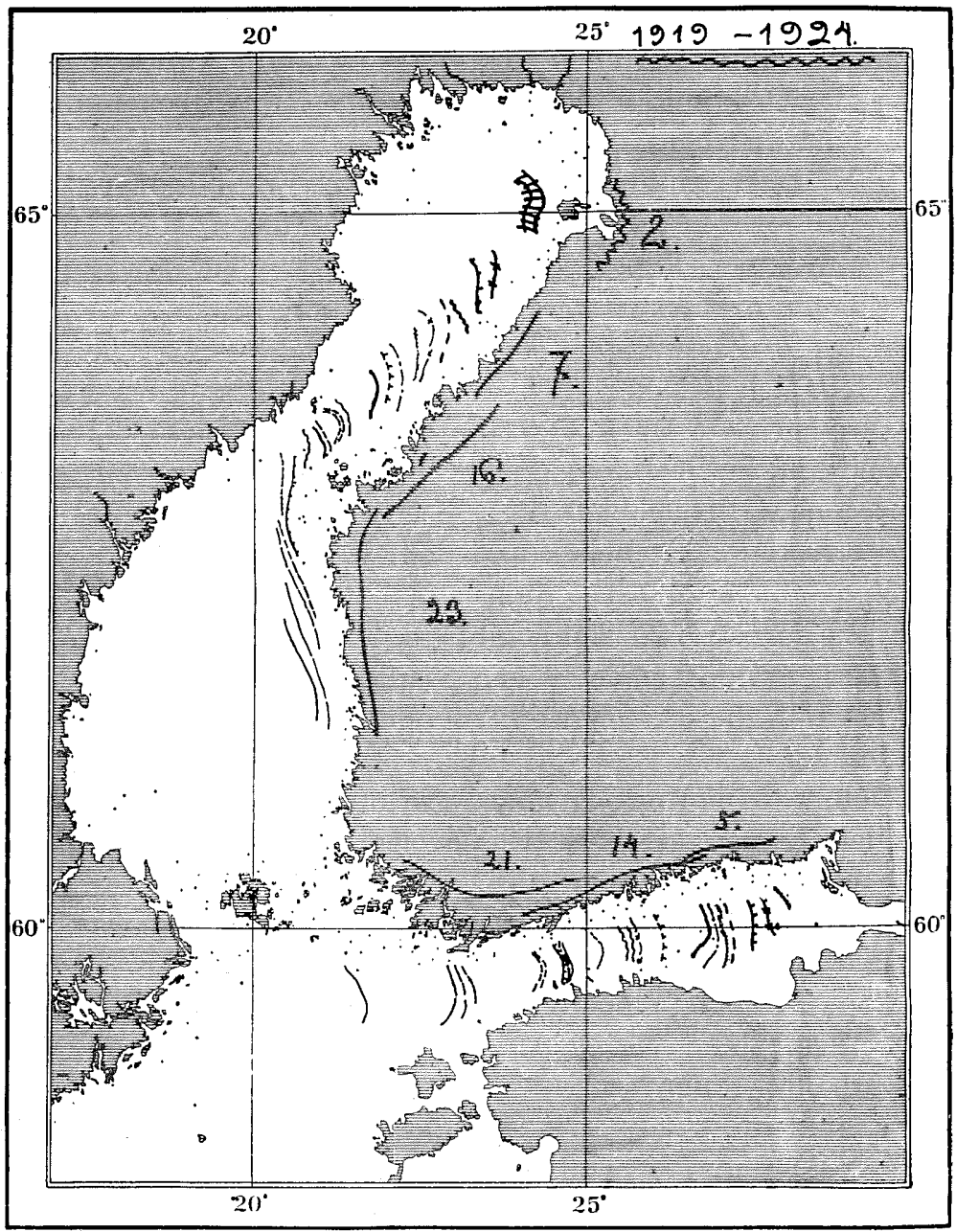

Fig. 16. Aus dem zweiten Versuch den allgemeinen Verlauf des Eiswinters vermittels der Freitagslagen der Winter 1920-1924 kartographisch darzustellen: Die einander entsprechenden, gleichzeitigen und ein wenig geglätteten Grenzen des ausserhalb der Bräme des festen Küsteneises gelegenen Eises in den GStadien des Vor-und Nachwinters.

mit der Bräme des festen Küsteneises - nur in grossen Zügen zahlenmässig, nicht aber in eigentlicher regionaler Beziehung, die Eisverhältnisse im Meer ausserhalb der Bräme des festen Küsteneises.

Es erschien darum notwendig auch die Frequenzzahlen für solche Meeresgebiete festzustellen, die gleich der Bräme des festen Küsteneises durch wirkliche Eisgrenzen — offene Seerinnen, Eisspal- 
ten, Eiswälle, die äusseren Grenzen des gepackten Meereseises und den Rand des noch eisfreien Meeres - bestimmt waren. Um diesen "Rand zweiter Ordnung" und dadurch die durch die Erscheinung selbst gegebenen "natürlichen» Meeresgebiete zu bestimmen, zeichneten wir sämtliche offene Seerinnen, Eisspalten und Eiswallbildungen aus den Wintern 1920-1924 sowie die Grenzen des offenen Meeres auf drei besonderen Karten (Fig. 16, 17 und 19). Als eine "vorkommende» Grenze war dann jeder Rand zweiter Ordnung aufzufassen, der in diesen 5 Wintern mindestens dreimal auftrat.

Es zeigte sich jedoch später, dass die Bestimmung der Frequenzzahlen bei einer derartigen Verteilung der Meeresteile in Gebiete allzu zeitraubend und ihrem Zwecke nicht entsprechend war. Wir beschlossen deswegen als Teilgebiete des Meeres die von dem Rande der Bräme des festen Küsteneises und dem Rande des offenen Wassers begrenzten Gebiete zu betrachten. In diesen so begrenzten Meeresgebieten bestimmten wir dann einfach, wie oft es dort in diesen fünf Wintern in den verschiedenen Stadien Eis gab.

65. Damit die Frequenzen, die die Eisverhältnisse ausserhalb der Bräme des festen Eises darstellen sollten, besser der Wirklichkeit entsprächen, bestimmten wir noch, wie oft in fünf Jahren das ausserhalb der Bräme gelegene Eis in jedem einzelnen Stadium lose (Fig. 15 und 18: die Zahlen oberhalb des Dreiecks) oder ganz zusammengefroren (die Zahlen oberhalb des Vierecks) war. Somit wurde das Eis auch ausserhalb der Bräme des festen Küsteneises in bezug auf einige seiner wichtigen Eigenschaften charakterisiert. Die den allgemeinen Verlauf des Eiswinters darstellenden Normalstadien erhielten hierdurch, im Vergleich mit den "Bildern" des Normalwinters im Schärenmeer (Fig. 11-13), einen den wirklichen Eislagen mehr entsprechenden Aufbau.

\section{B. Die Mittwinterzeit.}

66. Da in der Zeit des Mittwinters - nach unserer Definition desselben - die Veränderungen in der Ausdehnung des Eises beinahe immer und überall auf dem Meere ausserhalb der Bräme des festen Küsteneises vor sich gehen, ergänzten wir in diesem unserem zweiten Versuch das "Bild» des Mittwinters dadurch, dass wir auf einer besonderen Karte (Fig. 17) sämtliche Grenzen des offenen Wassers und die offenen Seerinnen des Mittwinters zeichneten.

Auf diese Weise erhielt auch das "Bild» des Mittwinters eine die wirklichen Verhältnisse besser wiedergebende Form als in der das Schärenmeergebiet behandelnden Untersuchung, wo das ausserhalb 


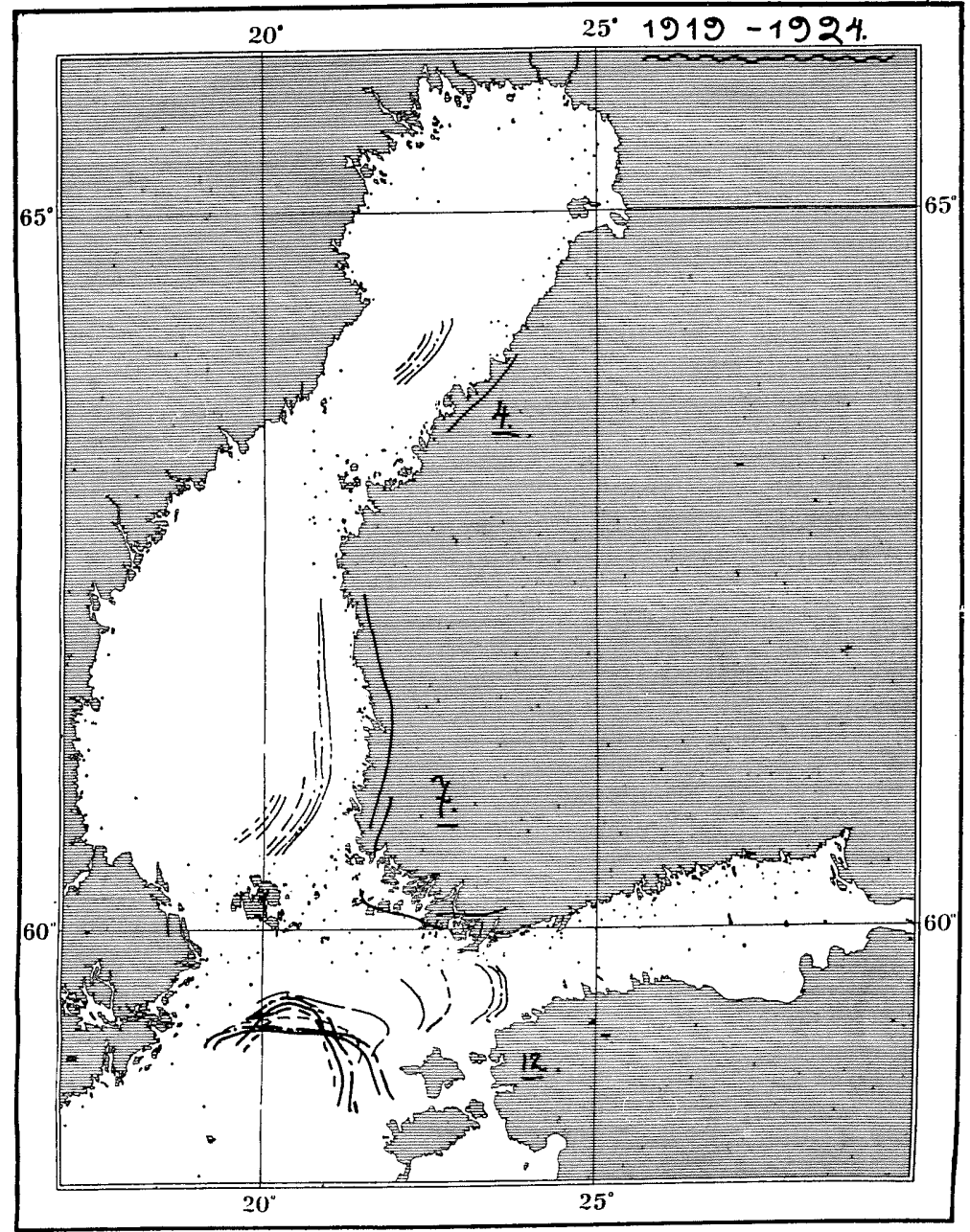

Fig. 17. Aus dem zweiten Versuch den allgemeinen Verlauf des Eiswinters vermittels der Freitagskarten der Winter 1920-1924 kartographisch darzustellen: Die Grenzen des noch eisfreien Meeres, bzw. die offenen Seerinnen in der Mittwinterzeit.

der Bräme des festen Eises gelegene Eis entweder nur durch Frequenzzahlen (Fig. 12) oder durch Frequenzzahlen und Kurven (Fig. 14) dargestellt wurde. Doch war auch dieses „Bild» der Mittwinterzeit immer noch unvollständig. Bei der definitiven Darstellung der Eisverhältnisse unserer Meere war dieser Teil des Winters im Aufbau ebenso den wirklichen Verhältnissen entsprechend zu gestalten, wie sich der Teil des Anfangs und des Endes des Eiswinters erwies. 


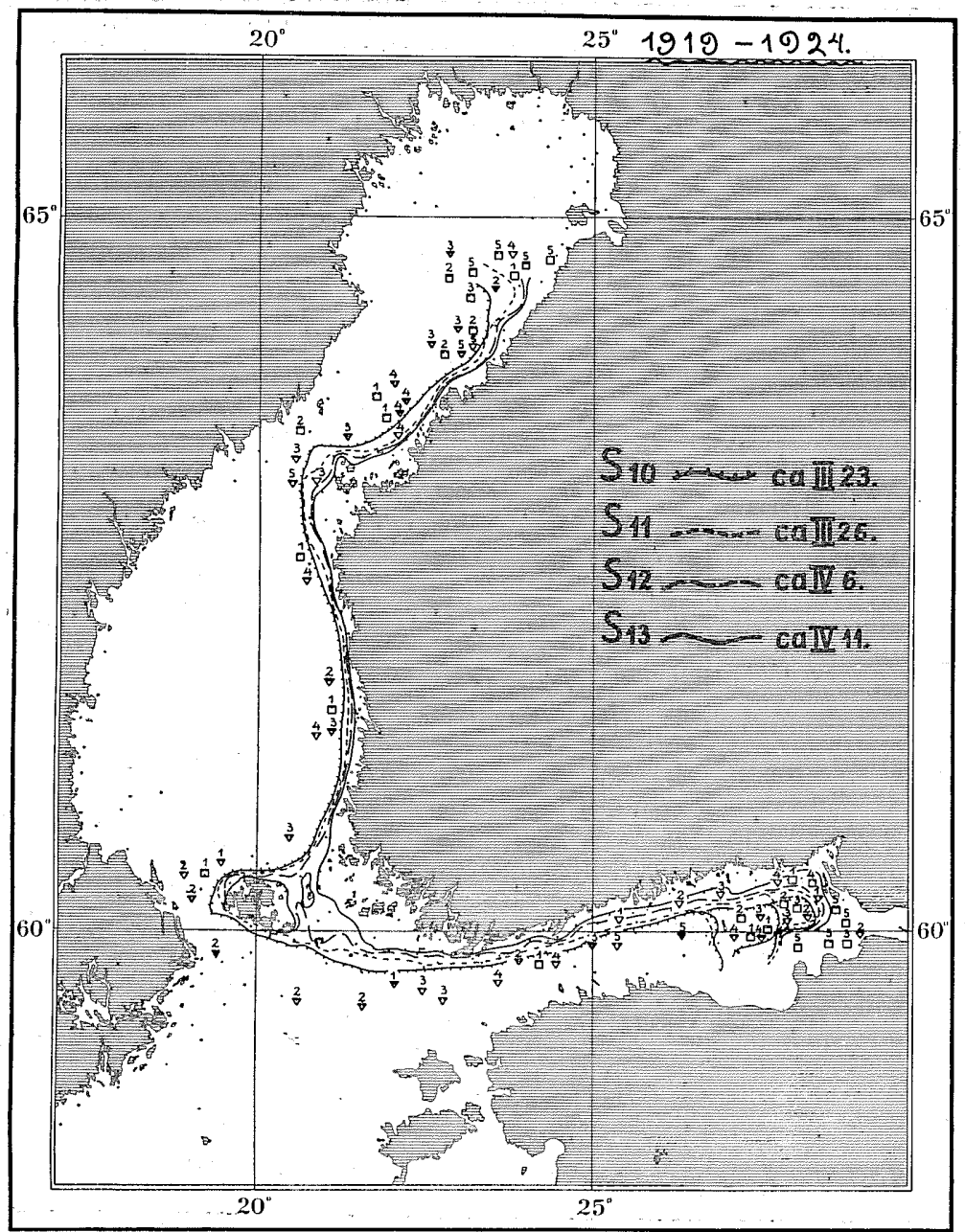

Fig. 18. Aus dem zweiten Versuch den allgemeinen Verlauf des Eiswinters vermittels der Freitagskarten kartographisch darzustellen. Die Generalstadien $S_{10}, S_{11}, S_{12}$ und $S_{13}$, die der Reihe nach ungefähr den Daten III. 23., III. 26., IV. 6. und IV. 11. entsprechen. Die $Z$ ahl oberhalb des Dreiecks $(\nabla)$ ist die Frequenzzahl des ausserhalb der Bräme des festen Küsteneises gelegenen losen Eises; die Zahl oberhalb des Vierecks (ㅁ) wiederum die Frequenzzahl des zusammengefrorenen Meerescises.

\section{Eintrittszeiten der Generalstadien.}

67. Bei diesem 2. Versuch, dessen Zweck zunächst war, die bei der Untersuchung der Eisverhältnisse im Schärenmeer benutzte Methode versuchsweise auf Finnlands ganzes Meeresgebiet auszudehnen, war 
die Bestimmung der Eintrittszeit der Generalstadien eine sekundäre Aufgabe. Ausser der Feststellung der Anwendbarkeit der Methode begnügten wir uns damit, das Eintreten der G-Stadien durch die

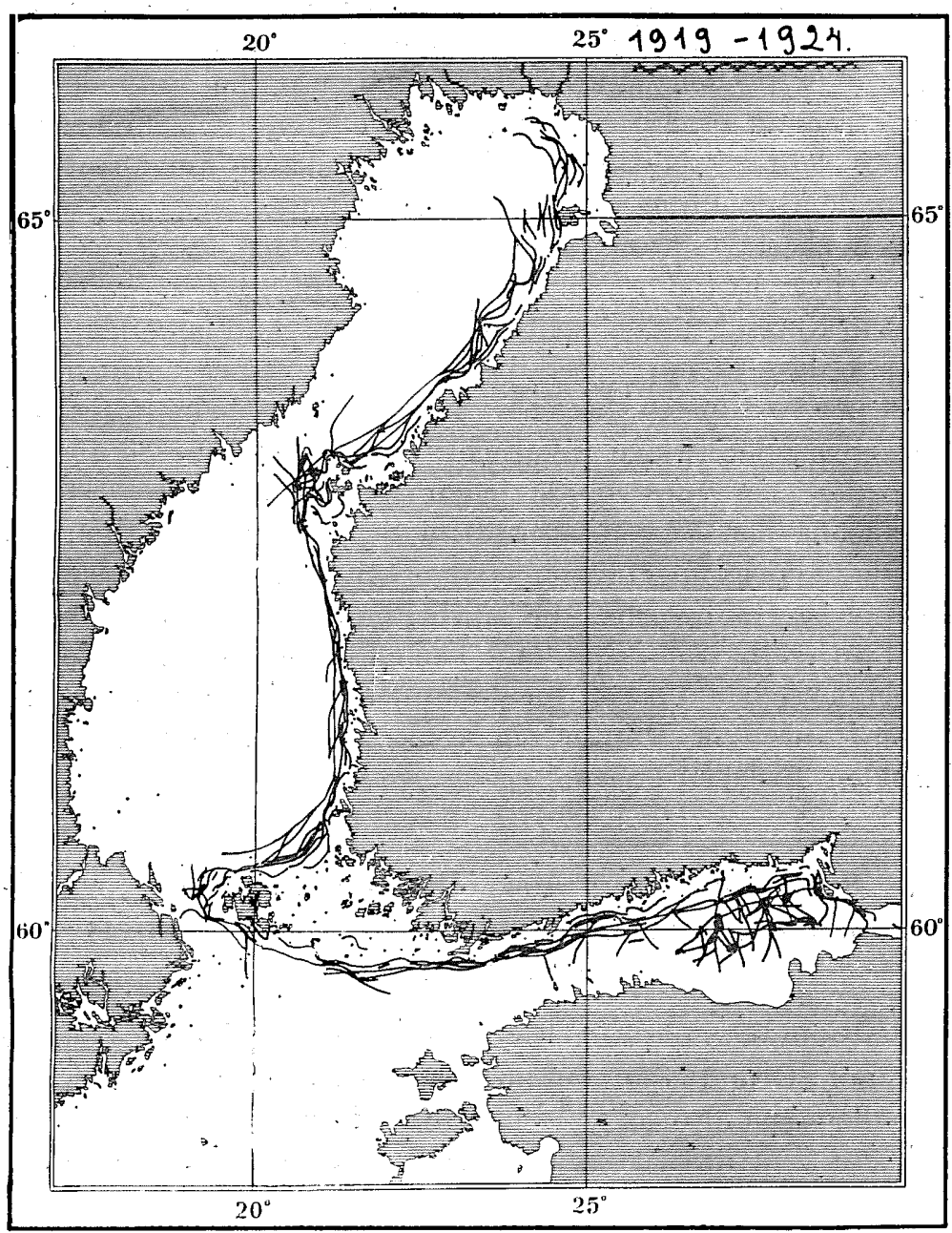

Fig. 19. Aus dem zweiten Versuch den allgemeinen Verlauf des Eiswinters vermittels der Freitagslagen der Winter 1920-1924 kartographisch darzustellen. Die Ränder zweiter Ordnung: die offenen Seerinnen, Eisspalten und Eiswallbildungen.

Mittelzahl der Daten der jedem Stadium entsprechenden Eislagen zu bestimmen. Dadurch wurde die Zeit auch hier, wie bei der ersten Untersuchung, an gewisse Phasen - die Generalstadien des Eiswinters und nicht, wie gewöhnlich, das Ereignis an bestimmte Zeitpunkte geknüpft. 
68. Die oben angeführten Resultate zeigten, dass wir, wenn wir die bei der Darstellung der Eisverhältnisse im Schärenmeer benutzte Methode auf Finnlands ganzes Meeresgebiet ausdehnen, ebenfalls sehr befriedigende Ergebnisse erhalten. Bevor wir zur endgültigen Darlegung der Eisverhältnisse in den an Finnland grenzenden Teilen des Baltischen Meeres übergingen, war die Methode jedoch einigermassen $\mathrm{zu}$ ergänzen und zu vervollständigen, und zwar so, dass jedes definitiv bestimmte Normalstadium so aufgebaut wurde, dass alle dem Stadium entsprechenden Freitagslagen so weit wie möglich in bezug sowohl auf die Ausdehnung des Eises als auf ihre Eintrittszeiten im Normalstadium einbegriffen waren. Den definitiven Normalstadien sollte diese Eigenschaft aus dem Grunde zukommen, dass es nur unter dieser Voraussetzung möglich ist allgemeiner zu bestimmen, welcher Stelle im "normalen» Verlauf des Winters eine jede Eislage entspricht; hierdurch wird eine allgemeine Analyse des Verlaufes eines jeden Winters möglich. Die bei der Darlegung der Eisverhältnisse im Schärenmeer erhaltenen Stadien sowie die oben angeführten ersten G-Stadien genügen dazu nicht, da sie in bezug auf sowohl die Ausdehnung des Eises als ihre Eintrittszeit zu "gebunden» sind und keinen »Spielraum» für die augenscheinlich denselben Phasen im Verlaufe der Winter entsprechenden, aber von Winter zu Winter ein wenig im Bau und in der "Zeit» variierenden Eislagen geben.

\section{Ergänzung und Vervollständigung der Normal- stadien. Der Aufbau der G-Stadien vermittels der S-Stadien.}

Damit nun u. a. die Analyse des allgemeinen Verlaufes eines Eiswinters auf Grund der definitiven Normalstadien möglich war, mussten dieselben also sowohl in bezug auf die Ausdehnung des Eises als auf ihre Eintrittszeit ergänzt und vervollständjgt werden.

\section{A. Ergänzung und Vervollständigung in bezug auf die Bräme des festen Küsteneises und die Frequenzzahlen.}

69. Da der Rand der Bräme in den dem Normalstadium entsprechenden Eislagen keine genau bestimmte und als solche immer von neuem auftretende Grenze ist, sondern in seinem Verlauf einigermassen in den verschiedenen Wintern schwankt, musste der »Rand» des Normalstadiums so bestimmt werden, dass er diese Schwankungen umfasste. Sowohl in der das Schärenmeer behandelnden Unter- 
suchung als in den von uns dargestellten Generalstadien der Eiswinter 1920-1924 entsprach der Rand nur annähernd der Mittellinie der Ränder der Bräme des festen Eises der Eislagen. Dagegen musste j e t z t - damit also schon in dem Normalstadium die Schwankungen im Verlauf des „Randes» in den demselben Stadium entsprechenden Eislagen zum Ausdruck kommen - die ganze Gruppe der Eisränder ber ücksichtigt werden. Gleichzeitig musste jedes Stadiu m - und nicht nur die Stadien des Mittwinters, wie in den Generalstadien der Eiswinter 1920-1924 (Fig. 17) durch die den Rand des noch eisfreien Meeres und die die Frequenzzahlen darstellenden Kurven ergänzt werden.

\section{B. Ergänzung und Vervollständigung in den Eintrittszeiten.}

70. Ebenso wie oben bei der Bestimmung der definitiven Normalstadien auf eine geeignete und zweckmässige Weise die Schwankungen im Verlauf des Randes des festen Küsteneises in den demselben Normalstadium entsprechenden Eislagen beachtet werden mussten, war für jedes Normalstadium die "Zeit» so zu bestimmen, dass sie auch die "Beweglichkeit» der Zeitpunkte des Erscheinens der dem Stadium entsprechenden Eislagen umfasste.

\section{Der Aufbau der G-Stadien vermittels der S-Stadien.}

71. Wenn die Bestimmung der Generalstadien in der Weise geschieht, wie bei ihrer ersten Herleitung der Fall war, nämlich dass ein Stadium für Finnlands ganze Küste und sämtliche Meere auf einmal bestimmt wird, so setzt dieses Verfahren eine grössere Regel- und Gleichmässigkeit im Verlauf des Winters in Finnlands ganzem Meeresgebiet voraus, als in Wirklichkeit der Fall ist. Somit entstanden mancherlei Schwierigkeiten und das endgültige Resultat schien zweifelhaft. Um dies zu vermeiden, musste Finnlands ganzes Meeresgebiet in zweckentsprechende Teile eingeteilt und in einem jeden dieser Me eresteile der Verlauf des Eiswinters für sich bestimmt werden. Erst auf Grund der so erhaltenen Normalstadien der Meeresteile oder der S-Stadien waren dann die das ganze Meeresgebiet Finnlands umfassenden normalen Ge neral - oder G-Stadien aufzubauen.

Die Meeresteile waren die folgenden (Fig. 1): die Bottenwiek, der Kvark, die Bottensee, das Alandsmeer nebst dem Schärenmeer und der Finnische Meerbusen. Die Grenzen dieser Meeresteile werden später im vierten Teil näher bestimmt. 


\section{Zweiter Abschnitt: Die definitiven S-Stadien.}

\section{Die definitive Bestimmung der Normalstadien und des allgemeinen Verlaufs des Eiswinters der Meeresteile.}

A. Die Gruppierung der Freitagskarten der Winter 1915-1925 für die verschiedenen Meeresteile.

Als wir schliesslich zum drittenmal - und zwar auf Grund der Freitagiskarten der Eiswinter 1915 bis 1925 - den allgemeinen Verlauf des Winters in den Meeresteilen Finnlands zu untersuchen begannen, wurde die Arbeit von Anfang an so angelegt, dass die oben in den Punkten 69, 70 und 71 erwähnten Gesichtspunkte sowohl bei der anfänglichen Gruppierung der Eislagen als bei der weiteren Ausführung der Arbeit die bestimmenden waren.

a. Die erste Gruppierung der Freitagskarten in drei Hauptgruppen, die dem Vor- oder Herbstwinter, Mittwinter und Spät- oder Friihlingswinter entsprechen.

72. Die Gruppierung der Eislagen wurde natürlich immer unter Berücksichtigung des Verlaufs des Winters desjenigen Meeresteiles, dessen Eisverhältnisse aufzuklären waren, ausgeführt. Anfänglich hatten wir nur vier Meeresteile, nämlich: die Bottenwiek, die Bottensee, das Ålandsmeer nebst dem Schärenmeer und den Finnischen Meerbusen. Bald fügten wir den Kvark als ein besonderes Gebiet hinzu, was zunächst dadurch bedingt wurde, dass er die "Pforte" der Bottenwiek und das Übergangsgebiet zwischen der Bottenwiek und der Bottensee ist. Später erwies sich jedoch, dass eine selbständige Behandlung der Eisverhältnisse in diesem Gebiete keine leichte Aufgabe war. Dieses Gebiet kann überhaupt nicht - also auch nicht in bezug auf die Eisverhältnisse - als ein selbständiges Gebiet betrachtet werden: das östlich und nördlich von der Linie Norrskär-Valsörarna-Snipan gelegene Gebiet gehört in erster Linie 
zur Bottenwiek, wogegen das diesseits der Linie gelegene Gebiet für die Bottensee charakteristische Merkmale aufweist.

Wir bezeichnen, wie schon früher erwähnt wurde, die Meeresteile mit folgenden Buchstaben: $\mathbf{a}=$ die Bottenwiek, $\mathbf{b}=\operatorname{der}$ Kvark, $\mathbf{c}=$ die Bottensee, $\mathbf{d}=$ das Allandsmeer nebst dem Schärenmeer und der nördlichen Ostsee und $\mathbf{e}=$ der Finnische Meerbusen.

In Fig. 1 umgeben die verschieden bezeichneten Rechtecke die betreffenden Meeresteile. Diese werden jedoch keineswegs durch natürliche Grenzen wie Schwellen, Schärenhöfe, Inseln usw. abgegrenzt, sondern die fraglichen Meeresteile sind jedesmal nur etwas über den Bereich des Meeres oder des Meeresgebietes, das denselben Namen wie der Meeresteil trägt, ausgedehnt worden.

73. In der ersten, für jeden der Meeresteile $\mathbf{a}, \mathbf{b}, \mathbf{c}$, $\mathbf{d}$ und e besonders durchgeführten Gruppierung der Eislagen wurden dieselben in $\mathrm{dr}$ e i Ha $\mathrm{H}$ tg r u p e n eingeteilt. Diese entsprechen der Reihe nach den drei Hauptabschnitten im Verlauf des Eiswinters: die erste Hauptgruppe dem Vorwinter mit dem Beginn der Eislegung und dem Zuwachs der Bräme des festen Eises, die zweite Hauptgruppe dem Mittwinter, wo die Bräme des festen Eises sowie das mit Eis bedeckte Gebiet ihre grösste Ausdehnung erreicht haben, und die dritte Hauptgruppe dem Nachwinter, während dem die Bräme des festen Eises immer schmaler wird und schliesslich ganz verschwindet.

In der Darstellung der Eisverhältnisse des Schärenmeeres haben wir die drei Hauptabschnitte des Eiswinters mit dem Herbst, dem Mittwinter und dem Frühling des Winters bezeichnet. Wir werden diese Benennungen auch im folgenden benutzen.

Die erste Gruppierung der Eislagen der Meeresteile in diese Hauptgruppen geschah also einzig danach, o b die $\mathrm{Bräm}$ e des festen Küsteneises im Wachstum begriffen war, ob sie ihre weiteste Ausdehnung erreicht hatteoder ob sie im Abnehmen und Verschwinde $n$ begriffen war. So wurde auch dann verfahren, wenn die Eislage - im Vergleich mit den nächstliegenden Lagen - einen Rückgang der Vereisung im Herbst oder dessen Zunahme im Frühjahr zeigte, d. h. auch dann, wenn in der Bräme des festen Küsteneises einer Eislage eine Veränderung in entgegengesetzter Richtung stattgefunden hatte, als im fraglichen Teil im allgemeinen Verlauf des Winters als "natürlich» zu erwarten gewesen wäre.

Diese Gruppierung der Eislagen in die drei Hauptgruppen war für alle Meeresteile im allgemeinen leicht durchzuführen. Nur in der Mitte des Winters vorgekommene Perioden mit sehr bedeutendem 
Rückgang des Meereseises sowie dem Mittwinter entsprechende Eislagen gewisser kurzer Eiswinter bereiteten in einigen Meeresteilen Schwierigkeiten.

\section{b. Die Verteilung der Hauptgruppen auf Untergruppen, von denen jede die Eislagen umfasst, die einem Normalstadium entsprechen.}

74. Nachdem die Hauptgruppen bestimmt waren, teilten wir sie in Untergruppen ein. Hierbei wurden die in bezug auf die Bräme des festen Eises m ögli ch st g l e i c h en E is lag e n zu derselben Untergruppe zusammengefasst. Aus diesen waren dann die Normalstadien des Eiswinters, von denen eine jede somit einer ganz bestimmten Untergruppe mit ihren Eislagen entsprach, herzuleiten.

Bei dieser Gruppierung der Eislagen diente somit als Einteilungsgrund - ebenso wie früher bei der Untersuchung der Eisverhältnisse des Schärenmeeres und bei der ersten Herleitung der Generalstadien - der äussere Rand des festen Küsteneises, d. h. eine wirkliche Grenze. Schon KaRstrs bemerkte in seiner Untersuchung vom Jahre 1911 im Zusammenhang mit der Darstellung des allgemeinen Eiswinterverlaufes, dass die in den verschiedenen Zeitpunkten des Eiswinters wechselnde Breite, d.h. die wechselnde Lage des äusseren Randes der Bräme des festen Küsteneises, für die „Eisverhältnisse (= Eislage) charakteristisch ist» (40).

Die Bräme des festen Küsteneises bildet den dauerhaftesten Teil des Eises. Kurzes Tauwetter oder gelinde Kälte verursachen im allgemeinen keine nennenswerten Veränderungen in ihr, wogegen das ausserhalb der Bräme gelegene Eis, wenigstens zum Teil, den ganzen Winter ziemlich leicht seine Lage verändert, zeitweise von Tag zu Tag. Bei der Einteilung der Eislagen in Unterg r u p en wurde das ausserhalb der Bräme des festen Küsteneises gelegene Eis deshalb als ein sekundäres Merkmal betrachtet, obwohl es ein mit der Bräme wenigstens gleichwertiges Element der Eislage ist. Ebenso wurde auch bis auf weiteres mit dem Rande des "noch eisfreien Meeres» verfahren, weil hier die Veränderungen meist von meteorologischen Verhältnissen abhängig sind.

Obwohl dem ausserhalb der Bräme des Küsteneises gelegenen Eis somit bei der Gruppierung der Eislagen eine sekundäre Stellung gegeben wurde, hat es im allgemeinen Verlauf des Eiswinters eine ebenso grosse, zeitweise sogar grössere Bedeutung als die Bräme. Dass die Lage des Randes der festen Küsteneisbräme als Einteilungs- 
grund gewählt wurde, beruhte jedoch nicht nur auf ihrer Beständigkeit, sondern vor allem, wie schon im Anfang dieses Teils bemerkt ist, darauf, dass ihr Rand in den verschiedenen Wintern einen in grossen Zügen gleichen Verlauf zeigt.

Da das ausserhalb der Bräme des festen Küsteneises liegende "Meereseis» anderseits jedoch einen besonders wichtigen Teil der Eislagen umfasst, muss diesem »Meereseis» natürlich ein seiner Bedeutung entsprechender Anteil in den den allgemeinen Verlauf des Winters darstellenden Normalstadien zugewiesen werden. An den Stellen dieser Untersuchung, wo das ausserhalb der Bräme des festen Küsteneises liegende Eis behandelt wird, wird teilweise zur numerischen Methode gegriffen. Es ist jedoch zu beachten, dass auch dabei alle Zahlenwerte vermittels wirklicher Eisgrenzen hergeleitet werden. Ihre Beständigkeit kann jedoch im allgemeinen, wie oben bemerkt wurde, mit der Beständigkeit der Bräme des festen Küsteneises nicht verglichen werden, aber bei einigen bieten die Untiefen, Gründe und Inseln des Meeres Stütz- oder Anhaltspunkte. Beim Spalten, Zerbrechen und Treiben oder beim Zusammenschieben, Pressen und Packen des "Meereseises» verleihen diese Stützpunkte dem nach der Küste zu gelegenen Teil des »Meereseises» eine grössere Festigkeit und dadurch eine grössere Haltbarkeit als dem nach dem Meere zu gelegenen Teil. Aber die im Schutze dieser Anhalts- oder Stützpunkte entstehenden Eisränder $\| \mathrm{z}$ w e i t e r O r d n u n g» wechseln doch sowohl hinsichtlich ihrer Lage als ihres allgemeinen Verlaufes in einem und demselben und in verschiedenen Wintern innerhalb sehr weiter Grenzen, vor allem je nachdem, wie die Herbsthälfte des meteorologischen Winters war.

75. Als die Eislagen, die in einem und demselben Meeresteil in bezug auf die Bräme des festen Küsteneises einander am besten entsprachen, in Untergruppen geordnet wurden, erhielten wir eine solche Verteilung der Eislagen der Winter 1915-1925 in den verschiedenen Meeresteilen, wie aus der graphischen Darstellung in Fig. 20-24 hervorgeht. Später werden diese eingehender beschrieben, hier sei nur folgendes bemerkt:

Eine jede Kolumne entspricht einem Winter. Die Jahreszahl des Winters befindet sich oben (für die Herbsthälfte) und unten (für die Frühlingshälfte) in der Kolumne. Die benutzten Eislagen sind für jeden Winter in Zeitfolgen geordnet und die Zahlen bezeichnen die Ordnungszahl der Untergruppe, zu der die betreffende Eislage gehört. In den ml-Bildern der Figuren haben wir das Untergruppen$\mathrm{schema}$ des normalen oder mittellangen (ml-) Winters, in den l-Bildern das entsprechende Schema des langen (1-) Winters (vertreten 


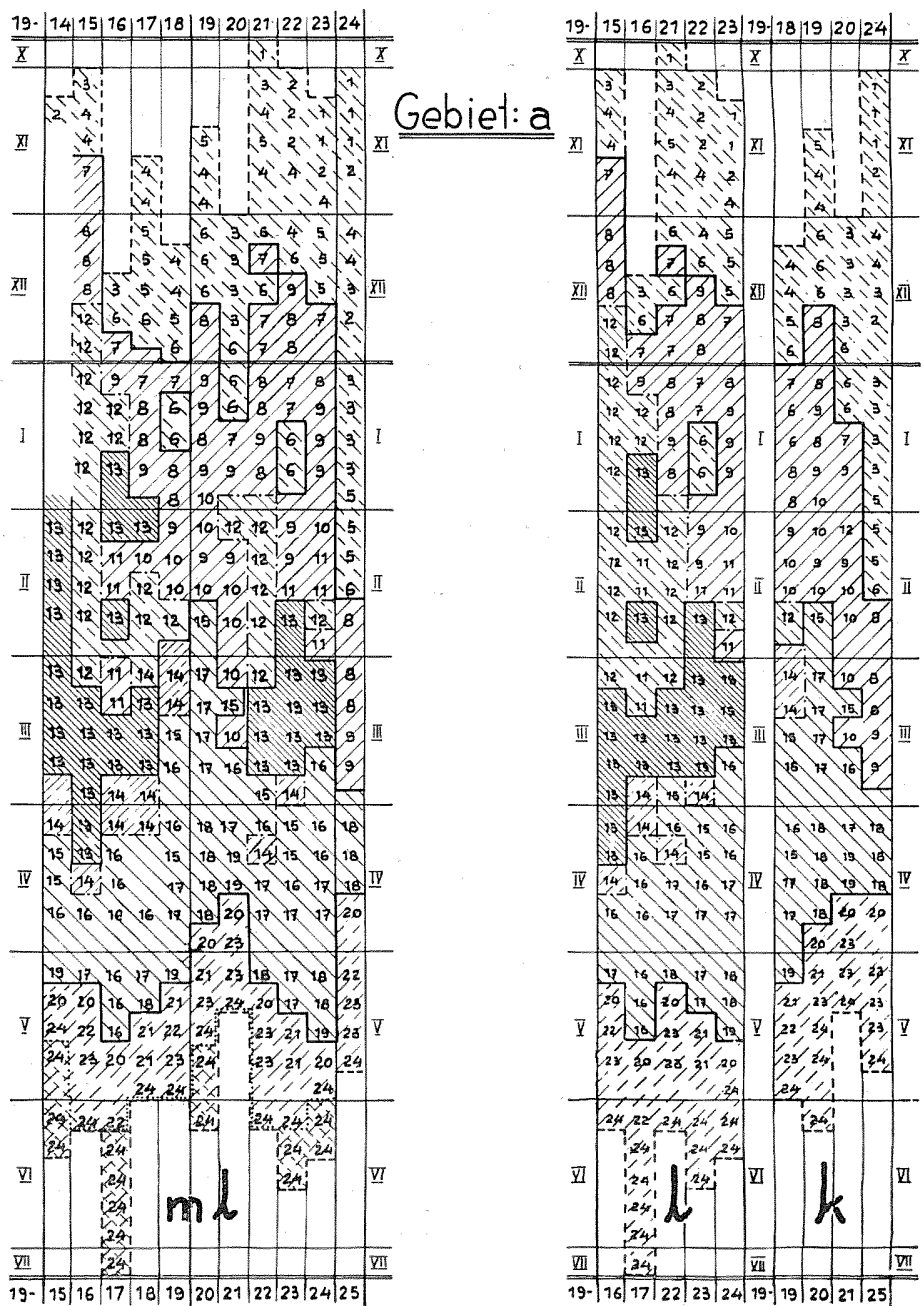

Fig. 20. Graphische Darstellung der Verteilung der Eislagender Winter 1915-1925 auf Untergruppen für das Gebiet a. ml das Untergruppenschema des normalen oder mittellangen (ml-), I des langen (l-) und $\mathbf{k}$ des kurzen $(\mathrm{k}-)$ Winters.

durch die Winter 1916, 1917, 1922, 1923 und 1924), und in den k-Bildern das Schema des kurzen (k-) Winters (vertreten durch die Winter 1919, 1920, 1921 und 1925).

Jeder Winter ist ausserdem in den $\mathrm{h}$ i e r dargestellten Untergruppenschemata in ganz bestimmte, den allgemeinen Verlauf des Winters verdeutlichende Abschnitte - wie später eingehender in dieser Untersuchung dargelegt wird - geteilt. Diese letzterwähnten 


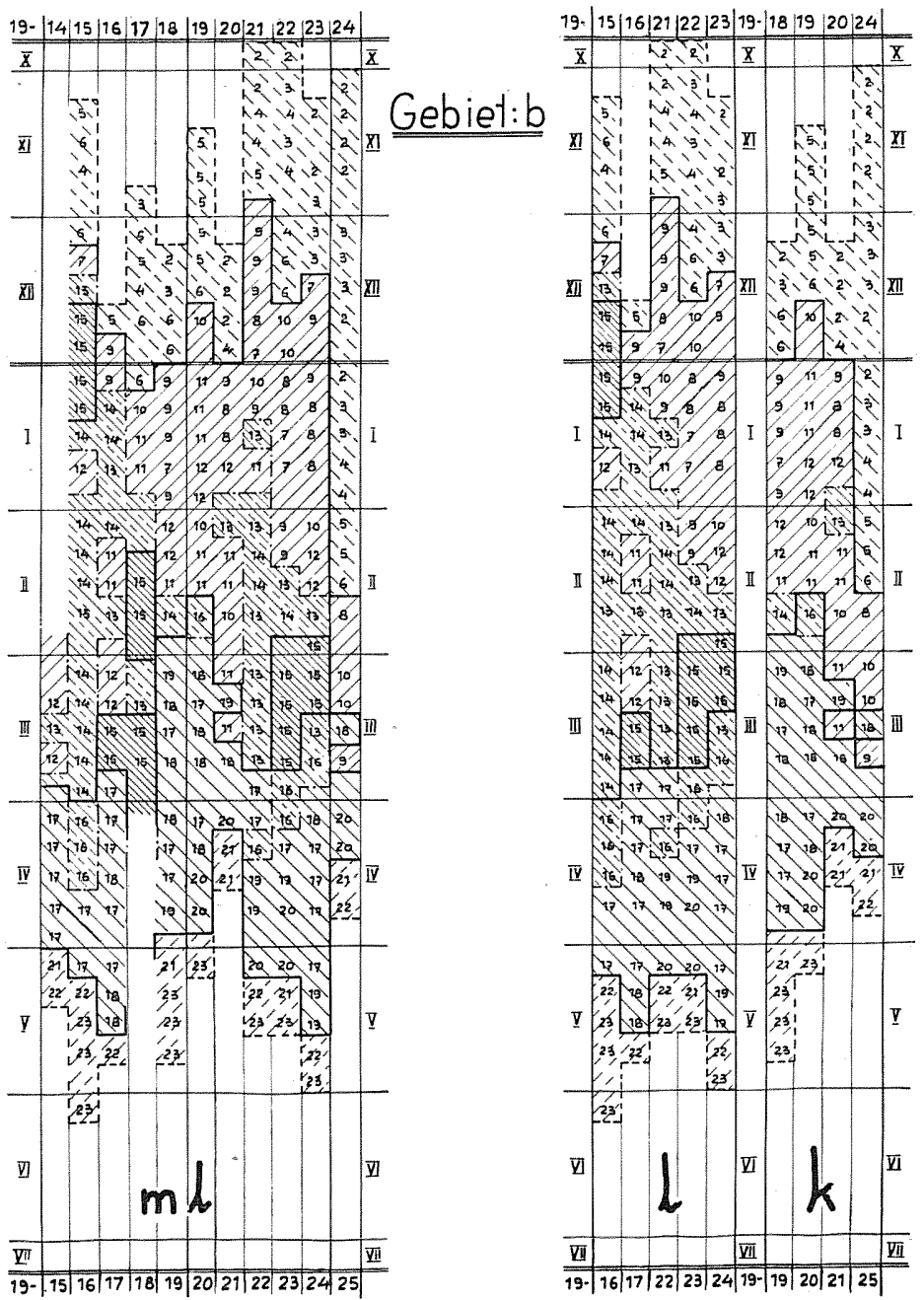

Fig. 21. Graphische Darstellung der Verteilung der Eislagen der Winter 1915-1925 aut Untergruppen fii $r$ d as Gebiet b. ml das Untergruppenschema des normalen oder mittellagen (ml-), $\mathbf{l}$ des langen ( $(-)$ und $\mathbf{k}$ des kurzen

(k-) Winters.

Abschnitte sind durch verschiedene Schraffierung voneinander leicht zu unterscheiden, so dass man aus den Schemata schon bei flüchtiger Musterung eine Auffassung von dem hier schematisch dargestellten, in Wirklichkeit aber sehr wechselnden und verschiedenen Aufbau der Eiswinter 1915-1925 bekommt. Die dichteste Schraffierung, von einer ausgezogenen Linie begrenzt, bezieht sich — insofern dieselbe überhaupt in einem Winter vorkommt - in 




Fig. 22. Graphische Darstellung der Verteilung der Eislagen der Winter 1915-1925 auf Untergruppen fïr das Gebiet e. ml das Untergruppenschema des normalen oder mittellangen (ml-), $\mathbf{l}$ des langen ( $1-$ ) und $\mathbf{k}$ des kurzen (k-) Winters.

den Schemata auf den Teil des Eiswinters, bei dem die Wahrscheinlichkeit des jährlichen Eintretens höchstens 5/10, im Gebiete des Bottnischen Meerbusens jedoch 6/10 ist. Den kurzen (k) und deshalb im allgemeinen hinsichtlich des Umfangs der Vereisung entsprechend leichten Wintern fehlt dieser Mittwinterabschnitt des Winters vollständig. Der folgende Winterabschnitt reicht auf beiden Seiten des Kulminationsgebietes des Eiswinters bis zur ersten 


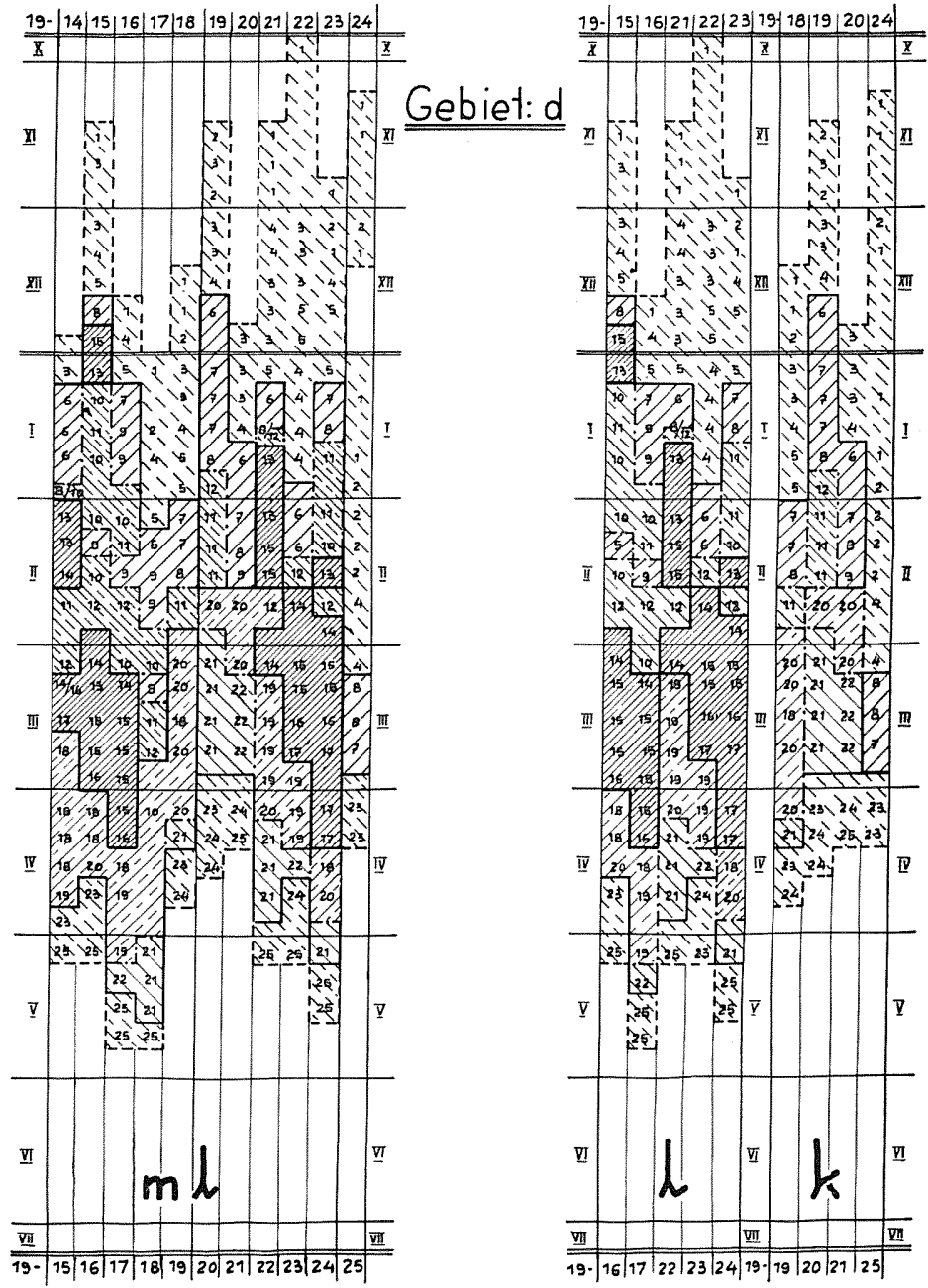

Fig. 23. Graphische Darstellung der Verteilung der Fislagen der Winter 1915-1925 auf Untergruppen für das Gebi et d. ml das Untergruppenschema des normalen oder mittellangen (ml-), $\mathbf{l}$ des langen ( $(-)$ und $\mathbf{k}$ des kurzen (k-) Winters.

unterbrochenen Grenzlinie., welche die Stellen in dem allgemeinen Verlauf der Winter 1915-1925 angibt, wo einerseits die dem letzten im Herbstwinter jeden Winters zu erwartenden und also mit der Wahrscheinlichkeit 10/10 eintretenden herbstlichen Normalstadium, anderseits die dem ersten im Frühling jeden Winters mit der Wahrscheinlichkeit 10/10 eintretenden Normalstadium des Frühlings entsprechenden Eislagen erschienen sind. Diese Grenzlinie verläuft 

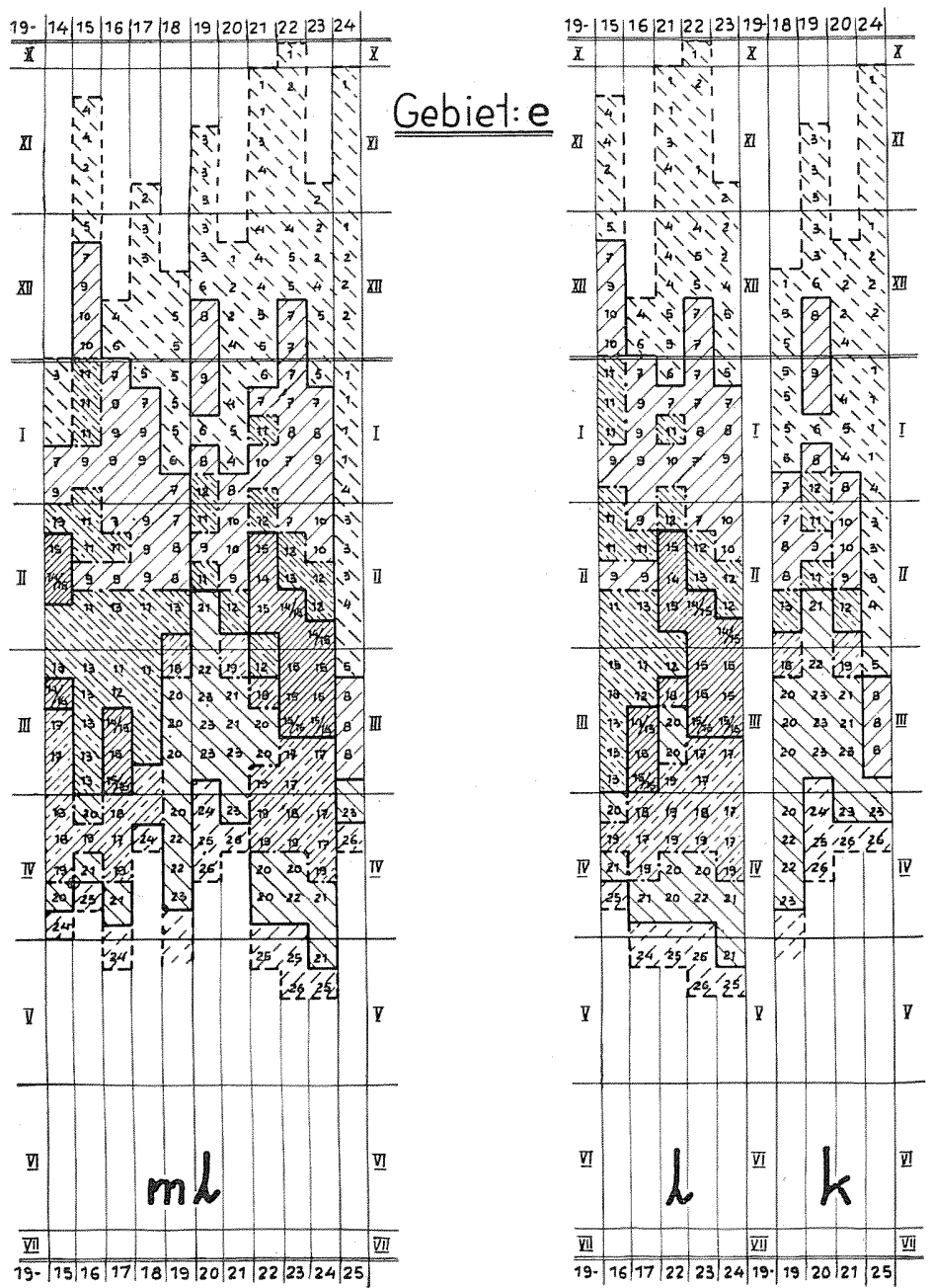

Fig. 24. Graphisehe Darstellung der Verteilung der Eislagen der Winter 1915-1925 auf Untergruppen für das Ge bi et e. ml das Untergruppenschema des normalen oder mittellangen (ml-), 1 des langen ( $(-)$ und $\mathrm{k}$ des kurzen (k-) Winters.

in Fig. 20-24 zwischen folgenden Untergruppen: Im Herbst: im a-Gebiete und c-Gebiete zwischen den Untergruppen 11 und 12, im b-Gebiete zwischen 12 und 13, im d-Gebiete zwischen 9 und 10 und im e-Gebiete zwischen 10 und 11; im Frühling: im a-Gebiete zwischen den Untergruppen 14 und 15, im b-Gebiete zwischen 16 und 17 , im c-Gebiete zwischen 18 und 19, im d-Gebiete zwischen 20 und 21 und im o-Gebiete zwischen 19 und 20. Die 
Schraffierung des Gebietes von der Grenze »10/10» bis zur Grenze des Gebietes ॥5/10» besteht aus schrägen, abwechselnd ausgezogenen und unterbrochenen Linien. In den kurzen (k) Eiswintern 1919, 1920, 1921 und 1925 gab es im allgemeinen einige entweder den ersteren oder letzteren, bzw. beiden Normalstadien dieses Winterabschnittes entsprechende Eislagen.

Die folgende Grenzlinie, die ausgezogene gerade Linie liegt, wenn wir in den Schemata einerseits weiter gegen den Herbst, anderseits weiter gegen den Frühling gehen: im Herbst: im d-Gebiete zwischen den Untergruppen 5 und 6 , anderswo zwischen den Untergruppen 6 und 7; im Frühling: im a-Gebiete zwischen 19 und 20, im b-Gebiete zwischen 20 und 21, im $\mathbf{e}$-Gebiete zwischen 21 und 22, im d-Gebiete zwischen 22 und 23 und im e-Gebiete schliesslich zwischen 23 und 24. Im Schärenmeer oder im d-Gebiete zeigt diese Grenzlinie im Herbst, wo in dem allgemeinen Verlauf der Eiswinter 19151925 die grossen Inselgruppen des südwestlichen Schärenhofs vollständig vom festen Eis umschlossen waren (Normalstadium Sd 5), im Frühling wiederum, wo bei dem Zurückgehen des Eises der Rand des festen Küsteneises ungefähr eine entsprechende Lage eingenommen zu haben scheint (zwischen den Normalstadien Sd 22 und Sd 23). In der Bottensee oder im e-Gebiet sowie im Finnischen Meerbusen oder im e-Gebiet schliesst sich die Grenzlinie im Herbste vermittels der Normalstadien Sc 6 und Se 6 schon hinsichtlich der Zeit an das entsprechende Stadium des d-Gebietes (Normalstadium. Sd 5) an; im Frühling aber entsprechen die zum Normalstadium Sc 21 bzw. Se 23 gehörenden Eiszustände der Winter 1915-1925 am ehesten den zu dem herbstlichen Normalstadium Sc 7 bzw. Se 7 gehörenden Eislagen derselben Winter. So beginnen also, und zwar sehr zweckmässig, in den $\mathbf{e}$ - und e-Gebieten die Normalstadien Sc 7 und Se 7 und beenden die Normalstadien Se 21 und Se 23 den Teil des Winters, der in den Schemata zur Grenze »10/10» mit ausgezogenen, schrägen Linien schraffiert ist. In der Bottenwiek oder im a-Gebiete ist in den dem Normalstadium Sa 6 entsprechenden Eislagen die Bräme des festen Küsteneises, obwohl stellenweise noch sehr schmal, schon längs dem ganzen Ufer des Meeres entstanden, und die zum folgenden Normalstadium oder Sa 7 und dem Normalstadium des Frühlings Sa 19 gehörenden Zustände entsprechen einander wieder ganz so, wie die oben zu den Normalstadien Sc 7 und Se 21 bzw. Se 7 und Se 23 gehörenden. Im Kvark oder im b-Gebiete entspricht die Lage der Grenzlinie in bezug auf die Zeit sowohl im Herbst wie im Frühling am besten der Lage derselben Grenzlinie in der Bottenwiek oder im a-Gebiete. 
Zuäusserst haben wir schliesslich in Fig. 19-23 für den Anfang und den Schluss des Winters die mit unterbrochenen Linien gezeichneten Grenzen, sowie die mit schrägen kurzen Linien schraffierten und im Herbst das an diesen Grenzlinien beginnende Gebiet: den Anfangsteil des Eiswinters, und im Frühling das an diesen Grenzlinien endende Gebiet: den Endteil des Eiswinters. - Später werden wir, wie schon früher erwähnt ist, u. a. bei der Herleitung des langen (1-) und des kurzen (k-) Winters sowie im vierten Teil auf die Untergruppenschemata zurückkommen.

76. Nachdem die Untergruppierung der Eislagen eines Meeresteiles z. B. der Bottenwiek oder des a-Gebietes ausgeführt war, wurde von allen zu einer, z. B. zur n. Untergruppe gehörenden Eislage der Rand der Bräme des festen Küsteneises in eine Karte, die wir als S-Karte bezeichnen, eingetragen. Auf einer anderen Karte, der F-Karte, wurden dann die Grenzen des ausserhalb der Bräme gelegenen Eises und andere Grenzen "zweiter Ordnung》 dargestellt. Diese

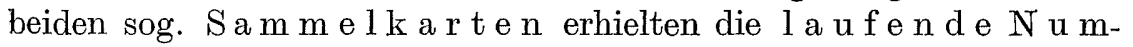
$\mathrm{m}$ e $\mathrm{r}$ der entsprechenden Untergruppe, in dem erwähnten Beispiel
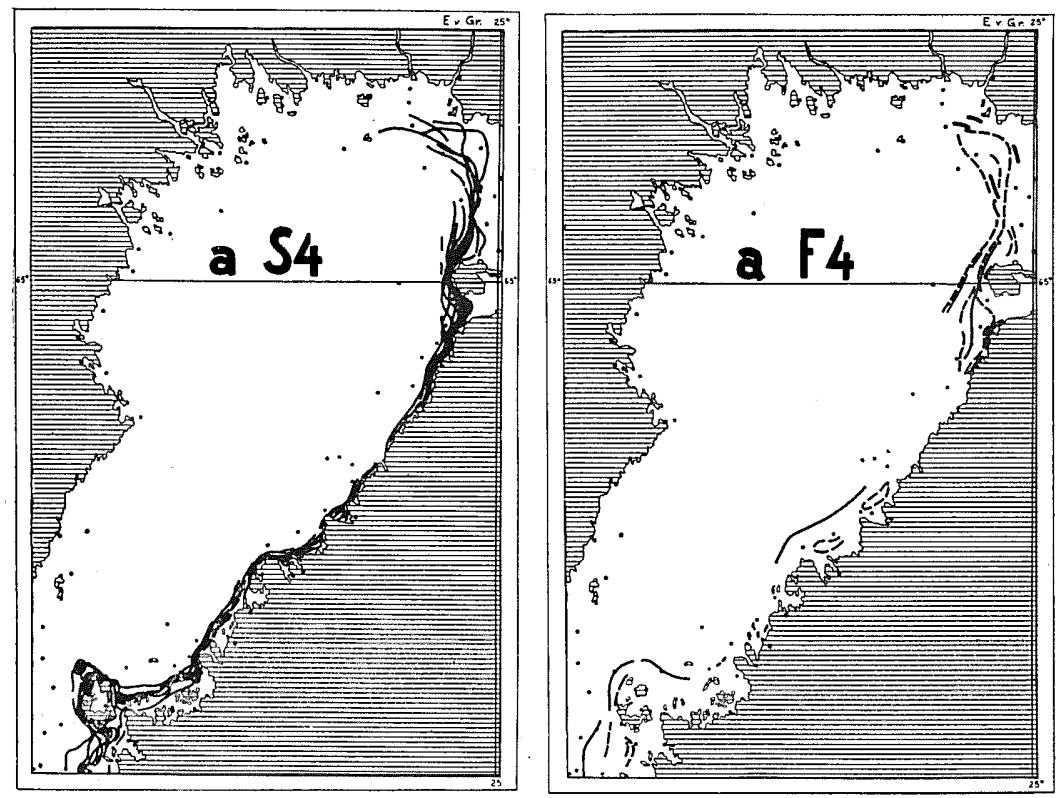

Fig. 25. Sammelkarten zur definitiven Bestimmung des allgemeinen Verlaufes des Eiswinters eines Meeresteiles. Sammelkarte a S4 (die Ränder der Bräme des festen Küsteneises) und a F4 (die ausserhalb der Bräme gelegenen Ränder "zweiter Ordnung») der Bottenwiek oder des a-Gebietes. 
die Nummer n. Somit waren ihre vollständigen Kennzeichen a Sn und a Fn.

Fig. 25-29 stellen solche Sammelkarten der Gebiete der Bottenwiek, der Bottensee, des Schärenmeeres und des Finnischen Meerbusens dar.

\section{B. Die Sammelkarten Sn und Fn, von denen das n. Normalstadium eines Meeresteils hergeleitet wird.}

\section{a. Die Sammelkarten a Sn, b Sn, c Sn, d Sn und e Sn.}

7\%. Da die offenbar demselben Punkt oder Moment im allgemeinen Verlauf des Eiswinters entsprechenden Eislagen unter sehr verschiedenen meteorologischen und thalassologischen Verhältnissen entstehen können, zeigen sie in den einzelnen Wintern einen etwas abweichenden Bau. So zerbrechen, wenigstens teilweise, die herbstlichen und die später im Anfang des eigentlichen Winters bei kaltem Wetter entstandenen äussersten Teile der Bräme des festen Küsteneises oft dann, wenn der Wind sich wendet und das Wetter milder wird. Dann bildet das nachgebliebene, noch nicht zerbrochene feste Eis eine "neue» Bräme mit anders verlaufendem Rand, der in verschiedenen Wintern in bezug auf seine Lage einigermassen variieren kann, je nachdem welche Richtung, Stärke und Dauer der das Eis zerbrechende Wind jeweils hat, wie dick das Eis ist usw. Im Mittwinter hingegen variiert die Lage der Eisspalten und der grossen Seerinnen, obgleich meistens nur einigen Hauptrichtungen folgend, in verschiedenen Wintern, ja sogar während eines und desselben Winters, u. a. je nachdem, wie die meteorologischen Verhältnisse im allgemeinen gewesen sind, d.h. unter welchen Verhältnissen das Eis entstanden ist und welchen mechanischen Prozessen es somit unterworfen war, wie beschaffenauf Grund des vorher Erwähnten - das Eis seinem Aufbau nach war und wie dick es wurde; ausserdem welcher Richtung, wie stark und anhaltend der Wind, der das Zerbrechen des Eises verursachte und die Seerinnen öffnete, war usw. Im Frühlingswinter schliesslich kann der Rückgang der Bräme des festen Küsteneises sogar innerhalb eines und desselben Meeresteils, z. B. im Finnischen Meerbusen, unter sehr verschiedenen Verhältnissen geschehen. Die Entwicklung des meteorologischen Frühlings, seine Wind- und Temperaturverhältnisse und ausserdem noch der verschiedenartige Aufbau der Bräme in ihren einzelnen Teilen, erhöht die Möglichkeit der Schwan- 

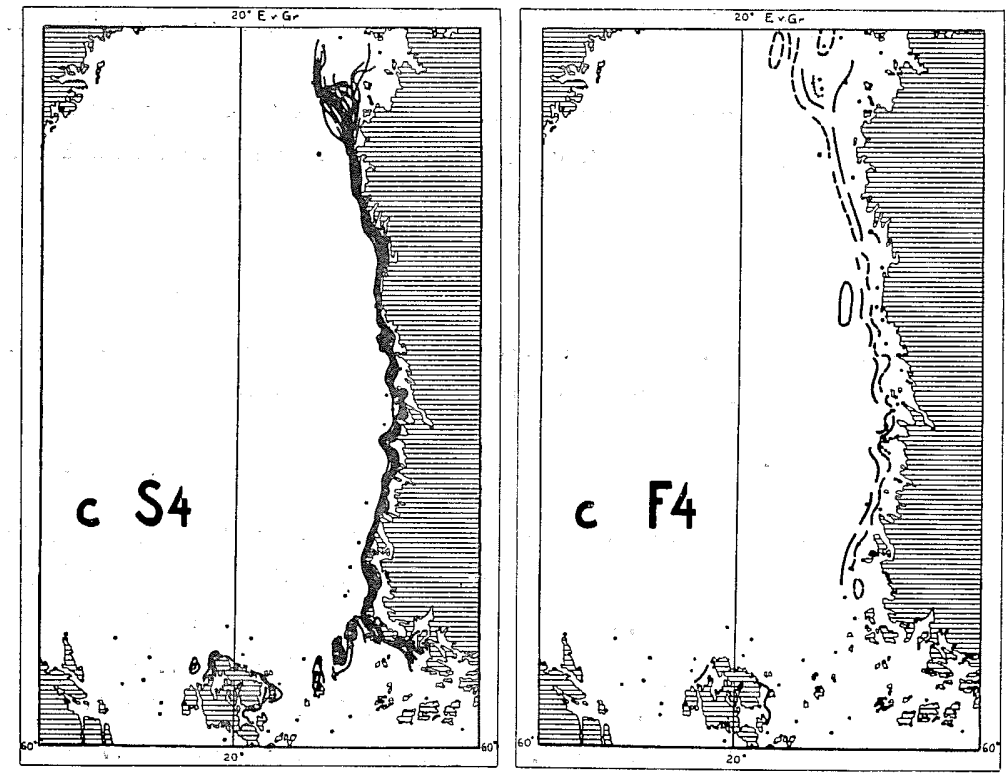

Fig. 26. Sammelkarten zur definitiven Bestimmung des allgemeinen Verlaufes des Eiswinters eines Meeresteiles. Sammelkarte c S4 (die Ränder der Bräme des festen Küsteneises) und c F4 (die ausserhalb der Bräme gelegenen Ränder "zweiter Ordnung») der Bottensee oder des e-Gebietes.

kungen im allgemeinen Verlauf des Eisrandes in den frühjahrlichen Rückgangszuständen der Bräme. Wir sehen somit während des Winters, welche entscheidende Bedeutung die meteorologischen Faktoren sowohl für das Entstehen wie für den allgemeinen Verlauf des Randes der Bräme des Küsteneises haben. Zugleich verstehen wir auch, dass der Verlauf der Ränder der Bräme des festen Küsteneises in den zur selben Untergruppe Sn gehörenden Eislagen schon auf Grund der beinahe unbegrenzten Schwankungen, denen die meteorologischen Faktoren unterworfen sind, einander nicht decken können, sondern einen Gürtel bilden müssen. Ferner ist zu beachten, dass wir zu Beginn der Untersuchung nur über Eislagen aus 10-11 Wintern verfügten, so dass jedem Normalstadium nur wenige Eislagen entsprechen. Deshalb mussten beinahe alle Eislagen, ob sie unter "günstigen» oder "ungünstigen» Verhältnissen entstanden waren, beim Aufbau des Normalstadiums zur Anwendung kommen.

Das oben Erwähnte erklärt auch, weshalb die Kurvenschar einer S-Sammelkarte als solche nicht den »Rand» der Bräme des festen Küsteneises der Stadien bilden konnte; im Gegenteil mussten wir beim Zeichnen des »Randes» des definitiven Stadiums auf Grund 
der Sammelkarte a Sn die dem nächstrorangehenden und dem darauffolgenden Stadium entsprechenden Kurven der Sammelkarte a $S(n-1)$ und a $S(n+1)$ beachten. Erst nachdem eine »Ausgleichung» der Kurvenschar vollzogen war, konnte der Rand des Normalstadiums endgültig gezeichnet werden. In Punkt 8993 werden wir zeigen, wie die "Ausgleichung» auf den Karten der Meeresteile vorgenommen wurde.

78. Die Ausgleichung der Kurvenschar der S-Sammelkarten scheint zu ergeben, dass der Eiswinter als Erscheinung in seinem allgemeinen Verlauf keine solche Regelmässigkeit befolgt, wie wir anfänglich vorausgesetzt haben. In Wirklichkeit verhält es sich jedoch nicht so. Wir können im Gegenteil immer von neuem feststellen, dass der Rand der Bräme des festen Küsteneises in seinem Verlauf ganz unverkennbar der Topographie des Gebietes folgt. Um aber diese Abhängigkeit genauer verfolgen zu können, würde ein viel ausgiebigeres Eislagenmaterial nötig sein. Dazu reichen die Eislagen eines Jahrzehntes nicht aus, am allerwenigsten, wenn es sich um ein grösseres und anders beschaffenes Gebiet als das Schären-
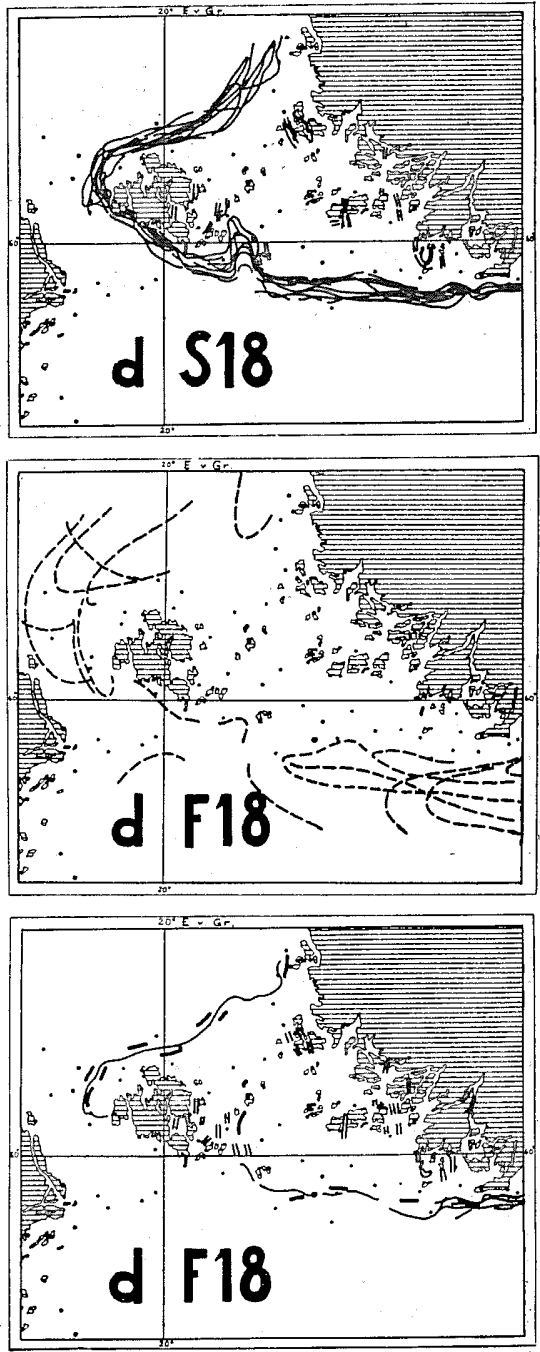

Fig. 27. Sammelkarten zur definitiven Bestimmung des allgemeinen Verlaufes des Eiswinters eines Meeresteiles. Sammelkarte d S 18 (die Ränder der Bräme des festen Küsteneises) und d F 18 (die ausserhalb der Bräme gelegenen Ränder "zweiter Ordnung 》) des Schärenmeeres oder des d-Gebietes. meer handelt. Das Schärenmeergebiet bietet nämlich seines abweichenden Aufbaus wegen vortreffliche Möglichkeiten zur Erörterung dieser Frage. Östlich und nördlich davon verändert sich die Topographie der Küste beträchtlich. Erst 
der Schärenhof von Vaasa bildet ein ähnliches Gebiet. Und wie die Wiederkehr eines physikalischen Phänomens auch theoretisch nur bei verschwindend kleinen Veränderungen möglich ist, ist hier die strengere Wiederholung der Bräme des festen Küsteneises nur in sehr kleinen Teilen der Bräme theoretisch zu erwarten. Je weiter sich die Bräme die Küste entlang erstreckt, desto geringer sind die Möglichkeiten für eine gleichartige und gleichzeitige Veränderung aller ihrer Teile. Denn die eventuelle verschiedenartige Einwirkung der die Bildung der Bräme bestimmenden Faktoren wird um so grösser, je länger die Bräme sich erstreckt. Somit sollten eigentlich bei der Bestimmung der definitiven Normalstadien anstatt der Meeresteile noch kleinere Gebiete verwendet werden. Dies hätte jedoch unsere Arbeit zu sehr erschwert, so dass wir darauf verzichteten.

Vor der Ausgleichung der Kurvenschar der S-Sammelkarten bestimmten wir auf jeder Sammelkarte unter Berücksichtigung der nächstvorhergehenden und der darauffolgenden Karten, welche Teile des Randes der Bräme in einigen Eislagen besonders grosse Abweichungen vom allgemeinen Verlauf aufwiesen. Diese Lagen des Randes wurden dann ganz weggelassen. Wie wir später sehen werden, ist ihre Anzahl bedeutend geringer als man in Anbetracht der Anzahl der den regelmässigen Verlauf störenden Faktoren hätte erwarten können.

Bei der Untergruppierung der Eislagen wurde bisweilen dieselbe Eislage bei der Bestimmung zweier Normalstadien verwendet. Dies geschah, wenn die Eislage, obwohl sie als solche der einen Gruppe angehörte, in ihrem Aufbau auch für die andere Gruppe charakteristische Merkmale aufwies oder wenn sie zur Bestimmung der Eintrittszeit der anderen Gruppe verwendet werden konnte. Derartig ist beispielsweise die Eislage 1922 I. 20. des Schärenmeergebietes, die der Untergruppe 12 angehört. Die nächstvorhergehende Eislage 1922 I. 13. gehörte der Untergruppe 6 an. Die Eislegung des Meeresteiles ging somit - nach den Eislagen - unmittelbar aus der 6 . in die 12. Untergruppe über. Unter den fehlenden Übergangseislagen befindet sich auch diejenige, in der die Eisbrücke über den nördlichen Teil des Schärenhofes nach Åland hin entsteht. Deshalb wurde die Eislage vom 1922 I. 20. bei der Bestimmung des Zeitpunktes der Entstehung dieser Eisbrücke nach Åland verwendet.

Schliesslich sei noch betr. die Gruppierung der Eislagen in den Untergruppen bemerkt, dass dann, wenn infolge eines bedeutend abweichenden Verlaufs des Randes der Bräme des festen Küsteneises einer Eislage dieser Rand entweder teilweise oder ganz unbeachtet geblieben ist, doch alle Ränder zweiter Ordnung einer solchen Eislage in die Sammelkarte $\mathrm{F}$ eingetragen wurden. 


\section{b Die Sammelkarten a Fn, b Fn, e Fn, d Fn und e Fn.}

79. Auf diese Karten kamen, wie schon oben erwähnt wurde, solche Ränder und Grenzkurven der Eislagen, $\mathrm{f} \ddot{\mathrm{r}} \mathrm{welche}$ erst die Frequenzzahlen, dann die entsprechenden Frequenzkurven bestimmt sind. Spät im Nachwinter, wenn das lose Eis wenigstens teilweise schon in getrennte Gebiete auseinandergetrieben ist, werden auch die Grenzen dieser Gebiete in die F-Karten eingetragen.

Auf Grund der Grenzen der F-Sammelkarten wurden also die allgemeinen Frequenzzahlen, d.h. die von der Art des Eises absehenden, nur das Auftreten des Eises bezeichnenden Zahlen bestimmt. Dies geschah ganz einfach in der Weise, dass das ganze von einer jeden Grenze des eisfreien Meeres nach der Küste zu gelegene Gebiet die Frequenzzahl 1 erhielt. Die Frequenzzahl wurde dem Gebiete auch in dem Falle gegeben, dass dort Öffnungen, Spalten oder offene Seerinnen vorhanden waren, wenn diese zufällig, beispielsweise durch die Veränderung der Richtung des Windes, entstanden waren. Eine Ausnahme von dieser Berechnungsweise bilden nur die Kurven einiger Herbsteislagen des Kvark sowie einiger Frühlingseislagen.

Da nun das von einer jeden Grenze des eisfreien Meeres nach der Küste zu gelegene Gebiet die Frequenzzahl 1 erhielt, so war die Frequenzzahl des ganzen innerhalb der äussersten Grenze des eisfreien Meeres gelegenen Gebietes 1, die Frequenzzahl des innerhalb der darauffolgenden Grenze des eisfreien Meeres gelegenen Gebietes 2, die Frequenzzahl des innerhalb der dritten Grenze des eisfreien Meeres gelegenen Gebietes 3 usw., so dass die Frequenzzahl des innerhalb der n-ten Grenze des eisfreien Meeres gelegenen Gebietes die allgemeine Frequenzzahl $n$ erhielt. Bei der Darstellung der diesen allgemeinen Frequenzzahlen entsprechenden Frequenzkurven wurde der Verlauf der Grenze des eisfreien Meeres in der Weise berücksichtigt, dass die Grenze oder ein Teil davon, in den Fällen, wo es möglich war, geradezu als Frequenzkurve verwendet wurde.

Nachdem vermittels der F-Sammelkarten die allgemeinen Frequenzzahlen erhalten worden waren, wurden sie in relative Zahlen pro 10 verwandelt. Dies geschah deshalb, weil die Anzahl der Eislagen in den verschiedenen Untergruppen sehr verschieden war (näher später im Teil IV.). Auf einer neuen Karte wurden dann unter Berücksichtigung des Verlaufes und der Gradienten der Kurven der F-Sammelkarten die relativen Frequenzkurven gezeichnet. Diese relativen Frequenzkurven entsprechen - von der äussersten 


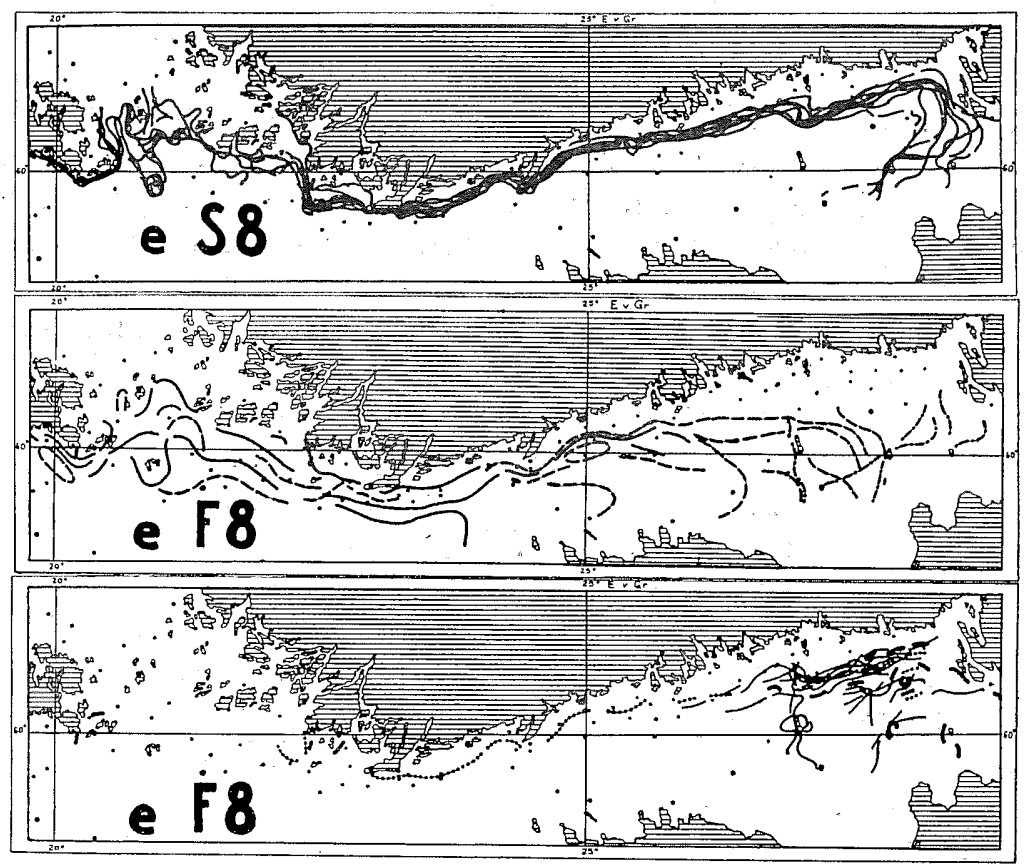

Fig. 28. Sammelkarten zur definitiven Bestimmung des allgemeinen Verlaufes des Eiswinters eines Meeresteiles. Sammelkarte e S8 (die Ränder der Bräme des festen Küsteneises) und e F8 (die ausserhalb der Bräme gelegenen Ränder "zweiter Ordnung») des Finnischen Meerbusens oder des e-Gebietes.

Grenze des noch eisfreien Meeres in dem Stadium gerechnet - der Reihe nach folgenden Werten der relativen Frequenzzahlen: 0.0-0.1, $0.2,0.5,0.8$ und 1.0. Die erste Frequenzkurve $(0.0-0.1)$ zeigt, bis wohin in einem Stadium, das einer Untergruppe eines Meeresteiles entspricht, das noch eisfreie Meer sich immer erstreckt (Eis in 1 von 10 Fällen). Die der Ordnung nach zweite Kurve (0.2) gibt an, wo das Meer in dem betreffenden Stadium praktisch gesehen beinahe immer eisfrei ist (Eis in 2 von 10 Fällen). Die dritte Kurve (0.5) zeigt, wo in diesem Stadium Eis ebenso oft wie offenes Wasser zu erwarten ist (Eis in 5 von 10 Fällen). Die vierte Kurve (0.8) gibt an, dass es hier in diesem Stadium praktisch gesehen beinahe immer Eis auf dem Meere gibt (Eis in 8 von 10 Fällen). Von der fünften und letzten Kurve (1:0) an gerechnet ist das Meer bis an die Bräme des festen Küsteneises immer mit Eis bedeckt (Eis in 10 von 10 Fällen). Doch können in den der letztgenannten Kurve entsprechenden Eislagen der Untergruppe - sowie auch in anderen Frequenzkurven entsprechenden Eislagen der Untergruppe - an der Bräme des festen 

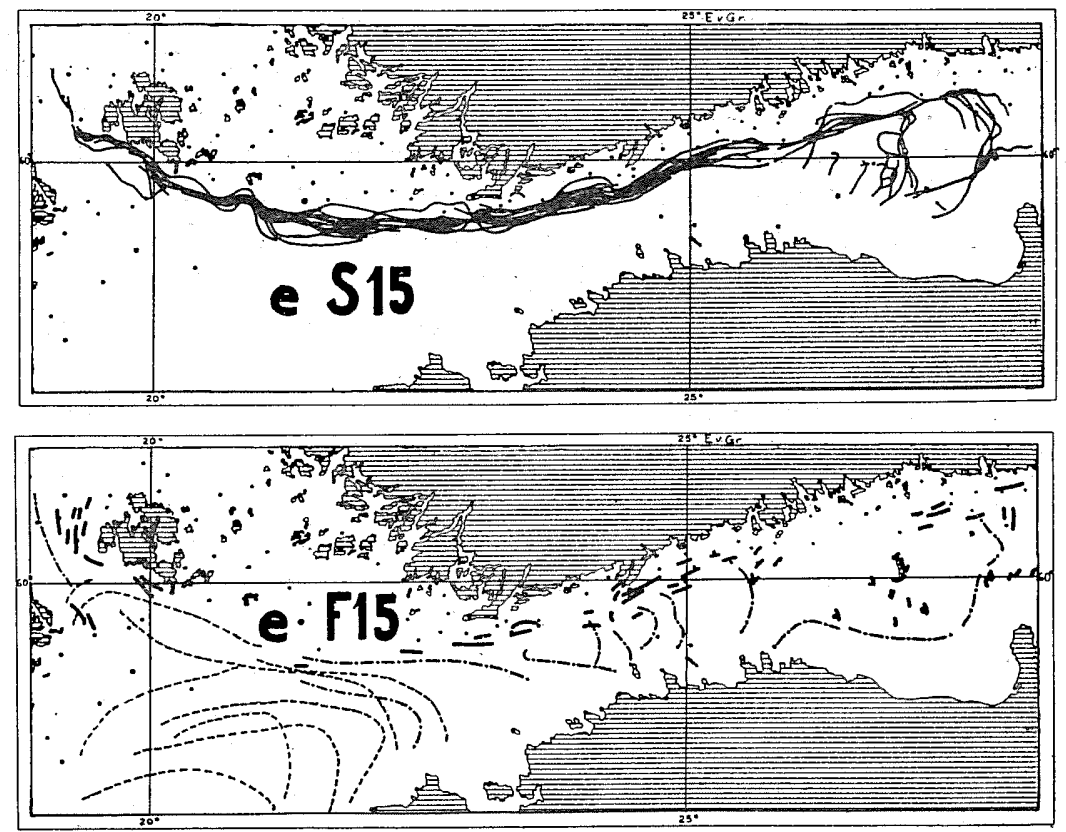

Fig. 29. Sammelkarten zur definitiven Bestimmung des allgemeinen Verlaufes des Eiswinters eines Meeresteiles. Sammelkarte e S15 (die Ränder der Bräme des festen Küsteneises) und e F15 (die ausserhalb der Bräme gelegenen Ränder "zweiter. Ordnung») des Finnischen Meerbusens oder des e-Gebietes.

Küsteneises entlang und auch anderswo Spalten und offene Seerinnen vorkommen.

Die Zahlenwerte der Frequenzkurven sind auf den Karten des Atlas mit .0-.1, .2, .5, .8 und 1.0 bezeichnet.

\section{c. Ergänzung der Frequenzzahlen durch Kennzeichen des neugebilde- ten, dïnnen Blaueises, des treibenden und des zusammenge- frorenen Meereseises.}

80. Bei unserem zweiten Versuch den allgemeinen Verlauf des Eiswinters vermittels der Eislagen herzuleiten, bestimmten wir, wie oft das ausserhalb der Bräme des festen Küsteneises gelegene Eis einerseits loses Eis, andererseits zusammengefrorenes Eis war. Das Kennzeichen des losen Eises war ein Dreieck $(\triangle)$, das des zusammengefrorenen Eises ein Viereck ( $\square$ ). In dieser definitiven Darstellung der Eisverhältnisse wurde ausserdem in den Stadien des Herbstwinters das ausserhalb der Bräme zuerst entstehende Meereseis und in den 
späteren Stadien das weiter draussen entstandene Neueis als eine "eigene» Eisart neben dem losen und dem zusammengefrorenen Eis betrachtet. Da dieses Eis meistens neugebildetes, dünnes Blau-, Teller- oder durch Zerbrechen des Blaueises entstandenes Breieis ist, bezeichnen wir die dieser "Eisart» entsprechende Frequenzzahl als die Frequenz des Blaueises. Ihr Kennzeichen ist ein Kreis ( $($ ). Das lose Eis ( $\triangle$-Eis) kann gewissermassen auch das Blaueis beinahe in allen seinen Formen umfassen. Doch erwies sich die oben erwähnte Einteilung als vorteilhaft um die "Verschiedenartigkeit» einerseits des in den Stadien des Herbstwinters ausserhalb der Bräme des festen Küsteneises entstandenen Eises bzw. des in den späteren, sogar in den Mittwinterstadien weiter draussen entstandenen Eises, andererseits des sonstigen losen Eises zu bezeichnen. Das ersterwähnte Eis ist vor allem dünnes Jungeis, das namentlich dann entsteht, wenn weite Gebiete in kurzer Zeit mit Eis bedeckt werden, wie in den 7.- -9. Stadien des Finnischen Meerbusens. Die Verwendung des Kennzeichens dieses neugebildeten Jungeises neben den $\Delta$ - und $\square$-Zeichen, zuerst in den den Untergruppen entsprechenden Stadien der Meeresteile, dann in den Generalstadien, gibt schon ein anschaulicheres Bild von der Verschiedenheit des „Alters» des Eises ausserhalb der Bräme des festen Küsteneises.

81. In einigen Stadien, in denen das lose Eis der inneren Teile der Meere treibendes, mechanischen Prozessen unterworfenes winterliches $\triangle$-Eis ist, wird dessenungeachtet das $\bigcirc$-Zeichen verwendet. Hiermit - so z. B. in der Nähe von Hochland im Stadium 9 des Finnischen Meerbusens - haben wir bezeichnen wollen, dass in dem betreffenden Gebiet zur Zeit des Stadiums noch so grosse Verschiebungen der Eismassen eintreffen können, dass erst nach einer neuen Eislegung die Eisdecke wieder zusammenhängend wird, oder auch, dass das Meer mit Blaueis bedeckt wird, bevor das "alte» Eis - bei Veränderung der Richtung des Windes - das neue Eis zerbrechend wiederkehrt. Besonders in den letzten Stadien des Herbstes und den ersten Stadien des Mittwinters, in denen die Temperatur durchschnittlich schon sehr niedrig ist, bildet sich, nachdem das Meereseis vom Winde abgetrieben ist, auf den offenen Wasserflächen beinahe sofort Blaueis. Dieses Eis kann, bald fest werdend, bei günstigen Witterungsverhältnissen wenigstens teilweise den ganzen Winter hindurch sogar als ebenes Eis fortbestehen. Vor allem für solche Fälle haben wir das Zeichen des Blaueises im 9. Stadium des Finnischen Meerbusens verwendet.

82. Betr. die Verwendung des $\bigcirc-Z e i c h e n s$ sei noch erwähnt, dass es in einigen frühen G-Stadien sowie im 8. G-Stadium im Kvark und 
im 12. G-Stadium in der Nördlichen Ostsee ausserhalb der Frequenzkurven angebracht wurde um anzudeuten, dass die $\mathrm{A} b \mathrm{k} u ̈ \mathrm{hlu} \mathrm{n}$ wenigstens in den obersten Schichten des Meeres schon so durchgreifend ist, dass eine Eislegung hier, also auch ausserhalb der Frequenzkurven, bei entsprechenden Witterungsverhältnissen eintreffen kann.

83. Auch in der Zeit der Frühlingsstadien, die in den verschiedenen Meeresteilen zu ganz verschiedenen Zeitpunkten des Frühlings und somit bei sehr ungleichen meteorologischen Verhältnissen eintreffen, kann auf dem eisfreien Meer in stillen und kalten Nächten eine Eishaut oder ganz dünnes Blaueis entstehen, wie beispielweise um Bogskär herum am 12.-16. und 18.-22. April 1906. Dass wir in solchen Stadien das $\bigcirc$-Zeichen nicht benutzt haben, beruht darauf, dass dieses Eis - die Eishaut oder das Blaueis - nun nicht mehr dieselbe Bedeutung hat, wie im Herbst- bzw. Mittwinter. Die Entstehung des $\bigcirc$-Eises im Frühling "verschiebt» nämlich nicht allein die Eislagen im Vergleich zu der Normalstadienfolge oder im allgemeinen Verlauf des Winters nach dieser oder jener Richtung. Die Entstehung der Eishaut oder des Blaueises ist nur eine „Episode», die sich ohne grössere Bedeutung an ganz besondere Wetterlagen anschliesst. Dieses $\bigcirc$-Eis des Frühlings verschwindet nämlich sehr oft schon im Laufe des Tages, indem es vom Wellenschlag zerbrochen wird oder in der Sonne auftaut, aber die Entwicklung der Eislage geht, der nächtlichen $\bigcirc$-Eisbildung sowie der gleichzeitigen Befestigung und des Trocknens des Küsten- und Schärenhofeises ungeachtet, gegen den Frühling. Bei lange andauernden Frostnachtfolgen im Frühling wird jedoch der Rückgang des Eises verlangsamt und ein kalter Frühling ist manchmal wie ein schwerer Mittwinter, die Ursache der sehr spät oder aussergewöhnlich spät auftretenden Eislagen. Aber auch in diesen Fällen verzögert das Blaueis, insofern es entsteht, nur den allgemeinen Rückgang des Eises, bedeutet also keineswegs eine eigentliche Entstehung von "neuem" Eis. Da die Entstehung der Eishaut und des Blaueises in den Frühlingsstadien anderseits jedoch ein an den allgemeinen Verlauf des Eiswinters sich zeitweise anschliessender Vorgang ist, werden wir ihn später an verschiedenen Stellen der vorliegenden Untersuchung näher behandeln.

84. Die Bestimmung der dem $\bigcirc$-Zeichen entsprechenden Eisarten und der Aufbau der den Untergruppen entsprechenden Stadien bereitete in dieser Hinsicht, wenn wir die Frühlingsstadien übergehen, keine Schwierigkeiten. Dagegen musste die Unterscheidung zwischen den $\triangle$ - und $\square$-Arten manchmal von Fall zu Fall vorgenommen werden. Beim Zeichnen der originalen Eislagekarten schien es 
ñämlich, als ob, vielleicht wegen der Unsicherheit der Aufzeichnungen, die Darstellungsweise der Eisarten manchmal einigermassen schwankte, was hier dadurch verstärkt wurde, dass schon durch die erste Gruppierung der Eislagen die Zeitfolge ganz gestört wurde. Dazu kommt noch, dass in bezug auf die Eisverhältnisse bei dem Heranrücken des Mittwinters auch tatsächlich die Bedeutung der $\triangle$ - und $\square$-Zahlen sich verändert. Denn in den Eislagen, die der Mittwinterzeit, wo der meteorologische Winter durchschnittlich »streng» ist, entsprechen, ist die $\mathrm{B}$ ewegungs $\mathrm{möglichkeit} \mathrm{und} \mathrm{somit}$ auch die $\mathrm{B}$ ewegli ch ke it des Meereseises in einem und demselben Meeresgebiet sehr veränderlich und in verschiedenem Umfang begrenzt. In den vinnersten» und sinneren» Teilen der Meere, um ganz allgemeine Benennungen zu gebrauchen, ist das Eis im allgemeinen gar nicht mehr »lose» in der Bedeutung, wie es in den Eislagen der Untergruppen und Stadien des Herbst- und Frühlingwinters war: Die Beweglichkeit beschränkt sich auf die der Spaltung und den Rinnen entsprechende Bewegung. Nur in den »mittleren» Teilen oder in der-»Mündung» der Meeresteile kann man noch von »losem» Eis sprechen und nur in diesen Teilen der Meeresgebiete ist das "Treiben" und die "Bewegung" des Eises noch möglich.

85. Das $\triangle$-Zeichen bezeichnet so im Laufe des Winters Eis von sehr verschiedener Beweglichkeit und Bewegungsmöglichkeit, die in einigen Mittwinterstadien in einigen Gebieten der Meeresteile bzw. im ganzen Meeresteile auf eine unbedeutende Verschiebung zusammenschrumpft. Diese tatsächliche Veränderung in der Beweglichkeit des Eises im Laufe des Winters ist der Grund, warum wir in der Erklärung der Zeichen der Atlaskarten das $\triangle$-Zeichen als vallgemein treibendes Eis» anstatt nur als »Treibeis», dem das Kennzeichen ursprünglich entsprach, definieren. Deshalb bedeutet das $\triangle$-Zeichen auf dem Meer dann, wenn das Meereseis wegen der niedrigen Lufttemperatur sonst nach allem zu urteilen ganz zusammengefroren ist und somit also als $\square$-Eis bezeichnet werden kann, dass dieses Eis dessenungeachtet unter besonderen meteorologischen Verhältnissen sich bewegen oder verschieben kann und dass immer noch eine Bewegungsmöglichkeit vorhanden ist, obwohl also das Eis nicht als eigentliches loses oder treibendes Eis im ursprünglichen Sinne dieser Benennungen aufzufassen ist. Das $\triangle$-Zeichen, das ursprünglich in den den Untergruppen entsprechenden Stadien das Kennzeichen des losen und treibenden Eises war, wird in schweren Eisstadien mit durch und durch zusammengefrorenem Meereseis, das Zeichen für noch vorhandene Bewegungs- oder Verschiebungsmöglichkeit des Eises. Gerade dies besagt das $\triangle$-Zeichen z. B. im Gebiet der Botten- 
wiek und des Kvark in der Mittwinterzeit (siehe Atlas S. 4 und 9). Umgekehrt bezeichnet das $\square$-Zeichen nicht nur, dass das Meereseis zusammengefroren ist, sondern dass das Eis unbeweglich ist.

86. Die Entstehung der grossen offenen Seerinne des Finnischen Meerbusens im Winter 1928 ist ein typisches Beispiel dafür, wie in einigen den Mittwinterstadien entsprechenden Eislagen bei der Bestimmung der Frequenzzahl das Kennzeichen $\square$ des Meereseises in das $\triangle$-Zeichen übergehen kann. Da die kartographische Darstellung des Vorganges uns zugleich ein Bild davon gibt, wie eine schnelle Veränderung der Eisverhältnisse durch Bewegung des Meereseises auch in der Zeit des Mittwinters sich abspielen kann, erwähnen wir hier zur Erklärung der von uns gezeichneten Karten (Fig. 30 a-c), folgendes:

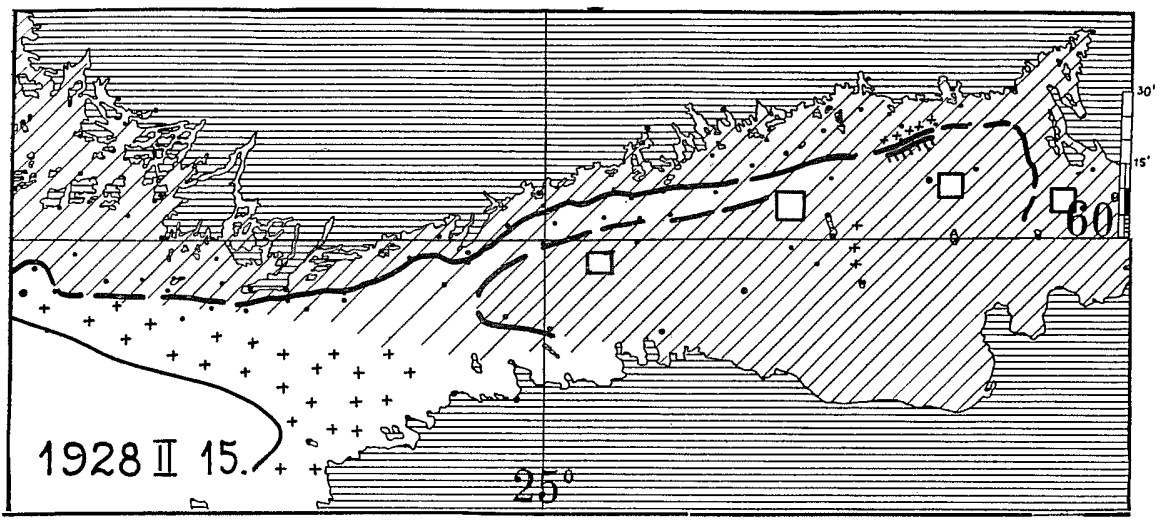

Fig. 30 a. Die Entstehung der grossen Seerinnedes Finnisehen Me erbusens 1928 II. 18.-22. Ein Beispiel für die Veränderung der Kennzeichen $\triangle$ und $\square$ des Meereseises in einigen den Mittwinterstadien entsprechenden Eislagen. Die Eislage 1928 II. 15. vor der Entstehung der Seerinne: Das Meereseis im Osten ganz zusammengefroren, also $\square$-Eis.

An der Sädküste Finnlands war 1928 II. 15. bei Windstille oder ganz schwachem Winde und einer Kälte von -12 à $-17^{\circ}$ das 20 bis 50 cm dicke Meereseis d e r Ost t e il e des Finnischen Meerbusens ganz zusammengefroren und - ausgenommen eine unbedeutende Spalte, welche durch das Sinken der Meeresoberfläche hervorgerufen war - unbeweglich. Dieses Eis im östlichen Teil des Finnischen Meerbusens können wir somit mit vollem Recht als $\square$-Eis ansehen. Den übrigen Teil des Finnischen Meerbusens bedeckte an demselben Tage ebenfalls im allgemeinen unbewegliches Eis bis zur Mündung des Finnischen Meerbusens, wo dünnes Blaueis sich etwas über die Linie Odensholm-Utö hinaus erstreckte (Fig. 30 a: 1928 II. 15.). An den folgenden Tagen, am 16. und 17. II., begann das Eis im Finnischen 

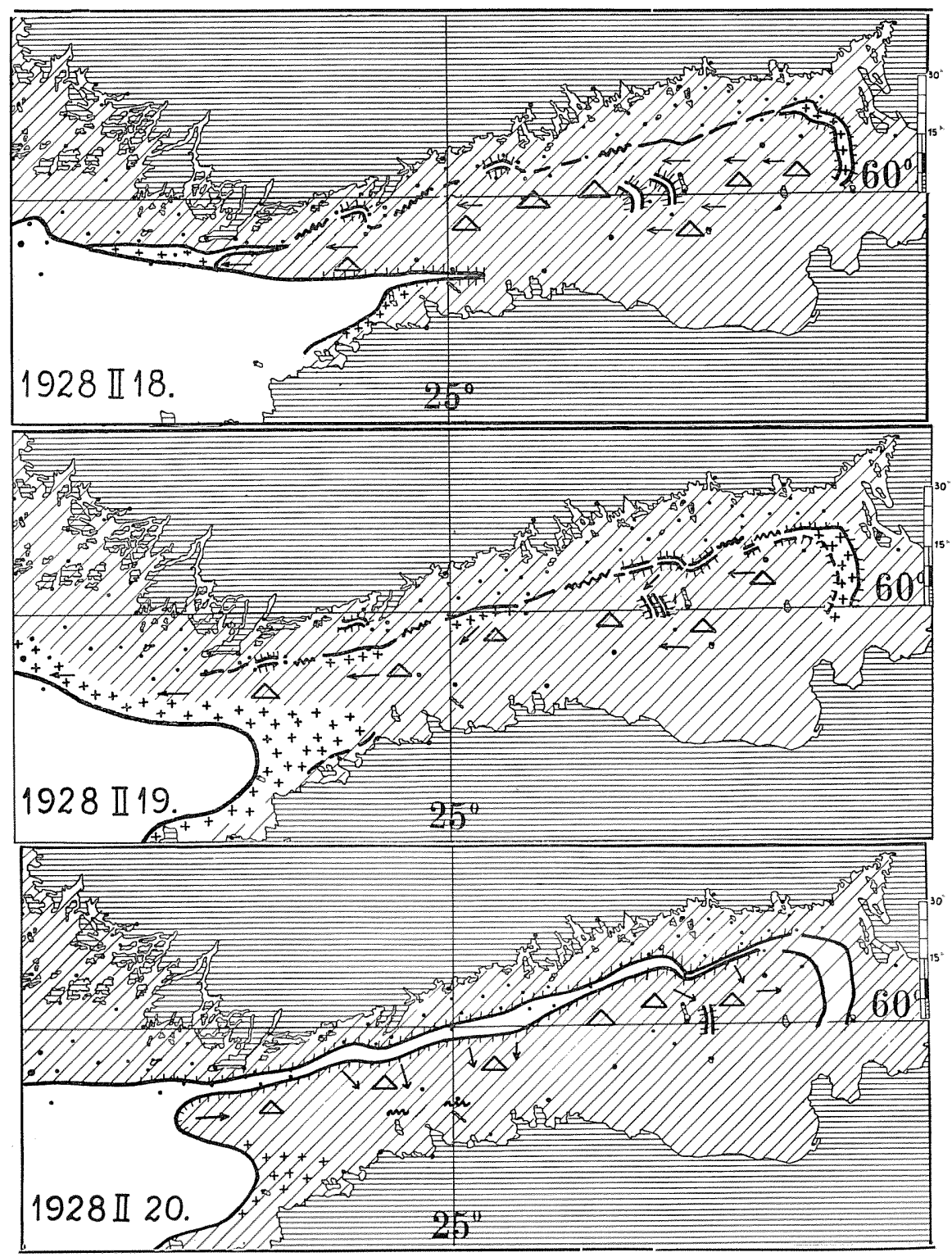

Fig. 30b. Die Entstehung der grossen Seerinne des Finnischen Me erbusens 1928 II. 18. - 22. Ein Beispiel für die Veränderung der Kennzeichen $\triangle$ und $\square$ des Meereseises in einigen den Mittwinterstadien entsprechenden Eislagen. Die Bewegung des Meereseises hat begonnen (II. 18.) und das $\square$-Eis ist in $\triangle$ Eis übergegangen. 
Meerbusen durch die Einwirkung des anfangs von SE, dann nach $\mathrm{E}$ sich wendenden und sehr stark gewordenen Windes ganz allgemein sich zu bewegen. Am 18. II. (Fig. 30 b: 1928 II. 18.) wurde das Meereseis von dem inneren Teil des Finnischen Meerbusens an durch den E-Wind, der nunmehr stark, stellenweise stürmisch geworden war, ganz allgemein nach $\mathrm{W}$ getrieben. Das Meereseis im östlichen Teil des Meerbusens hatte somit aus unbeweglichem $\square$-Eis sich in bewegliches $\triangle$-Eis verändert. Da die Drehung des Windes auch weiterhin gegen die Sonne anhielt und der Wind schon am Morgen II. 19. an der Südküste Finnlands von NE-N wehte, hatten sich längs der Bräme des festen Küsteneises an vielen Stellen schmale Spalten oder Rinnen gebildet (Fig. 30 b: 1928 II. 19.), welche jedoch beinahe sofort sich mit dünnem Eise bedeckten. Aber am folgenden Tage, II. 20., als der Wind sich im allgemeinen nach W gedreht hatte, hatte sich längs der ganzen Bräme die breite, "gg rosse» Seerinne des Finnischen Meerbusens gebildet, welche - stellenweise sogar 4-6' breit - weit in die innersten Teile des Meerbusens hineinreichte. Da das Eis sich in der Richtung S-SE bewegte, entstand auf der estnischen Seite des Finnischen Meerbusens Eispressung, welche, je nachdem die Seerinne sich verbreiterte und tiefer in den Meerbusen sich erstreckte, immer weiter nach Osten hin reichte. Am II. 21., als der Wind im allgemeinen von $\mathrm{N}$ wehte, war die Seerinne - zum grossen Teil jedoch von dünnem Eis bedeckt 6-8' breit (Fig. 30 c: 1928 II. 21.). Im Laufe des Tages trieb das Meereseis auch weiterhin nach »draussen» und am folgenden Tage, II. 22., war die Seerinne beinahe ganz mit Blaueis (Fig. 30 c: 1928 II. 22.) bedeckt und das Meereseis, bei schwachem N-Wind und einer Kälte von -10 à $-12^{\circ}$, im ganzen Finnischen Meerbusen wieder beinahe durchweg zusammengefroren und schliesslich unbeweglich geworden.

Das valte» Eis, welches die verschiedensten Prozesse des Zerbrechens und des Pressens durchgemacht hatte, hatte sich während II. 19. - 22. in der Mündung des Finnischen Meerbusens im ganzen schliesslich etwa $15^{\prime}$, in der Höhe von Äransgrund 10 bis $12^{\prime}$ und in der Gegend von Haapasaari 8 bis 10' bewegt. Die ungefähre Lage des nördlichen Randes dieses Eises am II. 23. ist in Fig. $30 \mathrm{c}$ mit Strichen angedeutet; das Meereseis ist dabei im Gebiete des ganzen Finnischen Meerbusens schon zusammengefroren und in Ruhe.

Da die Kälte II. 18.-21. nach den Beobachtungen der an der Küste des Finnischen Meerbusens gelegenen Stationen-also während der Bewegung des Meereseises - am Morgen - 10 à $-17^{\circ}$ betrug, war das Meereseis wenigstens in den östlichen Teilen des Meerbusens 

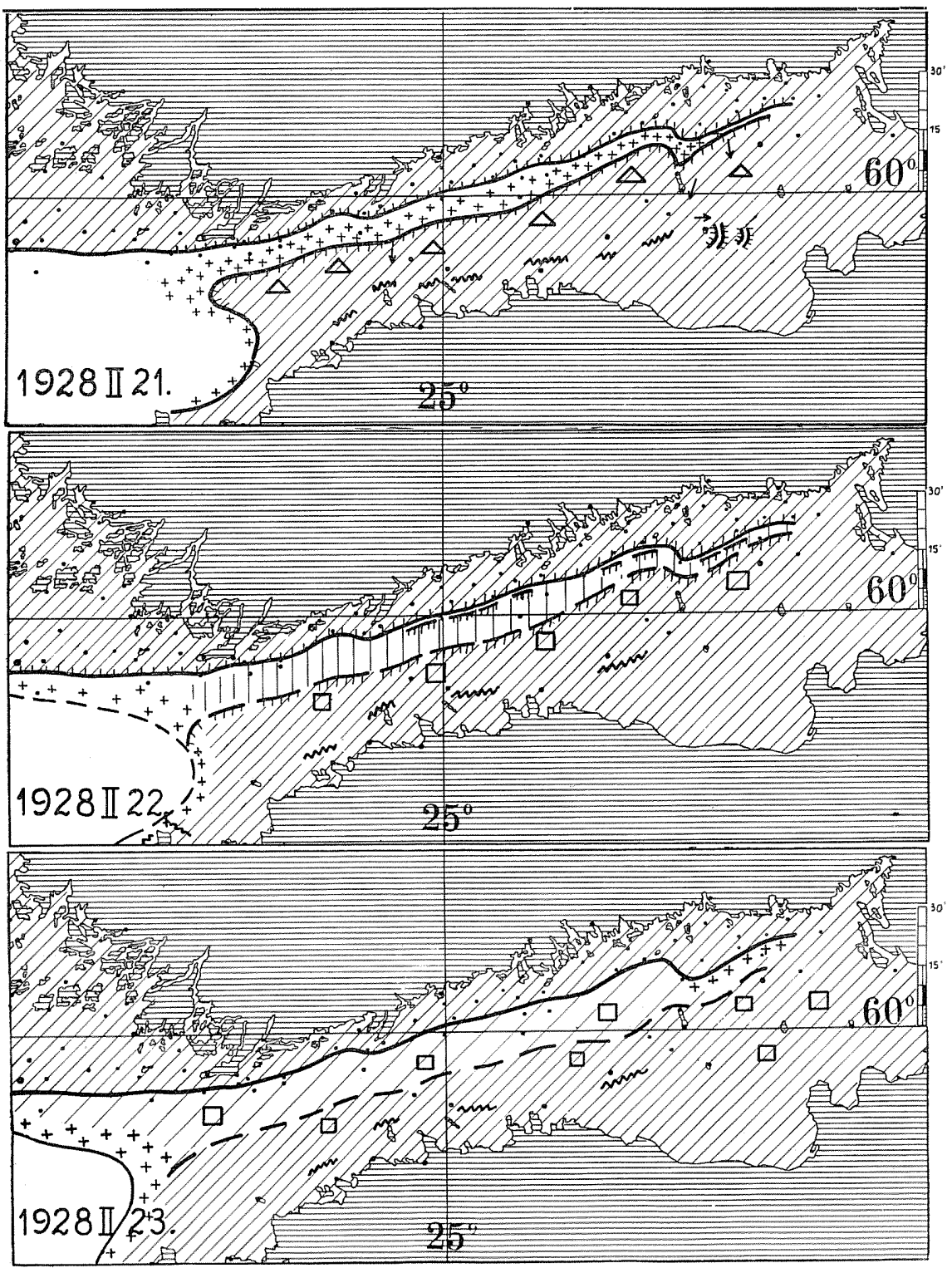

Fig. 30 c. Die Entstehung der grossen Seerinnedes Finnischen Me exbusens 1928 II. 18. - 22. Ein Beispiel für die Veränderung der Kennzeichen $\triangle$ und $\square$ des Meereseises in einigen den Mittwintérstadien entsprechenden Eislagen. Die Bewegung des Meereseises hört nach und nach auf, in der Seerinne entsteht Blaueis, II. 21., und alles ist wieder, II. 23., zusammengefroren oder mit 
augenscheinlich zum grossen Teil, obgleich es in Bewegung war, "zusammengefroren». Falls die Eislagen der fraglichen Tage bei der Herleitung der entsprechenden Sammelkarte F gebraucht würden, hätte das Kennzeichen des Meereseises der östlichen Teile des Finnischen Meerbusens $\square$ sein können, wie in den Eislagen von 1928 II. 15., II. 22. und II. 23. In Wirklichkeit haben wir jedoch in ähnlichen Fällen auf Grund der Beweglichkeit des Eises - also obgleich kein eigentliches "Treiben» des Meereseises in frühwinterlicher und spätwinterlicher Bedeutung vorgekommen ist - für das Meereseis in solchen mittwinterlichen Eislagen die Bezeichnung $\triangle$ gebraucht.

8\%. In den Frühlingsstadien (z. B. Sa 24, Sb 24, Sc 25 und Se 25), die den späten und letzten Untergruppen der Meeresteile entsprechen, bedeuten die einzelnen $\triangle$-Zeichen, dass zerstreute, aus Eisschollen und Eisstücken bestehende Eismassen in den diesen Stadien entsprechenden Eislagen auch ausserhalb der Frequenzkurven in dem sonst eisfreien Meer vorkommen können. Bisweilen haben wir durch die Grösse oder Anzahl der Zeichen die verschiedene Veränderlichkeit im Auftreten des Eises in diesen Eislagen zu veranschaulichen gesucht. Solches ausserhalb der Frequenzkurven liegendes Eis tritt in den Stadien der entsprechenden Untergruppen durch Vermittlung der Endeislagen der späten oder sehr späten Frühlinge auf. Das Eis bildet hierbei oft nur die letzten Überreste der Packeisgürtel und Eiswälle, die in solchen Wintern auf den äussersten Teilen der Bräme des festen Küsteneises, wie auch auf den Gründen und Untiefen des Aussenmeeres entstanden waren. - In den Stadien der Meeresteile: Sc 9, Sd 7 und Se 8 sowie in dem Generalstadium G 11 bedeutet das $\square$ Zeichen, dass eine »Brücke» von festem Eis über den nördlichen Teil des Schärenmeeres nach Åland hin gerade oder vor kurzem entstanden ist.

88. Was schliesslich die a $11 \mathrm{~g}$ emeine Verwendung der O-, $\triangle$ - und $\square$-Zeichen i $\mathrm{m}$ Atla s anbetrifft, sei hier bemerkt, dass das $\triangle$-Zeichen nicht immer auf den Karten der S-und Generalstadien eingetragen ist, die $\bigcirc$ - und $\square$-Zeichen dagegen beinahe immer gezeichnet sind. Deshalb ist in den die Stadien der Meeresteile und die Generalstadien darstellenden Figuren im Atlas das ausserhalb der Bräme des festen Küsteneises gelegene Meereseis immer als $\triangle$-Eis betrachtet, insofern kein anderes Zeichendie Eisartkennzeichnet. Soz.B. ist im Generalstadium G 10 (Atlas S. 34) das Meereseis im innersten Teil des Finnischen Meerbusens zwischen den Frequenzkurven .5 und .8 in drei Fällen $\bigcirc$-Eis, sonst $\triangle$-Eis usw. 
D. Ausgleichung des Verlanies der Schar der Ränder des festen Küsteneises bzw. der Frequenzkurven zwischen den Untergruppen eines und desselben Meeresteils.

89. Oben wurde gezeigt, wie schon die Einteilung der Frequenzzahlen in solche den $\triangle$ - und $\square$-Eis entsprechenden auf den Sammelkarten $\mathrm{F}$ der Untergruppen viele Schwierigkeiten bereitete. Da ausserdem einer jeden Untergruppe nur eine kleinere Anzahl Eislagen entsprach, so zeigten die Zahlenwerte der aufeinander folgenden Frequenzkarten im allgemeinen keinen so regelmässigen Verlauf, wie man hätte erwarten können. Deshalb war auch hier, wie in bezug auf die S-Sammelkarten, eine "Ausgleichung" der Frequenzen erforderlich. Erst danach zeigten die Frequenzzahlen und die nach ihnen gezeichneten Kurven eine dem allgemeinen Verlauf des Winters entsprechende "natürliche» Entwicklung: in der Zeit des Eiszuwachses am selben Ort ein Abnehmen der $\triangle$-Werte und ein Zunehmen der $\square$-Werte, in der Zeit des Rückganges des Eises oder der Enteisung wiederum ein Zunehmen der $\triangle$-Werte und ein Abnehmen der $\square$-Werte.

90. Wie schon oben eingehender gezeigt wurde, ist in Eislagen, welche sich augenscheinlich auf denselben Punkt in dem allgemeinen Verlauf des Winters beziehen, sowohl in dem Gang des Randes der Bräme des festen Küsteneises als auch in der Ausdehnung des ausserhalb der Bräme liegenden Eises eine solche Streuung möglich, dass irgend ein Ausgleich unter den einander am nächsten liegenden Sammelkarten im allgemeinen nötig ist, damit der natürliche Verlauf des Eiswinters - zunächst die dauernde Zunahme der Vereisung, dann die Kulmination in der Ausdehnung des Eises und zum Schluss die fortgesetzte Abnahme des Eises und sein definitives Verschwinden - in der Reihe der UntergruppenSammelkarten zur Regel wird. Diese Streuung beruht auf dem grossen Schwanken des Einflusses der Faktoren, welche den allgemeinen Verlauf des Eiswinters bestimmen, sowie auch in dieser Untersuchung darauf, dass die Anzahl der Eislagen in einer jeden Untergruppe im allgemeinen viel zu klein war, um die unter »ungünstigen» Verhältnissen entstandenen Eislagen ganz unberücksichtigt lassen zu können.

91. Die Ausgleichung der Kurvenschar der S-Sammelkarten geht am besten aus einem Beispiel hervor. In Fig. $31 \alpha-33 \alpha$ vertreten die dick gezogenen Linien die ersten, von den S-Sammelkarten a S6, a S7 und a S8 direkt nach »der Schar der Ränder» gezeichneten Grenzen, die »der Rand der Bräme des festen Küsteneises» in den 

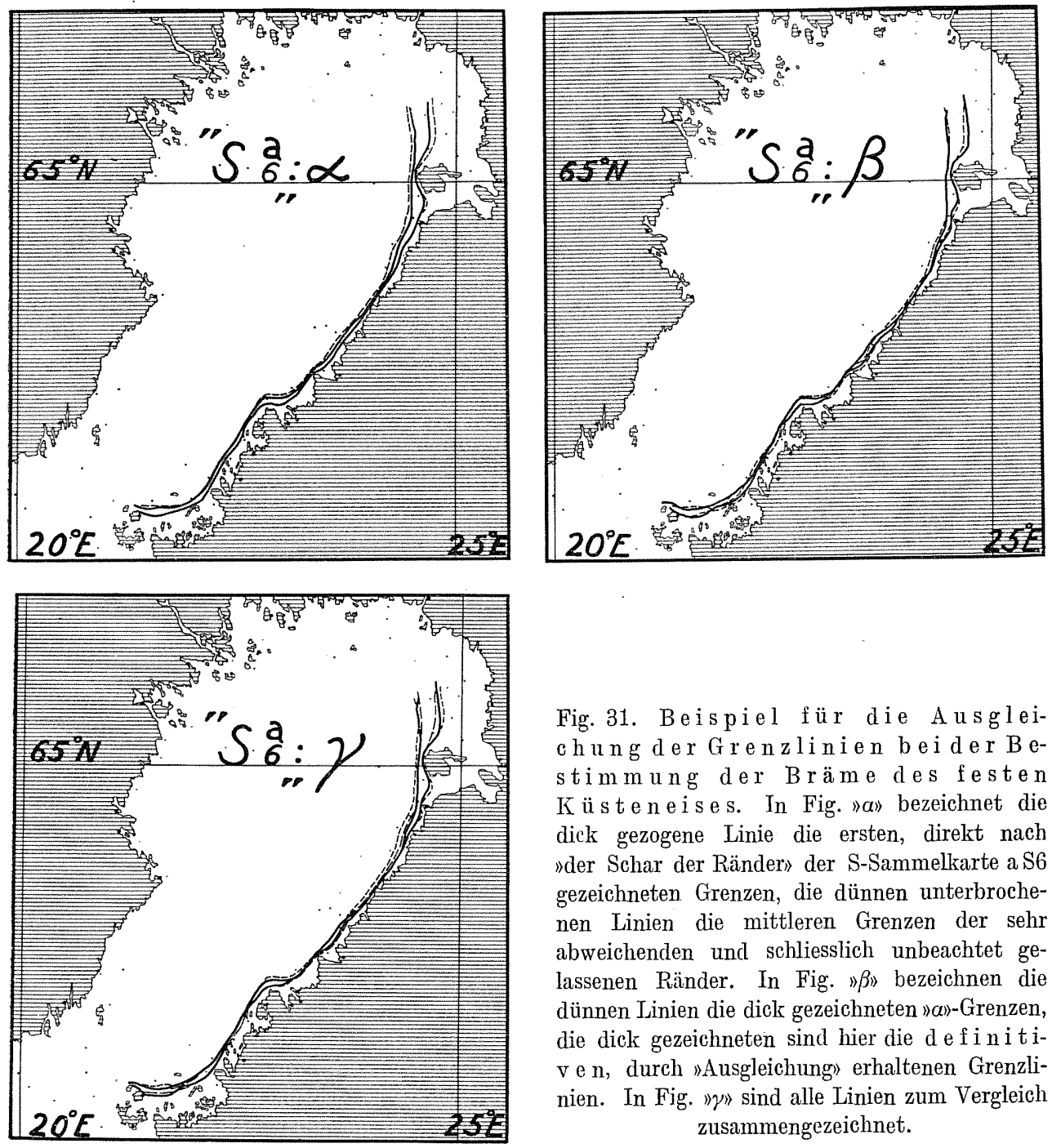

Fig. 31. Beispiel für die Ausgleichung der Grenzlinien beider Bestimmung der Bräme des festen $K$ üsteneises. In Fig. "a» bezeichnet die dick gezogene Linie die ersten, direkt nach »der Schar der Ränder» der S-Sammelkarte a S6 gezeichneten Grenzen, die dünnen unterbrochenen Linien die mittleren Grenzen der sehr abweichenden und schliesslich unbeachtet gelassenen Ränder. In Fig. $n \beta$ » bezeichnen die dünnen Linien die dick gezeichneten $» a\rangle_{-G}$-Grenzen, die dick gezeichneten sind hier die definitiv e $\mathrm{n}$, durch »Ausgleichung» erhaltenen Grenzlinien. In Fig. "zy) sind alle Linien zum Vergleich zusammengezeichnet.

den S-Sammelkarten a 6 , a 7 und a 8 entsprechenden Normalstadien sein müsste, falls die Ausgleichung nicht durchgeführt wurde. Diese Grenzlinien sind, wie früher schon erwähnt ist, so gezeichnet, dass sie beinahe alle Linien der Schar von Randlinien der S-Sammelkarten umfassen. Die ausserhalb dieser »beinahe aller» Randlinien liegenden Linien sind durch die dünnen, unterbrochenen Linien vertreten. Diese letztgenannten, die also die urter "ungünstigen Verhältniss€n» durch Zerbrechen, Spalten usw. entstandenen Randlinien bezeichnen 

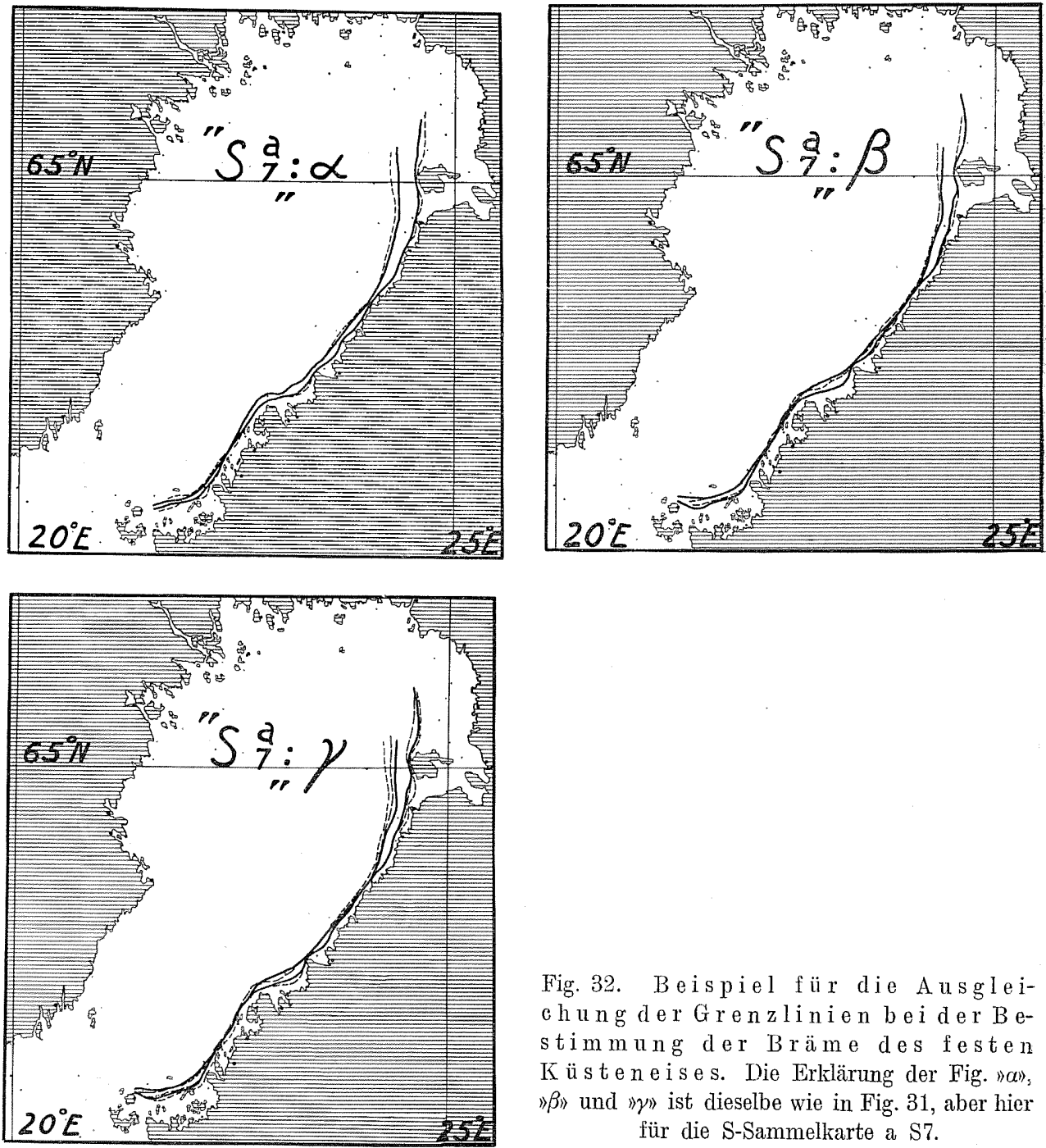

Fig. 32. Beispiel für die Ausgleichung der Grenzlinien bei der Bestimm ung der Bräme des festen $K$ üsten e is es. Die Erklärung der Fig. $\| \alpha\rangle_{,}$ $» \beta »$ und " $\gamma$ » ist dieselbe wie in Fig. 31, aber hier für die S-Sammelkarte a S7.

und die deshalb zum Schluss unbeachtet gelassen wurden, sind wieder so gezogen, dass sie die mittlere Lage dieser am meisten abweichenden Randlinien bezeichnen. In Fig. $31 \beta-33 \beta$ geben die dünn gezogenen Linien die dicken der Figuren $» \alpha »$ wieder; die nun dick gezeichneten Linien die definitiven Grenzlinien, die durch Vergleich mit den zuerst gezogenen entsprechenden Grenzlinien (den dicken » «-Linien) der nächstvorhergeh€nden und der nächstfolgenden S-Stadien durch "Ausgleichung» gezeichnet sind. In Fig. 

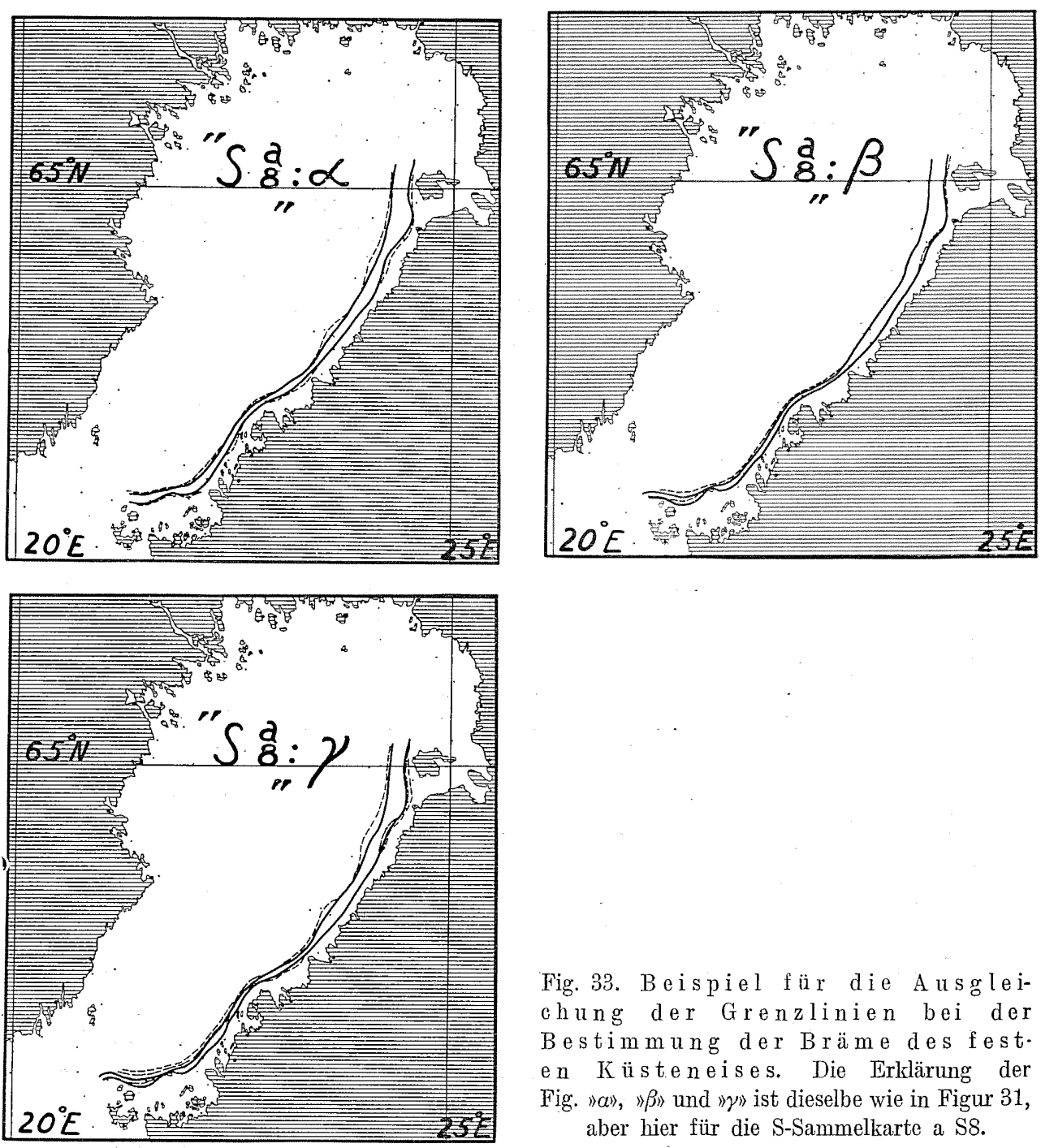

Fig. 33. Beispiel für die Ausgleichung der Grenzlinien bei der Bestimmung der Bräme des fest. e n K üsten eises. Die Erklärung der

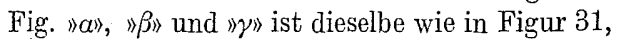
aber hier für die S-Sammelkarte a S8.

$31 \gamma-33 \gamma$ sind schliesslich zum Vergleich noch alle drei Linien gleichzeitig gezeichnet. - Wenn die Bräme sich bis zu den Meeresinseln und äusseren Gründen erstreckt, verzichten wir auf eine durchgreifende Ausgleichung, denn "die Streuung» der Ränder der Bräme entspricht hier mehr der Wirklichkeit.

92. Die Ausgleichung der Frequenzzahlen beleuchten wir am besten durch ein Beispiel. So erhielt bei der Bestimmung des der Untergruppe e F12 entsprechenden Stadiums u. a. das Mee- 
reseis in den mittleren Teilen des Finnischen Meerbusens anfänglich den Wert $\triangle 10$, obgleich wir in der Untergruppe e F11 des nächstvorhergehenden Stadiums in derselben Gegend den Zahlenwert $\triangle 9$ $+\square 1$ hatten und in der darauffolgenden Untergruppe e F13 den Wert $\triangle 5+\square 5$ erhielten. (Auf den Karten des Atlas stehen die Zahlen innerhalb der Zeichen und anstatt des + Zeichens sind das Dreieck und das Viereck übereinander gestellt worden.) Das zu bestimmende Stadium zeigte somit im Verhältnis zu dem vorhergehenden Stadium und im Gegensatz zu dem, was zu erwarten war, eine „Erleichterung" in den mittleren Teilen des Finnischen Meerbusens und zwar, trotzdem die Bräme des festen Küsteneises sowie die Eisdicke gleichzeitig in Zunahme begriffen waren und somit eine tatsächliche Erschwerung der Eisverhältnisse vorlag. Eine Ausgleichung zwischen den $\triangle$ - und den $\square$-Zeichen war somit in dem vorliegenden Falle erforderlich. Die Ausgleichung wurde unter den den Untergruppen e F10, e F11, e F12, e F13 und e F14 entsprechenden Stadien vollzogen. Als endgültige Werte erhielten wir für die Stadien Se 11, Se 12 und Se 13 des betreffenden Teiles des Finnischen Meerbusens $\triangle 10, \triangle 9+\square 1$ und $\triangle 5+\square 5$.

93. Die Ausgleichung der Frequenzk u $\mathrm{r}$ ven geschah in derselben Weise wie die Ausgleichung der Grenzlinien der Bräme durch Vergleich, aber mit dem Unterschied, dass hier noch die Z e it berücksichtigt wurde. Die Verschiebung der Frequenzkurven aus einer Untergruppe in die folgende ist nämlich viel grösser als die entsprechende Veränderung der Grenzlinien der festen Eisbräme. Hierbei muss nämlich die Zeit noch so berücksichtigt werden, dass der Zuwachs des Eises aus der einen Gruppe in die andere langsamer, der Rückgang des Eises dagegen rascher als die Zeit verläuft. Der Zuwachs und der Rückgang des Eises geschieht nämlich nicht linear mit der Zeit: in der Zeit des Zuwachses ist die "Zeitkurve» eher konkav, in der Zeit des Rückganges eher konvex als linear. Gerade dieses unlineare Verhalten zwischen den Veränderungen in der Ausdehnung der Eisdecke und der Zeit machte es notwendig die Zeit bei der Darstellung der ausgeglichenen Frequenzkurven zu berücksichtigen; die Konkavität oder Konvexität der "Zeitkurve» wurde jedesmal besonders abgeschätzt.

In den Meeresteilen, wo die allgemeine Frequenzzahl 10 ist und wo gleichzeitig die $\triangle$ - und $\square$-Zahlen sich bei der Ausgleichung stark verändert hatten, haben wir die diesen Zahlen entsprechenden Kurven im allgemeinen nur quer über den Meeresteil gezeichnet, d. h. bei der Darstellung der Kurven haben wir keine in bezug auf die Eisart physikalisch vielleicht richtigere Richtung gesucht. Die durch Zahlen- 
werte anfänglich ausgedrückte Verschiedenheit der Eisarten hat sich nämlich durch die Ausgleichung in dem Grad verändert, dass jede andere Richtung der Kurven nur ein scheinbar richtigeres Bild der Eisverhältnisse auf dem Meer geben würde.

\section{E. Definitives Stadium des Eiswinters eines Meeresteils ohne die Ein- trittszeiten und die Dicke des Eises.}

94. Nachdem die S- und F-Kurven sämtlicher Untergruppen eines Meeresteiles ausgeglichen waren, zeichneten wir alle zu derselbe n Untergruppe g e hörenden S-und F-Kurven auf eine neue, gemeinsame Karte. So erhieliten wir das der betreffenden Untergruppe entsprechende Normalstadium S. Dieses Stadium $S$ vertritt dann den bestimmten Punkt in dem allgemeinen Verlauf des Eiswinters, zu dem die bei der Herleitung dieses Stadiums benutzten Eislagen augenscheinlich gehören. Das Randgebiet der Bräme des festen Küsteneises entspricht hier dem Rande des festen Eises, die Frequenzkurven wieder dem ausserhalb der Bräme befindlichen Eise in den Eislagen. Dieses Normalstadium entspricht nicht nur den benutzten Freitagslagen, sondern auch anderen Eislagen, insofern nur der Rand des festen Eises in der Eislage innerhalb des Randgebietes der festen Eisbräme des betreffenden Stadiums und das ausserhalb der Bräme befindliche Eis der Eislage zwischen die Frequenzkurven des Stadiums fallen. Bei der Bestimmung, welchem Normalstadium irgend eine Eislage entspricht, müssen wir jedoch ausser der festen Eisbräme, den Frequenzkurven und den $\mathrm{O}^{-}, \triangle$ - und $\square$-Zahlen u. a. auch die Zahlenwerte der Dicke des Eises beachten, worüber später berichtet wird.

\section{F. Allgemeiner Verlaui des Eiswinters eines Meeresteils, durch die Normalstadien ohne Beriicksichtigung ihrer Zeitepochen dargestellt.}

95. Nachdem die sämtlichen Untergruppen eines Meeresteils entsprechenden Normalstadien bestimmt waren, erhielten wir aus diesen den allgemeinen Verlauf des Winters, wenn wir die Stadien so ordneten, dass sie dem Zuwachs der 
Vereisung, der Kulmination und dem Rückgang des Eises entsprachen. So stellt die Stadienfolge den Eiswinter als ein physikalisches, von der Zeit vorderhand unabhängiges Ereignis dar. In jedem Stadium geben das den Rand der festen Eisbräme vertretende »Randgebiet» und die Frequenzkurven des ausserhalb der Bräme befindlichen Eises dem Eis die Möglichkeit zu sehr bedeutender regionaler Abwechselung. Ein solches Normalstadium umfasst gerade hierdurch sowohl die Eislagen, die wir bei seiner Bestimmung verwendet haben, als ausserdem noch eine grosse Anzahl bisher nicht festgestellter, trotzdem aber doch ganz bestimmter Eislagen. Und ebenso wie die derselben Phase des Winters entsprechenden Eislagen in verschiedenen Wintern einigermassen wechseln, so können wir aus den Normalstadien solche Grenzlinien der Bräme des festen Eises und Frequenzkurven auswählen, die in derselben Phase des Winters in bezug auf die Eislegung oder den Rückgang des Eises einem schnellen oder langsamen Verlauf, einer durchgreifenden oder gelinden Vereisung, einem starken oder gəringan Rückgang des Eises usw. entsprechen.

\section{Anknüpfung der Zeit an die Normalstadien der Meeres- teile.}

96. Damit die Normalstadien auch in bezug auf die Zeit eine der Wirklichkeit entsprechende "Beweglichkeit» haben, wurde auf Grund der Daten der zu einer jeden Untergruppe gehörenden Eislagen erst der mittlere Zeitpunkt des Eintretens des der Untergruppe entsprechenden Stadiu ms, danach auf Grund der extremen Daten derselben Eislagen die extrem en Z e it e n des Eintretens des Stadiums bestimmt.

\section{A. Mittlere Eintrittszeit der Normalstadien.}

9\%. Der mittlere, in den Karten des Atlas etwas grösser gezeichnete Zeitpunkt des Eintretens eines Stadiums ist im allgemeinen nicht die Durchschnittszahl der Daten der der Untergruppe entsprechenden Eislagen. Die Eislagen der Untergruppe zeigen nämlich in bezug auf die Zeit eine so grosse Streuung, dass die Durchschnittszahl der Daten als solche nicht verwendet werden konnte. Denn die so erhaltenen Durchschnittszahlen würden 
den Stadien im allgemeinen eine andere Ordnung verleihen als die oben erwähnte "natürliche» Ordnung. Um den regelmässigen Verlauf des Winters beizubehalten, musste man unter den Eislagen einer Untergruppe erst jene wählen, die dem betreffenden Stadium am besten entsprachen. Diesen wurde dann bei der Bestimmung der mittleren Zeit des Eintretens des Stadiums grösseres Gewicht beigemessen. Im allgemeinen wurde so verfahren, dass, wenn aus demselben Winter mehrere Eislagen in dieselbe Untergruppe kamen, bei der Bestimmung des mittleren Zeitpunktes des Stadiums das Datum der zuerst eingetretenen Eislagen verwendet wurde.

98. In den Fällen, wo die Streuung der Daten der Eislagen einer Untergruppe ausserordentlich gross war, wurde der mittlere Zeitpunkt des Eintretens des Süadiums nur von den Daten der Eislagen bestimmt, die dem entsprechenden Stadium seinen Platz im allgemeinen Verlauf des Eiswinters angaben, den es schon oben in Punkt 95 erhalten hatte. Dieses Verfahren wurde hinsichtlich einiger Frühlingsstadien benutzt, deren Zeitpunkt dann durch den der anliegenden Stadien bestimmt wurde. Einmal konnte der endgültige Zeitpunkt eines Stadiums nur vermittels der Generalstadien bestirmt werden, obgleich sein Platz in der Stadienfolge S schon von vornherein gegeben war.

99. Die Tatsache, dass das Eintreten einiger Frühlingsstadien in der eben erwähnten Weise bestimmt wurde, hatte seinen Grund darin, dass der Rückgang des Eises gegen das Ende des Winters sehr schnell verläuft, wie aus den $\mathrm{Zeit}$ - oder E p o chendiagra mmen hervorgeht (Fig. 39-44). Solche Eislagen, die im Frühling zu nacheinander folgenden Normalstadien eines Meeresteils gehören, entstehen nämlich im allgemeinen mit so kurzen Intervallen, dass von den Frühlingseislagen in den Wintern 1915-1925 nur ein Teil im Laufe desselben Frühlings an Freitagen, der andere Teil dagegen an anderen Wochentagen erschien.

100. Auf welche Weise die mittleren Zeiten des Eintretens eines jeden Normalstadiums eines Meeresteils und jedes Generalstadiums bestimmt wurden, geht näher aus dem später erscheinenden vierten und fünften Teil hervor.

\section{B. Extreme Eintrittszeiten der Normalstadien.}

101. Einen Begriff davon, wie die mittleren ("m»-) und die extremen (die sog. $\left.\| f\rangle_{,-} \| \mathbf{S f}\right\rangle-$, $\left.\| \mathrm{S}\right\rangle-$. und $\left.\| \mathrm{SS}\right\rangle-$ ) Eintrittszeiten einiger Normalstadien eines Meeresteiles nach dem Eislagematerial 


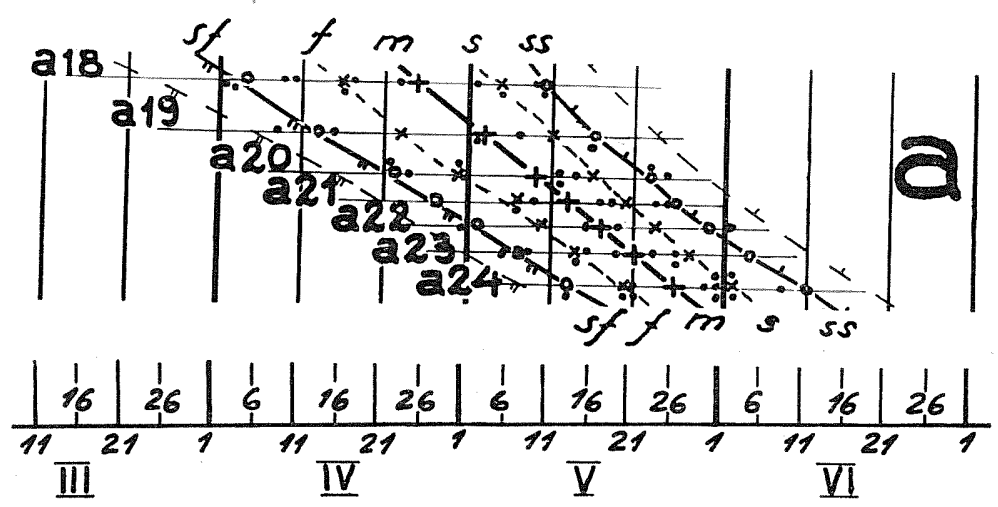

Fig. 34. Ein Teil des Zeit- oder Epochendiagramms der Bottenwiek. Als Abszisse die Zeit, als Ordinate die Normalstadien a 18 -a 24. Das Diagramm ist so gezeichnet, dass die Kreuze, die die mittlere Zeit des Eintretens der Stadien, bzw. die diesen entsprechenden Eislagen darstellen, auf einer Geraden mm liegen. Die durch die schrägen Kreuze links $\mathrm{bzw}$. rechts von $\mathrm{mm}$ gehenden Linien $\mathrm{f}-\mathrm{f}$ und $\mathrm{s}-\mathrm{s}$ entsprechen den frihen (f) und späten (s), die weiter nach links, bzw. rechts von mm durch die kleinen Kreise gehenden Linien sf-sf und ss-ss entsprechen den sehr frühen (sf), bzw. den sehr späten (ss) Eintrittszeiten der Stadien oder der den Stadien entsprechenden Eislagen.

aus den Jahren 1915-1925 sich ordn€n, erhalten wir aus Fig. 34, die einen Teil der Zeit- oder Epochendiagramme der Bottenwiek darstellt. Die Normalstadien (Sa) 18, 19..24 der Bottenwiek bilden die Ordinate, die Zeit die Abszisse. Die Figur ist so gezeichnet, dass die dem mittleren Eintreten der Stadien entsprechende Kurve als eine gerade Linie dargestellt ist. Dies hat zur Folge, dass in den Zeitdiagrammen Fig. 39-44 die Grenzkurven, zu deren Bestimmung das vorhandene Eislagematerial nicht genügte, einen unregelmässigen Verlauf erhielten, ein Umstand, auf den wir später zurückkommen werden.

Die kleinen Punkte (.) auf den den Stadien entsprechenden, zur Abszisse parallelen Linien bezeichnen die Daten der zur Herleitung der Stadien benutzten Eislagen. Die stehenden Kreuze $(+)$, die die gerade Linie $\mathrm{mm}$ bilden, geben die berechneten mittleren Zeiten des Eintretens der Stadien an. Zu beiden Seiten der Linie $\mathrm{mm}$ bezeichnen die Kurven links: "f» ein frühes und 1sf» ein sehr frühes Eintreten, rechts 15 » ein spätes und wss》 ein sehr spätes Eintreten der Stadien, bzw. der den Stadien entsprech€nden Eislagen. Die Kurven "ff» und "s» sind nach den Daten der zur Herleiturg der Stadien benutzten "früh» und sspät» eingetretenen Eislagen gezeichnet worden, die Kurven "sf» und «ss» wieder um nach den Daten der benutzten sehr früh und sehr spät eingetretenen Eislagen. 
102. Wenn die Kurven »f» und »s» sowie die Kurven »sf» und »ss» keinen linearen Verlauf erhielten, so beruhte dies darauf, dass der Zweck der vorliegenden Untersuchung war, auf eine möglichst einfache Weise den allgemeinen, durchschnittlichen Verlauf des Winters und nicht seine ungewöhnliche Entwicklung klarzulegen. Da die Eiswinterreihe 1915-1925 für die Darstellung des allgemeinen normalen Verlaufs des Winters in vielen Hinsichten sich als zu kurz erwies, ist es ohne weiteres klar, dass dieses selbe Material für den ungewöhnlichen Verlauf des Winters ungenügend ist. Die Kurven in Fig. 3944 hätte man natürlich dessenungeachtet alle linear ziehen können. Dies geschah jedoch deshalb nicht, weil wir es in keiner Weise als ohne weiteres klar betrachteten, dass die Entwicklung einer Eislage, die einem bestimmt n Stadium entspricht, aus einer anderen, die ihrerseits zu einem anderen Stadium gehört, z. B. in einem sehr langen oder strengen Winter, in bezug auf die Zeit ganz auf dieselbe Weise geschieht wie in einem mittellangen oder mittelstrengen oder in einem sehr kurzen oder gelinden Winter. Im Gegenteil scheint es viel natürlicher, dass die Zeiúintervalle zwischen aufeinander folgenden Eislagen, bzw. Stadien in verschieden langen oder verschieden schweren Wintern in ganz anderen Beziehungen zueinander stehen können, als in einem normalen oder mittellangen Winter. Spätere Untersuchungen werden diese ebenso wie viele andere Fragen aufklären. Erst nach erneuten, gründlichen Untersuchungen können wir die hier angeführten Kurven durch vollständigere ersetzen.

\section{Normalstadien der Meeresteile mit ihren Zeitepochen.}

103. Die Normalstadien der Meeresteile mit ihren Z eite po chen sind im Atlas S. 1-26 dargestellt. Hierbei ist die mittlere Zeit des Eintretens der Stadien in der Mitte der Gruppe der Zeitepochen etwas grösser gezeichnet. U̇ber derselben sind die dem verfrühten, unter derselben die dem verspäteten Eintreten entsprechenden Zeitepochen angegeben. Unter den »verfrühten» Zeiten entspricht die oberste Zeitepoche der sf-, unter den "verspäteten» die unterste der ss-Kurve des Epochendiagramms. Obgleich wir für einige Stadien noch ein ausserordentlich frühes und ein ausserordentlich spätes Eintreten erhalten haben, haben wir diese Zeitangaben nicht auf den Karten vermerkt, sondern sie nur in den Zeitdiagrammen der Meeresteile und an besonderen Stellen in verschiedenem Zusammenhang im Text berücksichtigt. 
104. Die den allgemeinen Verlauf des Eiswinters eines Meeresteiles darstellenden Normalstadien haben somit schliesslich neben den durch den Rand der Bräme des festen Küsteneises und die Frequenzkurven gegebenen Variationsmöglichkeiten in der Ausdehnung des Eises auch eine entsprechend grosse "Beweglichkeit» in bezug auf die Zeit. Die »Normalbilder» des Winters, welche aus den Freitagslagen hergeleitet sind, haben also nun die, beabsichtigten Ergänzungen und Vervollständigungen, die den wirklichen Verhältnissen am besten entsprechen, bekommen.

Im ganzen haben wir auf Grund des benutzten Eislagematerials 26 Normalstadien für das Bottenwiekgebiet (Atlas S. 1-7: Die Karten Sa 1-26), 24 Normalstadien für das Kvarkgebiet (Atlas S. 8-9: Die Karten Sb 1-24), 26 Normalstadien für das Bottenseegebiet (Atlas S. 11-14: Die Karten Sc 1-26), 25 Normalstadien für das Gebiet des Schärenmeers, des Alandsmeers und der Nördlichen Ostsee (Atlas S. 16-18: Die Karten Sd 1-25) und 28 Normalstadien für das Gebiet des Finnischen Meerbusens (Atlas S. 20-26: Die Karten Se $1-28$ ) bestimmt.

\section{Dicke des Eises der Normalstadien der Meeresteile.}

105. Damit auch die Zahlenwerte der Dicke des Eises in den Normalstadien der Meeresteile der betreffenden Phase des Winters entsprechen, müssen dieselben aus den zur Bestimmung des entsprechenden Stadiums benutzten Eislagen berechnet werden. M. a. W. die Zahlen der Dicke des Fises, die eine Eisbeobachtungsstation bei vorgenommenen Messungen erhalten hat, wurden anfänglich nach demselben Schema (Fig. 20-24: »ml») gruppiert, nach welchem die Eislagen in Untergruppen eingeteilt wurden. Die dann berechneten Mittelwerte der Dicke des Eises bezeichnen somit die Dicke des Eises an der betreffenden Beobachtungsstation in den den Untergrupper entsprechenden Stadien.

106. Die aufrechten Zahlen auf den die Normalstadien der Meeresteile darstellenden Karten im Atlas bezeichnen die auf solche Weise berechnete mittlere Dicke des festen Eises in $\mathrm{cm}$. Auf den Karten ist weiter ausserhalb der Bräme des festen $K_{\text {isteneises im Gebiet der }}$ Frequenzkurven die Dicke des im Anfang des Winters losen, später grösstenteils zusammengefrorenen Meereseises mit kursiven Zahlen angegeben. Diese letztgenannten Mittelzahlen geben, obwohl sie auf verhältnismässig geringem Material basieren, einen Begriff davon, wie sich die Eisdicke ausserhalb der eigentlichen Bräme des festen Küsteneises im Verlauf des Eiswinters verändert. 
Die Mittelwerte der Dicke des Eises an den Beobachtungsstationen sind auf den S-und G-Karten des Atlas gezeichnet und später im vierten Teil gesammelt und tabelliert, wobei die Reihenfolge der Normalstadien der Meeresteile beibehalten ist. Vermittels dieser Zahlenwerte sind dann, den mittleren Eintrittszeiten der Normalstadien folgend, die Atlaskurven »Dicke des Eises in cm» gezeichnet. Diese Kurven zeigen somit den jährlichen Verlauf der Dicke des Eises an den Stationen bzw. im Meer in einem normalen mittellangen Winter.

Die Kurven der Dicke des Eises der Bottenwiek- und Kvarkstationen sind auf S. 10 im Atlas, diejenigen der Botcenseestationen auf S. 15, die der Schärenmeer-, Ålandsmeer- und der Nördlichen Ostseestationen auf S. 19 und die der Stationen des Finnischen Meerbusens auf S. 27 und 28 dargestellt.

10\%. Die obenerwähnten Zahlen der Dicke des Eises entsprechen, wie gesagt, dem normalen Winter, d. h. einem Winter, der von mittlerer Länge und entsprechend von »mittlerer» Kälte ist. Um einen Begriff davon zu erhalten, innerhalb welcher Grenzen die Zahlen der Dicke des Eises in den Normalstadien sich verändern, wenn die Stadien einen kurzen bzw. langen, oder gelinden bzw. strengen Winter vertreten, verfuhren wir auf folgende Weise:

Da die Eiswinter, sie mögen kurz bzw. lang oder mild bzw. streng gewesen sein, entweder ganz oder zum grössten Teil aus den, den von uns hergeleiteten Normalstadien entsprechenden Eislagen aufgebaut sind, wurden die Eislagen der Winter 1915-1925 und mit diesen die Zahlen der Dicke des Eises in zwei Gruppen, "k» und »"», eingeteilt. In die erste Gruppe »k» kamen die Eislagen und die entsprechenden Dicken des Eises der kurzen oder milden Winter 1919, 1920, 1921 und 1925, in die zweite Gruppe »l» dagegen die Eislagen und die entsprechenden Dicken des Eises der langen oder strengen Winter 1916, 1917, 1922, 1923 und 1924. Danach gruppierten wir die Zahlen der Dicke des Eises einer jeden benutzten Beobachtungsstation in der Weise, dass die Zahlen der zum selben Stadium gehörenden Eislagen in den beiden $\gg \mathbf{k}\rangle-$ und $\gg\rangle$-Reihen, in jeder für sich, eigene Untergruppen bildeten, die den Untergruppenschemata $\| \mathbf{k} »$ und "ly in Fig. 20-24 entsprechen. Die letztere Gruppierung wurde also inbetreff eines jeden Winters dieselbe, wie in den allgemeinen Schemata, d. h. inbetreff des »kurzen» oder »milden» Winters dieselbe wie die Untergruppierung der Eislagen der Winter 1919, 1920, 1921 und 1925, inbetreff des »langen» und »strengen» Winters wieder wie in der Untergruppierung der Eislagen der Winter 1916, 1917, 1922, 1923 und 1924. Die mittlere Dicke des Eises der einem kurzen oder 
milden, bzw. einem langen oder strengen Winter entsprechenden Stadien erhielten wir, indem wir einfach den Mittelwert der den Stadien entsprechenden »)» bzw. 》» Eisdickegruppen berechneten.

Bei der Berechnung der Mittwinterwerte der Eisdicke, die den Maximalwerten entspricht, wurden ausser den Wintern 19151925 auch andere berücksichtigt. Hierbei wurde als Regel betrachtet, dass die benutzten Zahlenwerte nur solchen Eislagen entnommen wurden, die den Mittwinterstadien entsprachen. Später im sechsten Teil werden wir diese Fragen eingehender behandeln.

108. Die Gruppierung der $\gg \mathbf{k} »-$ und $\gg \mathbf{l}\rangle$-Zahlen ist also auch sowohl betreffs der kurzen als langen Winter dieselbe wie in den Stadien des mittellangen Winters. Damit die so erhaltenen mittleren Eisdickezahlen auch in bezug auf die Zeit einerseits den kurzen, andererseits den langen Wintern entsprachen, musste die Zeit des Eintretens der Normalstadien für diese Fälle von neuem bestimmt werden.

Als Leitgedanke diente hierbei, dass das Eintreten der Normalstadien der »kurzen» Winter nach den Daten der späten Eislagen der Herbst-Hälfte und der frühen Eislagen der Frühlings-Hälfte des Winters bestimmt wurde, das Eintreten der Normalstadien der »langen» Winter dagegen nach den Daten der frühen Eislagen der Herbst-Hälfte und der späten Eislagen der Frühlings-Hälfte des Winters. Da wir jedoch schon oben in 101 vermittels der Daten der hier genannten Eislagen das frühe und sehr frühe, das späte und sehr späte Eintreten der Normalstadien des mittellangen Winters bestimmt haben, war die Verwendung derselben bei der Bestimmung der entsprechenden Stadien des »kurzen» und des »langen» Winters zweckdienlich. Als Zeitpunkt des Eintretens der Normalstadien des »kurzen» Winters wurden somit die Mittelwerte der späten und sehr späten Eintrittszeiten der Stadien der HerbstHälfte und der frühen und sehr frühen Eintrittszeiten der Stadien der Frühjahrshälfte des Winters gèommen; als Zeitpunkt des Eintretens der Normalstadien des 》langen» Winters wurden die Mittelwerte der frühen und sehr frühen Eintrittszeiten der Stadien der HerbstHälfte und der späten und sehr späten Eintrittszeiten der Stadien der Frühjahrshälfte des Winters gewählt. Die Verwendung der Mittelwerte anstatt der extremen Werte der Eintrittszeiten der Stadien folgte aus der Beschaffenheit des benutzten Materials. Die Winter 1919, 1920, 
1921 und 1925 sind durchaus nicht im selben Grade »kurz», ebensowenig wie die Winter 1916, 1917, 1922, 1923 und 1924 alle »lang» sind. Eher entspricht ein auf Grund der ersten Gruppe hergeleiteter Winter einem "mittelkurz» kurzen Winter, ein auf Grund der zweiten Gruppe hergeleiteter Winter einem "mittellang» langen Winter, und so entsprechen auch die Zeitepochen des Eintretens der Stadien im »kurzen» und "langen» Winter "mittelfrühen» und "mittelspäten». Das folgende Beispiel zeigt, auf welche Weise vermittels der Zeitepochen des Eintretens zweier Normalstadien, von denen das eine der Herbst-Hälfte des Winters, das andere der Frühlings-Hälfte des Winters angehört, einerseits ein Zeitabschnitt eines »kurzen», andererseits eines »langen» Winters bestimmt wurde.

Die Zeitpunkte des Erscheinens der Normalstadien d 7 und $\mathrm{d} 21$ des Schärenmeeres, bzw. der diesen entsprechenden Eislagen sind bei sehr frühem, frühem, mittlerem, spätem und sehr spätєm Erscheinen folgende (Tabelle 7):

\section{Tabelle 7.}

Die sehr frühe, frühe, mittlere, späte und sehr späte Eintrittszeit der Normalstadien d'y und d21 des Schärenmeeres.

\begin{tabular}{|c|r|r|r|r|r|}
\hline Stadium & sehr früh & Irüh & im Mittel & spät & sehr spät \\
\hline $\mathrm{S}_{\mathrm{d} 7}$ & I. 1. & I. 9. & I. 21. & I. 30. & II. 11. \\
$\mathrm{S}_{\mathrm{d} 21}$ & III. 24. & IV. 2. & IV. 11. & IV. 19. & IV. 28. \\
\hline
\end{tabular}

Aus diesen Daten erhielten wir vermittels des erwähnten Rechenverfahrens die Zeitpunkte des Eintretens der Stradien d7 und d21 während eines "kurzen» und »langen» Winters und die Länge des Winters zwischen den Stadien, die in Tabelle 8 zusammengestellt sind.

\section{Tabelle 8.}

Die Eintrittszeiten der Normalstadien d' und d21 des Schärenmeeres bei »kurzen», "mittellangen» und »langen» Wintern und die entsprechenden Zeitdifferenzen $t_{d 21}-t_{d \gamma}$

\begin{tabular}{|c|c|c|c|}
\hline Stadium \Winter & "kurzer» & "mittellanger" & "langer \\
\hline $\begin{array}{l}\mathrm{S}_{\mathrm{d} 7} \\
\mathrm{~S}_{\mathrm{d} 11}\end{array}$ & $\begin{array}{l}\text { II. } 5 . \\
\text { III. } 28 .\end{array}$ & I. 21. & I. 5. \\
\hline $\begin{array}{c}\text { Zeitdifferenz } t_{\mathrm{d} 21}-t_{\mathrm{d} 7} \\
\text { in Tagen }\end{array}$ & 51. & 80. & 109. \\
\hline
\end{tabular}


109. Im Vergleich zu dem "mittellangen» Winter treten die Stadien in den »kurzen» Wintern näher aneinander. Dies geschieht in der Weise, dass einige Stadien des Mittwinters, wie die Stadien d11 — d19 des Schärenmeergebietes, gänzlich verschwinden, so dass der Winter »kurz» wird. Im »langen» Winter werden die Zwischenzeiten zwischen den Stadien länger und somit auch der Winter länger. Da einerseits bei dem Übergang aus dem mittellangen in den kurzen Winter einige Stadien des Mittwinters ganz verschwinden, so treten andererseits beim Übergang eines mittellangen Winters in einen langen Winter und bei entsprechender Erschwerung des Winters neue Stadien im Mittwinter auf, deren Aufbau bisher noch nicht bestimmt ist. Unten im dritten Abschnitt bei IV: Der Aufbau der mittwinterlichen G-Stadien werden wir diese Frage näher behandeln. Zur Darstellung der Jahreskurven der Dicke des Eises ist die Kenntnis dieser die Mittwinterzeit erschwerenden Normalstadien jedoch nicht nötig. Die Mittelwerte der Eisdickezahlen basieren nämlich praktisch gesehen beinahe ausschliesslich auf Messungen an den fesţen Stationen, die sich in der Mittwinterzeit in der Bräme des festen Küsteneises oder in dem sich daran anschliessenden Frequenzgebiet der Normalstadien befinden. Beide Gebiete sind jedoch auf Grund der hier bestimmten Stadien in bezug auf ihren allgemeinen Aufbau bekannt.

Die dem »kurzen» und dem »langen» Winter entsprechenden Mittelzahlen der Dicke des Eises werden später im sechsten Teil in Tabellen und Kurven dargestellt.

\section{Wahrscheinlichkeit des jährlichen Eintretens der Normal- stadien der Meeresteile.}

110. Unter den Eislagen, vermittels deren der allgemeine Verlauf der Winter der Meeresteile bestimmt worden ișt, gibt es natürlich ausser den jeden Winter eintretenden Eislagen auch solche, die nur in einigen Jahren eingetreten sind. Je "schwerer» die Eislagen in bezug auf die Ausdehnung des Eises von einer gewissen Grenze an gerechnet werden, desto geringer ist die Wahrscheinlichkeit ihres jährlichen Eintretens wie auch des entsprechenden Stadiums.

In jedem Eiswinter eines Meeresteiles treten im Herbst und im Frühling immer solche Eislagen ein, die den meisten Normalstadien des Herbstwinters und des Frühlingswinters sowie den meisten Endstadien des Frühlings entsprechen, so dass die Wahrscheinlichkeit des jährlichen Eintretens dieser Stadien 1 ist. Die anderen 
Normalstadien dagegen treten mit geringerer Wahrscheinlichkeit ein. Die Wahrscheinlichkeit des jährlichen Eintretens eines Stadiums ist allgemein $N^{\prime} / N$, wobei $N^{\prime}$ die Anzahl der Winter bezeichnet, in deren Verlauf eine diesem bestimmten Stadium entsprechende Eislage eingetreten ist, und $N$ die ganze Anzahl der Winter vertritt. Solche, einem bestimmten Normalstadium entsprechende Eislagen können jedoch mehrmals im Laufe desselben Winters eintreten: entweder so, dass sie beinahe unverändert mehrere Wochen dauern, oder dass sie sich in grossen Zügen wiederholen. In solchen Fällen nehmen wir hier an, dass die dem Stadium entsprechende Eislage nur einmal im Winter eingetreten ist.

Wenn nun von $N$ Wintern in $N^{\prime}$ Wintern $\left(N \geq N^{\prime}\right)$ im ganzen $n\left(n \geqq N^{\prime}\right)$ einem bestimmten Normalstadium $\mathrm{S}$ entsprechende Eislagen eingetroffen sind, besteht zwischen den Zahlen $n, N^{\prime}$ und $N$ folgendes Verhältnis:

$$
\frac{n}{N^{\prime}} \geqq \frac{n}{N} \geq \frac{N^{\prime}}{N}
$$

in dem $\frac{N^{\prime}}{N}$ höchstens $=1$. Die Bruchzahl $\frac{n}{N^{\prime}}$ zeigt, wievielmal die dem Stadium S entsprechenden Eislagen durchschnittlich pro Jahr in diesen $N^{\prime}$ Eiswintern vorkamen, in welchen sie überhaupt eingetreten sind, die Zahl $\frac{n}{N}$ wiederum gibt an, wievielmal eine solche Eislage in den ingesamt benutzten $N$ Eiswintern pro Jahr berechnet eingetreten ist. Die Zahl $\frac{N^{\prime}}{N}$ schliesslich bezeichnet, in wie vielen Wintern von allen $N$ Wintern die dem Stadium S entsprechende Eislage konstatiert worden ist, und ist wie gesagt die Wahrscheinlichkeit des jährlichen Eintretens des Stadiums S.

Die Wahrscheinlichkeit des jährlichen Eintretens der Normalstadien der Meeresteile wurde in der Weise bestimmt, dass sie zunächst dem jährlichen Eintreten der Eislagen in den Jahren 1915-1925 entspricht. Die abgerundete Wahrscheinlichkeitszahl ist auf den Karten der Normalstadien im Atlas durch eine Bruchzahl angegeben, deren Nenner 10 ist. Diese Zahl steht auf den Karten der Meeresteile unmittelbar nach dem Kennzeichen des Stadiums, nur auf den Karten des Meeresteiles e und in den G-Stadien steht die Zahl unter den Eintrittszeiten der Stadien.

111. Die Wahrscheinlichkeit des jährlichen Eintretens derjenigen Normalstadien der Meeresteile, die den schwereren Eislagen des Mittwinters entsprechen, schwankt sehr beträchtlich in den verschiedenen 
Meeresteilen. So ist das Schärenmeer auf Grund seiner geographischen Lage weit im Südwesten sowie die anliegenden zum d-Gebiet gehörenden Teile anderer Meere sehr günstig gelegen. Dagegen ist die Bottenwiek, die am weitesten im Norden liegt und von der ziemlich tiefen und weiten Bottensee durch die seichte Schwelle des Kvark getrennt ist, von allen Meeren Finnlands am ungünstigsten gelegen. „Ostseeisch» und somit eigentlich "günstig» gelegen ist der Finnische Meerbusen, der sich ohne jegliche Schwelle an die Ostsee anschliesst; die Bottensee ist ein weites, ziemlich tiefes, und beinahe wirkliches Meer.

Diese Verschiedenheit in der geographischen Lage und dem Aufbau der Meeresteile Finnlands spiegelt sich deutlich in der Wahrscheinlichkeit des jährlichen Eintretens der mittwinterlichen Normalstadien wider. Einigermassen haben vielleicht auf die Wahrscheinlichkeitszahlen des jährlichen Eintretens die in dem betr. Zeitabschnitt in varschiedenen Teilen des Landes möglicherweise vorgekommenen, mehr abweichenden durchschnittlichen meteorologischen Umstände sowie vielleicht eingetroffene Schwankungen im Aufbau des Wasserkörpers des Meeres einwirken können. Da aber die Erörterung dieser wichtigen und komplizierten Fragen eine besondere Behandlung erfordern würde, beschränken wir uns hier auf das Gesagte.

112. Die Schwankungen in der Wahrscheinlichkeit des jährlichen Eintretens der Mittwinternormalstadien der Meeresteile gehen aus Tabelle 9 hervor.

Die Tabelle ist so aufgestellt, dass die Wahrscheinlichkeit des jährlichen Eintretens der Mittwinterstadien der Meeresteile, deren Zeitpunkt des Eintretens ganz oder nahezu den Stadien 12-18 des d-Gebietes entspricht, auf die Kolumnen d 12-d 18 verteilt ist. Falls in irgendeinem Meeresteile ein solches Stadium nicht vorkommt,

Tabelle 9.

Die Wahrscheinlichkeit (in Zehnteln) des jährlichen Eintretens der Normalstadien der Meeresteile $\mathbf{a}, \mathbf{b}, \mathbf{c}, \mathbf{d}$ und $\mathbf{e}$, die dieselbe mittlere Eintrittszeit haben wie die Normalstadien d12-d18 des Schärenmeeres.

\begin{tabular}{|c|c|c|c|c|c|c|c|}
\hline & $\mathrm{d} 12$ & $\mathrm{~d} 13$ & $\mathrm{~d} 14$ & $\mathrm{~d} 15$ & $\mathrm{~d} 16$ & $\mathrm{~d} 17$ & $\mathrm{~d} 18$ \\
\hline $\mathbf{a}$ & 10 & 8 & $6-7^{*}$ & 6 & 6 & 6 & 7 \\
$\mathbf{b}$ & $9^{*}$ & 8 & 6 & $4-5$ & 5 & 6 & $7^{*}$ \\
$\mathbf{c}$ & $7-6^{*}$ & $6^{*}$ & 5 & $4-5$ & 5 & $5-6^{*}$ & 7 \\
$\mathbf{d}$ & $\mathbf{7 - 6}$ & $\mathbf{5}$ & $\mathbf{4 - 5}$ & $\mathbf{4}-\mathbf{5}$ & $\mathbf{4}-\mathbf{5}$ & $\mathbf{5}$ & $\mathbf{6}-\mathbf{7}$ \\
$\mathbf{e}$ & 8 & $7^{*}$ & 5 & $4-5$ & 6 & $6-7^{*}$ & 7 \\
\hline
\end{tabular}


interpolierten wir aus der Wahrscheinlichkeit der nächsten Normalstadien die Wahrscheinlichleit eines solchen Stadiums, die in der Tabelle mit einem Stern (*) versehen ist.

Die günstige Lage des d-Gebietes im Verhältnis zu den anderen Meeresteilen geht aus der Tabelle deutlich hervor. Die »schwersten» Normalstadien dieses Meeresteiles erscheinen im allgemeinen mit einer geringeren jährlichen Wahrscheinlichkeit als in den anderen Gebieten. Das in bezug auf die Günstigkeit seiner Lage folgende Gebiet ist die Bottensee, wo die den Normalstadien d 12 und d 13 samt d 16 und d 17 entsprechenden c-Stadien mit einer geringeren Wahrscheinlichkeit als die entsprechenden e-Stadien oder die des Finnischen Meerbusens eintreten. Der Kvark - das b-Gebiet - bildet wiederum ein Übergangsgebiet von der Bottensee zur Bottenwiek, wo die Wahrscheinlichkeit des jährlichen Eintretens der den Normalstadien d $12-\mathrm{d} 15$ entsprechenden a-Stadien am grössten ist.

Aus den Zahlenwerten der Tabelle 9 ersehen wir, dass die Wahrscheinlichkeit des jährlichen Eintretens der den Normalstadien d 12 und d 13 des Schärenmeeres entsprechenden Stadien anderer Meeresteile sehr stark, von $6-7$ bis sogar 10 , schwankt, wogegen die dem Stadium d 18 entsprechenden Werte für alle Gebiete dieselben oder etwa 7 sind. Dies zeigt wieder die Verschiedenartigkeit der Meeresteile: die »Mittwinterzeit» fängt nach den Wahrscheinlichkeitszahlen im Norden und Osten am frühesten an, »endet» jedoch beinahe überall gleichzeitig. Wir sehen noch im Verlauf der Zahlenwerte eine gewisse Unregelmässigkeit in dem $\mathbf{b}$ - und dem $\mathbf{e}$-Gebiete. In bezug auf die den Normalstadien d 14-d 16 der Zeit nach entsprechenden Stadien des Kvark macht sich wahrscheinlich die Wirkung der Bottensee, in den letzten Stadien die der Bottenwiek geltend. Wie oben erwähnt wurde, bildet der Kvark in dem Umfang, in dem wir ihn in der vorliegenden Untersuchung behandeln, kein einheitliches, besonderes Meeresgebiet, sondern seine südlichen Teile schliessen sich deutlich an die nördlichen Teile der Bottensee, seine mittleren und nördlichen Teile an die südlichen Teile der Bottenwiek an. In bezug auf den Finnischen Meerbusen überwiegen wohl in den den Normalstadien d 16 und d 17 entsprechenden Stadien die Eisverhältnisse der mittleren und östlichen Teile diejenigen der westlichen des Meerbusens, wodurch mehr dessen Natur als tief in den Kontinent eindringenden Busen denn als eine Verzweigung der Ostsee hervorgehoben wird.

113. Die verschiedene Wahrscheinlichkeit des jährlichen Eintretens der den "schwereren» Eislagen der Meeresteile entsprechenden Normalstadien ist $u$. a. der Grund, warum die Bestimmung der Finn- 
lands ganze Küste umfassenden allgemeinen Normalstadien oder G-Stadien nur in einigen Fällen ohne weiteres möglich ist. Ein möglicher Ausweg beim Aufbau dieser G-Stadien war dabei zuerst die Normalstadien der Meeresteile und dann die Finnlands ganze Küste und sämtliche Meeresteile umfassenden allgemeinen Stadien zu bestimmen. Aber auch hierbei waren wir gezwungen solche Stadien der Meeresteile, deren Wahrscheinlichkeit des jährlichen Eintretens sehr bedeutend, z. B. zwischen 5 und 8 Zehnteln, schwankt, wie in der Gruppe d 13 der Tabelle 9, zu konnektieren. In welcher Weise das geschah, geht aus dem dritten Abschnitt dieses Teils hervor.

Tabelle 10.

Das Eintreten der den Normalstadien d 12 bis d 18 des Mittwinters des Schärenmeeres entsprechenden Eislagen in den Eiswintern 19001924. Das + Zeichen bezeichnet, dass eine dem Stadium entsprechende Eislage eingetreten ist, das - Zeichen, dass eine dem Stadium entsprechende Eislage $n i c h t$ eingetreten ist.

\begin{tabular}{|c|c|c|c|c|c|c|c|}
\hline Jahr & d 12 & d 13 & d 14 & d 15 & d 16 & d 17 & d 18 \\
\hline 1900 & + & + & + & + & + & + & + \\
\hline 1901 & + & + & + & + & + & + & + \\
\hline 1902 & + & + & + & + & + & + & + \\
\hline $\begin{array}{l}1903 \\
1904\end{array}$ & $\bar{t}$ & $\bar{t}$ & $\bar{t}$ & - & $\bar{t}$ & $\bar{t}$ & $\overline{+}$ \\
\hline & & & & & & & \\
\hline $\begin{array}{l}1900 \\
1906\end{array}$ & E & - & E & - & - & 二 & - \\
\hline 1907 & I & I & - & I & E & - & E \\
\hline 1908 & + & + & + & + & + & + & + \\
\hline 1909 & + & + & + & + & + & + & + \\
\hline 1910 & - & - & - & - & - & - & - \\
\hline 1911 & - & - & - & - & - & - & - \\
\hline 1912 & + & + & - & - & - & + & + \\
\hline 1913 & - & - & - & - & - & - & - \\
\hline 1914 & - & - & - & -- & - & - & - \\
\hline 1915 & + & + & + & + & + & + & + \\
\hline 1916 & + & + & + & + & + & + & + \\
\hline 1917 & + & + & + & + & + & + & + \\
\hline 1918 & + & + & + & - & + & + & + \\
\hline 1919 & + & & - & - & - & - & + \\
\hline 1920 & + & - & - & - & - & - & + \\
\hline 1921 & & - & - & - & - & - & \\
\hline 1922 & + & + & + & + & + & + & + \\
\hline 1923 & & & & + & & + & + \\
\hline 1924 & + & + & + & + & + & + & + \\
\hline
\end{tabular}


Fortsetzung der Tabelle 10.

\begin{tabular}{|c|c|c|c|c|c|c|c|}
\hline Jahresgruppe & d 12 & d 13 & d 14 & d 15 & d 16 & d 17 & d 18 \\
\hline $\begin{array}{l}1900-1904 \\
1905-1909 \\
1910-1914 \\
1915-1919 \\
1920-1924 \\
\end{array}$ & $\begin{array}{l}4 \\
2 \\
1 \\
5 \\
4 \\
\end{array}$ & $\begin{array}{l}4 \\
2 \\
1 \\
4 \\
3 \\
\end{array}$ & $\begin{array}{r}4 \\
2 \\
4 \\
3 \\
\end{array}$ & $\begin{array}{l}3 \\
2 \\
3 \\
3 \\
\end{array}$ & $\begin{array}{l}4 \\
2 \\
4 \\
3 \\
\end{array}$ & $\begin{array}{l}4 \\
2 \\
1 \\
4 \\
3 \\
\end{array}$ & $\begin{array}{l}4 \\
2 \\
1 \\
5 \\
4 \\
\end{array}$ \\
\hline $\begin{array}{l}1900-1909 \\
1905-1914 \\
1910-1919 \\
1915-1924 \\
\end{array}$ & $\begin{array}{l}6 \\
3 \\
6 \\
9 \\
\end{array}$ & $\begin{array}{l}6 \\
3 \\
5 \\
7 \\
\end{array}$ & $\begin{array}{l}6 \\
2 \\
4 \\
7 \\
\end{array}$ & $\begin{array}{l}5 \\
2 \\
3 \\
6 \\
\end{array}$ & $\begin{array}{l}6 \\
2 \\
4 \\
7 \\
\end{array}$ & $\begin{array}{l}6 \\
3 \\
5 \\
7 \\
\end{array}$ & $\begin{array}{l}6 \\
3 \\
6 \\
9 \\
\end{array}$ \\
\hline $\begin{array}{l}1900-1919 \\
1905-1924\end{array}$ & $\begin{array}{l}12 \\
12\end{array}$ & $\begin{array}{l}11 \\
10 \\
\end{array}$ & $\begin{array}{r}10 \\
9 \\
\end{array}$ & $\begin{array}{l}8 \\
8\end{array}$ & $\begin{array}{r}10 \\
9 \\
\end{array}$ & $\begin{array}{l}11 \\
10 \\
\end{array}$ & $\begin{array}{l}12 \\
12 \\
\end{array}$ \\
\hline $1900-1924$ & 16 & 14 & 13 & 11 & 13 & 14 & 16 \\
\hline
\end{tabular}

114. Die Wahrscheinlichkeit des jährlichen Eintretens eines Generalstadiums bestimmt der Meeresteil, dessen diesem G-Stadium entsprechendes Stadium die geringste Wahrscheinlichkeit hat. Dieser Meeresteil ist das d-Gebiet, so dass die Wahrscheinlichkeit des jährlichen Eintretens eines G-Stadiums dieselbe ist wie die Wahrscheinlichkeit des diesem G-Stadium entsprechenden d-Stadiums. Um eine Vorstellung davon zu erhalten, inwiefern die Wahrscheinlichkeit des jährlichen Eintretens der schwersten d-Stadien und somit auch der entsprechenden G-Stadien in einer längeren Zeitfolge als der von uns benutzten Eiswinter 1915-1925 sich möglicherweise verändert, bestimmten wir die Wahrscheinlichkeit der Stadien, die den in den Jahren 1900-1914 im Schärenmeergebiet eingetretenen grössten Vereisungen entsprachen. Tabelle 10 gibt an, in welchen Wintern von den Wintern 1900-1924 die den Normalstadien d 12 bis d 18 entsprechenden Eislagen eingetreten sind und die Wahrscheinlichkeit des jährlichen Eintretens der Stadien d 12-d 18 bzw. der diesen Stadien entsprechenden Eislagen während der verschiedenen Jahresgruppen der vorhergehenden Tabelle ist in der folgenden Tabelle 11 zusammengestellt.

115. Die sehr grossen Schwankungen der weitesten Vereisung in den verschiedenen Wintern gehen sehr anschaulich aus der Tabelle 10 hervor. So erreichten die "schwersten" Eislagen in bezug auf die Ausdehnung des Eises die den Stadien d 14-d 16 entsprechende Grösse: in den Wintern 1900-1904 drei bis viermal, in den Wintern 1905-1909 nur zweimal und in den Wintern 1910-1914 kein einziges Mal; in den folgenden Fünfjahresperioden 1915-1919 
Tabelle 11.

Die Wahrscheinlichkeit des jährlichen Eintretens der Stadien d 12-d 18; die Zahlen Zehntel.

\begin{tabular}{|c|c|c|c|c|c|c|c|}
\hline Jahresgruppe & d 12 & d 13 & $\mathrm{~d} 14$ & d 15 & d 16 & d 17 & d 18 \\
\hline $\begin{array}{l}1900-1904 \\
1905-1909 \\
1910-1914 \\
1915-1919 \\
1920-1924 \\
\end{array}$ & $\begin{array}{r}8 \\
4 \\
2 \\
10 \\
8 \\
\end{array}$ & $\begin{array}{l}8 \\
4 \\
2 \\
8 \\
6 \\
\end{array}$ & $\begin{array}{l}8 \\
4 \\
8 \\
6\end{array}$ & $\begin{array}{l}6 \\
4 \\
6 \\
6\end{array}$ & $\begin{array}{r}8 \\
4 \\
8 \\
6\end{array}$ & $\begin{array}{l}8 \\
4 \\
2 \\
8 \\
6\end{array}$ & $\begin{array}{r}8 \\
4 \\
2 \\
10 \\
8\end{array}$ \\
\hline $\begin{array}{l}1900-1909 \\
1905-1914 \\
1910-1919 \\
1915-1924 \\
\end{array}$ & $\begin{array}{l}6 \\
3 \\
6 \\
9 \\
\end{array}$ & $\begin{array}{l}6 \\
3 \\
5 \\
7 \\
\end{array}$ & $\begin{array}{l}6 \\
2 \\
4 \\
7 \\
\end{array}$ & $\begin{array}{l}5 \\
2 \\
3 \\
3 \\
6 \\
\end{array}$ & $\begin{array}{l}6 \\
2 \\
4 \\
7 \\
\end{array}$ & $\begin{array}{l}6 \\
3 \\
5 \\
7 \\
\end{array}$ & $\begin{array}{l}6 \\
3 \\
6 \\
9 \\
\end{array}$ \\
\hline $\begin{array}{r}1900-1919 \\
1905-1924 \\
\end{array}$ & $\begin{array}{l}6 \\
6 \\
\end{array}$ & $\begin{array}{l}5.5 \\
5 \\
\end{array}$ & $\begin{array}{l}5 \\
4.5 \\
\end{array}$ & $\begin{array}{l}4 \\
4 \\
\end{array}$ & $\begin{array}{c}5 \\
4.5 \\
\end{array}$ & $\begin{array}{l}5.5 \\
5 \\
\end{array}$ & $\begin{array}{l}6 \\
6 \\
\end{array}$ \\
\hline $1900-1924$ & 6.4 & 5.6 & 5.2 & 4.4 & 5.2 & 5.6 & 6.4 \\
\hline m Atlas benutzt & $7-6$ & 5 & $4-5$ & $4-5$ & $4-5$ & 5 & $6-7$ \\
\hline
\end{tabular}

und 1920-1924 wieder drei bis viermal; und in den Zehnjahresgruppen 1900-1909 und 1915-1924 fünf bis siebenmal, in den dazwischen liegenden 1905-1914 und 1910-1919 nur zwei bis viermal.

116. Die nach den schwersten Eislagen der Winter 1900-1924 bestimmte Wahrscheinlichkeit des jährlichen Eintretens der Normalstadien Sd 12-d 18 ist in Tabelle 11 in Zehnteln angegeben; die anfänglich bestimmte und auf den Karten des Atlas benutzte Wahrscheinlichkeit befindet sich in der letzten Reihe der Tabelle. Die Wahrscheinlichkeit des jährlichen Eintretens der Stadien d 12, d 15 und d18, die $0.64,0.44$ und 0.64 ist, entspricht somit gut den für diese Stadien anfänglich hergeleiteten und im Atlas benutzten Werten 7-6/10,4-5/10 und 7-6/10. Der grosse Unterschied zwischen der für die Stadien d 13 und d 14 bzw. d 16 und d 17 aus der langen Jahresfolge bestimmten Wahrscheinlichkeit und der aus der zur Herleitung der Normalstadien benutzten Jahresfolge erhalt enen Wahrscheinlichkeit beruht vermutlich einfach darauf, dass die Bestimmung solcher Eislagen, die den Stadien d 13 und d 14 bzw. d 16 und d 17 in den Wintern 1900-1914 entsprechen, schwerer ist als die Bestimmung der Eislagen einerseits der Stadien d 12 und d 18, anderseits des Stadiums der grössten Eislegung oder d 15. Dies beruht darauf, dass bei den erstgenannten, d. h. in den den Stadien 
d 13 und d 14 bzw. d 16 und d 17 entsprechenden Eislagen die Vereisung schon so bedeutend wird, dass der äussere Rand des Eises gewöhnlich weit im Meere liegt und die Ausdehnung des Eises darum immer einigermassen von der Deutung, d.h. davon abhängig ist, welchen Wert man den Aufzeichnungen des losen und somit sich bedeutend verändernden Eises, die an den am weitesten gelegenen Beobachtungsstationen gemacht sind, beimisst. In den Wintern 1915 - 1924 dagegen sind die Eisverhältnisse durch die Eislagen ein für allemal bestimmt.

Die anfänglich erhaltene Wahrscheinlichkeit des jährlichen Eintretens der mittwinterlichen Normalstadien des d-Gebietes entspricht somit im grossen ganzen nach der Tabelle 11 der weitesten Ausdehnung der Vereisung dieses Gebietes im Verlauf von 25 Jahren. Da die Wahrscheinlichkeit des jährlichen Eintretens der Normalstadien des d-Gebietes zugleich die der G-Stadien ist, gibt sie auch eine Vorstellung von der Entstehung der letztgenannten in demselben Zeitabschnitt, d. i. im Verlauf von 25 Jahren.

11\%. Die Wahrscheinlichkeit des jährlichen Eintretens der SStadien und der G-Stadien erschwert vielleicht einigermassen die Anwendbarkeit und die Verständlichkeit der Bilder dieser Stadien. Die Normalstadien sind schon ohnedies durch zweifache, oder besser dreifache Wahrscheinlichkeit belastet: in bezug auf die Ausdehnung des Eises und, obwohl bis auf weiteres nur angedeutet, auf die Eintrittszeiten der Stadien und auf die Dicke des Eises. Doch obwohl die Verständlichkeit der Bilder der Normalstadien somit einigermassen durch die Wahrscheinlichkeit des jährlichen Eintretens erschwert ist, so bedeutet dies doch anderseits, dass die Bilder erst dadurch die wirklichen Verhältnisse in richtiger Weise wiedergeben. Denn erst unter Berücksichtigung der Wahrscheinlichkeit des jährlichen Eintretens der Stadien können wir durch mögliche Kombinationen der Eintrittszeiten, der Randlinien der Bräme des festen Küsteneises und der Frequenzkurven derselben, theoretisch »richtige», verschieden lange Eiswinter aufbauen.

\section{Kurzer (k-), mittellanger (m-) und langer (l-) Winter der Meeresteile.}

118. Unter einem mittellangen oder normalen und gleichzeitig in bezug auf die Ausdehnung des Eises mittelschweren Eiswinter verstehen wir in der vorliegenden Untersuchung einen Winter, in 
dem: 1) die Eislagen in den mittleren Zeitepochen der entsprechenden Normalstadien eintreten oder höchstens 6 Tage von ihnen abweichen (näheres unten im fünften Abschnitt der Methode) und 2) die Wahrscheinlichkeit des jährlichen Eintretens der den Eislagen der weitesten Vereisung entsprechenden Stadien gleich 5/10 ist. Ein Winter wird kürzer und gleichzeitig in bezug auf die Ausdehnung des Eises "milder" als ein mittellanger und mittelstrenger Winter, wenn die die weiteste Vereisung wiedergebenden Eislagen solchen Normalstadien entsprechen, deren Wahrscheinlichkeit grösser als 5/10 ist, und die Zeitpunkte des Eintretens der Eislagen in bezug auf die mittlere Zeit der Normalbilder den Winter verkürzend sich einander nähern. Von diesen, vermittels der Normalstadien aufgebauten kurzen Wintern, ist derjenige in bezug auf die Ausdehnung des Eises der mildeste, dessen Eislagen nur solchen Stadien entsprechen, die mit voller Wahrscheinlichkeit 10/10 eintreten. Ein Winter wird "strenger» und länger als ein mittellanger und mittelstrenger Winter, falls die Wahrscheinlichkeit des jährlichen Eintretens der den Eislagen der weitesten Vereisung entsprechenden Stadien kleiner als 5/10 ist und die Eislagen im Vergleich zu denjenigen der mittleren Eintrittszeit der Stadien in der Weise eintreten, dass sie den Winter verlängern.

Vermittels der Stadien der Meeresteile können wir somit, indem. wir die Zeitpunkte des Eintretens und die Wahrscheinlichkeitszahlen des jährlichen Erscheinens sowie die Frequenzkurven, die Grenzen der Bräme des festen Eises und der Dicke des Eises auf verschiedene Weise kombinieren die meist verschiedenen Eiswinter aufbauen. Diese sind in bezug auf die Zeit auf verschiedene Weise kurz, mittellang oder lang und in bezug auf die Ausdehnung des Eises entsprechend verschieden mild, mittelstreng oder streng.

119. Vermittels dieser Normalbilder können wir jedoch nicht den "kurzen» Winter aufbauen, zu dem nur solche Eislagen gehören, welche den Stadien mit der Wahrscheinlichkeit 10/10 entsprechen, der aber noch kürzer sein sollte als ein auf Grund der "meist verkürzenden» Epochen der Stadien hergeleiteter Winter. Bei seinem Aufbau können wir wohl die ungewöhnlich späten herbstlichen und ungewöhnlich frühen frühjahrlichen Eintrittszeiten der Stadien benutzen, aber weil die Folge dieser Zeitpunkte noch unvollständig ist, ist die Verwendung der Normalbilder hier unsicher. Andererseits wiederum entsprechen in bezug auf die »langen» Winter die von uns hergeleiteten Stadien der weitesten Vereisung nur solchen Eislagen, deren geringste Wahrscheinlichkeit des jährlichen Eintretens 4-5/10 ist. Unter den Bildern der Normalstadien fehlen somit gänzlich noch 
seltener eintretende und entsprechend schwerere Eisverhältnisse wiedergebende Bilder. Eine weitere Aufgabe ist somit die Anzahl der Stadien des Mittwinters zu vermehren, indem man solche neuen Normalstadien aufbaut, deren Wahrscheinlichkeit des jährlichen Eintretens der Reihe nach $4 / 10,3 / 10,2 / 10,1 / 10,9 / 100$ usw. ist. In der vorliegenden Untersuchung, deren Zweck zunächst die Darstellung des allgemeinen Verlaufes des Eiswinters ist, nimmt diese Frage einen sekundären Platz ein. Erst später, als die Normalstadien schon gezeichnet und gedruckt waren und wir somit vermittels dieser durch die Analyse des zeitlichen Verlaufes der Eiswinter hinreichend viele neue "schwerere» Eislagen haben feststellen können, ist eine eingehende Behandlung dieser Frage genau genommen überhaupt möglich gewesen.

120. Oben haben wir den mittellangen oder normalen Winter in bezug auf die Ausdehnung des Eises so definiert, dass die Eislage der weitesten Vereisung einem Normalstadium entspricht, dessen Wahrscheinlichkeit des jährlichen Eintretens 5/10 ist. Wie aus Tabelle 11 hervorging, ist die Wahrscheinlichkeit der der grössten mittwinterlichen Vereisung der Meeresteile entsprechenden Stadien im a-Gebiete 6/10, in den anderen Gebieten 4-5/10. In den »Bildreihen» der Normalstadien der Meeresteile, die im Atlas dargestellt sind, vertritt somit die der Bottenwiek einen etwas milderen (und möglicherweise auch kürzeren) Winter als der normale und mittellange, die Bildreihen der anderen Meeresteile geben einen etwas strengeren (und wahrscheinlich längeren) Winter wieder.

Da nun jedoch schon in diesen mittwinterlichen Stadien der Bottenwiek das Meer ganz mit Eis bedeckt ist und die grösste Vereisung somit in diesen mit der Wahrscheinlichkeit 6/10 eintretenden Stadien erreicht ist, und da die mittleren Eintrittszeiten dieser Stadien sowie die Dicke des Eises den Mittelwerten für die Zeitperiode entsprechen, so stellen die Karten Sa1-a 26 auf S. 1-7 im Atlas in der Tat den allgemeinen Verlauf des mittellangen oder normalen Winters in der Bottenwiek dar. Die Reduzierung auf einen wirklich mittellangen (5/10) oder, wie in bezug auf die G-Stadien durchgeführt wurde, auf einen mit der Wahrscheinlichkeit $4-5 / 10$ eintretenden Winter, wirkt zunächst nur auf die Zahlenwerte der Frequenzkurven und auf die Frequenzzahlen des losen $(\triangle)$ und des zusammengefrorenen ( $\square$ ) Eises. Dies zeigt sich bei einem Vergleich der mittwinterlichen Sa-Karten und der G-Karten (Atlas, S. 30-44) hinsichtlich des Bottenwiekgebietes. Wir werden diese Frage weiter unten im dritten Abschnitt dieses Teils in Bb näher behandeln. 
Weil nun von den Meeresteilen im d-Gebiet, das geographisch am günstigsten gelegen ist, nach der den mittwinterlichen Verlauf von 25 Wintern darstellenden Tabelle 11 nur das Stadium d 15 die Wahrscheinlichkeit 44/100 des jährlichen Eintretens hat, die nächsten Stadien d 14 und d 16 dagegen schon 52/100 haben, können wir mit gutem Grunde voraussetzen, dass auch die Wahrscheinlichkeit des schon bestimmten "schwersten» Stadiums des c- und des e-Gebietes sich ebenso sehr oder noch mehr dem Wert 50/100 des mittellangen Winters nähert, als die Wahrscheinlichkeitszahlen 4-5/10 auf den Karten im Atlas eigentlich zeigen. Da ausserdem die mittleren Eintrittszeiten der Normalstadien und die Zahlen der Eisdicke des c-, d- und e-Gebietes auch jetzt den Mittelwerten der anfänglich benutzten Wintergruppe 1915-1925 entsprechen, stellen die Karten Sc 1-26, Sd $1-25$ und Se 1-28 (S. 11-14, $16-18$ und 20-26 im Atlas) als solche somit in ihren Hauptzügen den allgemeinen Verlauf des mittellangen oder normalen Winters in der Bottensee, im Schärenmeer und im Finnischen Meerbusen dar, jedoch so, das die äussersten Frequenzkurven (und -zahlen) wohl etwas "schwereren» als "mittleren» Eisverhältnissen entsprechen.

\section{Die Eisverhältnisse ausserhalb des Gesichtskreises der festen Beobachtungsorte.}

121. Obgleich es uns an Eisbeobachtungen aus einigen ausserhalb des Gesichtskreises der festen Beobachtungsorte gelegenen Gebieten gänzlich oder wenigstens zeitweise fehlt, ist es doch möglich in einigen Fällen, u. a. zur Zeit der weitesten Ausdehnung des Eises auf Grund gewisser Tatsachen einige Schlussfolgerungen über die Frequenzverhältnisse zu zi hen.

Die Weite des Sehkreises der Eiskarten wird zunächst durch die Aufzeichnungen der Beobachter bestimmt. Sie erstreckt sich im allgemeinen, insofern nichts anderes angegeben ist, bis zu dem der Höhe des Beobachtungsortes entsprechenden Horizont. Den ungefähren Verlauf dieses berechneten Sehkreises der festen Eisbeobachtungsorte stellen die ausgezogenen Linien in Fig. 35 dar.

In der Bottensee erstreckt sich dieser berechnete Sehkreis so weit, wie ihn HEILsTRöM in seiner Untersuchung (27) angegeben hat. Mit Ausnahme des Bottenwiekgebietes haben wir Eisaufzeichnungen zum mindesten aus einem Teil des Winters auch aus den ausserhalb dieses Sehkreises gelegenen Gebieten. 


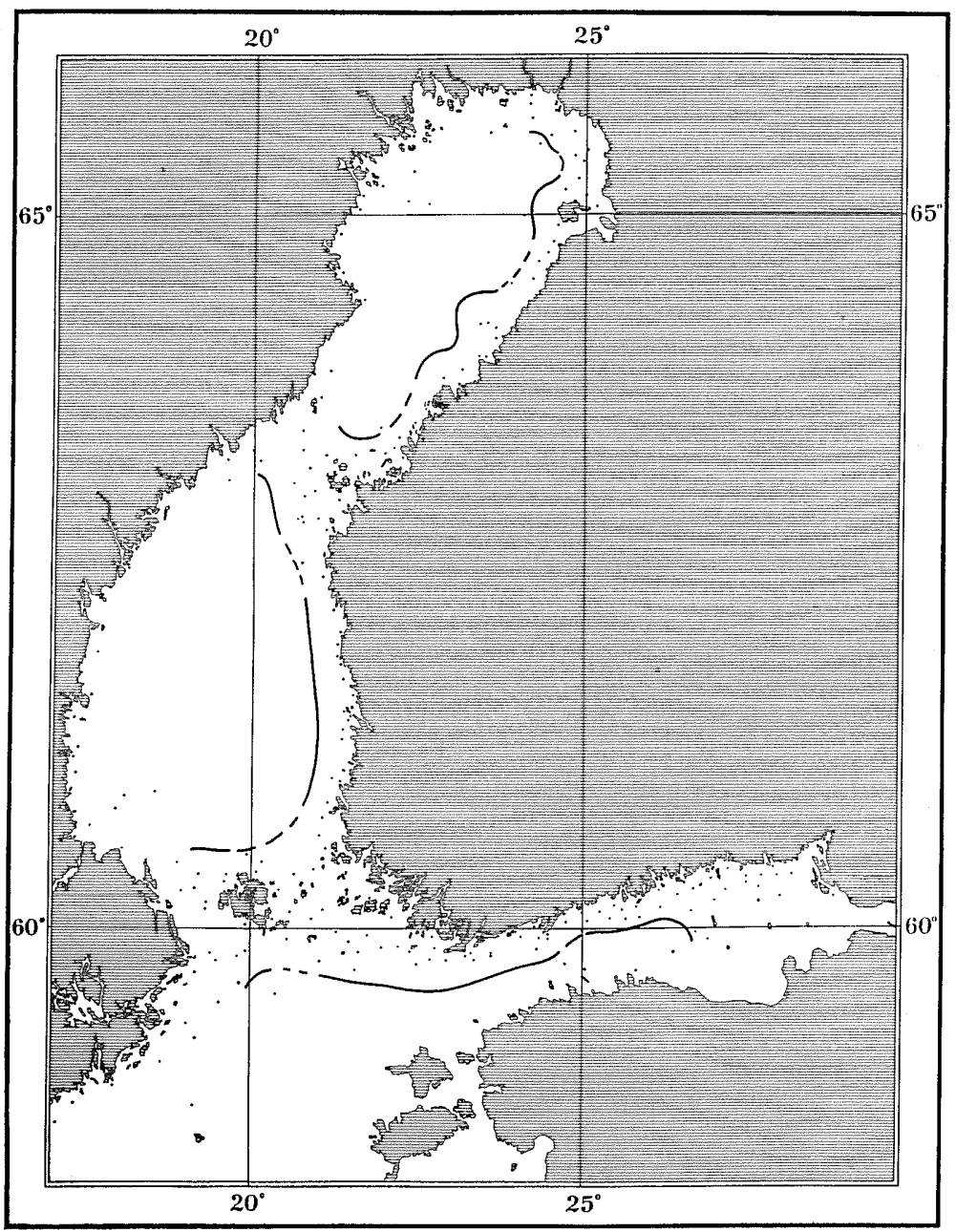

Figur 35. Die der berechneten Sehweite entsprechende, ungefähre Grenzlinie.

122. In bezug auf die Eisverhältnisse der unmittelbar ausserhalb des Gesichtskreises gelegenen Gebiete haben wir folgendes Prinzip befolgt: wenn treibendes, bzw. zusammengefrorenes Eis bei günstigen Winden hinaus ins Meer getrieben wurde und teilweise oder ganz aus dem Gesichtskreis der Beobachtungsorte verschwand und somit auch nicht mehr in den Eislagen vermerkt wurde, wenn es sich aber nach den zu jener Zeit obwaltenden meteorologischen Verhältnissen - z. B. bei Nordwind und starker Kälte in der Mündung des Finnischen Meerbusens oder bei östlichem oder südöstlichem Wind und 
kaltem Wetter im südöstlichen Teil der Bottensee - sicher erhalten hat, so haben wir dieses Eis bei der Bestimmung der Frequenzzahlen des betreffenden Meeresteiles und somit auch bei der Darstellung der entsprechenden Frequenzkurven beachtet. Denn es ist augenscheinlich, dass in den Stadien, die zunächst in Betracht kommen, d. h. in den Stadien des Mittwinters, in denen die grössten Veränderungen der Eisverhältnisse das Gebiet der Frequenzkurven betreffen, wenn das Eis aus dem Sehkreis hinaus ins Meer getrieben wird, dieses Eis der Kontinuität der Frequenzzahlen wegen doch beachtet werden muss. Wie lange dieses ins »Unsichtbare» getriebene Meereseis bei der Bestimmung der Frequenzzahlen zu beachten ist, haben wir von Fall zu Fall, unter Berücksichtigung aller einwirkenden Faktoren, abgeschätzt.

Falls wiederum das aus dem Sehkreis getriebene Meereseis binnen kurzem zurückgekehrt ist und somit sich die ganze Zeit erhalten hat, haben wir dieses Eis vermittels der das Spalten und Abtreiben des Eises sowie die Rückkehr des Eises und das Zugehen der Seerinnen anzeigenden Eislagen in den Frequenzen beachtet.

In solchen Fällen wiederum, in denen das Meereseis ausserhalb des Sehkreises getrieben wurde und die Umstände darauf deuteten, dass es sich dort erhalten würde, wenn es aber trotz günstiger und anhaltender Winde nicht wieder erschien, haben wir dieses Eis in den Frequenzen als verschwunden bezeichnet. Solche Fälle leiten oft die Rückgangszeit des Eises z. B. in der Nördlichen Ostsee ein. Das Eis wird hier bei günstigen Winden ins Meer getrieben und kehrt, nachdem sich der Wind gedreht hat, nicht wieder zurück. Wohl verschwindet es im offenen Meer nicht sogleich, sondern kann sich, von den Winden und Meeresströmungen getrieben, recht lange erhalten, wie aus den Eisaufzeichnungen und Eismeldungen der Dampfer hervorgeht. Aber diese "gemeldeten" Fälle haben wir im allgemeinen in den Frequenzen nicht berücksichtigt, da sie nur zu sehr kleinen Frequenzzahlen und unregelmässigen Frequenzkurven, deren »Glättung» auf Grund des geringen Materials mehr oder weniger willkürlich wäre, führen würden. 


\section{Dritter Abschnitt: Die definitiven G-Stadien.}

\section{Auibau des allgemeinen Normalstadiums oder G-Stadiums aus den Normalstadien der Meeresteile oder S-Stadien.}

123. Nachdem sämtliche S-Stadien des a-, b-, $\mathbf{c}-$, $\mathbf{d}-$ und $\mathbf{e}-\mathrm{Ge}-$ bietes mit allen ihren Elementen, d. h. den Grenzlinien der Bräme des festen Küsteneises, den Frequenzzahlen und -kurven, den Eintrittszeiten und der Wahrscheinlichkeit des jährlichen Eintretens sowie den Eisdickezahlen bestimmt waren, war es unsere nächste Aufgabe vermittels dieser S-Stadien die gleichzeitig und ununterbrochen Finnlands ganze Küste und alle Meeresteile umfassenden allgemeinen Normalstadien oder G-Stadien aufzubauen.

\section{A. Prinzipielle Lösung der Aufgabe.}

124. Ein normales allgemeines oder G-Stadium bezeichnet, wie oben erwähnt wurde, ein Stadium, das die »normale» Eislage zu einem ganz bestimmten Zeitpunkt $t$ an Finnlands ganzer Küste und in sämtlichen Finnland umgebenden Meeren wiedergibt. Eine solche, dem Zeitpunkt t entsprechende "normale» Eislage erhalten wir in der Weise, dass wir jene Stadien der Meeresteile aneinanderfügen, deren mittlere Eintrittszeit t ist.

So einfach wie diese Aufgabe prinzipiell auch erscheint, so bereitet ihre Lösung doch recht grosse Schwierigkeiten.

125. Die erste Schwierigkeit, der wir gleich im Anfang begegnen, geht aus Tabelle 12 hervor. Dort sind alle S-Stadien verzeichnet. Die Stadien eines jeden Meeresteiles sind durch ihre Kennzeichen $a_{1}, a_{2} \ldots ; b_{1}, b_{2} \ldots ; c_{1}, c_{2} \ldots ; d_{1}, d_{2} \ldots ; e_{1}, e_{2} \ldots$ in Kolumnen monatsweise und nach den mittleren Eintrittszeiten geordnet. Aus der Tabelle ersehen wir, dass die Normalstadien der Meeresteile mit Ausnahme der Mittwinterzeit im März kein einziges Mal gleichzeitig am selben Tage in allen Meeresteilen eingetreten sind. Durch blosses Aneinanderfügen der S-Stadien können wir somit - mit teilweiser Ausnahme des März - die G-Stadien nicht 
aufbauen. Dies wird nur dadurch möglich, dass die S-Stadien, die zu einem dem Zeitpunkt $\mathrm{t}$ entsprechendem G-Stadium gehören, aber noch fehlen, erst vermittels der dem Zeitpunkt am nächsten stehenden S-Stadien bestimmt worden sind. So müssten wir, wie aus Tabelle 12 hervorgeht, um z. B. für den Zeitpunkt ca. I. 12. ein GStadium aufbauen zu können, vermittels folgender, schon gegebener S-Stadien ein neues $" Z Z w$ ischenstadium» herleiten: Für das a-Gebiet von $\mathrm{Sa} 8$ und $\mathrm{Sa} 9$, für das $\mathbf{b}$-Gebiet von $\mathrm{Sb} 8$ und $\mathrm{Sb} 9$ und für das d-Gebiet von Sd 5 und Sd 6. Aus dem e-Gebiet und e-Gebiet waren offenbar die Stadien Sc 7 und Se 7 als solche brauchbar. Wie das fragliche G-Stadium, das zehnte, schliesslich bestimmt wurde, geht u. a. aus dem fünften Teil hervor.

126. Die zweite Schwierigkeit, der wir bei der Ausführung unserer Aufgabe begegneten, die wir aber bei der Herleitung der Normalstadien aus den Freitagslagen nicht angetroffen hatten, und die des-

Tabelle 12.

Die S-Stadien $a_{1}, a_{2}, \ldots ; b_{1}, b_{2}, \ldots ; c_{1}, c_{2}, \ldots ; d_{1}, d_{2} \ldots ; e_{1}, e_{2}, \ldots$ nach den mittleren Eintrittszeiten geordnet.

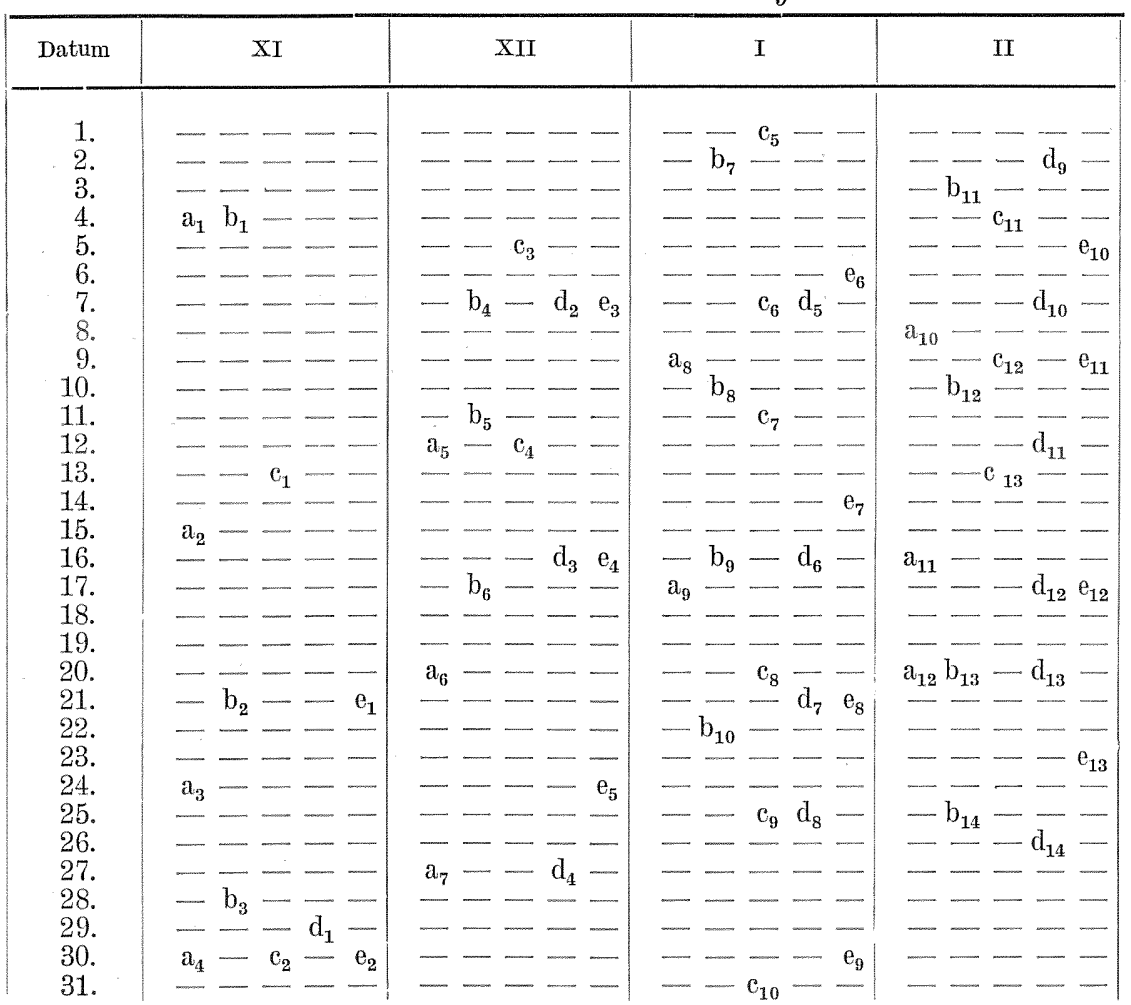


(Fortsetzung der Tabelle 12).

\begin{tabular}{|c|c|c|c|c|c|c|c|c|c|c|c|c|c|}
\hline Datum & \multicolumn{5}{|c|}{ III } & \multicolumn{2}{|r|}{ IV } & \multicolumn{3}{|c|}{$\mathrm{V}$} & \multicolumn{3}{|c|}{ VI } \\
\hline 1. & $a_{13}$ & - & $c_{14}$ & - & $e_{14}$ & -- & $c_{17}-\cdots$ & -- & -- & - & $-\ldots$ & $-\cdots$ & - \\
\hline 2. & $1)$ & - & 14 & - & $e_{15}^{14}$ & $a_{14}-$ & $-d_{18} e_{18}$ & -- & -- & $e_{27}$ & -- & $-\ldots$ & - \\
\hline 3. & 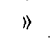 & - & - & - & 10 & 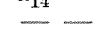 & -18 & $a_{19}-$ & -- & 27 & $a_{25}-$ & $-\ldots$ & - \\
\hline 4. & $\gg$ & $b_{15}$ & - & $\longrightarrow$ & 》) & - & $c_{18}-\cdots$ & $\underline{10}-$ & $c_{23} d_{25}$ & - & 20 & - & - \\
\hline 5. & $\gg$ & 11 & - & $d_{15}$ & ") & -- & $\stackrel{10}{-} d_{19}$ & -- & $-\infty$ & - & - & $-\ldots$ & - \\
\hline 6. & $"$ & ") & - & $\#$ & 》 & $-b_{17}$ & $--e_{19}$ & -- & -1 & - & - & $-\cdots$ & - \\
\hline 7. & 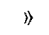 & 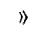 & $c_{15}$ & $》$ & 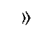 & $a_{15}-$ & $-d_{20}-$ & $-b_{21}$ & $c_{24}$ & - & - & -- & - \\
\hline 8. & 》 & 》) & 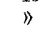 & » & 17 & - & $c_{19}-$ & -2 & $-d_{25}$ & - & -- & -- & - \\
\hline 9. & ) & ") & 1) & $»$ & ") & - & $-\mathrm{e}_{20}$ & $a_{20}-$ & -1 & - & -- & $-\ldots$ & - \\
\hline 10. & 1) & 1) & 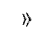 & " & 1) & $-b_{18}$ & --- & - & -- & - & -- & $-\cdots$ & - \\
\hline 11. & i) & $\gg$ & 》) & $"$ & $\gg$ & -10 & $c_{20} d_{21}-$ & - & - & - & -- & - & - \\
\hline 12. & 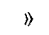 & $\gg$ & ) & ") & i) & $a_{16}-$ & $-\stackrel{-}{-} e_{21}$ & -- & -- & $e_{28}$ & $a_{26}-$ & $-\ldots$ & - \\
\hline 13. & 》) & 》) & 》) & 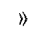 & 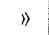 & - & --- & $a_{21} b_{22}$ & $-\ldots$ & 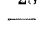 & -20 & -- & - \\
\hline 14. & 1) & $\gg$ & 》) & $\theta$ & $\mathrm{e}_{15}$ & $-b_{19}$ & $-d_{22}-$ & -1 & -- & - & - & - & - \\
\hline 15. & 》) & $\gg$ & $\gg$ & $d_{15}$ & $\mathrm{e}_{16}$ & -1 & $-\ldots$ & -- & $c_{25}-$ & - & $-\cdots$ & -- & - \\
\hline 16. & 1) & $\#$ & 1) & - & - & -- & $--\mathrm{e}_{22}$ & -- & -- & - & -- & $-\cdots$ & - \\
\hline 17. & 》) & $B$ & 1) & - & - & -- & $c_{21}--$ & $a_{22} b_{233}$ & $-\ldots$ & - & -- & $-\cdots$ & - \\
\hline 18. & 1) & $\#$ & $》$ & - & - & -- & $-d_{23}-$ & -- & -- & - & -- & $-\ldots$ & - \\
\hline 19. & 》) & $\#$ & $c_{15}$ & - & - & -- & $--e_{23}$ & -- & -- & - & -- & $-\cdots$ & - \\
\hline 20. & $"$ & $" 1$ & - & - & - & $a_{17}-$ & $c_{22}-\cdots$ & $-\cdots$ & $-\cdots$ & - & $-\longrightarrow$ & $-\cdots$ & - \\
\hline 21. & $》$ & $b_{15}$ & - & $\overline{7}$ & - & -- & $--e_{24}$ & $a_{23}-$ & -- & - & -- & $-\cdots$ & - \\
\hline 22. & a" & - & $c_{16}$ & $d_{16}$ & - & $-\cdots$ & $-\bar{d}=$ & - & -- & - & -- & --- & - \\
\hline $\begin{array}{l}23 . \\
24 .\end{array}$ & $\mathrm{a}_{13}$ & - & - & & $e_{17}$ & -- & $-\mathrm{d}_{24}-$ & -- & - & - & $-\cdots$ & $-\cdots$ & - \\
\hline 25. & - & - & - & - & - & $\overline{a_{18}}=$ & $- \pm e_{25}$ & $\overline{-b_{24}}$ & $c_{26}=$ & - & \pm & -5 & - \\
\hline 26. & - & - & - & $d_{17}$ & - & $\stackrel{-18}{-} b_{20}$ & -- & $a_{24} \stackrel{24}{-}$ & -- & - & - & $-\ldots$ & - \\
\hline 27. & - & - & - & $\stackrel{11}{-}$ & - & -20 & $--\cdots$ & $-\ldots$ & - & - & - & $-\cdots$ & - \\
\hline 28. & - & $b_{16}$ & - & - & - & $-\cdots$ & $--e_{26}$ & -- & -- & - & $-\cdots$ & $-\cdots$ & - \\
\hline 29. & - & - & - & $\longrightarrow$ & - & $-\cdots$ & --- & -- & $-\cdots$ & - & -- & $-\cdots$ & - \\
\hline 30. & - & - & - & - & - & $-\cdots$ & $--\cdots$ & -- & $-\cdots$ & - & - & $-\cdots$ & - \\
\hline 31. & - & - & - & - & -1 & -- & $-\cdots$ & -- & $-\ldots$ & - & -- & $-\cdots$ & - \\
\hline
\end{tabular}

halb bei der Fortsetzung der Untersuchung uns viel Arbeit verursachte, beruhte darauf, dass wir im Hochwinter solche S-Stadien aneinander fügen mussten, deren Wahrscheinlichkeit des jährlichen Eintretens sehr verschieden war. Diese Tatsache geht beispielsweise aus Tabelle 13 hervor.

Tabelle 13.

Die Wahrscheinlichkeit des jährlichen Eintretens der S-Stadien, die bei der Bestimmung der den ungefähren Daten II. 10., II. 15., II. 25. und III. 1. entsprechenden G-Stadien benutzt sind.

\begin{tabular}{|c|c|c|c|c|c|}
\hline $\begin{array}{c}\text { Ungefähre } \\
\text { Daten der noch } \\
\text { unbestimmten } \\
\text { G-Stadien }\end{array}$ & \multicolumn{4}{|c|}{ Die Wahrscheinlichkeit des jährlichen Tintretens der } \\
\cline { 2 - 6 } S-Stadien in den verschiedenen Gebieten
\end{tabular}


Die ungefähren Daten der noch unbestimmten G-Stadien sind in der ersten Kolumne der Tabelle 13 angegeben. In den anderen Kolumnen ist die Wahrscheinlichkeit des jährlichen Eintretens der einem jeden Zeitpunkt entsprechenden S-Stadien der Meeresteile verzeichnet. Aus der Tabelle ersehen wir, dass z. B. das Generalstadium, das im Mittel ungefähr um den 15. Februar zu erwarten ist, aus solchen S-Stadien aufgebaut werden muss, deren Wahrscheinlichkeit in den verschiedenen Meeresteilen die folgende ist: im a-Gebiet 10/10, im b-Gebiet $10 / 10$ und 8/10, im c-Gebiet $7 / 10$, im d-Gebiet $7 / 10$ und $6 / 10$ sowie im e-Gebiet $8 / 10$. Schon oben in Punkt 94 haben wir diese sehr verschiedene Wahrscheinlichkeit der bei der Herleitung der G-Stadien zu benutzenden S-Stadien angedeutet und sie weiter im Zusammenhang mit einer etwas anders gestellten Frage durch die Tabelle $9 \mathrm{zu}$ beleuchten versucht.

12\%. Solche Generalstadien, in denen die Wahrscheinlichkeit des jährlichen Eintretens der ihnen entsprechenden S-Stadien verschieden ist, gibt es unter 30 nur 8, nämlich die Generalstadien G 14, G 15, G 16, G 17, G 18, G 19, G 20 und $G 21$, die in dem mittellangen normalen Winter die Zeit von II. 9. bis IV. 7. umfassen. Aber schliesslich bereitet nur bei dem Aufbau von 5 G-Stadien, nämlich der G-Stadien G 14, G 15, G 16, G 17 und G 21, die verschiedene Wahrscheinlichkeit der S-Stadien grössere Schwierigkeiten, wie unten in Punkten 135-13\% näher gezeigt wird.

\section{B. Ausfïhrung der Aufgabe.}

128. Die Normalstadien der Meeresteile liegen, wie aus der Tabelle 12 hervorgeht, geordnet nach den mittleren Daten ihres Eintretens, sehr zerstreut. Bei der Bestimmung der S-Stadien, aus denen die G-Stadien hergeleitet wurden, bereitete dieser Umstand jedoch im allgemeinen keine besonderen Schwierigkeiten. Hier war die Bedingung erstens, dass die Zeitpunkte des mittleren Eintretens der aneinanderzufügenden S-Stadien - teils der ursprünglichen S-Stadien, teils der aus ihnen hergeleiteten Zwischenstadien - möglichst nahe beieinander lagen, und zweitens, dass sich die Grenzlinien der Bräme des festen Eises und die Frequenzlkurven der betreffenden S-Stadien möglichst natürlich aneinander schlossen. Die letztgenannte Bedingung war in dem Falle, dass alle S-Stadien dieselbe Wahrscheinlichkeit des jährlichen Eintretens hatten, ganz leicht zu erfüllen. Für den Fall jedoch, dass die Wahrscheinlichkeit des Eintretens der S-Stadien verschieden war, wurden, um die Bedingung zu er- 
füllen, anstatt der Frequenzkurven neue, miteinander gleichwertige Kurven »Frequenz mal Wahrscheinlichkeit» gewählt.

129. Die neuen sog. $\mathrm{Z}$ wis chenstadien der Meeresteile wurden bei Bedarf in derselben Weise gezeichnet, wie die Ausgleichung der Grenzlinien des festen Eises und der Frequenzkurven bei den Stadien eines Meeresteiles oben in Punkt 89-93 ausgeführt war. Auf einer Karte wurden sämtliche Linien der beiden aufeinanderfolgenden Stadien des betreffenden Meeresteiles gezeichnet, so dass im allgemeinen doppelte äussere und innere Grenzlinien der Bräme des festen Eises sowie doppelte Frequenzkurven erhalten wurden. Zwischen diesen Kurven wurden dann neue, dem Zwischenstadium entsprechende Kurven interpoliert. Hierbei berücksichtigten wir, dass die Veränderung der Stadien in bezug auf die Zeit unlinear war. Sowohl in der Zeit der Zunahme der Vereisung als beim Rückgang des Eises geht die eine Eislage - dem Gezetz der „Trägheit> folgend - anfangs langsamer in die andere über als die Zeit verläuft. So ist, wie auch u. a. in grossen Zügen die Kurven der Dicke des Eises im Atlas (S. 10, 15, 19, 27 und 28) zeigen, in der Zeit des Zuwachses des Eises der Verlauf der den »Zuwachs» darstellenden Kurve oder des Kurventeils im Verhältnis zur Zeit konkav und in der Zeit des Rückganges des Eises wiederum die dem „Rückgang» entsprechende Kurve oder der Kurventeil konvex. Die Konkavität oder die Konvexität des Verlaufes wurde jedesmal von Fall zu Fall besonders abgeschätzt.

130. Die Generalstadien wurden unter Beachtung des vorher Erwähnten in folgender Weise aufgebaut: zunächst bestimmten wir, welche Stadien der Meeresteile auf Grund ihrer Daten sowie in bezug auf die Ausdehnung des Eises, d.h. in bezug auf die Bräme des festen Eises und die Frequenzkurven, am besten einander entsprechen und somit bei Zusammenfügung ein Generalstadium bilden würden. Dies bereitete im allgemeinen keine Schwierigkeiten. So war es z. B. augenscheinlich, dass jenes G-Stadium, das durchschnittlich gegen Weihnachten zu erwarten war und das später das Kennzeichen G8 erhielt, aus den S-Stadien Sa6, Sa 7; Sb6, Sb7; Sc4, Sc5; Sd4 und Se5 der Meeresteile bestimmt werden musste. Da die mittleren Zeitpunkte des Eintretens dieser Stadien der Meeresteile der Reihe nach die folgenden waren: XII. 20., XII. 27.; XII. 17., I. 2.; XII. 12., I. 1.; XII. 27. und XII. 24., so müsste das durch diese Daten bestimmte und aus ihnen berechnete G-Stadium seine mittlere Eintrittszeit etwa um den XII. 24. bekommen.

Nachdem das Datum eines G-Stadiums auf solche Weise annähernd ermittelt war, wurden dann die diesem Zeitpunkt entsprechenden er- 
forderlichen neuen S-Stadien gezeichnet. In dem oben erwähnten Beispiel waren die S-Stadien Sd 4: XII. 27. und Se 5: XII. 24. in bezug auf ihre Zeit genügend nahe dem ungefähren Zeitpunkte des zu bestimmenden G-Stadiums. Dagegen mussten neue Zwischenstadien für das $\mathbf{a}$-, $\mathbf{b}$ - und $\mathbf{e}$-Gebiet gezeichnet werden. Hierbei wurde am meisten Gewicht auf jenes Stadium des betreffenden Meeresteiles gelegt, welches in bezug auf die Zeit dem ungefähren Zeitpunkt des zu bestimmenden G-Stadiums am nächsten war. Hieraus folgte, dass bei der Berechnung des definitiven mittleren Zeitpunktes des Eintretens des zu bestimmenden G-Stadiums jene S-Stadien, denen bei dem Zeichnen der Bräme des festen Eises und der Frequenzkurven grösseres Gewicht beigelegt wurde, auch in bezug auf den Zeitpunkt ihres Eintretens eine entsprechend grössere Bedeutung erhielten.

Die definitiven mittleren Eintrittszeiten der G-Stadien wurden aus den schliesslich gleichwertigen Eintrittszeiten der bei der Herleitung des G-Stadiums benutzten S-Stadien - sowohl solcher, die unverändert gebraucht wurden, wie z. B. oben die S-Stadien Sd 4 und Se 5, als neuer Zwischenstadien - bestimmt unter Verwendung der Formel

$$
t_{G}=\left(t_{a}+t_{b}+t_{c}+t_{d}+t_{e}\right): 5,
$$

wo $t_{G}$ die berechnete mittlere Eintrittszeit des G-Stadiums ist und $t_{a}, t_{b}, t_{c}, t_{d}$ und $t_{e}$ die Eintrittszeiten der zur Herleitung des G-Stadiums schliesslich benutzten S-Stadien sind. Bei Verwendung der Zwischenstadien wurde ihre mittlere Eintrittszeit aus der Formel

$$
t_{Z}=\frac{g_{n} \cdot t_{S n}+g_{(n+1)} \cdot t_{S}(n+1)}{g_{n}+g_{(n+1)}}
$$

berechnet, wo $t_{S n}$ und $t_{S(n+1)}$ die Eintrittszeiten zweier auf einander folgenden S-Stadien sind und $g_{n}$ und $g_{(n+1)}$ die "Gewichte» derselben bei der Herleitung des G-Stadiums. Die Zahlenwerte $g_{n}$ und $g_{(n+1)}$ waren im allgemeinen 1 oder 2, nur in Ausnahmefällen 3.

131. Im ganzen erhielten wir 30 Generalstadien (Atlas S. 30-44: Die Generalstadien.). Die beim Aufbau dieser G-Stadien benutzten S-Stadien und die definitiven mittleren Zeitpunkte des Eintretens der G-Stadien gehen aus Tabelle 14 hervor. Wir ersehen daraus, dass 7 G-Stadien unmittelbar auf Grund der S-Stadien der Meeresteile bestimmt wurden, nämlich die G-Stadien G1, G4, G11, G18, G21, G27 und G29. Für einen Meeresteil mussten Zwischenstadien für im ganzen $12 \mathrm{G}$-Stadien gezeichnet werden, nämlich für die Stadien G2, G6, G7, G13, G14, G15, G16, G17, G25, G26, G28 und G30. Für zwei Meeresteile waren Zwischenstadien für drei Stadien, 
nämlich für $G 3, G 9$ und $G 22$, für drei Meeresteile dagegen für sieben Stadien, nämlich G 5, G 8, G 10, G 12, G 19, G 23 und G 24, und für vier Meeresteile schliesslich nưr für ein G-Stadium, nämlich G 20, zu zeichnen.

132. Die Konnektierung der demselben Zeitpunkt entsprechenden S-Stadien - sowohl solcher, die in bezug auf die Zeit ohne weiteres benutzt werden konnten, als auch neuer Zwischenstadien — bei dem Aufbau der G-Stadien geschah, wie früher erwähnt wurde, in verschiedener Weise, und zwar je nachdem, ob die Wahrscheinlichkeit des jährlichen Erscheinens aller betreffenden S-Stadien gleich oder verschieden war.

\section{a. Erster Fall: sämtliche zum Aufbau eines G-Stadiums benutzten S-Stadien haben dieselbe Wahrscheinlichkeit des jährlichen Eintretens.}

133. In diese Gruppe gehören jene G-Stadien, die aus den mit der Wahrscheinlichkeit 10/10 eintretenden S-Stadien hergeleitet wurden. Diese G-Stadien umfassen in der Folge der G-Stadien die Herbst-, einige Mittwinter- und sämtliche Frühlingsstadien, im ganzen 22 Stadien, nämlich die Stadien G1-13 und G22-30. (Atlas S. $30-36$ und $40-44$ ).

Bei dem definitiven Aufbau dieser Generalstadien war im allgemeinen eine Ausgleichung der Kurven der aneinandergrenzenden Meeresteile in den »Fugen» erforderlich. Diese Ausgleichung wurde von Norden, soweit es nötig war, der Reihe nach zwischen den Gebieten a und b, b und e, $\mathbf{c}$ und d sowie d und e durchgeführt. Falls eine neue Ausgleichung bei dem Vergleich eines Generalstadiums mit dem nächst vorhergehenden und dem folgenden sich noch als nötig erwies, wurde diese Ausgleichung in der entgegengesetzten Richtung, d.h. von dem e-Gebiet aus, vorgenommen.

Die Ausgleichung beruhte auch hier teils auf denselben Gründen, wie die früher zwischen aufeinanderfolgenden Stadien desselben Meeresteiles durchgeführte Ausgleichung der Kurven, teils wurde sie vielleicht dadurch notwendig, dass z. B. die eventuelle Unregelmässigkeit in den mittleren Abweichungen der Lufttemperatur, die in den Eiswintern 1915-1925 in den verschiedenen Meeresteilen möglicherweise eingetreten war, erst jetzt, wo die demselben Zeitpunkte entsprechenden Stadien der verschiedenen Meeresteile aneinandergefügt werden sollten, auch in den "Mittelbildern» hervortrat. 
Tabelle 14.

Die mittlere Eintrittszeit der G-Stadien und die zum Aufbau der G-Stadien benutzten S-Stadien, wobei den fettgedruckten S-Stadien mehr Gewicht beigelegt wurde.

\begin{tabular}{|c|c|c|c|c|c|}
\hline \multicolumn{2}{|c|}{ G-Stadium } & \multirow{2}{*}{ Aufgebaut aus S-Stadien } & \multicolumn{2}{|c|}{ G-Stadium } & \multirow{2}{*}{ Aufgebaut aus S-Stadien } \\
\hline Nr. & Datum & & Nr. & Datum & \\
\hline & XI. 4. & $a_{1}, b_{1}$. & 16 & II. 24. & $a_{12}, b_{14}, c_{13}, c_{14}, d_{14}, e_{13}$ \\
\hline & XI. 13. & $a_{2}, b_{1}, b_{2}, c_{1}$ & 17 & III. 2. & $a_{13}, b_{15}, c_{14}, d_{14}, d_{15}, e_{14}$ \\
\hline & XI. 24. & $a_{3}, b_{2}, b_{3}, c_{1}, \mathbf{c}_{2}, e_{1}$ & 18 & III. 11. & $\mathrm{a}_{13}, \mathrm{~b}_{15}, \mathrm{e}_{15}, \mathrm{~d}_{15}, \mathrm{e}_{15}$ \\
\hline & XI. 29. & $\mathrm{a}_{4}, \mathrm{~b}_{3}, \mathrm{c}_{2}, \mathrm{~d}_{1}, \mathrm{e}_{2}$ & 19 & III. 22. & $\mathrm{a}_{13}, \mathrm{~b}_{15}, \mathrm{~b}_{16}, \mathrm{c}_{15}, \mathrm{c}_{16}, \mathrm{~d}_{16}, \mathrm{e}_{16}, \mathrm{e}_{17}$ \\
\hline & XII. 2. & $\mathrm{a}_{4}, \mathrm{~b}_{3}, \mathrm{~b}_{4}, \mathrm{c}_{2}, \mathrm{c}_{3}, \mathrm{~d}_{1}, \mathrm{~d}_{2}, \mathrm{e}_{2}$ & 20 & III. 30. & $a_{13}, a_{14}, b_{16}, c_{16}, \mathbf{c}_{17}, d_{17}, d_{18}, e_{17}, \mathbf{e}_{18}$ \\
\hline & XII. 7. & $\mathrm{a}_{4}, \mathbf{a}_{5}, \mathrm{~b}_{4}, \mathrm{c}_{3}, \mathrm{~d}_{2}, \mathrm{e}_{3}$ & 21 & IV. 7. & $\mathrm{a}_{15}, \mathrm{~b}_{17}, \mathrm{c}_{19}, \mathrm{~d}_{20}, \mathrm{e}_{20}$ \\
\hline & XII. 14. & $\mathrm{a}_{5}, \mathrm{~b}_{5}, \mathrm{~b}_{6}, \mathrm{c}_{4}, \mathrm{~d}_{3}, \mathrm{e}_{4}$ & 22 & IV. 14. & $\mathrm{a}_{16}, \mathrm{~b}_{19}, \mathrm{e}_{20}, \mathrm{e}_{21}, \mathrm{~d}_{22}, \mathrm{e}_{21}, \mathrm{e}_{22}$ \\
\hline 8 & XII. 25. & $a_{6}, a_{7}, b_{6}, b_{7}, c_{4}, c_{5}, d_{4}, e_{5}$ & 23 & IV. 20. & $\mathbf{a}_{17}, \mathrm{a}_{18}, \mathrm{~b}_{19}, \mathrm{~b}_{20}, \mathrm{c}_{22}, \mathrm{~d}_{23}, \mathrm{~d}_{24}, \mathrm{e}_{23}$ \\
\hline 9 & 4. & $a_{7}, a_{8}, b_{7}, c_{5}, c_{6}, d_{5}, e_{6}$ & 24 & IV. 27. & $a_{18}, b_{20}, b_{21}, c_{22}, c_{23}, d_{24}, \mathbf{e}_{25}, e_{26}$ \\
\hline 10 & I. 12. & $a_{8}, a_{9}, b_{8}, b_{9}, c_{7}, d_{5}, \mathrm{~d}_{6}, e_{7^{\circ}}$ & 25 & V. 5. & $\mathbf{a}_{19}, \mathrm{a}_{20}, \mathrm{~b}_{21}, \mathrm{c}_{24}, \mathrm{~d}_{25}, \mathrm{e}_{27}$ \\
\hline 11 & I. $\quad 20$. & $\mathrm{a}_{9}, \mathrm{~b}_{10}, \mathrm{c}_{8}, \mathrm{~d}_{7}, \mathrm{e}_{8}$ & 26 & V. 11. & $\mathrm{a}_{20}, \mathrm{~b}_{22}, \mathrm{c}_{24}, \mathrm{c}_{25}, \mathrm{e}_{28}$ \\
\hline 12 & I. 27. & $\mathrm{a}_{9}, \mathrm{a}_{10}, \mathrm{~b}_{10}, \mathrm{~b}_{11}, \mathrm{c}_{9}, \mathrm{~d}_{8}, \mathrm{e}_{8}, \mathrm{e}_{9}$ & 27 & V. 16. & $\mathrm{a}_{22}, \mathrm{~b}_{23}, \mathrm{c}_{25}$ \\
\hline 13 & II. & $\mathrm{a}_{10}, \mathrm{~b}_{11}, \mathrm{c}_{11}, \mathrm{~d}_{9}, \mathrm{e}_{9}, \mathrm{e}_{10}$ & 28 & V. 22. & $a_{23}, b_{23}, b_{24}, c_{26}$ \\
\hline 14 & II. 9. & $\mathrm{a}_{10}, \mathrm{~b}_{12}, \mathrm{c}_{12}, \mathrm{~d}_{10}, \mathrm{~d}_{11}, \mathrm{e}_{11}$ & & V. 26. & $a_{24}$ \\
\hline 15 & II. 16. & $\mathrm{a}_{11}, \mathrm{~b}_{12}, \mathrm{~b}_{13}, \mathrm{c}_{13}, \mathrm{~d}_{12}, \mathrm{e}_{12}$ & 30 & VI.3-12. & $a_{25}, a_{26}$ \\
\hline
\end{tabular}

134. Ein Beispiel dafür, aus wie viel Freitagslagen der Meeresteile ein G-Stadium, diesmal G 12, mit 10/10 Wahrscheinlichkeit des jährlichen Eintretens, vermittels der S-Stadien schliesslich bestimmt wird, gibt die Tabelle 15. Da der Aufbau des Generalstadiums G12 nach der Tabelle 14 vermittels der $\mathrm{S}$-Stadien $\mathrm{S}_{9}^{\mathrm{a}}, \mathrm{S}_{10}^{\mathrm{a}}, \mathrm{S}_{10}^{\mathrm{b}}, \mathrm{S}_{11}^{\mathrm{b}}, \mathrm{S}_{9}^{\mathrm{c}}, \mathrm{S}_{8}^{\mathrm{d}}, \mathrm{S}_{8}^{\mathrm{e}}$, und $\mathrm{S}_{9}^{\mathrm{e}}$ geschehen ist und diese ihrerseits wiederum aus den folgenden Eislagen der Meeresteile hergeleitet sind, wurden zur Herleitung des Generalstadiums G12 im ganzen 100 Eislagen der Meeresteile benutzt.

\section{b. Zweiter Fall: die zum Aufbau eines G-Stadiums benutzten S-Stadien weisen verschiedene Wahrscheinlichkeit des jährlichen Eintre- tens auf.}

135. Der Aufbau der zu dieser Gruppe gehörenden Generalstadien G 14-21 bereitete, wie oben erwähnt wurde, einige prinzipielle Schwierigkeiten. Da die zu konnektierenden S-Stadien auf Grund der verschiedenen Wahrscheinlichkeit des jährlichen Eintretens nicht "gleichwertig» waren, so musste das Zusammenfügen sowohl der ursprünglichen S-Stadien als der hergeleiteten Zwischenstadien 
Tabelle 15.

\begin{tabular}{|c|c|c|c|}
\hline $\mathrm{S}_{9}^{\mathrm{a}}$ & $\mathrm{S}_{10}^{\mathrm{a}}$ & $\mathrm{S}_{10}^{\mathrm{b}}$ & $\mathrm{S}_{11}^{\mathrm{b}}$ \\
\hline $\begin{array}{l}1917 \text { I. } 5 . \\
1918 \text { I. } 25 . \\
1919 \text { II. } 7 . \\
1920 \text { I. 2., I. 9., I. } \\
\text { 23., II } 13 \\
1921 \text { I. } 28 . \\
1922 \text { I. 20., XII. } 15 . \\
1923 \text { II. 2., II. 9. } \\
1924 \text { I. } 11 ., 1.18 . .25 . \\
1925 \text { III. } 20 ., \text { III. } 27 .\end{array}$ & $\begin{array}{l}1918 \text { II. } 8 . \\
1919 \text { II. 14., II. } 21 . \\
1920 \text { I.30.,II.6., II.20 } \\
1921 \text { II. 18., II. } 25 . \text {, } \\
\text { III. 4., III. } 18 . \\
1924 \text { II. } 1 .\end{array}$ & $\begin{array}{l}1919 \text { XII. } 26 . \\
1920 \text { II. } 6 . \\
1921 \text { II. } 25 . \\
1922 \text { I. 6., XII. 22., } \\
\text { XII. } 29 . \\
1924 \text { II. 1. } \\
1925 \text { III. 6., III. } 13 .\end{array}$ & $\begin{array}{l}1917 \text { II. 9, II. } 16 . \\
1918 \text { I. } 18, \text { I. } 25 . \\
1920 \text { I2., I. 9., I. } 16 ., \\
\text { II. 13., II. 20. } \\
1921 \text { II. 11., II. } 18 . \\
\\
1922 \text { II. } 27 .\end{array}$ \\
\hline Eislagen 17 & 11 & 9 & 13 \\
\hline
\end{tabular}

\begin{tabular}{|c|c|c|c|}
\hline $\mathrm{S}_{9}^{\mathrm{c}}$ & $\mathrm{S}_{8}^{\mathrm{d}}$ & $S_{8}^{e}$ & $\mathrm{~S}_{9}^{\mathrm{e}}$ \\
\hline $\begin{array}{l}1915 \text { I. } 28 . \\
1917 \text { I. } 12 . \\
1919 \text { II. } 14 . \\
1920 \text { I. } 2 ., \text { I. } 9 ., \text { I. 16., } \\
\\
\text { I. } 23 . \\
1921 \text { II. } 4 . \\
1922 \text { I. } 20 . \\
1923 \text { II. } 16 . \\
1924 \text { I. } 11 ., \text { I. } 18 . \\
1925 \text { III. } 13 . \\
\end{array}$ & $\begin{array}{l}1915 \text { I. } 29 ., \text { XII. } 24 . \\
1919 \text { II. } 21 . \\
1920 \text { I. } 23 . \\
1921 \text { II. } 11 . \\
1922 \text { I. } 20 . \\
1924 \text { I. } 18 . \\
1925 \text { III. } 13 . \text { III. } 20 .\end{array}$ & $\begin{array}{l}1919 \text { II. } 14 ., \text { II. } 21 ., \\
\text { XII } 26 \\
1920 \text { I. } 23 . \\
1921 \text { I. } 28 . \\
1923 \text { I. } 19 . \\
1924 \text { I. } 18 . \\
1925 \text { III. 13.,III. 20., } \\
\\
\text { III. } 27 .\end{array}$ & $\begin{array}{l}1915 \text { I. } 29 ., \text { XII. } 17 . \\
1916 \text { I. } 28 ., \text { II. } 18 . \\
1917 \text { I.12.,I.19., I.26., } \\
\text { II. 2., II. 16. } \\
1918 \text { I.18.,I.25.,II.1., } \\
\text { II. 8., II. 15. } \\
1920 \text { I. 2,, II. } 13 . \\
1921 \text { II. 18. } \\
1924 \text { I. } 25 .\end{array}$ \\
\hline Eislagen 13 & 9 & 10 & 18 \\
\hline
\end{tabular}

in einer anderen Weise geschehen als oben im Fall a erwähnt wurde. Die Zusammenfügungsschwierigkeiten betrafen jedoch eigentlich nicht die Bräme des festen Eises der S-Stadien. Dies beruhte darauf, dass sie in diesen Stadien entweder im Begriff war ihre weiteste Ausdehnung zu erlangen oder sie schon erreicht hatte oder auch eben ihr Rückgang eingesetzt hatte. Dagegen bezogen sich die Schwierigkeiten auf die $\triangle$ - und $\square$-Zahlen sowie auf die Frequenzkurven.

Da in bezug auf die $\triangle$-und $\square$-Zahlen bzw. die Frequenzkurven der S-Stadien bei der Zusammenfügung grosse Ungleichheiten vorkamen, konnten sie prinzipiell nicht nur durch eine einfache Ausgleichung beseitigt werden. Der Aufbau der G-Stadien sollte eigentlich in der Weise geschehen, dass ausschliesslich auf Grund derjenigen Winter, die die Generalstadien G 14-21 herbeiführten, in allen Meeresteilen für den diesen Generalstadien entsprechenden Teil des Winters neue S-Stadien bestimmt werden. Aus diesen müssten dann ebenso wie oben in Fall a beschrieben ist, die Generalstadien aufgebaut werden. Da aber ein solches Verfahren kaum besondere Vorteile in bezug auf die Genauigkeit der Bestimmung der Lage der Kurven noch ein richtigeres Bild der durchschnittlichen Eisverhältnisse als 
auf einem "Umweg», wie sich weiter unten zeigen wird, gegeben hätte, haben wir die Untersuchung an dieser Stelle nicht umzuarbeiten begonnen, sondern versucht, dem „Umweg» folgend, vermittels der schon bestimmten S-Stadien auch die betreffenden G-Stadien herzuleiten.

136. Wie schon erwähnt wurde, betrafen die Zusammenfügungsschwierigkeiten vor allem die $\triangle$ - und $\square$-Zahlen sowie die Frequenzkurven. Was die letztgenannten anbetrifft, beschränkten sie sich, wie später aus dem fünften Teil näher hervorgeht, praktisch gesehen auf das Gebiet der Bottensee und des Finnischen Meerbusens. Um nun diese Schwierigkeiten zu vermeiden verfuhren wir auf folgende Weise:

In dem Falle z. B., wo die einem und demselben Zeitpunkt entsprechenden, aneinanderzufügenden Stadien im a-Gebiet die Wahrscheinlichkeit des jährlichen Eintretens 9/10, im b-Gebiet 8/10, im c-Gebiet 7/10, im d-Gebiet $6 / 10$ und im -Gebiet $7 / 10$ hatten, entspricht z. B. die Frequenzzahl 0.5 tatsächlich in jedem Gebiet der wirklichen Frequenz: $0.5 \times$ Wahrscheinlichkeit des S-Stadiums.

In dem erwähnten Falle ist somit der wirkliche Wert der Frequenzzahl 0.5 in den verschiedenen Meeresteilen:

\begin{tabular}{|c|c|c|c|c|c|}
\hline Gebiet & a & b & c & d & e \\
\hline wirkl. Freq. & 0.45 & 0.40 & 0.35 & 0.30 & 0.35 \\
\hline
\end{tabular}

In derselben Weise ist der wirkliche Wert der Frequenzzahl 1.0, falls die Wahrscheinlichkeit der S-Stadien die oben erwähnte ist, der Reihe nach in den verschiedenen Meeresteilen: 0.90, 0.80, 0.70, 0.60 und 0.70 .

Nun wird die Wahrscheinlichkeit des jährlichen Eintretens eines G-Stadiums durch jenen Meeresteil bestimmt, in dem die S-Stadien im allgemeinen die geringste Wahrscheinlichkeit des jährlichen Eintretens haben. Dieser Meeresteil ist derjenige, der die günstigsten Eisverhältnisse hat, und somit, wie wir aus Tabelle 10 ersehen haben, das d-Gebiet.

Die Wahrscheinlichkeit des jährlichen Eintretens der d-Stadien, die zum Aufbau der G-Stadien 14-21 benutzt wurden, wechselte zwischen $9 / 10$ und $4-5 / 10$. Innerhalb dieser Grenzen müsste somit auch die Wahrscheinlichkeit der betreffenden G-Stadien liegen, und die Frequenzzahlen 0.1, 0.2, 0.5, 0.8 und 1.0, bzw. die entsprechenden Frequenzkurven müssten somit in den Generalstadien G 14-21, unter Berücksichtigung der Wahrscheinlichkeit des jährlichen Eintretens, den Werten der Tabelle 16 entsprechen. 
Tabelle 16.

Die wirklichen Werte der Frequenzzahlen 0.10 .20 .50 .8 und 1.0 und der entsprechenden Frequenzkurven in den Generalstadien 14-21. (Frequenzzahl $\times$ Wahrscheinlichkeit des jährlichen Eintretens des entsprechenden G-Stadiums).

\begin{tabular}{|c|c|c|c|c|c|}
\hline $\begin{array}{c}\text { Freguenzzahlen } \\
\text { entsprechen in }\end{array}$ & 0.10 & 0.20 & 0.50 & 0.80 & 1.0 \\
\hline G 14 & 0.08 & 0.17 & 0.42 & 0.62 & 0.85 \\
G 15 & 0.06 & 0.13 & 0.32 & 0.52 & 0.65 \\
G 16 & 0.04 & 0.09 & 0.22 & 0.36 & 0.45 \\
G 17 & 0.04 & 0.09 & 0.22 & 0.36 & 0.45 \\
G 18 & 0.04 & 0.09 & 0.22 & 0.36 & 0.45 \\
G 19 & 0.04 & 0.09 & 0.22 & 0.36 & 0.45 \\
G 20 & 0.06 & 0.13 & 0.32 & 0.52 & 0.65 \\
G 21 & 0.09 & 0.18 & 0.45 & 0.72 & 0.90 \\
\hline
\end{tabular}

13\%. Der »Umweg», auf dem wir die bei der Herleitung der Generalstadien G14-21 sich ergebenden Schwierigkeiten vermieden, bestand darin, dass auf jeder Karte der einem bestimmten G-Stadium angehörenden S-Stadien vermittels der Frequenzkurven und unter Berücksichtigung der Kurvengradienten die den Zahlenwerten der obigen Tabelle entsprechenden und dadurch gleichwertigen neuen Frequenzkurven gezeichnet wurden. So zeichneten wir z. B. in den S-Stadien, aus denen das G-Stadium 15 aufgebaut wurde, unter Berücksichtigung der Formel: Frequenz $\times$ Wahrscheinlichkeit des jährlichen Eintretens des S-Stadiums, die neuen Frequenzkurven 0.06, $0.13,0.32,0.52$ und 0.65 . Dies geschah ganz einfach in der Weise, dass zuerst den Frequenzkurven einer jeden S-Karte vermittels der Formel: Frequenz $\times$ Wahrscheinlichkeit des S-Stadiums ihr wirklicher Wert gegeben wurde. Danach wurden auf Grund dieser Kurven die neuen gezeichnet. Nachdem diese letztgenannten Kurven auf sämtlichen Karten der Meeresteile gezeichnet waren, wurden die S-Stadien in derselben Weise konnektiert wie oben in Fall a, d. h. in derselben Weise, wie in dem Falle, wo alle S-Stadien dieselbe Wahrscheinlichkeit hatten.

So erhielten wir beispielsweise das Generalstadium 15, in dem der wirkliche Wert der Frequenzkurven der Reihe nach 0.06, 0.13, $0.32,0.52$ und 0.65 war. Da nun dieses Generalstadium dieselbe Wahrscheinlichkeit des jährlichen Eintretens wie das entsprechende d-Stadium hat, können wir den relativen Wert der Frequenzkurven nach der Formel: relative Frequenz $=$ wirkliche Frequenz $\times$ Wahrscheinlichkeit des jährlichen Eintretens des G-Stadiums, wieder einführen und den Kurven die Zahlenwerte 0.1, 0.2, 0.5,0.8 und 1.0 geben. Somit erhalten wir schliesslich das Generalstadium 15, 


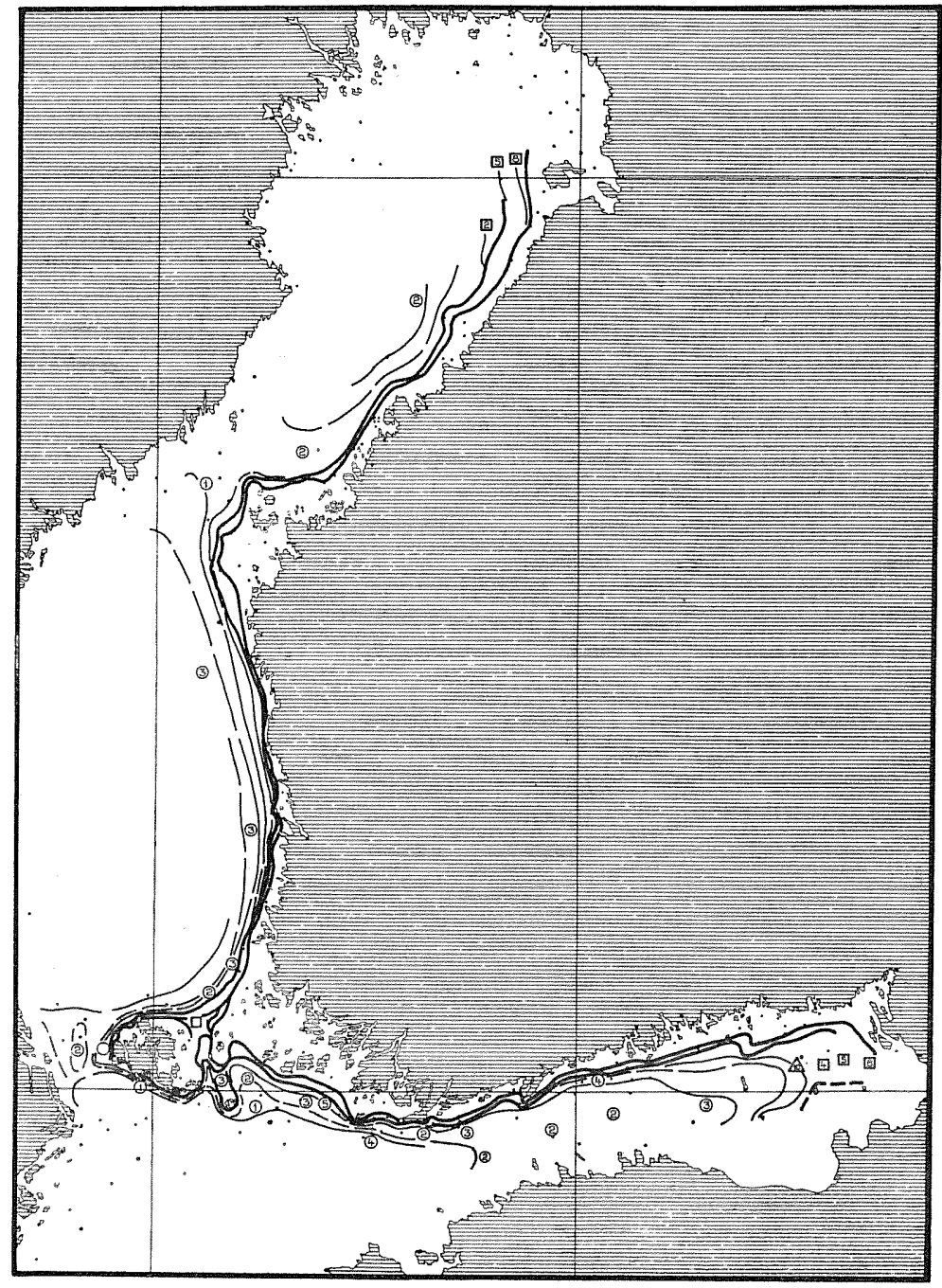

Fig. 36. Das 11. Generalstadium, jedoch ohne die Eisdickezahlen, die Eintrittszeiten und die Wahrscheinlichkeit des jährlichen Eintretens.

dessen Wahrscheinlichkeit des jährlichen Eintretens 7-6/10 ist und in dem die Werte der Frequenzkurven dieselben wie in den Normalstadien d. $\mathrm{h}: 0.1,0.2,0.5,0.8$ und 1.0 sind.

Die praktische Ausführung des oben beschriebenen Verfahrens war leichter als die obige Darstellung vermuten liess. Grössere Veränderungen in den Frequenzzahlen und -kurven der S-Stadien 
brauchte man nur bei der Bestimmung der Generalstadien 14-17 und 21 vorzunehmen. Beim Aufbau der Generalstadien 18 und 19 beschränkten sich die Veränderungen in den S-Stadien auf das a-Gebiet und auch dort betrafen sie nur die $\triangle$-und $\square$-Zahlen. Das Generalstadium 20 konnte beinahe ohne jegliche Veränderungen unmittelbar aus den S-Stadien aufgebaut werden, wie später im sechsten Teil dargelegt wird.

In Fig. 36 haben wir schliesslich ein definitives, in der Reihenfolge das 11. Generalstadium, jedoch bis auf weiteres ohne die Eisdickezahlen, die Eintrittszeiten und die Wahrscheinlichkeit des jährlichen Eintretens.

\section{Die Dicke des Eises der G-Stadien.}

138. Die Eisdickezahlen der G-Stadien erhielten wir unmittelbar aus den Kurven der Dicke des Eises der Beobachtungsorte (Atlas S. 10, 15, 19, 27 und 28), indem wir die Eisdicke, die der mittleren Eintrittszeit des betreffenden G-Stadiums entsprach, aus den Kurven bestimmten. Näheres später im siebenten Teil.

\section{Extreme Eintrittsdaten der G-Stadien.}

139. Die extremen Daten der G-Stadien sind graphisch aus den Grenzwerten der Daten der dem betreffenden G-Stadium entsprechenden S-Stadien bestimmt worden. Da im vierten Abschnitt dieses Teils diese Fragen näher behandelt werden, verweisen wir hier nur darauf.

\section{Der Aufbau der mittwinterlichen G-Stadien.}

140. Beim Aufbau der mittwinterlichen G-Stadien, d.h. bei der Herleitung der Kulminationsstadien des Winters wurden in dieselben auch solche Eislagen aufgenommen, die eher einem Stadium oder einigen Stadien entsprechen, deren Wahrscheinlichkeit des jährlichen Eintretens geringer als $4-5 / 10$ ist. Solche Eislagen waren u. a. einige Eislagen der Winter 1923 und 1924, wie z. B. die von 1923 III. 16., 1924 II. 29. und III. 14. Sie vertreten im Verlauf des Winters augenscheinlich solche Stadien, in denen die Vereisung des Ostseegebietes 
sich bedeutend weiter erstreckt und die Eisverhältnisse dadurch entsprechend schwerer sind als in den bisher bestimmten Stadien der grössten Ausdehnung des Eises. Da wir sehr mangelhafte Kenntnisse über die grösste Vereisung des Aussenmeeres in den Kriegsjahren besitzen, war es uns nicht möglich nur auf Grund der genannten und einiger anderer Eislagen solche Normalstadien zu bestimmen. Sämtliche "schwerste» Eislagen wurden darum zu den mittwinterlichen Generalstadien 17-19 gerechnet. Diese wenigen Eislagen mit sehr grosser Vereisung haben jedoch nicht erwähnenswert auf den allg e m einen Aufbau der betreffenden Generalstadien 17, 18 und 19 eingewirkt, da die Anzahl der Eislagen, die in die Generalstadien 17, 18 und 19 kamen, besonders aus dem d- und e-Gebiete, die sich unmittelbar an die Ostsee anschliessen, verhältnismässig gross ist.

Tabelle 17.

Die Generalstadien $G 17, G 18$ und $G 19$ wurden aus d-und e-Stadien aufgebaut, die ihrerseits durch folgende Anzahl Eislagen bestimmt waren.

\begin{tabular}{|c|c|r|}
\hline & $\mathrm{d}$ & $\mathrm{e}$ \\
\hline $\mathrm{G} 17$ & 21 & 6 \\
G 18 & 14 & 17 \\
G 19 & 13 & 13 \\
\hline
\end{tabular}

141. Falls der bei der Herleitung der Normalstadien berücksichtigte Zeitabschnitt auch noch die Eiswinter 1926 und 1929 umfasst hätte, besässen wir eine hinreichende Anzahl Eislagen mit so grosser Vereisung, dass wir solche neuen Normalstadien hätten bestimmen können, deren Wahrscheinlichkeit des jährlichen Eintretens geringer als $4-5 / 10$ war. M. a. W. falls die Folge der Freitagslagen genügend lang gewesen wäre, hätten wir aus den Kulminationsstadien des Winters, durch "Ausbreiten» derselben, neue "schwerere» mittwinterliche Normalstadien aufbauen können. Da diese neuen Normalstadien sowohl in der Zeit des Zuwachses des Eises als in der Zeit seines Rückganges eine grössere Ausdehnung der Vereisung und somit schwerere Eisverhältnisse als die bereits hergeleiteten Kulminationsstadien zu vertreten hätten, so würden sie auch eine geringere Wahrscheinlichkeit des jährlichen Eintretens als die letzterwähnten haben. Zuerst hätten wir natürlich diejenigen Normalstadien hergeleitet, deren Wahrscheinlichkeit des jährlichen Eintretens 4/10, dann $3 / 10,2 / 10,1 / 10$ usw. wäre. 
142. Auf Grund der von uns im Winter 1929 ausgeführten, allerdings nur orientierenden Untersuchung (32), zeigte sich aber schon, dass ein etwas länger dauernder Eisrand, der sich in der Nördlichen Ostsee bis zur Gegend der Parallele Gotska Sandön erstreckt, noch nicht in einer Eislage, die einem Stadium mit der Wahrscheinlichkeit 2/10 entspricht, eintritt, sondern erst in solchen Eislagen, die einem Stadium mit der Wahrscheinlichkeit 1/10 entsprechen. In diesen Eislagen kann natürlich dünnes Blaueis während kurzer Zeit auch weiter draussen das Meer bedecken, aber eine Vereisung des mittleren Teiles der Ostsee wäre dabei jedenfalls noch nicht $\mathrm{zu}$ erwarten. In der südlichen Ostsee erstreckte sich das Eis im erstgenannten Stadium etwas östlich von Bornholm, im letzterwähnten weiter nach $\mathrm{E}$, möglicherweise etwa bis zur Gegend des Meridians von Öland. - Wie erwähnt war jedoch diese Untersuchung nur orientierender Art. Erst auf Grund der vorliegenden Arbeit ist es möglich vermittels einer Analyse des allgemeinen Verlaufes der Eiswinter eine zuverlässige und richtige Auffassung über die Anzahl der langen und entsprechend schweren Winter in der Nördlichen Ostsee zu erhalten. Hier scheint nämlich die „Grenzlinie» der mit einer jährlichen Wahrscheinlichkeit von 10/100 eintretenden Winter eine zu nördliche Lage im Verhältnis zu der entsprechenden »Grenzlinie» der südlichen Teile der Ostsee einzunehmen. Der Grund kann teils der sein, dass die schwereren Eiswinter in der Südlichen Ostsee in der Zeit einer solchen allgemeinen Verteilung des Luftdruckes eingetreten sind, dass dort die SE und $\mathrm{E}$ Winde vorherrschend waren (55), während weiter nördlich zu gleicher Zeit der Wind mehr von NE kam. Unter solchen Windverhältnissen wurde das Eis in der Nördlichen Ostsee nach draussen getrieben, und der Zuwachs des mit Eis bedeckten Gebietes und die Beständigkeit des Eisrandes wurden geringer. Der beständigere Eisrand und somit auch die Frequenzkurve 10/100 wird entsprechend nördlicher liegen. Das betreffende Gebiet, d. h. die eigentliche Nördliche Ostsee liegt ausserdem gänzlich ausserhalb des Beobachtungsgebietes der Meeresinseln und der Küstenstationen, so dass direkte Eismeldungen vor dem Beginn des Winterverkehrs fehlen und man nur indirekte Schlussfolgerungen über dortige Verhältnisse ziehen kann. Aus der Zeit des Beginnes des Winterverkehrs besitzen wir dagegen sehr wertvolle Eisbeobachtungen auch aus den mittleren Teilen der Ostsee während einiger schwerer und eisreicher Winter. Regelmässige Eisaufzeichnungen wurden seit der Jahrhundertwende auf den Winterliniendampfern zwischen Finnland-Schweden und Finnland-Dänemark gemacht. Nur aus der Zeit des Weltkrieges fehlen solche Aufzeich- 
nungen. Auf Grund dieser Aufzeichnungen und vermittels der Analyse des allgemeinen Verlaufes des Eiswinters können wir jedoch schliesslich eine richtige Auffassung auch von den Eisverhältnissen dieses Teiles der Ostsee erhalten.

143. Nach unserer orientierenden Untersuchung sowie den Resultaten von SPEERSCHNEIDER war die Ostsee in solchen Eislagen, die den mit der jährlichen Wahrscheinlichkeit 7-5/100 eintretenden Stadien entsprechen, zeitweise vollständig zum mindesten mit dünnem Meereseis bedeckt. Das Eis ist aber in diesen Eislagen in den mittleren Teilen der Ostsee loses, treibendes Eis, das leicht zerbricht. Ausserdem kommen noch Breieis, Tellereis und Eisstücke vor, aber zeitweise kann das Eis auch ganze, ausserordentlich grosse Eisfelder bilden. Eine natürliche Folge der Beweglichkeit des Eises ist einerseits die Tatsache, dass man zusammengetriebenes, stellenweise sogar gepacktes Eis antreffen kann, anderseits, dass Eisspalten, offene Seerinnen und weites offenes Wasser vorkommen. Nur in windstillen, strengen Kälteperioden werden auch die mittleren Teile der Ostsee in diesen Eislagen praktisch gesehen ganz mit Eis bedeckt. Dieses Eis ist jedoch im allgemeinen, wie Erfahrungen aus den Jahren 1881, 1888 und 1893 erwiesen haben, dünn und leicht zerbrechlich, so dass ein starkgebauter Dampfer durchkommen kann.

Was dann solche Eislagen anbetrifft, die Stadien angehören, deren Wahrscheinlichkeit des jährlichen Eintretens geringer als 5/100 wäre, d.h. Stadien, die nur viermal, dreimal, zweimal usw. in hundert Jahren zu »erwarten» sind, so fehlen uns in bezug auf die Eisverhältnisse der mittleren Teile der Ostsee bis auf weiteres alle Nachrichten. Die Aufzeichnungen aus Eiswintern, die als solche betrachtet werden können, beziehen sich auf die Eisverhältnisse an den Küsten und an den Inseln Bornholm, Öland und Gotland, und solche Aufzeichnungen, z.B. dass man das Eis entlang aus Estland nach Schweden, aus Estland und aus Livland nach Dänemark usw. gefahren sei, besagen wohl eine Fahrt an der Küste entlang und keineswegs den kürzesten Weg quer über das Meer. Im Aussenmeer bedeutet eine entsprechende Erschwerung der Eisverhältnisse dickeres Eis und verminderte Beweglichkeit des Eises, die sich in den strengsten Wintern vielleicht nur auf eine Spaltung des Meereseises im mittleren Teile der Ostsee beschränkt. Zu solchen allerstrengsten Eiswintern gehört der Winter 1709, einer der schwersten in ganz Europa.

144. Die normalen Kulminationsstadien des Mittwinters können wir uns so in mehrere neue Stadien eingeteilt denken. Von diesen entsprechen die auf der Herbstseite liegenden neuen Stadien solchen Eislagen, in welchen die Vereisung in den mittleren Teilen der Ostsee 
immer grösser wird. Anderenseits entsprechen die neuen Stadien, die auf der Frühlingsseite des Kulminationspunktes des Mittwinters liegen, wiederum solchen Eislagen, in welchen sich das Eis im Rückgang von den erstgenannten Eislagen befindet. Mit anderen Worten: die schon hergeleiteten Normalstadien des Mittwinters können, falls wir ein genügend grosses Eislagematerial hätten, mit der Zeit so vervollständigt und weiter ausgebaut werden, dass sie auch die schwersten Vereisungen der Ostsee bzw. die entsprechenden Enteisungen umfassen und somit eine neue Gruppe Normalstadien in der Mittwinterzeit des Eiswinters bilden. Diese Vervollständigung können wir unmittelbar an die schon hergeleiteten Normalbilder anschliessen, da es jetzt - bei cler Herleitung der neuen Stadien — nur auf die Bestimmung der $\square$ - und $\triangle$-Zahlen und der entsprechenden Frequenzkurven auf dem hohen Meer ankommt. Hierbei müssten natürlich auch - vor allem in den schon bestimmten Kulminationsstadien - die wirklichen Werte der Frequenzkurven aufs neue bestimmt und die Kurven 0.09, 0.08 .. 0.01 usw. gezeichnet werden. Ausserdem würde natürlich auch eine neue Bestimmung der Eintrittszeiten dieser Stadien vonnöten sein, d. h. dass sie den Daten der Eislagen der schweren und sehr schweren Eiswinter entsprechen, sowie der Zahlen der Dicke des Eises, falls es genügendes Beobachtungsmaterial dazu gäbe.

145. Oben wurde die Frage der Verteilung der schon hergeleiteten Kulminationsstadien des Eiswinters auts neue besprochen. Von diesen neuen Stadien würden somit die auf die Seite des zunehmenden Eises fallenden solchen immer seltener eintretenden Eislagen entsprechen, in welchen die Vereisung auch in den mittleren Teilen der Ostsee umfassender, das Eis dicker und die Eisverhältnisse auch in anderer Hinsicht schwerer geworden sind. Die auf die Frühlingsseite fallenden neuen Stadien würden dagegen solchen Eislagen entsprechen, die bei der Enteisung der oben genannten sehr schweren Eislagen eintreten.

Die Zeit des Mittwinters in unseren Normalbildern können wir uns jedoch in ganz entgegengesetzter Richtung entwickelt denken, nämlich so, dass in den Wintern immer weniger Normalstadien des Mittwinters, bzw. diesen entsprechende Eislagen eintreten.

Die Mittwinterzeit kann sich nämlich auch so entwickeln, dass einigen mittwinterlichen Normalstadien entsprechende Eislagen gar nicht eintreten. So kann der Mittwinter anstatt einer weiteren Erschwerung eine weitere Erleichterung aufweisen, wie in den Wintern 1910, 1925 und 1930. Die weiteste Vereisung entsprach in diesen Wintern nicht - sicher nicht in den Wintern 1925 und 1930 und wahrscheinlich auch nicht im Winter 1910 - dem Normal- 
stadium d9 des d-Gebietes. Dieses d-Stadium müsste nach dem von uns anfänglich benutzten Material das letzte jährlich eintretende herbstliche Stadium des Schärenmeeres sein, d. h. das letzte herbstliche Stadium, dessen Wahrscheinlichkeit des jährlichen Eintretens 10/10 ist. In bezug auf den Winter 1910 haben wir nämlich keine Meldung oder Aufzeichnung gefunden, die besagt, dass eine Eisbrücke von festem Eis von der Küste über den nördlichen Teil des Schärenmeeres sich nach Åland erstreckte. Die nach den vorhandenen Eisbeobachtungen gezeichneten, die Eisverhältnisse 1910 ca. I. 28. und ca. II. 11. darstellenden Karten (Fig. 37a und b) zeigen jedoch, dass es neugebildetes, dünnes Eis bzw. Treibeis über Delet gab. Der Umstand, dass unter diesen Verhältnissen das Stadium d8 (oder d7) nicht das letzte jährlich eintretende normale d-Stadium ist, beruht darauf, dass neben dem Verlauf des Winters 1910 der des Winters 1925 im Verhältnis zu den von uns behandelten übrigen Wintern 1915-1924 so ungewöhnlich war, dass seinen Eislagen nicht dasselbe Gewicht bei der Bestimmung der Wahrscheinlichkeitszahl der Stadien beigelegt werden konnte wie den Eislagen anderer Winter. Die Ausnahmestellung des Winters 1925 bestätigte ein Vergleich mit den Wintern 1900-1914. Doch wurde dieser Winter in bezug auf seine geringe Vereisung vom Winter 1930 übertroffen, wie er in den letzten 150 Jahren nicht vorgekommen zu sein scheint. Die "schwerste» Eislage des Winters 1930 entspricht somit wegen ihrer geringen Vereisung einem Mittwinter, dessen Wahrscheinlichkeit des jährlichen Eintretens

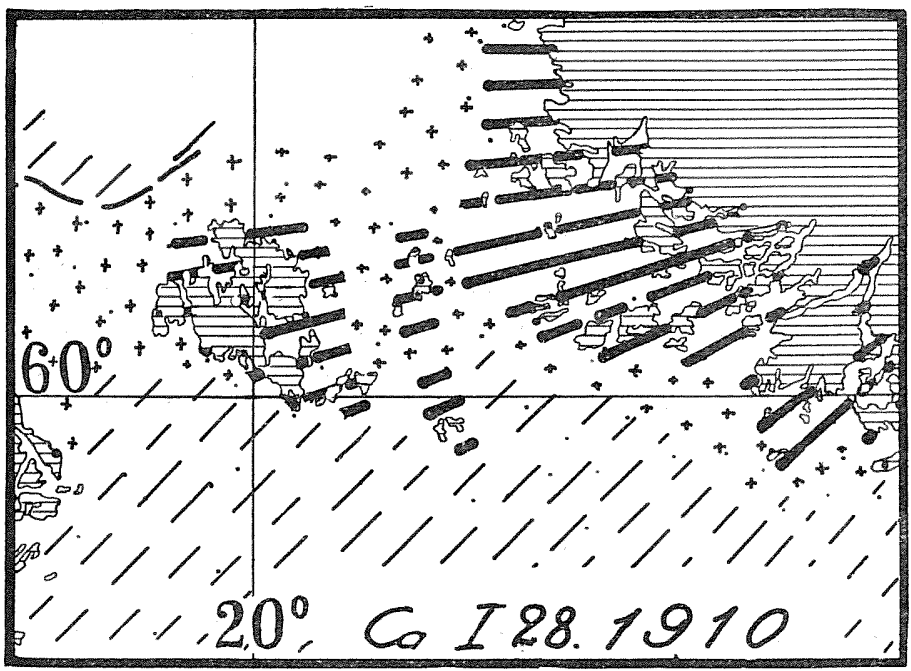

Fig. 37a. Die grösste Vereisung im Schärenmeer im Winter 1910 . Erklärungen siehe folgende Fig. 

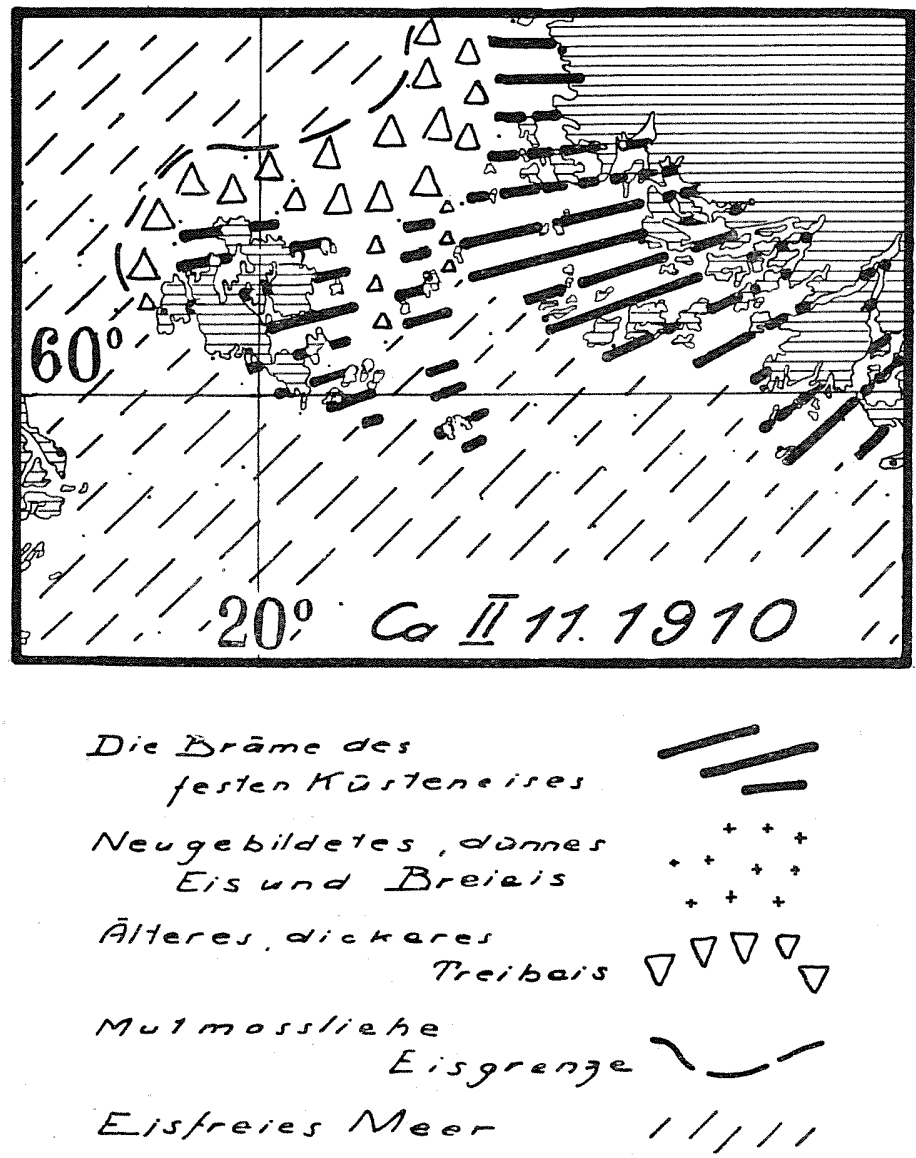

Fig. 37b. Die grösste Vereisung im Schärenmeer im Winter 1910. Fig. 37a gibt die grösste Vereisung etwa um I. 28. wieder, wo dïnnes, neugebildetes Eis und Breieis sich u. a. über die nördliche Hälfte des Alandsmeers erstreckte, Fig. $37 \mathrm{~b}$ die grösste Verbreitung des Eises mit älterem, dickerem Treibeis.

1/150 vielleicht noch geringer ist. Im Winter 1930 erstreckte sich nämlich die grösste Vereisung des d-Gebietes (Fig. 38) nur etwas weiter als die Frequenzkurve $0.0-0.2$ des S-Stadiums d6 angibt. Da diese weiteste Eislegung nicht an einem Freitage eingetreten war und da sie nur den Vormittag des 17. Februar andauerte, hätte sie bei der Herleitung der Stadien aus den Freitagskarten keinen Grenzwert gegeben. Da die länger dauernde Eislegung des d-Gebietes an der Frequenzkurve 0.5 des Stadiums d6 aufhörte, so entspricht dieses Stadium mit seiner Grenze 0.5 einer Vereisung, deren Wahrscheinlichkeit des jährlichen Eintretens somit wenigstens etwa 149/150 ist. 


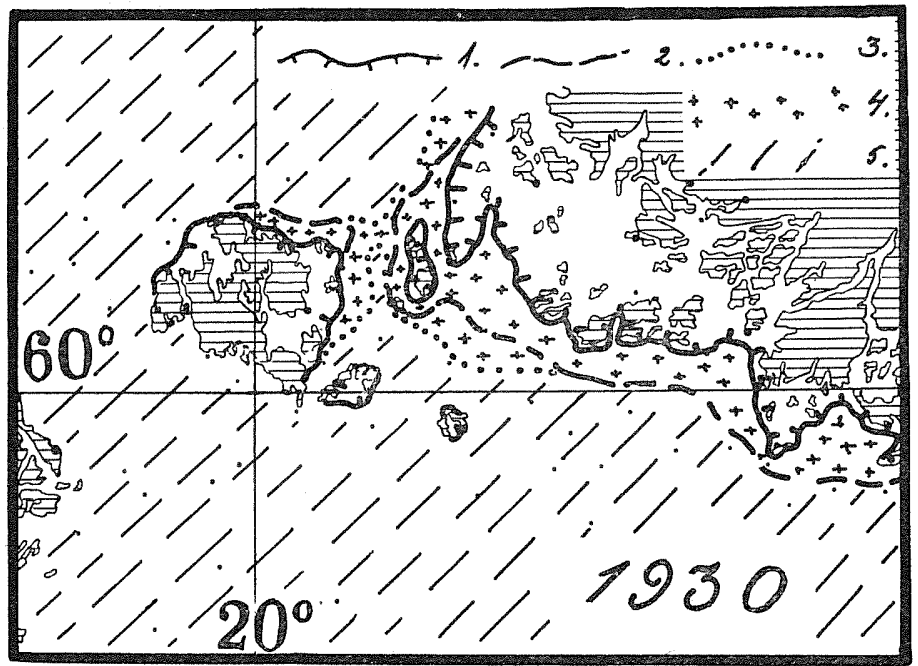

Fig. 38. Die grösste Vereisung im Schärenmeer im Winter 1930. 1: der Rand der Bräme des festen Küsteneises II. 14.; 2: der Rand des Eises am II.17. vormittags; 3: der Rand an demselben Tage nachmittags; 4: ganz dünnes neugebildetes Eis bzw. Breieis; 5: eisfreies Meer.

Wir werden die oben erwähnten Fragen später an verschiedenen Stellen eingehender behandeln. Hier erwähnen wir nur noch einmal, dass die Ergänzung der Normalstadienfolge in bezug auf die schwerer werdenden Eisverhältnisse des Mittwinters darauf hinzielt, solche neuen Normalstadien herzuleiten, deren Wahrscheinlichkeit des jährlichen Eintretens immer abnimmt, wogegen die Bestimmung der g e lind e r werdend e n »kulminierenden» Normalstadien nur eine Präzisierung der Wahrscheinlichkeit des jährlichen Eintretens der schon hergeleiteten Normalstadien bezweckt. Im letztgenannten Fall haben wir näher zu bestimmen, welche Wahrscheinlichkeit die letzten herbstlichen und ersten frühjahrlichen, jetzt mit 10/10 Wahrscheinlichkeit erscheinenden Stadien, bzw. die Kurven dieser Stadien, in Wirklichkeit haben. Mit anderen Worten: wir müssen bei den mit sukzessiv abnehmender ngrösster Vereisung» auftretenden Kulminationsstadien des Eiswinters die letzten herbstlichen sowie die ersten entsprechenden frühjahrlichen Eisränder bestimmen, deren Wahrscheinlichkeit 98/100, 99/100, 199/200 usw. ist. Wie oben gezeigt wurde, hat die Frequenzkurve $0.5 \mathrm{im}$ Stadium d6 eine jährliche Wahrscheinlichkeit von etwa 298/300, aber als äussere Grenze der "grössten Vereisung» eines Winters ist ihre jährliche Wahrscheinlichkeit also nur etwa 2/300. 


\section{Vierter Abschnitt: Die Zeitdiagramme der S- und G-Stadien. Die Länge des Winters bzw. Winterteils, berechnet nach der Ausbreitung und dem Rückgang der Bräme des festen Küsteneises.}

\section{Die Zeitdiagramme.}

\section{A. Die Zeitdiagramme im allgemeinen.}

146. In der Methode, deren wir uns bei der Darstellung der Eisverhältnisse bedient haben, war die Bestimmung der verschiedenen Phasen im allgemeinen Verlauf des Eiswinters, d. h. der Stadien desselben, die zentrale und zuerst auszuführende Aufgabe. Erst hiernach konnte die Frage der Zeit des Eintretens der Stadien entschieden werden. Die denselben Stadien im allgemeinen Verlauf des Eiswinters entsprechenden Eislagen traten nämlich, wie wir schon öfters gesehen haben, in verschiedenen Wintern zu sehr verschiedenen Zeiten ein, so dass erst, nachdem die ganze Folge der Stadien bestimmt war, die Eintrittszeiten der Stadien nach einem gemeinsamen Gesichtspunkte hergeleitet werden konnten. So erwies sich unsere Methode, die in bezug auf die "Struktur» der betreffenden Erscheinung als die zweckmässigste erscheint, auch als unvermeidlich.

Einen Begriff von der "Beweglichkeit» der zu einem Normalstadium gehörenden Eislagen in bezug auf die Zeit geben schon die Eintrittszeiten des betreffenden Normalstadiums. Eine Auffassung davon, wie gross die mögliche Variation in der Länge des ganzen Winters oder eines bestimmten Winterteils nach dieser "Zeitbeweglichkeit» der Eislagen sein kann, erhalten wir aus Tab. 18 und 19. Diese Tabellen sind vermittels der extremen, d.h. einerseits sehr frühen, andererseits sehr späten und der mittleren Eintrittszeiten hergeleitet worden. In sehr langen (sl-) Wintern entsprechen die Zeitpunkte des Eintretens der Normalstadien somit den sehr frühen herbstlichen und den sehr späten frühjahrlichen Daten der Stadien, in mittellangen (ml-) Wintern den mittleren Daten der Stadien und in sehr kurzen (sk-) Wintern den sehr späten herbstlichen und den sehr 
frühen frühjahrlichen Daten der Stadien. Der ganze Winter (Tabelle 18) ist vom ersten Normalstadium bis zum letzten Normalstadium, in dem die Bräme des festen Eises noch besteht oder das Meereseis noch die Frequenz 8/10 hat, berechnet. Der Teil des Winters dagegen, dessen Schwankungen in der Länge auf solchen Eislagen beruhen, die den $\mathrm{nicht}$ jährlich eintretenden Normalstadien entsprechen, umfasst (Tabelle 19) die Zeit von dem letzten herbstlichen mit der Wahrscheinlichkeit 10/10 eintretenden Normalstadium bis zum ersten frühjahrlichen mit derselben Wahrscheinlichkeit eintretenden Normalstadium. In der Tabelle 18 zeigt die Reihe [sl—sk] die Amplitude der Länge des ganzen Winters, in Tabelle 19 die Amplitude des dort angegebenen Teiles des Winters. In den letzten Reihen der beiden Tabellen ist das Verhältnis der Amplituden zu dem ganzen sehr langen, mittellangen und sehr kurzen Winter bzw. Winterteil dargestellt.

14\%. Ohne uns eingehender in die Tabellen 18 und $19 \mathrm{zu}$ vertiefen bemerken wir nur, dass die Schwankungen in der Länge des Winters in den verschiedenen Meeresteilen sehr bedeutend sind. Der aus den Normalstadien hergeleitete und wenigstens "theoretisch" mögliche sehr lange Winter dauert in der Bottenwiek 35 Wochen, der entsprechende sehr kurze Winter im Schärenmeer nur $151 / 2$ Wochen. Dagegen dauert der sehr kurze Winter in der Bottenwiek $231 / 2$ Wochen und der sehr lange im Schärenmeer $271 / 2$ Wochen. Die Amplitude der Länge des ganzen Winters wechselt unter Berücksichtigung sämtlicher Gebiete zwischen 11 bis 13 Wochen. Sie entspricht in den verschiedenen Meeresteilen einem Drittel bis ungf. der Hälfte des sl-Winters, vier bis sechs Zehnteln des ml-Winters, der Hälfte des sk-Winters im a- und b-Gebiet sowie etwa drei Vierteln in den anderen Gebieten.

Die Länge des ganzen Winters ist wie erwähnt von dem ersten Normalstadium an gerechnet. Da jedoch dieses, der ersten Eislegung entsprechende Normalstadium, wie auch teilweise das darauffolgende Normalstadium des Vorherbstes, durch beinahe die grösste Dispersion der Eislagen in bezug auf die Zeit gekennzeichnet ist, so geben die Zahlenwerte der Länge des ganzen Winters wegen der relativ geringen Bedeutung der ersten Eislegung ein etwas zu schweres "Bild» davon. Deshalb wäre es vielleicht zweckmässiger hier den eigentlichen Winter erst von dem zweiten Normalstadium. an zu rechnen. Da hier jedoch nur gezeigt werden sollte, wie die $\mathrm{m} \ddot{\mathrm{og}} \mathrm{li} \mathrm{ch}$ e, aus den Zeitwerten der Normalstadien hergeleitete Länge des Eiswinters - infolge der grossen Zeitstreuung der Eislagen - wechseln kann, haben wir diese Tabelle aufgestellt. 
Tabelle 18.

Die Länge des ganzen Winters, in Tagen ausgedrückt, in sk-, ml-, und sl-Wintern vom ersten Normalstadium $S_{1}$ bis zum letzten Normalstadium Sn, in dem die Bräme des festen Eises noch besteht oder das Meereseis noch die Frequenz 8/10hat, berechnet. Unter den Kennzeichen des Meeresteils sind die Normalstadien $\left(S_{1-n}\right)$ angegeben, vermittels deren die Länge des Winters berechnet ist. In den drei letaten Reihen ist das Verhältnis der Amplitude des Winters [sl-sk] zu dem sk-, ml-und st-Winter angegeben.

\begin{tabular}{|c|c|c|c|c|c|c|}
\hline Winter & $1-24$ & $1 \stackrel{\stackrel{b}{b}}{-22}$ & $\stackrel{\mathrm{c}}{1-24}$ & $1-\frac{\mathrm{d}}{24}$ & $1-\stackrel{e}{-27}$ & $1-\frac{\mathbf{G}}{-29}$ \\
\hline $\begin{array}{l}\mathrm{sk} \\
\mathrm{ml} \\
\mathrm{sl}\end{array}$ & $\begin{array}{l}165 \\
203 \\
244\end{array}$ & $\begin{array}{l}146 \\
190 \\
226\end{array}$ & $\begin{array}{l}124 \\
175 \\
215\end{array}$ & $\begin{array}{l}108 \\
145 \\
193\end{array}$ & $\begin{array}{l}118 \\
162 \\
206\end{array}$ & $\begin{array}{l}165 \\
203 \\
240\end{array}$ \\
\hline [sl_-sk] & 79 & 80 & 91 & 85 & 88 & 75 \\
\hline $\begin{array}{l}{[\mathrm{sl}-\mathrm{sk}] / \mathrm{sk}} \\
\mathrm{sl}-\mathrm{sk}] / \mathrm{ml} \\
{[\mathrm{sl}-\mathrm{sk}] / \mathrm{sl}}\end{array}$ & $\begin{array}{l}0.48 \\
0.39 \\
0.32\end{array}$ & $\begin{array}{l}0.55 \\
0.42 \\
0.35\end{array}$ & $\begin{array}{l}0.73 \\
0.52 \\
0.42\end{array}$ & $\begin{array}{l}0.79 \\
0.59 \\
0.44\end{array}$ & $\begin{array}{l}0.75 \\
0.54 \\
0.43\end{array}$ & $\begin{array}{l}0.45 \\
0.37 \\
0.31\end{array}$ \\
\hline
\end{tabular}

Aus der Tabelle 19 ersehen wir u. a., dass derjenige Teil des wenigstens theoretisch möglichen sl-Winters, der zwischen dem letzten herbstlichen und dem ersten frühjahrlichen mit der Wahrscheinlichkeit

Tabelle 19.

Die Anzahl der Tage zwischen den letzten herbstlichen mit der Wahrscheinlichkeit 10/10 eintretenden Stadien ( $S \varepsilon)$ und den ersten frïhjahrlichen mit derselben Wahrscheinlichkeit eintretenden Stadien ( $S \alpha)$ sowie zwischen den entsprechenden $G$-Stadien ( $G_{\varepsilon}$ und $G \alpha$ ) im sk-, bzw. $m l$ - und st-Winter. Unter den Kennzeichen der Meeresteile sind die Normalstadien ( $S \varepsilon$ und $S \alpha$ sowie $G \varepsilon$ und $G \alpha$ ) angegeben, vermittels deren die Länge des betreffenden Teils des Winters berechnet ist. Die Reihe [sl_sk] gibt die Amplitude des betreffenden Winterteils an. In den drei letzten Reihen ist das Verhältnis dieser Amplitude zu der Länge des Winterteils [10/10] im sk-, bzw. ml-und st-Winter angegeben.

\begin{tabular}{|c|c|c|c|c|c|c|}
\hline $\begin{array}{l}\text { Winterteil }\left[{ }^{10} / 10\right] \\
\operatorname{im}\end{array}$ & $11 \stackrel{\mathrm{a}}{-15}$ & $12 \stackrel{\mathbf{b}}{-17}$ & $11 \stackrel{\mathbf{c}}{-19}$ & $9 \stackrel{\text { d }}{-21}$ & $10 \stackrel{\mathrm{e}}{-} 20$ & ${ }_{13} \stackrel{\mathbf{G}}{-12}^{-1}$ \\
\hline $\begin{array}{l}\text { sk-Winter } \\
\text { ml-Winter } \\
\text { sl-Winter }\end{array}$ & $\begin{array}{r}(4) \\
50 \\
103\end{array}$ & $\begin{array}{r}(6) \\
55 \\
105\end{array}$ & $\begin{array}{r}17 \\
63 \\
105\end{array}$ & $\begin{array}{r}28 \\
68 \\
109\end{array}$ & $\begin{array}{r}21 \\
63 \\
111\end{array}$ & $\begin{array}{r}20 \\
62 \\
110\end{array}$ \\
\hline [sl-sk] & (99) & (99) & 88 & 81 & 90 & 99 \\
\hline $\begin{array}{l}\text { sl-sk]/sk } 10 / 10 \\
\text { sl-sk//ml } 10 / 10 \\
\text { sl-sk]/sl } \quad 10 / 10\end{array}$ & $\begin{array}{l}\overline{1.98} \\
0.96\end{array}$ & $\begin{array}{l}1 . \overline{80} \\
0.94\end{array}$ & $\begin{array}{l}(5.17) \\
1.39 \\
0.84\end{array}$ & $\begin{array}{l}2.89 \\
1.19 \\
0.74\end{array}$ & $\begin{array}{l}4.28 \\
1.43 \\
0.81\end{array}$ & $\begin{array}{l}4.50 \\
1.45 \\
0.82\end{array}$ \\
\hline
\end{tabular}


10/10 eintretenden Normalstadium liegt, 15-16 Wochen dauern kann, wogegen der entsprechende Teil des ml-Winters 7-10 und des skWinters 1-4 Wochen dauert. Die Schwankungen in der Länge dieses Winterteils sind somit $11 \frac{1}{2}-13$, in dem a- und dem b-Gebiet etwa 14 Wochen. Im Verhältnis zu der Länge des ganzen sl-, bzw. ml- und sk- Winters entspricht der betreffende Winterteil in den verschiedenen Meeren der Reihe nach: 4-6/10 des sl-, 2-5/10 des $\mathrm{ml}$ - und höchstens $1-2 / 10$ des sk-Winters.

148. Die grosse Dispersion der Normalstadien, oder besser der den Normalstadien entsprechenden Eislagen in bezug auf die Zeit, geht noch deutlicher als aus den Zahlenwerten der Tabellen aus den sog. Zeit- oder Epochendiagrammen der S- und G-St a dien (Fig. 39-44) sowie aus Fig. 34 hervor.

In Fig. 39-44 sowie in Fig. 34 geben die stehenden Kreuze $(+)$ die Zeitpunkte an, wo das Normalstadium, das links neben der durch das Kreuz parallel mit der Zeitachse gezogenen Linie angegeben ist, im Mittel erscheint, und die kleinen Punkte (.) die Daten der Fislagen,

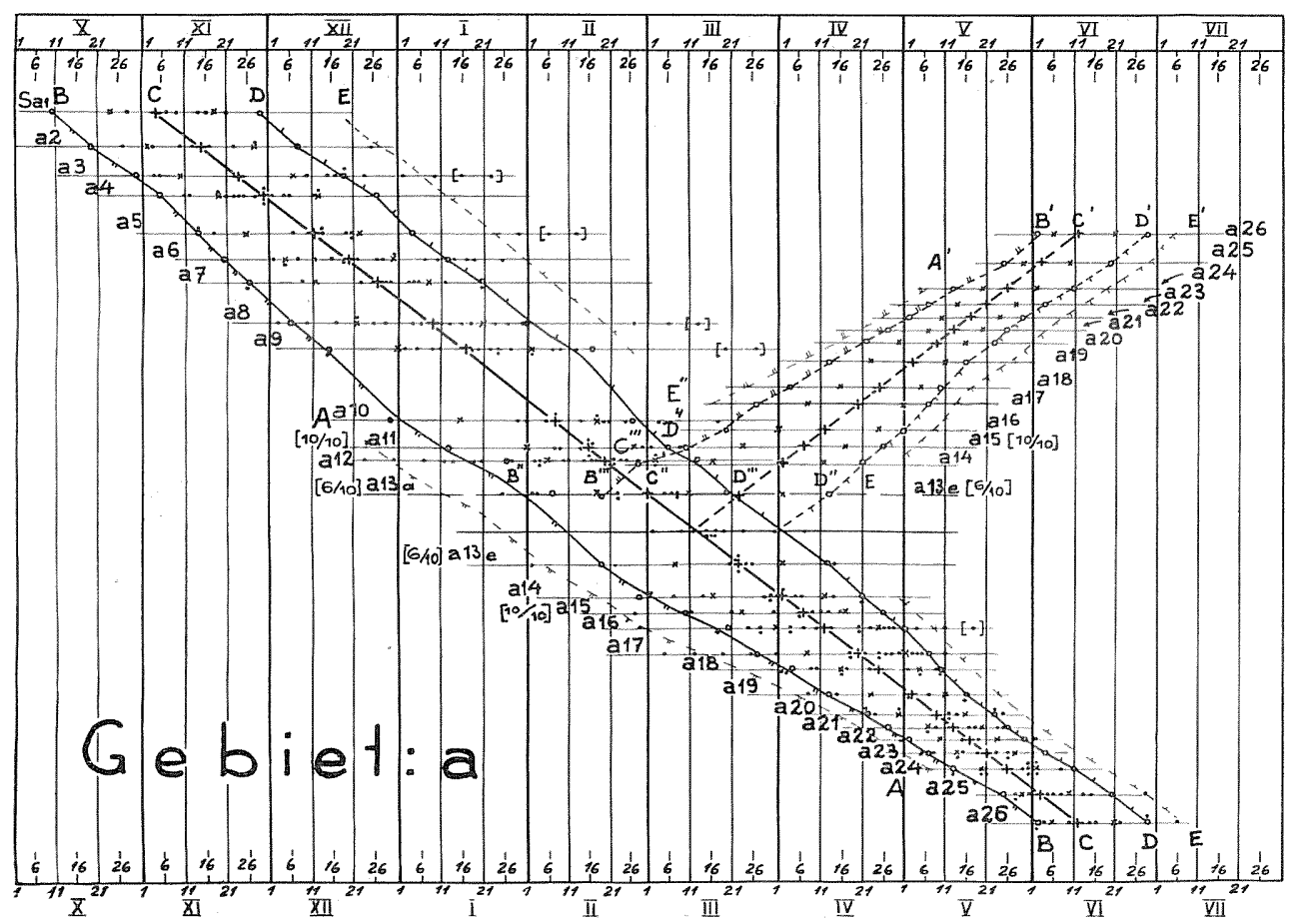

Fig. 39. Das Zeit- oder Epochendiagramm der Bottenwiek oder des Gebiets a. 
die bei der Herleitung des entsprechenden Normalstadiums benutzt wurden. Die Zeitdiagramme sind ausserdem so gezeichnet, dass die mittleren Eintrittszeiten der Normalstadien die gerade Linie CC bilden, die also den normalen oder mittellangen (ml-) Winter vertritt. In Figur 34 ist die entsprechende Linie $\mathrm{mm}$.

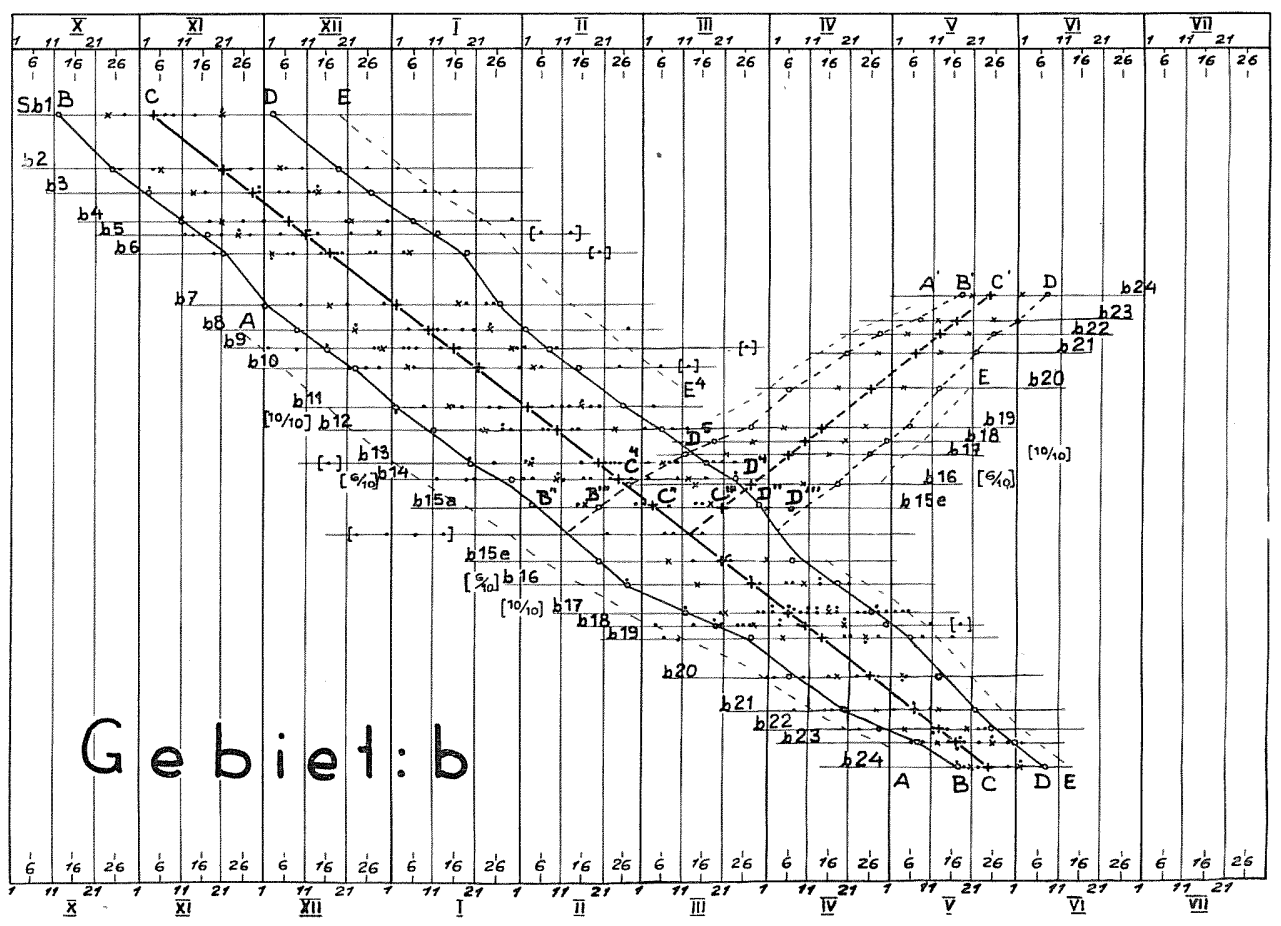

Fig. 40. Das Zeit- oder Epochendiagramm des Kvark oder des Gebiets b.

In den Zeitdiagrammen bedeuten ferner die liegenden Kreuze $(X)$ und die kleinen Kreise (o) zu beiden Seiten der Hauptlinie CC: links die frühen (f) und sehr frühen (sf), rechts die späten (s) und sehr späten (ss) Eintrittszeiten der Normalstadien. In Fig. 34 vereinigen die Linien $f-f$ bzw. sf-sf, $s-s$ und ss-ss die frühen bzw. sehr frühen, späten und sehr späten Eintrittszeiten der Normalstadien Sa 18-a 24 miteinander. Den eben erwähnten Kurven sf und ss entsprechen in Fig. 39-44 die Linien BB und DD, die also in bezug auf ihren Verlauf den "normal» entwickelten sehr frühen (sf-) bzw. sehr späten (ss-) Winter vertreten. In den Zeitdiagrammen sowie in Fig. 34 sind ausserdem noch mit dünnen, unterbrochenen Linien, die auf Grund einiger in dem Eislagenmaterial der Win- 


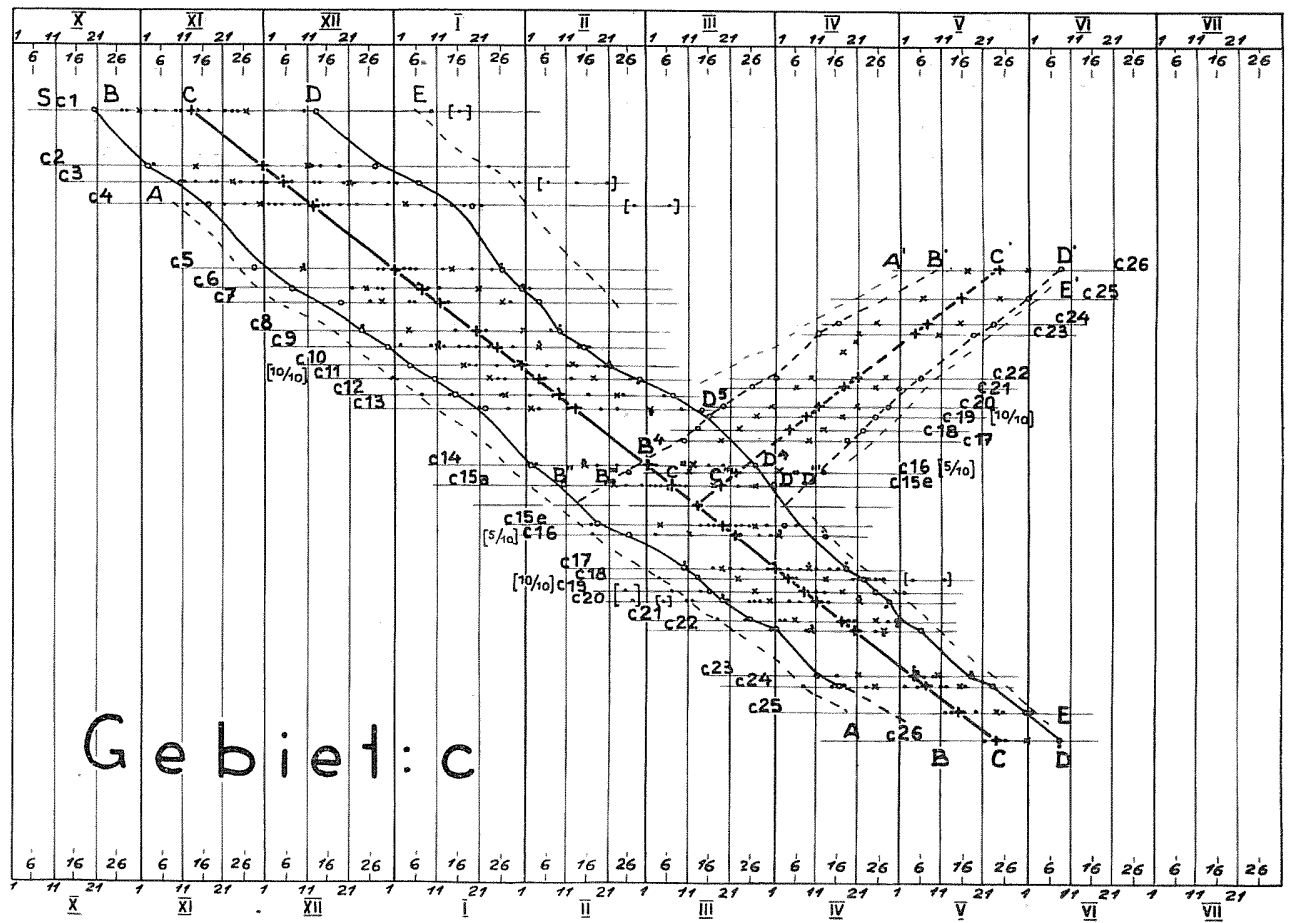

Fig. 41. Das Zeit- oder Epochendiagramm der Bottensee oder des Gebiets e.

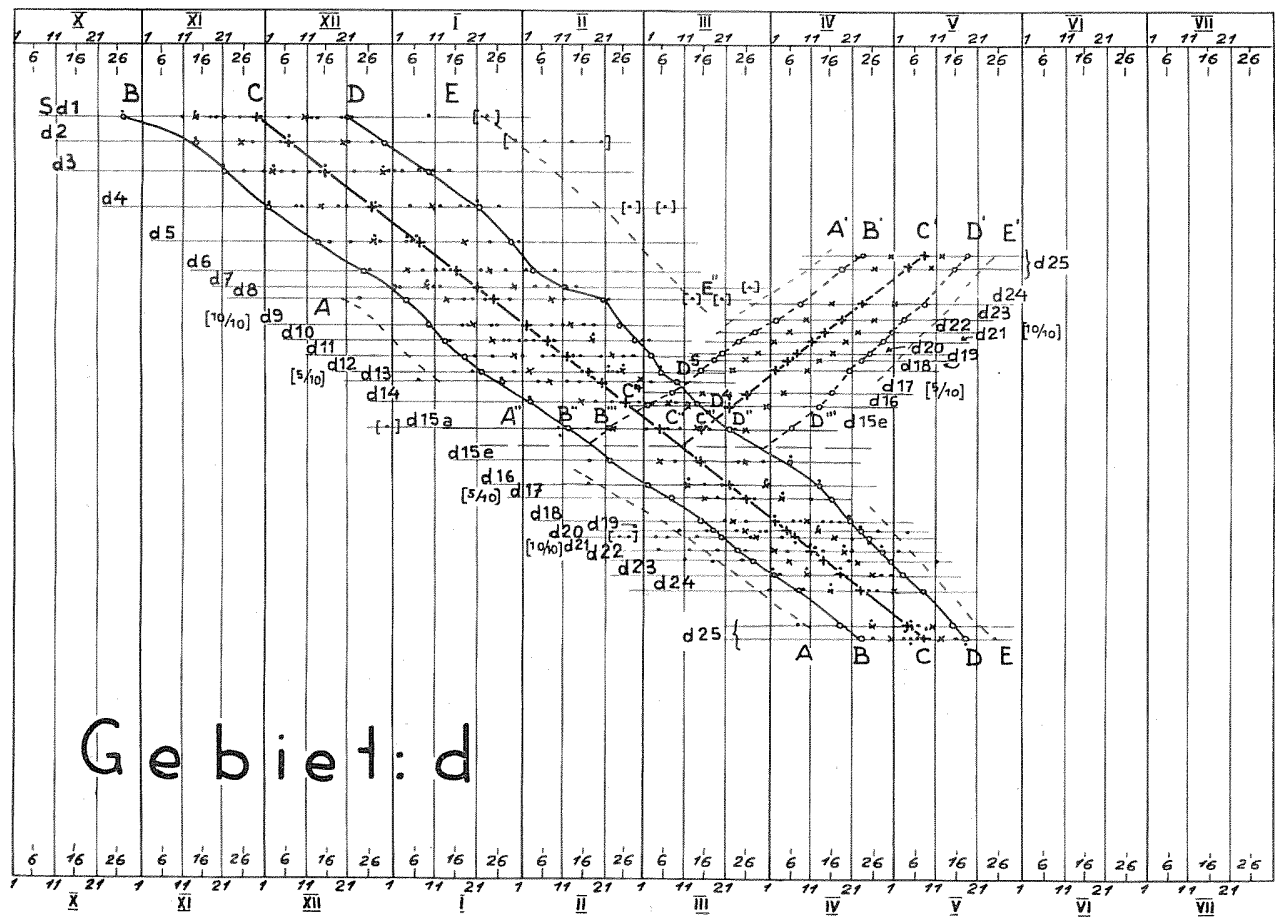

Fig. 42. Das Zeit- oder Epochendiagramm des Schärenmeers oder des Gebiets d. 


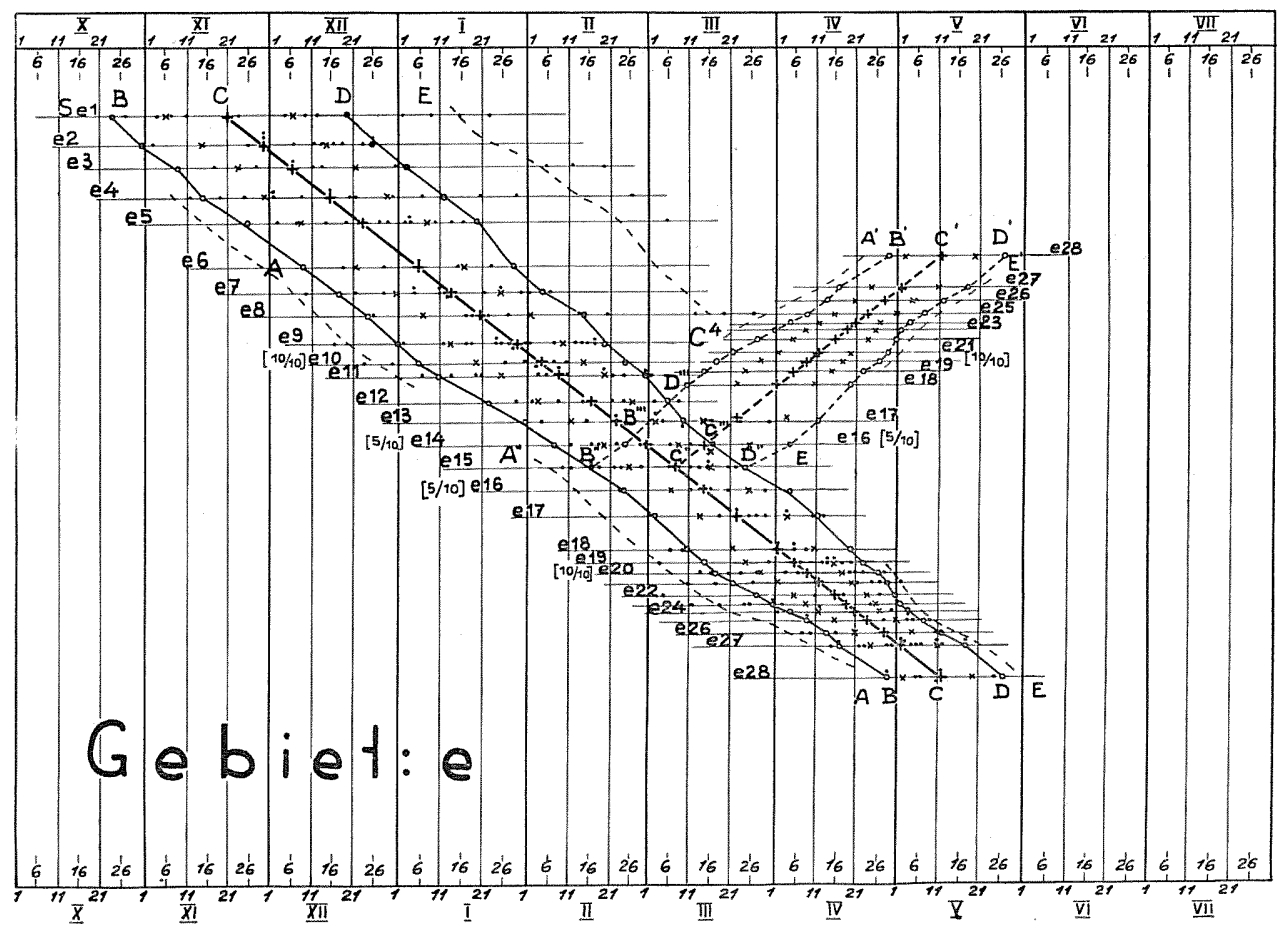

Fig. 43. Das Zeit- oder Epochendiagramm des Finnischen Meerbusens oder des Gebiets e.

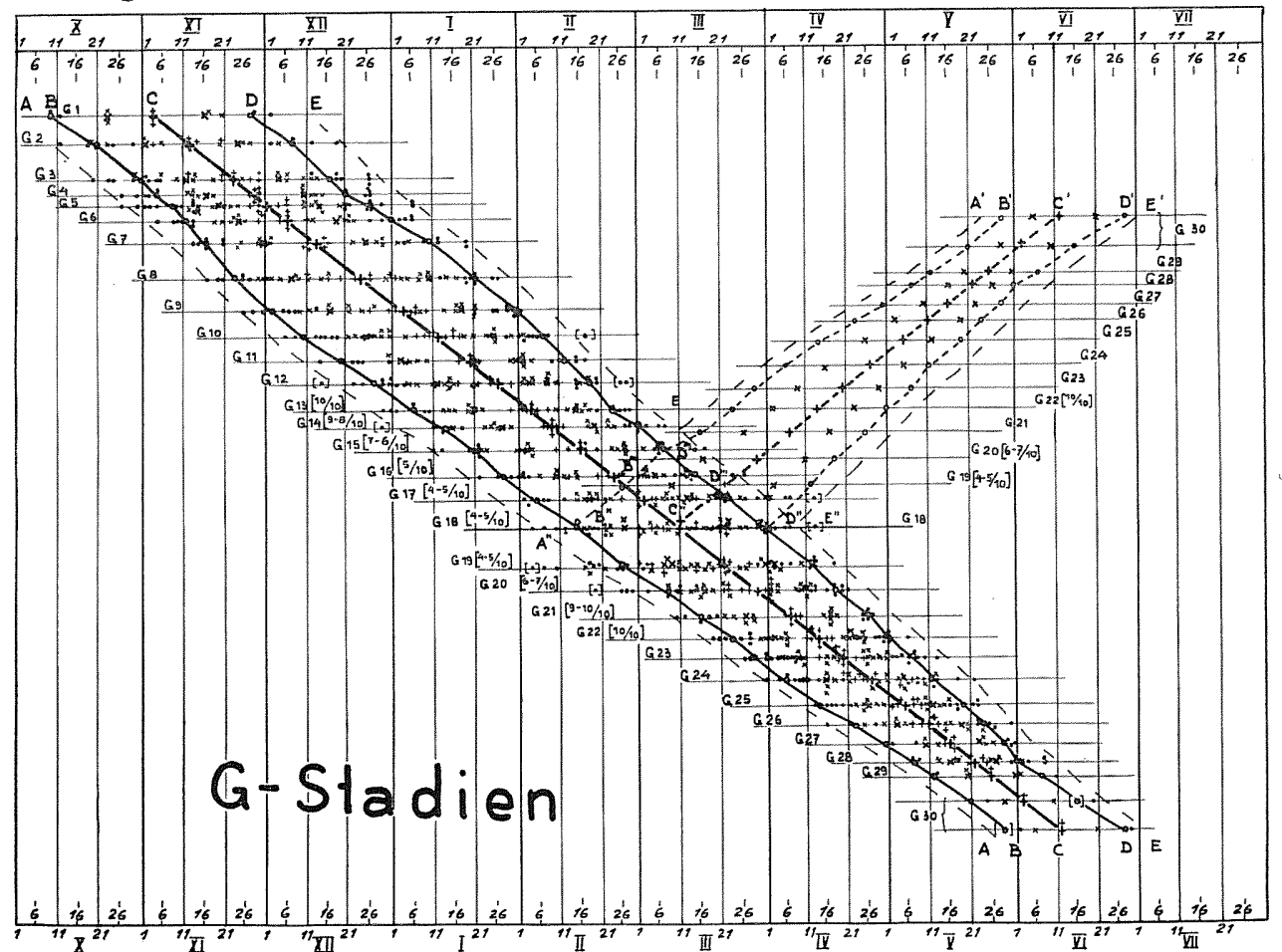

Fig. 44. Das Zeit- oder Epochendiagramm der G-Stadien. 
ter 1915-1925 vorkommenden ausserordentlich früh (aof) bzw. ausserordentlich spät (aos) erscheinenden Eislagen gezeichnet sind, die diesen entsprechenden, d. h. ausserordentlich frühen (aof) bzw. ausserordentlich späten (aos) Eintrittszeiten der Normalstadien angedeutet. Die Linien AA bezeichnen die ersteren, die Linien EE die letztgenannten. Da solche ausserordentlich früh bzw. ausserordentlich spät eintretenden Eislagen nur in einigen, nicht aber in allen Stadien des Winters vorkamen, haben wir diesmal darauf verzichtet, die entsprechenden Eintrittszeiten näher zu bestimmen.

149. Da wir später, vor allem in den Abschnitten, die den Verlauf der Normalwinter behandeln, auf die Zeitdiagramme zurückkommen werden, wollen wir sie hier nicht eingehender behandeln, sondern uns damit begnügen folgendes zu erwähnen. In den Zeitdiagrammen der Meeresteile bedeutet die eingeklammerte Zahl 10/10 das letzte herbstliche und das erste frühjahrliche Normalstadium, das jeden Winter zu erwarten ist; die Stadien der dazwischen liegenden Winterteile entsprechen somit dem Teil, der nicht jeden Winter erscheint. In entsprechender Weise bedeutet die eingeklammerte Zahl 5/10, in den a- und b-Gebiete jedoch die Zahl 6/10 diejenigen Normalstadien, zwischen welche der Winterteil, der seltener als jedes zweite Jahr zu erwarten ist, fällt. In dem Zeitdiagramm der G-Stadien sind noch in Klammern die Wahrscheinlichkeiten des jährlichen Eintretens der Stadien des letzten herbstlichen mit der Wahrscheinlichkeit 10/10 eintretenden Stadiums ( $G$ 13) bis zum entsprechenden ersten frühjahrlichen Stadium $\left(\begin{array}{ll}G & 22\end{array}\right)$ angegeben.

Um das Ablesen der Daten in den Zeitdiagrammen zu erleichtern, haben wir den 1.,11. und 21. Tag jedes Monats durch gerade Linien angegeben, wobei die den Beginn eines Monats bezeichnende Linie etwas dicker als die anderen ist. Weiter bezeichnen die kurzen Linien oben und unten in den Diagrammen den 6., 16. und 26. Tag jedes Monats.

150. Die praktische Bedeutung der Zeitdiagramme liegt vor allem darin, dass man durch sie den Verlauf sowohl der theoretisch möglichen regelmässigen, verschieden langen und verschiedenartigen Winter, die aus den Normalstadien aufgebaut sind, als auch den wirklichen Eiswinter in bezug auf die Zeit veranschaulichen kann.

So z. B. folgen die den Normalstadien entsprechenden Eislagen eines wenigstens theoretisch möglichen, in seinem Verlauf regelmässigen sl-Winters der Linie BB der Diagramme bis zur Kulmination des Mittwinters. Die diesen Stadien des sl-Winters entsprechenden Eislagen verbleiben dann während der Dispersionsintervalle in der Kulmination, wo natürlich auch solche Eislagen entstehen können, 
die bedeutend schwerer als die hergeleiteten normalen Kulminationsstadien sind. Nachdem die Eislagen die Kulmination des Winters passiert haben, folgen sie in der Zeit des Rückganges des Eises der Linie $D D$. Die Eislagen eines normalen oder ml-Winters wiederum folgen der geraden Hauptlinie $C C$ der Zeitdiagramme. Die Eislagen des sk-Winters schliesslich verlaufen längs der Linie $D D$ ungefähr bis zu dem Punkte $D^{4}$ im Zeitdiagramm a (Fig. 39), bis $D^{5}$ in den Zeitdiagrammen b, c und d (Fig. $40-42$ ), bis $D^{\prime \prime \prime}$ im Zeitdiagramm e (Fig. 43) und schliesslich bis $D^{4}$ in den G-Stadien (Fig. 44). Von diesem Punkt "D», der zugleich die grösste Vereisung des skWinters bezeichnet, verlaufen die Eislagen eines solchen Winters auf der Linie $B$ weiter, indem sie dem Teil dieser Linie folgen, der weiter gegen den Frühling von dem Schnittpunkt der Zeitlinie des Punktes " $D$ » mit der Linie $B$ liegt. Hierbei werden somit alle eventuell zwischen dem Punkt » $D$ » und dem Schnittpunkt auf der Linie $B$ liegenden Normalstadien als »nicht erschienen» übergangen.

In einem solchen Winter, in dem die Eislagen längs der Linie $B B$ verlaufen, treten die herbstlichen, mittwinterlichen und frühjahrlichen Stadien sehr früh ein. Somit ist auch der ganze Winter ein sehr früher. In bezug auf den allgemeinen Verlauf des Winters ist dieser sf-Winter in der Hinsicht ein "normaler», dass die den aufeinander folgenden Stadien entsprechenden Eislagen der Reihe nach mit den sf-Zeitintervallen der Stadien eintreten. Ein der Linie $C C$ folgender Winter vertritt, wie schon erwähnt wurde, den normalen ml-Winter. Ein in bezug auf seinen ganzen Verlauf sehr später (ss-) Winter ist derjenige, dessen Eislagen den Zeitwerten der Linie $D D$ folgen. In diesem Winter ist die Zeit der Vereisung und die Zeit des Rückgangs des Eises insoweit wieder "normal», als die aufeinanderfolgenden Eislagen mit den ss-Zeitintervallen der Normalstadien eintreten.

151. Den allgemeinen Verlauf eines bestimmten Winters können wir vermittels der Zeitdiagramme ganz einfach in der Weise darstellen, dass wir, nachdem wir zuerst bestimmt haben, welchen Normalstadien die Eislagen des betreffenden Winters am ehesten entsprechen, in den Zeitdiagrammen auf den durch die Normalstadien gehenden Parallelen der Zeitachse die Daten der den Stadien entsprechenden Eislagen durch ein Zeichen vermerken. Diese Zeichen werden in verschiedenen Wintern im allgemeinen zwischen den Linien $B B$ und $D D$ liegen, nur in den Fällen, wo die Eislagen im Vergleich mit den Normalstadien entweder ausserordentlich früh oder ausserordentlich spät eingetreten sind, liegen diese Zeichen natürlich ausserhalb der genannten Linien. 
Mit Rücksicht auf die praktische Ausführung der Analyse des Winterverlaufes wurden auf Grund der ursprünglichen Zeitdiagramme der Normalstadien bzw. der Generalstadien (Fig. 39-44) vereinfachte sog. Arbeitsdiagramme für die Zeitana$1 \mathrm{yse}$ des Eiswinters gezeichnet. Von diesen stellt Fig. 45 das Zeitdiagramm der d-Stadien, Fig. 46 dasjenige der G-Stadien dar. In den Arbeitsdiagrammen bezeichnet die dicke Mittellinie mit den stehenden Kreuzen und den hinzugefügten Nummern den normalen, mittellangen Winter. Die zu beiden Seiten dieser Hauptlinie parallel zu ihr gezogenen, dünneren Geraden entsprechen der Reihe nach solchen, in ihrem ganzen Verlauf mit dem Normalwinter identischen Wintern, die nur in bezug auf die Zeit von diesem abweichen. Auf der linken bzw, rechten Seite der Hauptlinie geben die erste, zweite, dritte usw. Linie solche Winter wieder, die 1, 2, 3 usw. Wochen zu früh bzw. zu spät verlaufen. Die Linien der ungeraden Wochenzahlen, d. h. die erste, dritte, fünfte usw. Linie links und rechts sind etwas dünner gezogen als die der geraden Wochenzahlen oder die zweite, vierte usw.

Schon ein Blick auf ein Diagramm mit ausgeführter Zeitanalyse gibt uns einen Begriff von dem allgemeinen Verlauf des Winters und von seiner Natur. Aus den Diagrammen können verschiedene

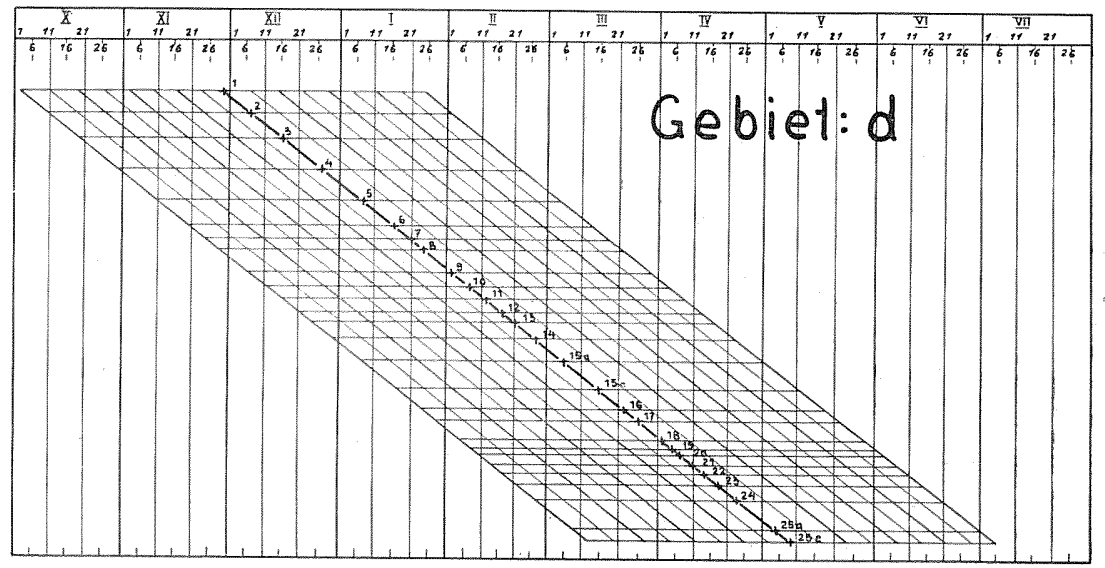

Fig. 45. Das Arbeitsdiagramm für die Analysedeszeitlichen Verlaufes eines Eiswinters im Schärenmeer oder d-Gebiet. Die dicke Mittellinie bezeichnet den Verlauf des mittellangen Normalwinters, wobei die Ziffern die Ordnungsnummern der Stadien angeben, deren Mittelepoche auf das nebenstehende Kreaz fillt. Die dünnen, parallel zu dieser Hauptlinie links und rechts gezogenen Linien entsprechen einem Verlauf des Eiswinters, der in bezug auf den normalen mittellangen Winter eine Woche, zwei Wochen usw. links "zu früh, rechts "zu späti ist. Die Limien der ungeraden Wochenzahlen sind etwas dünner als diejenigen der geraden Wochenzahlen gezogen. 
Ereignisse des Winters, z. B. eine rasche Vereisung oder Enteisung, eine allgemeine Beschleunigung bzw. Verzögerung usw. in bezug auf die Zeit bestimmt werden. Ausserdem kann man in einem eigentlichen Diagramm oder in einem ganz anders gezeichneten Zeitdiagramm, das jedoch auf den von einem eigentlichen Zeitdiagramm hergeleiteten Zahlenwerten basiert, in geeigneter Weise die auf den Verlauf des Eiswinters einwirkenden meteorologischen und talassologischen Faktoren projizieren. Ein solches »Generaldiagramm», in dem also der allgemeineVerlauf eines Winters unmittelbar an die den Verlauf desselben bestimmenden Faktoren anknüpft, gibt uns sofort ein zuverlässiges Bild nicht nur von dem Eiswinter selbst, sondern auch von den ihn bestimmenden Faktoren, unter welchen wir dann numerische Beziehungen suchen können.

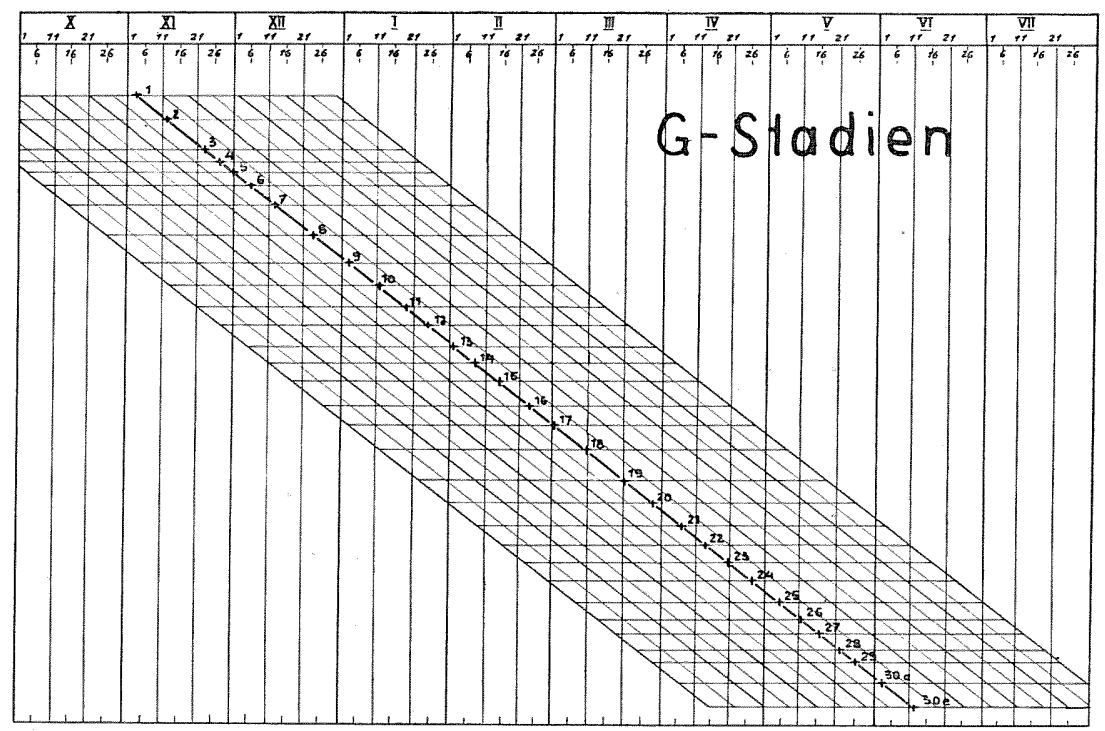

Fig. 46. Das Arbeitsdiagramm für dieAnalyse des zeitlichen Verlaufes eines Eiswinters mit den G-Stadien. Zur Erklärung der Figur siehe die vorhergehende Fig. 45.

152. Das ursprüngliche, nur die Kurven $B B, C C$ und $D D$ enthaltende Zeitdiagramm ist jedoch noch nicht so aufgestelle, dass der Verlauf des Eiswinters immer einfach und anschaulich vermittels desselben dargestellt werden kann. U. a. bereitet es gewisse Schwierigkeiten nur vermittels der Kurven $B B, C C$ und $D D$ z.B. solche Winter wiederzugeben, deren Verlauf insofern ungewöhnlich ist, als Eislagen, welche einigen oder sogar allen mittwinterlichen Normal- 
stadien entsprechen, nicht erscheinen, wie es z. B. im sk-Winter der Fall ist. Um deshalb vermittels des Zeitdiagramms auch solche Eiswinter befriedigend veranschaulichen zu können, wird das Zeitdiagramm derart vervollständigt, dass zu den Kurven $B B, C C$ und $D D$ - mit der Kulminationszeit des Winters beginnend - das Spiegelbild des frühjahrlichen Winterteils des Zeitdiagramms hinzugefügt wird.

\section{B. Die Spiegelbilder des frühjahrlichen Teiles der Zeitdiagramme. Die im Vergleich mit dem ml-Winter symmetrischen, asymmetrischen und verschobenen Winter.}

153. Das Spiegelbild des frühjahrlichen Teils des Zeitdiagramms beginnt mit dem Kulminationsstadium des Eiswinters. Falls das Kulminationsstadium - wie in den Gebieten $\mathbf{a}, \mathbf{b}$, $\mathbf{e}$ und $\mathbf{d}-$ besondere Zeitpunkte für den Beginn und das Ende hat, dient die Parallele der Zeitachse, welche die gerade Hauptlinie $C C$ mitten zwischen diesen Punkten schneidet (Fig. 54-57), als Spiegelungslinie. Die Fig. 54-57 ebenso wie die Fig. 58 und 59 geben nämlich die Stelle der Zeitdiagramme (Fig. 39-44) wieder, wo sich das Kulminationsstadium des Winters befindet. In den erstgenannten (Fig. 54-57) entsprechen die ausgezogenen Linien $B B_{0}, C C_{0}$ und $D D_{0}$, in den letztgenannten (Fig. 58 und 59) wiederum die Linien $B B^{\prime \prime}, C C^{\prime \prime}$ und $D D^{\prime \prime}$ den entsprechenden Stellen der Linien $B B, C C$ und $D D$ der Zeitdiagramme. Die Anfangsteile der gespiegelten Frühjahrshälfte dieser letzteren werden durch die unterbrochenen Linien $B_{0} B^{1}, C_{0} C^{1}$ und $D_{0} \mathrm{D}^{1}$, oder - in Fig. 58 und $59-B^{\prime \prime} B^{1}, C^{\prime \prime} C^{1}$ und $D^{\prime \prime} D^{1}$ bezeichnet. Die Gerade $B_{0} C_{0} D_{0}$ in Fig. 54-57 ist die in der Richtung der Zeitachse und durch den Punkt, der in der Mitte der mittleren Anfangs- und Endepochen des Kulminationsstadiums liegt, gehende Linie, die somit zugleich die "spiegelnde» Linie des frühjahrlichen Teils der entsprechenden Zeitdiagramme a, b, $\mathbf{c}$ und $\mathbf{d}$ (Fig. 39-42) ist. Falls wiederum für das Kulminationsstadium - wie im Gebiet e und in den Generalstadien $G$ - nur der Zeitpunkt seines durchschnittlichen Eintretens bestimmt ist, dient wie gesagt die durch das Kulminationsstadium gehende Parallele der Zeitachse als ispiegelnde» Linie. Die Gerade $B^{\prime \prime} C^{\prime \prime} D^{\prime \prime}$ in Fig. 58 und 59 ist diese, in der Richtung der Zeitachse gezogene "spiegelnde" Linie der Zeitdiagramme o und of (Fig. 43 und 44), die also durch den Punkt, der die mittlere Eintrittszeit des Kulminationsstadiums bezeichnet, geht. Die Gebiete a, b, e und d 
haben somit auf der dem Kulminationsstadium des Eiswinters entsprechenden Parallele der Zeitachse einen herbstlichen "Anfangspunkt» und einen frühjahrlichen "Endpunkt», in den e- und in den »G»Diagrammen fallen diese Punkte zusammen. Die Zeitdiagramme erhalten auf diese Weise jene definitive Form, welche sie in Fig. 39-44 haben, und in welcher der gespiegelte Teil der Zeitdiagramme $u$. a. durch die Linien $A^{\prime}, B^{\prime}, C^{\prime}, D^{\prime}$ und $E^{\prime}$ bezeichnet wird.

In den Spiegelbildern der Zeitdiagramme (Fig. 39-44) sind wiederum die mittleren Eintrittszeiten der Normalstadien durch stehende Kreuze bezeichnet. Auf den durch diese Kreuze zur Zeitachse parallel gezogenen Geraden bezeichnen wieder die liegenden Kreuze die frühen und die späten, die kleinen Kreise die

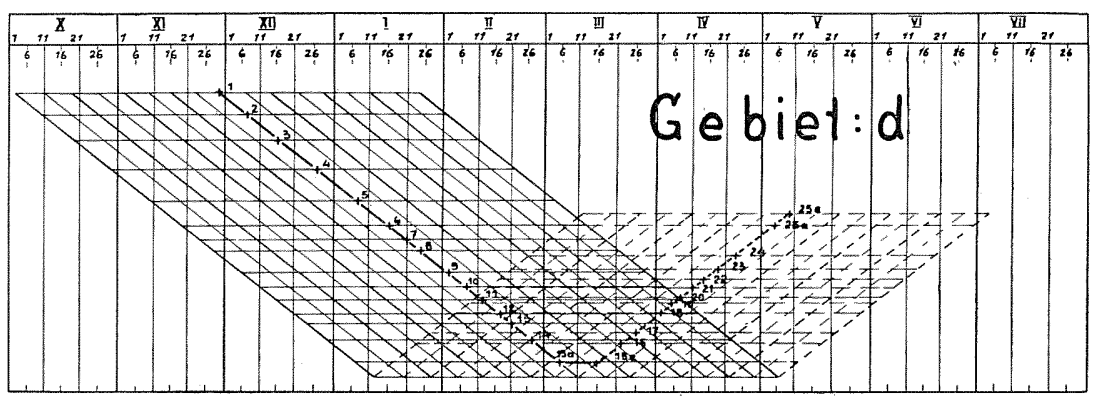

Fig. 47. Das Arbeitsdiagramm der d-Stadien für die Analyse des zeitlichen Verlaufs eines Eiswinters mit dem Spiegelbild der Frühjahrshälfte des »Winters». Die Linien des Spiegelbildes sind durch unterbrochene Linien bezeichnet. Weitere Erklärungen siehe Fig. 45 .

sehr frühen und die sehr späten Eintrittszeiten der Normalstadien. Auch die ausserordentlich frühen und ausserordentlich späten Fintrittszeiten sind durch die unterbrochenen Linien $A^{\prime}$ und $E^{\prime}$ angedeutet. Die Kennzeichen der Normalstadien sind rechts neben den in der Richtung der Zeitachse gezogenen Geraden gezeichnet, wo ausserdem in den Zeitdiagrammen der Meeresteile (Fig. 39-43) die in Klammern befindliche Zahl 5/10 (in den a- und b-Diagrammen, Fig. 39 und $40,6 / 10$ ) das Normalstadium zeigt, das im Frühjahr als das letzte mit dieser Wahrscheinlichkeit erscheint, und die Zahl 10/10 das erste Stadium angibt, das jedes Frühjahr zu erwarten ist. In dem G-Diagramm (Fig. 44) sind durch Ziffern innerhalb der Klammern die Frühjahrsstadien bezeichnet, welche mit der Wahrscheinlichkeit $4 \quad 5 / 10$ und $6-7 / 10$ erscheinen, und ausserdem noch das erste jedes Frühjahr, also mit der Wahrscheinlichkeit 10/10, erscheinende G-Stadium. 


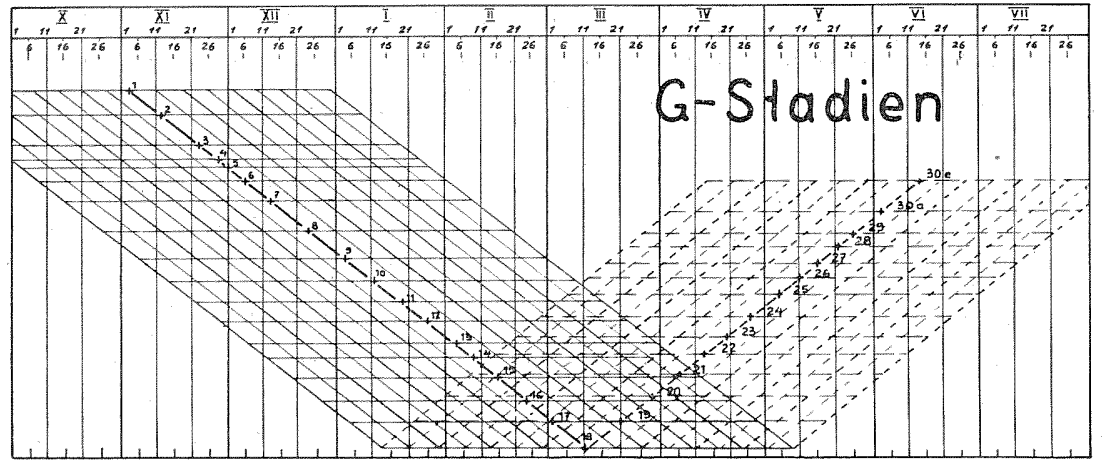

Fig. 48. Das Arbeitsdiagramm der G-Stadien für die Analyse des zeitlichen Verlaufes eines Eiswinters mitdem Spiegelbild der Frühjahrshälfte des „Winters». Die Linien des Spiegelbildes sind durch unterbrochene Linien bezeichnet. Weitere Erklärungen siehe Fig. 45 .

154. Die Figuren 47 und 48 zeigen die definitiven von uns gezeichneten A r beits diagra m m e (38) für die Analyse des zeitlichen Verlaufs eines Eiswinters. Das erstere Diagramm wird dann angewandt, wenn die Analyse vermittels der d-Stadien, das letztere wenn sie mit Hilfe der G-Stadien ausgeführt wird. In diesen definitiven Arbeitsdiagrammen ist die Frühjahrshälfte der ursprünglichen Arbeitsdiagramme (Fig. 45 und 46) ganz einfach durch ein von dem Kulminationsstadium an auf die oben gezeigte Weise erhaltenes Spiegelbild ersetzt worden. Die Linien des Spiegelbildes sind der Deutlichkeit halber unterbrochen gezeichnet.

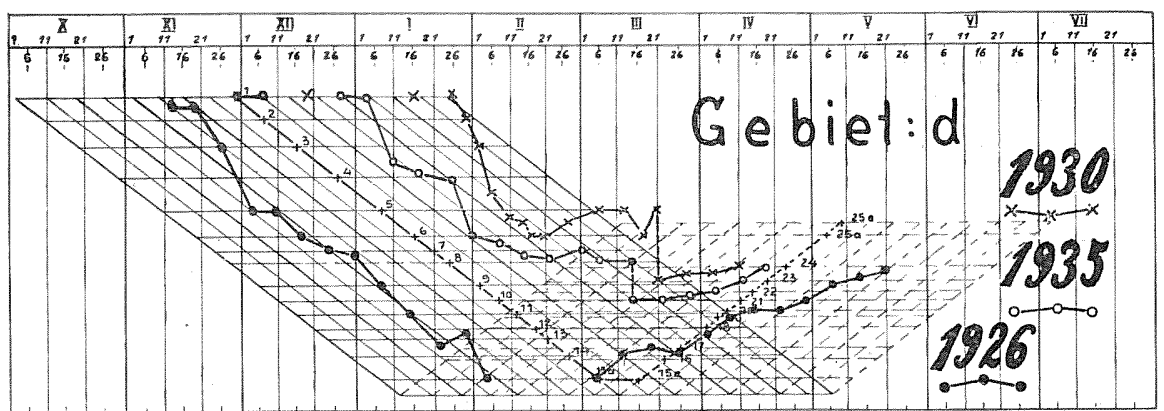

Fig. 49. Die vermittels der d-Stadien erhaltenen Analysen. resultate für den allgemeinen Verlauf der Eiswinter 1926 , 1930 und 1935 im Schärenmeer. 
155. Linige Beispiele von Zeitanalysen. Die Figuren 49-52 geben Beispiele von Analysen, welche mittels der d- und G-Stadien für einige ganze Eiswinter (Fig. 49 und 50) oder einen Teil von solchen (Fig. 51 und 52) ausgeführt worden sind $(38,39)$.

Ohne uns hier in die Resultate eingehender zu vertiefen, wollen wir folgende Umstände hervorheben.

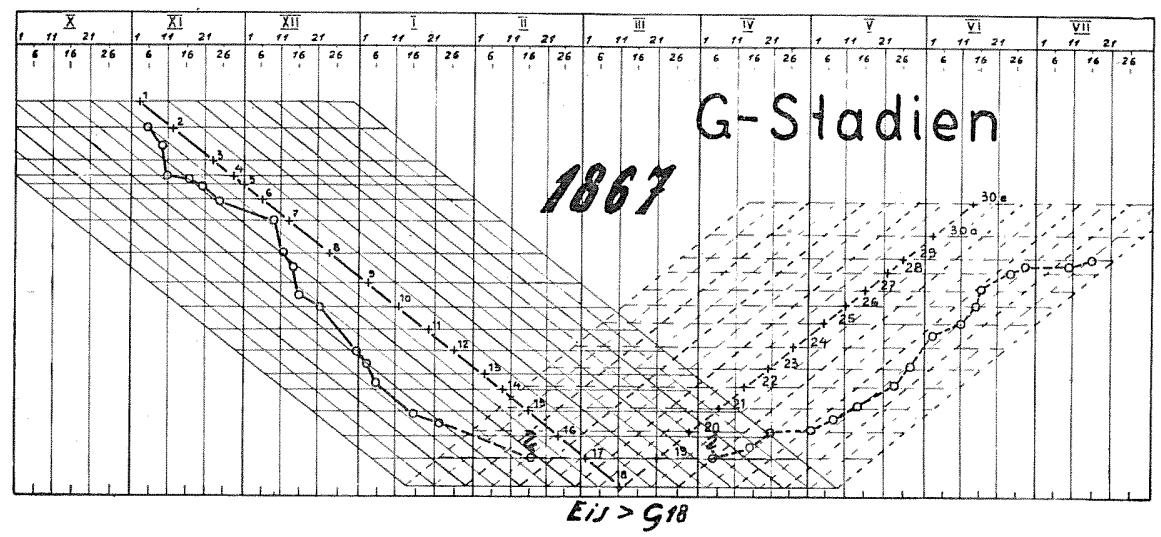

Fig. 50. Das vermittels der G-Stadien erhaltene Analysenresultat für den allgemeinen Verlauf des Eiswinters 1867.

Fig. 49 gibt eine ausgezeichnete Vorstellung davon, in wie weiten Grenzen im d-Gebiet die Länge des Eiswinters schon während einer so kurzen Zeitperiode wie eines Jahrzehntes (die Winter 1926 -1935) variieren kann. Im Herbst des Eiswinters 1926, d. b. im Herbst 1925 , erschien die dem Normalstadium d 2 am nächsten entsprechende Fislage schon ungefähr im Anfang der dritten Dekade des Novembers, im Winter 1930 erst in den letzten Tagen des Januars, d.h.10 Wochen später. Eine dem Schluss-

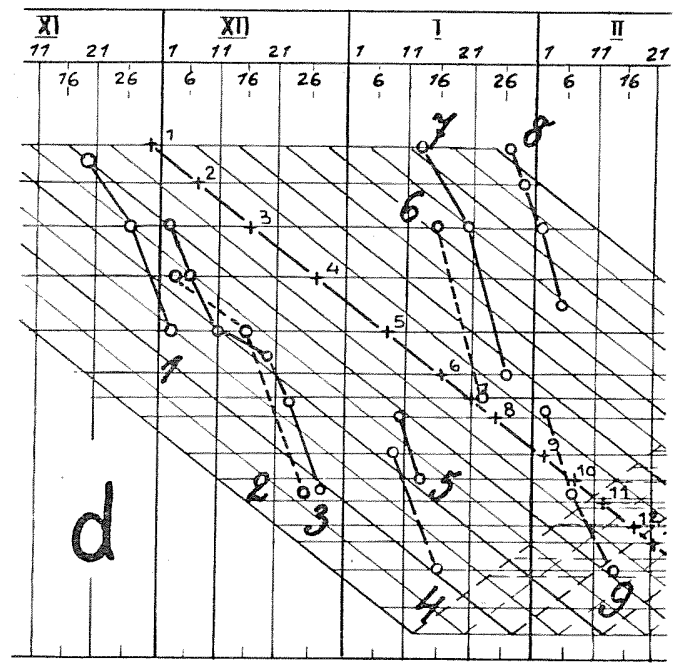

Fig. 51. Die Analysenresultate einiger sehr schnellen Vereisungen im d-G e bi e t. Die Kurven stellen Vereisungen in folgenden Wintern dar: 1: $1925(-26) ; 2: 1876(-77)$; 3: $1870(-71) ; 4: 1893 ; 5: 1881 ; 6: 1910,7: 1933 ; 8$ : 1930 und $9: 1929$. 
stadium d 24 des Eiswinters am nächsten entsprechende frühjahrliche Eislage erschien wiederum 1930 schon ungefähr am IV. 10., im Frühjahr 1926 dagegen erst ungefähr am V. 20., so dass der Zeitunterschied in diesem Punkt des allgemeinen Verlaufs ungefähr 6 Wochen betrug. Die Schwankung der Länge des Eiswinters zwischen den den Anfangs- und Schlussstadien d 2 und d 24 in dem allgemeinen Verlauf des Winters am nächsten entsprechenden Eislagen war somit in den Wintern 1926 und 1930 ungefähr 16 Wochen oder 4 Monate. Der Winter 1930 war allerdings, wie früher bereits hervorgehoben worden ist, ausserordentlich kurz, so dass ein ähnlicher Winter, soweit wir wissen, wenigstens seit etwa 150 Jahren nicht vorgekommen ist.

Fig. 50 zeigt den allgemeinen Verlauf des Winters des Hungerjahres 1867 vermittels der G-Stadien, die wegen des vorläufig zur Verfügung stehenden uneinheitlichen Eismaterials benutzt werden, hergeleitet. Aus der Figur erhellt, dass der Winter früher als durchschnittlich begann und so bis zum Mittwinter verblieb. Die Mittwinterzeit gestaltete sich auch bedeutend länger als gewöhn-

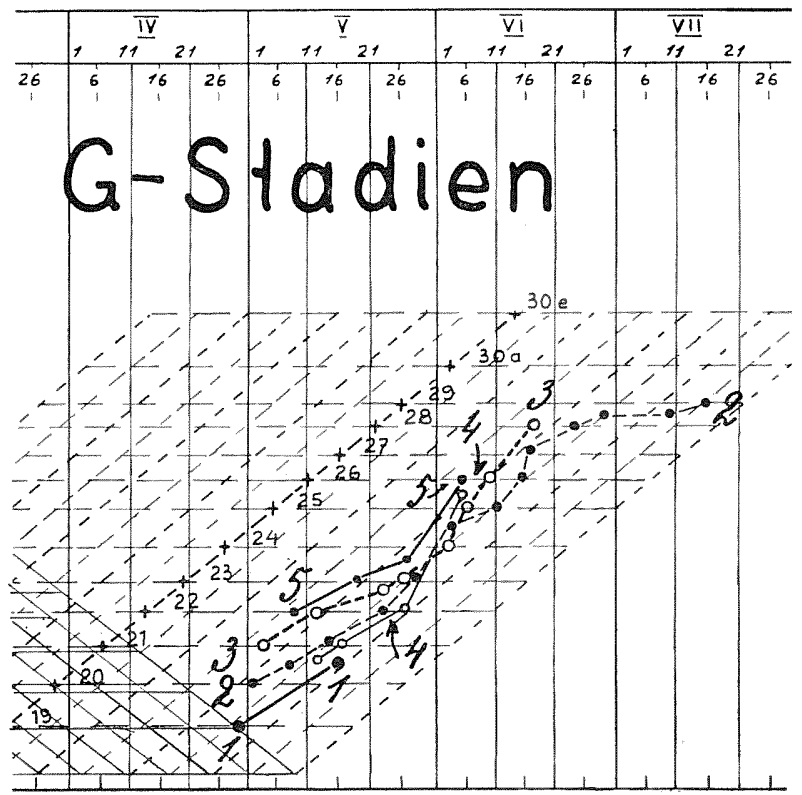

Fig. 52. Die vermittels der G-Stadien für einige sehr späte "Frühlinge" erhaltenen A na ly se nresultate. Die Kurven stellen die "Frühlinge" folgender Winter dar: 1: $1784 ; 2: 1867 ; 3: 1877 ; 4: 1881$ and $5: 1893$. 
lich, so dass die Zeit z. B. zwischen den Generalstadien G 16 und G 20 über 6 Wochen länger als im Mittel dauerte. Da der Mittwinter also sehr spät endigte und ausserdem der Frühling ungewöhnlich langsam fortschritt, verspätete sich das Ende des Eiswinters dementsprechend, so dass das Verschwinden des Meereseises im Frühling 1867 in Finnland ganz ungewöhnlich spät, ja vielleicht später als während der vorhergehenden 90 bis 100 Jahre stattfand. So konnte man z. B. die Eislage, die dem Endstadium G 29 des Winters entspricht und dessen mittlere Eintrittszeit V. 26. ist, noch am VII. 17. feststellen, so dass die Verlängerung des Eiswinters im Stadium G 29 über 7 Wochen oder beinahe 2 Monate betrug. - In Fig. 51 haben wir Beispiele von einigen sehr schnellen Vereisungen im d-Gebiet. Auffallend ist, dass die Kurven der festgestellten Vereisungen alle in dem Diagramm eine beinahe gleich grosse Neigung im Verhältnis zu der Hauptlinie, d.h. zu dem normalen ml-Winter, aufweisen.

In Fig. 52 sind schliesslich vermittels der G-Stadien bestimmte sehr späte »Frühlinge» einiger Eiswinter dargestellt. Von diesen »Frühlingen» traf das späteste am Ende des Mittwinters im Jahr 1784, das späteste eigentliche Frühjahr im schon früher erwähnten Jahr 1867 ein.

156. Nachdem die allgemeinen Schwankungen im Zeitverlauf eines Eiswinters im Verhältnis zum Normalwinter mittels der Arbeitsdiagramme für unsere Meeresteile festgestellt worden sind, können sie zwecks weiterer Behandlung in einer geeigneteren graphischen Darstellung, wie z. B. in Fig. 53, wiedergegeben werden (34). In dieser Figur bezeichnet die Basislinie den Normalwinter und die Kurven wiederum den Verlauf des Eiswinters 1934/35 sowohl in den verschiedenen Meeren, bzw. deren Teilen (wie z. B. in dem nördlichen und südlichen Teil der Bottenwiek, im Ålands- und Schärenmeer usw.) als an der ganzen Küste und in allen Meeresteilen gleichzeitig (vgl. die Kurve: Der allgemeine Verlauf des Winters). Wenn eine Kurve oder ein Teil derselben sich o b e $\mathrm{rha} / \mathrm{b}$ der Basislinie befindet, bedeutet dies, dass die Entstehung der verschiedenen Eislagen während dieser Zeit im Vergleich zu den mittleren Eintrittszeiten der entsprechenden Normalstadien während der Herbsthälfte des Winters später, während der Frühlingshälfte aber früher als im Mittel eingetroffen sind, wenn sie $u n$ t e $\mathrm{r}$ h a 1 b der Basislinie liegt, dass die Eislagen im Herbst früher, im Laufe des Frühjahrs dagegen später als normal entstanden sind. Die Abweichungen, welche aus den Arbeitsdiagrammen direkt abgelesen wurden, sind in Tagen angegeben. 
Ohne in diesem Zusammenhang auf eine nähere Beschreibung der Kurven einzugehen, sei hier nur hervorgehoben, dass diese Darstellung des Verlaufs eines Eiswinters noch durch solche Kurven vervollständigt werden kann, welche auf eine zweckentsprechende Weise den Gang bzw. die Abweichungen der Faktoren wiedergeben, welche die Schwankungen des Eiswinters bestimmen. Das Bild kann somit durch Kurven ergänzt werden, welche den Verlauf der Lufttemperatur, der Minimumtemperatur, der Kältesumme usw. oder deren Abweichungen von ihren Normalen zeigen, ferner durch die Windrichtung und Windstärke, und ausserdem - um das »Bild» des Eiswinters selbst zu vervollständigen - durch Kurven der Eisdicke, bzw. des Eisvolumens, des Areals der Eisdecke oder deren Abweichungen. So ergänzt, haben wir in ein und derselben gra-

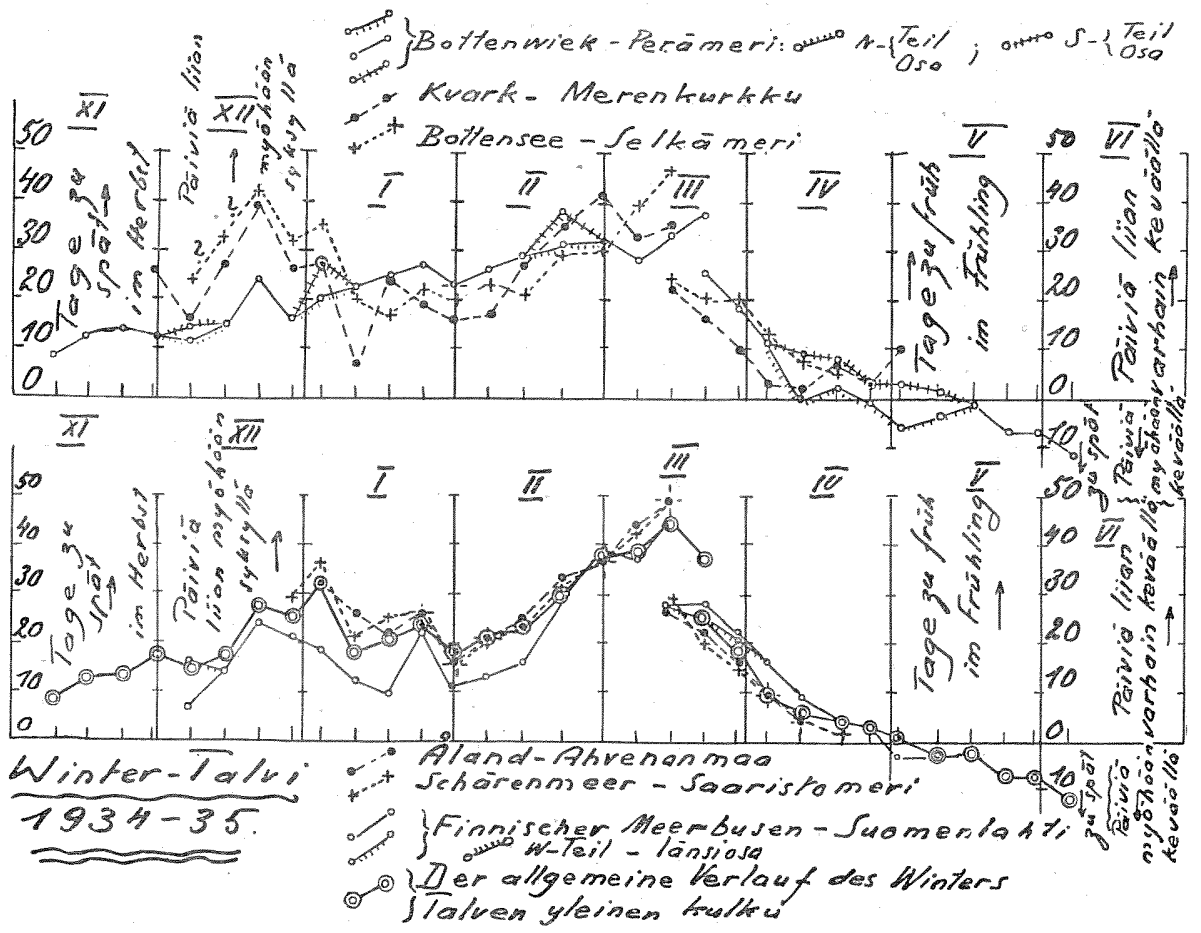

Fig. 53. Der Verlauf des Eiswinters $1934 / 35$ in den Finnland umgebenden Meeren im. Fergleich zu den Normalwintern. Die Kurven zeigen den Gang der Abweichungen der Eintrittszeiten der Eislagen von den mittleren Eintrittszeiten der entsprechenden Normalstadien: o b e $\mathrm{r}$ h a $\mathrm{l}$ b der Basislinie während der Herbsthälfte des Winters, dass die Eislagen später, während der Frühahrshälite dagegen frỉher als im Mittel eingetroffen sind; unterhalb der Basislinie wiederum, dass sie im Herbst fruher, im Frihjahr aber später als im Mittel entstanden sind. Die Abweichungen sind den Arbeitsdiagrammen entnommen und hier in Tagen angegeben. 
phischen Zusammenstellung einen Überblick sowohl über den Eiswinter selbst, als über die denselben bestimmenden Faktoren. Mit Hilfe solcher Zusammenstellungen können wir schliesslich numerische Relationen zwischen den Eiswintern, bzw. ihren Schwankungen und den dieselben bestimmenden Faktoren feststellen. Einige solcher Zusammenstellungen haben wir bereits $u$. a. für die Eiswinter 1926 und 1928 ausgeführt und zwar mit recht bemerkenswerten Resultaten, über welche wir in anderem Zusammenhang näher berichten werden.

15\%. In den Zeitdiagrammen (Fig. 39-44) sowie noch deutlicher in den Figuren, welche den Gang der Linien der Zeitdiagramme

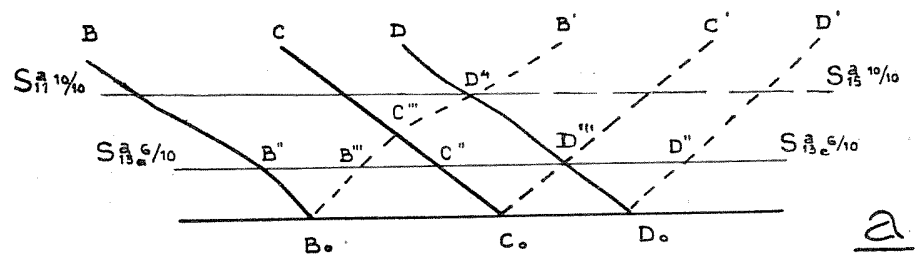

Fig. 54. Der Gang der Linien - sowohl der ursprünglichen als der gespiegelten-des Zeitdiagramm für das Gebiet a in der Umgebung des Kulminationsstadiums des $\mathrm{E}$ iswinters. Die ausgezogenen Linien sind die betreffenden Teile der Linien BB, CC und DD des Zeitdiagramms a (Fig. 39), die unterbrochenen Linien der Anfang des gespiegelten frühjahrlichen Teiles dieses Zeitdiagramms.

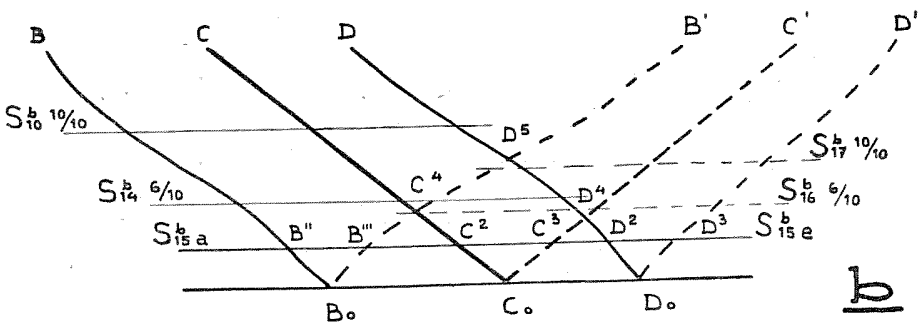

Fig. 55. Der Gang der Linien - sowohl der ursprünglichen als der gespiegelten - des $\mathrm{Z}$ eitdiagram $\mathrm{m}$ für das Gebiet $\mathbf{b}$ in der Umgebung des Kulminationsstadiums des $\mathrm{E}$ isw inters. Die Linien sind dieselben wie in Fig. 54, aber dem Zeitdiagramm b (Fig. 40) entnommen.

in der Umgebung des Kulminationsstadiums des Eiswinters wiedergeben (Fig. 54-59), wird der Verlauf einiger früher genannten Winter, d.h. der sehr kurzen (sk-), der sehr späten (ss-), der mittellangen (ml-), der sehr frühen (sf-) und der sehr langen (sl-) Winter durch folgende (in dem frühjahrlichen Teil des Winters 
gespiegelte) Linien der Tabelle 20 wiedergegeben. (In Fig. 55 sind die Indexe der Buchstaben bisweilen mit Ziffern statt Strichen versehen, z. B. $C C^{2} C^{3} C^{\prime}$ pro $C C^{\prime \prime} C^{\prime \prime \prime} C^{\prime}$ usw.)

\section{Tabelle 20.}

Die den allgemeinen Verlauj des sk-, bzw. ss-, ml-, sf-und sl-Winters in den Zeitdiagrammen, Fig. 39-44, bzw. in den Fig. 54-59 darstellenden Kurven.

$\mathrm{sk}=$ sehr kurzer, $\mathrm{ss}=\mathrm{sehr}$ später, $\mathrm{ml}=$ mittellanger, $\mathrm{sf}=\mathrm{sehr}$ früher und $\mathrm{sl}=$ sehr langer Winter.

\begin{tabular}{|c|c|c|c|c|c|c|c|}
\hline \multirow{2}{*}{$\begin{array}{l}\text { Diagramm } \\
\text { oder } \\
\text { Figur }\end{array}$} & \multicolumn{7}{|c|}{ Winter } \\
\hline & sk & ss & & $\mathrm{ml}$ & & sf & sl \\
\hline $\mathbf{a}$ & $\mathrm{D} \mathrm{D}^{4} \mathrm{~B}^{\prime}$ & $\mathrm{D} \mathrm{D}^{\prime \prime \prime} \mathrm{D}^{\prime \prime} \mathrm{D}^{\prime}$ & $\mathrm{CO}^{\prime \prime}$ & $\mathrm{D}^{\prime \prime \prime}$ & $\mathrm{O}^{\prime}$ & $\mathrm{B} \mathrm{B}^{\prime \prime} \mathrm{B}^{\prime \prime \prime} \mathrm{B}^{\prime}$ & $\mathrm{B} \mathrm{B}^{\prime \prime} \mathrm{D}^{\prime \prime} \mathrm{D}^{\prime}$ \\
\hline b & $\mathrm{D} \mathrm{D}^{5} \mathrm{~B}^{\prime}$ & $D^{D^{2}} \quad D^{3} \quad D^{\prime}$ & $\mathrm{C} \mathrm{C}^{2}$ & $\mathrm{C}^{3}$ & $\mathrm{C}^{\prime}$ & $\mathrm{B} \mathrm{B}^{\prime \prime} \mathrm{B}^{\prime \prime \prime} \mathrm{B}^{\prime}$ & $\begin{array}{lll}\mathrm{B} \mathrm{B}^{\prime \prime} & \mathrm{D}^{3} & \mathrm{D}^{\prime}\end{array}$ \\
\hline e & $\mathrm{D} \mathrm{D}^{5} \mathrm{~B}^{\prime}$ & $\mathrm{D} \mathrm{D}^{\prime \prime} \mathrm{D}^{\prime \prime \prime} \mathrm{D}^{\prime}$ & $\mathrm{C} \mathrm{C}^{\prime \prime}$ & $\mathrm{C}^{\prime \prime \prime}$ & $\mathrm{C}^{\prime}$ & $\mathrm{B} \mathrm{B}^{\prime \prime} \overline{\mathrm{B}}^{\prime \prime \prime} \mathrm{B}^{\prime}$ & $\mathrm{B} \mathrm{B}^{\prime \prime} \mathrm{D}^{\prime \prime \prime} \mathrm{D}^{\prime}$ \\
\hline d & $\mathrm{D} \mathrm{D}^{5} \mathrm{~B}^{\prime}$ & $\mathrm{D} \mathrm{D}^{\prime \prime} \mathrm{D}^{\prime \prime \prime} \mathrm{D}^{\prime}$ & $\mathrm{C} \mathrm{C}^{\prime \prime}$ & $\mathrm{C}^{\prime \prime \prime}$ & $\mathrm{C}^{\prime}$ & $\mathrm{B} \mathrm{B}^{\prime \prime} \mathrm{B}^{\prime \prime \prime} \mathrm{B}^{\prime}$ & $\mathrm{B} \mathrm{B}^{\prime \prime} \mathrm{D}^{\prime \prime \prime} \mathrm{D}^{\prime}$ \\
\hline e & $\mathrm{D} \mathrm{D} \mathrm{D}^{\prime \prime} \mathrm{B}^{\prime}$ & $\mathrm{D} \mathrm{D}^{\prime \prime} \mathrm{D}^{\prime}$ & $\mathrm{C} \mathrm{C}^{\prime \prime}$ & $\mathrm{C}^{\prime}$ & & $\mathrm{B} \mathrm{B}^{\prime \prime} \mathrm{B}^{\prime}$ & $\mathrm{B} \mathrm{B}^{\prime \prime} \mathrm{D}^{\prime \prime} \mathrm{D}^{\prime}$ \\
\hline $\mathbf{G}$ & $\mathrm{D} \mathrm{D}^{4} \mathrm{~B}^{\prime}$ & $\mathrm{DD}^{\prime \prime} \mathrm{D}^{\prime}$ & $\mathrm{C} \mathrm{C}^{\prime \prime}$ & $\mathrm{C}^{\prime}$ & & $\mathrm{B} \mathrm{B}^{\prime \prime} \mathrm{B}^{\prime}$ & {$\left[\begin{array}{lll}\mathrm{B} \mathrm{B}^{\prime \prime} & \mathrm{D}^{\prime \prime} & \mathrm{D}^{\prime}\end{array}\right.$} \\
\hline
\end{tabular}

Ausser diesen Wintern, die vermittels der Normalstadien möglichst einfach aus den Kurven der Zeitdiagramme hergeleitet werden können, lassen sich auf Grund der Diagramme noch einige ihrem allgemeinen Verlauf nach sehr regelmässige Winter bestimmen, in

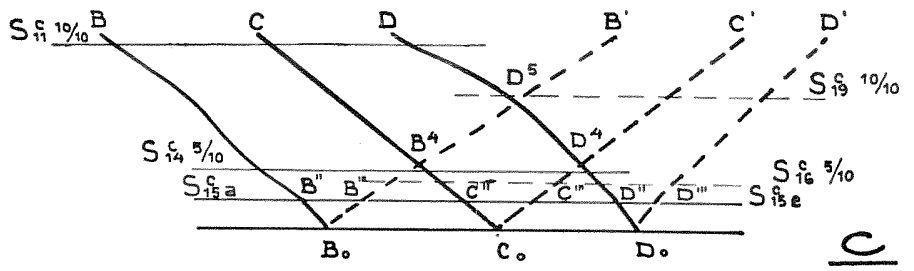

Fig. 56. Der Gang der Lini e n-sowohl der ursprünglichen als der gespiegelten-des Zeitdiagramms für das Gebiet e in der Umgebung des Kulminations tadiums des $\mathrm{E}$ isw inters. Die Linien sind dieselben wie in Fig. 54, aber dem. Zeitdiagramm e (Fig. 41) entnommen.

denen entweder der Herbst oder der Frühling ganz normal ist und der geraden Hauptlinie des Diagramms folgt, wogegen die anderen Winterteile längs anderer Kurven der Diagramme verlaufen. In der folgenden Tabelle 21 ist der allgemeine Verlauf dieser Winter in bezug auf Herbst, Mittwinter und Frühling, hier vermittels der Figuren 54-59, bestimmt. 


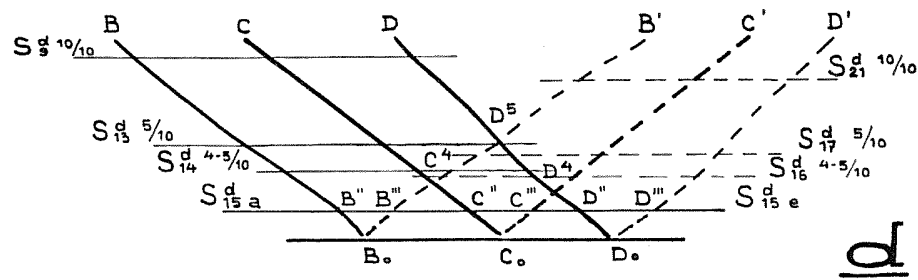

Fig. 57. Der Gang d e r Linien-sowohl der ursprünglichen als der gespiegelten-des Zeitdiagram s für das Gebiet d in der Umgebung des Kulminationsstadiums des $\mathrm{E}$ isw inters. Die Linien sind dieselben wie in Fig. 54, aber dem Zeitdiagramm d (Fig. 42) entnommen.

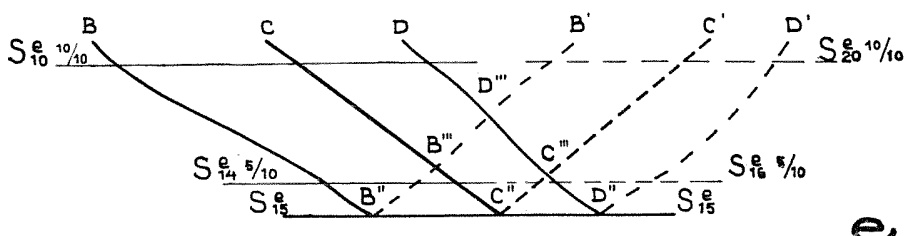

Fig. 58. Der Ga ng der Lini e $n-$ sowohl der ursprünglichen als der gespiegelten - des $\mathrm{Z}$ eitdiagramms für das Gebiet e in der Umgebung des Kulminationsstadiums des $\mathrm{E}$ isw inters. Die Linien sind dieselben wie in Fig. 54, aber dem Zeitdiagramm e (Fig. 43) entnommen.

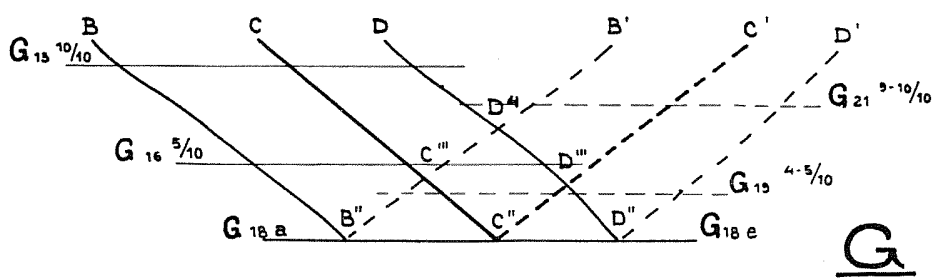

Fig. 59. D e r Gang der Lini e n-sowohl der ursprünglichen als der gespiegelten-des Z e itdiagram s der G-Stadien in der Umgebung des Kulminationsstadiums des E isw inters. Die Linien sind dieselben wie in Fig. 54, aber hier dem Zeitdiagramm G (Fig. 44) entnommen.

Tabelle 21.

$\mathrm{H}=$ Herbst, $\mathrm{M}=$ Mittwinter, $\mathrm{F}=$ Frühjahr; sf $=$ sehr früh; $\mathrm{n}=$ normal; ss $=$ sehr spät.

\begin{tabular}{|c|c|c|c|c|c|c|c|c|}
\hline \multicolumn{3}{|c|}{$\begin{array}{c}\text { Der allgemeine } \\
\text { Verlauf des }\end{array}$} & \multicolumn{6}{|c|}{ Figur } \\
\hline H & M & $\mathbf{F}$ & $\mathbf{a}$ & b & c & d & e & $\mathbf{G}$ \\
\hline ss & -- & $\mathrm{n}$ & $\mathrm{D} \mathrm{D}^{\prime \prime \prime} \quad \mathrm{C}^{\prime}$ & $\mathrm{D} \mathrm{D}^{4} \mathrm{C}^{\prime}$ & $\mathrm{D} \mathrm{D}^{4} \mathrm{C}^{\prime}$ & $\mathrm{D} \mathrm{D}^{4} \mathrm{C}^{\prime}$ & $\mathrm{D} \mathrm{C}^{\prime \prime \prime} \mathrm{C}^{t}$ & $\mathrm{D} \mathrm{D} \mathrm{D}^{\prime \prime \prime} \mathrm{C}^{\prime}$ \\
\hline $\mathrm{n}$ & -- & sf & $\mathrm{CO}^{\prime \prime \prime} \quad \mathrm{B}^{\prime}$ & $\mathrm{C} \mathrm{C}^{4} \mathrm{~B}^{\prime}$ & $\mathrm{CB}^{4} \mathrm{~B}^{\prime}$ & $\mathrm{C} \mathrm{C}^{4} \mathrm{~B}^{\prime}$ & $\mathrm{CB}^{\prime \prime \prime} \mathrm{B}^{\prime}$ & $\mathrm{CO}^{\prime \prime \prime} \mathrm{B}^{\prime}$ \\
\hline $\begin{array}{c}n \\
\text { ff }\end{array}$ & $n-s s$ & ss & $\mathrm{CO}^{\prime \prime} \mathrm{D}^{\prime \prime} \mathrm{D}^{\prime}$ & $\begin{array}{ll}C C^{2} & D^{3} \\
B^{\prime \prime} & C^{3}\end{array}$ & $\mathrm{D}^{\prime} \mathrm{C}^{\prime \prime} \mathrm{D}^{\prime \prime \prime}$ & ${ }^{\prime} \mathrm{C} \mathrm{C}^{\prime \prime} \mathrm{D}^{\prime \prime \prime}$ & $\mathrm{CO}^{\prime \prime} \mathrm{D}^{\prime \prime}$ & $\mathrm{O}^{\prime} \mid \begin{array}{lll}\mathrm{Cl}^{\prime \prime} & \mathrm{D}^{\prime \prime} & \mathrm{D}^{\prime}\end{array}$ \\
\hline SI & $\mathrm{si} \rightarrow \mathrm{n}$ & $\mathrm{n}$ & $\begin{array}{llll} & B & D & U\end{array}$ & B $\mathrm{C}^{\circ}$ & & & $\mathrm{B} B \mathrm{C}$ & $\begin{array}{llll} & B & 0\end{array}$ \\
\hline
\end{tabular}




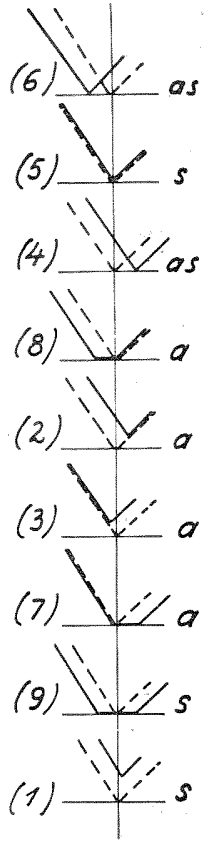

158. Die in den Tabellen 20 und 21 bestimmten Eiswinter vertreten 9 in ihrem Verlauf regelmässige, aber ihrer Art nach sehr verschiedene Winter, die sich möglichst einfach aus den von uns hergeleiteten Normalstadien aufbauen, nämlich ausschliesslich vermittels der sf-, m- oder ss-Eintrittszeiten der Normalstadien. Wenn wir diese Winter nach ihrer Länge ordnen und den Winter nach dem Verlauf seines Herbstes, Mittwinters und Frühlings in bezug auf den entsprechenden Teil des Normalwinters charakterisieren, erhalten wir Tabelle 22. Dieser Tabelle fügen wir noch eine besondere Kolumne "Wintertyp" hinzu, wo die Nummern (1), (2), (3) usw. den in Fig. 60 schematisch dargestellten Wintern entsprechen, und die beigefügten stehenden Buchstaben »s» bzw. „a» oder »as» den» Wintertyp» bezeichnen, d. h. angeben ob die Kurven der Winter (1), (2), (3) usw. im Vergleich mit der Kurve des mittellangen Normalwinters symmetrisch ( $(\Delta\rangle$,$) ,$ asymmetrisch („a») oder nur verschoben ("ass) sind.

159. Ausser den obenerwähnten Wintern könnten Fig. 60. Die wir natürlich in den Zeitdiagrammen, wenn wir die Kurve gibt den Eintrittszeiten der Stadien in verschiedener Weise mittellangen kombinieren, zahireiche, in ihrem Verlauf sehr variieNormalwinter,
die ausgezogene rende und sehr verschiedenartige Winter aufbauen. Die Kurve die Win- oben beschriebenen Winter, in die Zeitdiagramme ein-
ter der Tabelle 22 wieder, wobei gezeichnet, geben uns eine gute Vorstellung davon, wie die Nummer der die Länge des ganzen Winters schon in solchen Wintern, Figur sich auf von welchen nur vorausgesetzt wird, dass ihre herbstde Winternum- lichen, mittwinterlichen oder frühjahrlichen Teile als mer, wSy bzw. wa» solche in bezug auf die Zeit regelmässig, der ganze Wintertyp auf Verlauf aber dessenungeachtet unregelmässig entwickelt ${ }_{\text {bzw. }}$ Symmetrie isymme- ist, wechseln kann. Weiter unten wird diese Frage noch trie oder Ver- in der Hinsicht beleuchtet, dass für alle Meeresteile schiebung des Winters in bezug sowie für die ganze Küste und für das ganze Meeresauf den Normal- gebiet (G-Stadien) mit Hilfe der Zeitdiagramme bewinter bezieht. stimmt wird, wie in den oben definierten Wintern (1) bis (9) die Länge: 1) des ganzen Winters, 2) des Winterteils, der zwischen die letzten herbstlichen und ersten frühjahrlichen mit der Wahrscheinlichkeit 10/10 erscheinenden Normalstadien fällt, und 3) des Winterteils, der zwischen die ersten berbstlichen und die letzten frühjahrlichen mit der Wahrscheinlichkeit 5/10 (in den Gebieten $\mathbf{a}$ und $\mathbf{b}$ mit der Wahrscheinlichkeit 6/10) erscheinenden Normalstadien fällt, wechselt. 
Tabelle 22.

Die Länge des Winters (nach der Tabelle 24). Abkürzungen: $»$ s $^{2}=$ symmetrisch, $\|a\|=$ asymmetrisch,,$\| a s\rangle=$ verschoben, $s s=$ sehr spät, $n=$ normal, sf $=\operatorname{seh} r$ früh.

\begin{tabular}{|c|c|c|c|c|c|c|}
\hline \multicolumn{2}{|c|}{ Winter } & \multicolumn{3}{|c|}{ Der allgemeine Verlauf des } & \multicolumn{2}{|c|}{ Länge d. ganzen Winters } \\
\hline Nummer & Typ & Herbstes & Mittwintel & Friihlings & im d-Gebiet & n.d. G-Stadien \\
\hline (1) & 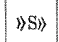 & SS & - & sf & 108 & 165 \\
\hline (2) & "alt & SS & - & $\mathrm{n}$ & 123 & 179 \\
\hline (3) & na" & $n$ & - & si & 130 & 189 \\
\hline (4) & |rass & ss & ss & SS & 138 & 195 \\
\hline (5) & $\| \mathrm{S}\rangle$ & $\mathrm{n}$ & $\mathrm{n}$ & $\mathrm{n}$ & 145 & 203 \\
\hline (6) & " $a$ S. & sf & sf & $s f$ & 156 & 214 \\
\hline (7) & nas & n & $n$ & SS & 160 & 219 \\
\hline (8) & nail & sf & sf & $n$ & 178 & 228 \\
\hline (9) & $\| S "$ & sft & sf & SS & 193 & 240 \\
\hline
\end{tabular}

C. Die Länge der einfachsten, auf Grund der $\mathbb{I r u r v e n} \mathbf{B B}, \mathbb{C C}$ und DD der Zeitdiagramme bestimmten Winter zwischen bestimmten

\section{Normalstadien.}

160. Um einen Begriff davon zu erhalten, auf welche Weise die Länge der verschiedenen Teile des Winters in den einerseits vermittels der S-Stadien, andererseits der G-Stadien hergeleiteten Wintertypen wechselt, haben wir Tabelle 24 aufgestellt. Die Länge des Winters bzw. Winterteils bezeichnet hier jedesmal die Z e it zwischen $z$ wei Normalstadien, also keineswegs die Länge des Winters an bestimmten Orten. Es handelt sich m.a. W. hier um Zeitintervalle zwischen bestimmten Punkten im allgemeinen Verlauf des Winters. Dies sind 1) das erste Normalstadium (Stadium: $\mathrm{S}_{1}, \mathrm{G}_{1}$ ) und das letzte Normalstadium, in dem es noch eine Bräme des festen Küsteneises gibt oder das Meereseis die Frequenz 8/10 hat (Stadium: $S_{n}, G_{n}$ ); 2) das letzte herbstliche mit der Wahrscheinlichkeit 10/10 eintretende Normalstadium (Stadium: $S_{10 / 10 \varepsilon}, G_{10 / 10 \varepsilon}$ ) und das erste frühjahrliche mit derselben Wahrscheinlichkeit eintretende Normalstadium (Stadium: $\mathrm{S}_{10 / 10 \alpha}, \mathrm{G}_{10 / 10 \alpha}$ ), sowie 3) (um eine Auffassung von den Variationen der Länge des Mittwinters zu erhalten) das erste herbstliche und das letzte frühjahrliche mit der Wahrscheinlichkeit 5/10 (im a- und b-Gebiet: 6/10) eintretende Normalstadium (Stadien: $S_{5 / 10 \alpha}, G_{5 / 10 \alpha}$ und $S_{5 / 10 \varepsilon}, G_{5 / 10 \varepsilon}$ ) 
Für die Mittwinterzeit entsprechen also die für die verschiedenen Meeresteile hergeleiteten Zahlen noch nicht vollständig einander. Wir können jedoch trotzdem, da es sich hier nur um eine erklärende Übersicht handelt, diese Zahlen benutzen.

In den verschiedenen Meeresteilen und in dem ganzen Meeresgebiet Finnlands $(G)$ entsprechen den obenerwähnten Punkten in dem allgemeinen Verlauf des Winters folgende Normalstadien:

Tabelle 23.

Normal- bzw. Generalstadien, die bei der Berechnung der Länge der verschiedenen Winterteile benutzt werden.

\begin{tabular}{|c|c|c|c|c|c|c|}
\hline Stadium|Gebiet & $\mathbf{a}$ & b & c & d & e & G \\
\hline 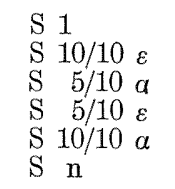 & $\begin{array}{l}\mathrm{Sa}_{1} \\
\mathrm{Sa}_{11} \\
\mathrm{Sa}_{13 \alpha} \\
\mathrm{Sa}_{13 \varepsilon} \\
\mathrm{Sa}_{15} \\
\mathrm{Sa}_{24}\end{array}$ & $\begin{array}{l}\mathrm{Sb}_{1} \\
\mathrm{Sb}_{12} \\
\mathrm{Sb}_{14} \\
\mathrm{Sb}_{16} \\
\mathrm{Sb}_{17} \\
\mathrm{Sb}_{22}\end{array}$ & $\begin{array}{l}\mathrm{Sc}_{1} \\
\mathrm{Sc}_{11} \\
\mathrm{Sc}_{14} \\
\mathrm{Sc}_{16} \\
\mathrm{Sc}_{19} \\
\mathrm{Sc}_{24}\end{array}$ & $\begin{array}{l}\mathrm{Sd}_{1} \\
\mathrm{Sd}_{9} \\
\mathrm{Sd}_{13} \\
\mathrm{Sd}_{17} \\
\mathrm{Sd}_{21} \\
\mathrm{Sd}_{24}\end{array}$ & $\begin{array}{l}\mathrm{Se}_{1} \\
\mathrm{Se}_{10} \\
\mathrm{Se}_{14} \\
\mathrm{Se}_{16} \\
\mathrm{Se}_{20} \\
\mathrm{Se}_{27}\end{array}$ & $\begin{array}{l}\mathrm{G}_{1} \\
\mathrm{G}_{13} \\
\mathrm{G}_{16} \\
\mathrm{G}_{19} \\
\mathrm{G}_{21} \\
\mathrm{G}_{29}\end{array}$ \\
\hline
\end{tabular}

161. Vermittels der Kurven der Zeitdiagramme bestimmten wir dann, um die Länge der verschiedenen Teile des Winters in den verschiedenen Wintertypen festzustellen, der Reihe nach die Zeitunterschiede in Tagen: $S_{n}-S_{1}, S_{10 / 10 \alpha}-S_{10 / 10 \varepsilon}$ und $S_{5 / 10 \varepsilon}-$ $\mathrm{S}_{5 / 10 \alpha .}$

Der erstgenannte Zeitunterschied $\mathrm{S}_{\mathrm{n}}-\mathrm{S}_{1}$ sowie der Zeitunterschied $\mathrm{G}_{n}-\mathrm{G}_{1}$ entspricht der Länge des ganzen Winters; die Zeitunterschiede $\mathrm{S}_{10 / 10 \alpha}-\mathrm{S}_{10 / 10 \varepsilon}$ und $\mathrm{G}_{10 / 10 \varepsilon}-\mathrm{G}_{10 / 10 \alpha}$ entsprechen der Länge jenes Winterteils, in dem diejenigen Eislagen sich befinden, welche nicht jeden Winter eintretenden Normalstadien entsprechen, und die Zeitunterschiede $S_{5 / 10 \alpha}-S_{5 / 10 \varepsilon}$ und $G_{5 / 10 \varepsilon}-G_{5 / 10 \alpha}$ geben endlich die Zeit der grössten Vereisung an.

Indem wir dann die verschiedenen Winter in derselben Weise wie in Tabelle 22 ordnen und die obenerwähnten Zeitunterschiede in die entsprechenden Kolumnen einführen, erhalten wir Tabelle 24.

Die Zahlenwerte dieser Tabellen haben wir im allgemeinen unmittelbar aus den Kurven $B B, C C$ und $D D$ der Zeitdiagramme erhalten. Da die den sehr früh bzw. sehr spät eintretenden Eislagen entsprechenden Zeitkurven $B B$, bzw. $D D$ nicht ganz linear verlaufen, folgen die «sf》-, bzw. «SS》- Zeiten der Normalstadien manchmal etwas schneller, manchmal etwas langsamer als auf der Hauptlinie $C C$ die "m»-Zeiten aufeinander. Wenn in der graphischen Darstellung (Fig. 61-66) der Zahlenwerte der Tabelle 24 einige Zahlen etwas abweichende Werte aufweisen, beruht dies auf dem glatten Gang der Kur- 
ven $B B$ und $D D$. Durch Glättung der betreffenden Kurventeile in Übereinstimmung mit den anliegenden Teilen können wir diese Zahlenwerte ausgleichen. In den Tabellen sind diese Zahlenwerte mit einem Stern (*) vermerkt.

Tabelle 24.

Die Länge des Winters in Tagen zwischen bestimmten Normalstadien in den vermittels der Kurven $B B, C C$ und $D D$ der Zeitdiagramme am einfachsten bestimmbaren, verschiedenen Wintern. In der Kolumne „Winter: Herbst, Mittwinter, Frühling» bedeutet sf $=$ sehr frïh, $n=$ normal und ss $=$ sehr spät. In der Kolumne "Der ganze Winter» ist die Winterlänge zwischen den Normalstadien, die den Stadien $S_{1}$ und $S_{n}$ der Tabelle 23 entsprechen, angegeben. In der Kolumne 10/10 ist die Winterlänge zwischen dem letzten Herbst- und dem ersten Frühlingsstadium, deren Wahrscheinlichkeit 10/10 ist, angegeben (Tabelle 23: $S_{10 / 10 \varepsilon}$ und $S_{10 / 10 \alpha}$, bzw. $G_{10 / 10 \varepsilon}$ und $\left.G_{10 / 10 \alpha}\right)$. In der Kolumne 5/10 ist die Winterlänge zwischen dem ersten Herbst- und dem letzten Frühlingsstadium, deren Wahrscheinlichkeit 5/10 (im Gebiete $\boldsymbol{a}$ und $\boldsymbol{b}$ 6/10) ist, angegeben (Tabelle 22: $S_{5 / 10 a}$ und $S_{5 / 10 \varepsilon}$, bzw. $G_{5 / 10 a}$ und $G_{5 / 10 \varepsilon}$ ).

Die Gebiete $\boldsymbol{a}$ und $\boldsymbol{b}$.

\begin{tabular}{|c|c|c|c|c|c|c|c|c|c|c|}
\hline \multicolumn{5}{|c|}{ Winter } & \multirow{2}{*}{$\left|\begin{array}{c}\text { Der ganze } \\
\text { Winter } \\
\mathbf{a}_{1-24}\end{array}\right|$} & \multirow{2}{*}{$\begin{array}{l}10 / 10 \\
a_{11-15}\end{array}$} & \multirow{2}{*}{$\begin{array}{c}5 / 10 \\
a_{13} \alpha-\varepsilon\end{array}$} & \multirow{2}{*}{$\left|\begin{array}{c}\text { Der ganze } \\
\text { Winter } \\
\mathbf{b}_{1-22}\end{array}\right|$} & \multirow{2}{*}{$\begin{array}{r}10 / 10 \\
b_{12-17}\end{array}$} & \multirow{2}{*}{$\begin{array}{c}5 / 10 \\
b_{14-16}\end{array}$} \\
\hline Herbst & Mit & twinter & Frühling & Nr. & & & & & & \\
\hline SS & - & - & sf & (1) & 165 & (4) & - & 146 & 6 & - \\
\hline SS & - & $一$ & $\mathrm{n}$ & (2) & 178 & $20^{*}$ & - & 161 & 31 & $\overline{15}$ \\
\hline$n$ & - & - & sf & (3) & 190 & (28) & - & 175 & 30 & (2) \\
\hline SS & SS & SS & SS & (4) & 194 & 44 & $19^{*}$ & $182^{*}$ & 51 & 25 \\
\hline$n$ & $\mathrm{n}$ & $n$ & $n$ & (5) & 203 & 50 & 23 & 190 & 55 & 31 \\
\hline st & sf & sf & sf & (6) & 215 & 56 & $28^{*}$ & 198 & 60 & (32) \\
\hline$n$ & $\mathrm{n}$ & SS & SS & (7) & 219 & 69 & 44 & 203 & 75 & 52 \\
\hline sf & $\mathrm{sl}$ & $\mathrm{n}$ & $n$ & (8) & 228 & 84 & 51 & 213 & 85 & 57 \\
\hline sf & sf & SS & SS & (9) & 244 & 103 & 62 & 226 & 105 & 78 \\
\hline
\end{tabular}

Die Gebiete c und $\boldsymbol{d}$.

\begin{tabular}{|c|c|c|c|c|c|c|c|c|c|c|}
\hline \multicolumn{5}{|c|}{ W in ter } & \multirow{2}{*}{$\left|\begin{array}{c}\text { Der ganze } \\
\text { Winter } \\
\mathbf{e}_{\mathbf{1 - 2 4}}\end{array}\right|$} & \multirow{2}{*}{$\begin{array}{r}10 / 10 \\
e_{11-19}\end{array}$} & \multirow{2}{*}{$\begin{array}{c}5 / 10 \\
e_{14-16}\end{array}$} & \multirow{2}{*}{$\begin{array}{c}\text { Der ganze } \\
\text { Winter } \\
\mathbf{d}_{\mathbf{1 - 2 4}}\end{array}$} & \multirow{2}{*}{$\begin{array}{l}10 / 10 \\
d_{9-21}\end{array}$} & \multirow{2}{*}{$\begin{array}{c}5 / 10 \\
d_{13-17}\end{array}$} \\
\hline Herbst & Mitt & winter & Frühling & $\mathrm{Nr}$. & & & & & & \\
\hline SS & - & - & sf & (1) & 124 & 17 & - & 108 & 28 & - \\
\hline SS & - & - & $\mathrm{n}$ & (2) & 145 & 40 & - & 123 & 46 & $11^{*}$ \\
\hline $\mathrm{n}$ & - & - & sf & (3) & 154 & 40 & - & 130 & 50 & 16 \\
\hline SS & ss & SS & SS & (4) & 161 & 57 & 17 & 138 & 63 & $32^{*}$ \\
\hline $\mathrm{n}$ & $\mathrm{n}$ & $n$ & $n$ & (5) & 175 & 63 & 21 & 145 & 68 & 34 \\
\hline sf & sf & sf & sf & (6) & $182^{*}$ & 65 & 24 & $156^{*}$ & 74 & 40 \\
\hline $\mathrm{n}$ & $\mathrm{n}$ & SS & sS & (7) & 191 & 80 & 44 & 160 & 85 & 55 \\
\hline sf & Sf & $n$ & $n$ & (8) & 199 & 88 & 48 & 178 & 92 & 58 \\
\hline sf & sf & SS & SS & (9) & 215 & 105 & 70 & 193 & 109 & 73 \\
\hline
\end{tabular}


(Fortsetzung der Tabelle 24.)

Das Gebiet $\boldsymbol{e}$ und die $\mathbf{G}$-Stadien.

\begin{tabular}{|c|c|c|c|c|c|c|c|c|c|c|}
\hline \multicolumn{5}{|c|}{ Winter } & \multirow{2}{*}{$\mid \begin{array}{c}\text { Der ganze } \\
\text { Winter } \\
\mathrm{e}_{1-27}\end{array}$} & \multirow{2}{*}{$\begin{array}{r}10 / 10 \\
\mathrm{e}_{10-20}\end{array}$} & \multirow{2}{*}{$\begin{array}{c}5 / 10 \\
\mathrm{e}_{14-16}\end{array}$} & \multirow{2}{*}{$\left|\begin{array}{c}\text { Der ganze } \\
\text { Winter } \\
\mathbf{G}_{1-29}\end{array}\right|$} & \multirow{2}{*}{$\begin{array}{c}10 / 10 \\
G_{13-21}\end{array}$} & \multirow{2}{*}{$\begin{array}{c}5 / 10 \\
\mathrm{G}_{16-19}\end{array}$} \\
\hline Herbst & Mittw & vinter & Frühling & Nr. & & & & & & \\
\hline SS & - & $\longrightarrow$ & sf & (1) & 118 & 21 & - & 165 & 20 & - \\
\hline ss & - & $\ldots$ & $\mathrm{n}$ & (2) & 133 & 43 & - & 179 & 42 & (7) \\
\hline $\mathrm{n}$ & - & - & sf & (3) & 147 & 41 & - & 189 & 40 & $10^{*}$ \\
\hline SS & SS & SS & SS & (4) & 149 & $58 *$ & $15^{*}$ & $195^{*}$ & 61 & $26^{*}$ \\
\hline $\mathrm{n}$ & $\mathrm{n}$ & $n$ & $\mathrm{n}$ & (5) & 162 & 63 & 15 & 203 & 62 & 26 \\
\hline sI & sf & sf & sf & (6) & 175 & 71 & 17 & 214 & 69 & 29 \\
\hline $\mathrm{n}$ & $n$ & ss & Ss & (7) & 178 & 81 & 36 & $219^{*}$ & 81 & 47 \\
\hline sf & sf & $n$ & $\mathrm{n}$ & (8) & 190 & 93 & $43^{*}$ & 228 & 91 & 53 \\
\hline sf & sf & SS & SS & (9) & 206 & 111 & 56 & 240 & 110 & 74 \\
\hline
\end{tabular}

Tabelle 25.

Die Amplituden [A] oder die Differenz der Länge der Winter (9) und (1) bzw. deren Teile in den verschiedenen Meeresteilen bzw. in den G-Stadien. $[\mathrm{g} W]=$ der ganze Winter; $[10 / 10]=$ der Winterteil $S_{10 / 10 \alpha}-S_{10 / 10 \varepsilon},[5 / 10]=$ der Winterteil $S_{5 / 10 \varepsilon}-S_{5 / 10 \alpha}$.

\begin{tabular}{|c|c|c|c|c|c|c|}
\hline$[\mathrm{A}]$ & $\mathbf{a}$ & $\mathbf{b}$ & $\mathbf{c}$ & $\mathbf{d}$ & $\mathbf{e}$ & $\mathbf{G}$ \\
\hline$[\mathrm{gW}]_{(9)-[\mathrm{gWW}}$ & 79 & 80 & 91 & 85 & 88 & 75 \\
{$[10 / 10]_{(9)-[10 / 10](1)}$} & 99 & 99 & 88 & 81 & 90 & 90 \\
{$[5 / 10]_{(9)-[5 / 10]}$} & 62 & 78 & 70 & 73 & 56 & 67 \\
\hline
\end{tabular}

Tabelle 26.

Das Verhältnis der Amplitude [A]gW des ganzen Winters zu der ganzen Länge [sk] des sk-bzw. [ml] des ml-und [sl] des sl-Winters in den verschiedenen Meeresteilen bzw. in den G-Stadien.

\begin{tabular}{|c|c|c|c|c|c|c|}
\hline$[\mathrm{A}] \mathrm{gW} /[\mathrm{gW}]$ & $\mathrm{a}$ & $\mathrm{b}$ & $\mathrm{c}$ & $\mathrm{d}$ & $\mathrm{e}$ & $\mathrm{G}$ \\
\hline & 0.48 & 0.55 & 0.73 & 0.79 & 0.75 & 0.45 \\
{$[\mathrm{~A}] /[\mathrm{sk}]$} & 0.39 & 0.42 & 0.52 & 0.59 & 0.54 & 0.37 \\
{$[\mathrm{~A}] /[\mathrm{ml}]$} & 0.32 & 0.35 & 0.42 & 0.44 & 0.43 & 0.31 \\
\hline $\mathrm{A}] /[\mathrm{s}]]$ & & &
\end{tabular}

Tabelle 27.

Das Verhältnis der Amplitude [A]10/10 zu dem entsprechenden Teil des sk-, ml- und sl-Winters in den verschiedenen Meeresteilen bzw. in den G-Stadien.

\begin{tabular}{|c|c|c|c|c|c|c|}
\hline$[\mathrm{A}] 10 / 10 /[10 / 10]$ & a & b & c & d & e & $G$ \\
\hline$[\mathrm{A}] / \mathrm{sk}]$ & - & - & $(5.17)$ & 2.89 & $(4.28)$ & $(4.50)$ \\
\hline $\begin{array}{l}{[\mathrm{A}] /[\mathrm{ml}]} \\
{[\mathrm{A}] /[\mathrm{sl}]}\end{array}$ & $\begin{array}{l}1.98 \\
0.96\end{array}$ & $\begin{array}{l}1.80 \\
0.94\end{array}$ & $\begin{array}{l}1.39 \\
0.84\end{array}$ & $\begin{array}{l}1.19 \\
0.74\end{array}$ & 1.43 & 1.45 \\
\hline
\end{tabular}


Tabelle 28.

Das Verhältnis der Amplitude [A]5/10 zu dem entsprechenden Teil des sk-, ml-und sl-Winters in den verschiedenen Meeresteilen bzw. in den G-Stadien.

\begin{tabular}{|l|c|c|c|c|c|c|}
\hline$[\mathrm{A}] 5 / 10 /[5 / 10]$ & $\mathrm{a}$ & $\mathrm{b}$ & $\mathrm{c}$ & $\mathrm{d}$ & $\mathrm{e}$ & $\mathrm{G}$ \\
\hline$[\mathrm{A}] /[\mathrm{sk}]$ & - & - & - & - & - & - \\
{$[\mathrm{A}] /[\mathrm{ml}]$} & 2.70 & 2.52 & 3.33 & 2.15 & 3.73 & 2.58 \\
{$[\mathrm{~A}] /[\mathrm{sl}]$} & 1.00 & 1.00 & 1.00 & 1.00 & 1.00 & 0.90
\end{tabular}

Ohne uns in die Werte der Tabellen $24-28$ eingehender zu vertiefen, wollen wir hier nur - mit Hilfe der nach denselben gezeichneten Kurven (Fig. 61-66) - die Variationen der Länge des ganzen Winters $[\mathrm{gW}]$, sowie der Winterteile $[10 / 10]$ und $[5 / 10]$ der aus den Zeitdiagrammen hergeleiteten Winter (1), (2), (3) .... in ihren Hauptzügen aufklären.

In den Figuren zeigen die linksstehenden Kurven unter der Überschrift "Zahl der Tage», wie die Länge des ganzen Winters (Kurve $[\mathrm{gW}]$ ) sowie die Länge des Winters zwischen den Stadien $\mathrm{S}_{10 / 10 \varepsilon}$ und $\mathrm{S}_{10 / 10 \alpha}$ (Kurve [10/10]) und zwischen den Stadien $\mathrm{S}_{5 / 10 \alpha}$ und $S_{5 / 10 \varepsilon}$ (Kurve [5/10]) in den Meeresteilen bzw. nach den GStadien wechselt, wenn der Winter von dem sk-Winter (1) durch den Winter (2), (3) usw. in den sl-Winter (9) übergeht.

Weiter geben in Fig. 61-66 rechts unter der Ủberschrift »\% die oberen Kurven [5/10], [10/10] und [g W] die Länge dieser Teile der Winter (1), (2), (3) usw. in \% der entsprechende Länge ( Nml [5/10], $\mathrm{Nml}[10 / 10]$ und $\mathrm{Nml}[\mathrm{g} \mathrm{W}]$ ) des normalen mittellangen Winters (5) wieder. Unten folgen noch die Kurven, die das prozentuale Verhältnis des Winterteils [5/10] zum Teil [10/10], und des Teils [10/10] bzw. [5/10] zur ganzen Länge [gW] desselben Winters (1), (2), (3) . . veranschaulichen.

16\%. Die Länge des ganzen Winters [gW] wechselt somit in dem Gebiet a zwischen 165 und 244, in dem Gebiet b zwischen 146 und 226, in dem Gebiet c zwischen 124 und 215, in dem Gebiet d zwischen 108 und 193 und in dem Gebiet e zwischen 118 und 206 Tagen. Der kürzeste Winter (1) hat also im Norden (Gebiet a) eine Länge von 165, im Südwesten (Gebiet d) von nur 108 Tagen, während die Länge des normalen mittellangen Winters (5) in diesen Gebieten 203 bzw. 145 Tage, die Dauer des längsten Winters (9) 244 und 193 Tage ist.

Die Länge des Winterteils [10/10] wechselt in den verschiedenen Gebieten auf folgende Weise: in dem Gebiet a zwischen 4 und 103, in dem Gebiet b zwischen 6 und 105, in dem Gebiet c zwischen 


\section{Gebiet a}

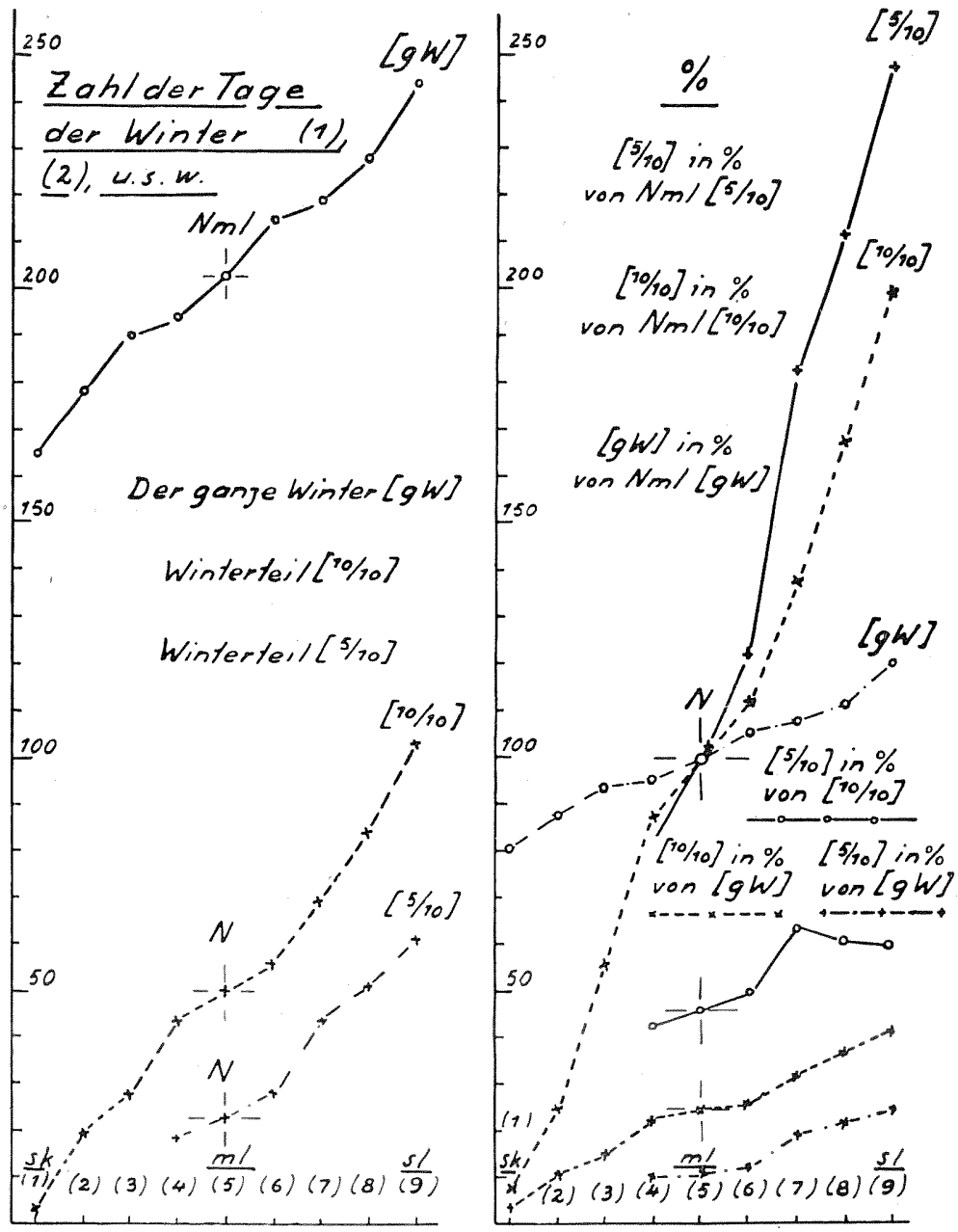

Fig. 61. Links unter der Überschrift $" \mathrm{Z}$ a h l der Tagen gibt nach Tabelle 24 - die Kurve $[\mathrm{gW}]$ die Länge des ganzen Winters wieder, die Kurven $[10 / 10]$ bzw. [5/10] die Länge des Winterteils, der zwischen den Normalstadien $\mathrm{S}_{10 / 10 \varepsilon}$ und $\mathrm{S}_{10 / 10 \alpha}, \mathrm{bzw} . \mathrm{S}_{5 / 10 \alpha}$ und $\mathrm{S}_{5 / 10 \varepsilon}$ (Tabelle 23) der Winter (1), (2), (3)... liegt im Gebiet a. - Rechts unter der Überschrift $" \% "$ zeigen die oberen drei Kurven den Gang des prozentualen Verhältnisses der Winterteile $[5 / 10],[10 / 10]$ und $[5 / 10]$ der Winter (1), (2), (3) ... zu dem entsprechenden Teil des normalen, mittellangen Winters, und die unteren Kurven das Verhältnis des Winterteils [5/10] und [10/10] zu. dem Winterteil $[10 / 10]$, bzw. [ $\mathrm{gW}]$ in denselben Wintern (nach den Zahlen der Tabelle 24 berechnet) im Gebiet $\mathbf{a}$.

17 und 105, in dem Gebiet d zwischen 28 und 109 und in dem Gebiet 0 zwischen 21 und 111 Tagen. Die Amplitude ist hierbei also verhältnismässig bedeutend grösser als für die Länge des ganzen Winters. 


\section{Gebiet 6}

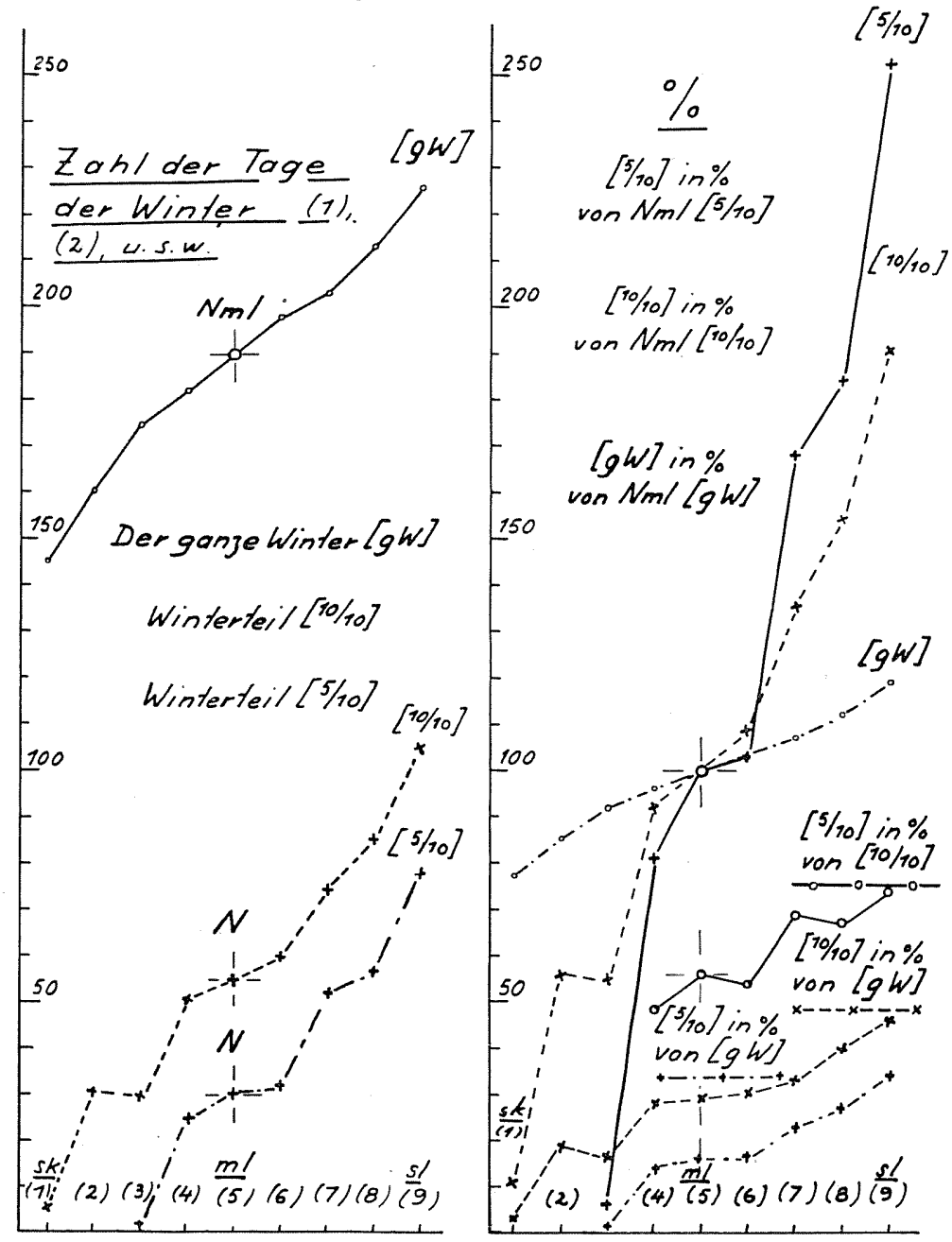

Fig. 62. Die "Zahl der Tage» usw. des Gebietes b. Die Erklärungen siehe Fig. 61.

Der Winterteil [5/10] erscheint in den Gebieten a, $\mathbf{c}$ und e erst im sehr späten (ss-) Winter (4), in dem Gebiet b jedoch im Winter (3), aber in dem Gebiet d schon im Winter (2). Die Länge dieses Winterteils wechselt in den verschiedenen Gebieten wie folgt: in dem Gebiet a zwischen 19 und 62, in dem Gebiet b zwischen 2 und 78, in dem Gebiet e zwischen 17 und 70, in dem Gebiet d zwischen $11^{*}$ und 73 und in dem Gebiet e zwischen $15^{*}$ 


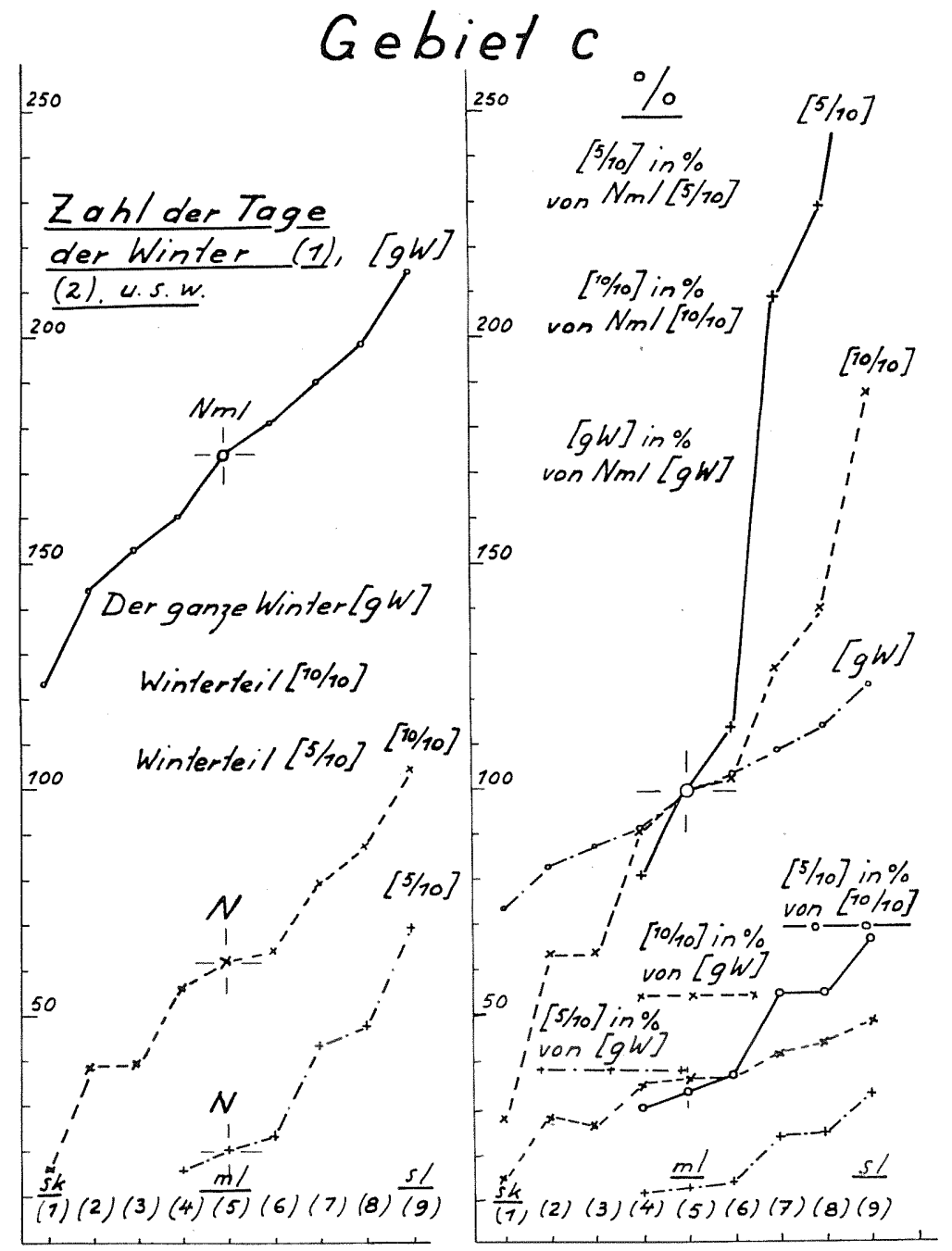

Fig. 63. Die "zahl der Tage» usw. des Gebietes e. Die Erklärungen siehe Fig. 61 .

und 56 Tagen. Auch für diesen Winterteil ist also die Schwankung der Länge verhältnismässig grösser als für die Länge des ganzen Winters, was übrigens ganz natürlich ist.

Die entsprechenden Zahlen bzw. Kurven der G-Stadien ergeben, dass die Länge des ganzen Winters $[\mathrm{gW}]$ zwischen 165 und 240, die Länge des Winterteils [10/10] zwischen 20 und 110 und des Winterteils $[5 / 10]$ zwischen 7 und 74 Tagen wechselt. 


\section{Gebiet d}

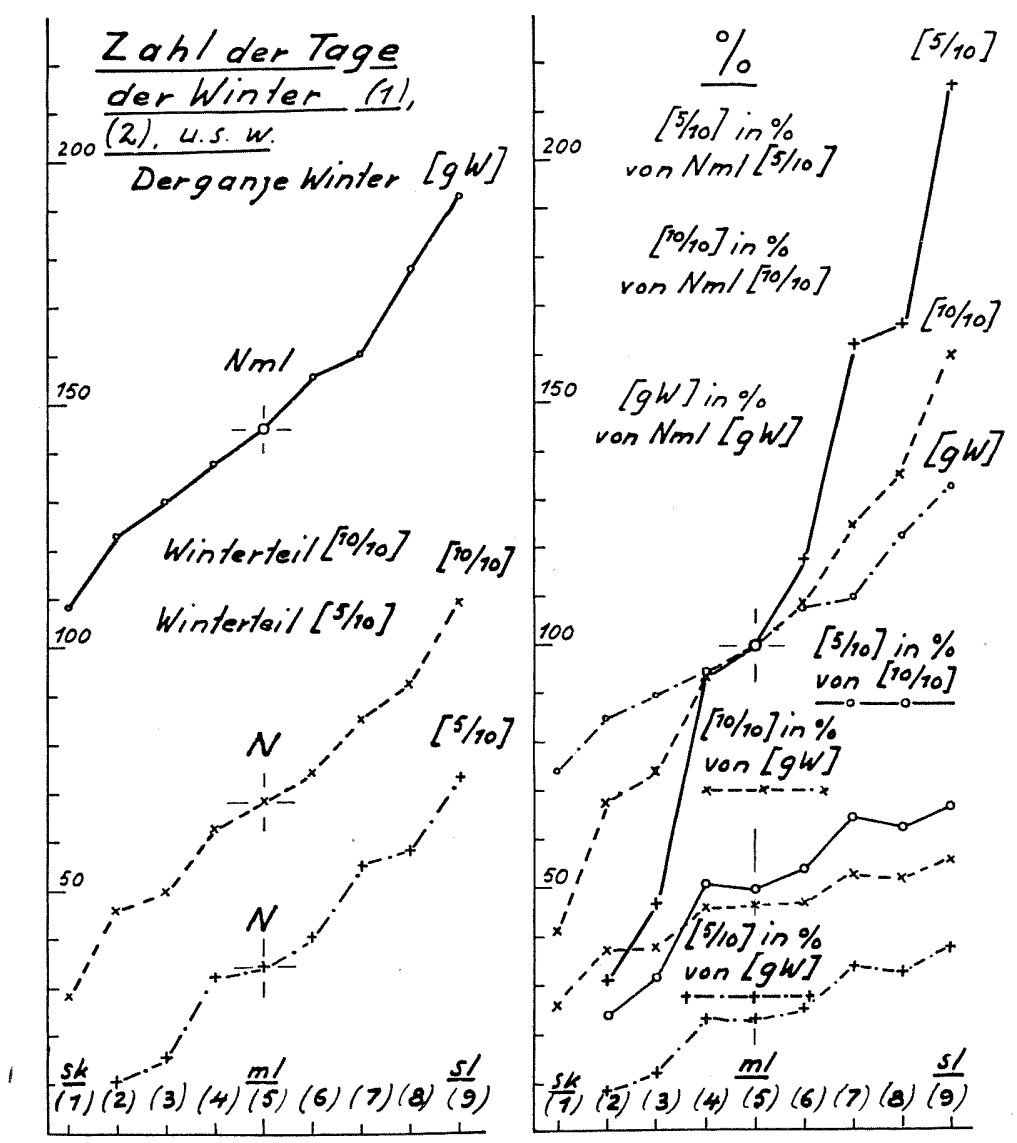

Fig. 64. Die "zahl dex Tage» usw. des Gebietes d. Die Erklärungen siehe Fig. 61.

Die Schwankungen in der ganzen Länge [gW] sowie in der Länge der Teile [10/10] und [5/10] der verschiedenen Winter (1), (2), (3) . . in den Gebieten $\mathbf{a}, \mathbf{b}, \mathbf{e}, \mathbf{d}$ und $\mathbf{e}$ und nach den $\mathbf{G}$-Stadien gehen noch übersichtlicher aus Tabelle 29 und Fig. 67 hervor, deren Kurven, bzw. kleine Kreise in den Kolumnen »G» nach Tabelle 29 gezeichnet sind.

163. In Tabelle 29 sind nämlich die Zahlen der Tabelle 24 nach den Wintern (1), (2) ... geordnet, d.h.so, dass die Länge desselben Winters in den Meeresteilen zu je einer Gruppe zusammengestellt ist. In der Überschrift der Gruppe der Tabelle ist ausser 
der Nummer des Winters noch die Beschaffenheit (»n», "sS», 》sf») des Herbstes, des Mittwinters und des Frühlings des betreffenden Winters angegeben. Die Kurven der entsprechenden Figur 67 zeigen die Schwankungen in der Länge desselben Winters in den Meeresteilen: in der ersten Gruppe in bezug auf den ganzen Winter, in der folgenden Gruppe in bezug auf den Winterteil [10/10] und in der letzten Gruppe in bezug aut den Winterteil [5/10]. Die Kurven sind mit der Nummer des entsprechenden Winters versehen. - In der Kolumne $G$ ist noch vermittels kleiner Kreise die Länge des den betreffenden Kurvengruppen entsprechenden Winterteils, nach dem Zeitdiagramm der G-Stadien berechnet, angegeben.

Wir wollen hier auf Grund der Zahlen der Tabellen und der Kurven der Figuren noch folgendes hervorheben. Da der längste Winter, der ungefähr 245 Tage umfasst, der sl-Winter der Bottenwiek ist, und der kürzeste Winter, der ungefähr 110 Tage beträgt, der skWinter des Schärenmeers ist, so ist die grösste Amplitude des Winters von dem nördlichsten Teil der Bottenwiek bis zum südwestlichen Schärenhof ungefähr 135 Tage. Diese Amplitude ist $23 \%$ länger als der kürzeste Winter und entspricht $53 \%$ des längsten Winters. Die Kurven des Winterteils [10/10] haben einen entgegengesetzten Verlauf als die [gw]-Kurven: jene haben die kleinsten Werte für das a-Gebiet, die grössten für das d-Gebiet, diese

Tabelle 29.

Die Buchstaben nach der Winternummer (in Klammern) beziehen sich: auf den Herbst; auf den Anfangsteil und auf den Endteil des Mittwinters; auf den Frühling. Hierbei bedeuten ss, $n$, und sf wieder, dass der Herbst bzw. Mittwinter und Frühling in bezug auf den normalen mittellangen Winter sehr spät, normal oder sehr früh ist.

Winter (1): ss; - -; sf (=sk-Winter).

\begin{tabular}{|c|c|c|c|c|c|c|}
\hline Winterteil & a & b & c & d & e & G \\
\hline$[\mathrm{gw}]$ & 165 & 146 & 124 & 108 & 118 & 165 \\
{$[10 / 10]$} & $(4)$ & 6 & 17 & 28 & 21 & 20 \\
{$[5 / 10]$} & - & - & - & - & - & - \\
\hline
\end{tabular}

Winter (2): ss; - - - $n$.

\begin{tabular}{|c|c|c|c|c|c|c|}
\hline Winterteil & a & b & c & d & e & G \\
\hline $\begin{array}{l}{[g w]} \\
10 / 10] \\
{[5 / 10]}\end{array}$ & $\begin{array}{c}178 \\
20^{*} \\
\end{array}$ & $\begin{array}{r}161 \\
31 \\
\end{array}$ & $\begin{array}{r}145 \\
40 \\
\end{array}$ & $\begin{array}{c}123 \\
46 \\
11^{*}\end{array}$ & $\begin{array}{r}133 \\
43 \\
\end{array}$ & $\begin{array}{r}179 \\
42 \\
(7)\end{array}$ \\
\hline
\end{tabular}


(Fortsetzung der Tabelle 29.)

Winter (3): $n$; - - - st.

\begin{tabular}{|l|c|c|c|c|c|c|}
\hline Winterteil & a & b & c & d & e & G \\
\hline$[\mathrm{gw}]$ & $\begin{array}{c}190 \\
{[0 / 10]}\end{array}$ & $\begin{array}{r}175 \\
30\end{array}$ & $\begin{array}{r}154 \\
40\end{array}$ & $\begin{array}{r}130 \\
50\end{array}$ & $\begin{array}{r}147 \\
41\end{array}$ & $\begin{array}{c}189 \\
40\end{array}$ \\
{$[5 / 10]$} & - & $(2)$ & - & 16 & - & $10^{*}$ \\
\hline
\end{tabular}

Winter (4): ss; ss, ss; ss (=ss-Winter).

\begin{tabular}{|l|c|c|c|c|c|c|}
\hline Winterteil & a & b & e & d & e & G \\
\hline$[g w]$ & 194 & $182^{*}$ & 161 & 138 & 147 & $195^{*}$ \\
{$[10 / 10]$} & 44 & 51 & 57 & 63 & $58^{*}$ & 61 \\
{$[5 / 10]$} & $19^{*}$ & 25 & 17 & $32^{*}$ & $15^{*}$ & $26^{*}$ \\
\hline
\end{tabular}

Winter (5): $n ; n, n ; n$ (=ml-Winter).

\begin{tabular}{|l|r|r|r|r|r|r|}
\hline Winterteil & a & b & c & d & e & G \\
\hline$[\mathrm{gw}]$ & 203 & 190 & 175 & 145 & 162 & 203 \\
{$[10 / 10]$} & 50 & 55 & 63 & 68 & 63 & 62 \\
{$[5 / 10]$} & 23 & 31 & 21 & 34 & 15 & 26 \\
\hline
\end{tabular}

Winter (6): sf; sf, sf; sf (=sf-Winter).

\begin{tabular}{|l|c|c|c|c|c|r|}
\hline Winterteil & a & b & c & d & e & G \\
\hline$[\mathrm{gw}]$ & 215 & 198 & $182^{*}$ & $156^{*}$ & 175 & 214 \\
{$[10 / 10]$} & 56 & 60 & 65 & 74 & 71 & 69 \\
{$[5 / 10]$} & $28^{*}$ & $(32)$ & 24 & 40 & 17 & 29 \\
\hline
\end{tabular}

Winter ("y): $n$; $n, s s ; s s$.

\begin{tabular}{|l|r|r|r|r|r|r|}
\hline Winterteil & a & b & c & d & e & G \\
\hline & 219 & 203 & 191 & 160 & 178 & $219 *$ \\
{$[$ gW] } & 69 & 75 & 80 & 85 & 81 & 81 \\
{$[10 / 10]$} & 44 & 52 & 44 & 55 & 36 & 47 \\
\hline $5 / 10]$ & & &
\end{tabular}

Winter (8): sf; sf, $n ; n$.

\begin{tabular}{|l|r|r|r|r|r|r|}
\hline Winterteil & a & b & c & d & e & G \\
\hline$[\mathrm{gw}]$ & 228 & 213 & 199 & 178 & 190 & 228 \\
{$[10 / 10]$} & 84 & 85 & 88 & 92 & 93 & 91 \\
{$[5 / 10]$} & 51 & 57 & 48 & 58 & $43^{*}$ & 53 \\
\hline
\end{tabular}


(Ende der Tabelle 29.)

Winter (9): sf; sf, ss; ss (=st-Winter).

\begin{tabular}{|c|c|c|r|r|r|r|}
\hline Winterteil & a & b & c & d & e & G \\
\hline$[\mathrm{gw}]$ & 244 & 226 & 215 & 193 & 206 & 240 \\
{$[10 / 10]$} & 103 & 105 & 105 & 109 & 111 & 110 \\
{$[5 / 10]$} & 62 & 78 & 70 & 73 & 56 & 74 \\
\hline
\end{tabular}

\section{Gebiete}

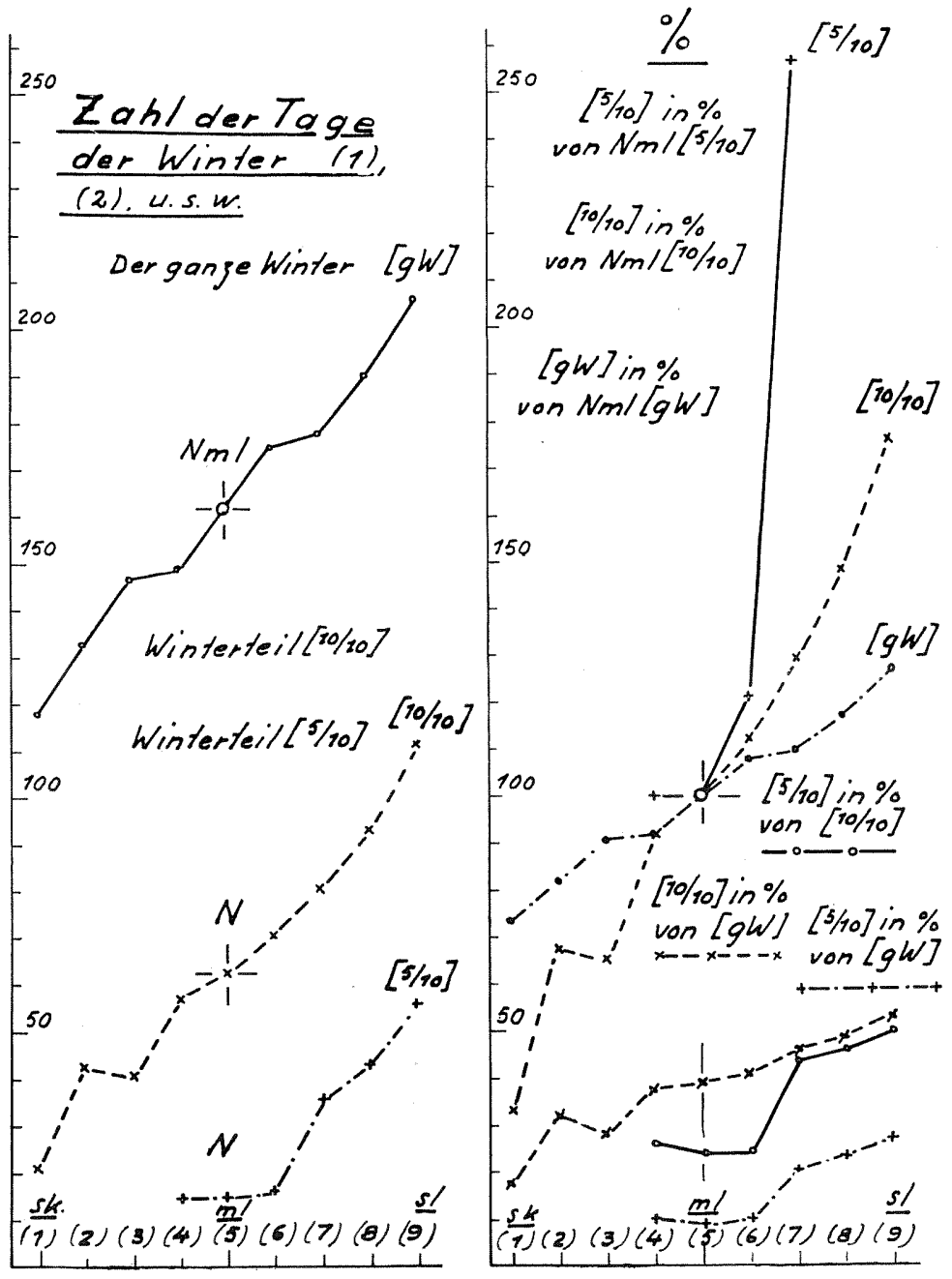

Fig. 65. Die "Zahl der Tage" usw. des Gebietes e. Die Erklärungen siehe Fig. 61 . 


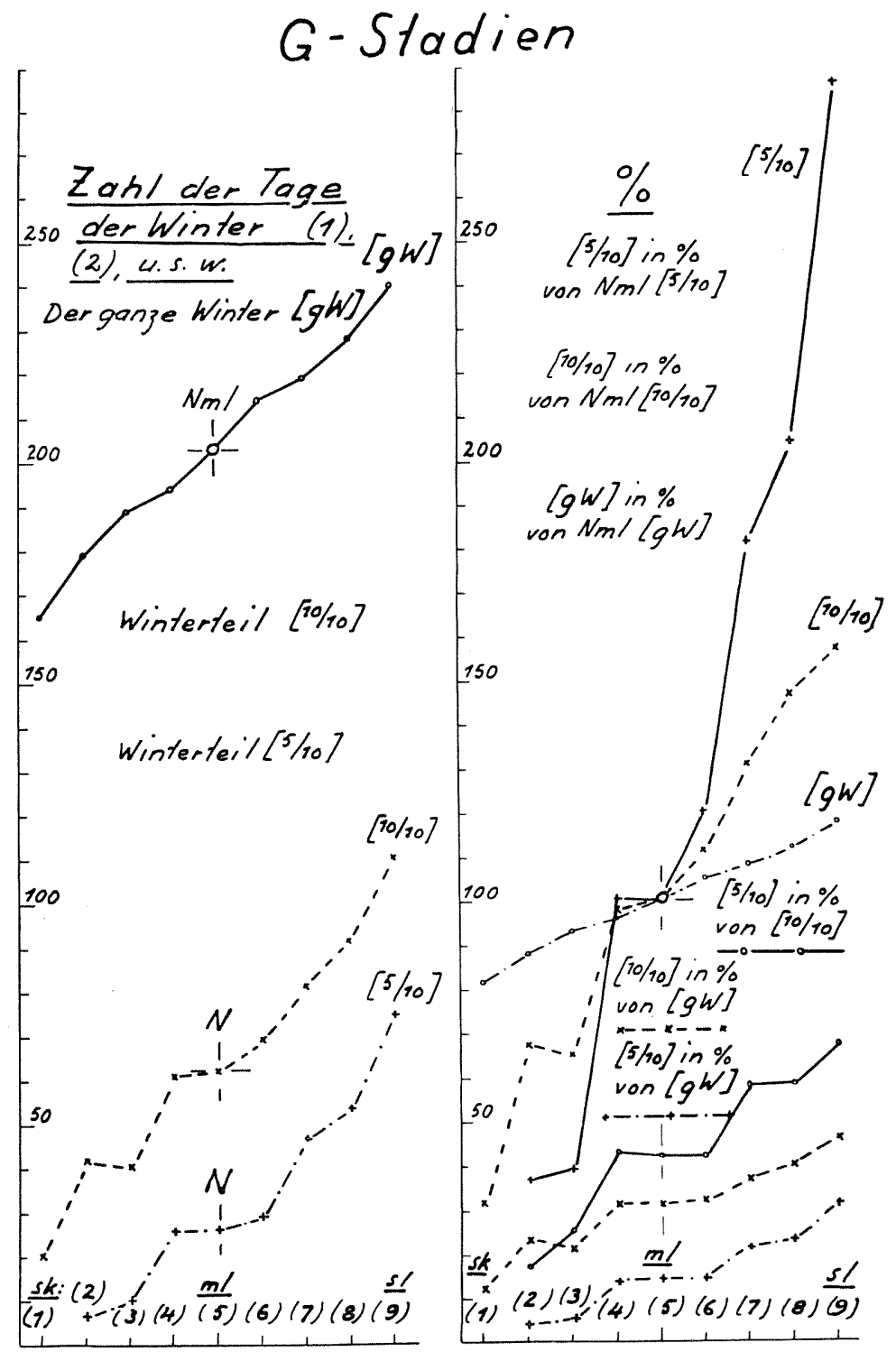

Fig. 66. Die "Zahl der Tage» usw. nach den G-Stadien. Die Erklärungen siehe Fig. 61 .

meist umgekehrt. Bei der Verlängerung des Winters werden die Zahlenwerte der verschiedenen Meeresteile bedeutend gleichmässiger, so dass in bezug auf die Winter (8) und (9) der Unterschied für den Winterteil [10/10] zwischen den verschiedenen Meeresteilen nur 7-9 
Tage ist. - Die Kurven des Winterteils [5/10] verlaufen im allgemeinen ungleichmässiger, aber weisen doch zwei deutliche Maxima auf, die den inselreichen Gebieten b und $\mathbf{d}$ entsprechen.

164. In allen Meeresteilen bemerken wir, dass bei einer Verlängerung des Winters die Zeit der schwereren Eislagen, d. h. die Winterteile [10/10] und [5/10] prozentual i m mer zunehmen und zwar bedeutend schneller als die Länge des ganzen Winters selbst, was auch ganz natürlich ist. So ist die Länge des ganzen sk-Winters etwa 70 bis $80 \%$, die des sl-Winters etwa 120-135\% derjenigen des mlWinters, aber der Winterteil [10/10], der im sk-Winter nur 10$40 \%$ von dem Teil [10/10] des ml-Winters beträgt, ist in dem sl-Winter etwa 160-200\%, und der Teil [5/10] wächst, wieder in bezug auf den entsprechenden Teil des ml-Winters, von $\gg 0 » \% \mathrm{im}$ sk-Winter auf etwa $200-400 \%$ im sl-Winter.

Der Anteil der Winterteile [10/10] und [5/10] in einem und demselben Winter wächst, wenn die Länge des ganzen Winters zunimmt, wieder so, dass, wenn in den »kurzen Wintern» der erstgenannte Teil $5-25 \%$, der letztgenannte Teil etwa $1-15 \%$ der Länge des ganzen Winters beträgt, er in den langen und sehr langen Wintern etwa $40-55 \%$, bzw. etwa $25-40 \%$ ausmacht. Auch das Verhältnis zwischen den Winterteilen [5/10] und [10/10] zueinander in einem und demselben Winter verändert sich in gleicher Richtung: in den mittellangen Wintern ist das prozentuale Verhältnis des Teils [5/10] zum Teil [10/10] etwa $25-50 \%$, in den sehr langen Wintern etwa $50-75 \%$.

165. Untersuchen wir die Amplitude [A] der verschiedenen Winterteile $[\mathrm{gW}],[10 / 10]$ und [5/10] und ihr Verhältnis in \% zu der Länge des sk-, ml- und sl-Winters (Tab. 25-28 und Fig. 68), bemerken wir folgendes:

Die Amplitude $[\mathrm{A}] \mathrm{gW}$ des ganzen Winters ist ziemlich gleichmässig 80 - 90 Tage in allen Meeresteilen Finnlands. Die Amplitude [A]10/10 des Winterteils [10/10] ist teilweise etwas grösser, indem sie zwischen etwa $80-100$ Tagen schwankt, und die Amplitude $[\mathrm{A}] 5 / 10$ des Winterteils [5/10] varüert zwischen etwa $55-80$ Tagen.

Das prozentuale Verhältnis der Amplitude $[\mathrm{A}] \mathrm{gW}$ zu der Länge des ganzen sk-, bzw. ml- oder sl-Winters schwankt sehr stark in den verschiedenen Meeresteilen. So ist diese Amplitude im Verhältnis zu dem sk-Winter am kleinsten, ungefähr $50 \%$, in der Bottenwiek; am grössten, nahezu $80 \%$, ist sie im Schärenmeer. Ebenso verhält es sich sowohl in dem ml- als in dem sl-Winter, aber die Kurve des sl-Winters ist ziemlich glatt und die Verhältniszahl in 
$\%$ in dem c-, d- und e-Gebiete nahezu dieselbe. Da nun in mlWintern die \%-Zahlen in den Gebieten der Bottenwiek und des Schärenmeers ungefähr 40 und 60, und in sl-Wintern ungefähr 30 und
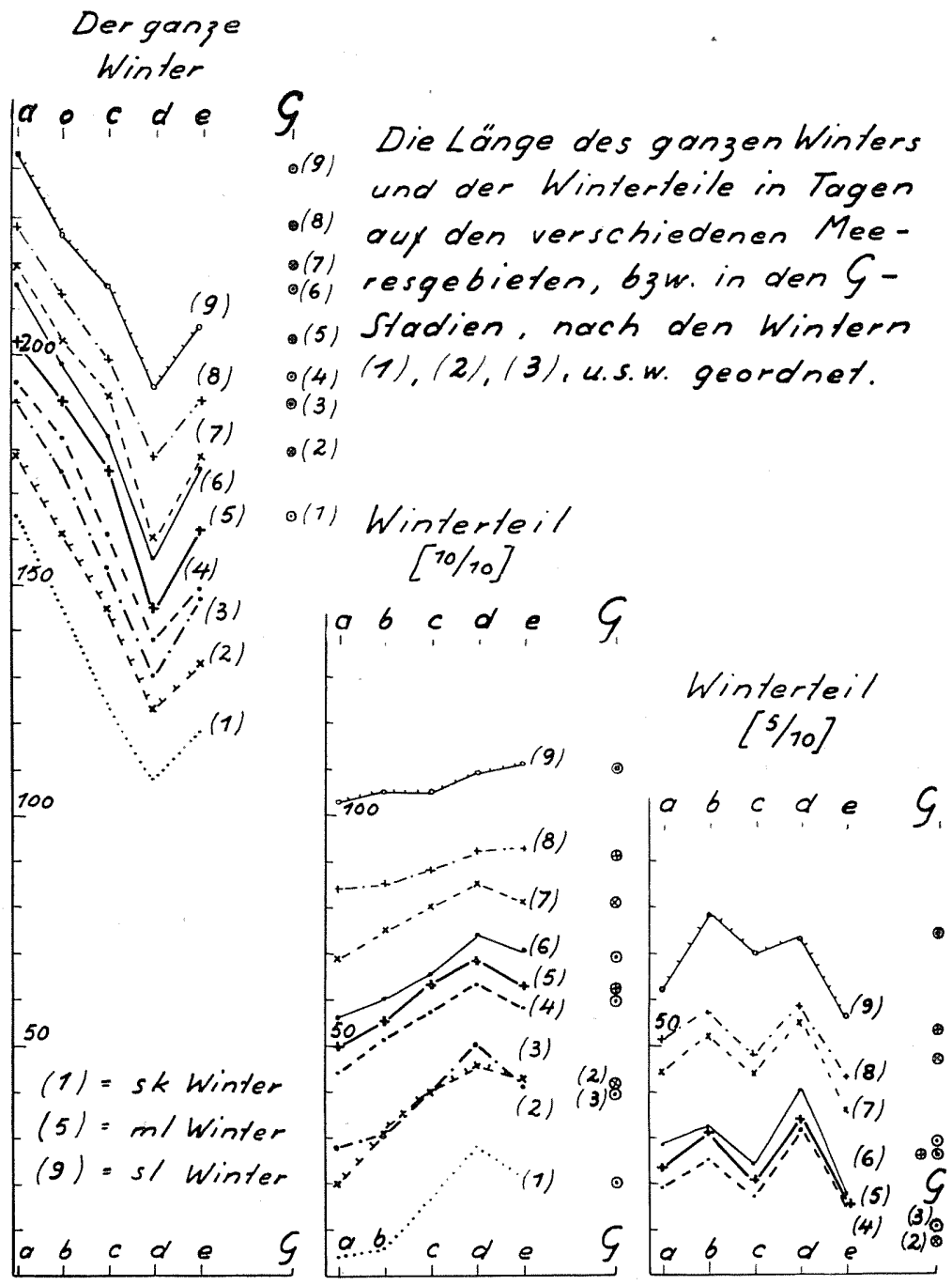

Fig. 67. Die Läng e des ganzen Winters, bzw. der Winterteile [10/10] und $[5 / 10]$ in den Meeresgebieten und nach den G-Stadien (Kolumne G) nach den Wintern (1), (2), (3) ... geordnet.

45 sind, ist die Schwankung am grössten in SW (und $\mathrm{S}$ ), am geringsten in $\mathrm{N}$.

Der Gang des Verhältnisses der Amplitude des Winterteils [10/10] zu dem entsprechenden Teil des ml- und sl-Winters ist bei dem Ver- 


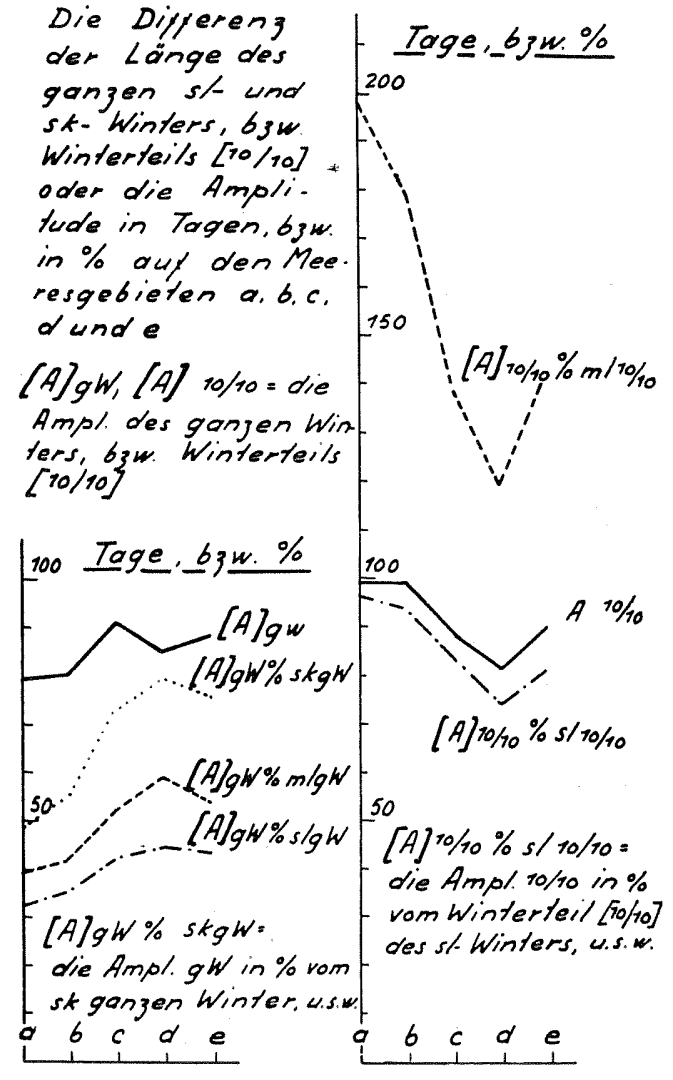

Fig. 68. Die a usgezo genen Linien [A]gW und $[\mathrm{A}] 10 / 10 \mathrm{geben}$ den Verlauf der Amplitude der Winterteile [gW] und [10/10] oder der Differenz [gW]sl-[gW]sk, bzw. $[10 / 10] \mathrm{sl}-[10 / 10] \mathrm{sk}$ in den verschiedenen Meeresteilen wieder. gleich mit den Kurven $[\mathrm{A}] \mathrm{gW} \% \mathrm{skW}$ usw. (Fig. 68) entgegengesetzt. Am grössten ist das Verhältnis in $\mathrm{N}$ (in der Bottenwiek und im Kvark), am kleinsten in SW (im Schärenmeer). So ist die Amplitude $[\mathrm{A}]_{10 / 10}$ in der Bottenwiek in den ml-Wintern ungefähr 200 $\%$ und in den sl-Wintern ungefähr $95 \%$ des Winterteils 10/10, im Schärenmeer dagegen ungefähr 120 , bzw . $75 \%$. Die Amplitude $[\mathrm{A}]_{5} / 10$ ist gleich dem Winterteil [5/10] des sehr langen Winters und ist für die verschiedenen Meere etwa $270,255,335,215$ und $375 \%$ des Winterteils [5/10] des ml-Winters. Somit ist in den sl-Wintern die Länge des Winterteils [5/10] ungefähr 2-4 mal grösser als in den mlWintern.

Diese Zunahme der Prozentzahlen der Amplituden $[\mathrm{A}]_{\mathrm{gW}},[\mathrm{A}]_{10 / 10}$ und $[\mathrm{A}]_{5 / 10}$ bei dem Gang von dem sk-Winter über den ml-Winter in den sl-Winter zeigt, dass bei einer Verlängerung des Winters die grössten Veränderungen zunächst im Mittwinter, wo die schwersten Eislagen eintreten, danach in dem Teil des Winters, zu dem die den "nicht jährlich eintretenden» Normalstadien entsprechenden Eislagen gehören und zuletzt in den den ersten und letzten Normalstadien des Winters entsprechenden Winterteilen eintreten.

166. Untersuchen wir noch die Amplitude eines und desselben Winters (1), (2), (3). . . in den Meeresteilen, d. h. bestimmen wir den Unterschied zwischen der längsten (im a-Gebiet) und der kürzesten (im d-Gebiet) Dauer eines Winters (1), (2), (3). .., so finden 
wir (Tabelle 30), dass diese Amplitude des ganzen Winters 50-60 Tage ist. Die Amplitude des Winterteils [10/10] beträgt im allgemeinen 16-26 Tage; in den Wintern (8) und (9) jedoch im a- und e-Gebiet 8 und 9 Tage. Die Amplitude des Winterteils [5/10] ist im Winter (8) nur 7 Tage, im allgemeinen 11-13 Tage, im Winter (3) jedoch 16 Tage.

Tabelle 30 .

Die Differenz zwischen der Länge der Winterteile [gW], [10/10] und [5/10] derselben Winter (1), (2), (3) ... in den Gebieten $\boldsymbol{\alpha}$ und $\boldsymbol{d}$.

\begin{tabular}{|c|c|c|c|c|c|c|c|c|c|}
\hline & $(1)$ & $(2)$ & $(3)$ & $(4)$ & $(5)$ & $(6)$ & $(7)$ & $(8)$ & $(9)$ \\
\hline $\begin{array}{c}([\mathrm{A}] \mathrm{gW}) \mathrm{a}-([\mathrm{A}] \mathrm{gW}) \mathbf{d} \\
([\mathrm{A}] 10 / 10) \mathrm{a}-(\mathrm{A}] 10 / 10) \mathbf{d}\end{array}$ & $\begin{array}{c}57 \\
(24)\end{array}$ & 55 & 60 & 56 & 58 & 59 & 59 & 50 & 51 \\
$([\mathrm{~A}] 5 / 10) \mathrm{a}-([\mathrm{A}] 5 / 10) \mathbf{d}$ & - & $11^{*}$ & 16 & 19 & 18 & 18 & 16 & 9 & 8 \\
\end{tabular}

16\%. Obwohl der allgemeine Verlauf eines Winter nicht genügend durch die Bestimmung seiner ganzen Länge und der Länge seiner Teile [10/10] und [5/10] klargelegt ist, so geben diese Zahlen doch, wenn wir noch die Zeitpunkte des Anfangs und des Endes des Winters berücksichtigen, ein sehr klares Bild von der allgemeinen Natur desselben. Eine eingehende Darstellung des Verlaufs eines Winters erfordert jedoch möglichst viel verwendbare Eislagen, deren Stelle dann in den Zeitdiagrammen oder besser in den Arbeitsdiagrammen bestimmt werden muss.

\section{Die Länge des ganzen bzw. ganz bestimmter Teile des sk-, bzw. ml- und sl- Winters, berechnet nach der Ausbreitung und dem Rückgang der Bräme des festen Küsteneises in den verschiedenen Meeresteilen.}

168. Ein Beispiel dafür, wie man ausschliesslich mit Hilfe der Normalstadien und nur die Hauptlinien $B B, C C$ und $D D$ der Zeitdiagramme verfolgend ein sehr anschauliches Bild vom Verlauf der verschieden langen Winter erhalten kann, geben die Tabellen 32-35. Die Zahlen dieser Tabellen sind nämlich in der Weise hergeleitet worden, dass bestimmt wurde, wann in einem sehr kurzen, mittellangen und sehr langen Winter die Bräme des festen Küsteneises nach den G-Stadien dieselben, ganz bestimmten Lagen erreicht hat. 
Die Länge des ganzen Winters, ebenso wie die Länge bestimmter Teile des Winters war in den Tabellen 24 und 29 immer vermittels der Normalstadien für das ganze Me eresgebiet berechnet worden. Da nun anderseits die Länge des Winters in den verschiedenen Teilen desselben Meeresgebietes bedeutend wechselt und der allgemeine Verlauf des Winters deshalb auf verschiedene Weise sich gestaltet, wurde bei der Aufstellung der Tabellen 32 und 33, bzw. 34 und 35, ein wenig anders verfahren. Um nämlich die »individuellen» Eigenschaften der verschiedenen Teile desselben Meeresgebiets genügend zu berücksichtigen, wurden bei der Verfolgung der Ausbreitung bzw. des Rückganges der Bräme des festen Küsteneises in den G-Stadien die grösseren Meeresgebiete a, e und $\mathbf{e}$ in passende Teilgebiete zerlegt, und der Verlauf des Winters für diese statt für das ganze Gebiet bestimmt. Aber auch nun zeigen die Tabellen nur einige ganz bestimmte, vermittels der Bräme des festen Küsteneises charakterisierte Phasen in dem allgemeinen Verlauf des Winters, geben also noch kein vollständiges Bild davon.

Die Gebiete a und c haben wir zwecks Bestimmung der Zahlenwerte der Tabellen in die Teilgebiete N, M und S, welche der Reihe nach dem nördlichen, mittleren und südlichen Teile dieser Gebiete entsprechen, eingeteilt; das e-Gebiet wiederum in die Teilgebiete $W$, M und E, die dem westlichen, mittleren und östlichen Teile des Finnischen Meerbusens entsprechen. Diese Teilgebiete umfassen: Das aN-Teilgebiet den nördlichsten Teil der Bottenwiek bis zur Gegend von Raahe (6) (die Zahl in Klammern hinter dem Namen bezeichnet die Stelle auf der Karte der Beobachtungsorte S. $29 \mathrm{im}$ Atlas); das aM-Teilgebiet den Teil der Bottenwiek zwischen Raahe (6) und Tankar (10); das aS-Teilgebiet die Bottenwiek von Tankar (10) bis ungefähr Björkö (12) im Süden; das eN-Teilgebiet die Bottensee von Strömmingsbådan (17b) und Bergö (16) bis südlich von Högklubb (20); das cM-Teilgebiet die Bottensee südlich von Högklubb (20) bis südlich von Bergskär (25); das eS-Teilgebiet die Bottensee südlich von Bergskär (25) an dem Leuchtturm von Isokari (29) vorbei südwärts bis an die nördliche Grenze des Schärenmeeres; das eW-Teilgebiet den Finnischen Méerbusen westlich von Russarö (57) bis in die Nähe von Porkkala (61); das eM-Teilgebiet den Finnischen Meerbusen von Porkkala (61) bis westlich von Hochland (73) und Kaunissaari (69), und das eE-Teilgebiet den Finnischen Meerbusen östlich von den letztgenannten Inseln.

169. Als charakteristische "Lagen» in der Ausbreitung und im Rückgang der Bräme des festen Küsteneises, vermittels welcher der 
Verlauf des Winters in seinen Hauptzügen herzuleiten war, wurden für die Tabellen 32 und 33 die G-Stadien gewählt, während welcher: 1) die Eislegung der Küste beginnt (Tabelle 31: die Kolumne G-Stadium $\alpha$ ); 2) die Bräme des festen Eises sich über den inneren Schärenhof erstreckt (G-Stadium: $\mathbf{i}_{\alpha}$ ); 3) die Bräme des festen Eises

Tabelle 31.

Die Generalstadien, in denen die Bräme des festen Küsteneises in bezug auf ihre Ausdehnung ganz bestimmte Lagen erreicht. $G_{\alpha}=G$-Stadium, in dem die Eislegung der Küste beginnt; $G i_{\alpha}=$ G-Stadium, in dem die Bräme des testen Eises den inneren Schärenhof bedeckt; $G a_{\alpha}=G$-Stadium, in dem die Bräme des festen Eises den äusseren Schärenhof bedeckt; Gmx $x_{\alpha}$ $=$ G-Stadium, in dem die Bräme des festen Eises praktisch gesehen ihre weiteste Ausdehnung erreicht; $G m x_{\varepsilon}=G$-Stadium, in dem der Rückgang der Bräme des festen Eises beginnt; Ga $a_{\varepsilon}=$ G-Stadium, in dem der Rückgang des festen Eises bis zum äusseren Schärenhof fortgeschritten ist; $G i_{\varepsilon}=G$-Stadium, in dem der Rückgang der Bräme des festen Eises bis zum inneren Schärenhof fortgeschritten ist; $G_{\vartheta}=G$ Stadium, in dem die Bräme des festen Küsteneises gänzlich verschwunden ist.

\begin{tabular}{|c|c|c|c|c|c|c|c|c|}
\hline & $\mathbf{G}_{\alpha}$ & $\mathrm{Gi}_{\alpha}$ & $\mathbf{G a}_{\alpha}$ & $\mathrm{Gmx}_{\alpha}$ & $\mathbf{G m x}_{\varepsilon}$ & $\mathrm{Ga}_{\varepsilon}$ & $\mathbf{G i}_{\mathcal{\varepsilon}}$ & $G, 9$ \\
\hline a: $\begin{array}{c}N \\
M \\
S\end{array}$ & $1 \frac{(1)}{1} 2$ & $\begin{array}{l}3 \\
6 \\
5\end{array}$ & $\begin{array}{r}9-10 \\
11-12 \\
10-11\end{array}$ & $\begin{array}{l}13 \\
16 \\
15\end{array}$ & $\begin{array}{c}22-23 \\
21-22 \\
21\end{array}$ & $\begin{array}{c}26 \\
22-23 \\
22-23\end{array}$ & $\begin{array}{c}28-29 \\
25-26 \\
26\end{array}$ & $\begin{array}{c}29 \\
26-27 \\
26-27\end{array}$ \\
\hline b: & 1 & 5 & $10-11$ & 15 & $20-21$ & 22 & 25 & $26-27$ \\
\hline c: $\begin{array}{l}N \\
M \\
S\end{array}$ & $\begin{array}{l}2 \\
2-3 \\
2-3\end{array}$ & $7 \frac{7}{8} 8$ & $\begin{array}{l}12 \\
13 \\
13\end{array}$ & $\begin{array}{l}15-16 \\
15-16\end{array}$ & $\begin{array}{c}20 \\
20 \\
19-20\end{array}$ & $\begin{array}{c}21-22 \\
21 \\
21\end{array}$ & $\begin{array}{l}24 \\
23 \\
23\end{array}$ & $\begin{array}{l}25-26 \\
24-25 \\
24-25\end{array}$ \\
\hline d: & $3-4$ & 9 & 14 & $16-17$ & $19-20$ & $20-21$ & $22-23$ & 24 \\
\hline e: $\begin{array}{l}\mathrm{W} \\
\mathrm{M} \\
\mathrm{E}\end{array}$ & $\begin{array}{c}3 \\
3 \\
2-3\end{array}$ & $\begin{array}{c}8-9 \\
8 \\
7\end{array}$ & $12 \frac{13}{12}-13$ & $\begin{array}{c}15-16 \\
15 \\
15\end{array}$ & $\begin{array}{l}19-20 \\
19-20 \\
20-21\end{array}$ & $\begin{array}{l}21 \\
22 \\
23\end{array}$ & $\begin{array}{l}23-24 \\
23-24 \\
24-25\end{array}$ & $\begin{array}{l}24 \\
24 \\
25\end{array}$ \\
\hline
\end{tabular}

den ganzen Schärenhof bis zu den äusseren Inseln umfasst (G-Stadium: $\left.\mathbf{a}_{\alpha}\right)$; 4) die Bräme des festen Eises praktisch gesehen ihre weiteste Ausdehnung erreicht hat (G-Stadium: $\mathbf{m x}_{a}$ ); 5 ) der Rückgang der Bräme des festen Eises beginnt (G-Stadium: $\mathrm{mx}_{\varepsilon}$ ); 6) der Rückgang der Bräme bis zum äusseren Schärenhof fortgeschritten ist (G-Stadium: $\mathbf{a}_{\varepsilon}$ ); 7) der Rückgang der Bräme bis zum inneren Schärenhof fortgeschritten ist (G-Stadium: $\mathbf{i}_{\varepsilon}$ ), und 8) die Bräme des festen Eises endgültig verschwindet (G-Stadium: $\vartheta$ ). 
In Tabelle 31 bezeichnen also die Zahlen in der Kolumne $\mathrm{G}_{\alpha}$ jenes G-Stadium, in dem die Eislegung beginnt, in den Kolumnen Gi $\mathrm{i}_{\alpha}$ und $\mathrm{Gi}_{\varepsilon}$ die G-Stadien, in denen die Bräme des festen Eises einerseits den ganzen inneren Schärenhof umfasst, andererseits ihr Rückgang bis $\mathrm{zu}$ diesem Gebiet fortgeschritten ist; in den Kolumnen $\mathrm{Ga}_{\alpha}$ und $\mathrm{Ga}_{\varepsilon}$ die entsprechenden G-Stadien des äusseren Schärenhofes und in den Kolumnen $\mathrm{Gmx}_{\alpha}$ und $\mathrm{Gmx}_{\varepsilon}$ jene G-Stadien, welche den Beginn und das Ende der weitesten Ausdehnung der Bräme des festen Eises umfassen. Da die Eislegung und der Rückgang des Eises nicht durch gleich gebaute Normalstadien gehen, so haben wir unter den frühjahrlichen Stadien jene gewählt, in denen die Lage der Bräme am besten den herbstlichen Lagen $\mathrm{Gi}_{\alpha}$ und $\mathrm{Ga}_{\alpha}$ entspricht. Die G-Stadien der Tabelle und die aus ihnen hergeleiteten Zahlenwerte geben somit nur in grossen Zügen - und nur vermittels der Bräme des festen Küsteneises - den Gang der Vereisung und der Enteisung wieder.

1\%0. Die Bestimmung des »inneren» und »äusseren» Schärenhofes in den G-Stadien $\mathbf{i}_{\alpha}$ und $\mathbf{i}_{\varepsilon}$ sowie $\mathbf{a}_{\alpha}$ und $\mathbf{a}_{\varepsilon}$ bereitet auf Grund des topographischen Aufbaus der Küsten einige Schwierigkeiten: an einigen Stellen - wie in den mittleren Teilen der Bottenwiek und den östlichsten Teilen des Finnischen Meerbusens - ist die Küste beinahe ohne Inseln oder gibt es nur wenige Inseln, die anderen Teile weisen stellenweise den fast inselreichsten Schärenhof der Welt auf. Wegen dieser Verschiedenheit im Charakter der Küsten haben wir gar nicht versucht diese Schärengürtel näher zu bestimmen, sondern von Anfang an, vor allem da aus der Erfahrung bekannt ist, wie die Schären im allgemeinen zufrieren bzw. sich öffnen, als »innere Schären» einige bestimmte, der Küste am nächsten gelegene Teile der Schären gewählt, in welchen die Eisverhältnisse im Vergleich mit den übrigen Teilen der Schären dem Begriff »innere Schären» am besten entsprechen.

Den ausserhalb dieses Gebietes liegenden Teil des Schärenhofes bezeichnen wir als den »äusseren» Schärenhof. Weiter draussen liegen die Meeresinseln, Gründe und Untiefen, welche die weiteste Ausdehnung der Bräme des festen Eises bestimmen. In den nahezu insellosen Teilen des Küstengebietes haben wir die Gi- und Ga-Stadien so gewählt, dass die Bräme des festen Eises sich natürlich an die benachbarten Teile der angrenzenden Teilgebiete anschliesst. Gerade auf Grund dieses "natürlichen" Anschlusses sind in den Tabellen 32 einige, anfangs direkt hergeleitete Zahlenwerte, mit Hilfe der Zahlen der anschliessenden Teilgebiete berichtigt und als solche mit einem Stern $(*)$ versehen worden, wie z. B. in der Kolumne $a_{\varepsilon}$ des sk-Winters Zeile aM die Zahl 13. 
Da nun die Zahlen der Tabelle 32 darauf beruhen, wie man den inneren und den äusseren Schärenhof bestimmt, und von welehem Zeitpunkt an man annimmt, dass die Bräme des festen Eises ihre weiteste Ausdehnung erreicht hat, so ist es leicht möglich, vermittels der Tabelle $31 \mathrm{zu}$ entscheiden, auf welche Weise die Zahlenwerte der Tabelle 32 sich verändern, wenn man eine andere Einteilung des Schärengebietes als die hier benutzte verwenden wollte.

171. Vermittels dieser $\mathbf{G}_{\alpha^{-}}, \mathbf{G i}_{\alpha^{-}}, \mathbf{G a}_{\alpha^{-}}, \mathbf{G m x}_{\alpha^{-}}, \mathbf{G m x}_{\varepsilon^{-}}, \mathbf{G a}_{\varepsilon^{-}}, \mathbf{G \mathbf { i } _ { \varepsilon ^ { - } }}$ und $\mathbf{G} \vartheta$-Stadien haben wir dann berechnet, wie viel Tage die Bräme des festen Eises die Gebiete (i), (a) und (mx) bedeckt. Diese Zeit kann direkt entweder aus dem Zeitdiagramm der G-Stadien oder den Tabellen 36-38 erhalten werden, welche die Zeitunterschiede der G-Stadien sowohl in dem "normalen» sk- wie in dem »normalen» ml- und in dem "normalen" sl-Winter in Tagen angeben.

Die Zeit zwischen den Eintrittszeiten der Stadien $\mathrm{G}_{\alpha}$ und $\mathrm{Gi}_{\alpha}, \mathrm{Gi}_{\alpha}$ und $\mathrm{Ga}_{\alpha}, \mathrm{Ga}_{\alpha}$ und $\mathrm{Gmx}_{\alpha}, \mathrm{Gmx}_{\alpha}$ und $\mathrm{Gmx}_{\varepsilon}, \mathrm{Gmx}_{\varepsilon}$ und $\mathrm{Ga}_{\varepsilon}, \mathrm{Ga}_{\varepsilon}$ und $\mathrm{Gi}_{\varepsilon}$ samt $\mathrm{Gi}_{\varepsilon}$ und $\mathrm{G} \vartheta$ sind in Tabelle 32 in den Kolumnen $\left(\mathbf{i}_{\alpha}\right),\left(\mathbf{a}_{\alpha}\right),\left(\mathbf{m x}_{\alpha}\right)$ $\left(\mathbf{m x}_{\varepsilon}\right),\left(\mathbf{a}_{\varepsilon}\right),\left(\mathbf{i}_{\varepsilon}\right)$ und $(\vartheta)$ angegeben.

Die Zahlenwerte der Tabelle 32 sind in Tabelle $33 \mathrm{zu}$ Gruppen $\left(\mathbf{i}_{\alpha}+\mathbf{a}_{\alpha}\right) ; \quad\left(\mathbf{i}_{\alpha}+\mathbf{a}_{\alpha}+\mathbf{m} \mathbf{x}_{\alpha}\right)=\left(\mathbf{V}_{\alpha}\right) ; \quad(\mathbf{m x}) ; \quad\left(\mathbf{a}_{\varepsilon}+\mathbf{i}_{\varepsilon}\right) ; \quad\left(\mathbf{a}_{\varepsilon}+\mathbf{i}_{\varepsilon}+\vartheta\right)=\left(\mathbf{V}_{\varepsilon}\right)$ sowie (V) zusammengestcllt. Diese Gruppen bezeichnen der Reihe nach: $\left(\mathbf{i}_{\alpha}+\mathbf{a}_{\alpha}\right)$ die Anzahl der Tage, innerhalb welcher nach der ersten Eislegung der ganze Schärenhof von der Bräme des festen Eises bedeckt ist; $\left(\mathbf{V}_{\alpha}\right)$ die Anzahl der Tage, innerhalb welcher nach der ersten Eislegung die Bräme des festen Eises ihre weiteste Ausdehnung erreicht, welche Winterphase dann ( $\mathbf{m x})$ Tage anhält; $\left(\mathbf{a}_{\varepsilon}+\mathbf{i}_{\varepsilon}\right)$ bezeichnet wieder die Anzahl der Tage, innerhalb welcher der Rückgang der Bräme von ihrer weitesten Ausdehnung bis zum inneren Schärenhof fortgeschritten ist, und (V) die Länge des ganzen Winters.

172. Die Zahlen der Tabelle 32 sowie die Fig. 69 zeigen, dass der innere Schärenhof (Kolumne und Kurve $\left(\mathbf{i}_{\alpha}\right)$ ) des nördlichsten Teils der Bottenwiek und des östlichen Teils des Finnischen Meerbusens in der kürzesten Zeit, 3 bis 4 Wochen, von der Bräme des festen Eises bedeckt wird. Diese Eislegung dauert am längsten - teils natïrlich schon wegen der Lage, teils aber wegen des topographischen Aufbaus des Gebietes - an der südwestlichen Küste (d-Gebiet), wo die Zeit $\left(i_{\alpha}\right)$ in sk- und ml-Wintern $5 \frac{1}{2}-6$ Wochen ist. In sl-Wintern sind die Unterschiede zwischen den verschiedenen Teilen der Küste ziemlich gering und die Zeit der Eislegung dauert an der ganzen Küste $3-4$ Wochen. 
Die Eislegung des äusseren Schärenhofes (Kolumne und Kurve $\left(\mathbf{a}_{\alpha}\right)$ geht in sk- und ml-Wintern in der Weise vor sich, dass die Zahlenwerte am kleinstén (31/2 -5 Wochen) in SW, am grössten (51/2-7

Tabelle 32.

Die Zeitunterschiede zwischen den G-Stadien der Tabelle 31 in Tagen angegeben. Nach dem Beginn der Eislegung ist der innere Schärenhof nach $\left(i_{a}\right)$, der äussere nach $\left(a_{a}\right)$ Tagen mit festem Eis bedeckt. Hiernach erreicht die Bräme des festen Eises in ( $\left.m x_{\alpha}\right)$ Tagen ihre weiteste Ausdehnung. Die letzterwähnte Winterphase dauert ( $\left.m x_{\varepsilon}\right)$ Tage. $\left(a_{\varepsilon}\right)$ Tage später ist die Bräme des festen Eises aus dem äusseren Schärenhof, nach wiederum $\left(i_{\varepsilon}\right)$ Tagen aus dem inneren Schärenhof und schliesstich

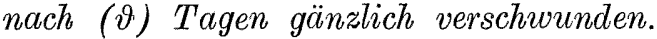

Der sk-Winter

\begin{tabular}{|c|c|c|c|c|c|c|c|c|}
\hline & & $\left(\mathrm{i}_{\alpha} \alpha\right)$ & $\left(\mathbf{a}_{a}\right)$ & $\left(\mathrm{mx}_{\alpha}\right)$ & $\left(m x_{\varepsilon}\right)$ & $\left(\mathrm{a}_{\varepsilon}\right)$ & $\left(\mathbf{i}_{\varepsilon}\right)$ & $(\vartheta)$ \\
\hline a: & $\begin{array}{l}\mathrm{N} \\
\mathrm{M} \\
\mathrm{S}\end{array}$ & $\begin{array}{l}19 \\
29 \\
29\end{array}$ & $\begin{array}{l}48 \\
45 \\
44\end{array}$ & $\begin{array}{l}20 \\
12^{*} \\
14\end{array}$ & $\begin{array}{l}30 \\
20 \\
20\end{array}$ & $\begin{array}{l}28 \\
13^{*} \\
10\end{array}$ & $\begin{array}{l}16 \\
20 \\
28\end{array}$ & $\begin{array}{l}2 \\
8 \\
9 *\end{array}$ \\
\hline b: & & 29 & 44 & 14 & 20 & 8 & 21 & 12 \\
\hline c: & $\begin{array}{l}\mathrm{N} \\
\mathrm{M} \\
\mathrm{S}\end{array}$ & $\begin{array}{l}33 \\
34 \\
40\end{array}$ & $\begin{array}{l}39 \\
40 \\
34\end{array}$ & $\underline{6}$ & $\begin{array}{l}20 \\
20 \\
20\end{array}$ & $\underline{4}$ & $\begin{array}{l}17 \\
13 \\
13\end{array}$ & $\begin{array}{l}12 \\
12 \\
12\end{array}$ \\
\hline d: & & 43 & 24 & - & 20 & - & 10 & 10 \\
\hline e: & $\begin{array}{l}\mathrm{W} \\
\mathrm{M} \\
\mathrm{E}\end{array}$ & $\begin{array}{l}40 \\
35 \\
28\end{array}$ & $\begin{array}{l}29 \\
31 \\
39\end{array}$ & $\begin{array}{l}\overline{3} \\
6\end{array}$ & $\begin{array}{l}20 \\
20 \\
20\end{array}$ & $\begin{array}{r}-8 \\
13\end{array}$ & $\begin{array}{r}10 \\
9 \\
12\end{array}$ & $\begin{array}{r}10 \\
4 \\
4\end{array}$ \\
\hline
\end{tabular}

Der ml-Winter

\begin{tabular}{|c|c|c|c|c|c|c|c|c|}
\hline & & $\left(\mathbf{i}_{\varepsilon}\right)$ & $\left(\mathrm{a}_{\alpha}\right)$ & $\left(\mathrm{mx}_{\alpha}\right)$ & $\left(\mathbf{m x}_{\varepsilon}\right)$ & $\left(a_{\varepsilon}\right)$ & $\left(\mathrm{i}_{\varepsilon}\right)$ & $(\vartheta)$ \\
\hline a: & $\begin{array}{l}\mathrm{N} \\
\mathrm{M} \\
\mathrm{S}\end{array}$ & $\begin{array}{l}26^{*} \\
28 \\
28\end{array}$ & $\begin{array}{l}45 \\
48 \\
46\end{array}$ & $\begin{array}{l}27 \\
32 \\
31\end{array}$ & $\begin{array}{l}72 \\
54^{*} \\
50\end{array}$ & $\begin{array}{r}24 \\
7 \\
10\end{array}$ & $\begin{array}{l}13 \\
21 \\
24\end{array}$ & $\begin{array}{l}\text { (2) } \\
6 \\
5^{*}\end{array}$ \\
\hline b: & & 28 & 46 & 31 & 46 & 11 & 21 & 8 \\
\hline c: & $\begin{array}{l}\mathrm{N} \\
\mathrm{M} \\
\mathrm{S}\end{array}$ & $\begin{array}{l}31 \\
31 \\
36\end{array}$ & $\begin{array}{l}44 \\
46 \\
41\end{array}$ & $\begin{array}{l}24 \\
20 \\
16\end{array}$ & $\begin{array}{l}38 \\
34 \\
34\end{array}$ & $\begin{array}{r}11 \\
8 \\
8\end{array}$ & $\begin{array}{l}16 \\
13 \\
13\end{array}$ & $\begin{array}{l}11 \\
11 \\
11\end{array}$ \\
\hline d: & & 38 & 36 & 18 & 27 & 8 & 14 & 10 \\
\hline & $\begin{array}{l}\mathrm{W} \\
\mathrm{M} \\
\mathrm{E}\end{array}$ & $\begin{array}{l}36 \\
31 \\
26\end{array}$ & $\begin{array}{l}36 \\
37 \\
44\end{array}$ & $\begin{array}{l}16 \\
16 \\
20\end{array}$ & $\begin{array}{l}34 \\
38 \\
46\end{array}$ & $\begin{array}{l}12 \\
19 \\
17\end{array}$ & $\begin{array}{l}16 \\
10 \\
11\end{array}$ & $\begin{array}{l}4 \\
4 \\
4\end{array}$ \\
\hline
\end{tabular}


(Fortsetzung der Tabelle 32)

Der sl-Winter

\begin{tabular}{|c|c|c|c|c|c|c|c|c|}
\hline & & $\left(\mathbf{i}_{\alpha}\right)$ & $\left(\mathrm{a}_{\alpha}\right)$ & $\left(\mathrm{mx}_{\mathrm{a}}\right)$ & $\left(\mathbf{m x}_{\varepsilon}\right)$ & $\left(a_{\varepsilon}\right)$ & $\left(\mathbf{i}_{\varepsilon}\right)$ & $(\vartheta)$ \\
\hline a: & $\begin{array}{l}\mathrm{N} \\
\mathrm{M} \\
\mathrm{S}\end{array}$ & $\begin{array}{l}22 \\
28 \\
30\end{array}$ & $\begin{array}{l}36 \\
42 \\
36\end{array}$ & $\begin{array}{l}30 \\
35 \\
36\end{array}$ & $\begin{array}{r}118 \\
90 \\
95\end{array}$ & $\begin{array}{r}20 \\
6 \\
8\end{array}$ & $\begin{array}{l}11 \\
18 \\
20\end{array}$ & $\begin{array}{l}3 \\
5 \\
5 *\end{array}$ \\
\hline b: & & 30 & 36 & 36 & 91 & 9 & 18 & 8 \\
\hline c: & $\begin{array}{l}N \\
M \\
S\end{array}$ & $\begin{array}{l}27 \\
25 \\
28\end{array}$ & $\begin{array}{l}41 \\
46 \\
43\end{array}$ & $\begin{array}{l}28 \\
22 \\
18\end{array}$ & $\begin{array}{l}84 \\
80 \\
80\end{array}$ & $\begin{array}{r}10 \\
8 \\
11\end{array}$ & $\begin{array}{l}12 \\
11 \\
11\end{array}$ & $\begin{array}{r}10 \\
8 \\
8\end{array}$ \\
\hline d: & & 30 & 42 & 18 & 73 & 7 & 12 & 7 \\
\hline & $\begin{array}{l}\mathrm{W} \\
\mathrm{M} \\
\mathrm{E}\end{array}$ & $\begin{array}{l}28 \\
23 \\
22\end{array}$ & $\begin{array}{l}38 \\
38 \\
41\end{array}$ & $\begin{array}{l}18 \\
20 \\
24\end{array}$ & $\begin{array}{l}80 \\
84 \\
91\end{array}$ & $\begin{array}{l}11 \\
16 \\
15\end{array}$ & $\begin{array}{r}13 \\
8 \\
8\end{array}$ & $\begin{array}{c}(2) \\
(2) \\
4\end{array}$ \\
\hline
\end{tabular}

Wochen) in $\mathrm{N}$ und $\mathrm{O}$ sind. In sl-Wintern wechselt die Eislegung des äusseren Schärenhofes zwischen 5 und 6 1/2 Wochen. Die kleinsten Werte finden wir hier im allgemeinen in den nördlichen und südlichen Küstengewässern, die grössten an der westlichen Küste. Die Bräme des festen Küsteneises erreicht praktisch gesehen (Kolumne und Kurve $\left(\mathbf{m x}_{a}\right)$ ) ihre weiteste Ausdehnung in dem südlichen Teil der WKüste, in SW und $\mathrm{S}$, nämlich in ml- und sl-Wintern in $2 \frac{1}{2}-3$ Wochen oder in beinahe doppelt so kurzer Zeit wie in dem südlichen Teil der Bottenwiek und des Kvark, wo sie $4 \frac{1}{2}$ - 5 Wochen dauert.

Das mx-Stadium der Bräme des festen Küsteneises ist (Kolumne und Kurve $\left(\mathbf{m}_{\varepsilon}\right)$ ) am kürzesten in den Gebieten $\boldsymbol{c}$ und $\mathbf{d}$ sowie $\mathbf{e}: W$ und $\mathrm{M}$, wo auch der Winter am kürzesten ist: in ml-Wintern 4$51 / 2$ Wochen, in sl-Wintern 101/2-12 Wochen. Am längsten währt diese Winterphase in $\mathrm{N}$ (in dem a- und $\mathbf{b}$-Gebiet), wo sie in $\mathrm{ml}$ Wintern $6 \frac{1}{2}-10 \frac{1}{2}$, in sl-Wintern 13-17 Wochen, sowie in $\mathrm{E}(\mathbf{e E})$, wo sie in ml- Wintern $6 \frac{1}{2}$, in sl-Wintern 13 Wochen dauert.

173. Der Rückgang der Bräme des festen Eises von der Lage $\left(\mathbf{m x}_{\varepsilon}\right)$ bis zum äusseren Schärenhof findet (Kolumne und Kurve $\left(\mathbf{a}_{\varepsilon}\right)$ ) in allen Wintern und beinahe überall recht schnell in $1-1 \frac{1}{2}$ Wochen statt. Die grössten Abweichungen finden wir in den Teilgebieten $\mathrm{aN}$, eM und $\mathrm{eE}$, wo der Rückgang am längsten dauert: in dem erstgenannten Teilgebiet 3-4 Wochen, in den beiden letzten 2-3 Wochen. Der fortgesetzte Rückgang der Bräme des $\mathrm{f}$ sten Küsteneises von der Lage $\left(\mathbf{a}_{\varepsilon}\right)$ bis zur Lage $\left(\mathbf{i}_{\varepsilon}\right)$ geschieht (Kolumne und Kurve $\left(i_{\varepsilon}\right)$ ) an der W-Küste, in SW und $S$ in allen Wintern recht 
gleichmässig in $1 \frac{1}{2}-2 \frac{1}{2}$ Wochen, in den Teilgebieten aM und aS sowie im Kvark dauert er jedoch bedeutend länger, 21/2-4
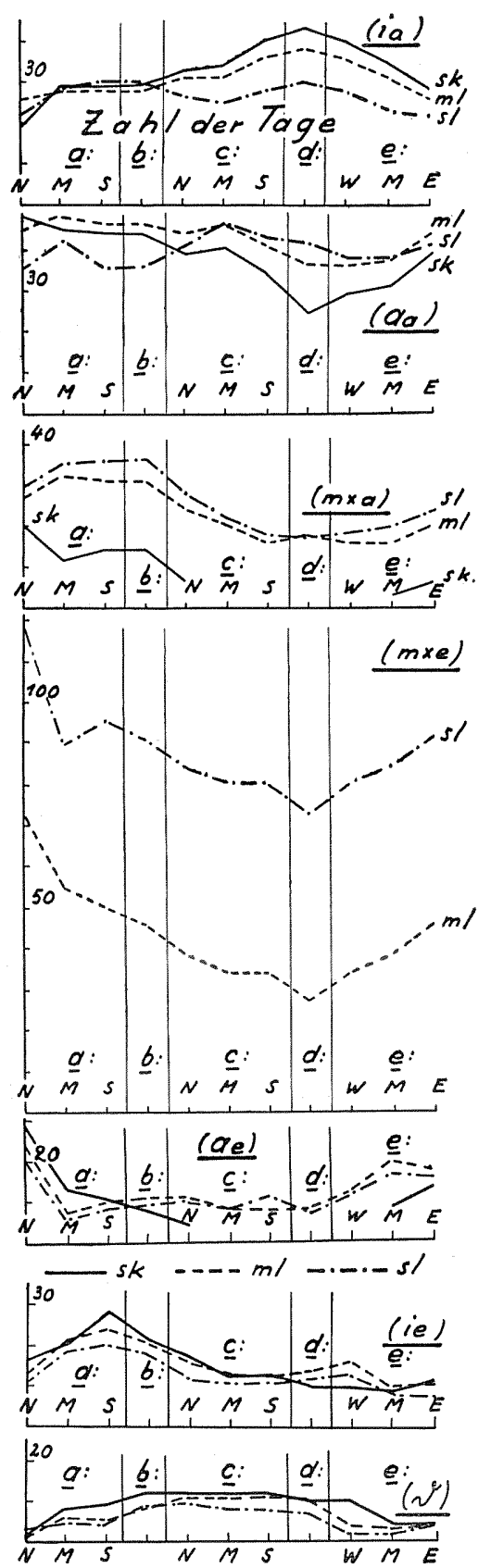

Wochen. Das definitive Verschwinden der Bräme des festen Eises findet schliesslich (Kolumne und Kurve ( $(9)$ ) am schnellsten ( $1 / 2-1$ Woche) in ml- und sl-Wintern in der Bottenwiek und an der südlichen Küste statt, an anderen Stellen und in allen Wintern etwas langsamer und ziemlich gleichmässig, nämlich in $1-1 \frac{1}{2}$ Wochen.

Die Bräme des festen Küsteneises erstreckt sich über den ganzen Schärenhof (Kolumne und Kurve $\left.\left(\mathbf{i}_{\alpha}+\mathbf{a}_{\alpha}\right)\right)$ in allen Wintern in nahezu derselben Zeit (Tab. 33 und Fig. 70): in sk-Wintern in $91 / 2-101 / 2$ Wochen, in ml-Wintern in 10-11 Wochen und in sl-Wintern in 9-10 Wochen. Ihre weiteste Ausdehnung erreicht die Bräme in sk-Wintern in der kürzesten Zeit (Kolumne und Kurve $\left(\mathbf{V}_{a}\right)$ ): 91/210 Wochen in SW in dem $\mathbf{d}$-Gebiet und in $\mathrm{S}$ in den Teilgebieten $\mathbf{e W}$ und eM, am längsten dauert sie im Kvark und in der Bottenwiek, nämlich 121/2 Wochen. In ml- und sl-Wintern ist der Gang der Zahlen in grossen Zügen derselbe: die $\left(\mathbf{V}_{\alpha}\right)$-Zahlen sind in

Fig. 69. Die Zahl der Tage, während welcher (nach der Tabelle 32) die Bräme des festen Küsteneises sich in der Zeit der Vereisung im sk-, bzw. ml- und sl-Winter über den inneren Schärenhof $\left(\mathrm{i}_{\alpha}\right)$, dann den äusseren Schärenhof $\left(\mathrm{a}_{\alpha}\right)$ und bis $\mathrm{zu}$ ihrer äussersten Lage erstreckt $\left(\mathrm{mx}_{\alpha}\right)$ und dort verweilt $\left(\mathrm{mx}_{\varepsilon)}\right)$ und in der Zeit der Enteisung über den äusseren Schärenhof $\left(\mathrm{a}_{\alpha}\right)$, dann durch den inneren $\left(i_{\varepsilon}\right)$ sich zurückzieht und gänzlich verschwindet $(\vartheta)$. Die Kurven "sks», bzw. "ml» und "sl» entsprechen den gleichbezeichneten Winter. (Die Indexe $\mathrm{a}=\alpha, \mathrm{e}=\varepsilon$ ). 
DIE EISVERHÄLTNISSE AN DEN KÜSTEN FINNLANDS.

179

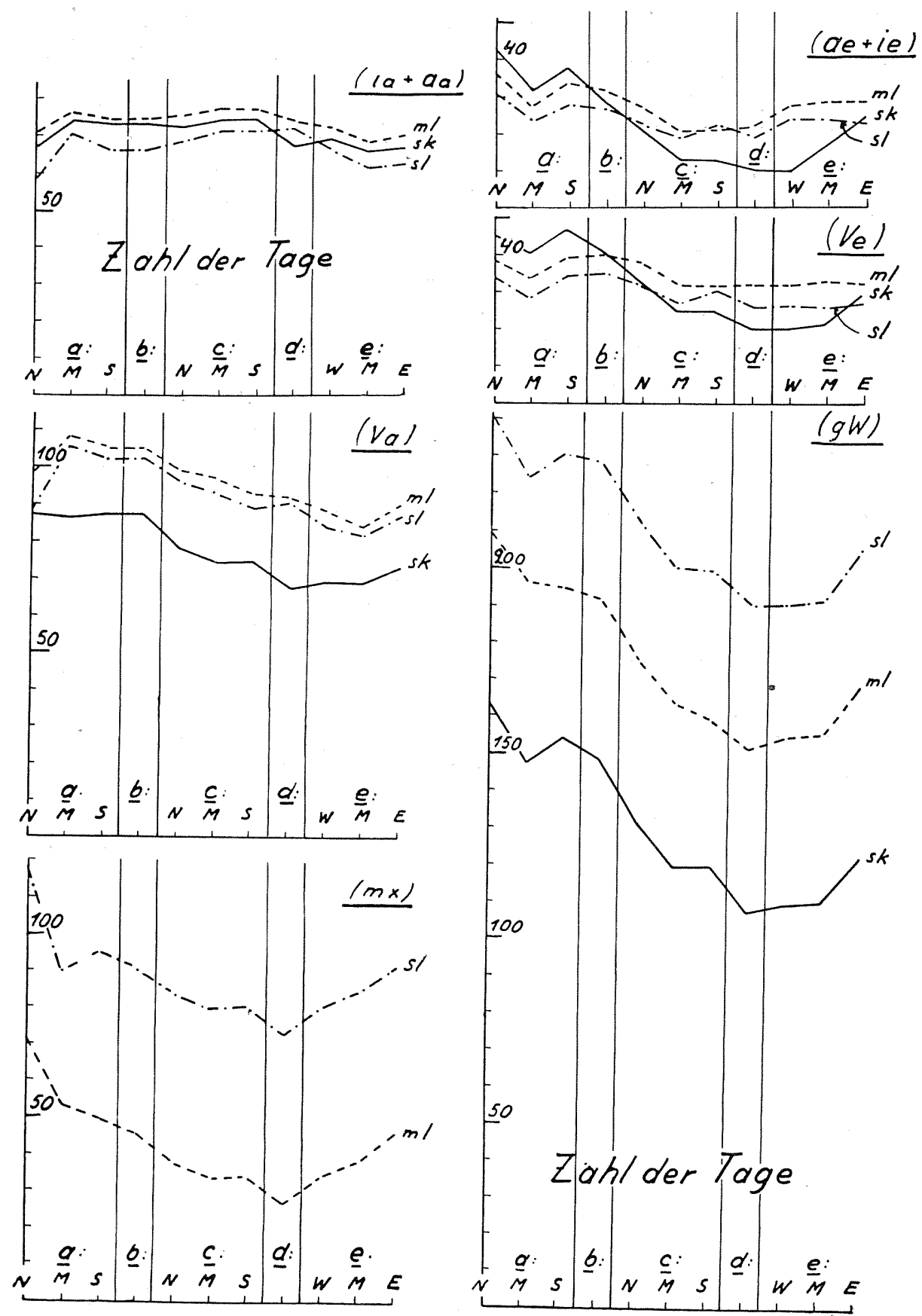

Fig. 70. Die Zahl der Tag e im sk-, bzw. ml- und sl-Winter, während welcher sich die Bräme des festen Küsteneises in der Zeit der Vereisung über den ganzen Schärenhof $\left(\mathrm{i}_{\alpha}+\mathrm{a}_{\alpha}\right)$ verbreitet, ihre grösste Ausdehnung $\left(\mathrm{V}_{\alpha}\right)=\left(\mathrm{i} \alpha+\mathrm{a}_{\alpha}+\mathrm{mx}_{\alpha}\right)$ erreicht und dort verbleibt $\left(\mathrm{mx}_{\varepsilon}\right)$, und während der Zeit der Enteisung sich über den ganzen Schärenhof zurückzieht $\left(a_{\varepsilon}+i_{\varepsilon}\right)$ sowie schliesslich verschwindet $\left(V_{\varepsilon}\right)=\left(a_{\varepsilon}+i_{\varepsilon}+\vartheta\right)$. Die Länge des ganzen Winters $(\mathrm{V})=(\mathrm{gW})=\left(\mathrm{i}_{\alpha}+\mathrm{a}_{\alpha}+\mathrm{mx}_{\alpha}+\mathrm{mx}_{\varepsilon}+\mathrm{a}_{\varepsilon}+\mathrm{i}_{\varepsilon}+\vartheta\right)$.

(Die Indexe $\mathrm{a}=\alpha, \mathrm{e}=\varepsilon$ ). 
$\mathrm{S}$ und SW am kleinsten, 12-13 Wochen, aber ausserdem noch im Teilgebiet $\mathrm{aN}$ in sl-Wintern $12 \frac{1}{2}$ Wochen, am grössten aber im Teilgebiet aM und b $15-15 \frac{1}{2}$ Wochen.

174. Der Rückgang der Bräme des festen Küsteneises von ihrer weitesten Lage $\left(\mathbf{m x}_{\varepsilon}\right)$ über den äusseren Schärenhof zum inneren Schärenhof verläuft (Kolumne und Kurve $\left(\mathbf{a}_{\varepsilon}+\mathbf{i}_{\varepsilon}\right)$ ) in sk-Wintern am schnellsten im d- und eW-Gebiet (in $1 \frac{1}{2}$ Wochen), am langsamsten im a- und b-Gebiet (in 4-6 Wochen) sowie im Teilgebiet-eE (in $3 \frac{1}{2}$ Wochen). In $\mathrm{ml}$ - und sl-Wintern findet dieser Rückgang langsamer im c-, d- und e-Gebiet (in 3-4 Wochen) statt, im a- und $\mathbf{b}$ - Gebiet dagegen findet er ebenso schnell oder auch schneller als in sk-Wintern (in 4-5 Wochen) statt. Die Zeit des ganzen Rückganges (Kolumne und Kurve $\left(\mathbf{V}_{\varepsilon}\right)$ ) dauert in sk-Wintern in $W$ in den Teilgebieten eM und eS, in $\mathrm{SW}$ im d-Gebiet und in $\mathrm{S}$ in den Teilgebieten eW und cM $3-3 \frac{1}{2}$ Wochen d. h. halb so lang wie in der Bottenwiek und im Kvark (6-6 $\frac{1}{2}$

Tabelle 33 .

Die Bräme des festen Eises erstreckt sich über den ganzen Schärenhof binnen $\left(i_{\alpha}+a_{\alpha}\right)$ Tagen nach dem Beginn der Eislegung. Die Bräme des festen Eises erreicht in praktisch gesehen $\left(V_{\alpha}\right)=\left(i_{\alpha}+a_{\alpha}+m x_{\alpha}\right)$ Tagen nach dem Beginn der Eislegung ihre weiteste Ausdehnung, welche $\left(m x_{\varepsilon}\right)$ Tage dauert. Der Rückgang von dieser Lage über den inneren Schärenhof geschieht in $\left(a_{\varepsilon}+i_{\varepsilon}\right)$ Tagen, ihr endgültiges Verschwinden in $\left(V_{\varepsilon}\right)=\left(a_{\varepsilon}+i_{\varepsilon}+\vartheta\right)$ Tagen. Die Länge des ganzen Winters ist $(V)=\left(V_{\alpha}\right)+(m x)+\left(V_{\varepsilon}\right)=\left(i_{\alpha}+a_{\alpha}+m x_{\alpha}+m x_{\varepsilon}+a_{\varepsilon}+\right.$ $\left.i_{\varepsilon}+\vartheta\right)$ Tage.

Der sk-Winter.

\begin{tabular}{|c|c|c|c|c|c|c|c|}
\hline & & $\left(\mathrm{i}_{\alpha}+\mathrm{a}_{\alpha}\right)$ & $\left(\mathbf{v}_{a}\right)$ & $(\mathrm{mx})$ & $\left(\mathrm{a}_{\varepsilon}+\mathrm{i}_{\varepsilon}\right)$ & $\left(\mathrm{V}_{\varepsilon}\right)$ & (V) \\
\hline a: & $\begin{array}{l}\mathrm{N} \\
\mathrm{M} \\
\mathrm{S}\end{array}$ & $\begin{array}{l}67 \\
74 \\
73\end{array}$ & $\begin{array}{l}87 \\
86 \\
87\end{array}$ & $\begin{array}{l}30 \\
20 \\
20\end{array}$ & $\begin{array}{l}44 \\
33 \\
38\end{array}$ & $\begin{array}{l}46 \\
41 \\
47^{*}\end{array}$ & $\begin{array}{l}163 \\
147 \\
154^{*}\end{array}$ \\
\hline b: & & 73 & 87 & 20 & 29 & 41 & 148 \\
\hline c: & $\begin{array}{l}N \\
M \\
S\end{array}$ & $\begin{array}{l}72 \\
74 \\
74\end{array}$ & $\begin{array}{l}78 \\
74 \\
74\end{array}$ & $\begin{array}{l}20 \\
20 \\
20\end{array}$ & $\begin{array}{l}21 \\
13 \\
13\end{array}$ & $\begin{array}{l}33 \\
25 \\
25\end{array}$ & $\begin{array}{l}131 \\
119 \\
119\end{array}$ \\
\hline d: & & 67 & 67 & 20 & 10 & 20 & 107 \\
\hline & $\begin{array}{l}\mathrm{W} \\
\mathrm{M} \\
\mathrm{E}\end{array}$ & $\begin{array}{l}69 \\
66 \\
67\end{array}$ & $\begin{array}{l}69 \\
69 \\
73\end{array}$ & $\begin{array}{l}20 \\
20 \\
20\end{array}$ & $\begin{array}{l}10 \\
17 \\
25\end{array}$ & $\begin{array}{l}20 \\
21 \\
29\end{array}$ & $\begin{array}{l}109 \\
110 \\
122\end{array}$ \\
\hline
\end{tabular}


(Fortsetzung der Tabelle 33.)

Der ml-Winter.

\begin{tabular}{|c|c|c|c|c|c|c|}
\hline & $\left(\mathrm{i}_{\alpha}+\mathbf{a}_{\alpha}\right)$ & $\left(\mathbf{v}_{a}\right)$ & $(\mathrm{mx})$ & $\left(a_{\varepsilon}+i_{\varepsilon}\right)$ & $\left(\mathbf{v}_{\varepsilon}\right)$ & $(\mathrm{V})$ \\
\hline a: $\begin{array}{l}\mathrm{N} \\
\mathrm{M} \\
\mathrm{S}\end{array}$ & $\begin{array}{l}71 \\
76 \\
74\end{array}$ & $\begin{array}{r}98 \\
108 \\
105\end{array}$ & $\begin{array}{l}72 \\
54^{*} \\
50\end{array}$ & $\begin{array}{l}37 \\
28 \\
34\end{array}$ & $\begin{array}{l}39 \\
34 \\
39\end{array}$ & $\begin{array}{l}209 \\
196 \\
194\end{array}$ \\
\hline b: & 74 & 105 & 46 & 32 & 40 & 191 \\
\hline c: $\begin{array}{l}\mathrm{N} \\
\mathrm{M} \\
\mathrm{S}\end{array}$ & $\begin{array}{l}75 \\
77 \\
77\end{array}$ & $\begin{array}{l}99 \\
97 \\
93\end{array}$ & $\begin{array}{l}38 \\
34 \\
34\end{array}$ & $\begin{array}{l}27 \\
21 \\
21\end{array}$ & $\begin{array}{l}38 \\
32 \\
32\end{array}$ & $\begin{array}{l}175 \\
163 \\
159\end{array}$ \\
\hline d: & 74 & 92 & 27 & 22 & 32 & 151 \\
\hline e: $\begin{array}{l}\mathrm{W} \\
\mathrm{M} \\
\mathrm{E}\end{array}$ & $\begin{array}{l}72 \\
68 \\
70\end{array}$ & $\begin{array}{l}88 \\
84 \\
90\end{array}$ & $\begin{array}{l}34 \\
38 \\
46\end{array}$ & $\begin{array}{l}28 \\
29 \\
28\end{array}$ & $\begin{array}{l}32 \\
33 \\
32\end{array}$ & $\begin{array}{l}154 \\
155 \\
168\end{array}$ \\
\hline
\end{tabular}

Der sl-Winter.

\begin{tabular}{|c|c|c|c|c|c|c|}
\hline & $\left(\mathbf{i}_{\alpha}+\mathbf{a}_{\alpha}\right)$ & $\left(\mathbf{v}_{a}\right)$ & $(\mathrm{mx})$ & $\left(\mathrm{a}_{\varepsilon}+\mathrm{i}_{\varepsilon}\right)$ & $\left(\mathbf{v}_{\varepsilon}\right)$ & (V) \\
\hline a: $\begin{array}{l}\mathrm{N} \\
\mathrm{M} \\
\mathrm{S}\end{array}$ & $\begin{array}{l}58 \\
70 \\
66\end{array}$ & $\begin{array}{r}88 \\
105 \\
102\end{array}$ & $\begin{array}{r}118 \\
90 \\
95\end{array}$ & $\begin{array}{l}31 \\
24 \\
28\end{array}$ & $\begin{array}{l}34 \\
29 \\
33\end{array}$ & $\begin{array}{l}240 \\
224 \\
230\end{array}$ \\
\hline b: & 66 & 102 & 91 & 27 & 35 & 228 \\
\hline c: $\begin{array}{l}N \\
M \\
S\end{array}$ & $\begin{array}{l}68 \\
71 \\
71\end{array}$ & $\begin{array}{l}96 \\
93 \\
89\end{array}$ & $\begin{array}{l}84 \\
80 \\
80\end{array}$ & $\begin{array}{l}22 \\
19 \\
22\end{array}$ & $\begin{array}{l}32 \\
27 \\
30\end{array}$ & $\begin{array}{l}212 \\
200 \\
199\end{array}$ \\
\hline d: & 72 & 90 & 73 & 19 & 26 & 189 \\
\hline e: $\begin{array}{l}\mathrm{W} \\
\mathrm{M} \\
\mathrm{E}\end{array}$ & $\begin{array}{l}66 \\
61 \\
63\end{array}$ & $\begin{array}{l}84 \\
81 \\
87\end{array}$ & $\begin{array}{l}80 \\
84 \\
91\end{array}$ & $\begin{array}{l}24 \\
24 \\
23\end{array}$ & $\begin{array}{l}26 \\
26 \\
27\end{array}$ & $\begin{array}{l}190 \\
191 \\
205\end{array}$ \\
\hline
\end{tabular}

Wochen). In ml-Wintern sind die Unterschiede zwischen den verschiedenen Gebieten unbedeutend: $\left(\mathbf{V}_{\varepsilon}\right)$ wechselt zwischen $4 \frac{1}{2}-$ $5 \frac{1}{2}$ Wochen. Der allgemeine Verlauf ist jedoch, dass die Rückgangsperiode $\left(\mathbf{V}_{\varepsilon}\right)$ im ml-Winter in $\mathrm{W}, \mathrm{SW}$ und $\mathrm{S}$ länger ist als die entsprechende Winterphase des sk-Winters, im $\mathbf{a}$ - und $\mathbf{b}$-Gebiet dagegen ebenso lang oder auch kürzer. In den sl-Wintern sind die Schwankungen in der Zahlenfolge dieselben wie in ml-Wintern. Der Unterschied liegt nur darin, dass die $\left(\mathbf{V}_{\varepsilon}\right)$-Periode $1-1 \frac{1}{2}$ Wochen kürzer ist als der entsprechende Teil des ml-Winters. 
Die vermittels der Bräme des festen Eises berechnete ganze Länge des Winters (Kolumne und Kurve (V)) zeigt in den verschiedenen Wintern einen in grossen Zügen gleichartigen Verlauf. Der Winter ist immer am kürzesten in dem d-Gebiet und den Teilgebieten $\mathbf{e W}$ und $\mathbf{e M}$, darauf folgen die Teilgebiete eS und cM, ferner die Teilgebiete eE und cN; am längsten dauert der Winter natürlich im Teilgebiet

Tabelle 34 .

Die Zeitabschnitte $\left(i_{\alpha}\right),\left(a_{\alpha}\right),\left(m x_{\alpha}\right),\left(m x_{\varepsilon}\right),\left(a_{\varepsilon}\right),\left(i_{\varepsilon}\right)$ und $(\vartheta)$ in Prozenten der ganzen Winterlänge $(V)$ des sk-, ml-und sl-Winters ausgedrückt.

Der sk-Winter.

\begin{tabular}{|c|c|c|c|c|c|c|c|c|}
\hline & & $\left(\mathrm{i}_{\alpha}\right)$ & $\left(\mathrm{a}_{\alpha}\right)$ & $\left(m x_{\alpha}\right)$ & $\left(\mathrm{mx}_{\varepsilon}\right)$ & $\left(\mathrm{a}_{\varepsilon}\right)$ & $\left(\mathrm{i}_{\varepsilon}\right)$ & $(\vartheta)$ \\
\hline a: & $\begin{array}{l}\mathrm{N} \\
\mathrm{M} \\
\mathrm{S}\end{array}$ & $\begin{array}{l}12 \\
20 \\
19\end{array}$ & $\begin{array}{l}29 \\
31 \\
29\end{array}$ & $\begin{array}{r}12 \\
8 \\
9\end{array}$ & $\begin{array}{l}18 \\
14 \\
13\end{array}$ & $\begin{array}{r}17 \\
9 \\
6\end{array}$ & $\begin{array}{l}10 \\
14 \\
18\end{array}$ & $\begin{array}{l}1 \\
5 \\
6\end{array}$ \\
\hline b: & & 20 & 30 & 9 & 14 & 5 & 14 & 8 \\
\hline c: & $\begin{array}{l}\mathrm{N} \\
\mathrm{M} \\
\mathrm{S}\end{array}$ & $\begin{array}{l}25 \\
29 \\
34\end{array}$ & $\begin{array}{l}30 \\
34 \\
29\end{array}$ & $\begin{array}{l}4 \\
0 \\
0\end{array}$ & $\begin{array}{l}15 \\
17 \\
17\end{array}$ & $\begin{array}{l}3 \\
0 \\
0\end{array}$ & $\begin{array}{l}13 \\
11 \\
11\end{array}$ & $\begin{array}{r}9 \\
10 \\
10\end{array}$ \\
\hline d: & & 40 & 22 & 0 & 19 & 0 & 9 & 9 \\
\hline e: & $\begin{array}{l}\mathrm{W} \\
\mathrm{M} \\
\mathrm{E}\end{array}$ & $\begin{array}{l}37 \\
32 \\
23\end{array}$ & $\begin{array}{l}27 \\
28 \\
32\end{array}$ & $\begin{array}{l}0 \\
3 \\
5\end{array}$ & $\begin{array}{l}19 \\
18 \\
16\end{array}$ & $\begin{array}{r}0 \\
7 \\
10\end{array}$ & $\begin{array}{r}9 \\
8 \\
11\end{array}$ & $\begin{array}{l}9 \\
4 \\
3\end{array}$ \\
\hline
\end{tabular}

Der ml-Winter.

\begin{tabular}{|c|c|c|c|c|c|c|c|}
\hline & $\left(\mathrm{i}_{\alpha} \alpha\right)$ & $\left(a_{a}\right)$ & $\left(\mathrm{mx}_{a}\right)$ & $\left(\mathrm{mx}_{\varepsilon}\right)$ & $\left(\mathrm{a}_{\varepsilon}\right)$ & $\left(\mathrm{i}_{\varepsilon}\right)$ & (y) \\
\hline a: $\begin{array}{l}\mathrm{N} \\
\mathrm{M} \\
\mathrm{S}\end{array}$ & $\begin{array}{l}12 \\
14 \\
14\end{array}$ & $\begin{array}{l}22 \\
24 \\
24\end{array}$ & $\begin{array}{l}13 \\
16 \\
16\end{array}$ & $\begin{array}{l}34 \\
28 \\
26\end{array}$ & $\begin{array}{r}12 \\
4 \\
5\end{array}$ & $\begin{array}{r}6 \\
11 \\
12\end{array}$ & $\begin{array}{l}1 \\
3 \\
3\end{array}$ \\
\hline b: & 15 & 24 & 16 & 24 & 6 & 11 & 4 \\
\hline c: $\begin{array}{l}N \\
M \\
S\end{array}$ & $\begin{array}{l}18 \\
19 \\
23\end{array}$ & $\begin{array}{l}25 \\
28 \\
26\end{array}$ & $\begin{array}{l}14 \\
12 \\
10\end{array}$ & $\begin{array}{l}22 \\
21 \\
21\end{array}$ & $\begin{array}{l}6 \\
5 \\
5\end{array}$ & $\begin{array}{l}9 \\
8 \\
8\end{array}$ & $\begin{array}{l}7 \\
7 \\
7\end{array}$ \\
\hline d: & 25 & 24 & 12 & 18 & 5 & 9 & 7 \\
\hline 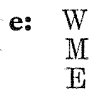 & $\begin{array}{l}23 \\
20 \\
16\end{array}$ & $\begin{array}{l}23 \\
24 \\
26\end{array}$ & $\begin{array}{l}10 \\
10 \\
12\end{array}$ & $\begin{array}{l}22 \\
25 \\
27\end{array}$ & $\begin{array}{r}8 \\
12 \\
10\end{array}$ & $\begin{array}{r}10 \\
6 \\
7\end{array}$ & $\begin{array}{l}3 \\
3 \\
2\end{array}$ \\
\hline
\end{tabular}


(Fortsetzung der Tabelle 34.)

Der sl-Winter.

\begin{tabular}{|c|c|c|c|c|c|c|c|c|}
\hline & & $\left(\mathrm{i}_{\alpha} \alpha\right)$ & $\left(\mathbf{a}_{\alpha}\right)$ & $\left(\mathrm{mx}_{\alpha}\right)$ & $\left(\mathrm{mx}_{\varepsilon}\right)$ & $\left(\mathbf{a}_{\varepsilon}\right)$ & $\left(\mathrm{i}_{\varepsilon}\right)$ & (外) \\
\hline & $\begin{array}{l}N \\
M \\
S\end{array}$ & $\begin{array}{r}9 \\
12 \\
13\end{array}$ & $\begin{array}{l}15 \\
19 \\
16\end{array}$ & $\begin{array}{l}12 \\
16 \\
16\end{array}$ & $\begin{array}{l}49 \\
40 \\
41\end{array}$ & $\begin{array}{l}8 \\
3 \\
3\end{array}$ & $\begin{array}{l}5 \\
8 \\
9\end{array}$ & $\begin{array}{l}1 \\
1 \\
2\end{array}$ \\
\hline b: & & 13 & 16 & 16 & 40 & 4 & 8 & 4 \\
\hline c: & $\begin{array}{l}\mathrm{N} \\
\mathrm{M} \\
\mathrm{S}\end{array}$ & $\begin{array}{l}12 \\
12 \\
14\end{array}$ & $\begin{array}{l}19 \\
23 \\
22\end{array}$ & $\begin{array}{r}13 \\
11 \\
9\end{array}$ & $\begin{array}{l}40 \\
40 \\
40\end{array}$ & $\begin{array}{l}4 \\
4 \\
6\end{array}$ & $\begin{array}{l}6 \\
6 \\
6\end{array}$ & $\begin{array}{l}5 \\
4 \\
4\end{array}$ \\
\hline d: & & 16 & 21 & 10 & 39 & 4 & 6 & 4 \\
\hline e: & $\begin{array}{l}\mathrm{W} \\
\mathrm{M} \\
\mathrm{E}\end{array}$ & $\begin{array}{l}15 \\
12 \\
10\end{array}$ & $\begin{array}{l}20 \\
20 \\
20\end{array}$ & $\begin{array}{r}9 \\
10 \\
12\end{array}$ & $\begin{array}{l}42 \\
44 \\
44\end{array}$ & $\begin{array}{l}6 \\
8 \\
7\end{array}$ & $\begin{array}{l}7 \\
4 \\
4\end{array}$ & $\begin{array}{l}1 \\
1 \\
2\end{array}$ \\
\hline
\end{tabular}

aN. Während der sk-Winter in dem d-Gebiet nur 15 Wochen umfasst, dauert der sl-Winter in dem Teilgebiet aN ungefähr $34 \frac{1}{2}$ Wochen oder reichlich das Doppelte, und da der sk-Winter des Teilgebietes aN ungefähr 23 Wochen beträgt, ist die Länge des sl-Winters im d-Gebiet ungefähr 27 Wochen oder nur einen Monat länger.

175. Die Bedeutung des oben Angeführten beleuchten ausserdem die Zahlen der Tabellen 34 und 35, welche die Länge der Winterteile $\left(\mathbf{i}_{\alpha}\right),\left(\mathbf{a}_{\alpha}\right),\left(\mathbf{m} \mathbf{x}_{\alpha}\right),\left(\mathbf{m} \mathbf{x}_{\varepsilon}\right),\left(\mathbf{a}_{\varepsilon}\right),\left(\mathbf{i}_{\varepsilon}\right)$ und $(\vartheta)$, ebenso wie die Länge

Tabelle 35 .

Die Zeitabschnitte $\left(i_{\alpha}+a_{\alpha}\right),\left(V_{\alpha}\right),(m x),\left(a_{\varepsilon}+i_{\varepsilon}\right)$ und $\left(V_{\varepsilon}\right)$ in Prozenten der ganzen Winterlänge $(V)$ des sk-, ml-und sl-Winters ausgedrïckt.

Der sk-Winter.

\begin{tabular}{|c|c|c|c|c|c|c|}
\hline & & $\left(\mathrm{i}_{\alpha}+\mathrm{a}_{\alpha}\right)$ & $\left(\mathbf{v}_{\alpha}\right)$ & $(m x)$ & $\left(\mathbf{a}_{\varepsilon}+\mathbf{i}_{\varepsilon}\right)$ & $\left(\mathrm{v}_{\varepsilon}\right)$ \\
\hline & $\begin{array}{l}\mathrm{N} \\
\mathrm{M} \\
\mathrm{S}\end{array}$ & $\begin{array}{l}41 \\
51 \\
47\end{array}$ & $\begin{array}{l}53 \\
59 \\
57\end{array}$ & $\begin{array}{l}18 \\
14 \\
13\end{array}$ & $\begin{array}{l}27 \\
23 \\
25\end{array}$ & $\begin{array}{l}28 \\
28 \\
30\end{array}$ \\
\hline b: & & 49 & 59 & 14 & 20 & 28 \\
\hline & $\begin{array}{l}\mathrm{N} \\
\mathrm{M} \\
\mathrm{S}\end{array}$ & $\begin{array}{l}55 \\
63 \\
63\end{array}$ & $\begin{array}{l}59 \\
63 \\
63\end{array}$ & $\begin{array}{l}15 \\
17 \\
17\end{array}$ & $\begin{array}{l}16 \\
11 \\
11\end{array}$ & $\begin{array}{l}25 \\
21 \\
21\end{array}$ \\
\hline d: & & 63 & 63 & 19 & 9 & 19 \\
\hline & $\begin{array}{l}\mathrm{W} \\
\mathrm{M} \\
\mathrm{E}\end{array}$ & $\begin{array}{l}63 \\
60 \\
55\end{array}$ & $\begin{array}{l}63 \\
63 \\
60\end{array}$ & $\begin{array}{l}19 \\
18 \\
16\end{array}$ & $\begin{array}{r}9 \\
15 \\
20\end{array}$ & $\begin{array}{l}18 \\
19 \\
24\end{array}$ \\
\hline
\end{tabular}


(Fortsetzung der Tabelle 35.)

Der ml-Winter.

\begin{tabular}{|c|c|c|c|c|c|}
\hline & $\left(\mathbf{i}_{\alpha}+\mathbf{a}_{\alpha}\right)$ & $\left(\mathbf{v}_{\alpha}\right)$ & $(\mathrm{mx})$ & $\left(a_{\varepsilon}+i_{\varepsilon}\right)$ & $\left(\mathbf{v}_{\varepsilon}\right)$ \\
\hline a: $\frac{N}{M}$ & $\begin{array}{l}34 \\
39 \\
38\end{array}$ & $\begin{array}{l}47 \\
55 \\
54\end{array}$ & $\begin{array}{l}34 \\
28 \\
26\end{array}$ & $\begin{array}{l}18 \\
15 \\
18\end{array}$ & $\begin{array}{l}19 \\
18 \\
20\end{array}$ \\
\hline b: & 39 & 55 & 24 & 17 & 21 \\
\hline c: $\begin{array}{l}\mathrm{N} \\
\mathrm{M} \\
\mathrm{S}\end{array}$ & $\begin{array}{l}43 \\
47 \\
48\end{array}$ & $\begin{array}{l}57 \\
59 \\
59\end{array}$ & $\begin{array}{l}22 \\
21 \\
21\end{array}$ & $\begin{array}{l}15 \\
13 \\
13\end{array}$ & $\begin{array}{l}22 \\
20 \\
20\end{array}$ \\
\hline d: & 49 & 61 & 18 & 15 & 21 \\
\hline e: $\begin{array}{l}W \\
M \\
\mathrm{E}\end{array}$ & $\begin{array}{l}47 \\
44 \\
42\end{array}$ & $\begin{array}{l}57 \\
54 \\
54\end{array}$ & $\begin{array}{l}22 \\
24 \\
27\end{array}$ & $\begin{array}{l}18 \\
19 \\
17\end{array}$ & $\begin{array}{l}21 \\
21 \\
19\end{array}$ \\
\hline
\end{tabular}

Der sl-Winter.

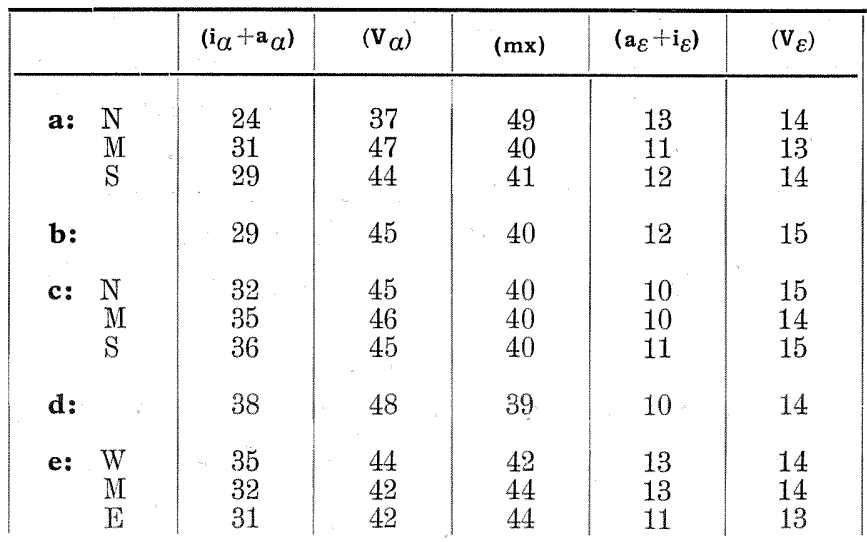

der aus diesen gebildeten Winterteile $\left(\mathbf{i}_{\alpha}+\mathbf{a}_{\alpha}\right),\left(\mathbf{V}_{a}\right),(\mathbf{m x}),\left(\mathbf{a}_{\varepsilon}+\mathbf{i}_{\varepsilon}\right)$ und $\left(\mathbb{V}_{\varepsilon}\right)$ in Prozenten der Länge des ganzen Winters $(\mathbf{V})$ in den sk-, bzw. ml- und sl- Wintern zeigen. Die Kurven der Figuren 71-73, die nach den Wintern geordnet sind, sind nach den Zahlen der Tabellen 34 und 35 gezeichnet.

Im sk-Winter nimmt die Vereisung des ganzen Schärenhofes $\left(\mathbf{i}_{a}+\mathbf{a}_{\alpha}\right)$ in den Gebieten $\mathbf{a}$ und $\mathbf{b}$ ungefähr die Hälfte $(41-51 \%)$, in den anderen Gebieten über die Hälfte (55-63\%) der ganzen Winterzeit in Anspruch. Der Zeitabschnitt $\left(\mathbf{V}_{\alpha}\right)$, in dem die Bräme des festen Eises ihre weiteste Ausdehnung erreicht, entspricht 53 -63 $\%$ der ganzen Winterlänge. Die Dauer $\left(\mathbf{m x}_{\varepsilon}\right)$ der weitesten Ausdehnung der Bräme des festen Küsteneises ist 13-19\%, die Rückgangsperiode 
$\left(\mathbf{V}_{\varepsilon}\right)$ der Bräme in den Gebieten a und b 28-30\%, in den anderen Gebieten 18-25\% der ganzen Winterlänge.

Im $\mathrm{ml-Winter}$ nimmt die Vereisung des ganzen Schärenhofes $\left(\mathbf{i}_{a}+\mathbf{a}_{\alpha}\right)$ in den Gebieten $\mathrm{a}$ und $\mathrm{b} 34-39 \%$, in den anderen Gebieten 42-49\% der ganzen Winterzeit in Anspruch. Die Zeit $\left(\mathbf{V}_{a}\right)$, in der die Bräme des festen Küsteneises ihre weiteste Ausdehnung erreicht, entspricht 47-61\% der ganzen Winterlänge. Die Dauer $\left(\mathbf{m x}_{\varepsilon}\right)$ der weitesten Ausdehnung der Bräme ist im Teilgebiet aN $34 \%$, in dem d-Gebiet nur $18 \%$ der ganzen Winterzeit. Die Rückgangsperiode $\left(\mathbf{V}_{\varepsilon}\right)$ der Bräme ist prozentual sehr gleichmässig in allen Teilen der Küste und entspricht 18-22\% der ganzen Winterlänge.

Im sl-Winter gestalten sich die Verhältnisse im Vergleich mit dem sk- und $\mathrm{ml}-$ Winter insofern ganz anders, als die Dauer $\left(\mathbf{m x}_{\varepsilon}\right)$ der weitesten Ausdehnung der Bräme
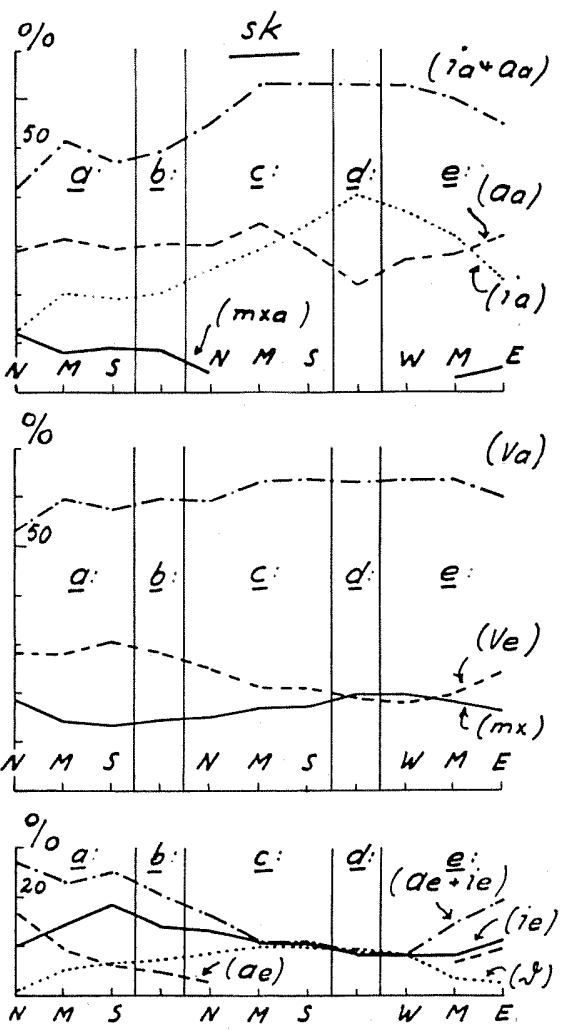

Fig. 71. Der Gang des prozentualen Verhältnisses der Winterteile $\left(\mathrm{i}_{\alpha}\right),\left(\mathrm{a}_{\alpha}\right),\left(\mathrm{mx}_{\alpha}\right)$, $\left(\mathrm{mx}_{\varepsilon}\right),\left(\mathrm{a}_{\varepsilon}\right),\left(\mathrm{i}_{\varepsilon}\right)$ und $\left({ }_{\vartheta}\right)$ sowie $\left(\mathrm{i}_{\alpha}+\mathrm{a}_{\alpha}\right),\left(\mathrm{V}_{\alpha}\right)$, $\left(a_{\varepsilon}+i_{\varepsilon}\right)$ und $\left(V_{\varepsilon}\right)$ zu der Länge des ganzen sk-Winters nach Meeresteilen geordnet. Die Bedeutung der Winterteile siehe z. B. die

Fig. 69 und 70. (Die Indexe $a=\alpha, e=\varepsilon$.) des festen Küsteneises, die im sk - und ml-Winter etwa von der Grössenordnung der Rückgangsperiode $\left(\mathbf{V}_{\varepsilon}\right)$ ist, jetzt beinahe so lang wie der Zeitabschnitt $\left(\mathbf{V}_{\alpha}\right)$ ist. Ferner ist die Eislegungszeit $\left(\mathbf{i}_{\alpha}+\mathbf{a}_{\alpha}\right)$ prozentual kürzer als im sk- oder ml-Winter. Der Zeitabschnitt $\left(\mathbf{i}_{\alpha}+\mathbf{a}_{\alpha}\right)$ entspricht nämlich in dem Gebiet $\mathbf{a}$ und $\mathbf{b}$ 24-31 \%, in den anderen $31-38 \%$ der ganzen Winterlänge. Der Zeitabschnitt $\left(\mathbf{V}_{\alpha}\right)$ ist in dem Teilgebiet aN $37 \%$, in den anderen $42-48 \%$ der ganzen Winterzeit. Die Dauer $\left(\mathbf{m} \mathbf{x}_{\alpha}\right)$ der weitesten Ausdehnung der Bräme des festen Küsteneises entspricht im Teilgebiet aN $49 \%$, in den anderen $39-44 \%$ des ganzen Winters. Die Rückgangsperiode $\left(\mathbf{V}_{\varepsilon}\right)=\left(\mathbf{a}_{\varepsilon}+\mathbf{i}_{\varepsilon}+\vartheta\right)$ ist in allen Gebieten 13-15\% der ganzen Winterlänge. 

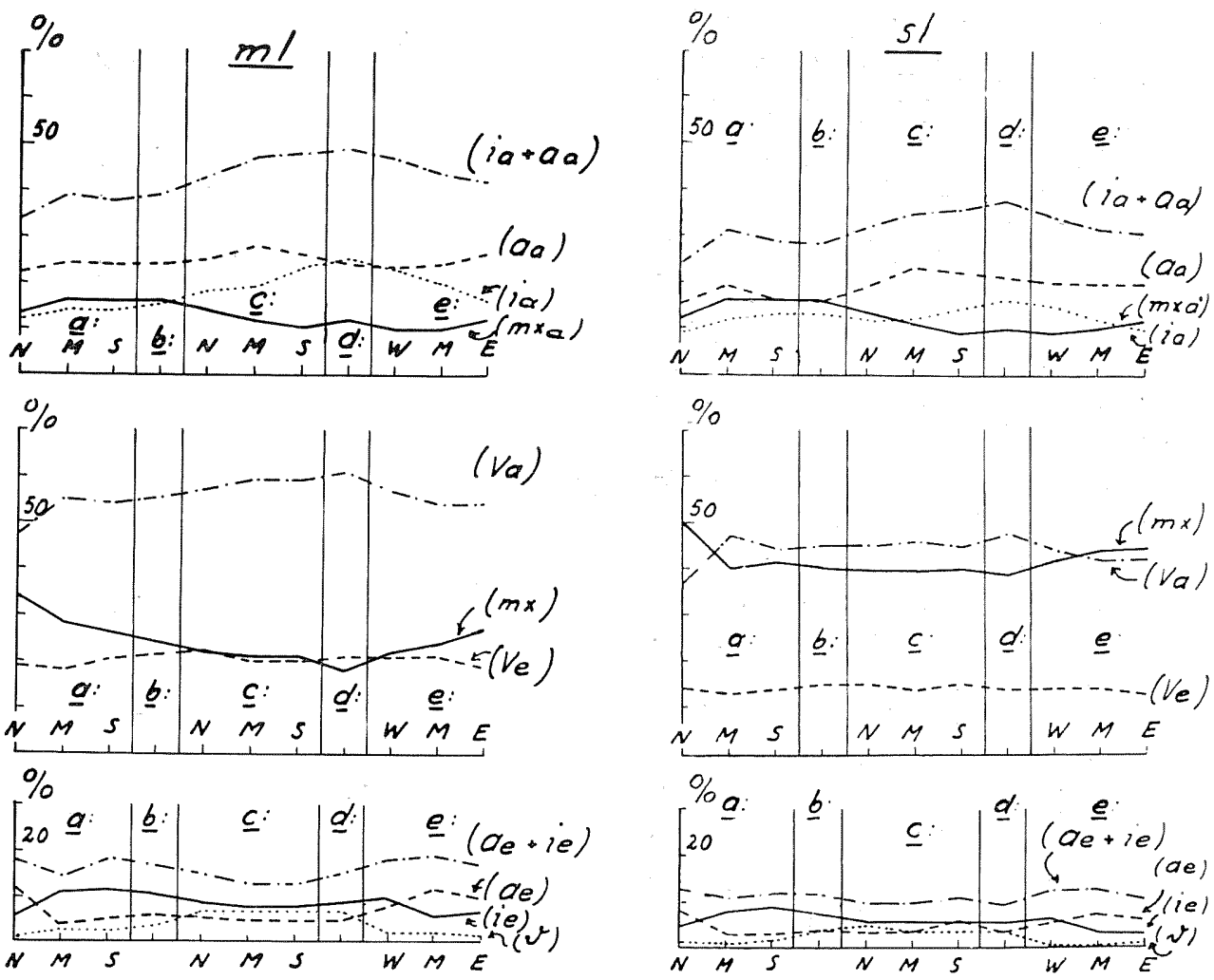

Fig. 72. Der Gang des prozentualen Verhältnisses der Winterteile $\left(\mathrm{i}_{\alpha}\right),\left(\mathrm{a}_{\alpha}\right) \ldots$. (wie in Fig. 71) zu der Länge des ganzen ml-Winters, nach den Meeresteilen geordnet. (Die Indexe $\mathrm{a}=a, \mathrm{e}=\varepsilon$.)

Fig. 73. Der Gang des prozentualen Verhältnisses der Winterteile $\left(\mathrm{j}_{\alpha}\right),\left(\mathrm{a}_{\alpha}\right) \ldots \ldots$ (wie in Fig. 71) zu der Länge des ganzen sl-Winters, nach den Meeresteilen geordnet. (Die Indexe $\mathrm{a}=\alpha, \mathrm{e}=\varepsilon$.)

1\%6. Vergleichen wir den sk-, den ml- und den sl-Winter miteinander, bemerken wir, dass die Vereisungszeit des Schärenhofes $\left(\mathbf{i}_{\alpha}+\mathbf{a}_{\alpha}\right)$ prozentual zu Gunsten der Dauer der weitesten Ausdehnung der Bräme des festen Küsteneises abnimmt und dass die Rückgangsperiode $\left(\mathbf{V}_{\varepsilon}\right)$ prozentual kürzer wird. Diese Zahlen bestätigen, dass bei einer Verlängerung des Winters seine Dauer an der Küste und im Schärenhof sich bedeutend weniger verändert als an der Grenze des eigentlichen Meeres. Wir erhalten somit ausschliesslich auf Grund der Beobachtungen an den Küsten und in den Schären kein genügend zuverlässiges Material für die Abschätzung der Länge des ganzen Eiswinters, u. a. auch des Winters im Aussenmeer. Aus der Länge des Eiswinters an der Küste und in den Schären kann man m.a. W. die Länge des Winters des eigentlichen Meeres nicht direkt bestimmen, 
und darum können, wenn Eisbeobachtungen vom Aussenmeer gänzlich fehlen, Schlüsse von den Eisverhältnissen an der Küste und in den Schären auf diejenigen des Aussenmeeres nur unter Beachtung der meteorologischen Verhältnisse, vor allem der Lufttemperatur und des Windes, gezogen werden.

1\%\%. Was die vorher erwähnten symmetrischen und asymmetrischen Winter anbetrifft, so beruht ihre Symmetrie oder Asymmetrie - soweit dies von der Entwicklung, der Kulmination und dem Rückgang der Bräme des festen Küsteneises bestimmt wird -hauptsächlich darauf, auf welche Weise die Zeitwerte $\left(\mathbf{i}_{\alpha}\right),\left(\mathbf{a}_{\alpha}\right),\left(\mathbf{m} \mathbf{x}_{\alpha}\right)$, $\left(\mathbf{m x}_{\varepsilon}\right),\left(\mathbf{a}_{\varepsilon}\right),\left(\mathbf{i}_{\varepsilon}\right)$ und $(\vartheta)$ sich im Verhältnis zueinander verändern. Vielleicht liesse sich bei der Erklärung der Abweichungen dieser Zahlen von ihren Mittelwerten zeigen, welchen Anteil die Schichtungen des Wasserkörpers und der Wärmevorrat des Meeres im Verlauf des Eiswinters haben. Denn es ist offenbar, dass die Schichtungsverhältnisse wie auch die Grösse des Wärmevorrats in den Stadien des Vorwinters von Bedeutung sind; hinsichtlich der weiteren Entwicklung des Winters, m. a. W. der mehr mittwinterlichen sowie der frühjahrlichen Teile derselben, sind die meteorologischen Faktoren dagegen, nach allem zu schliessen, beinahe die einzig bestimmenden.

\section{Die Tabelle betr. die Anzahl der Tage zwischen den G- Stadien in dem sk-, bzw. ml- und sl-Winter.}

178. Da nun die Eislagen, welche offenbar denselben »Punkt» in dem allgemeinen Verlauf des Winters angeben, mit einer sehr grossen Zeitstreuung - wie sich schon mehrmals früher bei der Verteilung der Eislagen in den Zeitintervallen gezeigt hat erscheinen, und da aus diesen, denselben »Punkt» des allgemeinen Verlaufs des Winters angebenden Eislagen das ihnen entsprechende Normalstadium hergeleitet ist, ist diesem Normalstadium, damit es auch hinsichtlich der Zeit der jedesmal in Frage kommenden Eislage entspricht, ein von den letztgenannten hergeleitetes und von deren $\|$ sf» $\rangle$ - und $\gg$ ss»-Eintrittszeiten begrenztes Zeitgebiet als eine mögliche »Eintrittszeit» gegeben.

Auf dieselbe Weise, wie die meist verschiedenen Winter aus augenscheinlich "gleichartigen», d. h. denselben Normalstadien ent- 
sprechenden Eislagen »aufgebaut» sind, welche innerhalb der Grenzen der Kurven der Zeitdiagramme liegen - zeitweilig sogar, bis aufs weitere jedoch unregelmässig ausserhalb derselben - ebenso können wir, aber diesmal vermittels der Normalstadien und innerhalb der Grenzen ihrer Eintrittszeiten, die meist verschiedenen Winter zusammenstellen. Oben haben wir schon in Punkt 160 und 161 eine Anzahl solcher, vermittels der G-Stadien aufgebauten Winter angeführt. Von diesen seien hier der »normale» sehr kurze, der «normale» mittellange und der "normale» sehr lange. Winter erwähnt. Da im nächsten Abschnitt ebenso wie auch weiterhin unsere Darstellung der Eisverhältnisse sich zum grossen Teil auf diesen "Grenzwinter» bezieht, wollen wir hier die Tabellen betr. die Anzahl der Tage zwischen den G-Stadien gerade in den erwähnten "normalen» Wintern anführen. In Tabelle 36 sind die Daten des "normalen» sehr kurzen, in Tabelle 37 des "normalen» mittellangen und in Tabelle 38 des "normalen» sehr langen Winters angegeben.

179. Die Tabellen umfassen, was ganz natürlich ist, nur die normalen G-Stadien, die auf Grund der Eislagen der Winter 19151925 hergeleitet wurden. Da die schwersten Stadien des Eiswinters hier noch mit der Wahrscheinlichkeit 4-5/10 auftreten, ist die Mittwinterzeit unvollständiger vertreten als der "Herbst» und der "Frühling» des Winters. Dieser Nachteil wird jedoch einigermassen dadurch aufgewogen, dass man sich für die Mittwinterzeit mit Frequenzkurven von niedrigen Werten begnügt, weil die Erschwerung der Eisverhältnisse sich dabei, abgesehen von der allgemeinen Zunahme der Dicke des Eises, auf das Eis weit draussen auf dem eigentlichen Meere bezieht.

180. Der "normale» sehr kurze, und der "normale» sehr lange Winter sind nicht, wie schon früher oft hervorgehoben ist, wie der normale mittellange Winter zuerst für die verschiedenen Meeresgebiete, und von diesen für das ganze Gebiet hergeleitet, sondern diese Winter, d. h. der »normale» sk-, bzw. sl-Winter, sind ganz einfach aus den G-Stadien für die ganze Küste und alle Meere auf einmal hergeleitet worden. Dabei haben wir zwar ausser Acht gelassen, dass es möglicherweise Stadien gibt, die besser als die schon hergeleiteten den äussersten Eintrittszeiten der Normalstadien entsprechen. Da es sich jedoch hierbei nur um eine nähere Bestimmung einiger Frequenzkurven handelt, die jedenfalls schon in den hergeleiteten Normalstadien vorkommen, hielten wir dies nicht für nötig, vor allem da wir uns dabei alle die Schwierigkeiten ersparten, welche 
mit dem "Aneinanderfügen» der S-Stadien verknüpft sind, wenn die G-Stadien vermittels dieser aufgebaut werden.

181. Den »normalen» sehr kurzen, ebenso wie den »normalen» sehr langen Winter erhalten wir vermittels der G-Stadien so, dass wir für den normalen sehr kurzen Winter die G-Stadien mit ihren sehr späten ('ssi)) herbstlichen und sehr frühen (»sf») frühjahrlichen Eintrittszeiten, für den normalen sehr langen Winter wiederum die G-Stadien mit ihren sehr frühen (»sf)) herbstlichen und sehr späten ("ss») frühjahrlichen Eintrittszeiten benutzen.

182. Inbetreff des »normalen» sehr kurzen Winters können wir jedoch hier zwei sk-Winter verschiedener Beschaffenheit unterscheiden, welche beide hinsichtlich der Zeit beinahe den ganzen Winter gleich lang sind, inbetreff der Entwicklung der Eisverhältnisse im Mittwinter aber sich bedeutend voneinander unterscheiden. Der "mildere» - hier in der Bedeutung der grössten Ausdehnung der Vereisung - von diesen sk-Wintern umfasst nur die G-Stadien, bei denen die Wahrscheinlichkeit des jährlichen Eintretens 10/10 ist. Hierher gehören somit nur die allgemeinen Normalstadien $\mathrm{G}_{1-13}$ und $\mathrm{G}_{21-30}$, während die Stadien $\mathrm{G}_{14-20}$ in diesem Winter gar nicht vorkommen. Der andere Winter, der inbetreff der Zeit sonst, ausser an den Stellen der fehlenden G-Stadien, gleich lang ist, ist in bezug auf die Eisverhältnisse insofern der "schwerere" sk-Winter, als er alle die G-Stadien, welche hinsichtlich der Zeit noch gut in die Reihe der mittwinterlichen G-Stadien des kurzen Winters passen, umfasst. Dieser »normale» sehr kurze Winter umfasst die allgemeinen Normalstadien $G_{1-15}$ und $G_{20-30}$, so dass in diesem Winter nur die Stadien $\mathrm{G}_{16-19}$ des Mittwinters fehlen.

183. Die Veränderung der Dicke des Eises in den G-Stadien, wenn diese bald einen sehr kurzen, bald einen sehr langen Winter vertreten, kann, ebenso wie auch die Dicke des Eises selbst, infolge des unvollständigen uns zur Verfügung stehenden Materials nur ungefähr bestimmt werden. Später im sechsten Teil wird diese Frage eingehender behandelt und die hergeleiteten Eisdicken des »kurzen» (k-) und des »langen» (1-) Winters sind in Tabellen zusammengefasst, ebenso wie die Veränderungen in der Eisdicke, wenn ein G-Stadium sich "verschiebt» um der Reihe nach den "normalen» sehr kurzen, den "normalen» mittelangen und den »normalen» sehr langen Winter zu vertreten.

Auf den Tabellen 36-38 basieren die Zahlen des folgenden Abschnittes wie auch später die Zahlen des ganzen achten Teils. 
Tabelle 36.

Die Anzahl der Tage zwischen den G-Stadien im "normalen» sehr kurzen (sk-) Winter.

$\begin{array}{rrrrrrrrrrrrrrrr} & \mathrm{G}_{2} & \mathrm{G}_{3} & \mathrm{G}_{4} & \mathrm{G}_{5} & \mathrm{G}_{6} & \mathrm{G}_{7} & \mathrm{G}_{8} & \mathrm{G}_{9} & \mathrm{G}_{10} & \mathrm{G}_{11} & \mathrm{G}_{12} & \mathrm{G}_{13} & \mathrm{G}_{14} & \mathrm{G}_{15} & \mathrm{G}_{16} \\ \mathrm{G}_{1} & 10 & 19 & 23 & 29 & 34 & 43 & 54 & 64 & 71 & 76 & 82 & 88 & 93 & 99 & - \\ \mathrm{G}_{2} & - & 9 & 13 & 19 & 24 & 33 & 44 & 54 & 61 & 66 & 72 & 78 & 83 & 89 & - \\ \mathrm{G}_{3} & - & - & 4 & 10 & 15 & 24 & 35 & 45 & 52 & 57 & 63 & 69 & 74 & 80 & - \\ \mathrm{G}_{4} & - & - & - & 6 & 11 & 20 & 31 & 41 & 48 & 53 & 59 & 65 & 70 & 76 & - \\ \mathrm{G}_{5} & - & - & - & - & 5 & 14 & 25 & 35 & 42 & 47 & 53 & 59 & 64 & 70 & - \\ \mathrm{G}_{6} & - & - & - & - & - & 9 & 20 & 30 & 37 & 42 & 48 & 54 & 59 & 65 & - \\ \mathrm{G}_{7} & - & - & - & - & - & - & 11 & 21 & 28 & 33 & 39 & 45 & 50 & 56 & - \\ \mathrm{G}_{8} & - & - & - & - & - & - & - & 10 & 17 & 22 & 28 & 34 & 39 & 45 & - \\ \mathrm{G}_{9} & - & - & - & - & - & - & - & - & 7 & 12 & 18 & 24 & 29 & 35 & - \\ \mathrm{G}_{18} & - & - & - & - & - & - & - & - & - & 5 & 11 & 17 & 22 & 28 & - \\ \mathrm{G}_{11} & - & - & - & - & - & - & - & - & - & - & 6 & 12 & 17 & 23 & - \\ \mathrm{G}_{12} & - & - & - & - & - & - & - & - & - & - & - & 6 & 11 & 17 & - \\ \mathrm{G}_{13} & - & - & - & - & - & - & - & - & - & - & - & - & 5 & 11 & - \\ \mathrm{G}_{14} & - & - & - & - & - & - & - & - & - & - & - & - & - & 6 & - \\ \mathrm{G}_{15} & - & - & - & - & - & - & - & - & - & - & - & - & - & - & -\end{array}$

\begin{tabular}{|c|c|c|c|c|c|c|c|c|c|c|c|c|c|c|}
\hline & $\mathrm{G}_{17}$ & $\mathrm{G}_{18}$ & $\mathrm{G}_{19}$ & $\mathrm{G}_{20}$ & $\mathrm{G}_{21}$ & $\mathrm{G}_{22}$ & $\mathrm{G}_{23}$ & $\mathrm{G}_{24}$ & $\mathrm{G}_{25}$ & $\mathrm{G}_{26}$ & $\mathrm{G}_{27}$ & $G_{28}$ & $\mathrm{G}_{29}$ & $\mathrm{G}_{30}$ \\
\hline $\mathrm{G}_{1}$ & - & - & - & 100 & 108 & 116 & 121 & 129 & 137 & 146 & 153 & 160 & 165 & 174 \\
\hline & - & - & - & 90 & 98 & 106 & 111 & 119 & 127 & 136 & 143 & 150 & 155 & \\
\hline & - & - & - & 81 & 89 & 97 & 102 & 110 & 118 & 127 & 134 & 141 & 146 & \\
\hline & - & - & - & 77 & 85 & 93 & 98 & 106 & 114 & 123 & 130 & 137 & 142 & \\
\hline & - & - & - & 71 & 79 & 87 & 92 & 100 & 108 & 117 & 124 & 131 & 136 & \\
\hline & - & - & - & 66 & 74 & 82 & 87 & 95 & 103 & 112 & 119 & 126 & 131 & \\
\hline & - & - & - & 57 & 65 & 73 & 78 & 86 & 94 & 103 & 110 & 117 & 122 & \\
\hline & - & - & - & 46 & 54 & 62 & 67 & 75 & 83 & 92 & 99 & 106 & 111 & \\
\hline & - & - & - & 36 & 44 & 52 & 57 & 65 & 73 & 82 & 89 & 96 & 101 & \\
\hline 10 & - & 一 & - & 29 & 37 & 45 & 50 & 58 & 66 & 75 & & 89 & 4 & \\
\hline 11 & - & - & - & 24 & 32 & 40 & 45 & 53 & 61 & 70 & 77 & 84 & 89 & \\
\hline 12 & - & - & - & 18 & 26 & 34 & 39 & 47 & 55 & 64 & 71 & 78 & 83 & \\
\hline 13 & - & - & - & 12 & 20 & 28 & 33 & 41 & 49 & 58 & 65 & 72 & 77 & \\
\hline 1 & - & - & - & 7 & 15 & 23 & 28 & 36 & 44 & 53 & 60 & 67 & 72 & \\
\hline 15 & - & - & - & 1 & 9 & 17 & 22 & 30 & 38 & 47 & 54 & 61 & 66 & \\
\hline 16 & 二 & I & I & $=$ & - & - & 二 & - & - & - & - & - & - & \\
\hline & - & I & - & - & - & - & & 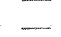 & I & & & & & \\
\hline 15 & - & - & - & - & - & - & - & - & - & & & - & & \\
\hline 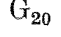 & - & - & - & - & 8 & 16 & 21 & 29 & 37 & 46 & 53 & 60 & 65 & \\
\hline & - & - & - & - & - & 8 & 13 & 21 & 29 & 38 & 45 & 52 & 57 & \\
\hline & - & - & - & - & - & - & & 13 & 21 & & & & 49 & \\
\hline & - & - & - & - & - & - & - & 8 & 16 & & & & 44 & \\
\hline & - & - & 一 & - & - & - & - & - & 8 & 17 & & & & \\
\hline & - & - & - & - & - & - & - & - & - & 0 & & & & \\
\hline & - & - & - & - & - & $\cdots$ & - & - & - & - & 7 & 14 & 19 & \\
\hline & - & - & - & - & - & - & - & - & - & & & & 12 & \\
\hline & - & $F$ & - & - & - & - & - & - & - & - & & & 5 & \\
\hline & - & - & - & - & 一 & - & - & - & - & - & - & - & - & \\
\hline
\end{tabular}


Tabelle 37.

Die Anzahl der Tage zwischen den G-Stadien im "normalen» mittellangen ( $m l-)$ Winter. In der Kolumne $G_{30}$ bezeichnet die erste Zahl den Beginin des Stadiums (d. h. das erste Datum der Mittelepoche: VI. 3.), die zweite Zahl das Ende des Stadiums (d. h. das leizte Datum der Mittelepoche: VI. 12.).

$\begin{array}{lllllllllllllll}\mathrm{G}_{2} & \mathrm{G}_{3} & \mathrm{G}_{4} & \mathrm{G}_{5} & \mathrm{G}_{6} & \mathrm{G}_{7} & \mathrm{G}_{8} & \mathrm{G}_{9} & \mathrm{G}_{10} & \mathrm{G}_{11} & \mathrm{G}_{12} & \mathrm{G}_{13} & \mathrm{G}_{14} & \mathrm{G}_{15} & \mathrm{G}_{16}\end{array}$

$\begin{array}{llllllllllllllll}\mathrm{G}_{1} & 9 & 20 & 25 & 28 & 33 & 40 & 51 & 61 & 69 & 77 & 84 & 92 & 97 & 104 & 112\end{array}$

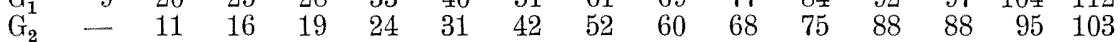

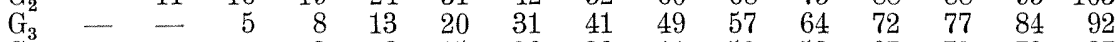

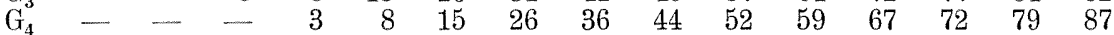

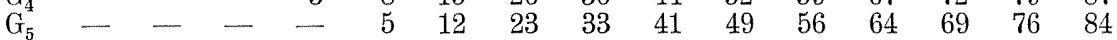

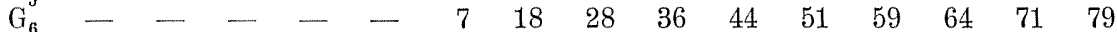

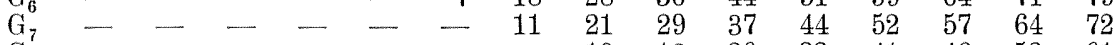

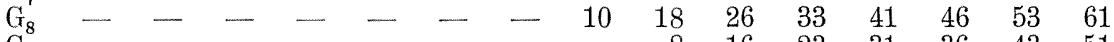

$\mathrm{G}_{9}$ - - - - - - - $-8 \begin{array}{rrrrrr}10 & 23 & 31 & 36 & 43 & 51\end{array}$

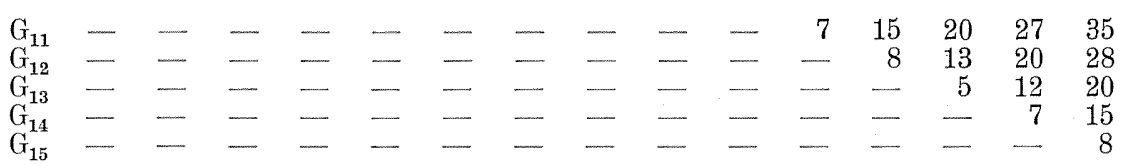

$\begin{array}{llllllllllllll}\mathrm{G}_{17} & \mathrm{G}_{18} & \mathrm{G}_{19} & \mathrm{G}_{20} & \mathrm{G}_{21} & \mathrm{G}_{22} & \mathrm{G}_{23} & \mathrm{G}_{24} & \mathrm{G}_{25} & \mathrm{G}_{26} & \mathrm{G}_{27} & \mathrm{G}_{28} & \mathrm{G}_{29} & \mathrm{G}_{30}\end{array}$

$\begin{array}{lllllllllllllll}\mathrm{G}_{1} & 118 & 127 & 138 & 146 & 154 & 161 & 167 & 174 & 182 & 188 & 193 & 199 & 203 & 211-220\end{array}$

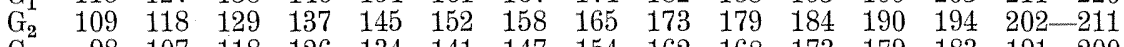

$\begin{array}{lllllllllllllll}\mathrm{G}_{3} & 98 & 107 & 118 & 126 & 134 & 141 & 147 & 154 & 162 & 168 & 173 & 179 & 183 & 191-200\end{array}$

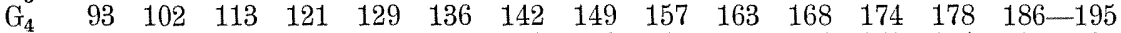

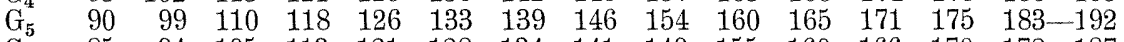

$\begin{array}{lllllllllllllll}\mathrm{G}_{6} & 85 & 94 & 105 & 113 & 121 & 128 & 134 & 141 & 149 & 155 & 160 & 166 & 170 & 178-187\end{array}$

$\begin{array}{lllllllllllllll}\mathrm{G}_{7} & 78 & 87 & 98 & 106 & 114 & 121 & 127 & 134 & 142 & 148 & 153 & 159 & 163 & 171-180\end{array}$

$\begin{array}{lllllllllllllll}\mathrm{G}_{8} & 67 & 76 & 87 & 95 & 103 & 110 & 116 & 123 & 131 & 137 & 142 & 148 & 152 & 160-169\end{array}$

$\begin{array}{lllllllllllllll}\mathrm{G}_{9} & 57 & 66 & 77 & 85 & 93 & 100 & 106 & 113 & 121 & 127 & 132 & 138 & 142 & 150-159\end{array}$

$\begin{array}{lllllllllllllll}\mathrm{G}_{10} & 49 & 58 & 69 & 77 & 85 & 92 & 98 & 105 & 113 & 119 & 124 & 130 & 134 & 142-151\end{array}$

$\begin{array}{rrrrrrrrrrrrrrr}\mathrm{G}_{11} & 41 & 50 & 61 & 69 & 77 & 84 & 90 & 97 & 105 & 111 & 116 & 122 & 126 & 134-143 \\ \mathrm{G}_{12} & 34 & 43 & 54 & 62 & 70 & 77 & 83 & 90 & 98 & 104 & 109 & 115 & 119 & 127-136\end{array}$

$\begin{array}{lllllllllllllll}\mathrm{G}_{13} & 26 & 35 & 46 & 54 & 62 & 69 & 75 & 82 & 90 & 96 & 101 & 107 & 111 & 119-128\end{array}$

$\begin{array}{lllllllllllllll}\mathrm{G}_{14} & 21 & 30 & 41 & 49 & 57 & 64 & 70 & 77 & 85 & 91 & 96 & 102 & 106 & 114-123\end{array}$

$\begin{array}{lllllllllllllll}\mathrm{G}_{15} & 14 & 23 & 34 & 42 & 50 & 57 & 63 & 70 & 78 & 84 & 89 & 95 & 99 & 107-116\end{array}$

$\begin{array}{lllllllllllllll}\mathrm{G}_{16} & 6 & 15 & 26 & 34 & 42 & 49 & 55 & 62 & 70 & 76 & 81 & 87 & 91 & 99-108\end{array}$

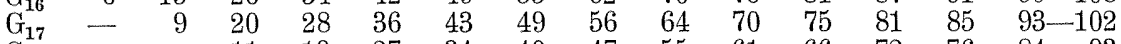

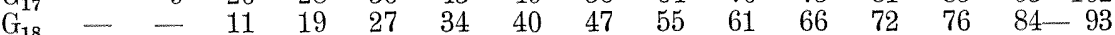

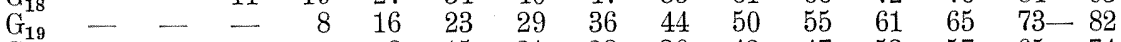

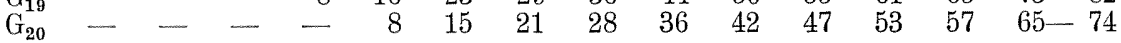

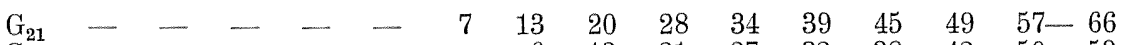

$\mathrm{G}_{22}-\quad-\quad-\quad-\quad-\quad 6 \quad \begin{array}{rrrrrrrr}13 & 21 & 27 & 32 & 38 & 42 & 50-59\end{array}$

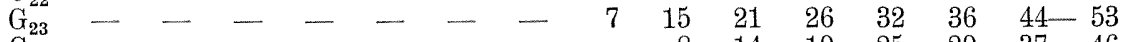

$\mathrm{G}_{24}$ - - - - - - - $814 \quad 19252937-46$

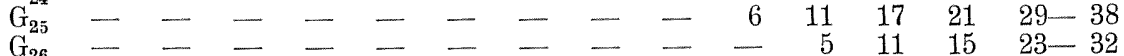

$\mathrm{G}_{26}$ - - - - - - - - - - - 6 - 10 18 27

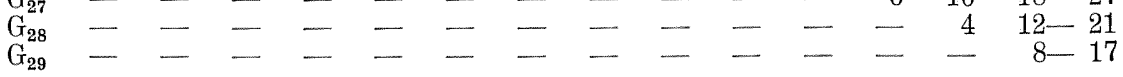


Tabelle 38.

Die Anzahl der Tage zwischen den G-Stadien im "normalen» sehr langen (st-) Winter. $G_{18 a}$ bzw. $G_{18 \varepsilon}$ bezeichnet den Beginn des 18. Stadiums bei seinem sehr frühen Eintreten (II. 15.) bzw. das Ende desselben bei seinem sehr späten Verschwinden (III. 31.). In der Kolumne $G_{30}$ entspricht die erste Zahl dem späten mittleren Beginn (d.h. der späten Mittelepoche VI. 12.), die zweite Zahl dem sehr späten Verschwinden (VI. 28.) dieses Stadiums.

$\begin{array}{lllllllllllllll}\mathrm{G}_{2} & \mathrm{G}_{3} & \mathrm{G}_{4} & \mathrm{G}_{5} & \mathrm{G}_{6} & \mathrm{G}_{7} & \mathrm{G}_{8} & \mathrm{G}_{9} & \mathrm{G}_{10} & \mathrm{G}_{11} & \mathrm{G}_{12} & \mathrm{G}_{13} & \mathrm{G}_{14} & \mathrm{G}_{15} & \mathrm{G}_{16}\end{array}$ $\begin{array}{llllllllllllllll}\mathrm{G}_{1} & 11 & 22 & 26 & 30 & 33 & 38 & 45 & 54 & 62 & 71 & 79 & 88 & 96 & 103 & 110\end{array}$

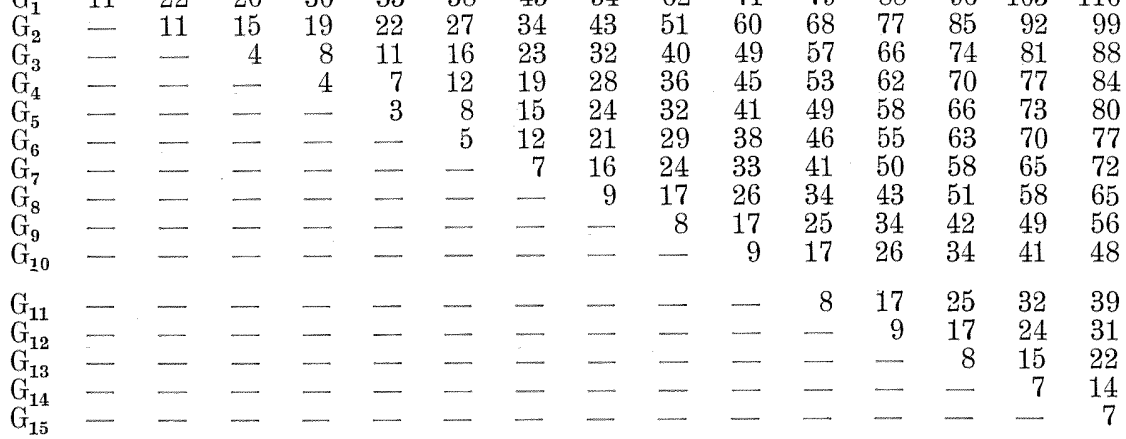

$\begin{array}{lllllllllllllll}\mathrm{G}_{17} & \mathrm{G}_{18 \alpha} & \mathrm{G}_{18 \varepsilon} & \mathrm{G}_{19} & \mathrm{G}_{20} & \mathrm{G}_{21} & \mathrm{G}_{22} & \mathrm{G}_{23} & \mathrm{G}_{24} & \mathrm{G}_{25} & \mathrm{G}_{26} & \mathrm{G}_{27} & \mathrm{G}_{28} & \mathrm{G}_{29} & \mathrm{G}_{30}\end{array}$

$\begin{array}{lllllllllllllllll}\mathrm{G}_{1} & 118 & 128 & 172 & 184 & 190 & 198 & 203 & 209 & 213 & 221 & 226 & 231 & 234 & 240 & 245 & -261\end{array}$

$\begin{array}{lllllllllllllllll}\mathrm{G}_{2} & 107 & 117 & 161 & 173 & 179 & 187 & 192 & 198 & 202 & 210 & 215 & 220 & 223 & 229 & 234 & 250\end{array}$

$\begin{array}{lllllllllllllllll}\mathrm{G}_{3} & 96 & 106 & 150 & 162 & 168 & 176 & 181 & 187 & 191 & 199 & 204 & 209 & 212 & 218 & 223 & -239\end{array}$

$\begin{array}{lllllllllllllllll}\mathrm{G}_{4} & 92 & 102 & 146 & 158 & 164 & 172 & 177 & 183 & 187 & 195 & 200 & 205 & 208 & 214 & 219 & -235\end{array}$

$\begin{array}{llrlllllllllllllll}\mathrm{G}_{5} & & 88 & 98 & 142 & 154 & 160 & 168 & 173 & 179 & 183 & 191 & 196 & 201 & 204 & 210 & 215 & -231\end{array}$

$\begin{array}{lllllllllllllllll}\mathrm{G}_{6} & 85 & 95 & 139 & 151 & 157 & 165 & 170 & 176 & 180 & 188 & 193 & 198 & 201 & 207 & 212 & 228\end{array}$

$\begin{array}{lllllllllllllllll}\mathrm{G}_{7} & 80 & 90 & 134 & 146 & 152 & 160 & 165 & 171 & 175 & 183 & 188 & 193 & 196 & 202 & 207 & -223\end{array}$

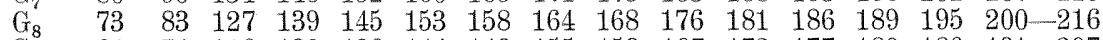

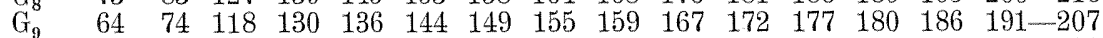

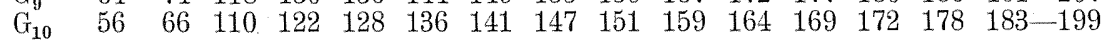

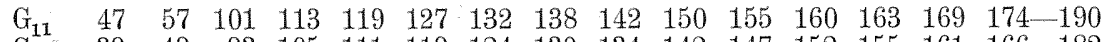

$\begin{array}{lllllllllllllllll}\mathrm{G}_{12} & 39 & 49 & 93 & 105 & 111 & 119 & 124 & 130 & 134 & 142 & 147 & 152 & 155 & 161 & 166 & -182\end{array}$

$\begin{array}{llllllllllllllll}\mathrm{G}_{13} & 30 & 40 & 84 & 96 & 102 & 110 & 115 & 121 & 125 & 133 & 138 & 143 & 146 & 152 & 157-173\end{array}$

$\begin{array}{lllllllllllllllll}\mathrm{G}_{14} & 22 & 32 & 76 & 88 & 94 & 102 & 107 & 113 & 117 & 125 & 130 & 135 & 138 & 144 & 149 & -165\end{array}$

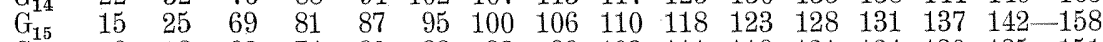

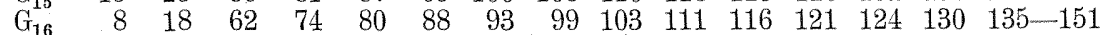

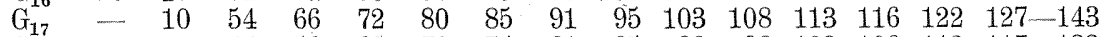

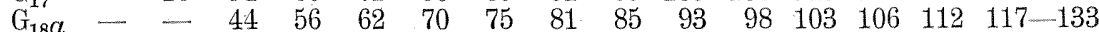

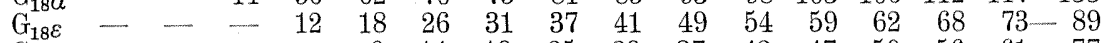

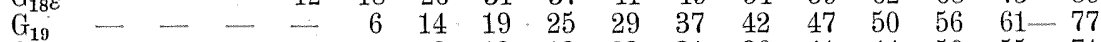

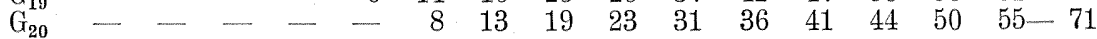

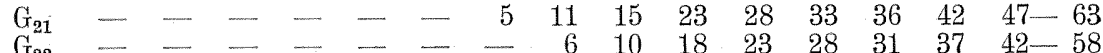

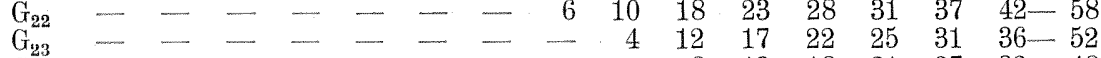

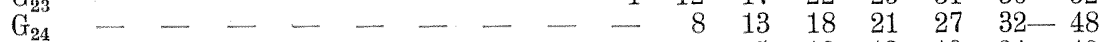

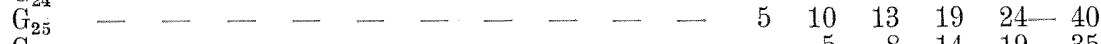

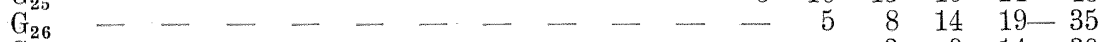

$\mathrm{G}_{27}-\ldots-\ldots-\ldots-30$

$\mathrm{G}_{28}-\div-\ldots-\ldots-\ldots-\ldots-11-27$ 


\section{Fünfter Abschnitt: Die Einordnung der Eislagen in die von den Zeitpunkten der S- und G-Stadien bestimmten Zeitintervalle.}

\section{Einordnung der Eislagen in die Zeitintervalle.}

184. Auf den Karten der S- und G-Stadien sind die Eintrittszeiten der Normalstadien durch fünf Daten angegeben. Von diesen bezeichnet, wie bekannt, das in der Mitte stehende und etwas grösser gezeichnete Datum die mittlere (m) Eintrittszeit, die oberhalb bzw. unterhalb befindlichen Daten geben die frühe (f) bzw. die späte (s), und das zuoberst bzw. zuunterst stehende Datum die sehr frühe (sf) bzw. die sehr späte (ss) Eintrittszeit an.

Um zu ermitteln, auf welche Weise die bei dem Aufbau der Normalstadien benutzten Eislagen sich um die erwähnten Daten gruppieren, teilten wir die ganze Zeitfolge $t_{s s}-t_{\text {sf }}$ in fünf "Zeitintervalle» ein. Das erste Zeitintervall erstreckt sich zu beiden Seiten der Epoche $t_{m}$ halbwegs bis zu den Zeitpunkten $t_{f}$ und $t_{s}$. Alle Eislagen, deren Daten in dieses Zeitintervall "m» fallen, sind um die mittlere Eintrittszeit des Normalstadiums erschienen. Die folgenden, an das "m»-Gebjet sich unmittelbar anschliessenden Zeitintervalle umfassen auf der linken Seite - das Gebiet »f» - die Eislagen, welche früher, auf der rechten Seite - das Gebiet ns》 - wiederum die Eislagen, welche später als durchschnittlich erschienen waren. Diese Zeitgebiete "f) und ॥S》 erstrecken sich: das erstere von der Mitte der Zeitpunkte $t_{m}$ und $t_{f}$, das letztere von der Mitte der Zeitpunkte $t_{s}$ und $t_{m}$ entsprechend bis zur Mitte der Zeitpunkte $t_{f}$ und $t_{s f}$, bzw. $t_{s}$ und $t_{s s}$. Ausserhalb dieser Zeitgebiete "f» und "s» erstrecken sich noch von dem Zeitpunkt $t_{\text {sf }}$, bzw. $t_{\text {ss }}$, nach links um etwa $1 / 2$ $\left(t_{\mathrm{f}}-t_{\mathrm{sf}}\right)$ bzw. nach rechts um etwa $1 / 2\left(t_{\mathrm{ss}}-\mathrm{s}_{\mathrm{s}}\right)$ die Zeitgebiete $\| \mathrm{sf}$ » und "ss", welche einerseits die sehr früh, anderseits die sehr spät erschienenen Ejslagen umfassen.

185. Nachdem die oben durchgef “hrte Finteilung der Zeitgebiete sowohl in den S- als in den G-Stadien ausgeführt war, zeigte es sich, wie auch zu erwarten war, dass die Länge der Zeitintervalle in 
Tagen im Laufe des Winters etwas variierte. In den Tabellen $40 \mathrm{a}-45$ a sind die "Daten» der Zeitintervalle von $t_{\mathrm{m}}$ an gerechnet der Mittelwert von fünf aufeinanderfolgenden Normalstadien (nur in der letzten Gruppe schwankt die Anzahl der Stadien in den verschiedenen Meeresteilen etwas). Am Ende jeder einzelnen Tabelle sind die durchschnittlichen »Daten» eines jeden Zeitintervalls während des ganzen Winters angegeben, wobei die "Daten» aus sämtlichen Stadien von $t_{m}$ an berechnet sind.

Die "Breiten» der Zeitintervalle, welche also den Werten der Tabellen 40 a -45 a entsprechen, gehen aus der Tabelle 39 hervor. So z. B. ist in dem $\boldsymbol{d}$-Gebiet die mittlere "Breite» (in der Kolumne M) 10 Tage, in den anderen Gebieten 11 Tage. Gegen den Frühling nimmt sie von $12-14$ Tagen auf $7-9$ Tage ab. In den Zeitintervallen sf, $f, m, s$, ss sind weiter die Schwankungen der Breite in den verschiedenen Meeresteilen, bzw. nach den G-Stadien etwas unregelmässiger, die allgemeine Tendenz ist jedoch im ganzen dieselbe, wie z. B. in der Stadiengruppe Sc 6-10, wo bei dem Übergang aus sf

Tabelle 39 .

Die »Breite» der Zeitintervalle sf, $f, m$, s und ss der S-bzw. der G-Stadien in Tagen. In den Kolumnen $M$ ist die mittlere "Breite» der Zeitintervalle in den Stadiengruppen $S_{1-5}, S_{6-10} u s w$. angegeben. In den Reihen $a_{1-26}, \quad b_{1-24}, \quad c_{1-26}, \quad d_{1-25}, \quad e_{1-28}$ und $G_{1-30}$ erscheint die »Breite» der Zeitintervalle als Mittelwert des ganzen Winters.

Gebiet a Zahl der Tage

Gebiet b

\begin{tabular}{|l|r|r|r|r|r|r|l|r|r|r|r|r|r|}
\hline & sf & f & m & s & ss & m & & sf & f & m & s & ss & M \\
\hline & 14 & 13 & 13 & 12 & 12 & 13 & $b_{1-5}$ & 10 & 12 & 15 & 15 & 14 & 13 \\
$\mathrm{a}_{1-5}$ & 16 & 17 & 15 & 12 & 12 & 14 & $\mathrm{~b}_{6-10}$ & 14 & 15 & 16 & 12 & 10 & 13 \\
$\mathrm{a}_{6-10}$ & 14 & 14 & 12 & 10 & 10 & 12 & $\mathrm{~b}_{11-15}$ & 14 & 14 & 15 & 12 & 10 & 13 \\
$\mathrm{a}_{\mathbf{1 1 - 1 5}}$ & 10 & 10 & 10 & 8 & 6 & 9 & $\mathrm{~b}_{16-20}$ & 12 & 12 & 12 & 10 & 10 & 11 \\
$\mathrm{a}_{\mathbf{1 6 - 2 0}}$ & 6 & 7 & 6 & 8 & 8 & 7 & $\mathrm{~b}_{21-24}$ & 6 & 6 & 7 & 8 & 8 & 7 \\
$\mathrm{a}_{\mathbf{2 1 - 2 6}}$ & 12 & 12 & 11 & 10 & 10 & 11 & $\mathrm{~b}_{\mathbf{1 - 2 4}}$ & 12 & 11 & 13 & 11 & 10 & 11 \\
$\mathrm{a}_{\mathbf{1 - 2 6}}$ & 12 & & & & & & & & & & & &
\end{tabular}

Gebiet e

Zahl der Tage

Gebiet d

\begin{tabular}{|c|c|c|c|c|c|c|c|c|c|c|c|c|c|}
\hline & sf & f & m & $\mathbf{s}$ & ss & MI & & sf & f & $\mathbf{m}$ & $\mathrm{s}$ & ss & MI \\
\hline$c_{1-5}$ & 12 & 13 & 16 & 15 & 16 & 14 & $d_{1-5}$ & 14 & 13 & 12 & 11 & 10 & 12 \\
\hline$c_{6-10}$ & 14 & 13 & 13 & 11 & 10 & 12 & & 10 & 11 & 11 & 10 & 12 & 11 \\
\hline$c_{11-15}$ & 12 & 12 & 12 & 12 & 12 & 12 & $\mathrm{~d}_{11-15}$ & 12 & 12 & 11 & 9 & 8 & 10 \\
\hline$c_{16-20}$ & 10 & 12 & 11 & 10 & 8 & 10 & $\mathrm{~d}_{16-20}$ & 8 & 9 & 9 & 10 & 10 & 9 \\
\hline$c_{21-26}$ & 10 & 11 & 10 & 8 & 8 & 9 & $\mathrm{~d}_{21-25}$ & 8 & 8 & 8 & 8 & 8 & \\
\hline$c_{1-26}$ & 12 & 12 & 12 & 11 & 10 & 11 & $d_{1-25}$ & 10 & 10 & 10 & 10 & 10 & 10 \\
\hline
\end{tabular}




\begin{tabular}{|c|c|c|c|c|c|c|c|c|c|c|c|c|c|}
\hline & sf & f & $\mathrm{m}$ & $\mathrm{s}$ & ss & IM & & sf & f & $\mathbf{m}$ & $\mathrm{s}$ & ss & IM \\
\hline$e_{1-5}$ & 14 & 14 & 16 & 13 & 12 & 14 & $G_{1-5}$ & 12 & 12 & 12 & 12 & 12 & 12 \\
\hline $\mathrm{e}_{6-10}$ & 14 & 15 & 13 & 10 & 12 & 13 & $\mathrm{G}_{6-10}^{1-5}$ & 14 & 15 & 15 & 14 & 12 & 14 \\
\hline$e_{11-15}$ & 12 & 12 & 11 & 9 & 8 & 10 & $\mathrm{G}_{11-15}$ & 14 & 14 & 13 & 11 & 10 & 12 \\
\hline $\mathrm{e}_{16-20}$ & 10 & 10 & 10 & 9 & 8 & 9 & $\mathrm{G}_{16-20}$ & 12 & 13 & 12 & 10 & 8 & 11 \\
\hline $\mathrm{e}_{21-28}$ & 8 & 9 & 9 & 8 & 8 & 8 & $\mathrm{G}_{21-25}$ & 12 & 10 & 9 & 8 & 8 & 9 \\
\hline$e_{1-28}$ & 12 & 12 & 11 & 9 & 8 & 11 & $\mathrm{G}_{26-30}$ & & 8 & 7 & 7 & 6 & 7 \\
\hline & & & & & & & $G_{1-30}$ & 12 & 12 & 11 & 10 & 9 & 11 \\
\hline
\end{tabular}

in ss die Breite der Zeitintervalle abnimmt. Besonders regelmässig tritt diese Tendenz in den sämtliche e- und G-Stadien umfassenden Werten $\left(e_{1-28}, G_{1-30}\right)$ auf. Die in zwei Richtungen, d. h. vom Herbst zum Frühling und von dem Zeitintervall sf bis ss vorsichgehende "Verschmälerung» der "Zeitgebiete» beleuchtet ihrerseits den Aufbau der Normalstadien.

186. Die aus den Daten der bei dem Aufbaủ der Normalstadien gebrauchten Eislagen bestimmten Zeitgebiete liegen somit nicht, wie man vielleicht erwarten könnte, symmetrisch um die mittlere Eintrittszeit $t_{m}$, sondern die Zeitpunkte liegen vielmehr gegen das Frühjahr und auf der "späten» Seite der Mittelepoche $t_{m}$ dichter beieinander, gegen den Herbst und auf der „früheren» Seite von $t_{m}$ wiederum weniger dicht und weiter auseinander. Dieses Resultat, obgleich es offenbar teilweise darauf beruht, dass die Verteilung der Zahlen durch die Berechnungsweise der durchschnittlichen Eintrittszeiten bestimmt ist, entspricht andererseits doch augenscheinlich einem wirklichen Zug in dem allgemeinen Verlauf des Eiswinters, welcher seinerseits von den die Stadien des Winters bestimmenden, vor allem meteorologischen Faktoren abhängt.

18\%. Ordnen wir die bei dem Aufbau der Normalstadien benutzten Eislagen nach ihren Daten in die diesen entsprechenden Zeit-

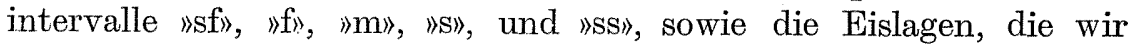
bei der Bestimmung der Eintrittszeiten wegen ihrer ausserordentlich frühen (aof) oder ausserordentlich späten (aos) Eintrittsdaten nicht verwerteten, ausserhalb jener in neue, diesen Daten entsprechende Zeitintervalle »aof» und »aos» ein, so erhalten wir die Zahlenwerte der Tabellen $40 \mathrm{~b}-45 \mathrm{~b}$. Diese zeigen somit, auf welche Weise sämtliche Eislagen der Winter 1915-1925 sich auf die Zeitintervalle der a-Tabelle 40a - 45a sowie ausserhalb dieser verteilen. Die Anzahl der Eislagen in den Zeitintervallen der G-Stadien haben wir in der Weise erhalten, dass wir sämtliche Eislagen, aus denen die zum Aufbau eines G-Stadiums benutzten S-Stadien bestimmt sind, addiert 
haben. So entsprechen z. B. dem Generalstadium $G_{8}$ dieselben Eis. lagen, aus denen die zum Aufbau dieses Stadiums benutzten SStadien $\mathrm{Sa}_{6}, \mathrm{Sa}_{7}, \mathrm{Sb}_{6}, \mathrm{Sb}_{7}, \mathrm{Sc}_{4}, \mathrm{Sc}_{5}, \mathrm{Sd}_{4}$ und $\mathrm{Se}_{5}$ bestimmt sind.

In den Tabellen $40 \mathrm{~b}-45 \mathrm{~b}$ haben sämtliche Eislagen dasselbe Gewicht. Bei der Herleitung der Mittelepochen erhielten dagegen die Eislagen eines und desselben Normalstadiums auf Grund verschiedener Umstände verschiedenes Gewicht, und die Daten einiger ungewöhnlich früh bzw. spät eingetretenen Eislagen blieben gänzlich unbeachtet. Verschiedenes Gewicht erhielten $u$. a. solche Eislagen, welche, obwohl sie demselben Stadium entsprechen, mehrmals im Laufe desselben Winters eingetreten sind. Hier wurde im allgemeinen den frühesten Daten das grösste Gewicht beigelegt. Die Folge davon ist, dass, falls solche Eislagen mit einer Zwischenzeit von ein bis zwei Wochen aufeinander folgen, diese wiederkehrenden Eislagen in den betreffenden Tabellen vor allem die Zahlen der $\gg$ s»- und der $\gg$ ss» $\rangle$-Gruppe vermehren. Hierauf beruht es, dass die »'s》- und $\rangle$ SS》-Werte im allgemeinen etwas grösser als die entsprechenden $\| f\rangle-$ und $\gg$ sf»-Werte sind, ein Umstand, welcher sonst darauf deuten würde, dass das Datum der Mittelepochen etwas zu früh eintritt.

188. Um weiter einen Begriff davon zu erhalten, auf welche Weise jene erwähnten Fislagen, welche wir wegen der ganz ungewöhnlichen Daten ihres Erscheinens bei der Herleitung der Eintrittszeiten gar nicht benutzt haben, sondern nur bei der Bestimmung der Bräme des festen Küsteneises und der Frequenzlkurven verwerteten, sich

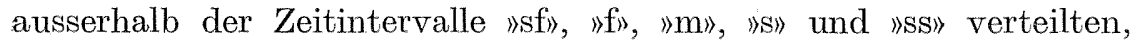
fügten wir, wie erwähnt, die Zeitintervalle »aof» und »aos» hinzu. Dadurch vermindert sich natürlich $u$. a. das prozentuale Verhältnis der

Tabelle 40 a.

Die in den Gruppen $a_{1-5}, a_{6-10}, \ldots$ der Normalstadien des a-Gebietes $z u$ den Zeitintervallen sf, $f, m, s$ und $s s$, von der Mittelepoche $t_{m}$ an gerechnet, gehörenden Tage.

\begin{tabular}{|l|c|c|c|c|c|c|}
\hline & sf & f & $\begin{array}{c}\mathrm{m} \\
\left(\mathrm{t}_{\mathrm{m}}\right)\end{array}$ & $\mathrm{s}$ & ss \\
\hline & $33-20$ & $19-7$ & $6-$ & -7 & $8-19$ & $20-31$ \\
$\mathrm{a}_{1-5}$ & $42-27$ & $26-10$ & $9-$ & -6 & $7-18$ & $19-30$ \\
$\mathrm{a}_{6-10}$ & $35-22$ & $21-8$ & $7-$ & -5 & $6-15$ & $16-25$ \\
$\mathrm{a}_{11-15}$ & $25-16$ & $15-6$ & $5-$ & -5 & $6-13$ & $14-19$ \\
$\mathrm{a}_{15-20}$ & $16-11$ & $10-4$ & $3-$ & -3 & $4-11$ & $12-19$ \\
$\mathrm{a}_{21-26}$ & $30-19$ & $18-7$ & $6-$ & -5 & $6-15$ & $16-25$ \\
\hline $\mathrm{a}_{1-26}^{1-2}$ & & & & & & \\
\hline
\end{tabular}


Tabelle $40 \mathrm{~b}$.

Die Anzahl der Eislagen, die in die Zeitintervalle sf, $f, m, s$ und ss der vorhergehenden Tabelle sowie ausserhalb dieser Zeitintervalle in die Kolumnen aof (ausserordentlich früh) und aos (ausserordentlich spät) fallen.

\begin{tabular}{|l|r|r|r|r|r|r|r|r|}
\hline & aof & sf & $\mathbf{f}$ & $\mathbf{m}$ & $\mathbf{s}$ & ss & aos & Summe \\
\hline & 0 & 4 & 8 & 17 & 9 & 4 & 9 & 51 \\
$\mathbf{a}_{\mathbf{1 - 5}}$ & 0 & 4 & 10 & 25 & 16 & 9 & 8 & 72 \\
$\mathbf{a}_{\mathbf{6}-10}$ & 7 & 8 & 9 & 44 & 9 & 4 & 0 & 81 \\
$\mathbf{a}_{\mathbf{1 1 - 1 5}}$ & 3 & 10 & 8 & 13 & 14 & 8 & 2 & 58 \\
$\mathbf{a}_{\mathbf{1 6 - 2 0}}$ & 1 & 5 & 11 & 18 & 16 & 12 & 6 & 69 \\
$\mathbf{a}_{\mathbf{2 1 - 2 6}}$ & 11 & 31 & 46 & 117 & 64 & 37 & 25 & 331 \\
$\mathbf{a}_{\mathbf{1 - 2 6}}$ & 11 & & & & &
\end{tabular}

Tabelle $40 \mathrm{c}$.

Die Zahlenwerte der vorhergehenden Tabelle in Prozenten.

\begin{tabular}{|l|l|r|r|r|r|r|r||r|r|r|}
\hline & aof & sf & f & m & s & ss & aos & aof $+\mathbf{s i}$ & $\mathbf{f}+\mathbf{m}+\mathbf{s}$ & $\mathbf{s s}+\mathbf{a o s}$ \\
\hline & 0 & 8 & 16 & 33 & 18 & 8 & 18 & 8 & 67 & 26 \\
$\mathbf{a}_{\mathbf{1 - 5}}$ & 0 & 6 & 14 & 35 & 22 & 12 & 11 & 6 & 71 & 23 \\
$\mathrm{a}_{\mathbf{6 - 1 0}}$ & 9 & 10 & 11 & 54 & 11 & 5 & 0 & 19 & 76 & 5 \\
$\mathbf{a}_{11-15}$ & 5 & 17 & 14 & 22 & 24 & 14 & 3 & 22 & 60 & 17 \\
$\mathbf{a}_{\mathbf{1 6 - 2 0}}$ & 1 & 7 & 16 & 26 & 23 & 17 & 9 & 8 & 65 & 26 \\
$\mathrm{a}_{\mathbf{2 1 - 2 6}}$ & 3 & 9 & 14 & 35 & 19 & 12 & 8 & 12 & 68 & 20 \\
$\mathrm{a}_{\mathbf{1 - 2 6}}$ & 3 & & & & & & & \\
\end{tabular}

Tabelle 41 a.

Die in den Gruppen $b_{1-5}, b_{6-10}, \ldots$ der Normalstadien des $\boldsymbol{b}$-Gebietes $z u$ den Zeitintervallen $s f, f, m, s$ und $s s$, von der Mittelepoche $t_{m}$ an gerechnet, gehörenden Tage.

\begin{tabular}{|c|c|c|c|c|c|c|}
\hline & sf & $\mathbf{f}$ & \multicolumn{2}{|c|}{$\underset{\left(t_{m}\right)}{\mathbf{m}}$} & $\mathbf{s}$ & ss \\
\hline$b_{1-5}$ & $29 \quad 20$ & $19-8$ & $7-$ & -8 & $9-23$ & $24-37$ \\
\hline$b_{6-10}$ & $37-24$ & $23-9$ & $8-$ & -8 & $9-20$ & $21-30$ \\
\hline$b_{11-15}$ & $36-23$ & $22-9$ & $8-$ & -7 & $8-19$ & $20-29$ \\
\hline$b_{16-20}$ & $30-19$ & $18-7$ & $6-$ & -6 & $7-16$ & $17-26$ \\
\hline$b_{21-24}$ & $15-10$ & $9-4$ & $3-$ & -4 & $5-12$ & $13-20$ \\
\hline$b_{1-24}$ & $29-18$ & $17-7$ & $6-$ & -7 & $8-18$ & $19-28$ \\
\hline
\end{tabular}


Tabelle $41 \mathrm{~b}$.

Die Anzahl der Eislagen, die in die Zeitintervalle sf, $f, m, s$ und ss der vorhergehenden Tabelle sowie ausserhalb dieser Zeitintervalle in die Kolumnen aof (ausserordentlich frïh) und aos (ausserordentlich spät) fallen.

\begin{tabular}{|l|r|r|r|r|r|r|r|r|}
\hline & aof & sf & f & m & s & ss & aos & Summe \\
\hline $\mathrm{b}_{\mathbf{1 - 5}}$ & 0 & 5 & 8 & 13 & 9 & 3 & 3 & 41 \\
$\mathrm{~b}_{\mathbf{6 - 1 . 0}}$ & 1 & 6 & 11 & 14 & 8 & 3 & 6 & 49 \\
$\mathrm{~b}_{\mathbf{1 1 - 1 5}}$ & 8 & 5 & 13 & 28 & 10 & 7 & 4 & 75 \\
$\mathrm{~b}_{\mathbf{1 6 - 2 0}}$ & 3 & 8 & 5 & 18 & 14 & 7 & 6 & 61 \\
$\mathrm{~b}_{\mathbf{2 1 - 2 4}}$ & 1 & 5 & 2 & 10 & 6 & 3 & 0 & 27 \\
$\mathrm{~b}_{\mathbf{1 - 2 4}}$ & 13 & 29 & 39 & 83 & 47 & 23 & 19 & 253 \\
\hline
\end{tabular}

Tabelle $41 \mathrm{c}$.

Die Zahlenwerte der vorhergehenden Tabelle in Prozenten.

\begin{tabular}{|l|r|r|r|r|r|r|r||r|r|r|}
\hline & aof & sf & $\mathbf{f}$ & $\mathbf{m}$ & $\mathbf{s}$ & $\mathbf{s s}$ & aos & aof $+\mathbf{s f}$ & $\mathbf{f}+\mathbf{m}+\mathbf{s}$ & $\mathbf{s s}+\mathbf{a o s}$ \\
\hline $\mathrm{b}_{\mathbf{1 - 5}}$ & 0 & 12 & 20 & 32 & 22 & 7 & 7 & 12 & 74 & 15 \\
$\mathrm{~b}_{\mathbf{6 - 1 0}}$ & 2 & 12 & 22 & 29 & 16 & 6 & 12 & 14 & 67 & 18 \\
$\mathrm{~b}_{\mathbf{1 1 - 1 5}}$ & 11 & 7 & 17 & 37 & 23 & 9 & 5 & 17 & 68 & 15 \\
$\mathrm{~b}_{16-20}$ & 5 & 13 & 8 & 30 & 33 & 12 & 10 & 18 & 61 & 21 \\
$\mathrm{~b}_{\mathbf{2 1 - 2 4}}$ & 4 & 19 & 7 & 37 & 22 & 11 & 0 & 22 & 67 & 11 \\
$\mathrm{~b}_{\mathbf{1 - 2 4}}$ & 5 & 12 & 15 & 33 & 19 & 9 & 8 & 17 & 67 & 17 \\
\hline
\end{tabular}

Tabelle 42 a.

Die in den Gruppen $c_{1-5}, c_{6-10}, \ldots$ der Normalstadien des c-Gebietes $z u$ den Zeitintervallen $s f, f, m, s$ und $s s$, von der Mittelepoche $t_{m}$ an gerechnet, gehörenden Tage.

\begin{tabular}{|c|c|c|c|c|c|c|}
\hline & sf & $\mathbf{f}$ & \multicolumn{2}{|c|}{$\underset{\left(\mathrm{t}_{\mathrm{tn}}\right)}{\mathbf{m}}$} & $\mathrm{s}$ & ss \\
\hline$c_{1-5}$ & $33-22$ & $21-9$ & $8-$ & -8 & $9-23$ & $24-39$ \\
\hline$C_{6-10}$ & $34-21$ & $20-8$ & $7-\infty$ & -6 & $7-17$ & $18-27$ \\
\hline$c_{11-15}$ & $30-19$ & $18-7$ & 6 & -6 & $7-18$ & $19-30$ \\
\hline$c_{16-20}$ & $28-19$ & $18-7$ & 6 & -5 & $6-15$ & $16-23$ \\
\hline$c_{21-26}$ & $26-17$ & $16-6$ & $5-$ & -4 & $5-12$ & $13-20$ \\
\hline$c_{1-26}$ & $30-19$ & $18 \quad-7$ & $6-$ & -6 & $7-18$ & $19-28$ \\
\hline
\end{tabular}


Tabelle $42 \mathrm{~b}$.

Die Anzahl der Eislagen, die in die Zeitintervalle sf, $f, m, s$ und ss der vorhergehenden Tabelle sowie ausserhalb dieser Zeitintervalle in die Kolumnen aof (ausserordentlich früh) und aos (ausserordentlich spät) fallen.

\begin{tabular}{|l|r|r|r|r|r|r|r|r|}
\hline & aof & sf & f & m & s & ss & aos & summe \\
\hline $\mathbf{c}_{\mathbf{1 - 5}}$ & 0 & 5 & 12 & 22 & 16 & 7 & 9 & 71 \\
$\mathbf{c}_{\mathbf{6 - 1 0}}$ & 1 & 2 & 11 & 15 & 4 & 9 & 1 & 43 \\
$\mathbf{c}_{\mathbf{1 1 - 1 5}}$ & 2 & 5 & 13 & 20 & 8 & 9 & 0 & 57 \\
$\mathbf{c}_{\mathbf{1 6 - 2 0}}$ & 8 & 5 & 7 & 10 & 8 & 9 & 3 & 50 \\
$\mathbf{c}_{\mathbf{2 1 - 2 6}}$ & 2 & 4 & 6 & 13 & 8 & 5 & 1 & 39 \\
$\mathbf{c}_{\mathbf{1 - 2 6}}$ & 13 & 21 & 49 & 80 & 44 & 39 & 14 & 260 \\
\hline
\end{tabular}

Tabelle 42 c.

Die Zahlenwerte der vorhergehenden Tabelle in Prozenten.

\begin{tabular}{|l|r|r|r|r|r|r|r||r|r|r|}
\hline & aof & sf & $\mathbf{f}$ & $\mathbf{m}$ & $\mathbf{s}$ & ss & aos & aof $+\mathbf{s i}$ & $\mathbf{f}+\mathbf{m}+\mathbf{s}$ & $\mathbf{s s}+\mathbf{a o s}$ \\
\hline $\mathrm{c}_{\mathbf{1 - 5}}$ & 0 & 7 & 17 & 31 & 23 & 10 & 13 & 7 & 70 & 23 \\
$\mathbf{c}_{\mathbf{6 - 1 0}}$ & 2 & 5 & 26 & 35 & 9 & 21 & 2 & 7 & 70 & 23 \\
$\mathbf{c}_{\mathbf{1 1} 1 \mathbf{1 5}}$ & 3 & 9 & 23 & 35 & 14 & 16 & 0 & 12 & 72 & 16 \\
$\mathbf{c}_{\mathbf{1 6} \mathbf{2 0}}$ & 16 & 10 & 14 & 20 & 16 & 18 & 6 & 26 & 50 & 24 \\
$\mathbf{c}_{\mathbf{2 1 - 2 6}}$ & 5 & 10 & 15 & 33 & 21 & 13 & 3 & 15 & 69 & 15 \\
$\mathbf{c}_{\mathbf{1 - 2 6}}$ & 5 & 8 & 19 & 31 & 17 & 15 & 5 & 13 & 67 & 20 \\
\hline
\end{tabular}

Tabelle 43 a.

Die in den Gruppen $d_{1-5}, d_{6-10}, \ldots$ der Normalstadien des $\boldsymbol{d}$-Gebietes $z u$ den Zeitintervallen $s f, t, m, s$ und ss, von der Mittelepoche $t_{m}$ an gerechnet, gehörenden Tage.

\begin{tabular}{|c|c|c|c|c|c|c|}
\hline & sf & f & \multicolumn{2}{|c|}{$\left(\begin{array}{c}m \\
\left(t_{m}\right)\end{array}\right.$} & $\mathrm{s}$ & ss \\
\hline $\begin{array}{l}d_{1-5} \\
d_{6-10} \\
d_{11-15} \\
d_{16-20} \\
d_{21-25}\end{array}$ & $\begin{array}{l}33-20 \\
27-18 \\
30-19 \\
22-15 \\
20-13\end{array}$ & $\begin{array}{l}19-7 \\
17-7 \\
18-7 \\
14-6 \\
12-5\end{array}$ & $\begin{array}{l}6- \\
6- \\
6- \\
5- \\
4-\end{array}$ & $\begin{array}{l}-6 \\
-5 \\
-5 \\
-4 \\
-4\end{array}$ & $\begin{array}{l}7-17 \\
6-15 \\
6-14 \\
5-14 \\
5-12\end{array}$ & $\begin{array}{l}18-27 \\
16-27 \\
15-22 \\
15-24 \\
13-20\end{array}$ \\
\hline $\mathrm{d}_{1-25}$ & $25-16$ & $15-6$ & $5-$ & -5 & $6-15$ & $16-25$ \\
\hline
\end{tabular}




\section{Tabelle $43 \mathrm{~b}$.}

Die Anzahl der Eislagen, die in die Zeitintervalle sf, $f, m, s$ und ss der vorhergehenden Tabelle sowie ausserhalb dieser Zeitintervalle in die Kolumnen aof (ausserordentlich früh) und aos (ausserordentlich spät) fallen.

\begin{tabular}{|l|r|r|r|r|r|r|r|r|}
\hline & aof & sf & f & m & s & ss & aos & Summe \\
\hline $\mathrm{d}_{\mathbf{1}-5}$ & 0 & 6 & 15 & 16 & 12 & 11 & 8 & 68 \\
$\mathrm{~d}_{6-10}$ & 1 & 3 & 9 & 13 & 8 & 7 & 3 & 44 \\
$\mathrm{~d}_{11-15}$ & 2 & 5 & 7 & 16 & 12 & 4 & 0 & 46 \\
$\mathrm{~d}_{16-20}$ & 6 & 2 & 8 & 8 & 9 & 6 & 1 & 40 \\
$\mathrm{~d}_{21-25}$ & 6 & 6 & 4 & 10 & 6 & 4 & 2 & 38 \\
$\mathrm{~d}_{\mathbf{1 - 2 5}}$ & 15 & 22 & 43 & 63 & 47 & 32 & 14 & 236 \\
\hline
\end{tabular}

Tabelle 43 с.

Die Zahlenwerte der vorhergehenden Tabelle in Prozenten.

\begin{tabular}{|l|r|r|r|r|r|r|r||r|r|r|}
\hline & aof & sf & $\mathbf{f}$ & $\mathbf{m}$ & $\mathbf{s}$ & ss & aos & aof $+\mathbf{s f}$ & $\mathbf{f}+\mathbf{m}+\mathbf{s}$ & $\mathbf{s s}+\mathbf{a o s}$ \\
\hline $\mathrm{d}_{\mathbf{1 - 5}}$ & 0 & 9 & 22 & 24 & 18 & 16 & 12 & 9 & 63 & 28 \\
$\mathrm{~d}_{\mathbf{6 - 1 0}}$ & 2 & 7 & 20 & 30 & 18 & 16 & 7 & 9 & 68 & 23 \\
$\mathrm{~d}_{11-15}$ & 4 & 11 & 15 & 35 & 26 & 9 & 0 & 15 & 76 & 9 \\
$\mathrm{~d}_{\mathbf{1 6 - 2 0}}$ & 15 & 5 & 20 & 20 & 22 & 15 & 2 & 20 & 62 & 18 \\
$\mathrm{~d}_{\mathbf{2 1 - 2 5}}$ & 16 & 16 & 11 & 26 & 15 & 10 & 5 & 32 & 53 & 16 \\
$\mathrm{~d}_{\mathbf{1 - 2 5}}$ & 6 & 9 & 18 & 27 & 20 & 14 & 6 & 16 & 65 & 20 \\
\end{tabular}

Tabelle 44 a.

Die in den Gruppen $e_{1-5}, e_{6-10} \ldots$. . der Norma'stadien des e-Gebietes zu den Zeitintervallen $s f, f, m, s$ und ss, von der Mittelepoche $t_{m}$ an gerechnet, gehörenden Tage.

\begin{tabular}{|c|c|c|c|c|c|c|}
\hline & sf & f & \multicolumn{2}{|c|}{$\begin{array}{c}m^{m} \\
\left(t_{m}\right)\end{array}$} & s & ss \\
\hline $\begin{array}{l}e_{1-j} \\
e_{6-10} \\
e_{11-15} \\
e_{16-20} \\
e_{21-25} \\
e_{26-28}\end{array}$ & $\begin{array}{l}36-23 \\
36-23 \\
30-19 \\
25-16 \\
22-15 \\
20-13\end{array}$ & $\begin{array}{l}22-9 \\
22-8 \\
18-7 \\
15-6 \\
14-6 \\
12-5\end{array}$ & $\begin{array}{l}8- \\
7- \\
6- \\
5- \\
5- \\
4-\end{array}$ & $\begin{array}{r}-8 \\
-6 \\
-5 \\
-5 \\
-4 \\
-4\end{array}$ & $\begin{array}{l}9-21 \\
7-16 \\
6-14 \\
6-14 \\
5-12 \\
5-12\end{array}$ & $\begin{array}{l}22-33 \\
17-28 \\
15-22 \\
15-22 \\
13-20 \\
13-18\end{array}$ \\
\hline$e_{1-28}$ & $30-19$ & $18-7$ & $6-$ & -5 & $6-14$ & $15-22$ \\
\hline
\end{tabular}


Tabelle $44 \mathrm{~b}$.

Die Anzahl der Eislagen, die in die Zeitintervalle st, $f, m, s$ und ss der vorhergehenden Tabelle sowie ausserhalb dieser Zeitintervalle in die Kolumnen aof (ausserordentlich frïh) und aos (ausserordentlich spät). fallen.

\begin{tabular}{|l|r|r|r|r|r|r|r|r|}
\hline & aof & sf & f & m & s & ss & aos & Summe \\
\hline $\mathrm{e}_{\mathbf{1 - 5}}$ & 0 & 4 & 12 & 16 & 12 & 7 & 9 & 60 \\
$\mathrm{e}_{\mathbf{6 - 1 0}}$ & 3 & 4 & 8 & 19 & 9 & 8 & 3 & 54 \\
$\mathrm{e}_{\mathbf{1 1 - 1 5}}$ & 0 & 5 & 13 & 17 & 9 & 7 & 3 & 54 \\
$\mathrm{e}_{\mathbf{1 6 - 2 0}}$ & 3 & 6 & 5 & 15 & 12 & 5 & 0 & 46 \\
$\mathrm{e}_{\mathbf{2 1 - 2 8}}$ & 8 & 9 & 5 & 12 & 7 & 9 & 1 & 51 \\
$\mathrm{e}_{\mathbf{1 - 2 8}}$ & 14 & 28 & 43 & 79 & 49 & 36 & 16 & 265 \\
\hline
\end{tabular}

Tabelle 44 c.

Die Zahlenwerte der vorhergehenden Tabelle in Prozenten.

\begin{tabular}{|c|c|c|c|c|c|c|c|c|c|c|}
\hline & aof & sf & f & m & s & ss & aos & aof + sf & $\mathbf{f}+\mathbf{m}+\mathrm{s}$ & ss + aos \\
\hline$e_{1-5}$ & 0 & 7 & 20 & 27 & 20 & 12 & 15 & 7 & 67 & 27 \\
\hline$e_{6-10}$ & 6 & 7 & 15 & 35 & 17 & 15 & 6 & 13 & 67 & 20 \\
\hline $\mathrm{e}_{11-15}$ & 0 & 9 & 24 & 32 & 17 & 13 & 6 & 9 & 72 & 19 \\
\hline$e_{16-20}$ & 7 & 13 & 11 & 33 & 26 & 11 & 0 & 20 & 70 & 11 \\
\hline$e_{21-28}$ & 16 & 18 & 10 & 24 & 14 & 18 & 2 & 33 & 47 & 20 \\
\hline$e_{1-28}$ & 5 & 11 & 16 & 30 & 18 & 14 & 6 & 16 & 65 & 20 \\
\hline
\end{tabular}

Tabelle 45 a.

Die in den Gruppen $G_{1-5}, G_{6-10}, \ldots$ der Generalstadien $z u$ den Zeitintervallen st, $f, m, s$ und ss, von der Mittelepoche $t_{m}$ an gerechnet, gehörenden Tage.

\begin{tabular}{|c|c|c|c|c|c|c|}
\hline & sf & f & \multicolumn{2}{|c|}{$\begin{array}{c}\mathrm{m} \\
\left(\mathrm{t}_{\mathrm{m}}\right)\end{array}$} & $\mathrm{s}$ & ss \\
\hline $\begin{array}{l}G_{1-5} \\
G_{6-10} \\
G_{11-15} \\
G_{16-20} \\
G_{21-25} \\
G_{26-30}\end{array}$ & $\begin{array}{l}30-19 \\
37-24 \\
35-22 \\
31-20 \\
27-16 \\
20-13\end{array}$ & $\begin{array}{l}18-7 \\
23-9 \\
21-8 \\
19-7 \\
15-6 \\
12-5\end{array}$ & $\begin{array}{l}6- \\
8- \\
7- \\
6- \\
5- \\
4-\end{array}$ & $\begin{array}{l}-6 \\
-7 \\
-6 \\
-6 \\
-4 \\
-3\end{array}$ & $\begin{array}{l}7-18 \\
8-21 \\
7-17 \\
7-16 \\
5-12 \\
4-10\end{array}$ & $\begin{array}{l}19-30 \\
22-33 \\
18-27 \\
17-24 \\
13-20 \\
11-16\end{array}$ \\
\hline $\mathrm{G}_{1-30}$ & $30-19$ & $18-7$ & $6-$ & -5 & $6-15$ & $16-25$ \\
\hline
\end{tabular}


Tabelle $45 \mathrm{~b}$.

Die Anzahl der Eislagen, die in die Zeitintervalle sf, $f, m, s$ und ss der vorhergehenden Tabelle sowie ausserhalb dieser Zeitintervalle in die Kolumnen aof (ausserordentlich frïh) und aos (ausserordentlich spät) fallen. Zu den Eislagen der G-Stadien wurden alle diejenigen Eislagen der Meeresteile gerechnet, die zu den beim Aufbau des betreffenden G-Stadiums verwendeten S-Stadien gehörten,

\begin{tabular}{|l|r|r|r|r|r|r|r|r|}
\hline & aof & sf & f & m & s & ss & aos & summe \\
\hline & & & & & & & & \\
$\mathrm{G}_{\mathbf{1 - 5}}$ & 7 & 20 & 42 & 63 & 58 & 33 & 33 & 256 \\
$\mathrm{G}_{\mathbf{6 - 1 0}}$ & 3 & 31 & 88 & 131 & 81 & 51 & 42 & 427 \\
$\mathrm{G}_{\mathbf{1 1}-15}$ & 5 & 33 & 75 & 88 & 58 & 45 & 41 & 354 \\
$\mathrm{G}_{\mathbf{1 6 - 2 0}}$ & 44 & 49 & 85 & 125 & 94 & 39 & 16 & 452 \\
$\mathrm{G}_{\mathbf{2 1 - 2 5}}$ & 27 & 59 & 37 & 58 & 64 & 32 & 16 & 293 \\
$\mathrm{G}_{\mathbf{2 6 - 3 0}}$ & 4 & 10 & 16 & 58 & 20 & 18 & 9 & 135 \\
$\mathrm{G}_{\mathbf{1 - 3 0}}$ & 90 & 202 & 343 & 523 & 375 & 218 & 157 & 1908 \\
& & & & & & & &
\end{tabular}

Tabelle 45 c.

Die Zahlenwerte der vorhergehenden Tabelle in Prozenten.

\begin{tabular}{|c|c|c|c|c|c|c|c|c|c|c|}
\hline & aof & $\mathrm{sf}$ & $\mathrm{f}$ & $\mathrm{m}$ & $\mathrm{s}$ & ss & aos & aof $+\mathrm{sf}$ & $\mathbf{f}+\mathbf{m}+\mathbf{s}$ & ss + aos \\
\hline$G_{1-5}$ & 3 & 8 & 16 & 25 & 23 & 13 & 13 & 11 & 64 & 26 \\
\hline $\mathrm{G}_{6-10}$ & 1 & 7 & 21 & 31 & 19 & 12 & 10 & 8 & 70 & 22 \\
\hline $\mathrm{G}_{11-15}$ & 1 & 10 & 22 & 25 & 17 & 13 & 12 & 11 & 64 & 25 \\
\hline $\mathrm{G}_{16-20}$ & 10 & 11 & 19 & 28 & 21 & 9 & 4 & 21 & 67 & 12 \\
\hline $\mathrm{G}_{21-25}$ & 9 & 20 & 13 & 20 & 22 & 11 & 5 & 29 & 54 & 16 \\
\hline $\mathrm{G}_{26-30}^{21-25}$ & 3 & 7 & 12 & 43 & 15 & 13 & 7 & 10 & 70 & 20 \\
\hline $\mathrm{G}_{1-30}$ & 5 & 11 & 18 & 27 & 20 & 11 & 8 & 15 & 65 & 20 \\
\hline
\end{tabular}

Eislagen der Zeitintervalle $» \mathrm{sf}\rangle, \| \mathrm{f}\rangle, \| \mathrm{m}\rangle$, $» \mathrm{~s}\rangle$ und $" \mathrm{ss}\rangle$, aber die Zeitdispersion kommt deutlicher als vorher zum Ausdruck.

189. Ohne hier die Zahlen der Tabellen 40-45 eingehender zu diskutieren, wollen wir gestützt auf die Tabellen $40 \mathrm{c}-45 \mathrm{c}$ und $46 \mathrm{~b}$ die die Zahlenwerte der Tabellen $40 \mathrm{~b}-45 \mathrm{~b}$. in \% der Summe der Eislagen jeder Stadiengruppe angeben, und betr. die Figuren $74-76$, deren Kurven nach den Zahlen der c-Tabellen gezeichnet sind, folgendes erwähnen:

Nach Fig. 74 bzw. Tab.43 c und $45 \mathrm{c}$ umfasste das Zeitintervall "m» im d-Gebiet und in der G-Stadiengruppe 27, in den anderen Meeresteilen 30 bis $35 \%$ der benutzten Eislagen. Die Prozentzahl ist um so kleiner, je günstiger in bezug auf die Eisverhältnisse, vom geographischen Standpunkt gesehen, der betreffende Meeres- 


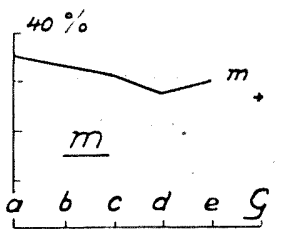

Die prozentuellen Verteilungen
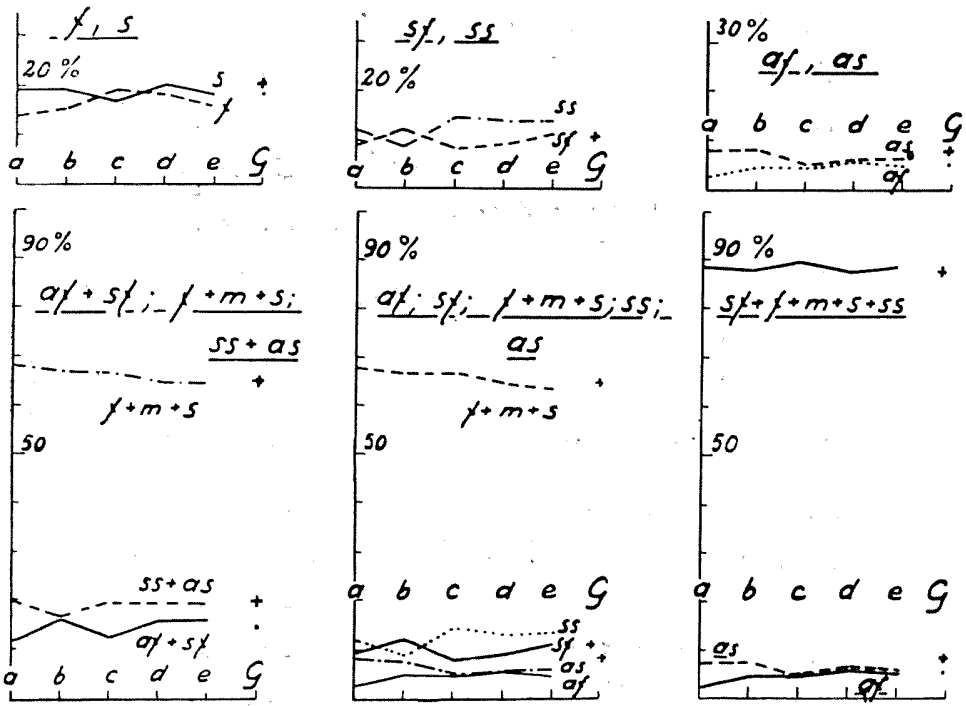

Fig. 74. Die prozentuale Verteilung der Eislagen nach ihren Daten auf

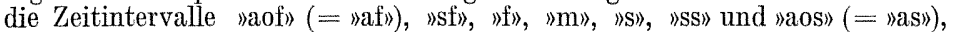
bzw. Gruppen derselben nach den Meeresteilen und den G-Stadien geordnet.

teil gelegen ist. Die Zeitintervalle »f» und 》S» umfassen: jener 14 bis 19 , dieser 17 bis $20 \%$ der Eislagen. In bezug auf die G-Stadien sind die Zahlen 18 und $20 \%$. Die »f»- und »s»-Werte der Meeresteile unterscheiden sich im allgemeinen nicht sehr voneinander, zeigen aber, ebenso wie die "sf》 und "SS》 Werte einen ungefähr entgegengesetzten Verlauf. Die "sf》- und »ss»-Intervalle umfassen 8-12 und $9-15 \%$, die »aof»- und »aos»-Intervalle 3-6 und 5-8\% aller Eislagen. In bezug auf die G-Stadien waren die »sf》, 》SS》, "aof» und »aos»-Werte der Reihe nach: 11, 11, 5 und $8 \%$.

190. In drei Gruppen, nämlich »aof + sf», »f $+\mathrm{m}+\mathrm{s} »$ und »ss + aos» geordnet, ist die prozentuale Verteilung der Eislagen die folgende: die mittlere Gruppe $» f+\mathrm{m}+\mathrm{s} »$ umfasst $65-68 \%$ oder $2 / 3$, die beiden anderen Gruppen 12-17, bzw. 17-20\% oder etwa 1/5 der Eislagen.

Teilen wir die Zeitintervalle in drei Gruppen, nämlich »aof», $\eta \mathrm{s} f+\mathrm{f}+\mathrm{m}+\mathrm{s}+\mathrm{ss}\rangle$ und »aos»») ein, so erhalten wir folgende $\%$-Zahlen. In 
Die progentuellen Verteilungender Eislagen nach ihren Daten in den Zeitintervallen af, sy, $t, m, s$, ss und as der Gruppen dor S-Stadien, bzw. der G-Stadien.
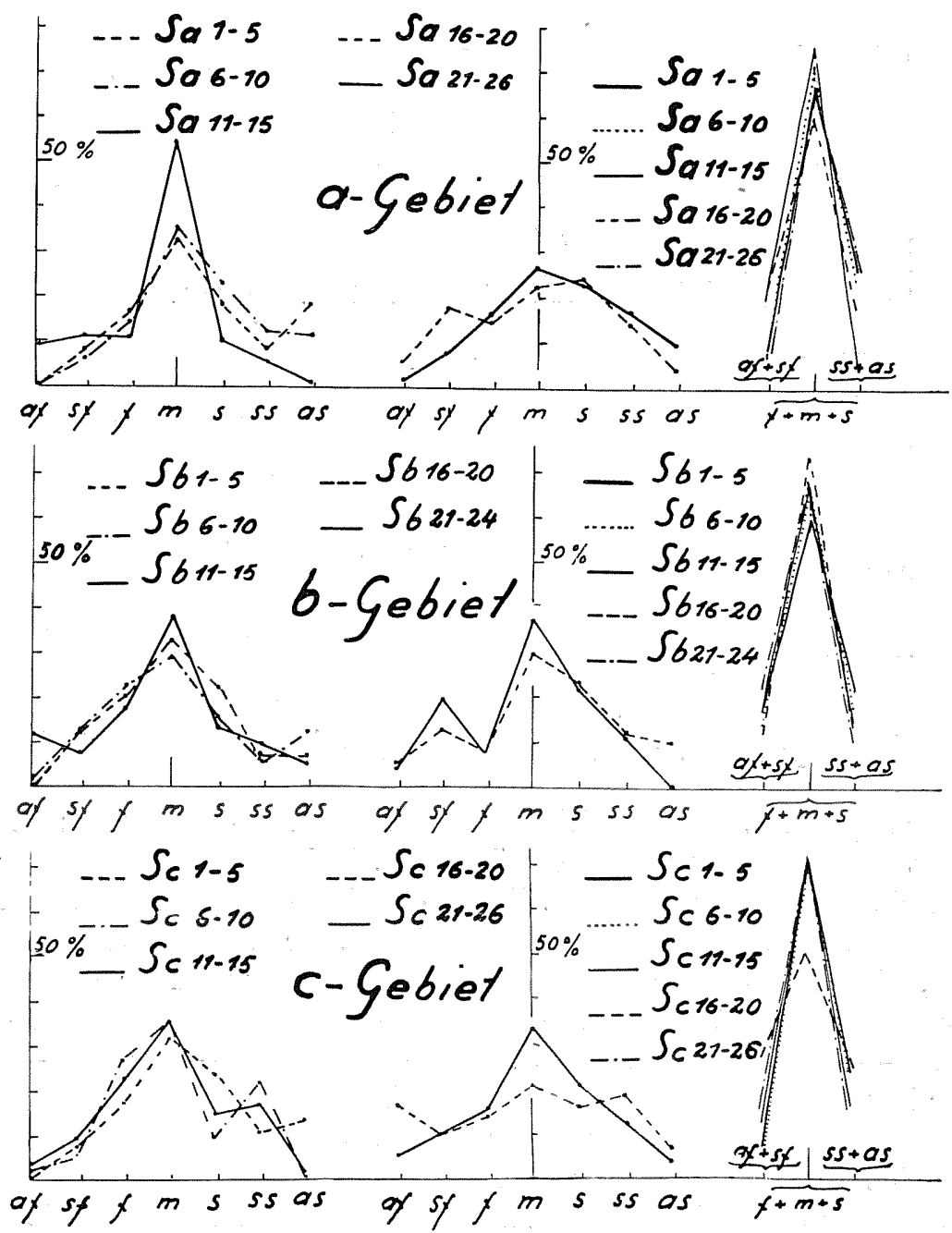

Fig. 75. Die prozentuale Verteilung der Eislagen auf die Stadiengruppen $S_{1-5}$, $\mathrm{S}_{6-10}$ usw. der Gebiete a, b und $\mathbf{e}$ nach ihren Daten auf die Zeitintervalle

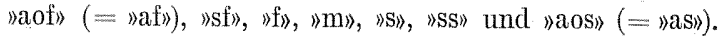


Die prozentwellen Verteilungen der Eislagen nach ihren Daten in den Zeitintervallen of, sy, $y, m, s$, ss und as der Gruppender S-Stadien, bzw. der $\mathcal{G}$. Stadien.
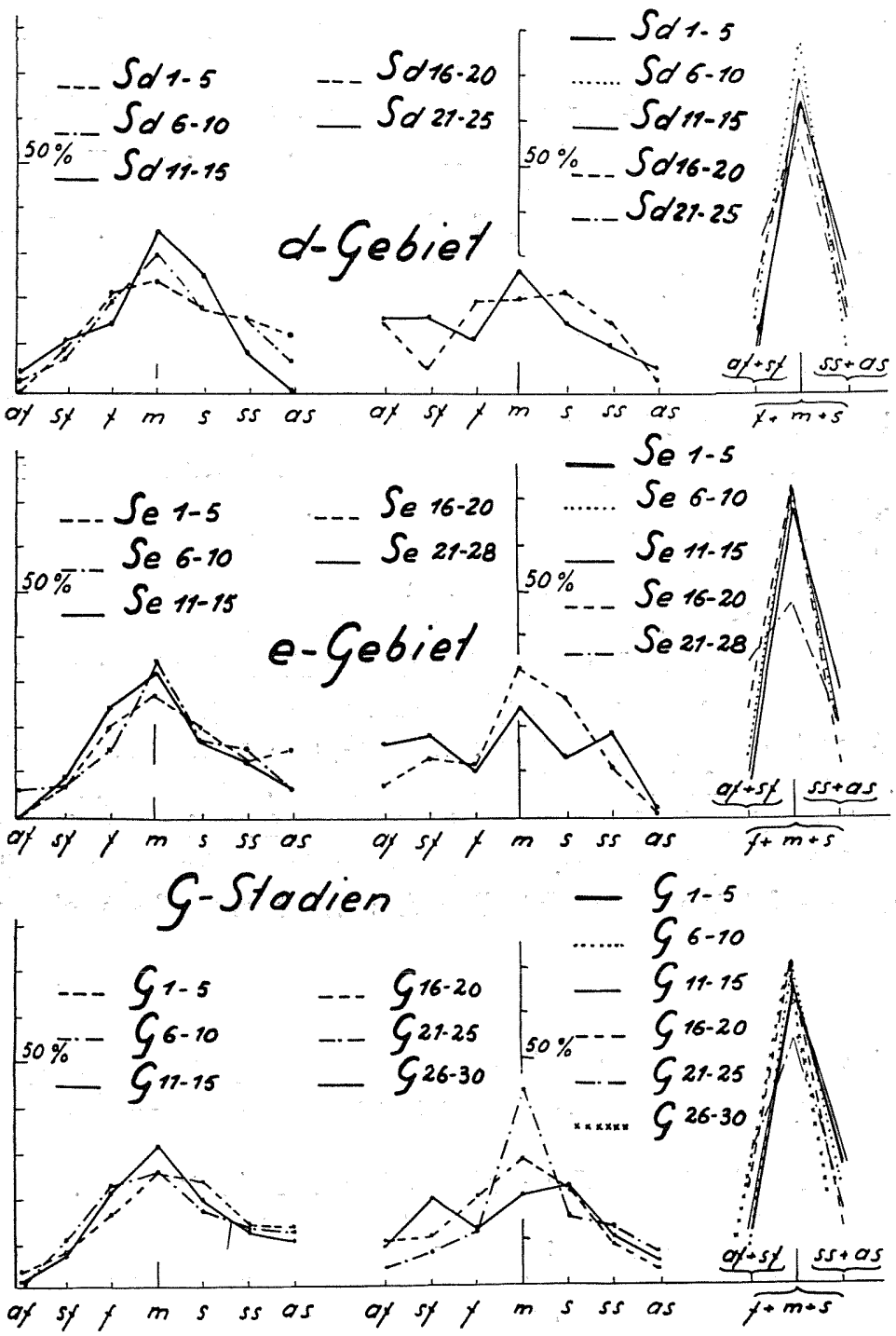

Fig. 76. Die prozentuale Verteilung der Eislagen auf die Stadiengruppen $S_{1-5}$, $\mathrm{S}_{6-10}$ usw. der Gebiete $\mathbf{d}$ und e sowie der G-Stadien auf die Zeitintervalle $\|$ aof» (= $» \mathrm{af} »),\|\mathrm{sf} »\| f »$, usw. 
der Gruppe »aof» schwanken die Zahlen zwischen 3 und $6 \%$; den kleinsten Wert, $3 \%$, finden wir im a-Gebiet, den grössten, $6 \%$, im d-Gebiet; der Wert der G-Stadien ist $5 \%$. In der Gruppe $» \mathrm{sf}+\mathrm{f}+\mathrm{m}+\mathrm{s}$ +ss» ist die \%-Zahl in den G-Stadien 87, in den Meeresteilen sehr gleichmässig 88 bis $90 \%$. Somit treten $9 / 10$ von allen Eislagen in bezug auf die Mittelepoche entweder sf, f, m, s oder ss ein. M. a.W. es traten 9/10 der Eislagen in einem Zeitintervall ein, das sich durchschnittlich ungefähr $3 \frac{1}{2}-4 \frac{1}{2}$ Wochen oder etwa einen Monat zu beiden Seiten der Mittelepoche $t_{m}$ erstreckte (Tab. 40 a-45 a).

191. Innerhalb der Normalstadiengruppen der Meeresteile ist die Verteilung der Eislagen auf die Zeitintervalle (Tab. $40 \mathrm{c}-45 \mathrm{c}$ und Fig. 75 und 76) nicht ebenso gleichmässig wie während des ganzen Winters. Dies ist selbstverständlich, da wie erwähnt das Eismaterial der Winter 1915--1925 viel zu gering ist um sich gleichmässiger auf Gruppen von fünf Stadien verteilen zu lassen, wobei noch die eventuellen Begrenzungen der Methode jetzt deutlicher zum Ausdruck kommen können als bei der Behandlung der dem ganzen Winter entsprechenden Zahlen.

Wir wollen jedoch auf einige Regelmässigkeiten in den Zahlenwerten der Normalstadiengruppen hinweisen, die gewiss wirkliche Verhältnisse abspiegeln. So verteilen sich die Eislagen in den Gruppen $\mathrm{S}_{1-5}, \mathrm{~S}_{6-10}$ und $\mathrm{S}_{11-15}$ der Normalstadien verhältnismässig zahlreicher - was am besten aus der graphischen Darstellung hervorgeht - auf

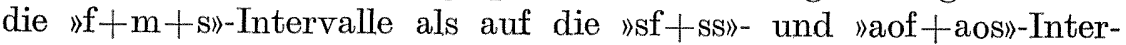
valle. Dagegen fallen in den Gruppen $S_{16-20}$ und $S_{21-n}$ der Normalstadien die Eislagen gleichmässiger in die Zeitintervalle. Doch gibt es Ausnahmen. So finden wir in der Gruppe $\mathrm{G}_{26-30}$, welche die letzten Generalstadien des Winters umfasst, eine recht

Tabelle 46 a.

Die den ganzen Winter (die Normalstadien $S_{1}-S_{n}$, bzw. $G_{1}-G_{30}$ ) umfassenden Zahlenwerte der Tabellen $40 \mathrm{~b}-45 \mathrm{~b}$.

1. Die Anzahl der Eislagen in den Zeitintervallen.

\begin{tabular}{|l|l|r|r|r|r|r|r|r|}
\hline & aof & sf & f & m & s & ss & aos & summe \\
\hline & 11 & 31 & 46 & 117 & 64 & 37 & 25 & 331 \\
$\mathrm{a}_{1 \mathbf{1 - 2 6}}$ & 13 & 29 & 39 & 83 & 47 & 23 & 19 & 253 \\
$\mathrm{~b}_{\mathbf{1 - 2 4}}$ & 13 & 21 & 49 & 80 & 44 & 39 & 14 & 260 \\
$\mathrm{c}_{\mathbf{1 - 2 6}}$ & 15 & 22 & 43 & 63 & 47 & 32 & 14 & 236 \\
$\mathrm{~d}_{\mathbf{1 - 2 5}}$ & 14 & 28 & 43 & 79 & 49 & 36 & 16 & 265 \\
$\mathrm{c}_{\mathbf{1 - 2 8}}$ & 14 & 202 & 343 & 523 & 375 & 218 & 157 & 1908 \\
$\mathrm{G}_{\mathbf{1 - 3 0}}$ & 90 & 202 & & & & & \\
\hline
\end{tabular}


Tabelle $46 \mathrm{~b}$.

Die Zahlen der vorhergehenden Tabelle in \% sowohl in den verschiedenen Zeitintervallen als in den Zeitintervallgruppen.

\begin{tabular}{|c|c|c|c|c|c|c|c|c|c|c|c|c|}
\hline & aof & sf & f & $\mathrm{m}$ & $\mathrm{s}$ & ss & aos & aof & sf & $\mathrm{f}+\mathrm{m}+\mathrm{s}$ & ss & aos \\
\hline$a_{1-26}$ & 3 & 9 & 14 & 35 & 19 & 12 & 8 & 3 & 9 & 68 & 12 & 8 \\
\hline$b_{1-24}$ & 5 & 11 & 15 & 33 & 19 & 9 & 8 & 5 & 11 & 67 & 9 & 8 \\
\hline$c_{1-26}$ & 5 & 8 & 19 & 31 & 17 & 15 & 5 & 5 & 8 & 67 & 15 & 5 \\
\hline$d_{1-25}$ & 6 & 9 & 18 & 27 & 20 & 14 & 6 & 6 & 9 & 65 & 14 & 6 \\
\hline$e_{1-28}$ & 5 & 11 & 16 & 30 & 18 & 14 & 6 & 5 & 11 & 64 & 14 & 6 \\
\hline $\mathrm{G}_{1-30}$ & 5 & 11 & 18 & 27 & 20 & 11 & 8 & 5 & 11 & 65 & 11 & 8 \\
\hline
\end{tabular}

\begin{tabular}{|l|c|c|c||c|c|c|}
\hline & aof $+\mathbf{s f}$ & $\mathbf{f}+\mathbf{m}+\mathbf{s}$ & $\mathbf{s s}+\mathbf{a} \mathbf{0 s}$ & aof & $\begin{array}{c}\mathbf{s}+\mathbf{f}+\mathbf{m}+ \\
\mathbf{s}+\mathbf{s s}\end{array}$ & aos \\
\hline $\mathbf{a}_{\mathbf{1 - 2 6}}$ & 12 & 68 & 20 & 3 & 89 & 8 \\
$\mathrm{~b}_{\mathbf{1 - 2 4}}$ & 17 & 67 & 17 & 5 & 88 & 8 \\
$\mathrm{c}_{\mathbf{1 - 2 6}}$ & 13 & 67 & 20 & 5 & 90 & 5 \\
$\mathrm{~d}_{\mathbf{1 - 2 5}}$ & 16 & 65 & 20 & 6 & 88 & 6 \\
$\mathrm{e}_{\mathbf{1 - 2 8}}$ & 16 & 65 & 20 & 5 & 89 & 6 \\
$\mathrm{G}_{\mathbf{1 - 3 0}}$ & 15 & 65 & 20 & 5 & 87 & 8 \\
\hline
\end{tabular}

symmetrische Verteilung der Eislagen zu beiden Seiten der $t_{\mathrm{m}}$ (»aof» $3 \%$, »m» $43 \%$, »aos» $7 \%$ ). Ziemlich symmetrisch verteilen sich die Eislagen in den Gruppen des a-Gebietes,was besonders deutlich hervortritt, wenn wir die aof-Eislagen weglassen. In den Gruppen $b_{1-5}, b_{6-10}$ und $b_{11-15}$ des $b$-Gebietes ist der Verlauf der Zahlenwerte ziemlich gleichmässig, in den Gruppen $b_{16-20}$ und $b_{21-24}$ dagegen ist die Anzahl der früh eingetretenen Eislagen verhältnismässig klein. In den Gruppen $c_{1-5}, c_{6-10}$ und $c_{11-15}$ des cGebietes zeigen die Zahlenwerte der Zeitintervalle »aof», "sf», "f» und "m» einen gleichartigen Zuwachs. Dagegen nehmen die Zahlenwerte der Zeitintervalle $\rangle \mathrm{S}\rangle$, , $/ \mathrm{SS}\rangle$ und "aos» etwas unregelmässiger ab. In der Gruppe $c_{16-20}$ sind die Schwankungen nicht gross und in der Gruppe $c_{21-26}$ verteilen sich die Zahlenwerte ziemlich symmetrisch zu beiden Seiten der $t_{m}$ (»aof» 5 , «f und vaos» $3 \%$ ). In dem d- und e-Gebiet sowie in den G-Stadien verteilen sich die entsprechenden Zahlenwerte in den Stadiengruppen $1-5,6-10,11-15$ ziemlich symmetrisch. In den Gruppen des Spätwinters ist wieder ein unregelmässigerer Verlauf zu bemerken, jedoch so, dass in den Gruppen $e_{16-20}$ und $G_{21-25}$ die Zahlenwerte des Zeitintervalls "m» wie erwähnt ein deutliches Maximum bilden. 


\section{Wahrseheinlichkeit des Eintretens der Eislagen in den verschiedenen Zeitintervallen.}

192. Die Resultate der Verteilung der Eislagen auf die Zeitintervalle bzw. Zeitintervallgruppen der Normalstadien geben uns zugleich eine Vorstellung von der Wahrscheinlichkeit, mit welcher eine Eislage zu einem Intervall bzw. einer Intervallgruppe gehört. Diese Wahrscheinlichkeit ist, in etwas abgerundeten Zahlen in der Tabelle 47 zusammengestellt. Von den Eislagen erscheinen somit, und zwar ganz allgemein genommen - teils schon wegen der Abrundung der Zahlen, teils aber auch wegen des zu geringen hierfür benutzten Eislagenmaterials und einiger bei der Verteilung der Eislagen in den Zeitintervallen entstandenen und hier gar nicht berücksichtigten Umstände - ein Drittel um die mittlere Eintrittszeit

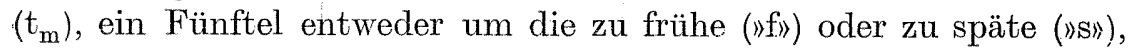
ein Zehntel um die sehr frühe (॥sf》), bzw. sehr späte (》ss») und schliesslich ein Zwanzigstel um die ausserordentlich frühe ("aof»), bzw. ausserordentlich späte (»aos) Eintrittszeit des entsprechenden Normalstadiums.

Tabelle 47.

Die Wahrscheinlichkeit, dass eine Eislage in den Zeitintervallen aof, $s f, f, m, s, s s$, aos bzw. in den Zeitintervallgruppen aof $+s f, f+$ $m+s, s s+a o s ;$ coof, $s f+f+m+s+s s$, aos des entsprechenden Normalstadiums erscheint. Die Zahlen abgerundet.

\begin{tabular}{|c|c|c|c|c|c|c|c|}
\hline Zeitintervall & aof & sf & $\mathrm{f}$ & $\mathrm{m}$ & $\mathrm{s}$ & $\mathrm{ss}$ & aos \\
\hline Wahrscheinlichkeit & $\frac{1}{20}$ & $\frac{1}{10}$ & $\frac{1}{5}$ & $\frac{1}{3}$ & $\frac{1}{5}$ & $\frac{1}{10}$ & $\frac{1}{20}$ \\
\hline
\end{tabular}

\begin{tabular}{|c|c|c|c||c|c|c|}
\hline Zeitintervallgruppe & aof $+\mathbf{s f}$ & $\mathbf{f}+\mathbf{m}+\mathbf{s}$ & $\mathbf{s s}+\mathbf{a o s}$ & $\mathbf{a o f}$ & $\mathbf{s f}+\mathbf{f}+\mathbf{m}+$ \\
$\mathbf{s}+\mathbf{s s}$ & aos \\
\hline Wahrscheinlichkeit & $\frac{1}{5}$ & $\frac{2}{3}$ & $\frac{1}{5}$ & $\frac{1}{20}$ & $\frac{9}{10}$ & $\frac{1}{20}$ \\
\hline
\end{tabular}




\section{Sechster Abschnitt: Die Eiswochenzahlen.}

\section{Die Eiswochenzahlen der Küste und des Meeres.}

\section{A. Begriff und Herleitung der Eiswochenzahlen.}

193. Die Eiswochenzahl gibt in dieser Untersuchung jene Zeit in Wochen an, während der an irgend einer stelle $P$ ausserhalb der Küstenlinie Eis, jedoch nur mitganzbestimmter Wahrscheinlichkeit des Auftretens, anzutreffen ist. Die Wahrscheinlichkeit des Auftretens des Eises wird von den Frequenzkurven bestimmt, vermittels welcher die Eiswochenzahl hergeleitet ist. So entspricht z. B., falls für die Stelle $\mathrm{P}$ eine Eiswochenzahl vermittels der Frequenzkurven 0.2 bestimmt ist, das Vorkommen des Eises an dieser Stelle in der betreffenden Zeit natürlich nur 2/10 der ganzen Eiswochenzahl, d. h. das tatsächliche Vorkommen des Eises ist immer nur die Eis-Wahrscheinlichkeit mal die Wochenzahl.

194. In dem oben Gesagten ist das Verfahren, durch welches die Wochenzahlen vermittels der Stadien hergeleitet werden sollen, gegeben. In den Normalstadien, sowohl den S- als den G-Stadien, folgen nämlich die die Grösse der Vereisung wiedergebenden Kurven, d. h. die Ränder der Bräme des festen Küsteneises und die Frequenzlinien - falls wir einer bestimmten Eintrittslinie der Stadien in den Zeitdiagrammen, z. B. einer der Linien sf, f, m, s oder ss folgen einander in bezug auf die Zeit kontinuierlich: In der Herbst$\mathrm{h}$ älfte des Winters geben sie den Zuwachs des Eises während der Vereisung ununterbrochen, in der Frühlingsh älfte des Winters den Rückgang wieder ununterbrochen wieder. Der tatsächliche Verlauf eines Winters ist nur ganz ausnahmsweise so kontinuierlich, und zwar nur in grossen Zügen. Denn für die Winter sind die zu verschiedenen Zeiten desselben eintretenden, sehr unregelmässigen Folgen der den Normalstadien entsprechenden Eislagen charakte- 
ristisch, die keine solche kontinuierliche Zeitfolge aufweisen, wie in dem idealen Verlauf nach den Eintrittslinien sf, f, m, s und ss der Zeitdiagramme. Da nun die Bestimmung der Anzahl der Eistage an einer Stelle $P$ unmittelbar aus den Eislagen nur mit Schwierigkeiten auszuführen ist, die nur durch mehr oder weniger konventionelle Präzisierungen oder nur durch ganz willkürliche Deutungen betr. das Auftreten des Eises zu beseitigen sind, beschloss ich die Eiswochenzahlen aus den Zeitdiagrammen herzuleiten, weil in diesen, wenn wir einer idealen Eintrittslinie der Normalstadien folgen, die aperiodischen und bis aufs weitere noch ganz unbestimmten Folgen der Eislagen beseitigt sind. Die so für den »normalen» sehr kurzen bzw. mittellangen oder sehr langen Winter erhaltenen Eiswochenzahlen entsprechen, wie übrigens auch jedenfalls alle vermittels anderer Methoden hergeleiteten, wohl nur einem in seinem g a $\mathrm{nz}$ e $\mathrm{n}$ Verlauf idealen sk-, bzw. ml- oder sl-Winter. Diese Zahlen sind jedoch, wenn auch von Ideal-Wintern hergeleitet, geeignet die Schwankungen in der Länge der wirklichen Winter darzulegen und somit einen Massstab für die Gruppierung der Winter in bezug auf ihre ganze Dauer zu bilden.

195. Die Eiswochenzahlen wurden nicht für jeden Meeresteil gesondert bestimmt, sondern für Finnlands ganzes Meeresgebiet auf einmal aus den G-Stadien. Die Berechnung der Eiswochenzahlen, welche beinahe zwei Jahre dauerte, wurde so früh begonnen, dass es noch nicht sicher war, ob die Kurven der S-Stadien, aus welchen irgend ein G-Stadium aufgebaut werden sollte, ihren richtigen Wert erhalten hatten, um der Wahrscheinlichkeit des jährlichen Eintretens des G-Stadiums zu entsprechen. Deshalb waren in einigen G-Stadien des Mittwinters noch nicht alle Frequenzkurven der verschiedenen Meeresteile auf die Wahrscheinlichkeit des jedesmal in Frage kommenden G-Stadiums reduziert, sondern diese Frequenzkurven der S-Stadien hatten noch nach ihrer „Überführung» in die G-Stadien dieselben Werte wie ursprünglich bei den Normalstadien des Meeresteils. Die Unterschiede zwischen diesen Frequenzkurven, welche also zu der Berechnung der Wochenzahlen gebraucht wurden, und den Frequenzkurven, welche auf denselben wirklichen Wert reduziert wurden, sind jedoch ganz gering, und beziehen sich betreffs der Wochenzahlen in dem a-Gebiet nur auf die Generalstadien $G_{14}$ und $G_{15}$, in dem b-Gebiete, in dem nördlichen Teil des c-Gebietes und in der Mündung des Finnischen Meerbusens auf die Generalstadien $\mathrm{G}_{16}, \mathrm{G}_{18}$ und $\mathrm{G}_{19}$. Die Wochenzahlkurven sind an den genannten Stellen später jedoch nicht verbessert worden, weil die zur Probe ausgeführte Berechnung bewies, dass die benutzten 
Kurven nirgends in ihrem Verlauf so grosse Veränderungen enthielten, dass eine vollständige Umrechnung vonnöten gewesen wäre.

196. Bei der Bestimmung der Wochenzahlen dienten als "Eisgrenze» der Reihe nach: für die Wochenzahlen, während welcher die Eis-Wahrscheinlichkeit 10/10 war, die ungefähren Mittellinien des Randgebietes der Bräme des festen Küsteneises oder, falls noch die Frequenzkurven 1.0 ausserhalb der Bräme lagen, diese Kurven; für die Wochenzahlen, während welcher die Eis-Wahrscheinlichkeit 8/10 war, die Frequenzkurven 0.8 oder, falls solche fehlten, die Frequenzkurven 1.0 oder auch die ungefähren Mittellinien des Randgebietes der Bräme des festen Eises; für die Wochenzahlen, während welcher die Eis-Wahrscheinlichkeit 5/10 war, die Frequenzkurven 0.5 oder, falls solche fehlten, die Frequenzkurven von höherem Wert, bzw. die Bräme des festen Eises usw. Somit sind die verschiedenen Eiswochenzahlen vermittels der entsprechenden Frequenzkurven oder, falls solche fehlen, vermittels Frequenzkurven von höherem Wert hergeleitet. Die "Zeit mit Eis» an einer Stelle $\mathrm{P}$ beginnt mit dem Zeitpunkt $t_{\mathrm{P}}$, wo der Rand des jeweils in Frage kommenden "Eises» mit der entsprechenden Frequenzkurve, eventuell mit der Bräme des festen Küsteneises während der Vereisung bis an diese Stelle P vorgeschritten ist und so lange fortgeht, bis dasselbe "Eis» wieder, aber nun bei dem Rückgang des Eises, in entgegengesetzter Richtung sich zurückziehend, durch diese Stelle $\mathrm{P}$ geht.

Das Gesagte geht am besten aus Fig. 77 und 78 hervor, von welchen die erstere das Fortschreiten des »Eises», die letztere den Rückgang des »Eises», dessen »Rand» die Frequenzkurve 0.2 ist, in der Nördlichen Ostsee bis zum Schärenhof darstellt. Erreicht der Eisrand eine Stelle $P$ in dem Stadium $G_{15}$ und entfernt er sich davon im Stadium $G_{20}$, so besteht dieses Eis an der Stelle $\mathbf{P}$ den "Zeitraum» zwischen den Stadien $G_{15}$ und $G_{20}$. Die Eiswochenzahl mit einer Eis-Wahrscheinlichkeit von 0.2 entspricht dem Zeitunterschied $\left(t_{G_{20}}-t_{G_{15}}\right)$, welcher im ml-Winter 6 Wochen und im sl-Winter $12 \frac{1}{2}$ Wochen beträgt. Im sk-Winter treten die Generalstadien $\mathrm{G}_{15}-\mathrm{G}_{\mathbf{2 0}}$ gar nicht ein.

197. Die praktische Ausführung der Bestimmung der Eiswochenzahlen z. B. für das »Eis» mit der Eis-Wahrscheinlichkeit 10/10 geschah auf folgende Weise:

Zuerst zeichneten wir auf einer Karte von den einander folgenden Generalstadien die Mittellinien des Randgebietes der wachsenden Bräme des festen Eises oder, wenn ausserhalb der Bräme des festen Eises die Frequenzkurve 1.0 liegt, diese. Jede Kurve wurde mit der 


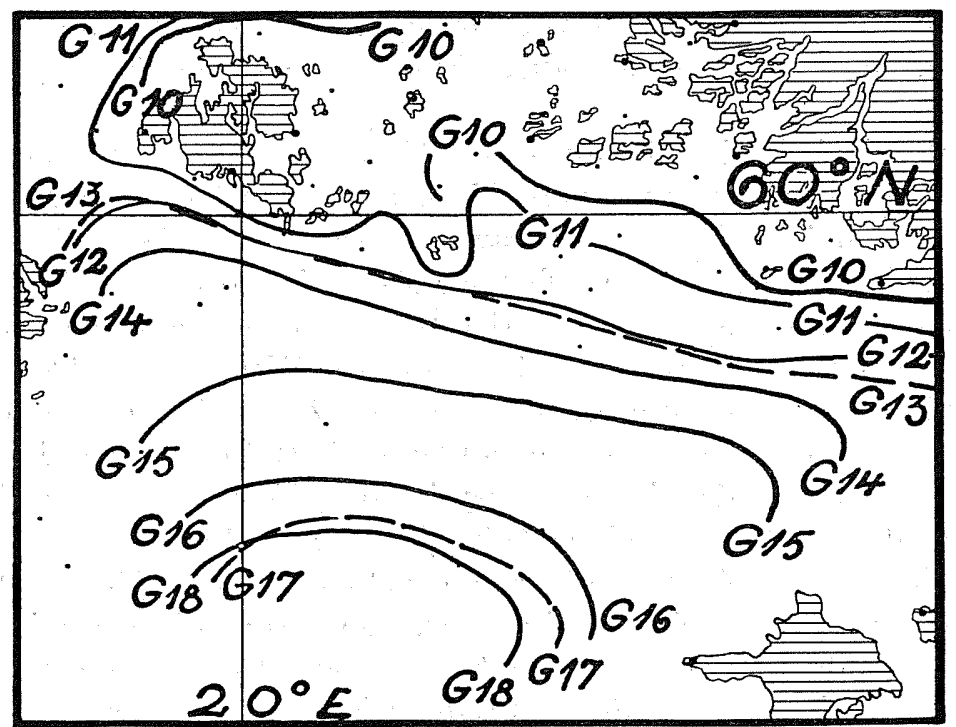

Fig. 77. Der der Nördlichen Ostsee entsprechende Teil der S a m m elkarte der Frequenzlinien 0.2 des wachsenden Eises, der zugleich die Ausdehnug. des"Eises» mit der EisWahrscheinlich keit 2/10 wi ed ergibt. Die Bezeichnungen auf den Kurven geben die G-Stadien an, in denen der Rand dieses "Eises» die betreffende Lage erreicht hat.

Nummer des entsprechenden Generalstadiums versehen. Somit erhielten wir den zeitlichen Verlauf der Ausdehnung des Eises mit der EisWahrscheinlichkeit 10/10. Hiernach zeichneten wir auf einer anderen Karte die Mittellinien des Randgebietes der zurückgehenden Bräme des festen Eises oder die ausserhalb der Bräme des festen Eises gelegenen Frequenzkurven 1.0, welche wir alle wieder mit den Nummern der entsprechenden Generalstadien des Zurückgehens des Eises versahen. Auf diese Weise hatten wir in die beiden letztgenannten $\mathrm{S}$ a mmelkarten alle die Kurven übertragen, von welchen die Eiswochenzahlen mit der Eis-Wahrscheinlichkeit 10/10 hergeleitet werden sollten.

Nachdem die beiden Sammelkarten gezeichnet waren, übertrugen wir statt der Kurven die ihnen entsprechenden Stadienzahlen auf eine dritte sog. $\dot{U}$ bertragungskarte, wobei wir den Zuwachs- und den Rückgangszahlen des Eises verschiedene Farben gaben. Die Karte wurde dann vermittels in der Richtung der Meridiane und der Parallelen gehender Linien in Vierecke geteilt, deren Seiten 5 Längen- und 5 Breitenminuten entsprachen. Mit Hilfe dieses Netzwerkes konnte man, unter Beachtung der »Fortschreitungs- 


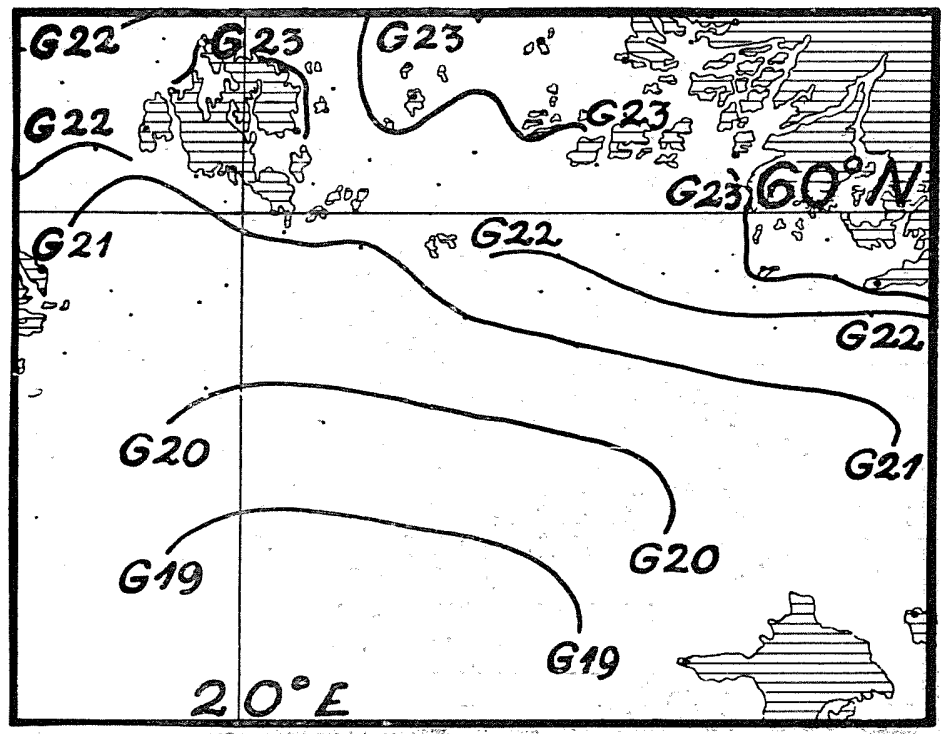

Fig. 78. Der der Nördlichen Ostsee entsprechende Teil der S a m m elkarte der Frequenzlinien 0.2 des sich zurückziehenden Eises, der zugleich den Rückgang des "Eises» mit der Eis-Wahrscheinlickeit $2 / 10$ wiedergibt. Die Bezeichnungen auf den Kurven geben die G-Stadien an, in denen der Rand dieses "Eises» die betreffende Lage erreicht hat.

geschwindigkeit» der Kurven und deren Gradienten, das Ankommen und das Verschwinden des »Eisrandes» an genau bestimmten Punkten, z. B. in den Ecken der Vierecke, schätzen.

198. Wir zeichneten solche Sammel- und Übertragungskarten für die Frequenzen 1.0, 0.8, 0.5, 0.2 und 0.1 , wobei wir also zugleich die Kurven, von denen wir die Eiswochenzahlen mit den Eis-Wahrscheinlichkeiten $10 / 10,8 / 10,5 / 10,2 / 10$ und $1 / 10$ herleiten wollten, erhielten. Für die Eis-Wahrscheinlichkeit 10/10 zeichneten wir im ganzen 8 Sammelkarten: zunächst besondere Karten für das zusammengefrorene ( $\square$-) Meereseis, das lose $\left(\triangle^{-}\right)$Meereseis und die Bräme des festen Eises, und danach endgültige Karten für den Zuwachs und den Rückgang des "10/10" Eises. Für die anderen Eis-Wahrscheinlichkeiten 8/10,5/10,2/10 und 1/10 waren nur je zwei Sammelkarten. nötig. Mit Hilfe der 10 endgültigen Sammelkarten zeichneten wir für jede Eis-Wahrscheinlichkeit eine besondere Übertragungskarte, also 5 solche Karten, und diese bildeten schliẹsslich das Grundmaterial, vermittels dessen erst die Eiswochenzahlen mit verschiedener Eis-Wahrscheinlichkeit einfach durch Umschreiben der Zahlen der Übertragungskarten nach den Tabellen $36-38$ in Tage 


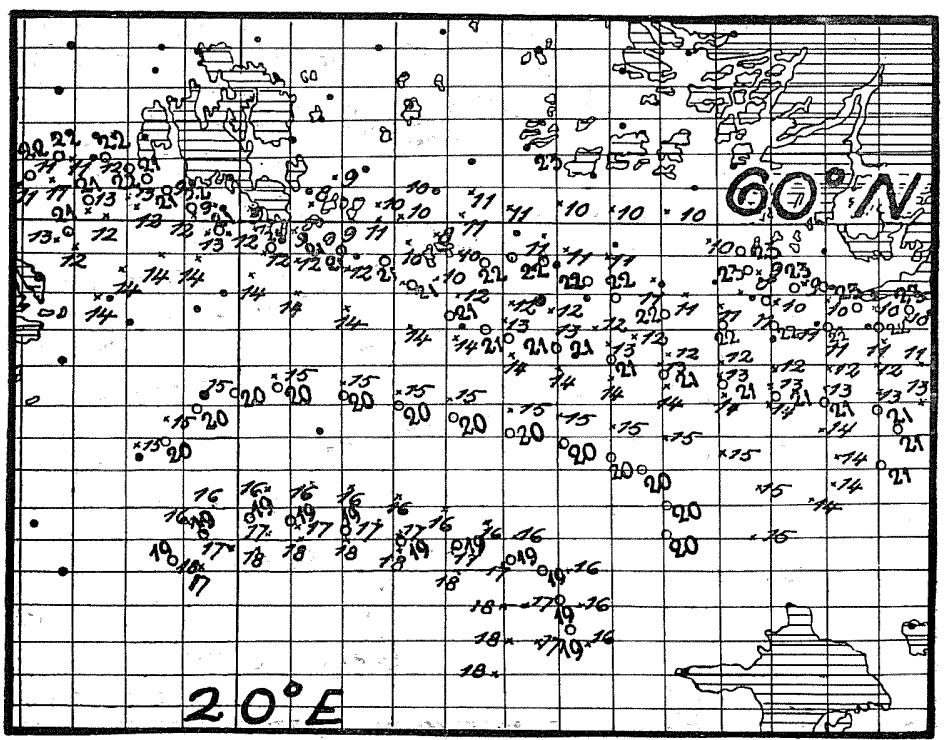

Fig. 79. Der der Nördlichen Ostsee entsprechende Teil der Ü b e r tragungskarte der Frequenzlinien 0.2, der zugleich die Übertragungskarte des "Eises» mit der Eis-Wahrs cheinlichkeit 2/10 ist. Die schrägen Ziffern geben die GStadien an, in denen der Rand des wachsenden "Eises", die aufrechten Ziffern jene G-Stadien, in denen der Rand des sich zurückziehenden "Eises" die betreffende Stelle erreicht hat. Die Seiten der Vierecke entsprechen 5 Längen-, bzw. Breitenminuten.

und Wochen verwandelt und dann, durch verschiedenes Verfahren, die Karten $" Z$ e it $\mathrm{m}$ it $\mathrm{E}$ is» des Atlas (S. $45-51$ ) und die Karten des folgenden Abschnitts hergeleitet sind.

199. Auf den Karten der Eiswochen sind die Kurven ebenso weit, wie die Frequenzkurven sich erstrecken, gezeichnet. Ausserhalb der Eiswochenkurven kann jedoch Eis vorkommen und das 》Aufhören». der Kurven bedeutet, einige Fälle ausgenommen, nur, dass wir inbetreff der Eisverhältnisse ausserhalb des Beobachtungs- und Erfahrungsgebiets, welches das zur Herleitung der G-Stadien gebrauchte Eislagematerial umfasst, gekommen sind, So können wir als sicher ansehen, dass die Eiswochenzahlkurven - mit abnehmender Wochenzahl - mit Hilfe eines grösseren und vollständigeren Eislagematerials im »normalen» sehr langen Winter für alle Eis-Wahrscheinlichkeiten ausserhalb der auf den Karten des Atlas (S. 50 und 51) gezeichneten Kurven herzuleiten wären, also auch auf der Karte des sl-Winters mit der Eis-Wahrscheinlichkeit 10/10. - In dem »normalen» mittellangen Winter beginnt das noch eisfreie Meer in der 


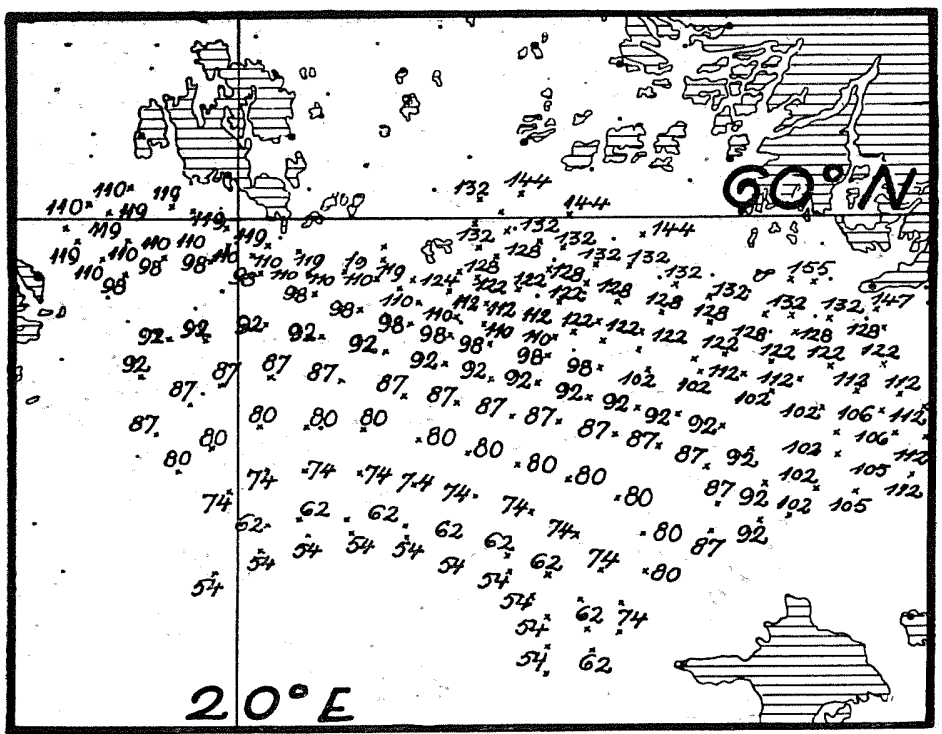

Fig. 80. Die Zahl der Eistage mit der Eis-Wahrscheinlichkeit 2/10 für die Nördliche Ostsee im sl-Winter. Die Zahlen, aus der Übertragungskarte Fig. 79 vermittels der Tabelle 38 erhalten, sind wegen der Verkleinerung nur zum Teil eingezeichnet und zwar übergross. Die kleinen Kreuze geben die Punkte an, auf welche sich die Ziffern beziehen.

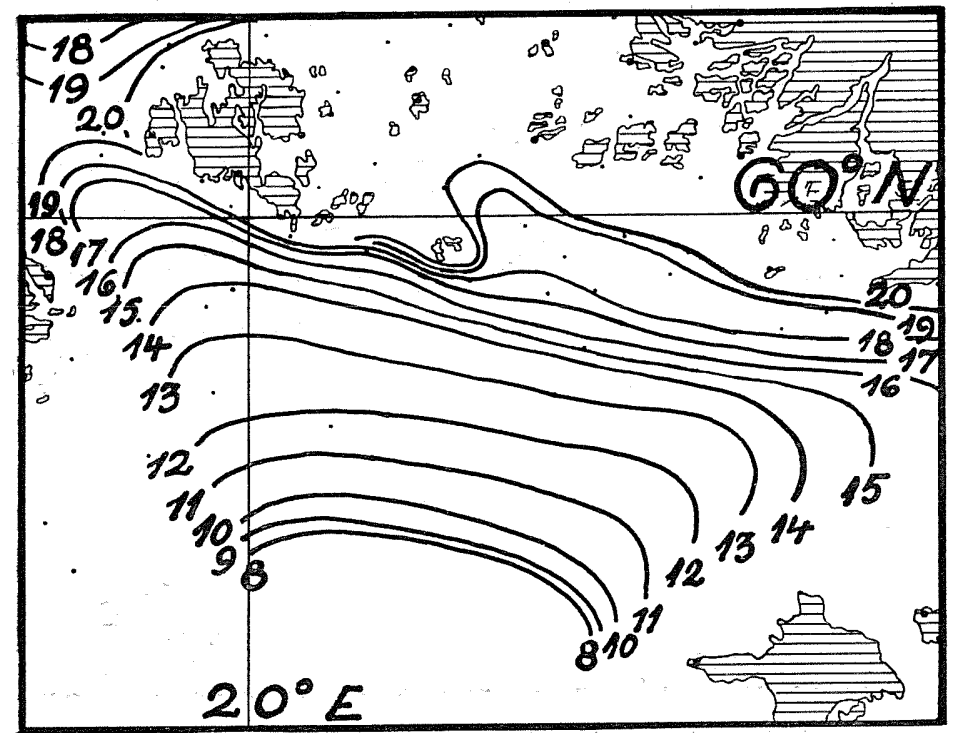

Fig. 81. Die definitive "Zeit mit Eis» in Wochen des "Eises" mit der Eis-Wahrscheinlichkeit $2 / 10$ für die Nördliche Ostsee im sn o rm a le n' s l-W inter. Die Kurven nach den Zahlen in Fig. 80 gezogen. 


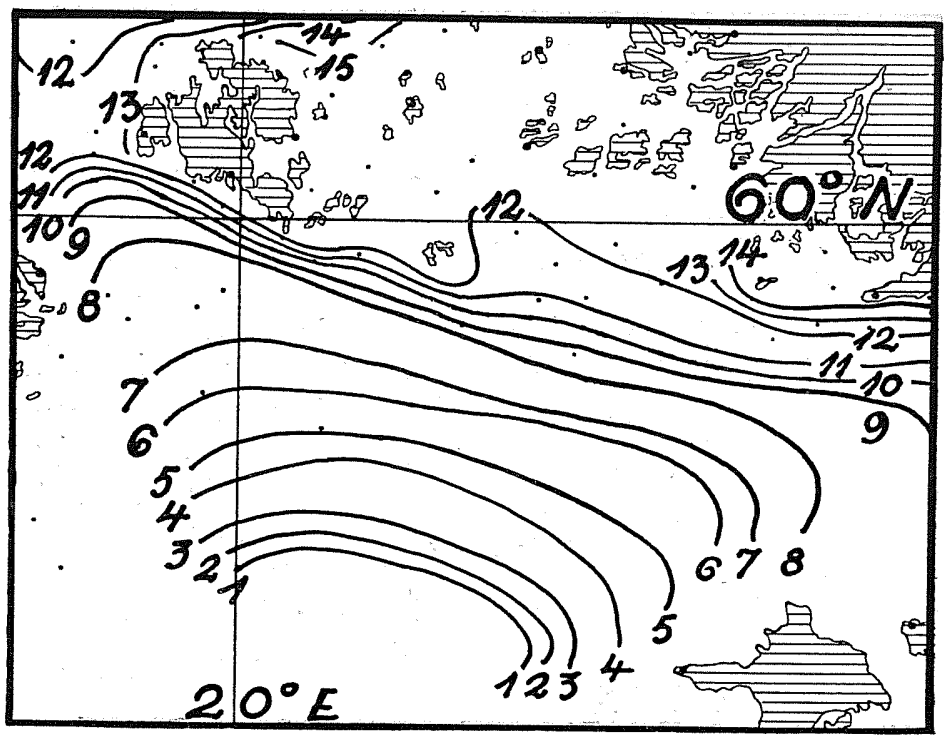

Fig. 82. Die definitive "Z eit mit Eis» in Wochen des »Eises» mit der Eis-Wahrscheinlichkeit $2 / 10$ für die Nördliche Ostsee im "n or mal e n» $\mathrm{m}$ l-W inter. Die Kurven sind nach den Ziffern der Übertragungskarte

(Fig. 79) vermittels der Tabelle 37 erhalten.

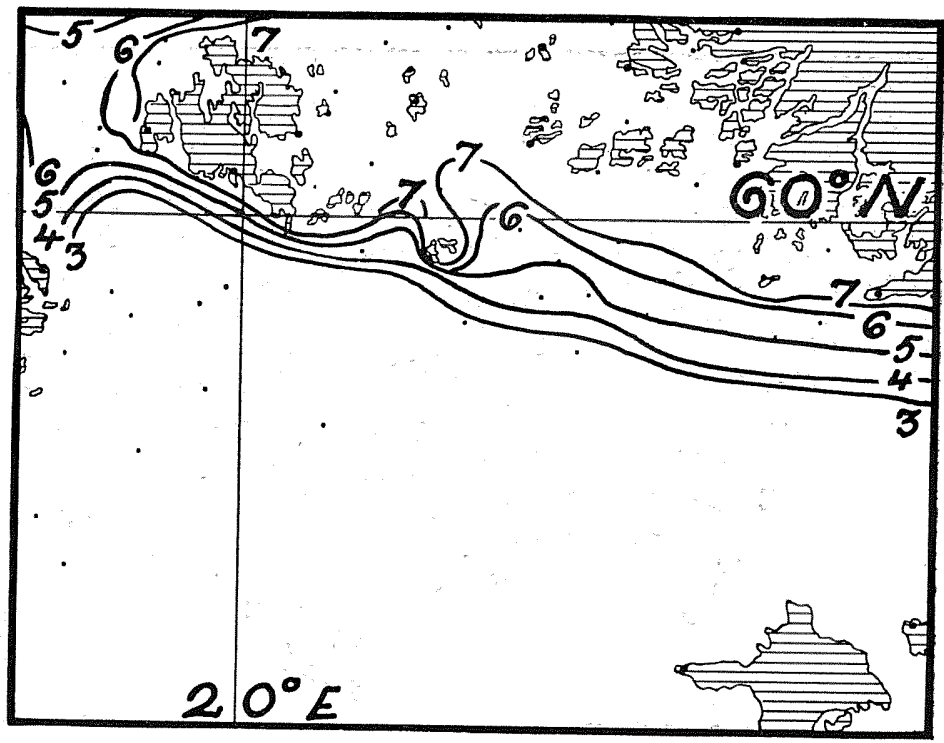

Fig. 83. Die definitive "Zeit mit Eis» in Wochen des "Eises» mit der Eis-Wahrscheinlichkeit $2 / 10$ für die Nördliche Ostsee im "n ormale n" $\mathrm{s} k-\mathrm{W}$ inter. Die Kurven sind nach den Ziffern der Übertragungskarte (Fig. 79) vermittels der Tabelle 36 erhalten. 


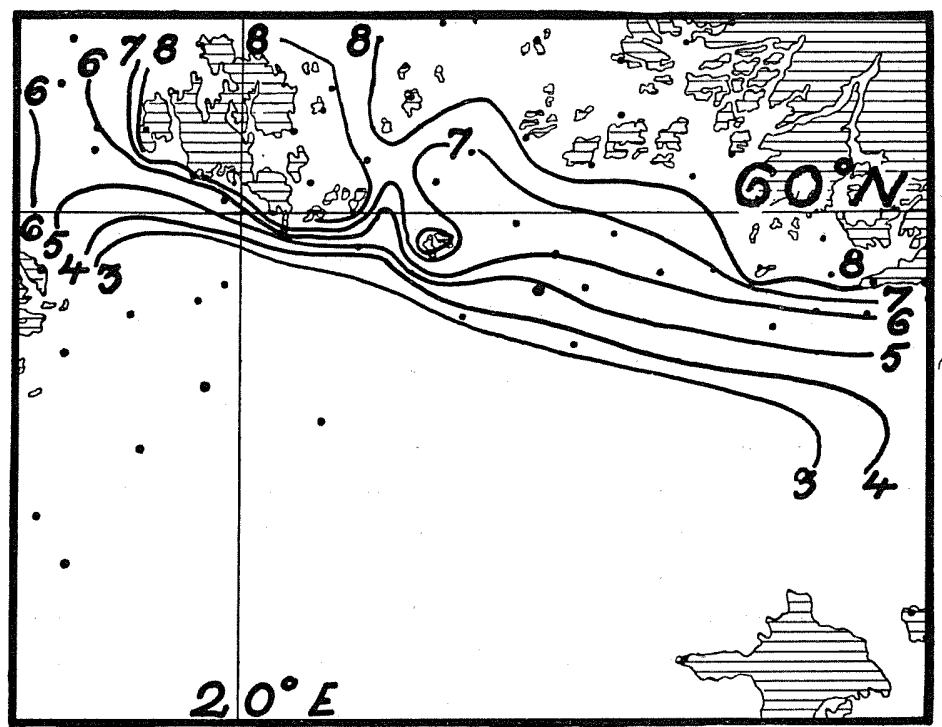

Fig. 84. Die definitive "Z e it $\mathrm{mit} \mathrm{E}$ is» in W oc he n des»Eises» mit der Eis-Wahrscheinlichkeit 1/10 für die Nördliche Ostsee im »n o r ma.le n» $\mathrm{s} \mathrm{k}$-W i n t e r. Die Kurven sind nach den Ziffern der Übertragungskarte der Frequenzlinie 0.1 , bzw. des "Eises" mit der Eis-Wahrscheinlichkeit 1/10 vermittels der Tabelle 36 erhalten. Auf der entsprechenden Karte im Atlas (S. 47) fehlt infolge eines Versehens die Kurve "33».

Nördlichen Ostsee ausserhalb der Kurven 3 (Atlas S. 48: ml-Winter mit der Eis-Wahrscheinlichkeit 10/10) und 1 (Karte des ml-Winters mit der Eis-Wahrscheinlichkeit 0.8), und ausserhalb der Kurve 4 in der Bottensee auf der Karte des ml-Winters mit der Eis-Wahrscheinlichkeit 10/10. Auf anderen Eiswochenkarten gibt es in diesen (d. h. ml-) Wintern sicher auch weiter draussen im Meer Eis. Auf den zwei ersten Karten des »normalen» sk-Winters beginnt das noch eisfreie Meer ausserhalb der Wochenkurven 2 und 3 in der Mündung des Finnischen Meerbusens, in der Nördlichen Ostsee, im Alandsmeer und in der Bottensee; anderswo gäbe es sicher Eiswochenkurven weiter draussen auf dem Meer. Auf der Karte des normalen sehr kurzen Winters mit der Eis-Wahrscheinlichkeit 1/10 (Atlas S. 47) ist in der Nördlichen Ostsee die äusserste Wochenkurve die Kurve »4»; auf allen Konzeptkarten ist jedoch ausserhalb dieser Kurve noch die Wochenkurve »3» gezeichnet. Aus Versehen ist sie beim Reinzeichnen unbeachtet geblieben und fehlt somit auf der fraglichen gedruckten Karte.. In Fig. 84 sind für die Nördliche Ostsee alle Wochenzahlkurven des "normalen» sk-Winters mit der EisWahrscheinlichkeit $1 / 10$, also auch die fehlende Kurve »3» gezeichnet. 
Eine eingehendere Behandlung der Eiswochenzahlen bzw. deren Herleitung sowie die der »Zeit mit Eis» werden wir später an verschiedenen Stellen des Textes, vor allem im achten Teil geben.

200. Die Figuren 77 und 78 zeigen, wie schon oben (197) bemerkt wurde, die Sammelkarten der Frequenzkurven 0.2 für die Nördliche Ostsee: die erstere bei der Zunahme des Eises, d.h. bei dem Vordringen des Eisrandes, die letztere bei dem Rückgang des Eises, d. h. des Eisrandes. An den Kurven ist immer das G-Stadium angegeben, während dessen der Eisrand die von der Kurve bezeichneten Lagen erreicht. Die Karten sind zugleich die Sammelkarten des mit derselben Eis-Wahrscheinlich keit, also 2/10, auftretenden E is es für die Nördliche Ostsee.

In Fig. 79 haben wir die Üb ertragungs karte (19\%) der Freguenzkurve 0.2 für die Nördliche Ostsee. Das Bild ist gleichzeitig die Übertragungskarte des mit der E is-Wahrschein lich keit $2 / 10$ a uftretenden Eises. Die schrägen Ziffern geben die G-Stadien an, in welchen der Eisrand an den jedesmal in Frage kommenden Lagen eintritt, die geraden Ziffern wiederum die G-Stadien, in welchen der Eisrand verschwindet. Die Seiten des Netzwerkes entsprechen, wie gesagt, immer 5 Längenund 5 Breitenminuten.

Indem wir statt der Ziffern der Übertragungskarte (Fig. 79), d. h. der Ordnungszahlen der das Eintreffen und das Verschwinden des Eisrandes bezeichnenden G-Stadien, die diesen Stadien entsprechende Zeitunterschiede aus den Tabellen 36-38 benutzen, erhalten wir als die "Zeit mit Eis» für Eis mit der Eis-Wahrscheinlichkeit $2 / 10$, in Wochen in der Nördlichen Ostsee für den der Reihe nach »normalen» sehr langen Winter Fig. 80 und 81, für den »normalen» mittellangen Winter Fig. 82 und für den »normalen» sehr kurzen Winter Fig. 83.

201. Die auf die oben gezeigte Weise erhaltenen Eiswochenzahlen sind jedoch in dem nördlichen Küstengewässer der Bottenwiek etwas zu klein, ebenșo wie auch stellenweise anderswo im Küstengewässer. (Näheres fünfter Teil.) . Die Beobachter des Instituts für Meeresforschung machen zwar programmgemäss auch Aufzeichnungen über das Zufrieren und den Eisgang in diesen Gewässern, da aber die Bedeutung dieser seichten Küstengewässer für den Schiffsverkehr ganz gering ist, hat man sie im allgemeinen nicht ebenso beachtet wie die Vereisung und die Enteisung in den von dem eigentlichen Schiffsverkehr angewandten Fahrstrassen und tieferen Gewässern. Deshalb sind für das von den ersten Frostnächten im Anfang des Herbstes verursachte 
Zufrieren der flachen Küstengewässer der nördlichsten Bottenwiek im allgemeinen keine Freitagslagen gezeichnet worden, sondern die erste Freitagslage des Winters gibt im allgemeinen einen etwas späteren Zeitpunkt an. Da nun anderswo die erste Vereisung regelmässig später eintrifft als in den innersten Teilen der Bottenwiek, macht sich die hier erwähnte Verspätung im Beginn der Aufzeichnung der Freitagslagen an anderen. Teilen der Küste nicht ebenso bemerkbar wie im Norden. Inbetreff der letzten Stadien des Frühlings mit verschwindendem Eis haben wir bei der Herleitung der Eiswochenzahlen unter Beachtung aller einschlägigen Faktoren zu bestimmen versucht, was für eine "Zeitverbesserung» jedesmal in den Eintrittszeiten dieser Stadien hinzuzufügen war, um den Zeitpunkt des definitiven Verschwindens des Eises an irgendeiner Stelle zu erhalten. Die notwendige Verbesserung betrug ein oder ein paar Tage, höchstens 1/2 Woche, welche Zeit dann zu den Eintrittszeiten der letzten Stadien mit Eis hinzugefügt wurde. Als Zeitunterschied zwischen irgend einem Generalstadium $G_{n}$ und dem letzten Generalstadium $G_{30}$ des Eiswinters haben wir für den normalen mittellangen Winter den Mittelwert der durchschnittlichen Eintrittszeiten VI. 3.-12. des Stadiums $G_{30}$ oder VI. 8. benutzt, für den normalen sehr langen Winter wiederum den Mittelwert der späten (VI. 16.) und sehr späten (VI. 28.) Eintrittszeit des Stadiums $\mathrm{G}_{30}$ oder VI. 22.

\section{B. Die Schwankungen oder die Variation der Eiswochenzahlen.}

202. Die "Schwankungen» der Eiswochenzahlen können auf verschiedene Weise bestimmt werden. Der grössten Schwankung derselben entspricht the oretis ch die Differenz zwischen den Eiswochenzahlen mit der Eis-Wahrscheinlichkeit 1/10 des sl-Winters und den Eiswochenzahlen mit der Eis-Wahrscheinlichkeit 10/10 des sk-Winters, d. h. der Unterschied zwischen den grössten Werten des sl-Winters und den kleinsten Werten des sk-Winters. Da jedoch die ersteren Eiswochenzahlen einem ausserordentlich langen sl-Winter entsprechen und somit einen bedeutend schwereren Winter vertreten als irgendeiner der Winter 1915-1925, so haben wir bei der Bestimmung der Schwankung sowohl in bezug auf den sl- als den skWinter jene Eiswochenzahlen benutzt, deren Eis-Wahrscheinlichkeit $5 / 10$ ist.

203. Die Bestimmung der Schwankungen geschah auf folgende Weise.. Auf den Originalkarten der Eiswochenkurven der sl- und 
sk-Winter mit der Eis-Wahrscheinlichkeit 5/10 (Atlas S. 51 und 47) bestimmten wir die Eiswochenzahlen für Punkte, deren Entfernung von einem jeden Beobachtungsorte nach dem Meere zu 0, 5, 10, 15 und 20 Seemeilen war. Für den sk-Winter wählten wir in der Nähe der Küste die Punkte dichter, um die Wochenzahl, die teilweise auch graphisch bestimmt wurde, genauer zu erhalten, weil in dem sk-Winter die Kurven nur ein ziemlich schmales Randgebiet vor der Küste umfassen. Die erhaltenen Zahlenwerte stellten wir sowohl für den sl- als sk-Winter in Tabellen zusammen und berechneten sodann die Unterschiede.

Nehmen wir nun an, dass die Eiswochenzahl mit der Eis-Wahrscheinlichkeit 5/10 des $\mathrm{ml}-\mathrm{W}$ inters der Mittelzahl der entsprechenden Eiswochenzahlen des sk- und sl-Winters entspricht was jedoch nicht mit der Wirklichkeit übereinstimmt - so würde die Hälfte der oben bestimmten grössten Schwankung der Eiswochenzahlen die sog. Schwankung der Mittelzahl ergeben: die Mittelzahl, d. h. die Eiswochenzahl des ml-Winters mit der Eis-Wahrscheinlichkeit 5/10 plus die Hälfte der grössten Schwankung der Eiswochenzahlen würde den grössten Wert, dieselbe Mittelzahl minus die Hälfte der grössten Schwankung den kleinsten Wert der Eiswochenzahl angeben. Deswegen wurden die Zahlenwerte in der Karte der "Veränderlichkeit» der Eiswochenzahlen (Atlas S. 45) kurz vor der Drucklegung auf die Hälfte reduziert, was jedoch vielleicht weniger zweckentsprechend war, da man so leicht nicht ganz richtige Schlussfolgerungen u. a. inbetreff der Eisverhältnisse in der Nördlichen Ostsee ziehen kann.

204. Die Eiswochenzahlen und ihre Schwankungen werden eingehender im achten Teil behandelt. Hier wollen wir noch die Methode der Herleitung der "Z e it, in Wochen, mit Eis» beschreiben und dabei 3 neue Karten, betr. die Schwankungen der "Zeit mit Eis» zwischen dem "normalen» sehr kurzen, "normalen» mittellangen und "normalen» sehr langen Winter hinzufügen, die auf eine ganz andere Weise erhalten sind.

\section{Die aus den G-Stadien unter Berücksichtigung der Wahr- scheinlichkeit des jährlichen Eintretens derselben be- rechneten Eiswochenzahlen des "normalen» sk-, ml- und sl-Winters.}

205. Die Karten "Zeit mit Eis» im Atlas S. 46-51 zeigen uns, wie die aus den G-Stadien hergeleiteten Eiswochenzahlen je nach der betreffenden Eis-Wahrscheinlichkeit schwanken. Die Eis-Wahr- 
scheinlichkeit ihrerseits, die der benutzten Frequenz gleich ist, beruht auf dem Aufbau der G-Stadien. Für die Eiswochenzahlen des verschieden langen Winters, d.h. für den sk-, ml- und sl-Winter zeichneten wir im ganzen 15 Karten, von denen 12 Karten, nämlich diejenigen, welche die Frequenz 1.0, 0.8, 0.5 und 0.1 und somit auch die Eis-Wahrscheinlichkeit $10 / 10,8 / 10,5 / 10$ und $1 / 10$ vertreten, im Atlas wiedergegeben sind.

Von diesen Eiswochenkarten zeigt jedoch keine einzige die durchschnittliche Dauer des »normalen» sehr kurzen, »normalen» mittellangen oder »normalen» sehr langen Winters in Wochen: Die Wochenzahlen mit der Eis-Wahrscheinlichkeit 10/10 sind gewiss zu klein, die mit der Eis-Wahrscheinlichkeit $1 / 10$ wiederum offenbar zu gross, um an und für sich einem von diesen idealen Wintern zu entsprechen. In erster Linie entsprechen wohl die Wochenzahlen, deren Eis-Wahrscheinlichkeit 5/10 ist oder zwischen 5/10 und 8/10 liegt, den Wintern. Weder aus den G-Stadien noch aus dem primären Eisbeobachtungsmaterial können wir nämlich unmittelbar bestimmen, welche Wochenzahlen der Länge des ganzen Winters am besten entsprechen würden. In Betreff der beiden - sowohl der G-Stadien als der primären Eisbeobachtungen - ist die Bestimmung der mittleren Länge des Winters nur so möglich, dass wir zunächst feststellen, was wir überhaupt unter "Zeit mit Eis» und dann unter der "mittleren Länge» des Winters verstehen wollen und dabei bestimmen, wie wir dann »die Zeit mit Eis» nach unseren-Definitionen am besten berechnen können. Denn auch dann, wenn wir aus dem primären Eismaterial die "Zeit mit. Eis» z. B. so zu bestimmen versuchen, dass wir immer in ganz bestimmten, verschiedenen Richtungen von den Beobachtungsorten nach dem Meere zu an denselben Punkten die Tage mit Eis rechnen, kommen gewisse Unklarheiten vor, die ohne vorhergehende »Definitionen» zu subjektiver Deutung führen. Dies geschieht, wenn wir ausserhalb des ganz mit Eis bedeckten Gebietes oder im grossen und ganzen ausserhalb der Frequenzkurven 1.0 kommen, d. h.dorthin, wo das Eis nur zum Teil und zeitweise das Meer bedeckt, und wo durch die Bewegung des Meereseises sehr oft grössere oder kleinere Spalten, Seerinnen und andere Öffnungen im Verlauf des Winters entstehen.

206. Da somit die Frage der „Zeit mit Eis» ganz unbestimmt war, beschloss ich sie vermittels der schon hergeleiteten und bestimmten Eiswochenzahlen, die den verschiedenen Eis-Wahrscheinlichkeiten entsprechen, zu berechnen. Um jedoch nun die »Zeit mit Eis» derart zu erhalten, dass sie, wenigstens innerhalb der Grenzen, welche der von uns benutzten Methode entsprechen, die Länge des 
"normalen» sehr kurzen, bzw. "normalen» mittellangen und »normalen» sehr langen Winters nach den Eintrittszeiten der G-Stadien wiedergeben, machten wir folgende $V$ oraussetzung:

Falls es an einer Stelle $\mathrm{P}$ ausserhalb der Küstenlinie mit der Wahrscheinlichkeit w während $W_{w}$ Wochen Eis gibt, d.h. falls die Zeit, welche vergeht, seitdem die Frequenzkurve w die Stelle $P$ erreicht hat, bis sie bei ihrer Rückkehr wieder zu derselben Stelle P zur ückgekommen ist, $W_{w}$ Wochen ist, so ist "die Zeit mit Eis» an der Stelle P gleich $\mathrm{w} \times \mathrm{W}_{\mathrm{w}}$ Wochen.

207. Aus folgendem Beispiel erhellt, wie nur mit Hilfe dieser einfachen Annahme die »berechneten Eiswochenzahlen» erhalten worden sind.

An einer Stelle $\mathrm{P}$, welche wir hier der Einfachheit halber als Beobachtungsort draussen im Meer betrachten können, erscheint in den G-Stadien im allgemeinen als das »erste Eis» das »Eis», dessen äusserer Rand die Frequenzkurve 0.1 darstellt; danach folgt solches »Eis», dessen äusserer Rand in den G-Stadien von der Frequenzkurve 0.2 gebildet ist; noch etwas später folgt »das Eis» der Frequenzkurve 0.5 usw., bis zuletzt das Eis erscheint, das die Frequenzkurve 1.0 als äusseren Rand hat. Beim Rückgang des Eises durch die Stelle P ist die Reihenfolge der Ränder des verschiedenen "Eises» im grossen und ganzen umgekehrt: zuerst zieht sich durch die Stelle $\mathrm{P}$ das Eis zurück, dessen äusserer Rand von der Frequenzkurve 1.0 angegeben wird, dann das der Frequenzkurve 0.8 entsprechende "Eis» usw., und schliesslich das "Eis» der Frequenzkurve 0.1, falls solches überhaupt noch vorkommt.

Bezeichnen wir nun die Zeitpunkte des Erscheinens der Frequenzkurven an der Stelle $\mathrm{P}$ bei dem Vorwärtsrücken der Vereisung mit $t_{0.1}^{\alpha}, t_{0.2}^{\alpha}, t_{0.5}^{\alpha}, t_{0.8}^{\alpha}$ und $t_{1.0}^{\alpha}$ und die des Wiedererscheinens an der Stelle $P$ beim Rückgang des Eises mit $t_{1.0}^{\varepsilon}, t_{0.8}^{\varepsilon}, t_{0.5}^{\varepsilon}, t_{0.2}^{\varepsilon}$ und $t_{0.1}^{\varepsilon}$, so können wir folgende Zeitdifferenzen bilden: $t_{1,0}^{\varepsilon}-t_{1.0}^{\alpha}, t_{0.8}^{\varepsilon}-t_{0.8}^{\alpha}$, $t_{0.5}^{\varepsilon}-t_{0.5}^{\alpha}, \quad t_{0.2}^{\varepsilon}-t_{0.2}^{\alpha}$ und $t_{0.1}^{\varepsilon}-t_{0.1}^{\alpha}$. Diese Zeitdifferenzen als solche zeigen, wie lange in Tagen das jeder fraglichen Frequenzkurve entsprechende "Eis», dessen Eis-Wahrscheinlichkeit mit der Frequenzkurve gleichwertig ist - allein genommen - an der Stelle P verbleibt. Diese Zeitdifferenzen sind in Wochen: $\left(t_{1.0}^{\varepsilon}-t_{1.0}^{\alpha}\right): 7=$ $W_{1.0} ;\left(t_{0.8}^{\varepsilon}-t_{0.8}^{a}\right): 7=W_{0.8}$, usw., wobei also die Zeit $W_{1.0}$ den "Aufenthalt» des Eises mit der Eis-Wahrscheinlichkeit 10/10, $W_{0.8}$ den des Eises mit der Eis-Wahrscheinlichkeit 8/10 usw. an der Stelle 
P wiedergibt. Aber das »Eis», das eine kleinere Eis-Wahrscheinlichkeit als 10/10 hat, "verbleibt" an der Stelle $\mathrm{P}$ nur eine bedeutend kürzere Zeit als die obengenannten Wochenzahlen zeigen. Das Eis, dessen Eis-Wahrscheinlichkeit 10/10 ist, „verblieb» natürlich die ganze Zeit, $W_{1.0}$ Wochen, an der Stelle $P$, das Eis mit der Eis-Wahrscheinlichkeit 8/10 hingegen nur $\left(W_{0.8}-W_{1.0}\right)$ Wochen; entsprechend "verbleibty das Eis mit der Eis-Wahrscheinlichkeit 0.5: $\left(W_{0.5}-W_{0.8}\right)$ Wochen usw., so dass die tatsächlichen "Aufenthaltszeiten» des Eises mit verschiedenen Eis-Wahrscheinlichkeiten der Reihe nach die folgenden sind: $W_{1.0} ;\left(W_{0.8}-W_{1.0}\right) ;\left(W_{0.5}-W_{0.8}\right) ;\left(W_{0.2} \div\right.$ $\left.W_{0.5}\right)$ und $\left(W_{0.1}-W_{0.2}\right)$. Durch Anwendung der oben gemachten Voraussetzung, dass die wirkliche »Zeit mit Eis» gleich der EisWahrscheinlichkeit w mal entsprechende Eiswochenzahl $W_{w}$ ist, erhalten wir als erste approximative »Zeit mit Eis» an der Stelle $\mathbf{P}$ vermittels der Frequenzkurven 1.0,0.8, 0.5, 0.2 und 0.1 der G-Stadien:

(1) $\stackrel{\Sigma}{P}^{1}=1.0 \times \mathrm{W}_{1.0}+0.8 \times\left(\mathrm{W}_{0.8}-\mathrm{W}_{1.0}\right)+0.5 \times\left(\mathrm{W}_{0.5}-\mathrm{W}_{0.8}\right)$ $+0.2 \times\left(W_{0.2}-W_{0.5}\right)+0.1 \times\left(W_{0.1}-W_{0.2}\right)$.

208. Je mehr Frequenzkurven die Generalstadien haben, um so genauer kann die "Zeit mit Eis» berechnet werden. Da wir in den Normalstadien nur die Frequenzen 1.0, 0.8, 0.5,0.2 und 0.1 sowie die entsprechenden Frequenzkurven benutzt haben, so können wir die Eiswochenzahlen nur vermittels derselben herleiten. Um jedoch den durch die mangelnden Frequenzen bedingten Fehler einigermassen auszugleichen, verbesserten wir die Formel (1) auf folgende Weise. Da während der Zeit $\mathrm{t}_{0.1}^{\alpha}$ bis $\mathrm{t}_{0.1}^{\varepsilon}$ an der Stelle $\mathrm{P}$ ausser der Frequenzkurve 0.1 (zu dem Zeitpunkt $t_{0.1}^{\alpha}$ ) und der Frequenzkurve 0.2 (zu dem Zeitpunkt $\mathrm{t}_{0.2}^{\alpha}$ ) auch die Frequenzkurven $0.11,0.12, \ldots$ und 0.19 zwischen den angegebenen Zeitpunkten erscheinen, so ist es richtiger als Koeffizient der Wochenzahl $W_{0.1}-W_{0.2}$ die Zahl 0.15 anstatt der Zahl $0.1 \mathrm{zu}$ verwenden, obgleich auch dies nur unter der Voraussetzung ganz richtig ist, dass die Frequenzkurven 0.10, 0.11, $0.12, \ldots$ und $0.20 \mathrm{mit}$ gleich langen Zeitintervallen aufeinander folgen.

Für die übrigen Frequenzen erhält man durch die gleiche Schlussfolgerung die Koeffizienten 0.35, 0.65, 0.90 mit 1.0, und die Formel (1) der Eiswochen erhält folgende verbesserte Form:

$$
\begin{aligned}
\sum_{P}=1.0 \times \mathrm{W}_{1.0} & +0.9 \times\left(\mathrm{W}_{0.8}-\mathrm{W}_{1.0}\right) \\
& +0.65 \times\left(\mathrm{W}_{0.5}-\mathrm{W}_{0.8}\right) \\
& +0.35 \times\left(\mathrm{W}_{0.2}-\mathrm{W}_{0.5}\right) \\
& +0.15 \times\left(\mathrm{W}_{0.1}-\mathrm{W}_{0.2}\right) .
\end{aligned}
$$




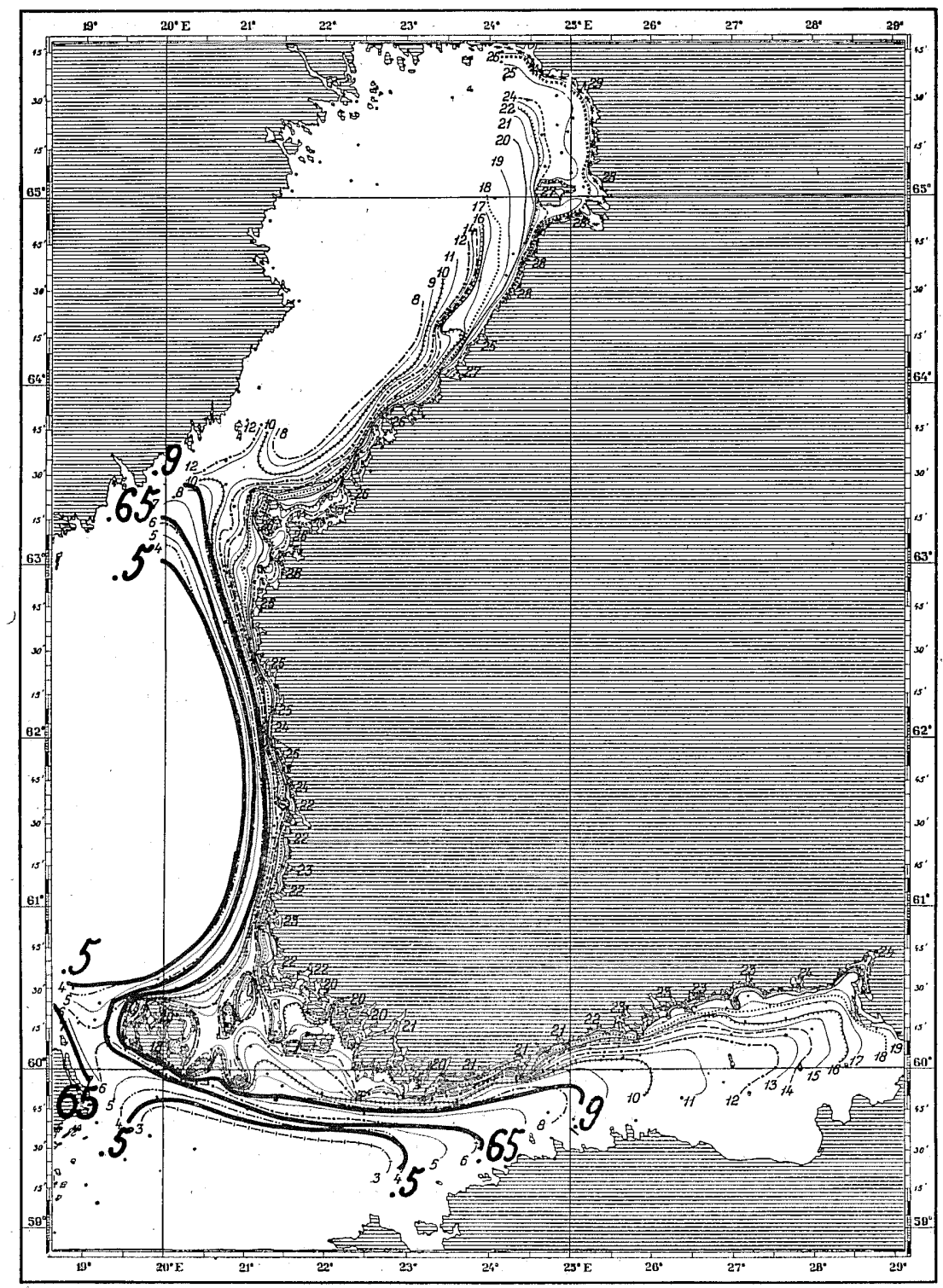

Fig. 85: Die dünnen Kurven bezeichnen die Wochenzahlkurven des Eises mit der EisWahrscheinlichkeit 10/10 im »normalen» ml-Winter. Die dicken Kurven . 9, . 65 und .5 zeigen, wo die diese Wochenzahllkurven bestimmende Frequenzkurve 10/10 der G-Stadien und somit auch die Wochenzahlen selbst die Wahrscheinlichkeit 9/10, 6-7/10 und $5 / 10$ haben. 
209. Der sk-Winter umfasst, wie frïher erwähnt wurde, nur diejenigen G-Stadien, deren Wahrscheinlichkeit des jährlichen Eintretens 10/10 ist, d. h. die Stadien $\mathrm{G}_{1-13}$ und $\mathrm{G}_{21-30}$. Der sl-Winter umfasst dagegen wenigstens sämtliche in der vorliegenden Untersuchung hergeleiteten G-Stadien. Deshalb müssen wir bei der Bestimmung der Summe der Eiswochenzahlen des sl-Winters sämtliche G-Stadien bzw. die ihnen entsprechenden Eislagen als erschienen betrachten, und darum allen Stadien in diesen sl-Wintern die Wahrscheinlichkeit $10 / 10$ geben. Da nun sämtliche bei der Berechnung der Eiswochensumme des sk- und des sl-Winters benutzten G-Stadien die Wahrscheinlichkeit 10/10 des jährlichen Eintretens entweder haben oder zugeteilt erhalten, kann die Eiswochenformel (2) unmittelbar angewendet werden.

210. Dagegen musste bei der Berechnung der Eiswochensumme des ml-Winters die verschiedene Wahrscheinlichkeit der G-Stadien berücksichtigt werden, denn nur dadurch wurde unseres Erachtens die Wahrscheinlichkeit der Normalstadien richtig und genügend berücksichtigt. Nur auf diese Weise bekamen die Eiswochenzahlen, die in der Wochensumme vermittels solcher G-Stadien eingeführt worden sind, deren Wahrscheinlichkeit des jährlichen Eintretens kleiner als 10/10 ist, ein entsprechend kleineres Gewicht als die Wochenzahlen der Wochensumme, die ihrerseits vermittels solcher GStadien, deren Wahrscheinlichkeit 10/10 ist, eingeführt sind. In Fig. 85-89 zeigen die dicken Kurven die Stellen an, wo die den verschiedenen Eis-Wahrscheinlichkeiten 10/10, 8/10, 5/10, 2/10 und 1/10 entsprechenden Wochenzahlkurven im ml-Winter von solchen GStadien vermittelt worden sind, deren Wahrscheinlichkeit des jährlichen Eintretens der Reihe nach 9/10,6-7/10 und 5/10 ist. Vermittels der Kurven dieser Figuren kann die Wahrscheinlichkeit der Wochenzahlen unter Berücksichtigung des Gradienten interpoliert werden. In Fig. 85, welche den Eiswochenzahlen, deren Eis-Wahrscheinlichkeit 10/10 ist, entspricht, sind auch die Eiswochenkurven dargestellt. In Fig. 86-89 ist angegeben, wo die Wochenzahlen, deren EisWahrscheinlichkeit 8/10 (Fig. 86), 5/10 (Fig. 87), 2/10 (Fig. 88) und $1 / 10$ (Fig. 89) ist, die Wahrscheinlichkeit $9 / 10,6-7 / 10$ und $5 / 10$ haben.

Je nachdem, an welcher Stelle der Punkt $\mathrm{P}$ in bezug auf die Wahrscheinlichkeitskurven der Figuren 85-89 zu liegen kommt, verändern sich bei der Berechnung der Eiswochensumme des mlWinters nach der Formel (2) die Koeffizienten der Wochenzahl $W_{1.0}$, und der Wochenzahldifferenzen $W_{0.8}-W_{1.0}, W_{0.5}-W_{0.8}$, $W_{0.2}-W_{0.5}$ und $W_{0.1}-W_{0.2}$. Falls nämlich der Punkt $P$ an einer 
solchen Stelle liegt, dass dort auf den Eiswochenkarten der EisWahrscheinlichkeiten 10/10,8/10.5/10,2/10 und 1/10 die Wahrscheinlichkeit $\mathrm{w}_{\mathrm{P} 1.0}, \mathrm{w}_{\mathrm{P} 0.8}, \mathrm{w}_{\mathrm{P} 0.5}, \mathrm{w}_{\mathrm{P}_{0.2}}$ und $\mathrm{w}_{\mathrm{P} 0.1}$ ist, so sind die genannten Koeffizienten der Formel (2): $\mathrm{w}_{\mathrm{P} 1.0} \times 1.0, \mathrm{w}_{\mathrm{P} 0.8} \times 0.9, \mathrm{w}_{\mathrm{P} 0.5} \times 0.65$, $\mathrm{w}_{\mathrm{P} 0.2} \times 0.35$ und $\mathrm{w}_{\mathrm{P} 0.1} \times 0.15$ statt einfach $1.0,0.9,0.65,0.35$ und 0.15 . Die Formel (2) lautet darum bei der Berechnung der Eiswochensumme des nnormalen" mittellangen Winters

$$
\begin{aligned}
\sum_{P}(\mathrm{ml})=\mathrm{W}_{\mathrm{P} 1.0} \times 1.0 \times \mathrm{W}_{1.0} & +\mathrm{W}_{\mathrm{P} 0.8} \times 0.9 \times\left(\mathrm{W}_{0.8}-\mathrm{W}_{1.0}\right) \\
& +\mathrm{W}_{\mathrm{P} 0.5} \times 0.65 \times\left(\mathrm{W}_{0.5}-\mathrm{W}_{0.8}\right) \\
& +\mathrm{W}_{\mathrm{P} 0.2} \times 0.35 \times\left(\mathrm{W}_{0.2}-\mathrm{W}_{0.5}\right) \\
& +\mathrm{W}_{\mathrm{P} 0.1} \times 0.15 \times\left(\mathrm{W}_{0.1}-\mathrm{W}_{0.2}\right)
\end{aligned}
$$

Aus dieser Formel erhalten wir die für den "normalen» sehr kurzen und den »normalen» sehr langen Winter gültige Formel (2), wenn wir $\mathrm{w}_{\mathrm{P} 1.0}=\mathrm{w}_{\mathrm{P} 0.8}=\mathrm{w}_{\mathrm{P} 0.5}=\mathrm{w}_{\mathrm{P} 0.2}=\mathrm{w}_{\mathrm{P} 0.1}=1.0$ setzen.

211. Wie aus Fig. $85-89$ hervorgeht, verschieben sich die betreffenden Wahrscheinlichkeitskurven um so weiter ins Meer, je geringerer Eis-Wahrscheinlichkeit die Wochenkurven entsprechen. So liegt z. B. die äusserste Wahrscheinlichkeitskurve auf der Karte, deren Eis-Wahrscheinlichkeit 8/10 entspricht (Fig. 86), in dem westlichen Teil der Bottensee beinahe im äussersten Sehkreis und in der Nördlichen Ostsee in der Richtung WNW-ESE innerhalb Bogskär. Auf derselben Karte erstreckt sich die Kurve 9, welche die Wahrscheinlichkeit 9/10 angibt, ununterbrochen aus dem Kvark ausserhalb des äusseren Schärenhofes der Bottensee und um Åland herum bis in die Mündung des Finnischen Meerbusens. Dagegen ist auf der Karte, die der Eis-Wahrscheinlichkeit 5/10 entspricht (Fig. 87), die Wahrscheinlichkeitskurve 5/10 ganz aus der Bottensee verschwunden und zuäusserst liegt dort die Kurve 6-7/10; die Kurve 5/10 befindet sich in der Höhe von Bogskär in der Nördlichen Ostșee und die Kurve 9/10, welche in der Bottensee schon teilweise weit ins Meer vorgedrungen ist, umschliesst die mittleren Teile des Alandsmeeres. Die Wahrscheinlichkeitskurven, welche den Wochenzahlen des Eises mit der Eis-Wahrscheinlichkeit 2/10 und 1/10 entsprechen, haben sich alle in die Nördliche Ostsee verschoben.

212. Die Tabelle 48 zeigt, wie wir die Berechnung der Eiswochensumme oder der "Zeit mit Eis» vermittels der Formeln (2) und (3) ausgeführt haben. Dort sind die Eiswochensummen für drei Beobachtungsorte: Röyttä (Station No. 1, Atlas S. 29), Utö (Station No. 42) und Seivästö (Station No. 84) für den »normalen» sk-, »normalen» ml- und "normalen» sl- Winter ausgerechnet. Da von diesen Orten 


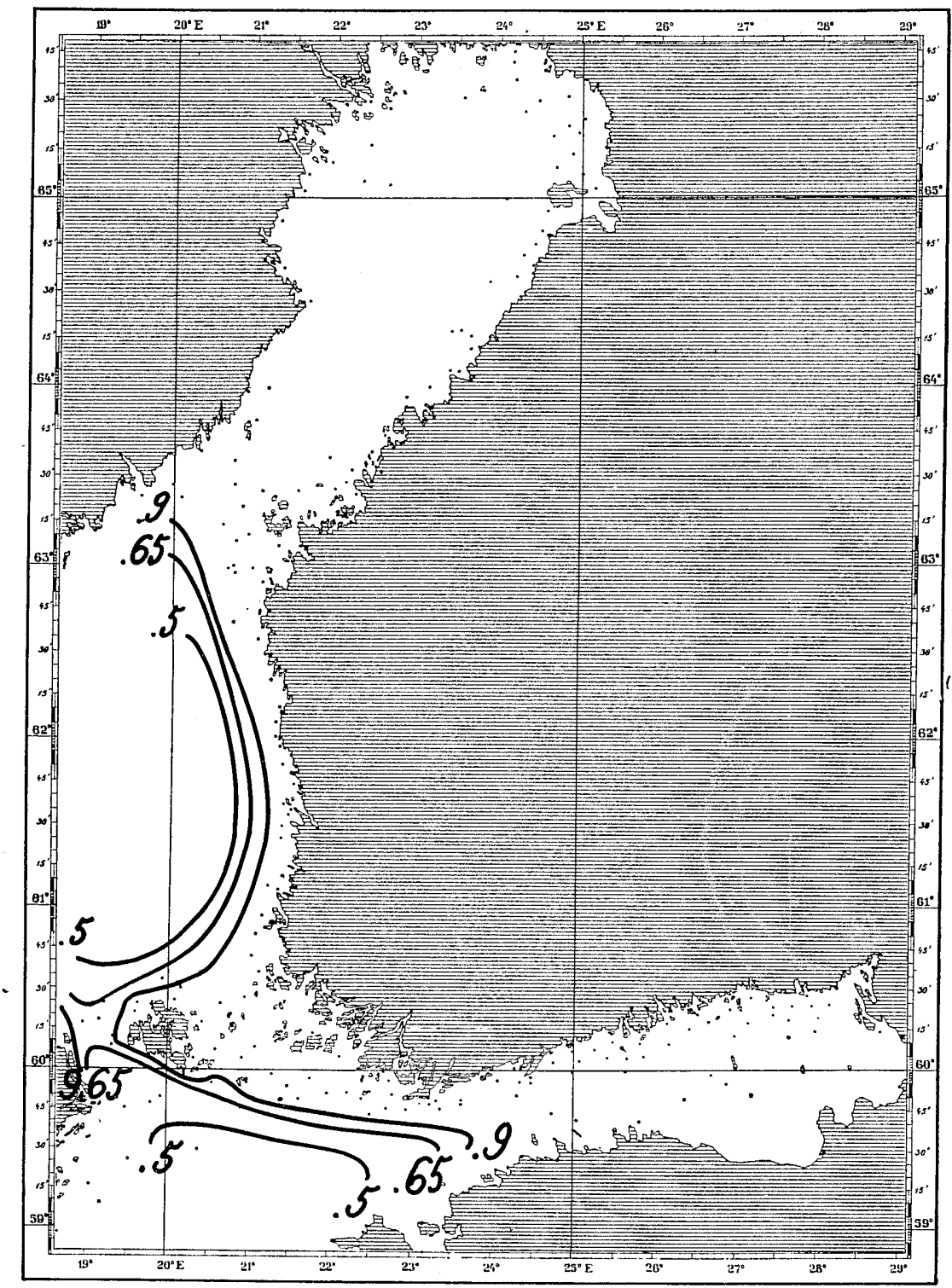

Fig. 86. Die Kurven $.9, .65$ und . 5 zeigen, wo die Wochenzahlen des "normalen» mlWinters, die vermittels der Frequenzkurve 0.8 der G-Stadien bestimmt sind und die darum dem Eis der Eis-Wahrscheinlichkeit 8/10 entsprechen, die Wahrscheinlichkeit 9/10,6-7/10 und 5/10 haben. Die entsprechende Karte des mormalen ml-Winters, d. h. die Karte mit den Wochenzahlkurven des Eises der Eis-Wahrs heinlicheit 8/10 in diesem Winter auf S. 48 im Atlas. 


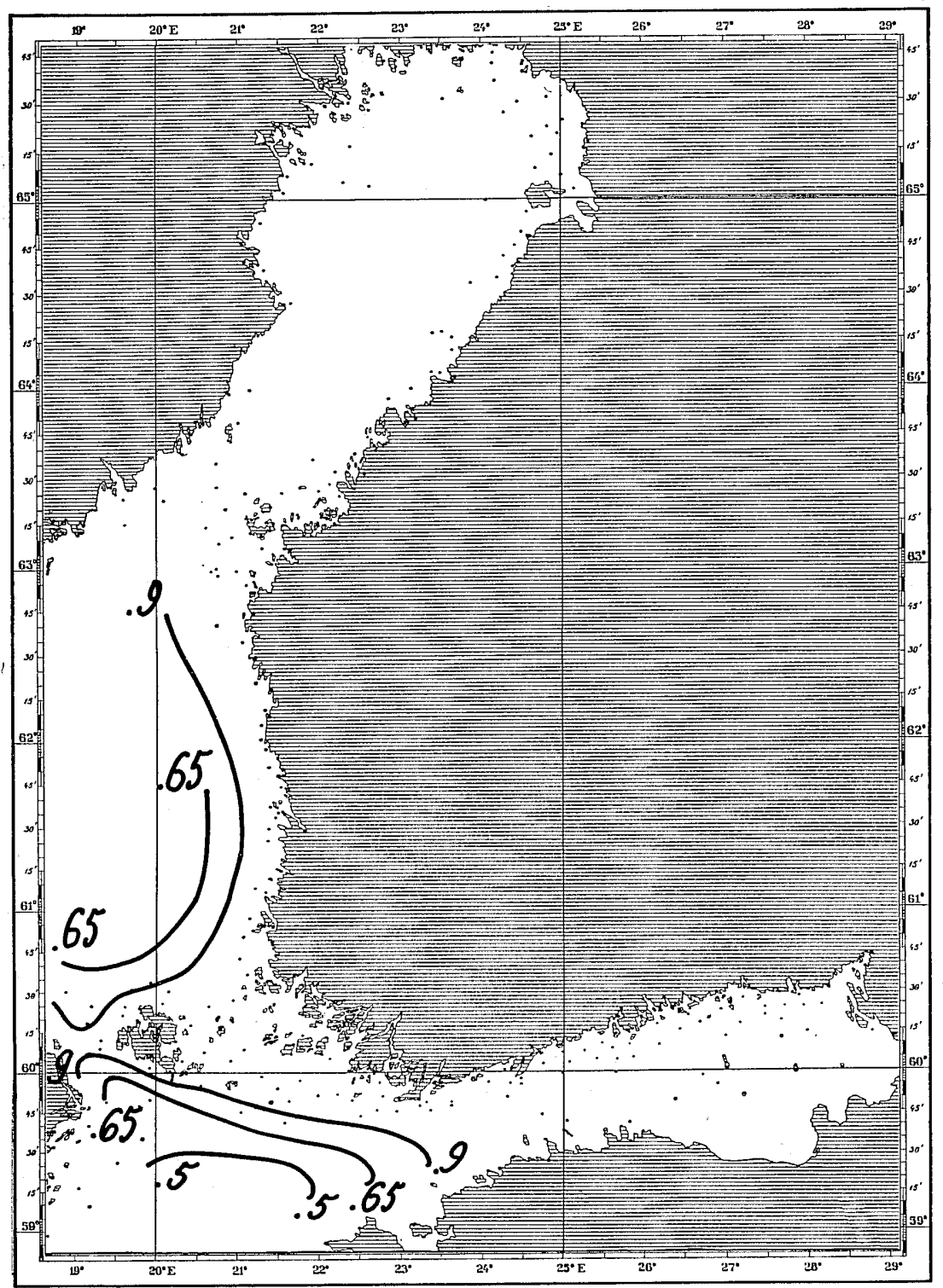

Fig. 87. Die Kurven $.9, .65$ und .5 zeigen, wo die Wochenzahlen des "normalen» mlWinters, die vermittels der Frequenzkurven 0.5 der G-Stadien bestimmt sind und die darum dem Eis der Eis-Wahrscheinlichkeit 5/10 entsprechen, die Wahrscheinlichkeit 9/10, 6-7/10 und 5/10 haben. Die entsprechende Karte des ml-Winters, d. h. die Karte mit den Wochenzahlkurven des Eises der Eis-Wahrs heinli hkeit 5/10 in diesem Winter auf S. 49 im Atlas. 


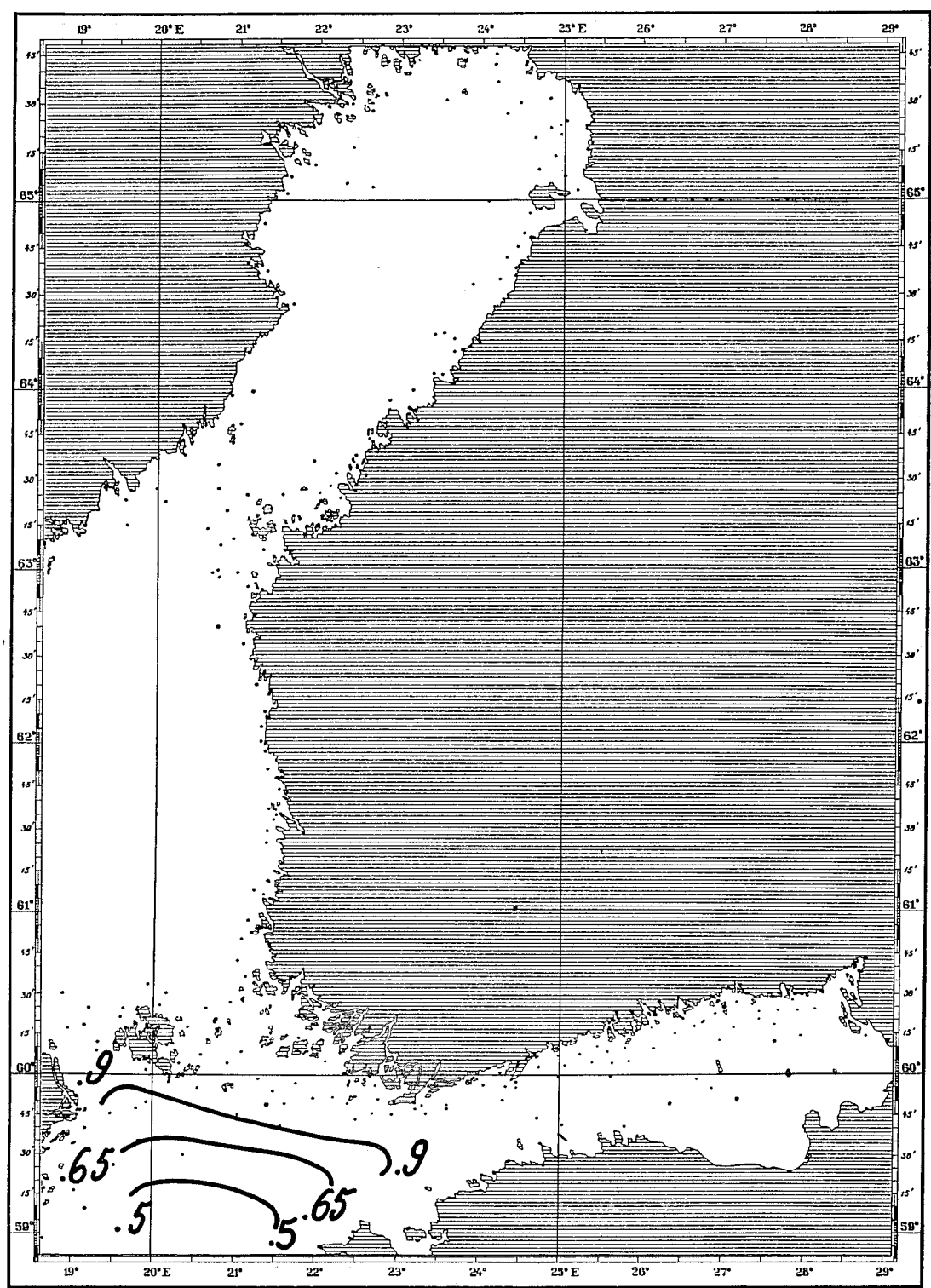

Fig. 88. Die Kurven .9, .65 und .5 zeigen, wo die Wochenzahlen des "normalen» mlWinters, die vermittels der Frequenzkurve 0.2 der G-Stadien bestimmt sind und die darum dem Eis der Eis-Wahrscheinlichkeit 2/10 entsprechen, die Wahrscheinlichkeit $9 / 10,6-5 / 10$ und 5/10 haben. Die entsprechende Karte des ml-Winters, d. h. die Karte mit den Wochenzahlkurven des Eises mit der Eis-Wahrscheinlichleit 2/10 in diesem Winter für die Nördliche Ostsee in Fig. 82. 


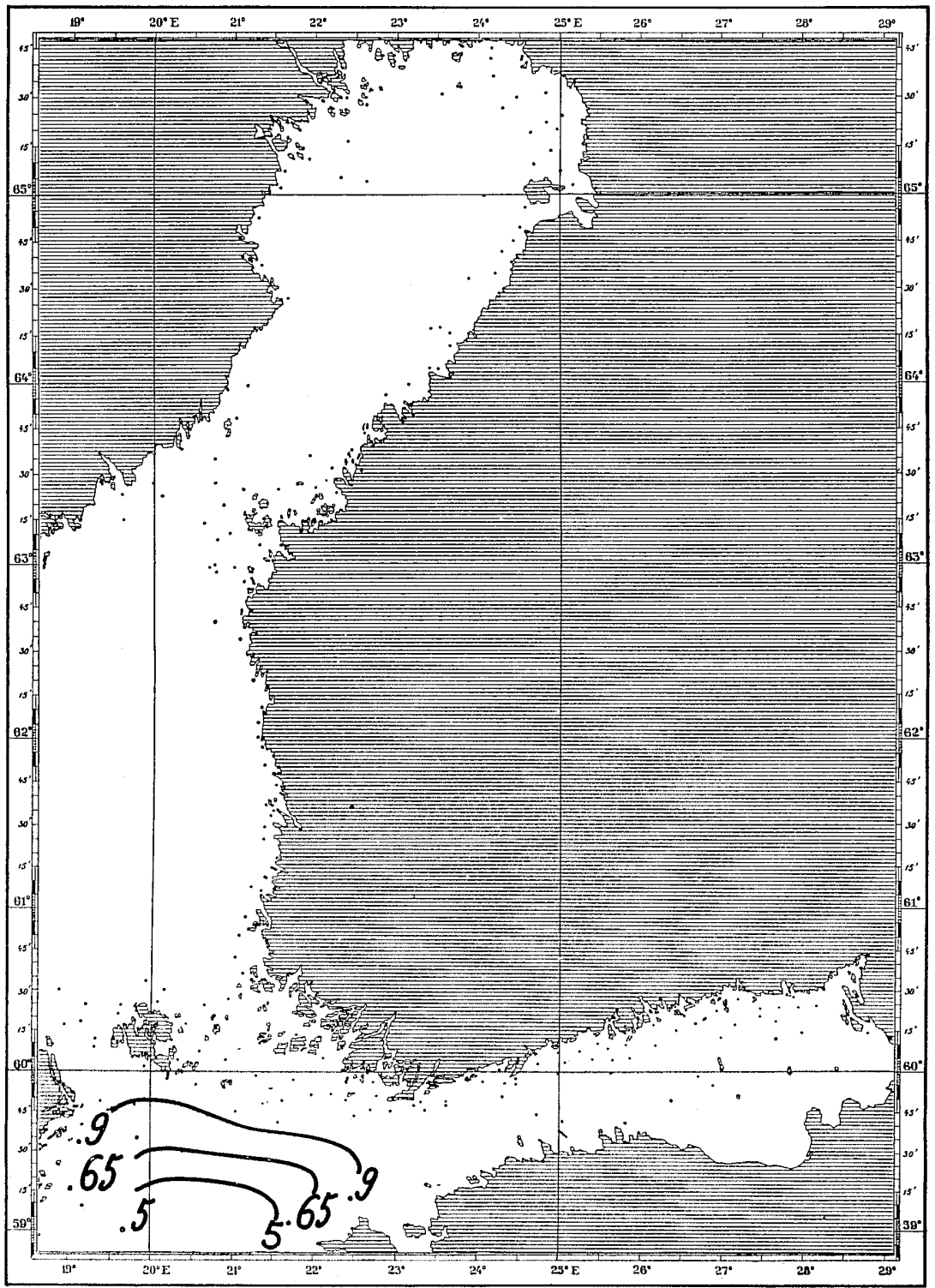

Fig. 89. Die Kurven .9, .65 und .5 zeigen, wo die Wochenzahlen des »normalen» mlWinters, die vermittels der Frequenzlkurve 0.1 der G-Stadien bestimmt sind und die darum dem Eis der Eis-Wahrscheinlichkeit 1/10 entsprechen, die Wahrscheinlichkeit 9/10, 6-7/10 und 5/10 haben. Die entsprechende Karte des ml-Winters, d. h. die Karte mit den Wochenzahlkurven des Eises mit der Eis-Wahrscheinlichkeit 1/10 in diesem Winter auf S. 49 im Atlas. 
Röyttä (1) der nördlichste Beobachtungsort ist, Utö (42) wiederum weit im Südwesten an der Nördlichen Ostsee gelegen und Seivästö (84) der östlichste Beobachtungsort ist, haben wir noch, um den Vergleich zu erleichtern, die erhaltenen Resultate in Tabelle 49 nebeneinander gestellt.

213. Ganz auf dieselbe Weise, wie in Tabelle 48 die "Zeit mit Eis» für drei Orte bestimmt wurde,wurde sie im ganzen für 84 Beobachtungsorte (siehe die Karte im Atlas, S. 29) sowohl in dem «sk»-, als $» m l »-$ und $» s l »$-Winter berechnet. Für jeden Ort wurde dabei ganz in derselben Weise, wie oben in Punkt 203, aber dort inbetreff der Eiswochenzahlen, hier. der Wochensummen - die Summe, an der Küste beginnend und nach dem Meere zu, immer an Stellen, die 5 Seemeilen voneinander liegen, bestimmt. Im sk-Winter wurden die Stellen jedoch - und zwar aus derselben Ursache wie in Punkt 205 inbetreff der Eiswochen - in der Nähe der Küste dichter gewählt. Durch Einzeichnen der zum Schluss als die "Zeit mit Eis» der verschiedenen Winter erhaltenen Wochensummen an entsprechenden Stellen in besondere Unterlagekarten und durch Vereinigen der Stellen, wo die "Zeit mit Eis» dieselbe war, durch Kurven, erhielten wir schliesslich die Karten in Fig. 90-92.

Fig. 90 zeigt die "Zeit mit Eis» des normalen sk-Winters oder auf Grund der Berechnungsweise, richtiger des normalen "mittellangen» sk-Winters, Fig. 91 des "normalen" ml-Winters und Fig. 92 entsprechend des normalen »mittellangen» sl-Winters. Fig. 91 ist sonst dieselbe wie die Karte "Zeit, in Wochen, mit Eis im Mittel», im Atlas Seite 45. In diesem Zusammenhang werden wir diese Karten nicht näher beschreiben, weil wir später hierauf wieder in anderem Zusammenhang zurückkommen werden.

214. Aus den wie in der Tabelle 48 berechneten Eiswochenzahlensummen der 84 verschiedenen Beobachtungsorte haben wir weiter u. a. solche Zahlen hergeleitet, welche angeben, wie sich die "Zeit mit Eis» verändert, wenn die Länge des Winters wächst, indem der Winter aus dem "normalen mittellangen» sehr kurzen durch den mittellangen in den "normalen mittellangen» sehr langen Winter übergeht. Die Veränderung der Eiswochensumme ist auf dieselbe Weise bestimmt, wie oben in Punkt 205, wo über die Bestimmung der Grösse der Schwankungen der Eiswochenzahlen berichtet wurde. Es wurden ganz einfach aus der $\Sigma$-Kolumne der der Tabelle 48 entsprechenden, aber alle Beobachtungsorte umfassenden Tabelle die Differenzen $\Sigma_{\mathrm{p}} \mathrm{ml}-\Sigma_{\mathrm{p}} \mathrm{sk}, \Sigma_{\mathrm{p}} \mathrm{sl}-\Sigma_{\mathrm{p}} \mathrm{ml}$ und $\Sigma_{\mathrm{p}} \mathrm{sl}-\Sigma_{\mathrm{p}} \mathrm{sk}$ einer und derselben Stelle P berechnet, wobei $\Sigma_{\mathrm{p}}$ die ZZeit mit Eis» an der Stelle P angibt und die Indexe den Winter bezeichnen. Die Differenz $\Sigma_{\mathrm{p}} \mathrm{ml}-$ 
Tabel-

Die Berechnung der "Z eit mit $E i s 》$ von Röyttä (Beobachtungsort

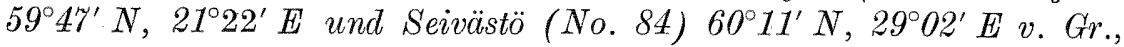
(ml) und "normalen 'mittellangen' sehr langen (sl-) Winter unter Beder G-Stadien. Die Berechnungen sind in bezug auf den sk- und stmittels der Formel

Die Wochenzahlen (W) des Eises, dessen Eis-Wahrscheinlichkeit lichkeit 0.8 ist, in der Kolumne $W_{0.8}$, usw. $\Delta_{0.9}=\left(W_{0.8}-W_{1.0}\right)$; Im ml-Winter ist auf einer Stelle $\mathrm{P}_{1.0}=\mathrm{w}_{\mathrm{P} 1.0} \times 1.0 ; \mathrm{w}_{0.9}=\mathrm{w}_{\mathrm{P} 0.8} \times 0.9$; den sk- und sl-Wintern ist $\mathrm{w}_{\mathrm{P} 1.0}=\mathrm{w}_{\mathrm{P} 0.9}=\mathrm{w}_{\mathrm{P} 0.65}=\mathrm{w}_{\mathrm{P} 0.35}=\mathrm{w}_{\mathrm{P} 0.15}=1$. $\mathrm{W}_{1.0}+\mathrm{W}_{0.9} \times \Delta_{0.9}+\mathrm{W}_{0.65} \times \Delta_{0.65}$ und die schliessliche $» \mathrm{Z}$ e it

$$
\mathrm{w}_{0.9} \times \Delta_{0.9}+\mathrm{w}_{0.65} \times \Delta_{0.65}+
$$

sk -

\begin{tabular}{|c|c|c|c|c|c|c|c|c|}
\hline & $\begin{array}{l}\mathrm{Ab}- \\
\text { stand. }\end{array}$ & $\mathrm{W}_{1.0}$ & $\mathrm{w}_{1.0}$ & $\Delta_{0.9}$ & $\mathrm{w}_{0.9}$ & $\mathrm{~W}_{0.8}$ & $\Delta_{0.65}$ & $\mathrm{w}_{0.65}$ \\
\hline Röyttä (1) & $0^{\prime}$ & 22.9 & 1.0 & 0.0 & 0.9 & $(22.9)$ & 0.0 & 0.65 \\
\hline Abstand in & $5^{\prime}$ & 20.0 & 1.0 & 0.6 & 0.9 & 20.6 & 0.3 & 0.65 \\
\hline \multirow{3}{*}{$\begin{array}{c}\text { der Richtung } \\
\text { S }\end{array}$} & $10^{\prime}$ & 18.8 & 1.0 & 0.9 & 0.9 & 19.7 & 0.9 & 0.65 \\
\hline & $15^{\prime}$ & 18.0 & 1.0 & 0.8 & 0.9 & 18.8 & 1.5 & 0.65 \\
\hline & $20^{\prime}$ & 16.3 & 1.0 & 1.7 & 0.9 & 18.0 & 2.1 & 0.65 \\
\hline Utö (42) & $0^{\prime}$ & - & - & - & _- & - & $\therefore$ & $\ldots$ \\
\hline Abstand in & $5^{\prime}$ & - & - & - & - & 二 & ב & - \\
\hline $\begin{array}{l}\text { der Richtung } \\
\text { SSW }\end{array}$ & $10^{\prime}$ & - & $\longrightarrow$ & - & - & - & - & - \\
\hline Seivästö (84) & $0^{\prime}$ & 12.0 & 1.0 & 1.0 & 0.9 & 13.0 & 1.0 & 0.65 \\
\hline Abstand in & $5^{\prime}$ & 10.6 & 1.0 & 2.0 & 0.9 & $\begin{array}{l}12.0 \\
12.6\end{array}$ & 0.4 & 0.65 \\
\hline \multirow{3}{*}{$\begin{array}{l}\text { der Richtung } \\
\text { WSW }\end{array}$} & $10^{\prime}$ & 9.8 & 1.0 & 1.7 & 0.9 & 11.5 & 1.0 & 0.65 \\
\hline & $15^{\prime}$ & 9.0 & 1.0 & 1.9 & 0.9 & 10.9 & 1.1 & 0.65 \\
\hline & $20^{\prime}$ & 8.4 & 1.0 & 1.1 & 0.9 & 9.5 & 2.3 & 0.65 \\
\hline Röyttä (1) & $0^{\prime}$ & 28.5 & 1.0 & 0.0 & 09 & 28.5 & & $\mathrm{mi}$ \\
\hline Abstand in & $5^{\prime}$ & 25.0 & $\begin{array}{l}1.0 \\
1.0\end{array}$ & $\begin{array}{l}0.0 \\
0.5\end{array}$ & $\begin{array}{l}0.9 \\
0.9\end{array}$ & $\begin{array}{l}28.5 \\
26.0\end{array}$ & $\begin{array}{l}0.0 \\
0.0\end{array}$ & $\begin{array}{l}0.65 \\
0.65\end{array}$ \\
\hline \multirow{3}{*}{$\underset{S}{\text { der Richtung }}$} & $10^{\prime}$ & 24.5 & $\begin{array}{l}1.0 \\
1.0\end{array}$ & 0.9 & $\begin{array}{l}0.9 \\
0.9\end{array}$ & 25.4 & 0.1 & $\begin{array}{l}0.65 \\
0.65\end{array}$ \\
\hline & $15^{\prime}$ & 24.0 & 1.0 & 0.5 & 0.9 & 24.5 & 0.5 & 0.65 \\
\hline & $20^{\prime}$ & 21.0 & 1.0 & 3.0 & 0.9 & 24.0 & 0.5 & 0.65 \\
\hline \multirow{9}{*}{$\begin{array}{l}\text { Utö (42) } \\
\text { Abstand in } \\
\text { der Richtung } \\
\text { SSW }\end{array}$} & $0^{\prime}$ & 7.6 & 0.9 & 0.4 & 0.9 & 8.0 & 1.0 & 0.6 \\
\hline & $5^{\prime}$ & 5.0 & 0.65 & $\begin{array}{l}.0 . \\
1.0\end{array}$ & 0.6 & 6.0 & $\begin{array}{l}1.0 \\
1.7\end{array}$ & 0.5 \\
\hline & $10^{\prime}$ & 3.3 & 0.5 & 0.7 & 0.5 & 4.0 & 2.5 & 0.4 \\
\hline & $15^{\prime}$ & $(2.0)$ & 0.5 & $(1.0)$ & 0.4 & 3.0 & 2.2 & 0.4 \\
\hline & $20^{\prime}$ & - & - & - & - & - & 4.0 & 0.3 \\
\hline & $25^{\prime}$ & - & - & - & - & - & 2.8 & 0.3 \\
\hline & $30^{\prime}$ & - & - & - & - & - & $(2.0)$ & 0.3 \\
\hline & $35^{\prime}$ & - & - & - & - & - & - & - \\
\hline & $40^{\prime}$ & - & - & - & - & - & - & - \\
\hline Seivästö (84) & $0^{\prime}$ & 19.0 & 1.0 & 1.0 & 0.9 & 20.0 & 0.5 & 0.65 \\
\hline Abstand in & $5^{\prime}$ & 18.0 & 1.0 & 0.5 & 0.9 & 18.5 & 1.5 & 0.65 \\
\hline der Richtung & $10^{\prime}$ & 17.5 & 1.0 & 0.5 & 0.9 & 18.0 & 1.8 & 0.65 \\
\hline WSW & $15^{\prime}$ & 17.0 & 1.0 & 0.5 & 0.9 & $\begin{array}{l}17.5 \\
\text { S }\end{array}$ & 1.5 & 0.65 \\
\hline & $20^{\prime}$ & 16.0 & 1.0 & 1.2 & 0.9 & 17.2 & 1.6 & 0.65 \\
\hline
\end{tabular}


le 48 .

No. 1 auf der Karte S. 29 des Allas) $65^{\circ} 46^{\prime} \mathrm{N}, 24^{\circ} 09^{\prime} \mathrm{E}$; Utö (No.42) für den "normalen mittelangen" sehr kurzen (sk-), "normalen mittellangen" achtung der verschiedenen Wahrscheinlichkeit des jährlichen Eintretens Winter vermittels der Formel (2), in bezug auf den ml-Winter ver(3) erhalten.

1.0 ist, sind in der Kolumne $W_{1.0}$; diejenigen, deren Eis-Wahrschein$\Delta_{0.65}=\left(W_{0.5}-W_{0.8}\right) ; \Delta_{0.35}=\left(W_{0.2}-W_{0.5}\right)$ und $\Delta_{0.15}=\left(W_{0.1}-W_{0.2}\right)$. $\mathrm{w}_{0.65}=\mathrm{w}_{\mathrm{P} 0.5} \times 0.65 ; \quad \mathrm{w}_{0.35}=\mathrm{w}_{\mathrm{P} 0.2} \times 0.35$ und $\mathrm{w}_{0.15}=\mathrm{w}_{\mathrm{P} 0.1} \times 0.15 ;$ in $\Sigma_{1.0}=\mathrm{w}_{1.0} \times \mathrm{W}_{1.0} ; \quad \Sigma_{0.8}=\mathrm{w}_{1.0} \times \mathrm{W}_{1.0}+\mathrm{w}_{0.9} \times \Delta_{0.9} ; \Sigma_{0.5}=\mathrm{w}_{1.0} \times$ $\mathrm{mit} \mathrm{E}$ i s $): \Sigma=$ der berechneten Eiswochenzahl $=\mathrm{w}_{1.0} \times \mathrm{W}_{1.0}+$ $\mathrm{w}_{0.35} \times \Delta_{0.35}+\mathrm{w}_{0.15} \times \Delta_{0.15}$.

Winter.

\begin{tabular}{|c|c|c|c|c|c|c|c|c|c|c|}
\hline$W_{0.5}$ & $\Delta_{0.35}$ & $\mathrm{w}_{0.35}$ & $\mathrm{~W}_{0.2}$ & $\Delta_{0.15}$ & $\mathrm{w}_{0.15}$ & $\mathrm{~W}_{0.1}$ & $\Sigma_{1.0}$ & $\Sigma_{0.8}$ & $\Sigma_{0.5}$ & $\Sigma$ \\
\hline (22.9) & 0.6 & 0.35 & 23.5 & 0.5 & 0.15 & 24.0 & 22.9 & 22.9 & 22.9 & 23.2 \\
\hline 20.9 & 2.0 & 0.35 & 22.9 & - & 0.15 & 22.8 & 20.0 & 20.5 & 20.7 & 21.4 \\
\hline 20.6 & 2.2 & 0.35 & 22.8 & - & 0.15 & 22.4 & 18.8 & 19.6 & 20.2 & 21.0 \\
\hline 20.3 & 2.3 & 0.35 & 22.6 & - & 0.15 & 22.0 & 18.0 & 18.7 & 19.7 & 20.5 \\
\hline 20.1 & 2.2 & 0.35 & 22.3 & - & 0.15 & 21.8 & 16.3 & 17.8 & 19.2 & 20.0 \\
\hline$(0.0)$ & 4.1 & 0.35 & 4.1 & 0.6 & 0.15 & 4.7 & - & - & 1.4 & 1.5 \\
\hline- & 2.8 & 0.35 & 2.8 & 1.0 & 0.15 & 3.8 & - & - & 1.0 & 1.2 \\
\hline- & - & - & - & - & - & - & - & - & - & - \\
\hline 14.0 & 1.0 & 0.35 & 15.0 & 0.4 & 0.15 & 15.4 & 12.0 & 12.9 & 13.5 & 14.0 \\
\hline 13.0 & 2.1 & 0.35 & 15.1 & 0.9 & 0.15 & 16.0 & 10.6 & 12.4 & 12.7 & 13.5 \\
\hline 12.5 & 2.6 & 0.35 & 15.1 & 0.9 & 0.15 & 16.0 & 9.8 & 11.3 & 11.9 & 12.9 \\
\hline 12.0 & 2.6 & 0.35 & 14.6 & 1.4 & 0.15 & 16.0 & 9.0 & 10.7 & 11.4 & 12.5 \\
\hline 11.8 & 2.2 & 0.35 & 14.0 & 2.0 & 0.15 & 16.0 & 8.4 & 9.4 & 10.9 & 12.0 \\
\hline \multicolumn{11}{|c|}{ Winter } \\
\hline 28.5 & 0.0 & 0.35 & 28.5 & 0.0 & 0.15 & 28.5 & 28.5 & 28.5 & 28.5 & 28.5 \\
\hline 26.0 & 1.5 & 0.35 & 27.5 & 0.5 & 0.15 & 28.0 & 25.0 & 25.4 & 25.4 & 26.0 \\
\hline 25.5 & 2.0 & 0.35 & 27.5 & 0.5 & 0.15 & 28.0 & 24.5 & 25.3 & 25.4 & 26.2 \\
\hline 25.0 & 2.5 & 0.35 & 27.5 & 0.0 & 0.15 & 27.5 & 24.0 & 24.4 & 24.7 & 25.6 \\
\hline 24.5 & 3.0 & 0.35 & 27.5 & 0.0 & 0.15 & 27.5 & 21.0 & 23.7 & 24.0 & 25.0 \\
\hline 9.0 & 1.6 & 0.35 & 10.6 & 0.5 & 0.15 & 11.1 & 6.8 & 7.2 & 7.8 & 8.5 \\
\hline 7.7 & 1.3 & 0.35 & 9.0 & 0.5 & 0.15 & 9.5 & 3.2 & 3.8 & 4.6 & 5.2 \\
\hline 6.5 & 1.5 & 0.3 & 8.0 & 0.2 & 0.1 & 8.2 & 1.6 & 2.0 & 3.0 & 3.4 \\
\hline 5.2 & 1.8 & 0.2 & 7.0 & 0.4 & 0.1 & 7.4 & $(1.0)$ & 1.4 & 2.3 & 2.7 \\
\hline 4.0 & 1.8 & 0.2 & 5.8 & 0.7 & 0.1 & 6.5 & - & - & 1.2 & 1.7 \\
\hline 2.8 & 2.2 & 0.2 & 5.0 & 0.0 & 0.1 & 5.0 & - & - & 0.8 & 1.2 \\
\hline$(2.0)$ & 2.0 & 0.2 & 4.0 & 0.0 & 0.1 & 4.0 & - & - & 0.6 & 1.0 \\
\hline- & 3.3 & 0.2 & 3.3 & 0.0 & 0.1 & 3.3 & - & - & - & 0.7 \\
\hline- & 2.0 & 0.2 & 2.0 & 0.0 & 0.1 & 2.0 & - & - & - & $(0.4)$ \\
\hline 20.5 & 0.5 & 0.35 & 21.0 & 0.7 & 0.15 & 21.7 & 19.0 & 19.9 & 20.2 & 20.5 \\
\hline 20.0 & 1.0 & 0.35 & 21.0 & 1.0 & 0.15 & 22.0 & 18.0 & 18.4 & 19.4 & 20.0 \\
\hline 19.8 & 2.2 & 0.35 & 22.0 & 0.0 & 0.15 & 22.0 & 17.5 & 17.9 & 19.1 & 19.9 \\
\hline 19.0 & 3.0 & 0.35 & 22.0 & 0.0 & 0.15 & 22.0 & 17.0 & 17.4 & 18.4 & 19.4 \\
\hline 18.8 & 2.2 & 0.35 & 21.0 & 1.0 & 0.15 & 22.0 & 16.0 & 17.1 & 18.1 & 19.1 \\
\hline
\end{tabular}


sl-

\begin{tabular}{|c|c|c|c|c|c|c|c|c|}
\hline & $\begin{array}{l}\mathrm{Ab}- \\
\text { stand }\end{array}$ & $W_{1.0}$ & $\mathrm{w}_{1.0}$ & $\Delta_{0.9}$ & $\mathrm{w}_{0,9}$ & $\mathrm{~W}_{0.8}$ & $\Delta_{0.85}$ & $\mathrm{w}_{0.65}$ \\
\hline Röyttä (1) & $0^{\prime}$ & 33.0 & 1.0 & 0.0 & 0.9 & 33.0 & 0.0 & 0.65 \\
\hline Abstand in & $5^{\prime}$ & 30.4 & 1.0 & 0.6 & 0.9 & 31.0 & 0.3 & 0.65 \\
\hline \multirow{3}{*}{$\underset{S}{d e r}$ Richtung } & $10^{\prime}$ & 29.6 & 1.0 & 0.6 & 0.9 & 30.2 & 0.5 & 0.65 \\
\hline & $15^{\prime}$ & 28.8 & 1.0 & 0.5 & 0.9 & 29.3 & 1.1 & 0.65 \\
\hline & $20^{\prime}$ & 28.0 & 1.0 & 0.2 & 0.9 & 28.2 & 1.9 & 0.65 \\
\hline \multirow{11}{*}{$\begin{array}{c}\text { Utö (42) } \\
\text { Abstand in } \\
\text { der Richtung } \\
\text { SSW }\end{array}$} & $0^{\prime}$ & 14.0 & 1.0 & 0.2 & 0.9 & 14.2 & 1.5 & 0.65 \\
\hline & $5^{\prime}$ & 12.0 & 1.0 & 0.9 & 0.9 & 12.9 & 1.3 & 0.65 \\
\hline & $10^{\prime}$ & 10.4 & 1.0 & 1.3 & 0.9 & 11.7 & 1.1 & 0.65 \\
\hline & $15^{\prime}$ & 8.2 & 1.0 & 1.8 & 0.9 & 10.0 & 1.5 & 0.65 \\
\hline & $20^{\prime}$ & - & - & 6.0 & 0.9 & 6.0 & 4.3 & 0.65 \\
\hline & $25^{\prime}$ & - & - & - & - & - & 8.4 & 0.65 \\
\hline & $30^{\prime}$ & - & - & - & - & - & - & $=$ \\
\hline & $35^{\prime}$ & - & - & - & - & - & - & - \\
\hline & $40^{\prime}$ & - & - & - & - & - & - & - \\
\hline & $45^{\prime}$ & - & - & - & - & - & - & - \\
\hline & $50^{\prime}$ & - & - & - & - & - & - & - \\
\hline Seivästö (84) & $0^{\prime}$ & 24.9 & 1.0 & 1.3 & 0.9 & 26.2 & - & 0.65 \\
\hline Abstand in & $5^{\prime}$ & 24.2 & 1.0 & 1.2 & 0.9 & 25.4 & 0.6 & 0.65 \\
\hline der Richtung & $10^{\prime}$ & 23.7 & 1.0 & 1.1 & 0.9 & 24.8 & 1.0 & 0.65 \\
\hline WSW & $15^{\prime}$ & 23.2 & 1.0 & 1.1 & 0.9 & 24.3 & 1.3 & 0.65 \\
\hline & $20^{\prime}$ & 22.7 & 1.0 & 1.3 & 0.9 & 24.0 & 1.4 & 0.65 \\
\hline
\end{tabular}

$\Sigma_{\mathrm{p}}$ sk gibt an, wie die Zunahme der "Zeit mit Eis» beim. Übergang von dem "normalen mittellangen» sehr kurzen Winter in den "normalen mittellangen» Winter vorsichgeht; die Differenz $\Sigma_{\mathrm{p}} \mathrm{s} l-\Sigma_{\mathrm{p}} \mathrm{ml}$ wiederum deren Zunahme, indem die Länge des Winters von dem "normalen mittellangen» in den "mittellangen sehr langen» sich verändert, und die Differenz $\Sigma_{\mathrm{p}} \mathrm{sl}-\sum_{\mathrm{p}} \mathrm{sk}$ schliesslich ihre ganze Veränderung beim Übergang von dem "normalen mittellangen» sehr kurzen in den "normalen mittellangen»s sehr langen Winter. Die obenerwähnten Differenzen, jede Gruppe für sich, wurden zuerst tabelliert und dann eine jede auf ihre eigene Unterlagenkarte übertragen, wobei, wenn auf den Karten die Stellen vereinigt wurden, wo die Differenzen der "Zeit mit Eis» gleich gross waren, man die Kurven in Fig. 93-95 erhielt.

Wir werden in dem später erscheinenden achten Teil di e E i swo chenzahlen sowie die "Z eit $\mathrm{mit} E$ is» näher behandeln.

215. In Fig. 93, welche also zeigt, wie die "Zeit mit Eis» sich verändert, wenn der Eiswinter innerhalb der hergeleiteten G-Stadien aus dem "normalen mittellangen» sehr kurzen Winter in den "normalen 
Winter

\begin{tabular}{|c|c|c|c|c|c|c|c|c|c|c|}
\hline $\mathrm{W}_{0.5}$ & $\Delta_{0.35}$ & $\mathrm{w}_{0.35}$ & $\mathrm{~W}_{0.2}$ & $\Delta_{0.15}$ & $\mathrm{w}_{0.15}$ & $\mathrm{~W}_{0.1}$ & $\Sigma_{1.0}$ & $\Sigma_{0.8}$ & $\Sigma_{0.5}$ & $\Sigma$ \\
\hline 33.0 & $(0.5)$ & 0.35 & $(33.5)$ & - & 0.15 & - & 33.0 & 33.0 & 33.0 & 33.2 \\
\hline 31.3 & 1.7 & 0.35 & 33.0 & 0.0 & 0.15 & 33.0 & 30.4 & 30.9 & 31.1 & 31.7 \\
\hline 30.7 & 2.1 & 0.35 & 32.8 & 0.0 & 0.15 & 32.8 & 29.6 & 30.1 & 30.4 & 31.1 \\
\hline 30.4 & 2.4 & 0.35 & 32.8 & 0.0 & $0 \cdot 15$ & 32.8 & 28.8 & 29.2 & 29.9 & 30.7 \\
\hline 30.1 & 2.7 & 0.35 & 32.8 & 0.2 & 0.15 & 33.0 & 28.0 & 28.2 & 29.4 & 30.3 \\
\hline 15.7 & 1.5 & 0.35 & 17.2 & 0.8 & 0.15 & 18.0 & 14.0 & 14.2 & 15.2 & 15.8 \\
\hline 14.2 & 1.1 & 0.35 & 15.3 & 0.7 & 0.15 & 16.0 & 12.0 & 12.8 & 13.6 & 14.1 \\
\hline 12.8 & 0.9 & 0.35 & 13.7 & 1.1 & 0.15 & 14.8 & 10.4 & 11.6 & 12.3 & 12.8 \\
\hline 11.5 & 1.3 & 0.35 & 12.8 & 0.7 & 0.15 & 13.5 & 8.2 & 9.8 & 10.8 & 11.4 \\
\hline 10.3 & 1.8 & 0.35 & 12.1 & 0.6 & 0.15 & 12.7 & - & 5.4 & 8.2 & 8.9 \\
\hline 8.4 & 2.9 & 0.35 & 11.3 & 0.6 & 0.15 & 11.9 & - & - & 5.5 & 6.6 \\
\hline- & 10.3 & 0.35 & 10.3 & 0.1 & 0.15 & 10.4 & - & - & - & 3.7 \\
\hline- & 9.2 & 0.35 & 9.2 & 0.3 & 0.15 & 9.5 & - & - & - & 3.3 \\
\hline- & - & - & - & 8.0 & 0.15 & 8.0 & - & - & - & $(1.2)$ \\
\hline- & - & - & - & 7.0 & 0.15 & 7.0 & - & - & - & $(1.0)$ \\
\hline- & - & - & - & 6.1 & 0.15 & 6.1 & - & - & - & $(0.9)$ \\
\hline- & - & 0.35 & - & - & 0.15 & - & 24.9 & 26.2 & 26.2 & 26.2 \\
\hline 26.0 & 1.1 & 0.35 & 27.1 & 0.1 & 0.15 & 27.2 & 24.2 & 25.3 & 25.7 & 26.1 \\
\hline 25.8 & 1.3 & 0.35 & 27.1 & 0.6 & 0.15 & 27.7 & 23.7 & 24.7 & 25.3 & 25.9 \\
\hline 25.6 & 1.5 & 0.35 & 27.1 & 0.8 & 0.15 & 27.9 & 23.2 & 24.2 & 25.0 & 25.6 \\
\hline 25.4 & 1.6 & 0.35 & 27.0 & 1.0 & 0.15 & 28.0 & 22.7 & 23.9 & 24.8 & 25.6 \\
\hline
\end{tabular}

Tabelle 49 .

Die aus den G-Stadien für Röyttä (R), Utö (U) und Seivästö (S) nach den Formeln (2) und (3) berechnete "Zeit mit Eis» des »normalen mittellangen» sk-, »normalen» ml- und "normalen mittellangen»sl-Winters.

\begin{tabular}{|c|c|c|c|c|c|c|c|c|c|}
\hline \multirow{2}{*}{$\begin{array}{l}\mathrm{Ab}- \\
\text { stand }\end{array}$} & \multicolumn{3}{|c|}{ sk-Winter } & \multicolumn{3}{|c|}{ ml-Winter } & \multicolumn{3}{|c|}{ sl-Winter } \\
\hline & $\mathrm{R}$ & $\mathrm{U}$ & s & $\mathrm{R}$ & $\mathrm{U}$ & $\mathrm{S}$ & $\mathbf{R}$ & $\mathrm{U}$ & $\mathrm{s}$ \\
\hline $0^{\prime}$ & 23.3 & 1.5 & 14.0 & 28.5 & 8.5 & 20.5 & 33.2 & 15.8 & 26.2 \\
\hline $5^{\prime}$ & 21.4 & 1.2 & 13.5 & 26.0 & 5.2 & 20.0 & 31.7 & 14.1 & 26.1 \\
\hline $10^{\prime}$ & 21.0 & - & 12.9 & 26.2 & 3.4 & 19.9 & 31.1 & 12.8 & 25.9 \\
\hline $15^{\prime}$ & 20.5 & - & 12.5 & 25.6 & 2.7 & 19.4 & 30.7 & 11.4 & 26.6 \\
\hline $20^{\prime}$ & 20.0 & - & 12.0 & 25.0 & 1.7 & 19.1 & 30.3 & 8.9 & 25.6 \\
\hline $25^{\prime}$ & - & - & - & - & 1.2 & - & - & 6.6 & - \\
\hline $30^{\prime}$ & - & - & - & - & 1.0 & - & - & 3.7 & - \\
\hline $35^{\prime}$ & - & - & - & - & 0.7 & - & - & 3.3 & - \\
\hline $40^{\prime}$ & - & - & - & - & $(0.4)$ & - & - & (1.2) & - \\
\hline $45^{\prime}$ & - & - & - & $\longrightarrow$ & - & $\rightarrow$ & - & $(1.0)$ & - \\
\hline $50^{\prime}$ & - & - & - & - & - & - & - & $(0.9)$ & - \\
\hline
\end{tabular}




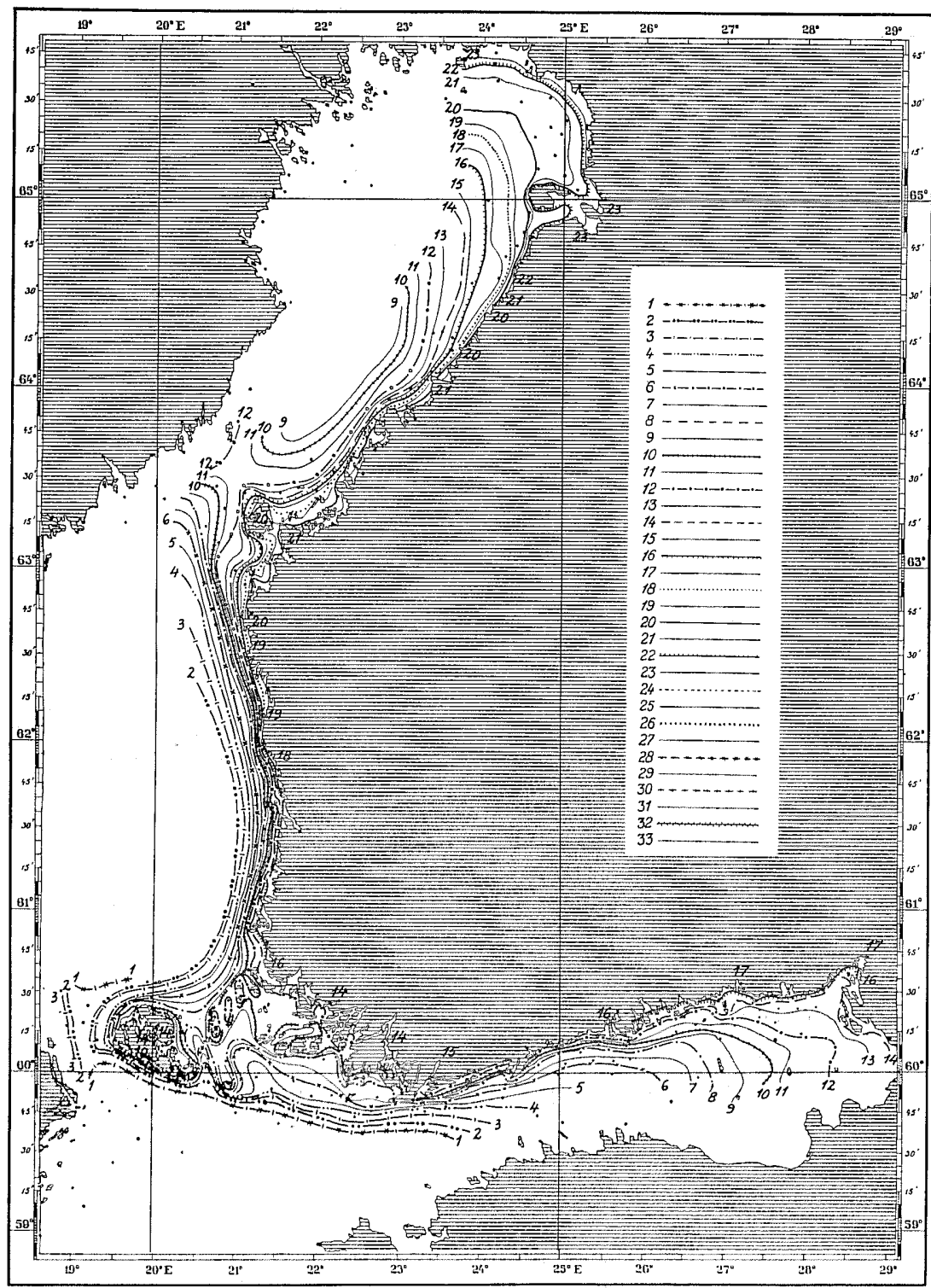

Fig. 90. Die "Z eit $\mathrm{mit} \mathrm{E}$ is» in Wochen in dem »normalen mittellangen»sehr lrurzen Winter nach der Formel (2) berechnet.

mittellangen» Winter übergeht, beträgt die grösste Veränderung des Winters 8 Wochen. Der entsprechende Gürtel der grössten Veränderung beginnt unmittelbar an der Küste im d-Gebiet, wo auch auf der Ostseite von Åland die Veränderung 8 Wochen beträgt; in dem 


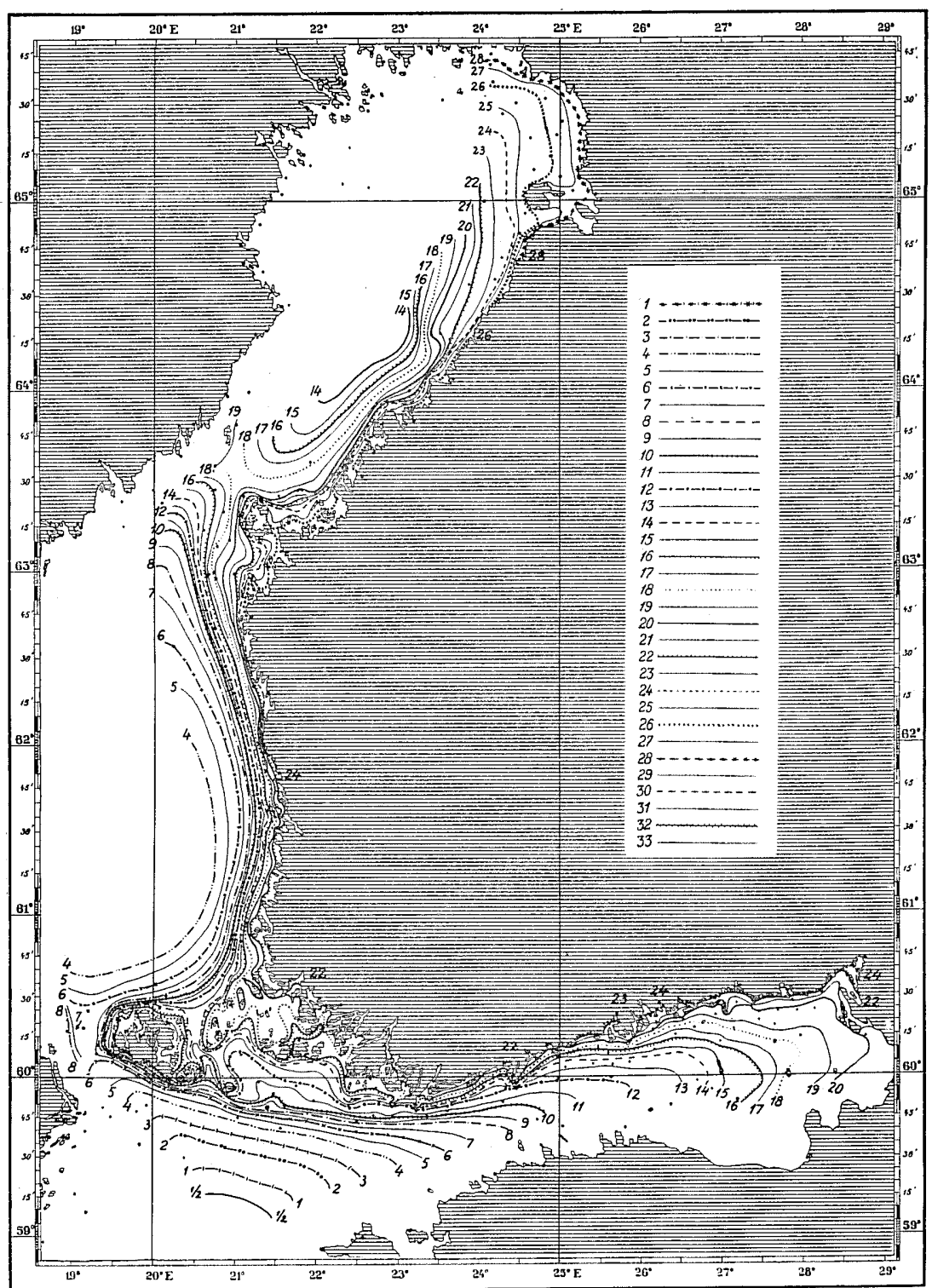

Fig. 91. Die "Zeit mit Eis» in Wochen im Mittel oder in dem "normalen" mittellangen Winter nach der Formel (3) berechnet.

c- und e-Gebiet liegt dieser Gürtel zum grössten Teil unmittelbar ausserhalb der Schärenzone, in den östlichen Teilen des $\boldsymbol{\theta}$-Gebietes gibt es ausserdem noch einen zweiten Gürtel mit der grössten Veränderung. Im Bereiche des $\mathbf{a}$ - und $\mathbf{b}$-Gebiets ist die grösste Verände- 


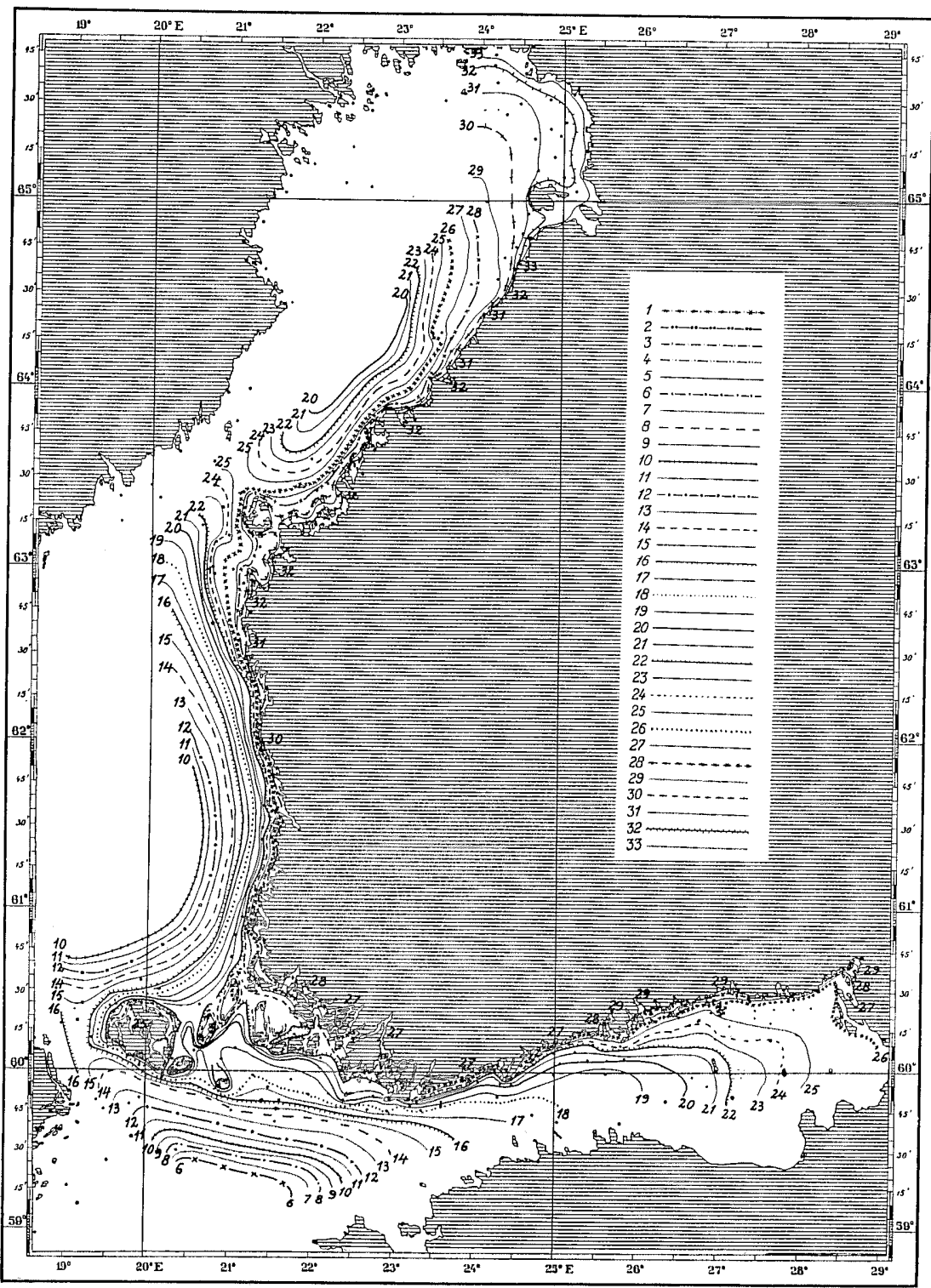

Fig. 92. Die "Z eit $\mathrm{mit} \mathrm{E}$ is» in Wochen in dem snormalen mittellangen"sehr langen. Winter nach der Formel (2) berechnet.

rung 7 Wochen und der entsprechende Gürtel befindet sich im aGebiet ganz ausserhalb der Schären. Auch in dem Bereiche des dGebiets ist in den südlichen Teilen desselben an der Grenze gegen die Nördliche Ostsee, wie ebenfalls um Åland herum vom Norden 


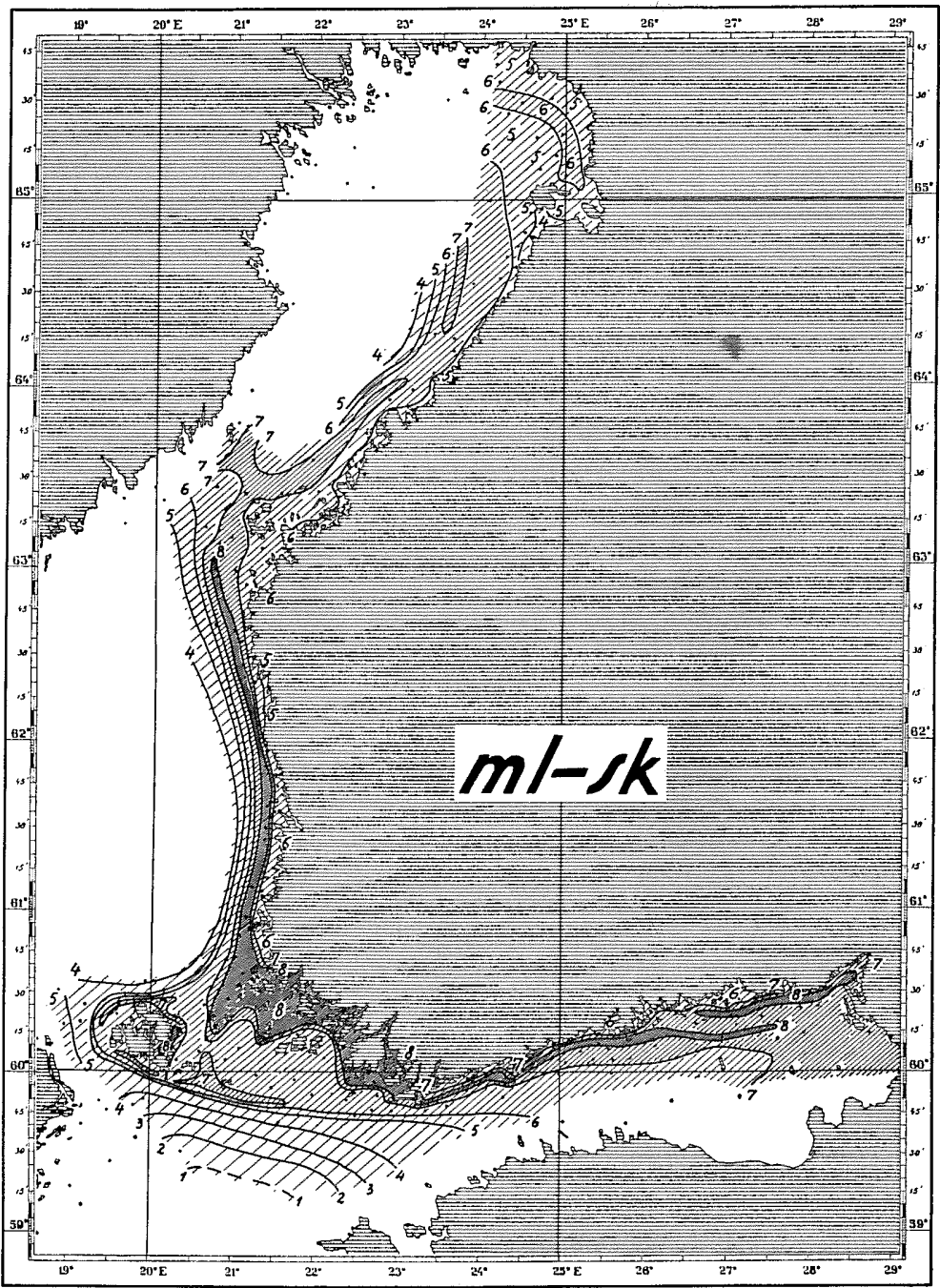

Fig. 93. Die Veränderung der »Zeit mit Eis» in Wochen vom "normalen mittellangen" sehr kurzen (sk-)Winter zum "normalen» mittellangen (ml-) Winter.

durch den Westen nach Süden ein solcher, jedoch sehr schmaler "7-Wochen»-Gürtel zu sehen.

Bei der weiteren Zunahme der Länge des Eiswinters vom normalen mittellangen Winter zum "normalen mittellangen» sehr langen Winter ist die Veränderung der "Zeit mit Eis» höchstens 9 Wochen (Fig. 94). Der Gürtel, welcher dieser Veränderung entspricht, erstreckt sich als zusammenhängendes Gebiet in der Bottensee 


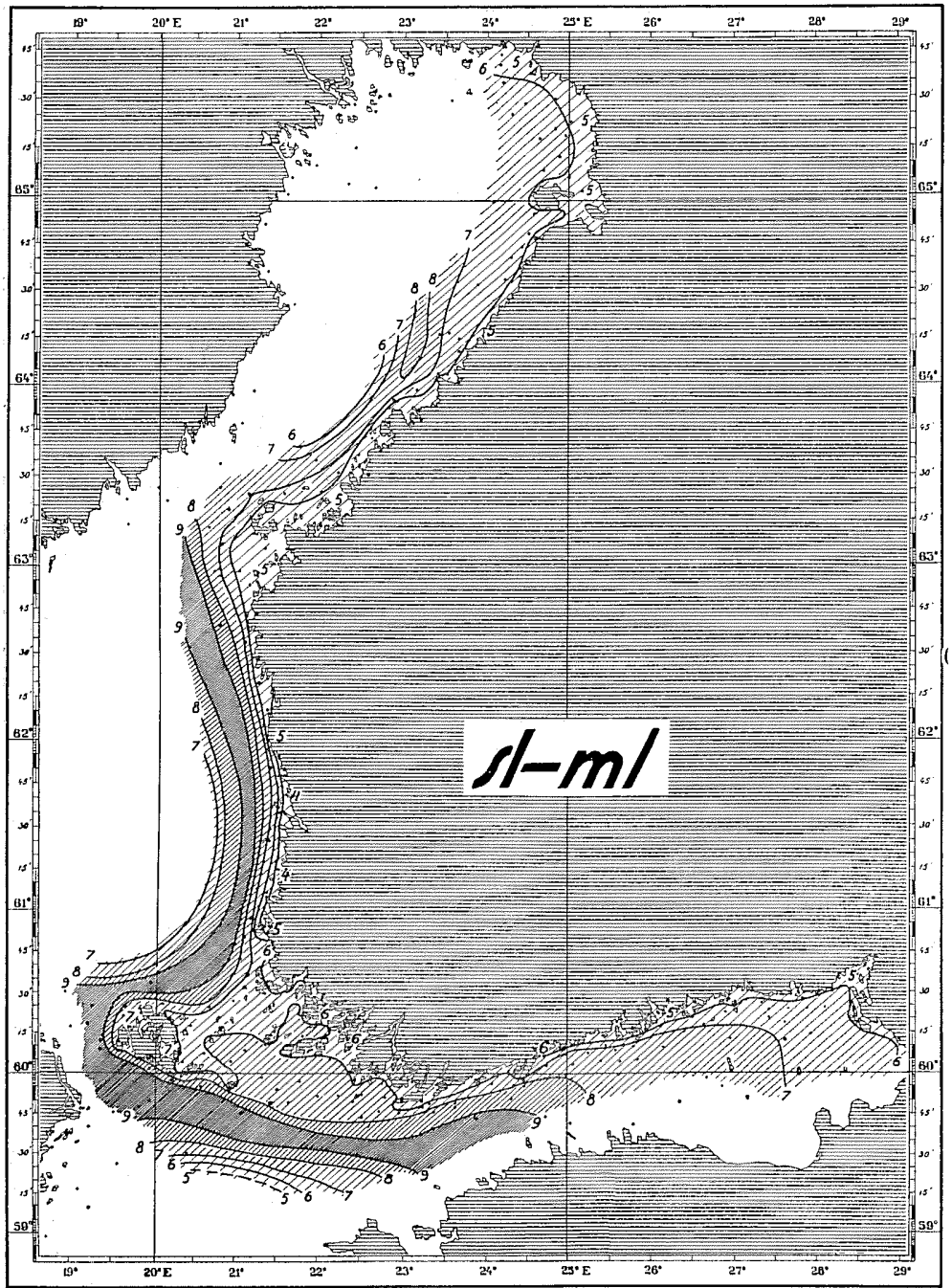

Fig. 94. Die Veränderung der »Zeit mit Eis» in Wochen vom "normalen" mittellangen (ml-) Winter zum "normalen mittellangen» sehr langen (sl-)winter.

erheblich ausserhalb des Schärenhofes und weiter über das Ålandsmeer und südlich von dem Schärenmeer nach den westlichen Teilen des Finnischen Meerbusens. In dem a-Gebiet oder der Bottenwiek beträgt die grösste Veränderung 8 Wochen in einem ganz kleinen Gürtel im mittleren Teil des Meeres; in den nördlichen Teilen der Bottenwiek sind die Veränderungen sehr gleichmässig, ca. 6 Wochen, ebenso wie 


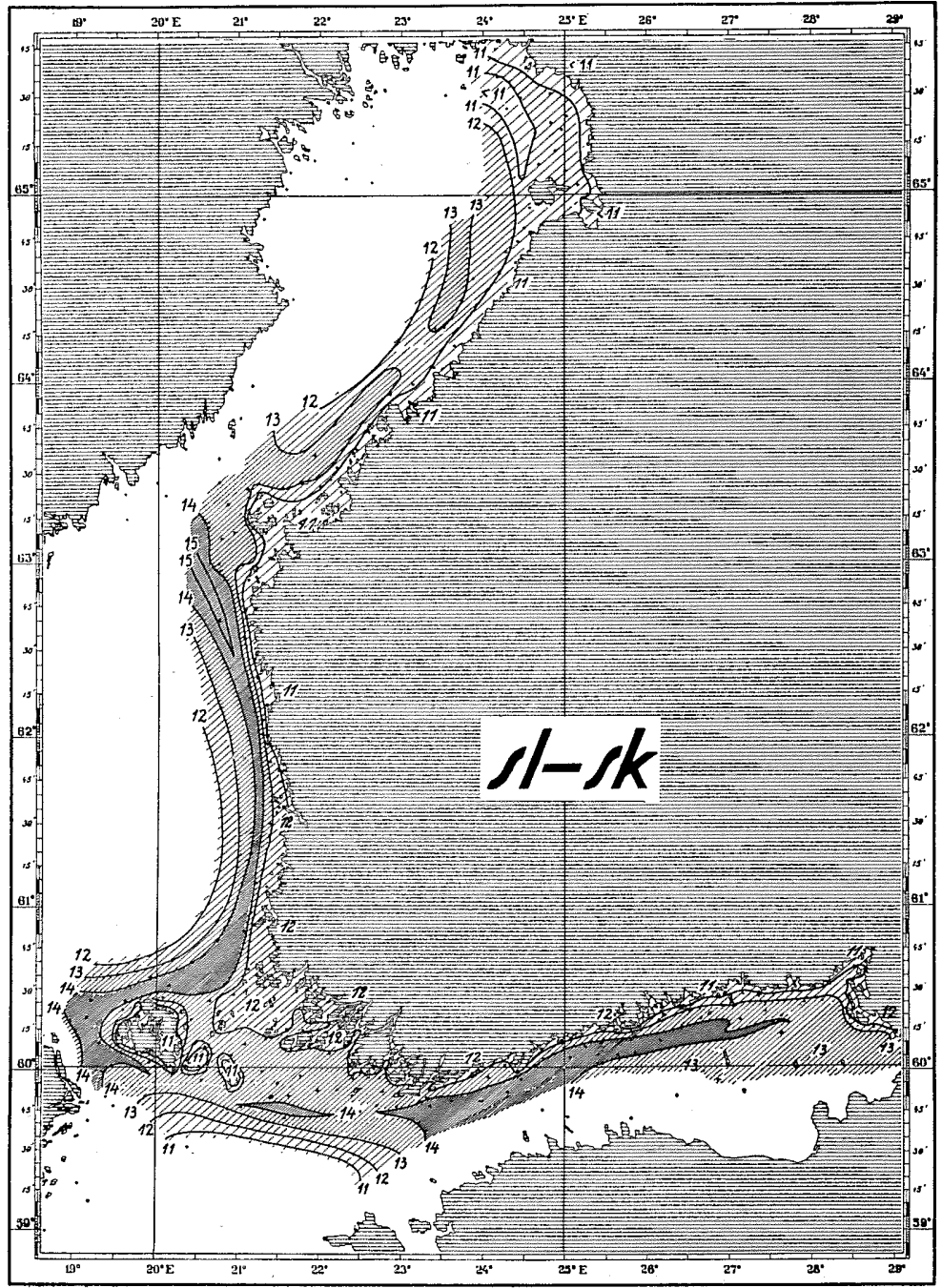

Fig. 95. Die Veränderung der „Zeit mit Eis» in Wochen vom "normalen mittellangen» sehr kurzen (sk-)Winter zum "normalen mittellangen" sehr langen (sl-) Winter.

in der östlichen Hälfte des Finnischen Meerbusens, wo die Veränderung $6-8$ Wochen ist beträgt.

Die ganze (sl-sk) Veränderung der "Zeit mit Eis», wenn die Länge des Eiswinters von dem »normalen mittellangen» sehr kurzen zu dem "normalen mittellangen» sehr langen wächst, ist 15 Wochen (Fig. 95). Der dieser grössten Veränderung entsprechende Gürtel befindet sich 
ausserhalb der Schären im nördlichen Teil der Bottensee. Übrigens beträgt die grösste Veränderung an der Westküste 14 Wochen und der Gürtel, welcher ihr entspricht, verläuft ausserhalb des Schärenhofs nach dem Ålandsmeer, wo er in dessen südlichen Teilen aufhört, und auch in dem Finnischen Meerbusen befindet sich der Gürtel „14 Wochen» ausserhalb des Schärenhofes. Ganz in der Nähe der südlichen Grenze des Schärenmeeres liegt ein ähnlicher Gürtel, der auch hier ausserhalb des eigentlichen Schärenhofes sich befindet. Im Bereich der Bottenwiek ist die grösste Veränderung 13 Wochen. Im grossen und ganzen scheint somit die "ganze» Veränderung der »Zeit mit Eis» hinsichtlich ihrer regionalen Verteilung irgend einer Mittellage zwischen den Veränderungen(sl-ml) und (ml-sk) zu entsprechen, was übrigens ganz natürlich ist.

Wir wollen uns hier nicht mehr in die "Zeit mit Eis» und in ihre Veränderungen vertiefen, denn wir werden später im achten Teil die Eiswochenzahlen und die vermittels dieser berechneten Wochensummen eingehender behandeln.

Welche prinzipiellen und eventuell sachlichen Einwände gegen die oben angeführte Berechnungsweise der "Zeit mit Eis» auch erhoben werden können, so schliesst sich diese Berechnungsweise jedenfalls ganz natürlich an die kartographische Methode an, auf der diese Untersuchung basiert und aus der sie sich ohne weiteres entwickelt.

In diesem zweiten Teil ist ziemlich eingehend die Methode beschrieben, vermittels welcher aus den Eislagen der Freitage der Winter 1915 - 1925 zuerst die Normalstadien der Meeresteile und dann die allgemeinen Normalstadien hergeleitet worden sind; ausserdem, wie vermittels der letzteren bei Benutzung der Kurven der Zeitdiagramme der sehr kurze, mittellange und sehr lange Winter theoretisch aufzubauen ist; weiter wie die Eiswochenzahlen dieser Winter und ihre Schwankungen und wie die "Zeit mit Eis» und deren Schwankungen durch die Eiswochensummen herzuleiten sind. M. a. W. wir beabsichtigten in diesem Teil d $\mathrm{r}$ Untersuchung zu zeigen, wie wir auf die Eislagen von nur 10-11 Wintern gestützt, die sowohl für die Untersuchung im allgemeinen als für eine genauere Beschreibung der Eisverhältnisse unserer Meere notwendigen Mittelbilder und Mittelzahlen herzuleiten versucht haben. Dabei ist auch auf die grossen und eigen- 
artigen Schwierigkeiten hinzuweisen, welche zu überwinden waren, von welchen der glatte Verlauf z. B. der Bildreihen der Normalstadien im Atlas keine rechte Vorstellung gibt.

Wenn auch später im Laufe dieser Arbeit noch Fragen methodischer Art vorkommen, so ist doch die eigentliche Methode der Untersuchung in der obigen systematischen Behandlung des ursprünglichen Freitagslagenmaterials von der Herleitung und dem Aufbau der Normalstadien bis zur "Zeit mit Eis» gegeben. 


\section{LITERATURVERZEICHNIS.}

(1) Atlas of Finland 1925 . The Geographical Society of Finland. Helsinki - Helsingfors 1925-1928. Chartpage N:o 11, charts $10-12$.

(2) Berättelse öfver Finska Vetenskaps-Societetens Meteorologiska Centralanstalts verksamhet u n d e r å r . . . O Öfversikt af Finska Vetenskaps-Societetens förhandlingar N:ris XLI-LIIT. Årgångarna 1898-1905: ERNST Biese; 1906-1907: Oso. V. Johansson; 1908-1910: G. Melander.

(3) Easton, C.: Les Hivers dans l'Europe occidentale. Leyden 1928.

(4) Fagerlund, L. W.: Anteckningar rörande samfärdseln emellan Sverige och Finland öfver Ålands haf och de åländska öarna. I. Åland VIII. Helsingfors 1925.

(5) Fe n n i a 12, N:o 1. Sällskapets för Finlands Geografi förhandlingar. Oktober 1894-december 1896. Den 20 oktober 1894: $\S 9$, den 19 januari 1895: § 2.

(6) Granqvist, Gunnar: Isarna vintern 1913-14 vid Finlands kust. Havsforskningsinstitutets Skrift N:o 3. Helsingfors 1921.

(7) $\rightarrow-$ Översikt av isarna vintern 1914-15. Havsforskningsinstitutets Skrift N:o 37. Helsingfors 1926.

(8) $\rightarrow-$ Översikt av isarna vintern 1915-16. Havsforskningsinstitutets Skrift N:o 40. Helsingfors 1926.

(9) $\longrightarrow$ - Översikt av isarna vintern 1917-18. Havsforskningsinstitutets Skrift N:o 42. Helsingfors 1926.

$(10) \rightarrow-$ Isarna vintern 1920-21. Havsforskningsinstitutets Skrift N:o 22. Helsingfors 1924 .

(11) $\rightarrow-$ Isarna vintern 1922 -23. Havsforskningsinstitutets Skrift N:o 28. Helsingfors 1925 .

(12) $\rightarrow-$ Översikt av isarna vintern 1924-25. Havsforskningsinstitutets Skrift N:o 44. Helsingfors 1926.

$(13) \rightarrow-$ Översikt av isarna vintern 1926-27. Havsforskningsinstitutets Skrift N:o 55. Helsingfors 1928.

$(14) \longrightarrow$ Översikt av isarna vintern 1927-28. Havsforskningsinstitutets Skrift N:o 56. Helsingfors 1928.

(15) $\longrightarrow-$ Översikt av isarna vintern 1928 - 29. Havsforskningsinstitutets Skrift N:o 64. Helsingfors 1929.

(16) $\rightarrow-$ Översikt av isarna vintern 1929-30. Havsforskningsinstitutets Skrift N:o 71, Helsingfors 1930. 
(17) Heinrichs, Axel: Isförhållandena i Östersjön och dess vikar I. Material. Fennia 21. Helsingfors 1903-1904.

(18) —- Snö- och isförhållandena i Finland år 1890. Bidrag till kännedom om Finlands natur och folk. H. 51. Helsingfors 1892.

(19) $\longrightarrow-$ Snö- och isförhållandena i Finland år 1891. Bidrag till kännedom om Finlands natur och folk. H. 54. Helsingfors 1894 .

(20) —- Snö- och isförhållandena i Finland år 1892. Bidrag till kännedom om Finlands natur och folk. H. 57. Helsingfors 1898.

$(21) \rightarrow-$ Etat des glaces et des neiges en Finlande pendant l'hiver 18921893. Kuopio 1904.

$(22) \longrightarrow$ - Etat des glaces et des neiges en Finlande pendant l'hiver 1893 1894. Helsingfors 1904.

$(23) \longrightarrow$ - Etat des glaces et des neiges en Finlande pendant l'hiver 18941895. Helsingfors 1905 .

$(24) \rightarrow-$ Etat des glaces et des neiges en Finlande pendant l'hiver 18951896. Helsingfors 1907.

$(25) \longrightarrow-$ Schnee- und Eisverhältnisse in Finland im Winter 1900-1901. Helsingfors 1906.

(26) - -- und Korhonen, V. V.: Etat des glases et des neiges en Finlande pendant l'hiver 1896-1897. Helsingfors 1909 -

(27) HetlströM, RAFAex H.: Bidrag till kännedom av isförhållandena i Bottenhavet. Isförhållandena vintrarna 1899-1909. Fennia 33, N:o 3. Helsingfors 1913.

(28) $\longrightarrow-$ Bidrag till kännedom av isförhållandena i Bottenhavet II. Fennia 38, N:o 2. Helsingfors 1915.

$(29) \longrightarrow-$ Talviliikenne Pohjanlahdella IV. Kokemuksia talvena 1916. Fennia 43, N:o 6. Helsingfors 1922-1923.

(30) Henning, R.: Katalog bemerkenswerter Witterungsereignisse von den ältesten Zeiten bis zum Jahre 1800. Abhandlungen des Königl. Preussischen Meteorologischen Instituts. Bd. II. No. 4. Berlin 1904.

(31) Ignatius, K. E. F.: Finlands Geografi. I. Helsingfors 1881-90.

(32) Jurva, Risto: Itämeren jäätymisestä. Suomen Paperi- ja Puutavaralehti 1929. N:o 4,

$(33) \rightarrow-$ Översikt av isarna vintern 1919-20. Havsforskningsinstitutets Skrift N:o 23. Helsingfors 1926.

$(34) \longrightarrow-$ Översikt av isarna vintern 1934-35. Havsforskningsinstitutets Skrift N:o 102. Helsingfors 1936.

$(35) \longrightarrow-$ Merenjäät Saaristomereen rajoittuvissa ympäröivien merien osissa. (Edeltävä katsaus). Suomen Maantieteellisen Seuran Aikakauskirja. 1924, 2-3. Helsinki 1924.

(36) - - Saaristomeren jääsuhteista. (Edeltävä katsaus.) Ensimmäisen määräaikaisen tutkijainkokouksen julkaisu II: Esitelmät. Helsinki 1925.

(37) —- Synkronisista jäänreunoista ja merenrailoista sekä niiden merkityksestä meriemme jääsuhteiden selvittelyssä. (Autoreferaatti). Suomen Maantieteellisen Seuran Aikakauskirja 1925. Helsinki 1925.

(38) $\longrightarrow-$ Tidsanalys av isvintrarnas förlopp. Nordiska 19. (Skandinaviska) Naturforskarmötet i Helsingfors 1936.

$(39) \longrightarrow$ - Vorläufige Mitteilung. V. Hydrologische Konferenz der Baltischen Staaten, Helsinki 1936. 
(40) Karsten, Hugo: Untersuchungen über die Eisverhältnisse im Finnischen Meerbusen und im nördlichen Teile der Ostsee. I. Beobachtungen während der Winter 1897-1902. Finnländische hydrographischbiologische Untersuchungen. N:o 6. Helsingfors 1911.

(41) Korhonen, W. W.: Etat des glaces et des neiges en Finlande pendant l'hiver. 1897-98. Helsingfors 1909.

$(42) \rightarrow-$ Schnee- und Eisverhältnisse in Finland im Winter 1898-1899. Kuopio 1912.

(43) $\longrightarrow-$ Schnee- und Eisverhältnisse in Finland im Winter 1899-1900. Kuopio 1915.

$(44) \rightarrow-$ Schnee- und Eisverhältnisse in Finland im Winter 1901-1902. Helsinki 1910.

$(45) \longrightarrow-$ Schnee- und Eisverhältnisse in Finland im Winter 1902-1903. Helsinki 1910.

$(46) \rightarrow-$ Schnee- und Eisverhältnisse in Finland im Winter 1903-1904. Helsinki 1911.

$(47) \rightarrow-$ Schnee- und Eisverhältnisse in Firland im Winter 1904-1905. Kuopio 1911.

$(48) \rightarrow-$ Schnee- und Eisverhältnisse in Finnland im Winter 1905-1906. Kuopio 1913.

$(49) \longrightarrow$ Schnee- und Eisverhältnisse in Finnland im Winter 1906-1907. Helsinki 1925.

(50) PalmḱN, E.: Översikt av isarna vintern 1916-17. Havsforskningsinstitutets Skrift N:0 50. Helsingfors 1928.

(51) - - Översikt av isarna vintern 1918-19. Havsforskningsinstitutets Skrift N:o 57. Helsingfors 1928.

(52) Patmén, K. E.: Om isbrytarefartyg och vintersjöfart. Tekniska föreningens i Finland Förhandlingar. 1894. Första och andra häftet. Helsingfors 1894.

(53) Pilgram, Anton: Untersuchungen über das Wahrscheinliche der Wetterkunde durch vieljährige Beobachtungen. Wien 1788.

(54) Speerschneider, C. I. H.: Om Isforholdene i Danske Farvande i ældre og nyere Tid. Aarene 690-1860. Publikationer fra det Danske Meteorologiske Institut. Meddelelser Nr. 2. Kjøbenhavn 1915.

$(55) \longrightarrow-$ Om Isforholdene i danske Farvande Aarene 1861-1906. Publikationer fra det Danske Meteorologiske Institut. Meddelelser Nr. 6. København 1927.

(56) Tawaststjerna, Werner: Pohjoismaiden viisikolmattavuotinen sota. Historiallisia tutkimuksia I. Helsinki 1918-20.

(57) Witring, Rolf: Atlas öfver Finland 1910. Kartblad 6. Text I. Isförhållanden. Fennia 30. Helsingfors 1911.

$(58) \rightarrow-$ Havsforskningsinstitutets värksambet under år 1919. Havsforskningsinstitutets Skrift N:o 1. Helsingfors 1920.

$(59) \longrightarrow-$ Havsforskningsinstitutets värksamhet under år 1921. Havsforskningsinstitutets Skrift N:o 14. Helsingfors 1922.

$(60) \longrightarrow-$ Havsforskningsinstitutets värksamhet under år 1922. Havsforskningsinstitutets Skrift N:o 25. Helsingfors 1923.

(61) - Havsforskningsinstitutets värksamhet under år 1923. Havsforskningsinstitutets Skrift N:o 31. Helsingfors 1924. 
(62) Wittring, Rolf: Havsforskningsinstitutets värksamhet under år 1924. Havsforskningsinstitutets Skrift N:o 35. Helsingfors 1925.

(63) $\longrightarrow-$ Havsforskningsinstitutets värksamhet under år 1925. Havsforskningsinstitutets Skrift N:o 41. Helsingfors 1926.

$(64) \longrightarrow-$ Havsforskningsinstitutets värksamhet år 1927. Havsforskningsinstitutets Skrift N:o 54. Helsingfors 1928.

$(65) \rightarrow-$ Havsforskningsinstitutets värksamhet år 1928. Havsforsknings. institutets Skrift N:o 63. Helsingfors 1929.

$(66) \longrightarrow-$ Havsforskningsinstitutets värksamhet år 1929. Havsforskningsinstitutets Skrift N:o 72. Helsingfors 1930.

(67) --- Hydrografisk-Biologiska Havsundersökningarna under år 1911. Öfv. af Finska Vet.-Soc. Förhandlingar. Bd. LIV. Afd. C. N:o 4. Helsingfors 1912.

(68) $\longrightarrow-$ Hydrografisk-Biologiska Havsundersökningarna under år 1913. Öfv. af Finska Vet.-Soc. Förhandlingar. Bd. LVI. Afd. C. N:o 3. Helsingfors 1914.

(69) $\longrightarrow-$ Hydrografisk-Biologiska Havsundersökningarna under ·år 1914. Öfv. af Finska Vet.-Soc. Förhandlingar. Bd. LVII. Avd. C. N:o 4. Helsingfors 1915.

(70) $\longrightarrow-$ Hydrografisk-Biologiska Havsundersökningarna under år 1915 . Öfv. af Finska Vet.-Soc. Förhandlingar. Bd. LVIII. Afd. C. N:o 5. Helsingfors 1916.

(71) —- J a hr buch 1911 enthaltend hydrographische Beobachtungen in den Finland umgebenden Meeren. Finländische hydrographischbiologische Untersuchungen. N:o 10. Helsingfors 1912.

$(72) \rightarrow-J a h r b u c h \quad 1912$ enthaltend hydrographische Beobachtungen in den Finland umgebenden Meeren. Finländische hydrographischbiologische Untersuchungen. N:o 12. Helsingfors 1913.

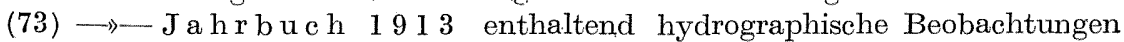
in den Finland umgebenden Meeren. Finländische hydrographischbiologische Untersuchungen. N:o 13. Helsingfors 1914.

(74) $\longrightarrow$ - Untersuchungen zur Kenntnis der Wasserbewegungen und der Wasserumsetzung in den Finland umgebenden Meeren. I. Der Bottnische Meerbusen in den Jahren 1904 und 1905. Erster Teil. Finnländische hydrographisch-biologische Untersuchungen. N:o 2. Helsingfors 1908.

(75) $\longrightarrow-$ Zusammenfassende Übersicht der Hydrographie des Bottnischen und Finnischen Meerbusens und der nördlichen Ostsee. Finländische hydrographisch-biologische Untersuchungen. N:o 7. Text. Helsingfors 1912 .

(76) $\AA$ bo Nya Tidningar 1789 , N:o 16.

(77) Öfversigt af Finska Vetenskaps-Societetens Förhand ling a r. I. 1838 -1 853 . Helsingfors 1853 .

(78) Öfversigt af förhandlingarna vid Finska Vetenskaps-Societetens sammanträden. Den 21 november 1898. Öfv. af Finska Vet.-Soc. Förhandlingar XLI 1898-1899. Helsingfors 1899. 


\section{MANUSKRIPTE.}

(79) Andersin, E. F.: Finlands fyrar med ständig bevakning. Historik I. 1800-1900 och Beskrifning IV. Das Manuskript im Archiv des Lotsenamtes in Helsinki.

(80) Östra issigna leringsomr ådet. Årgångarna: hösten 1915våren 1922: Svenska Lotsstyrelsen. 

